Historic, Archive Document

Do not assume content reflects current scientific knowledge, policies, or practices. 



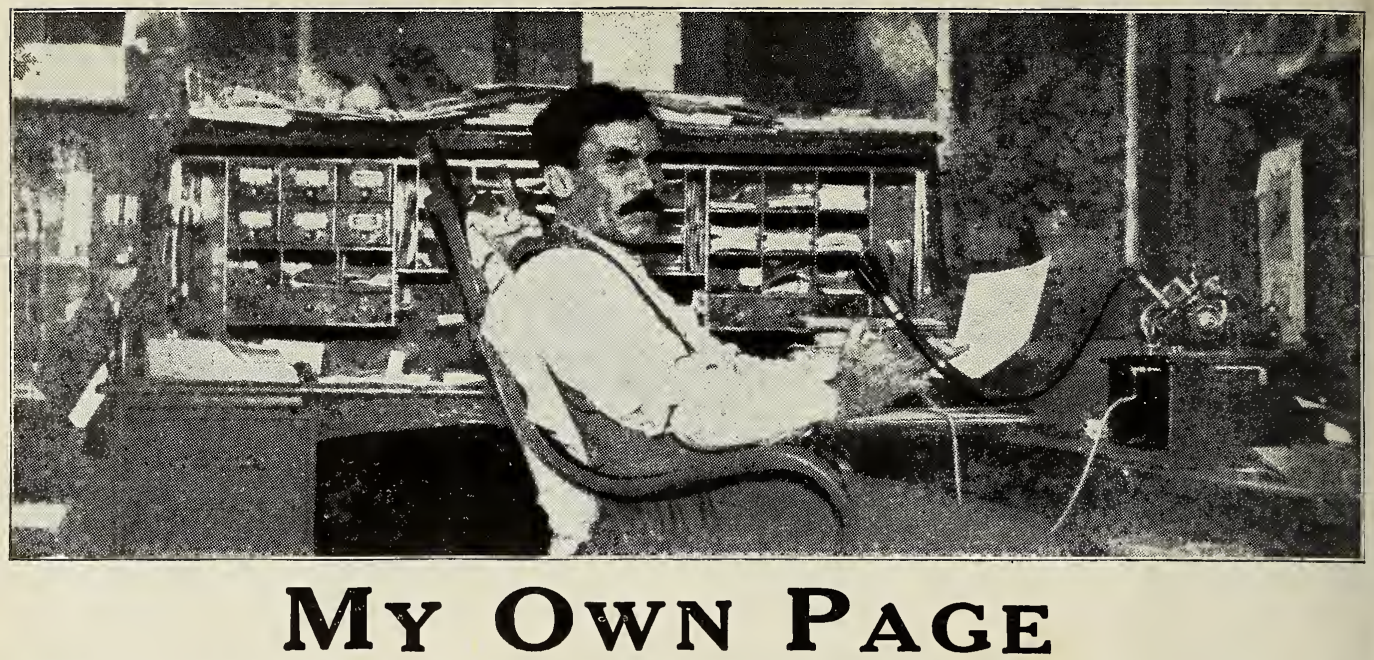

THIS PICTURE shnws how I answer your letters. I don't really write them. It would take too long. I just sit up all evening and talk it at the dictaphone just like I was talking direct to you, and next morning it takes two or three girls to copy it all off and send it to you. It works fine. I couldn't answer a tenth part of the letiers I get if it wasn't for this.

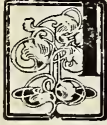

CALL this my own page. The rest of the book is written to suit you and the rest of the fo'ks. It must be done just about right. No mistakes, and no wrong grammar, and no waste space. But this page I write ju-t to suit myself. If it don't suit you, you don't have to read it. You can go on and read the rest of the book and come back to this later when you haven't anything else to do.

A catalog has to be written about so so. It musc be exact and painstaking and complete and just about a cross between an encyclopedia and a price list.

It's lots of work writing one. I have been working on this one several months. I wrote every word of it myself and laid out the pages, and watched it put in type, and corrected the proofs, and helped set the ink on the big press when it started runniris.

But it's dene now, all but this page. You know in a book of this lind the first page is always the last one printed. After the rest of the book is all in type, and waiting for the press to start on the last section, then I write this page.

It has been a great old year, hasn't it? How has it treated you, anyway? We came through pretty well, all things considered, and I guess we all did. We are pretty lucky to be alive and at work and with a prospect of making garden next s!ring,

The seed business ads been fine. Better than ever. We are getting more customers and better sustnmers all the time. Every one brings in two or three new ones. And they are all welcome.

And such nice letters we get from them. That is the best part of the seed business. My wite says she believes I would stay in the seed business any. way, even if I didn't make a cent, just for the sake of the lefters.

Printed in our own Private Printshop, of Course.
I hope you'll like the catalog. It's a sort of home-made affair and not specially artistic, but I have tried to make it helpful and honest and enter. taining. And we have done all the work on it ourselves from start to finish.

If you don't want to take time to read it you can look at the pictures anyway. It's great on pic tures. They are real pictures, too. Not the highly inflamed, imaginary kind you sometimes see.

I hope you all have fine gardens this year. I believe it's going to be a good year for all of us. Plan on having the best garden you ever had. (If course you ought to buy the seeds of me, but whether you do or not, read this catalog through and you will get a whole lot of good ideas about gardening that wont cost you a cent.

And if you will read Seed Sense regularly you will get a lot more. I will send you a sample copy either with this catalog or soon afterward. And if you happen to get an extra one, you can pass it on to a neighbor.

If the seeds have done well, and I have treated you right, and you like the catalog and Seed Sense, tell your neighbors about it, and loan them your catalog, or give it to them and I will send you an other. It all helps.

Come and see me sometime. I will be mighty pleased to see you and will show you all through the house. If you can't come and see me, write me a letter anyway. Whether you order or not, you can be friendly. If I can help you in any way with advice or information, or any other way, just help yourself.

Now, I won't bother you any more, and you can go ahead and read the catalog and fill out the order sheet in the back.

Write soon.

HENRY FIELD.

P. S.-Don't forget about Seed Sense. You can get it for a year for only $25 \mathrm{c}$, or get it free if you order $\$ 2.00$ or over.

Copyright 1917 by Henry Field Seed Co. 


\section{To the New Customer}

Or at least I hope you will prove to be a customer. Maybe not, but I will keep hoping . anyway. Of course I do not expect to get an order from everyone I send a catalog to, but I am one of those optimistic, hopeful sort of fellows who always look at the brightest side first.

So we will take it for granted that you will become one of my customers, for a trial trip anyway.

And now that you are accepted as "one of the family" I want you to "just reach and help yourself" as we say when we have company to dinner. Look all through the catalog...study it carefully, pictures and all... and then give your order for what you want.

If you can't send me an order, write to me anyway, so I will know you are interested and want your name kept on the list. But I hope that you will send me an order, even if only a small one for trial. Besides being a grower of seed corn...good seed corn too...l am a market gardener and sell garden seeds of the kind that gardeners like to use. And that kind is good enough for anyone. And then I grow flowers, too. In fact I can supply anything in the seed line, and in a quality that I am proud to put my name on. Take an hour and read the catalog through and see what you think of it anyway.

Yours truly.

HENRY FIELD.

Shenandoah, lowa. 



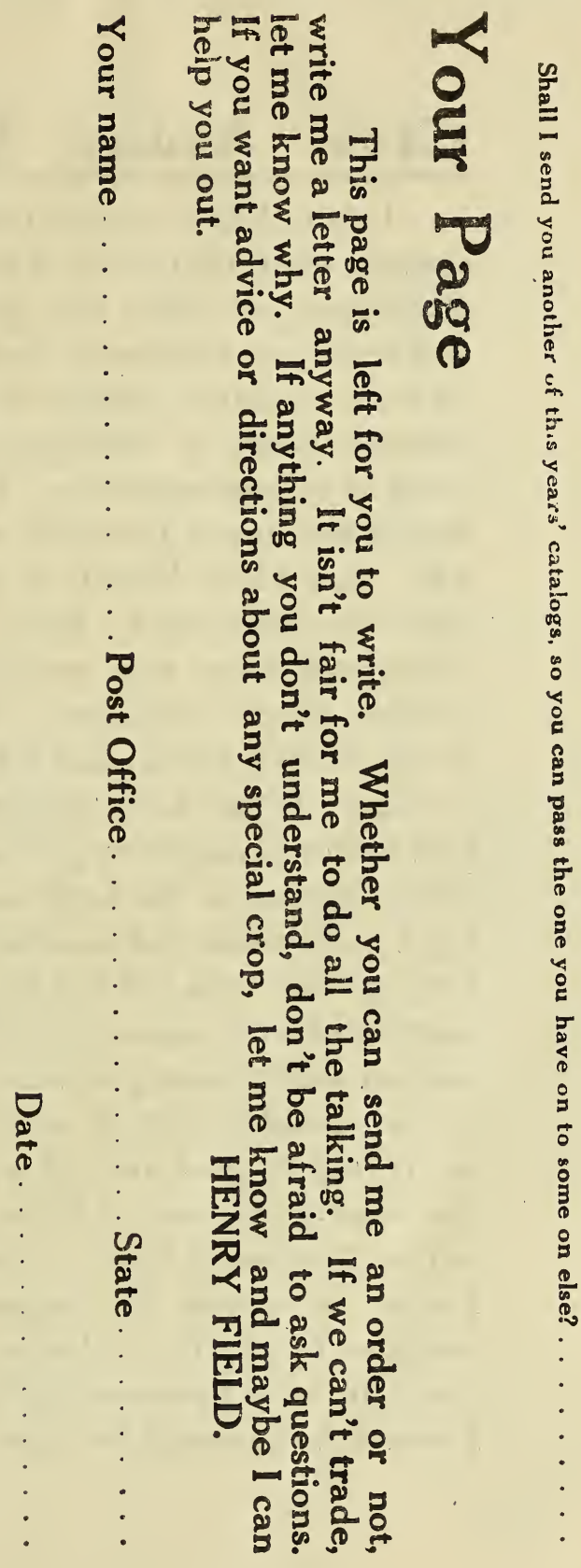




\section{Give Away Your Catalog}

I don't know of any better way you can do missionary work than to find someone who is not already a customer of mine and give them your catalog. I will send you another brand new one gladly, and will be ever so much obliged to you besides. You know yourself there is nothing goes so far as a personal word of recommendation. You have lots of neighbors who have never heard of me, and you have others who may have heard of me but have never been specially interested. Now, a personal word of endorsement from you would go a long ways toward making them customers. I feel that you would be doing them a favor, and I know you would be doing me one. If you have enjoyed my catalog, and really feel that you ought to give a word of encouragement and help, this is the best way you can possibly do it. I get hundreds and hundreds of orders every year from people who tell me that they are using a catalog borrowed from one of my customers. An order here and an order there gotten in this way will soon mount up to a good big lot of orders. Every order helps. I am trying to give you all a good, fair, square deal in the seed business,---a little better seeds and a little better treatment than you would get anywhere else. I want to spread the business and enlarge it just as much as I can. I am always wanting more customers. You can help by speaking to that neighbor of yours. I would do as much for you. Yours truly,

HENRY FIELD. 
AN APOLOGY: This story below is old to the old customers and I wish to apologize to them for printing it again, but it is new to the new customers, and I am reprinting it for their benefit. You old customers can sktp it or read it over again, just as you please. The new customer should read it, for nothing else will give so good an idea of what this business is like and why it grows as it does.

\section{THE BEGINNINGS OF A SEED BUSINESS}

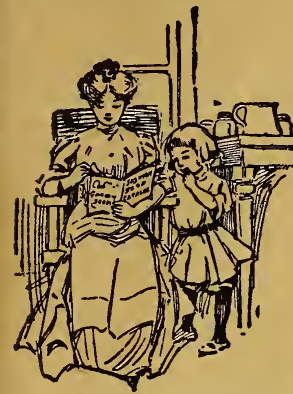

It all started from my mother reading the James Vick catalog to me; it was my dearest possession.

TT IS always interesting to look at a big business and know the inside 1 history of it, the reason for its being, and how it started. My seed business now ranks as one of the dozen largest in the United States. I have custom. ers at probably every postoffice in the country. I have a lovely big fire-proof building, and over one hundred people working for me, and it all traces back to 50 cents worth of home-grown flower seeds which I put up and sold over thirty-seven years ago when I was a boy five years old. I think it all started from the reading of the James Vick catalog. James Vick was really the father of the mail-order seed business, and I can remember yet just how that catalog looked to me. It was my dearest possess. ion, and I can remember having my mother reading it out loud to me. Up to that time my ambition had been somewhat divided, and I did not really know whether I wanted to be a policeman or a railroad engineer, but it certainly was to be one of the two. After studying the catalog, however, I wanted to be a seedsman, and I insisted that my mother write to Mr. Vick to that effect. The dear old man wrote me a personal letter in reply, which I carried around until I wore it out. He also sent me a colored picture of gladiolas, the first I had ever seen. All the next summer I was saving seed every chance I got, but when fall came, to my sore disappointment, I could not find any one who would buy them.

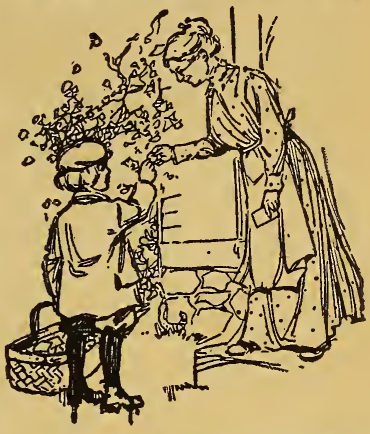

A kind-hearted old lady gave me an order for $50 \mathrm{C}$ worth of seeds. My first order.

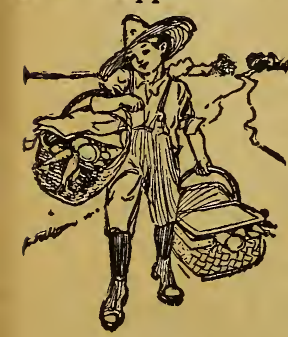

At eight years of age I embarked in the gardening business, walking 2 miles to town with garden stuff to sell,

Finally Aunt Martha Long, a kind-hearted old lady, out of the goodness of her heart, gave me an order for fifty cents worth of flower seeds, and I think I must have worked several days making up by hand the little envelopes to put the seed in, and getting them filled to my satisfaction. It may interest you to know that this old lady was until recently living at an advanced age out in California and was still a customer of the Henry Field Seed Co. At eight years old I embarked in the market garden business for myself, walking two miles to town with a bas. ket on each arm. My father and I were in partnership on the deal, and I got half the proceeds. The little old account book shows I cashed $\$ 3.65$ for my share. I was not in the seed business yet, but I was getting as near to it as I could. About this time I got a prize of a silver dollar from my Sunday school teacher for perfect attendance. I invested the whole thing in pansy seed and was going to get rich raising pansy plants to sell. After they were grown I was unable to sell any, as ours was a little country town with no market for flowers. Every year I got more and more into the market garden business. My father was a live-stock farmer, but my tastes ran entirely to gar-

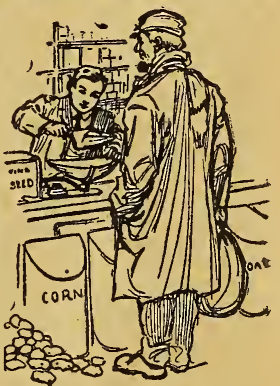

Worked in seed store at $\$ 3.50$ a week, but the inspiration I gained
made it worth while. den stuff and flowers and fruit. He humored me in this and allowed me to have practically a free hand at my kind of farming, and worked up quite a trade on strawberry plants and seed potatoes

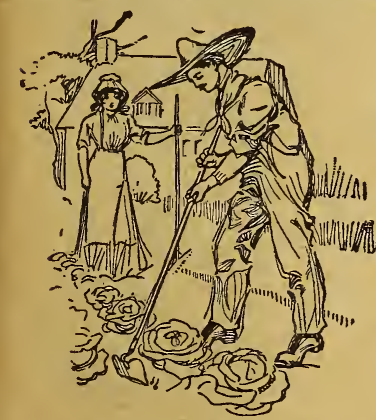

When I was twenty-one, I was doing a big market business on my own little truck farm. the chance, and it may interest you to know that the plans formu lated at that time, now over twenty-three years ago, are the identical plans

of improved varieties. At fifteen I got my first experience in real seed business. At that time Livingston's Seed Company, then and now of Columbus, Ohio, had a branch house at Des Moines, Iowa, in charge of one ot the sons, Jo. siah. I went to Des Moines and worked in the seedhouse all winter for him. It was there I met the late A. W. Livingston, of tomato fame, a lovable old man, and I gained from him a bigger and better idea of the seed business than I had ever had up to that time. I worked for $\$ 3.50$ a week that winter and paid $\$ 3.00$ of it for board, but what I learned, and the inspiration I gained, made it richly worth while.

I could not get into the seed business on my own account yet, however, as it kept me busy making a living, but all of out how I would run a seed business if I got 


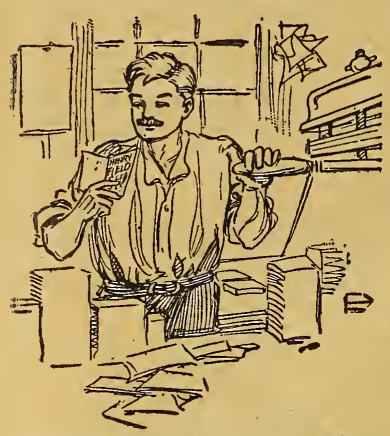

My first catalog .. a litt'e four page folder that I printed nights myself, on a hand-power printing press. My business was very small then. The next year I had a twe've-page catalog with some pictures in it.

a hand-power printing press. them. The next year I had a was as yet very small.

About 1902 I built my first

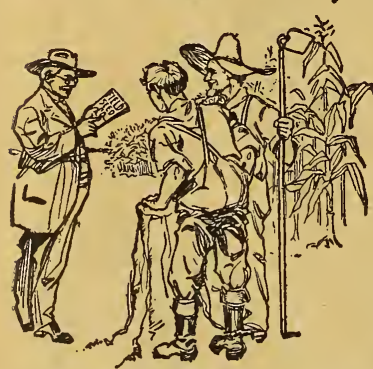

We are still growing. Every customer recommends me to two or three others. Most of our new business comes from personal recommendations of satisfied customers. But back of it all is the fact that I have delivered the goods. tically every seedsman in the United States now offers ear seed corn. Then along about 1906 I commenced grading my shelled seed corn,

that have made the Henry Field Seed Company the great and prosperous firm it is, and are still the backbone of the business. By the time I was twenty-one I was doing a big trucking and market-garden business on my own account, was married and settled down on a little truck-farm of my own (bought on long time). I had a big local trade in strawberry plants and seed potatoes, and about this time I began to broaden out into a seed business in a small way. I raised seeds myself from choice strains developed in my market-garden business. and the neighoors kept coming to me for seeds. They noticed that I had pretty fair luck with gardening, and they wanted the "same seeds that I used," so I took to soliciting orders among my neighbors every winter, and would work nights and stormy days putting up the seeds and getting them ready for delivery. I was the whole thing, from catalog to delivery wagon. I sold good dependable seeds at a reasonable price, and helped my customers in every way to make a success with them. Of course, the business spread.

It wasn't long before I was supplying half of the county, and getting mail orders from outside. I had to turn the front room of our little four. room house into an office, and the barn into a seedhouse. Pretty soon I had to get out a catalog or price list. This was in 1899.

It was a little four-page folder that I printed myself nights on I worked nights for two weeks or more getting out a few thousand of twelve-page catalog with some pictures in it, but of course the business st seedhouse, a story and a half structure cost
name in big letters across the front of it. Maybe you think I wasn't proud of it. It seemed a terrible venture to put that much money into a business, and the building was really bigger than it seemed I would ever need, but I had the nerve to go ahead with it. Below is a photograph of it.

That was 13 years ago. Well, we had to build an addition to that building every year. By 1907 we had built on every side of it and there was no room to build any farther. In 1903 we had put out our first catalog. It was thirty-two pages, nicely printed and with a colored cover.

About that time, possibly the next year, I started the crusade for selling seed corn in the ear instead of shelled. The seed trade laughed at me, then growled at me. They said I was unsettling the so it would run in an edge drop planter. This was the first attempt any seedsman ever made to do such a thing. They all do it now - they have to.

All this time the business has been growing and expanding until it had entirely out-grown our facilities, so in 1907 some of my friends told me I ought to incorporate the business and let them help me. They offered to go in with me and help put the business in shape so that we could take care of the customers in the right manner, so we organized the Henry

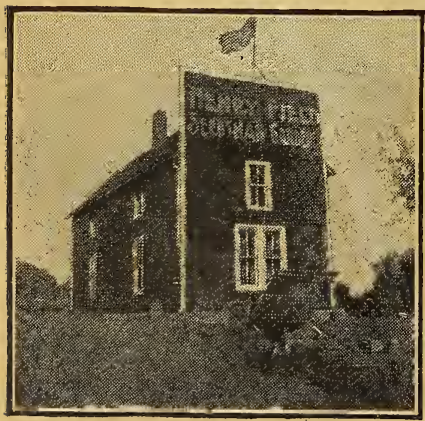

Field Seed Company with $\$ 75,000$ capital and put up a fine, big, fire. proof seed house down near the track where we could load and unload the cars right at our own platform. On the next page is a picture of the building just as it looks, but it does not show the seed corn annex, which is a building about the same size, but not so tall, on the other side of the main building as it shows in the picture.

We have beautiful grounds around the building, all planted to flowers, and trial grounds, and such as that. The seed growing is on farms further out, except small particular Iots which I have here on the home grounds, where they can be right under my eye. We have a splendid printing office right My First Seed House in 1902 in the building, where we do all of our own

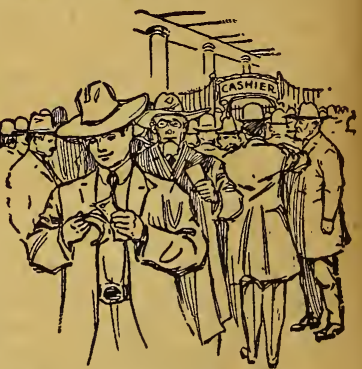

We furnish over one-half f the postal business of this town, and have the largest winter payroll in the town, employ. ing over $\alpha$ hundred poople in the

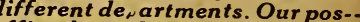
office here does more business than any other in this congress. ional district. We keep o r post. master and his employees on the rometimes,

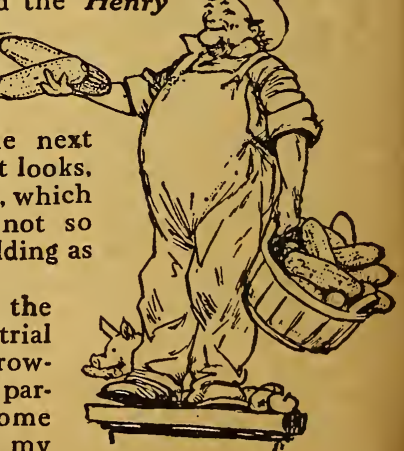

"From lowa and IProud of it" 


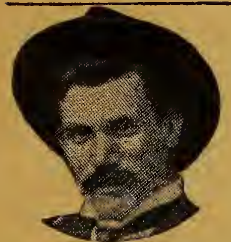

Henry Field Seedsman

Pres. and Gen. Mgr. Henry Field Seed Co. printing. In a busy time we have over 100 people working in the different departments. We furnish nearly one-third of the postal busi. ness of this town, and have the largest winter pay-roll in the place. We have probably the finest collection of peonies in the world, over $\mathbf{3 0 0}$ named varieties, many of them very rare. We have a collection of gladiolas which flower lovers have come hundreds of miles to see when they were in bloom. We have built up the grade of seed corn around Shenandoah until Page county is known for the excellence of the seed grown here, and it all traces back to the five-year old boy studying Vick's catalog and making a sale of $50 \mathrm{c}$ worth of flower seed.

And we are still growing. Our increase last year was over 50 per cent, At the time this is written, our increase this year so far is above 80 per cent over last year. Where it will stop I don't know. Every customer recommends me to two or three others. Of course, I have advertised, and sent out nice catalogs and all that; but back of it all is the fact that I have delivered the goods.

All the good advertising in the wcrld wouldn't do a bit of good if I didn't back it up with value received. I know that as well as you do. The advertising is simply my show-window to attract customers. After they come once, it is up to me to keep them coming, and I really believe that four.fifths of our new business comes not from advertising, but from the personal recommendations of satisfied customers.

HENRY Field.

P. S. - I want your help to make the business bigger yet. Speak a good word for me to that neighbor of yours and hand him your catalog. I will gladly sent you another.

H. F.

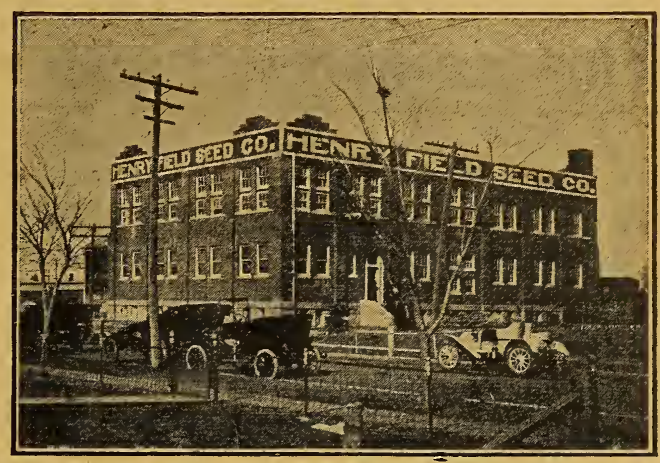

Our Big, New, Fireproof Building, Built in 1907

The Business as it is This story was written and printed several years ago, but there is nothing special to be added to it the same as ever, and following out the same policies that we have stuck to from the start. We are not getting rich, but we are getting three meals a day and a fair amount of clothes and a place to live, and that's about all any one is getting. The business is flourishing like a green bay tree. We have two more buildings now. have a big print shop, where we print this catalog and Seed Sense and all the other printed matter we use, and we have more customers and more friends and better seeds than ever. We send catalogs and seeds to practically every postoffice in the United States. Our postage expense last year was over $\$ 53,000.00$ or more than all the rest of Shenandoah put together.

In the busy time we have as high as 200 peo. ple working here at the seed house.

H. F.

\section{Buy Garden Tools Early}

W

ITH the present high prices of steel and labor, it was naturally to be expected that garden tools would advance in price, but we have managed to stave it off till now. And in fact we have managed to postpone it till about next April, which will give you a chance to get in ahead of the increase yet.

We have received notice from the factory that all garden tools will hereafter be billed to us at an advance of 25 per cent. in price. The Iron Age No. 6 for instance, which has been selling at $\$ 12.00$ will now be $\$ 15.00$ and so on. Other makes, I un. derstand, are affected in about the same way.

We have been expecting this and have been carrying about a carload of Iron Age garden tools ahead, all the time, and so we now have about that many on hand, bought at the old prices, and while they last we will sell them at the old prices So:

While present stock lasts (probably till about April 1st) we will sell Iron Age goods at old prices, as printed in our big catalog. When they are gone (April 1st or sooner) we will advance prices $12 \frac{1}{2}$ per cent. No promises good after August 1st.

You will note that when we do advance prices, we will divide the advance with you, assuming half of it ourselves. That will take care of the balance of the season, or up to August. After that there may be a new list higher yet.
Meanwhile, the thing for you to do is to get busy and buy your Iron Age garden tools now while you are sure of getting them at the old prices. You ought to have them, you can't scarcely garden without them, and at present prices they are the cheapest and best thing in the implement business.

\section{A Good Year to Make Garden}

With all kinds of eatables selling at recordbreaking prices, this year is going to be a splendid year to make garden. Either for home or market. The one sure way to beat the "high cost of living" is to raise your own living. It can be done easily. Maybe not all of it, but a big part of it.

It costs no more to make garden than it always did. No increase there. The garden will yield just as much and just as good stuff. With everything at the grocery store and the butcher shop about doubled in price and cut down in quality, it is time to declare your independence and grow your own eatables. Of course you can't live on vegetables entirely, but what is lacking can be supplied by a few hens, and you can grow most of the feed for them.

\section{Price of Sudan Seed. Page 85}

On page 35 , price of Sudan should read $40 \mathrm{c}$ per lb. postpaid, and Special Offer right below should read 3 lbs. for $\$ 1.00$, postpaid. 


\section{The Rainbow Chaser}

I started out to call this a page of fakes, and then I changed my mind, for my courage tailed me. I was afraid I might hurt some one's feelings; and by telling the truth about some of these wonderful "novelties", I am certainly stepping on the toes of some mighty prominent seedsmen. I confess that two or three of these things I have listed and sold myself with at least a half-way endorsement; but then I always was a little inclined to get a little bit over-enthusiastic, and some of these things really do seem attractive, especially the first year they are grown.

The Rainbow Chaser The rainbow chaser is hunting for something wonderful, something fine, something greater than anyone has ever had before. That is a commendable spirit, but sometimes carried to extremes; and, sad to say, some of the seedsmen have banked on this trait among their customers and offered wonderful "novelties", which, to say the least, were overboomed. It is a wonderful temptation to do this. Just as sure as one of those wonderful "novelties" is announced, I get hundreds of letters asking why I do not offer it for sale. They are all ready to buy and begging for a chance to spend their money, and they cannot understand why I want to wait and try it a year myself. They think I am behind the times.

All these new things that come out I try at least one year myself before I offer them, then, if I am pleased with it, I offer it for sale to my customers. On the contrary, if I am not suited with it, if it looks to me like a fake, I simply say nothing about it. At least that is the way I have always done, but have decided that this year I would take two pages for my own use, and tell the cold, brutal truth about some of these wonderful "novelties." I also offer them for sa e, and $m a n y$ not listed here I can supply. I fact, any wonderful novelty or new creation that you see offered by other seedsmen I can generally supply at a reason. able price, and also I can probably tell you the real truth about it, whether it is of real value or not.

Now, mind you, I don't say these things are fakes, pure and simple. I do say they have been over-boomed. They have points of value, and are of real value in some special locations, but they are not suited for general culture, as a rule, and

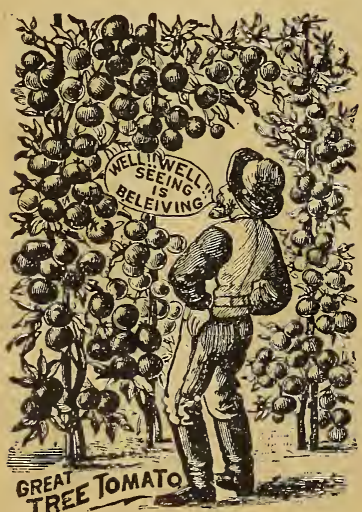
should not be planted on a large scale with. out thorough trial in a small way first.

\section{The Wonderberry}

The Wonderberry for instance - did you in. vest in that? Hundreds of my customers begged me for seed, but I was afraid of it. and wanted to wait a year

If you planted some, or your neighbor did, you know all about the wonderful $\mathrm{W}$ on $\mathrm{d}$ e $\mathbf{r}$. berry now. It was said

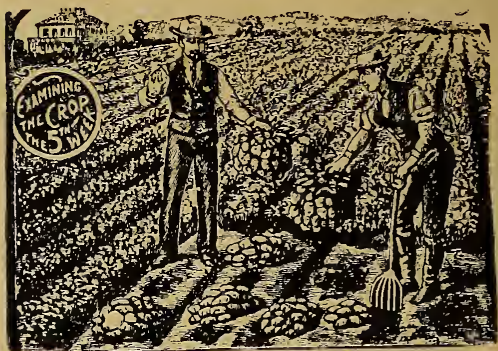

to be wonderfully delicious, even luscious. Have you eaten one? How did you like it? Did you cry for more? I know several people who have eaten some of the berries and I have not yet found any one who is leaving out his strawberries to plant Wonderberries.

Himalaya Berry It is barely possible that this will be very nearly what is claimed for it, but I am rather doubtful about it. On our own grounds it is certainly a strong grower, but it has not lived through a winter yet for me. Samples of the fruit which I have seen are much like blackberries, but rather small. I do not believe it will make us rich, or take the place of blackberries, but it is worth experimenting with.

Pencillaria. I plead guilty to having listed this myself for several years. Under favorable conditions it makes an enormous growth, and I was greatly pleased with it, and I still believe that in good weather and right conditions, it will make more growth than any fodder crop you can plant; but if you allow it to get much size it is too tough to be of any account. It is hard to get a stand, too. I thought honestly that it was different from Pearl millet, but I now really think it is absolutely the same thing as Pearl millet, or Cattail millet. Pkt. $10 \mathrm{c}, 30 \mathrm{c}$ per pound, postpaid.

Billion Dollar Grass (Japanese Millet, BarnBllon Dord Millet). This is simply an overgrown type of the common barnyard grass family. It makes a rank. ragged growth, and on rich ground will make a large yield of hay, but of doubtful quality. Price, large pkt. 10c, 30c per pound, postpaid.

Jerusalem Artichoke A rank weed that you set rid of. Yield of roots is small, and quality poor. Let them alone.

Helianti. This wonderful vegetable from France, Helianti. which was to revolutionize farming. I find to be very similar to the Jerusalem Artichoke, but not so good. The roots look like Artichokes, but are smaller and more tender.

Teosinte This is the wonderful fodder crop that Teosinte is supposed to yield 300 tons of green fodder per acre. The fact of the matter is that it is a sub-tropical plant which will not grow in this country except in the hottest weather and under the most favorable conditions and then will not make so much as good corn fodder would. It is quite a curiosity in that it stools, making sometimes 20 to 30 stalks from a single seed, and with great care and a warm location it will sometimes make a big growth of fodder. Large package, 25c, 75c per pound. 


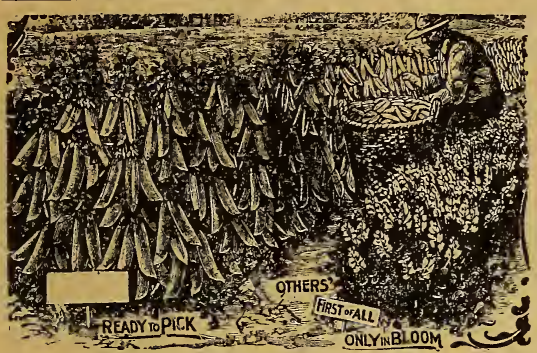

\section{Rainbow Chasers Continued}

I see right now that if I am going to name all these wonderful "novelties" that are offered to the public, it will take more pages than I can spare. You know the list about as well as I do. Here are some of the old timers:

Sacaline, the wonderful forage plant from the coast of Asia; Bohemian Oats, which were all the rage here about 15 years ago; the Tree Blackberry, from which we were all going to get rich; the Japanese Wine Berry, the Crimson Winter Rhubarb, Alaska Wheat, and so on,

It's no use to try going through the whole list It would take too long and wouldn't do any good anyway. I guess there's no way but to let the people buy these things if they want them. But coming down a little closer to actual values, here are a few things you want to look out for:

300 Bushel Corn You all know as well as I do this weak and erring world that we everget beyond 100 bushels of corn per acre. On small plots I have got 185 bushels per acre, but that's "going some," and when any one offers you 300-bushel corn or

\section{About Trying Novelties}

I don't want you to think from what I say above that 1 am opposed to new varieties. The horticultural world progresses by the addition of new and improved varieties, but a tendency with many seedsmen and nurserymen has been to run wild on these new things, to get over.enthused about them and to over-boom them. Now, I want you to try new varieties that look reasonable, possible and sensible, but don't risk your whole crop on any new variety and don't spend much money on it the first year. Try it out in a small way first, trying a few new things each year. Then after tney succeed well and look profitable, you can go after them hard the next year. And above all, don't fool with new things unless they look reasonable and possible. You can easily tell by reading the description and looking at the pictures whether the man is really trying to tell you the truth or is simply trying to hoodwink you. If he tells you things that you know from your own experience are absolutely foolish, don't bother with him for a minute.

Of course, you can see for yourself the difference between natural enthusiasm or personal pride in ynur own production, on the one hand, and downright guff on the other hand. even 200-bushel corn, just make him show his papers.

200 Bushei Oats Some oats are offered as 200 bushels and some as 17.5 per acre, and you know as well as I that even in the wonderful irrigation country it is seldom that they get over 100 bushels.

47-Day Tomato The best that any State Exable to go on tomatoes was 95 days from seeding to harvest.

35-Day Potato If you can get potatoes big planting the seed, enough to eat in 35 days from planting the seed, you are beating anything I can

That kind of potatoes would be worth about $\$ 100$ a bushel, but I haven't got them. Now, I could go on here all day, telling you about these things, but I don't believe it is necessary. If you want any of these wonderful things, I will sell them to you and you can get the experience cheaper than you could in most places; but you take my advice and stick to things that sound at least reasonable.

P. S. I knew one man who bought some 300 bushel oats. Hc said he didn't believe they would yield that much, but even discounting it 50 per cent they would be great stuff. I asked him how he fixed his percentage. If he admitted that the man who sold them was 50 per cent liar, why not 100 per cent.

He tried the oats, anyway, and he's raised his percentage.

P. S. While you are about it you might add the Thornless Cactus, the Seedless Apple, and the Belgian Hare; and you might as well add Ginseng, too.

P. P. S. Add the SeedIess Watermelon, too.

I wish to apologize for these pictures. They are simply specimens of the Rainbow Chaser style of pictures clipped from representative sources. Do they look familiar to you,

\section{A Prosperous Year}

We have just finished our 1916 year and I am happy to say we have had the biggest and best year in the history of our business.

The sales for the yesr were $\$ 412,91229$.

Here is our history for the last four years tabulated so you can see at a glance what we have been doing.

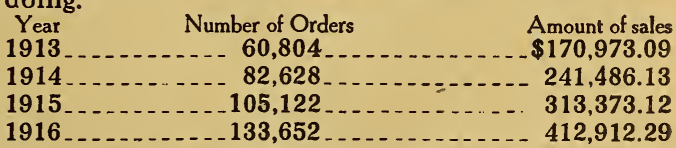

I could carry it back still farther, but this is far enough to show you how it is running. And it looks like the next four years would show an even greater percent of increase.

So far as I know there is no other catalog seed house in the west doing anywhere near as much business as we are, and not over half a dozen in the whole country. And none of them showing anywhere near our rate of gains.

Of course there is a good reason for all this, but $I$ am too modest to mention it: You can figure it out for yourself. One thing is sure, we couldn't make any such gains if we had to get a new lot of customers every year.

H. F. 


\section{Watermelon Contest for 1916}

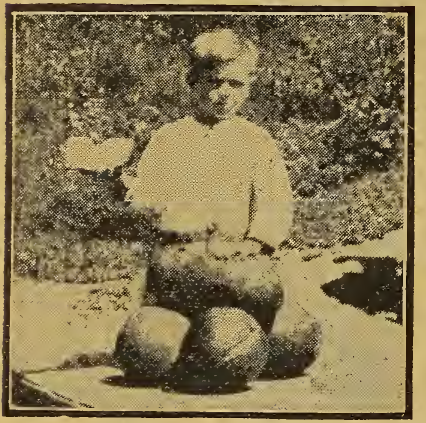

GLENN TAYLOR, Merrill, lowa, Rt. 2

"Papa gave me a little patch of ground near our house; and I planted the seed. Ihad ahout thirty hills and the seed grew fine. Thoed them and they were fine. When they were big and almost ripe some neighbor boys came and stole most of them and I didn't have very many left for my picture, but we had a few to eat and they were real good. I hopel will have better luck with my me ons nexlyear."

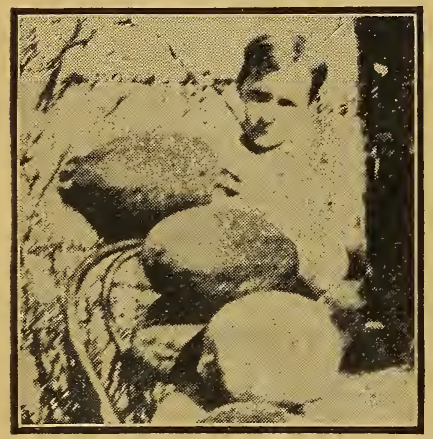

DOW CALHOUN. Gravette, Ark.

"I bought one package of boys' collection of watermelons. It had 340 seeds in it and I planted 56 hills. There was 12 missing hills I planted the hills 7 feet apart. I dug a hole and put one large scoop shovel full of manure out of the barn. They done well considering the dry weather. I am sending you my picture. I am 8 years old"

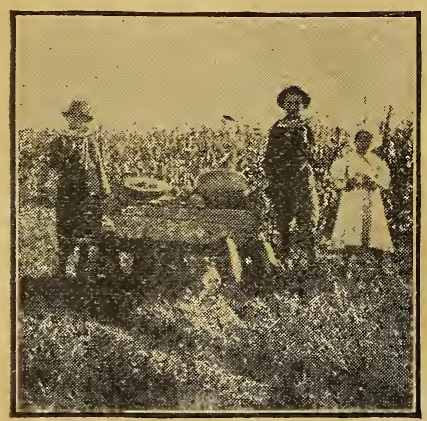

\section{RALPH AND FLOYD BISHOP,}

Benkelman, Nebr.

"We will send you a picture of our water melons. This is Floyd and Ralph Bishop. We planted a collection of seeds from you and raised a good many. We are 11 and 9 years old."

\section{Prizes awarded as follows: \\ 1 st Prize $\$ 5.00$ \\ Lloyd Matzinger, Hoyt, Kans. \\ Six Prizes of \$1.00 Each}

Virgil Lontz, Cement, Okla.

Philip Jenkins; Sioux Falls, S. Dak.

Alton and Clifton King, Piney Flats, Tenn.

Clifford Frederick, Blockton, lowa

Master Lawrence Phippen, Exira, lowa

Ben Dukeshier, Red Oak, lowa

The Following Received 50c Each

Dow Calhoun, Gravette, Arkansas

Harold Willcutt, Ida Grove, lowa

Amma Adsit, Foster, Nebraska

Curtis and Carl Tomlin, Unionville, lowa

Ira Baldwin, Litchfield, Minnesota

Homer Pike, Lusk, Wyoming

Rulie Elliott, Wild Cherry, Arkansas

Lela Lee, Harlan, lowa

Howard A. Routh, Hermon, Illinois

Sam C. Spessard, Cfinton, Tennessee

Glen and Mary Berndt, Ansley, Nebraska

Joe Webber, Jr., Platteville, Colorado

Myrtle Brewer, Limon, Colorado

Harriet Wardlon, Alberr Clty, lowa

Lee Forunon, Rand, West Virginia

Iva Brittain. Sidney, lowa

Virgil Pearson, Wakefield, Nebraska

Mrs. P. A. Herrick, Bethany. Nebraska

Ivan Davis, Knox City, Missouri

Rex Miller, Lexington, Nebraska

Alva Willingham, Charleston, Illinois

Thelma Halton, Waynoka, Oklahoma

Glenn Taylor, Merrill, lowa

Oren Postma, Monroe, lowa

Ralph and Floyd Bishop, Benkelman, Nebr. Jack Gilfillans Jro, Plattville, Colo.

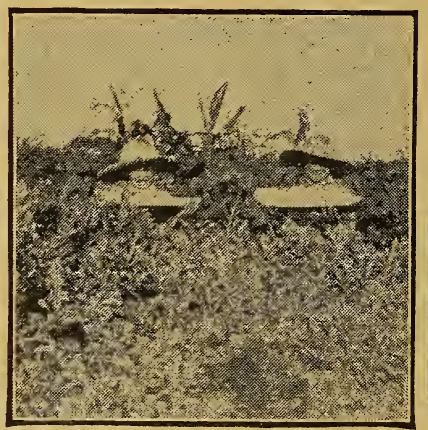

JOE WEBBER, JR, Platteville, Colo.

"Here is a picture of my brother and my" self in my watermelon patch. My brother is 8 and I am almost 10 . My watermelon patch was fine and we had a lot of them, but we gave most of them to the neighbors. I hoed them and took care of them myself and also helped to take care of the garden. Mama got her seed from you. This is the first time she used your seed and she had a good garden. The muskmelons that she got were fine. All the neighbors asked her where we got the seed and we told them from Henry Field. We got enough vegetables to last us all winter. Mama said she would always send to Henry Field af ter this for her garden seeds,"

Can You Do As Well As These Boys?

You surely ought to. Try it this year and see. It doesn't cost much for the seed. Most of these boys used the Boys' Watermelon Collection which I sell for $10 \mathrm{c}$. Wouldn't it be fine to have a patch of melons like these boys raised? And see the money some of them made, too. Get busy this year and show them,

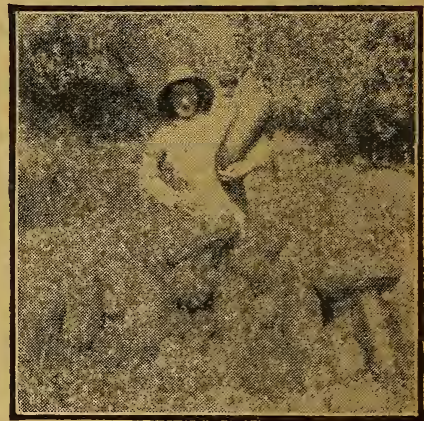

REX MILLER, Lexington, Nebr.

"I bought some melon seeds and planted them them the last half of May. They came up fine, so I put some tobacco dust around the roots to keep the bugs away. I hoed and cultivated them between the rows several times and I stirred and weeded them around the hills. I think the Kleckley Sweet melon is the largest and sweetest melon there is. The largest of my melons weighed from 20 to $35 \mathrm{lbs}$. a piece."

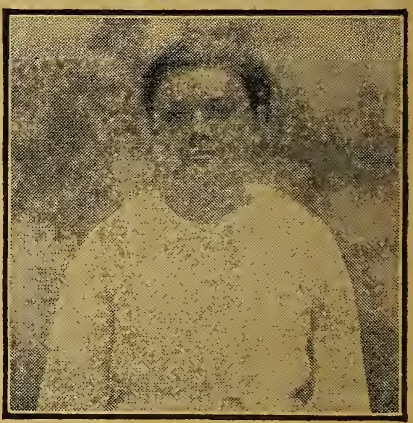

IVA BRITTAIN, Sidney, lowa

"I planted my melons May 25th. We hoed them four times and pulled the weeds twice. I believe every seed I planted grew. I had lots of melons to eat, as there were lots on the vines. The Halbert Honey was the finest melon, they were so sweet and juicy. I can recommend your garden seeds very tighly. I want to he sure and be in your melen contest next year."

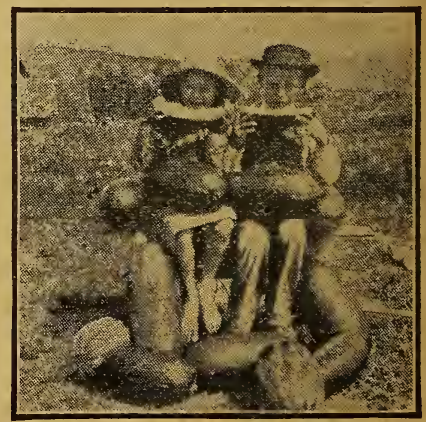

GLENN AND MARY BERNDT, Ansley, Nebr.

"I am sending you a picture of me and Mary and some melons we raised from the seed we got of you. We had some awful fine ones. I wish you would put our pictures in Seed Sense. I am 8 and my sister is 7 ." 


\section{Watermelon Contest For 1916}

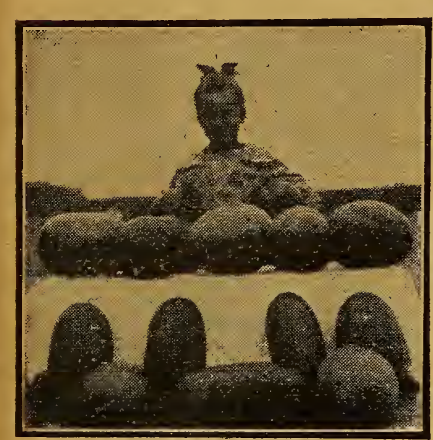

MYRTLE BREWER, Limon, Colo.

"My brothers are not old enough to en ter the contest so I thought I would try it. I planted the seed May 24th in hills $6 \mathrm{ft}$. apart each way, but the ground squirrels took them so bad that I had to replant them June 17th. This time they did fine and we had melons of all kinds, but the Princess was the first to get ripe. I am only 9 years old.'

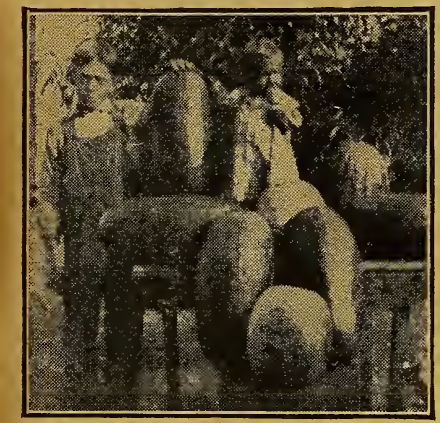

VIRGIL LONTZ, Cement, Okla.

"I had 75 hills. Two hills did not come up, leaving 73 hills. Were plowed and hoed four times. The first ones ripened July 8th. We had a fine lot of them and a large variety. They grew fast and soon covered the ground and ran away out on each side of the patch. Will send you a pi ture of me with a few of my melons and baby brother. The one $I$ am holding up on end weighed $49 \mathrm{lbs}$. It was a Tom Watson."

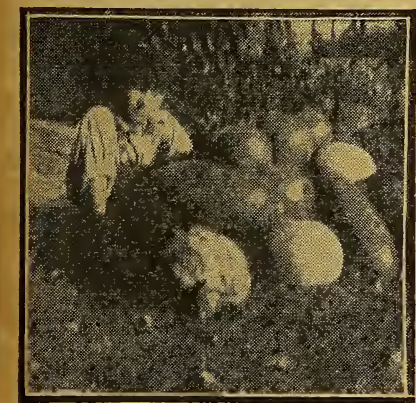

HAROLD WILLCUTT, Ida Grove, Iowa

"Here is a picture of myself and the melons I raised from my boys' watermelon collection, I planted seed May 15th. I plowed them four times and hoed them twice. They lid fine. We like the Princess and Golden Honey the best of all."

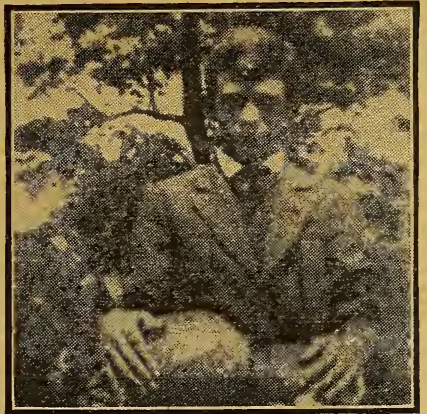

LEO FORUNON, Rand, W. Va.

"I am sending you one of my melon pictures I had made in my melon patch. My little 12 year old brother made it. It is the first picture he ever made and it is not very good. I am having very good melons this year. The picture is a Tom Watson and another kind I got of you.
I think the biggest one in the picture weighed about $25 \mathrm{lbs}$, but I had some larger ones than this one. I like the Angels Kiss better than any melon I ever tasted.

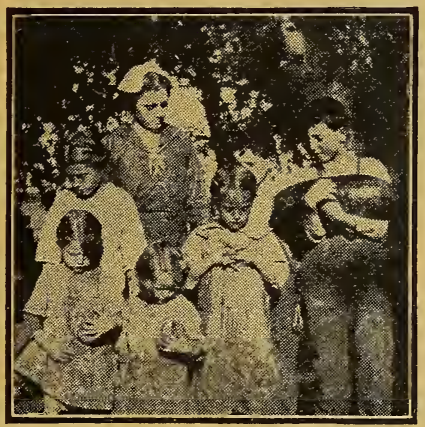

\section{LAWRENCE PHIPPEN, Exira, lowa}

"We just had one row of watermelons across the garden, which is a hout 3 rods, and one row of muskmelons. I raised the watermelons and my brother Earl the popcorn and my sister the muskmelons, $U_{s}$ boys dropped some watermelon seeds in the path across the end of the garden and they came up and mamma just left them there and they grew, and had lots of nice melons on them.

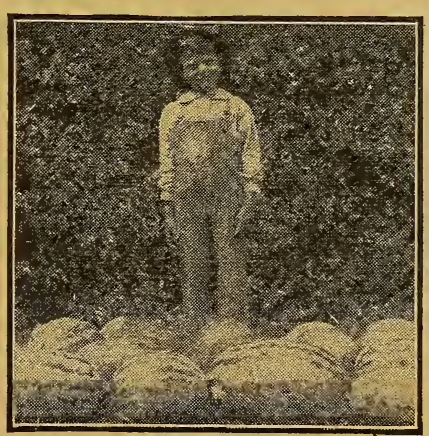

LLOYD MATZINGER, Hoyt, Kans.

"I am sending you a picture of myself and some of my watermelons. I raised 30. Three of them weighed $30 \mathrm{lbs}$. each. I planted them in an old hog lot fourfeet apart."

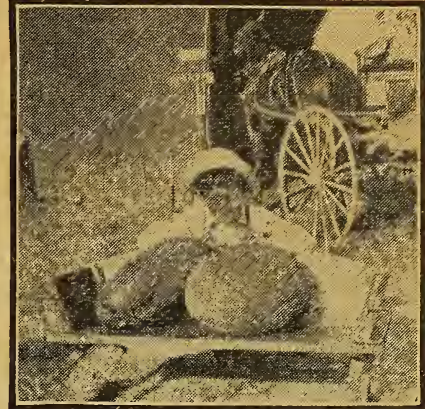

ALVA WILLINGHAM

Charleston, Ill., Route 7

"I planted 53 hills and got $\$ 2.55$ out of my melons. I got $20 \mathrm{c}$ a piece for these melons in the picture. I treated my schoolmates by taking 8 melons to sehool one day and we had melons to eat each recess and at noon. They all thanked me for them and said they were good. My grandpa lives with us and had a large melon patch. He helped me with mine and I helped him."

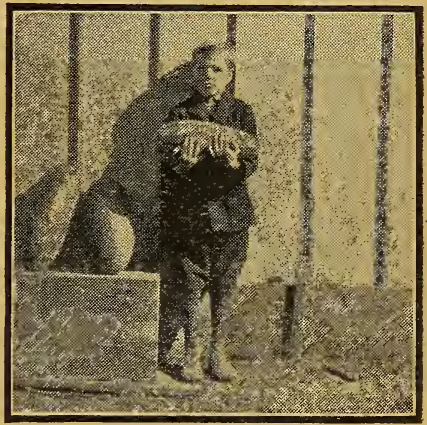

HOWARD A. ROUTH, Harmon, Ill.

"The watermelons didn't begin to grow good until late, and the cut worms and the little striped bugs eat them some, and the birds pulled about half of them up to get the seed, I got pretty hot hoeing them, and I sprinkled lime on them nearly every morning. I had enough seed to plant 76 hills. We ate the biggest ones, so did not get them in the picture, and they were fine.

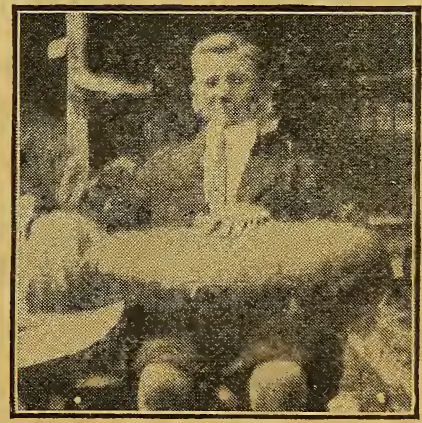

SAM C. SPESSARD, Clinton, Tenn.

"I raised some pretty good watermelons on an old shaggy hill from your watermelon collection. I planted the seed about the middle of April. They were plowed and hoed twice. The seed came up well and grew fast. 


\section{Girl's Muskmelon Contest for 1916}

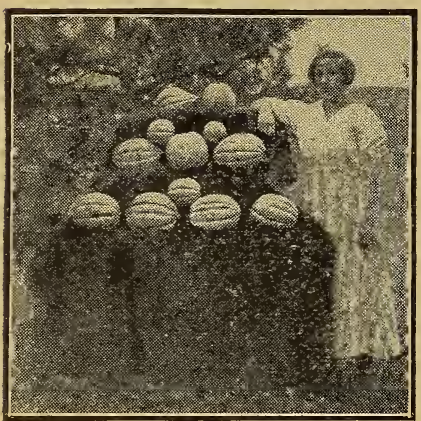

BESSIE HLINA, Fairmont, Nebr.

"I got a collection of your muskmelon last spring. I planted them only once and got a good stand. First I got the ground ready and then I dug holes about two feet apart, putting from five to six seeds in a hill. In a few days they all came up. I then thinned them out and kept them weeded and they grew very nicely. I think I had a pret ty good crop."

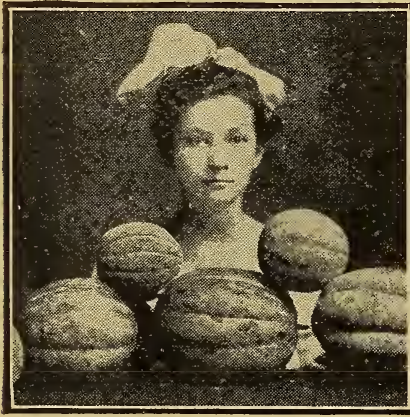

GOLDIE MILLARD, Lamar, Mo.

"I didn't have very good luck this year because it was so dry and hot. I am sending my picture and some of my muskmelons to you. Daddy had some fine watermelons from the seeds he bought from you last Mareh. He had one melon that weighed 55 nounds."

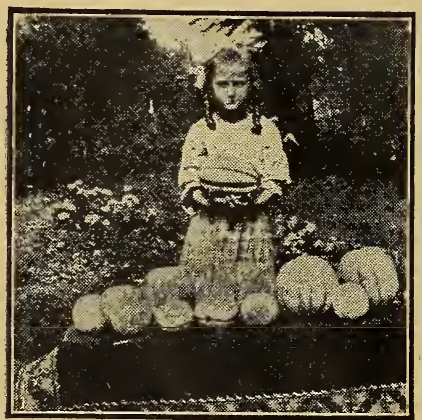

CECYLE POSTMA, Monroe, lowa

"I will send you a picture of myself and some of the muskmelons I raised from the package of the girls' muskmelon collection. I only planted about half the seed. I had only twenty hills. They all come up, but the cut worms took half of them. What I raised were good. I'm only seven years old. I'm going to try , some more of your seeds
Prizes awarded as follows:

\section{First Prize $\mathbf{\$ 5 . 0 0}$}

Grace Nichols, Burwell, Nelraska

\section{Four Prizes of $\$ 1.00$} Each

Miss Ollie Ramsey, Bern, Kansas

Goldie Millard, Lamar, Mo.

Bessie Hlina, Fairmont, Nabraska

Miss Bessie Muttersbaugh, Blufton, Indiana The Following Received 50c Each

Beulah Brittain, Sidney, lowa

Bernlce Brewer, Limon, Colorado

Mildred Routh, Hermon, Illinois

Hazel Lontz, Cement, Oklahoma

Hazel McLucas, Des Moines, lowa

Cecyle Postma, Monrne, lowa

Dolly V. Wales, Oltver, Illinois

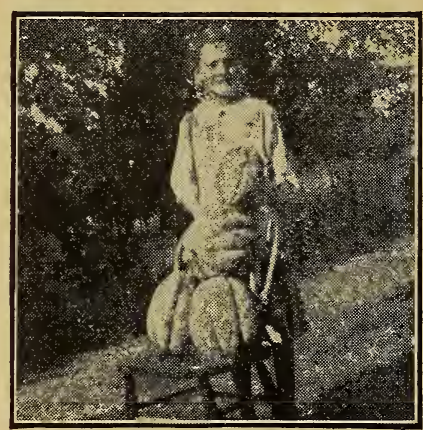

HAZEL McLUCAS, Des Moines, Iowa

'Last year I saw in your Seed Sense about the girls' melon contest and I thought I would like to try it. So papa sent for one of your ten cent collections. The ground they were planted on was fall plowed. I planted the seeds May 11 th, and the first ripe melon I had was on August 13th. It weighed 8 pounds. I am 13 years old and am in the $7 \mathrm{th}$ grade. I am sending you a picture of me and my melons. The one in the middle weighed ten pounds.

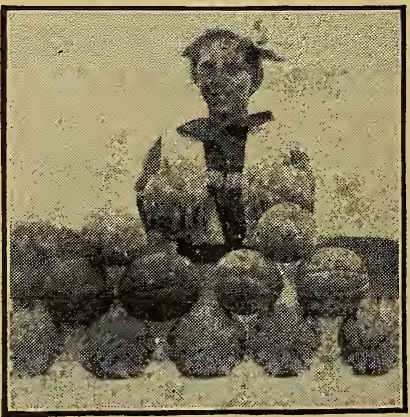

BERNICE BREWER, Limon, Colo.

"I am sending you a picture of me and my muskmelons. I had to plant them twice before I got a good stand. The first time they were planted May 24th; the second time June them well hoed and they grew fine, but the season was So short that we had a small wagon load that never got ripe. But the ones that did get ripe were surely fine. I am 12 years old.

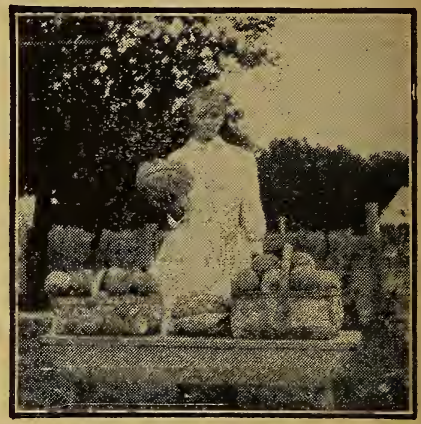

MISS OLLIE RAMSEY, Bern, Kans,

"I raised about $\mathbf{4 5 0}$ muskmelons and cantaloupes. I had some that weighed 16 lbsThey were great big ones and just as sweet as sugar, especially them orange color. We ate all we could eat and gave a lot away to the neighbors."

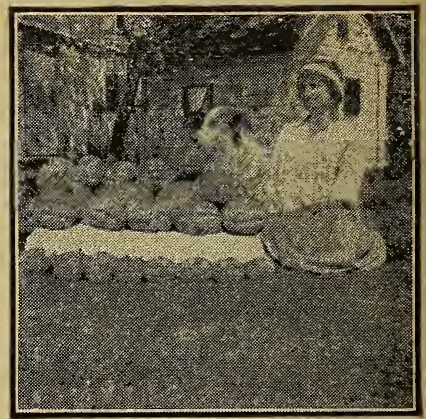

BESSIE MUTTERSBAUGH,

Bluffton, Ind.

"Last May I planted about one-half package of the contest muskmelon seed. We only had a small lot, so I could only plant about one half of the seed. The picture is off the melons I raised from them. They were all ripe when it was taken September 2. Field's Daisy is my favorite muskmelon.

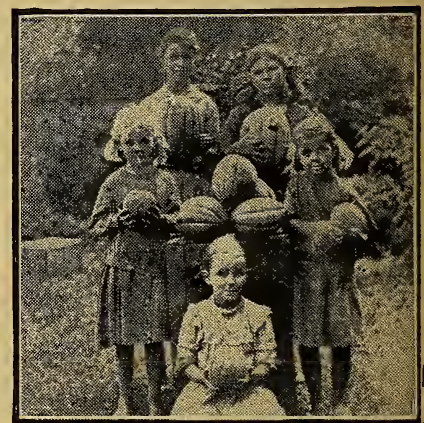

GRACE NICHOLS, Burwell, Nebr.

I hree of us girls planted the muskme'on seed May 10th. We hoed them ab ut four times and kept them clean of weeds. They all done pretty well but in July it got pretty dry. It did not rain for about six weeks. But we had more melons than we could eat. We sold some and gave some away. We like the Daisy Muskmelon the best." 


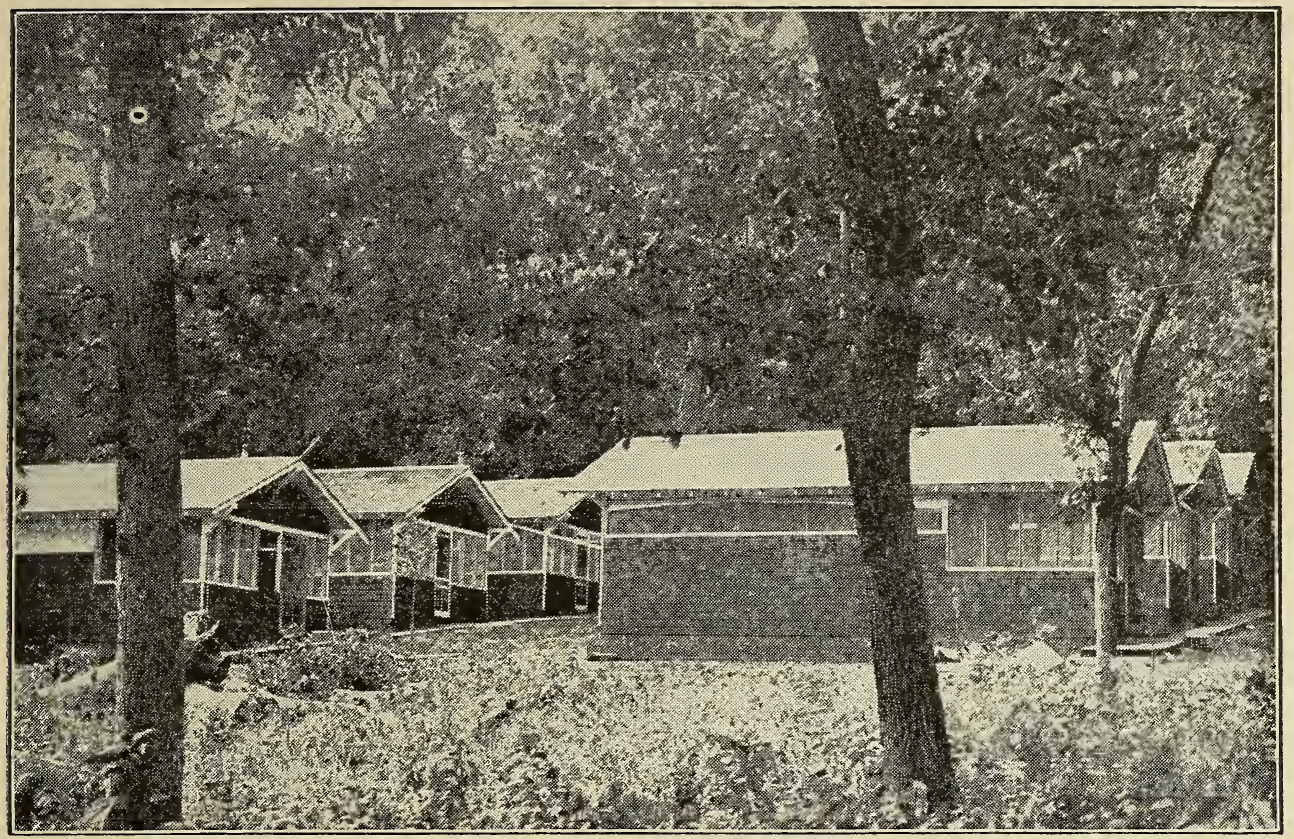

\section{Our Home In the Timber at Old Manti Near Shenandoah}

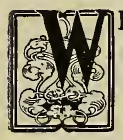

E HAVE always lived right next to the seed house, until last spring, when I built a home in a beautiful piece of timber about four miles out. We live there in the summer now and beside the seedhouse in the winter, We moved into town in November and will move back about May 1st when the roads get so I can drive back and forth to my work.

No, it is not a colony or a settlement. The houses are all for just us. You see there's lots of us and we take lots of house room, so we just divided up into six separate cottages, and the children do their own housekeeping. We have one house for a central dining room where we all eat together at noon,

It is a fine place to live there in the timber and we all enjoy it fine. We have our own electric light plant (a Delco) and a water and sewer system and all the comforts that ought to be in every farm home. In fact we have most all the comforts of both town and country.

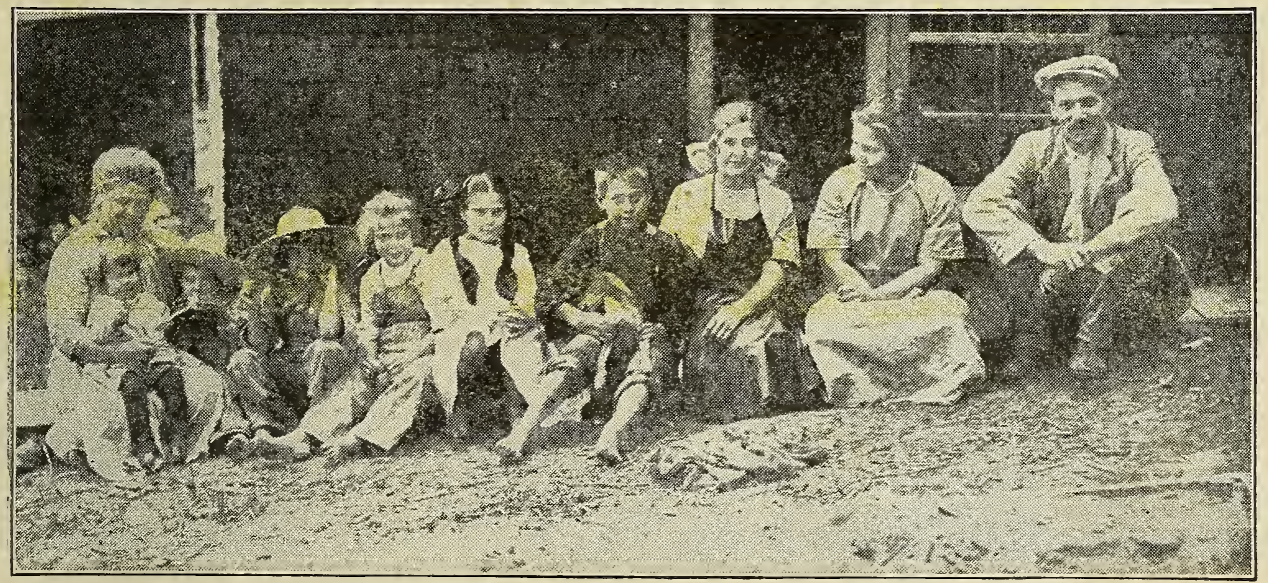

The Field Bunch in Their Everyday Clothes

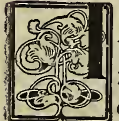

TOOK this picture out at our new home in the country, early one morning, when we were all at work or play in our everyday clothes. I didn't give anyone time to pose or fix up, so I got a very natural and lifelike picture. I gue ss most of you know the names of the children. Beginning next to me, there is Faith, Hope, Phillip. Josephine, Jessie, Mary, Ruth, and Georgia in her mamma's lap. And there is Frank who is not in the picture. 


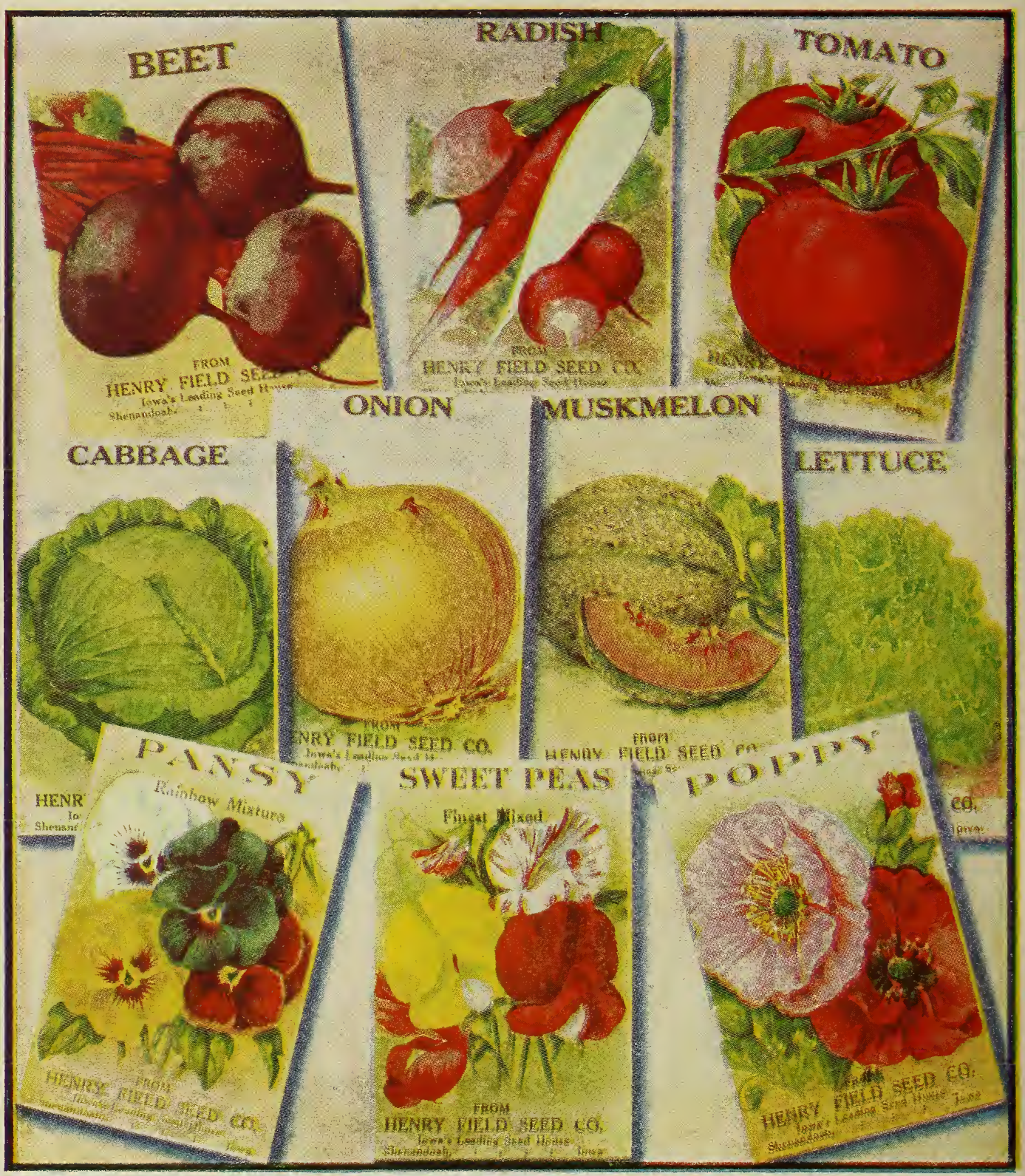

\section{Our Banner Seed Collection}

\section{A Whole Garden for 25 Cents. Suitable for Either Town, Country or City}

We have been asked dozens of times to make up a lowpriced collection of seeds for the small garden, the common everyday things that everyone grows, containing just the things needed in the right varieties, and at a low price. But we never got around to it till now. This year we have abundant crops; lots of seed, and we want 100,000 new customers. So we thought this introductory collection would be just the thing to make us acquainted with new customers.

, We are going to put the price so low that every one will buy it--10 packages for $25 \mathrm{c}$. And we are goins to make the quality so good that it will be a living and growing advertisement for us all summer. The seed is all new crop, tested, vigorous seed, the kind you always get from us. We want you to test it alongside of any seed you can get anywhere. The packages are big and full, enough for any ordinary gar- den. And the seed will grow, too.

And of course we are putting in some flowers, for a gar. den isn't right without flowers. See list above.

One package each of the varieties named above, 10 in all for $25 \mathrm{c}$. Can you beat it?

Think what a fine garden it would make for a boy or girl. We can not change the assortment listed above, as we can make this low price only by putting up the collection in enormous amounts a long ways ahead. If you want other things yeu can order them from the regular list in the catalog. Remember, these are not little skimpy sample packets, but real, sure-enough garden size, and good tested seed of the very best varieties. We have made the price low simply because we have good crops and we want 100,000 new cus. tomers. 


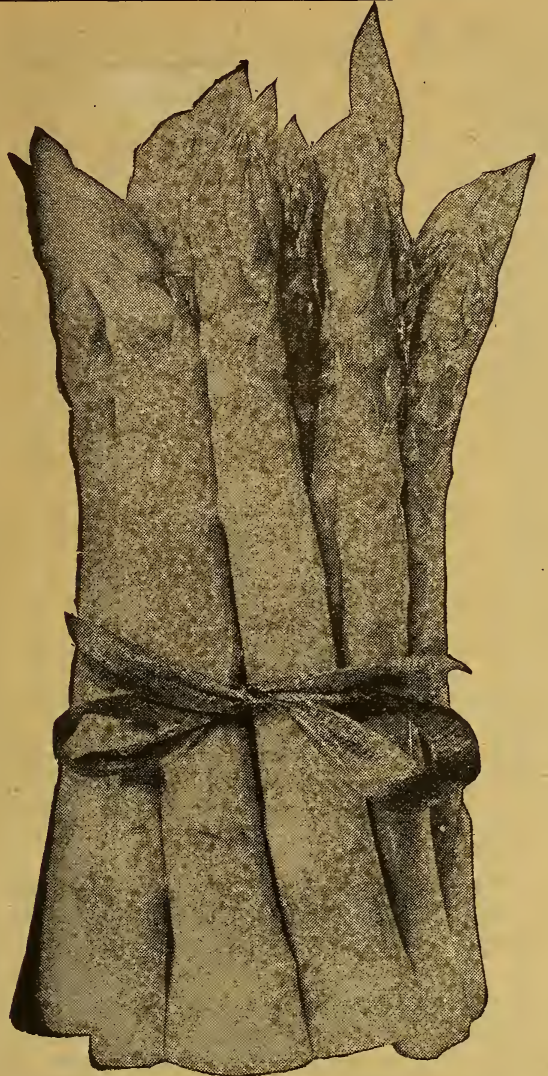

Asparagus

(See also page 129.)

Most people hesitate to plant this most delicious vegetable because they imagine it is hard to grow. but this is a mistake. Plant the seed just like you would onion seed, in good rich soil where you want it to stand, or in a bed from which you can move the plants to the proper place after one years' growth. Keep it well hoed and weeded the first year. And after that you can mulch it and not weed it at all. Special prices on large lots; write for prices. Full instructions given in our free leaflet. Ask for it.

Columbian Mammoth White. - A new and distinct variety having light green or white stalks. Very large and tender. It does not come entirely straight from seed, but will come about 80 per cent white. - Conover's Colossal. The standard sort. Large green stalks. Early and tender.-Palmetto. A standard large sort. Much grown east for market.

Bonvalette's Giant. - A new variety and the best of all. It has the advantage of coming into bearing fully a year ahead of other kinds. Yearling plants of this sort are as large as two-year plants of other kinds. It is also remarkably resistant to rust, which is such a drawback to asparagus in many places.

Asparagus Plants. - If you wish to buy asparagus plants instead of starting with seed, see page 129. Prices of Asparagus Seed.

Pkt. Oz. 1/4-Ib Bonvallette's Giant $10 \mathrm{c} 20 \mathrm{c} 50 \mathrm{c}$ Columbian Mammoth White ................ 05

Conover's Colossal .......

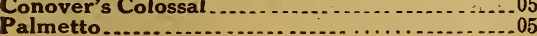

\section{Green - Podded Bush Beans}

The general opinion is that the green-podded beans are richer flavor than the others, and slightly hardier. To my mind the best of this kind is Field's First Early. This new green podded bean I have been growing for several years now, and I consider it the best early bean on the market.

Next in value of green beans I would put the Valentine. It differs from Field's First Early in being round-podded. In some markets this is an advantage, while in others it is not. The Valentine is a great favorite in the South for growing green beans to ship North early in the spring.

Refugee, or 1,000 to 1 , is a very heavy-yield ing, round-podded variety, but late. It is the kind that is almost always used by the canning factories, as it makes beautiful canned string beans.

Stringless Green Pod is similar to Valentine and makes a slightly larger pod, but sometimes not quite so many to the bush. It is similar also in being very tender and practically stringless, and is a splendid market or home-garden variety.

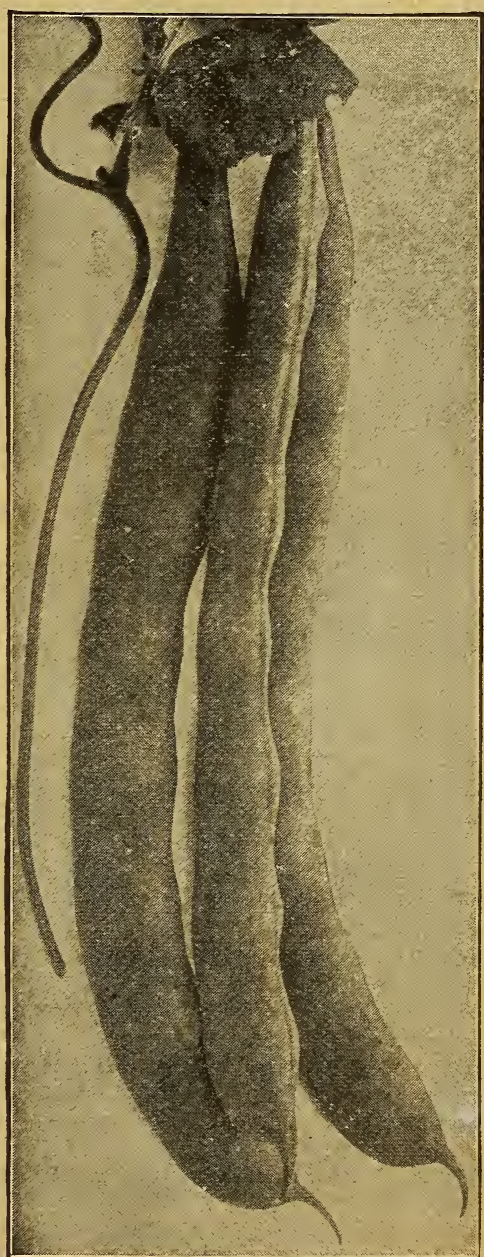

Field's First Early Beans 


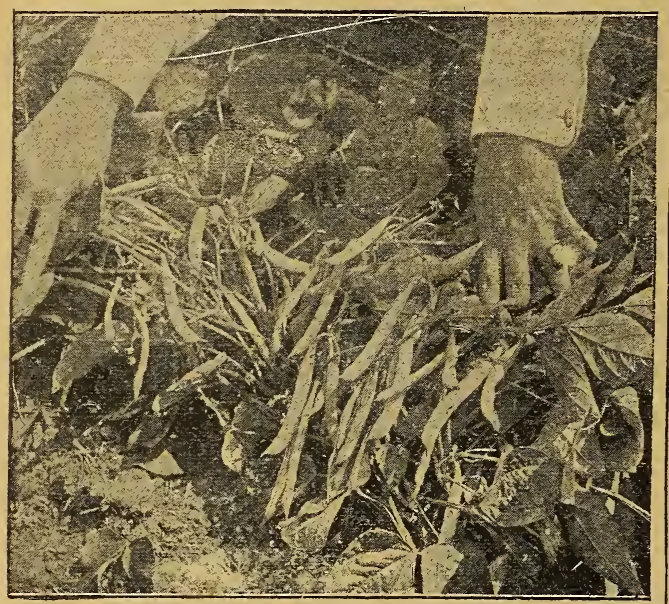

Davis White Kidney Wax Beans

A very prolific and handsome waxpodded market variety.

\section{Wax-Podded Bush Beans}

The yellow-podded beans are more beautiful in appearance than the green podded ones, asd in many markets bring a bigger price. They are gen erally good yielders, but are slightly more subject to rust or mildew than the green-podded sort.

The best of them to my mind is New String. less Yellow Pod. In appearance it is exactly like the Stringless Green Pod, except in color, but a true wax bean with a beautiful yellow pod. The pods look much like Black Wax, but are much larger, straighter, and on a larger bush. They hang as thick as Davis' Kidney Wax or Golden Wax, and will outyield any wax bean I have ever seen. Fine for home use and the best one of all for market gardeners. I don't see how it could be much im proved.

Golden Wax is somewhat similar, but with shorter, more stubby pods.

Davis White Kidney Wax is a very showy variety, and is very largely grown for shipping and for the canning factories.

A good old-fashioned variety is the Challenge Black Wax, which is well known by everyone. It has lots of pods, early and tender, but the pods are inclined to be small and crooked.

Of the flat-podded wax beans the best one is Perfection Wax It is somewhat similar to Ward. well's Kidney Wax, but with a larger, longer, pod, very often 7 or 8 inches long. They are a clear wax color, and perfectly tender. In fact they are just about perfection. First early and keeps in bearing a long time.

Wardwell s Kidney Wax is very similar, with long, straight, flat, yellow pods, 5 or. 6 inches long, very early and hardy Yields well and is extensively grown for market and shipping,

Hodson Wax is a shy yielder tough, and late. The same is true of the Pencil Pod Wax and the Yosemite Wax.

\section{Special Offer on Bush Beans}

We will send one $5 \mathrm{c}$ pkt. each of any 6 varieties of bush beans for $25 \mathrm{c}$ postpaid. This will give you a chance to try several sorts. A $5 c$ pkt. will plant about a rod of row.

\section{Busk. Beans For Shelling}

These varieties have tough pods so are no good for string beans, but are valuable for shelling ou green for succotash and the like, also for dry beans for winter.

Henderson's Bush Lima is the best of all bush limas. Bears all summer, small white flat seed.

Burpee's Bush Luma is the best of all bush limas. Bears all summer, large white, flat seed.

Dreer's Bush Lima and Fordhook Bush Lima are the same way. Very desirable on account of their quality, but pretty late for northern gardens,

The English Lima is not a true lima, but simi. lar in size and appearance. It is hardy and stands cold weather and frost like peas. Universally grown in Europe.

The popular varieties for succotash are: The Dwarf Horticultural, which has a round, speckled seed, the Red Kidney, which has a very large red seed, and the White Kidney, which is similar ex. cept that the seed is pure white. These are all very large and very rich in flavor and good yielders.

For white field beans, or white navies, as they are called, for winter use, I would recommend the Prolific Tree and the White Wonder. Both of these are small, round white beans of the true navy type and differing in size of bush, the White Won der being dwarf, while the Prolific Tree grows rather tall.

\section{Wax-Podded Pole Beans}

Of the wax-podded pole beans I know of only three that are a success. The best of these is the Kentucky Wonder Wax, which is practically iden. tical to the well-known Kentucky Wonder, except that the pod is of a beautiful waxy color. It is the same long, fat, tender string bean, the same strong vine and prolific yield as the parent variety, but has the advantage of having a wax pod. It is hardier and more prolific than any other wax pole bean I have ever found, but no wax pole bean is quite equal in hardiness to the green podded varieties.

Another good wax-podded pole bean is the Golden Cluster Wax, which has a beautiful large yellow pod, and pure white seed, and is sometimes called the Banana bean.

\section{Prices of Bush Beans}

Green Podded.

Pkt. 1/4.lb. 1-lb. Black Valentine................................ 10 c $35 \mathrm{c}$

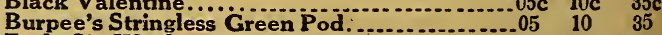
Early Six Weeks.................................... Field's First Early Giant Stringless Green Pod. Refugee, or 1,000 to $1 \ldots \ldots$
Round Pod Valentine $\ldots \ldots \ldots \ldots \ldots \ldots \ldots$ White.Seeded Stringless Green Pod............. 05 Wax Podded.

Challenge Black Wax

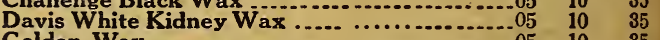

Golden Wax......................................

New Stringless Yellow Pod

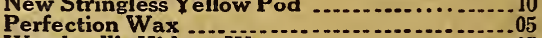

Wardwell's Kidney Wax.

Pencil Pod Black Wax Varieties for Shell Beans.

Burpee's Bush Lima.............................. 05

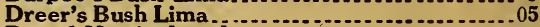

Dwarf Horticultural

Fordhook Bush Lima

Henderson's Bush Lima

Prolific Tree......................... 05

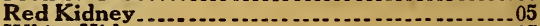

White Kidney

White Wonder

Tepary or "Dry Weather Bean"
10
15
10
10
10
15
10
10
10
15
10
10
10

40

35

35

35
40

$10 \quad 35$

$10 \quad 35$

$10 \quad 35$

1035

$10 \quad 35$

$10 \quad 35$

$10 \quad 35$

$10 \quad 35$

$\begin{array}{ll}10 & 30 \\ 10 & 35\end{array}$
$10 \quad 35$ 


\section{Pole Beans}

The beauty of the pole beans is that they bear much heavier than bunch beans ais keep on bearing all fall. They are more wrote and not so early as bunch beans, but ilit enormous yield and high quality will $w+i$ repay you for all your trouble. Many of the varieties of the highest quality can be $n a^{-}$ only in the pole form. They can be usec either as green beans to cook, pod and all. or they can be left for snelled beans.

\section{Green-Podded Pole Beans}

Improved Missour Wonder. - Of the pole beans proper I like this variety best of all. It is a variety that originated near-by here in Missouri, and I secured a start of seed from some of my custumers there. It is enormously prolific and so hardy that it will often come up voluntarily where tne seed has lain out in the ground over winter, It will grow ard bear in spite of any kind of weather, and will outyield any kind I have ever grown. Pods are light green, large and tender; stringless if picked when young. Fine for shell beans or succotash if let grow.

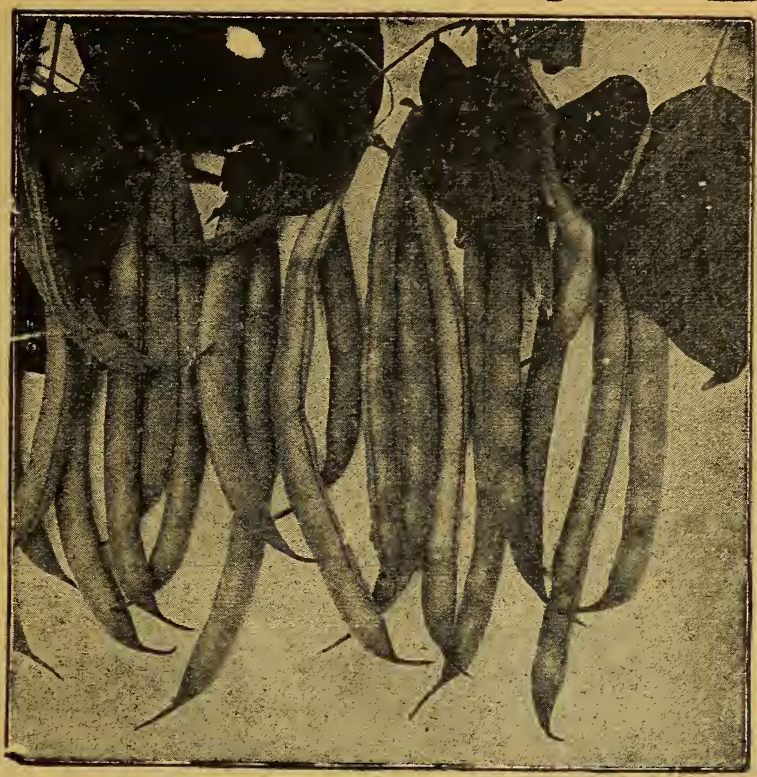

Next to the Missouri Wonder I like the Kentucky Wonder best of all. It is an old variety. but hard to beat. It has a long, very wrinkly pod, fat and tender, and good any time. Pod is light green and bean is brown in color.

There is also a bean advertised as WhiteSeeded Kentucky Wonder, which we find to be the same as Burger's Stringless, but it is a good bean under either name. It is a very early and tender variety.-Pods are rather small, round,

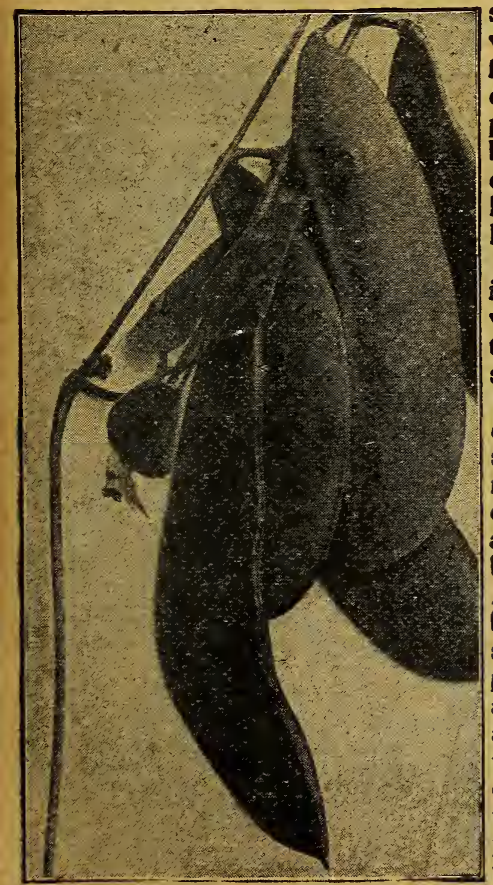

Extra Early Lima. or Butter Bean straight, and very tender. Probably the earliest of all pole beans. and bears continuously, Absolutely stringless.

Anothervariety with a pod very similar to this Burger's stringlessisthe White Creaseback. It has a small, straight round pod,tender and meaty, and great to bear. They are nice for string beans, and the seed, being a pure white, are nice to put away dry for winter use.Another good, white - seeded pole bean is the Dutch Case Knife, which has very wide, flac whice seea and a wide. flat pod as long and wide as the blade or a case knite.

One of the old favorites is Horticultural, or Cranberry, which is sometimes called the "Bird Egg" bean. The beans are marked in stripes, two shades of red, are very large and rich flavor. Are fine for shelling, but not so good for string beans. The same is true of the Cutshort, or Cornhill. It is great to bear and a good sort to plant in corn. The seeds are small, speckled, and closely crowded in the pod. There is also advertised a Whiteseeded Cutshort, but we find this to be much like Lazy Wife.

\section{Pole Lima Beans}

The best of all pole beans is Extra Early Lima, which is the old-fashioned "Butter Bean," the earliest and in many ways, the best. It is rather small in size, but bears enormously, is always sure to bear and is of fine flavor. It is the only one that is al. ways a success with us. It yields so heavily that many families grow a supply of them to put away for winter every year.

There is also an earlier type of the same bean called Seibert's Lima. It is not quite so large as the King Lima, but makes up for it in earliness.

Of the large type or true lima bean, the largest is the King Lima, or King of the Garden. It is the largest of all limas, and is fine in every way.

\section{Postpaid Prices of Pole Beans}

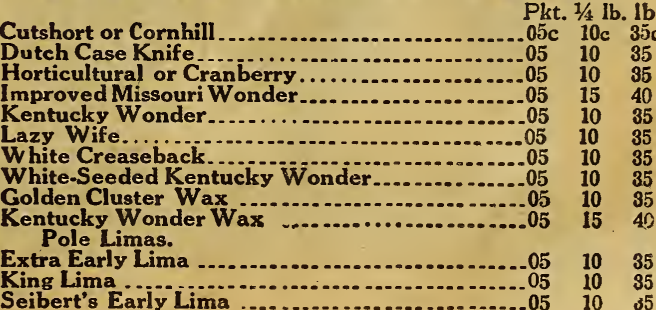




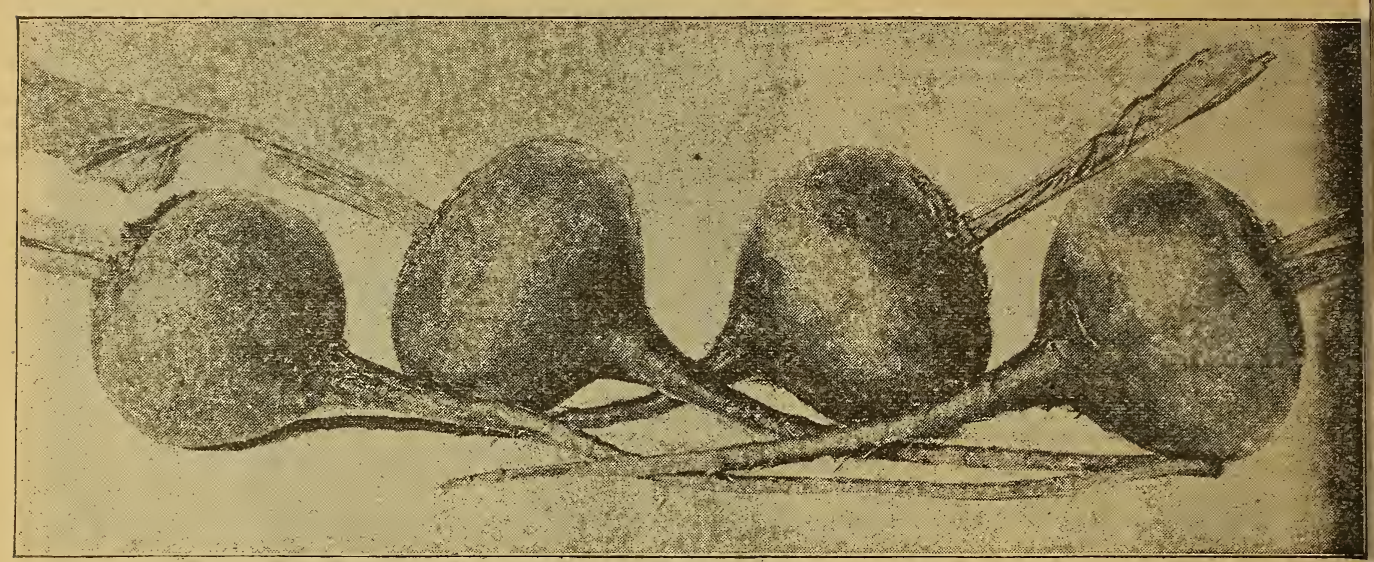

A Good Sample of Our Strain of Eclipse Table Beet

\section{Beets and Mangel-Wurzels}

1 have taken great pains to get the best beet want beets for late or winter use, use this variety seed to be had, and a crop from my seed will show planted in June or July.

it. I tried to get a strain with beets of uniform shape and color, small tops and small tap root, free from fibrous or sprongling roots. The seed is all tested for germination, but you must remember that beet seed must be sown early, as it comes best when the ground is cool.

The long beet requires the whole season for its growth, but the turnip shaped will mature in six or eight weeks.

Probably the best and most popular of all beets is the Eclipse, or, as it is sometimes called, the Extra-Early Eclipse. It is round or slightly pointed in shape; early, quick growing and tender, small tops and bright red flesh, not quite so dark red as the Egyptian, but a good color. It will sell
in the market ahead of any other variety. If you garden. It is said to be more tender than the old

Somewhat similar varieties are Blood Turnip and Detroit Dark Red. The Blood Turnip is the old-fashioned deep red, turnip-shaped beet so well known everywhere, while the Detroit Dark Red is evidently an improved strain of the same thing. It is dark red in color, like the Egyptian, but a per. fect globe-shaped, more like the Eclipse.

If you want a long large table beet, the best one is Long Blood. They are later than the turnip beets, and while they are fine quality and a beau. tiful red color, many people object to their long shape. They are good for late use, and keep well in the cellar all winter.

The new Swiss Chard "Lucullus" is very hand-

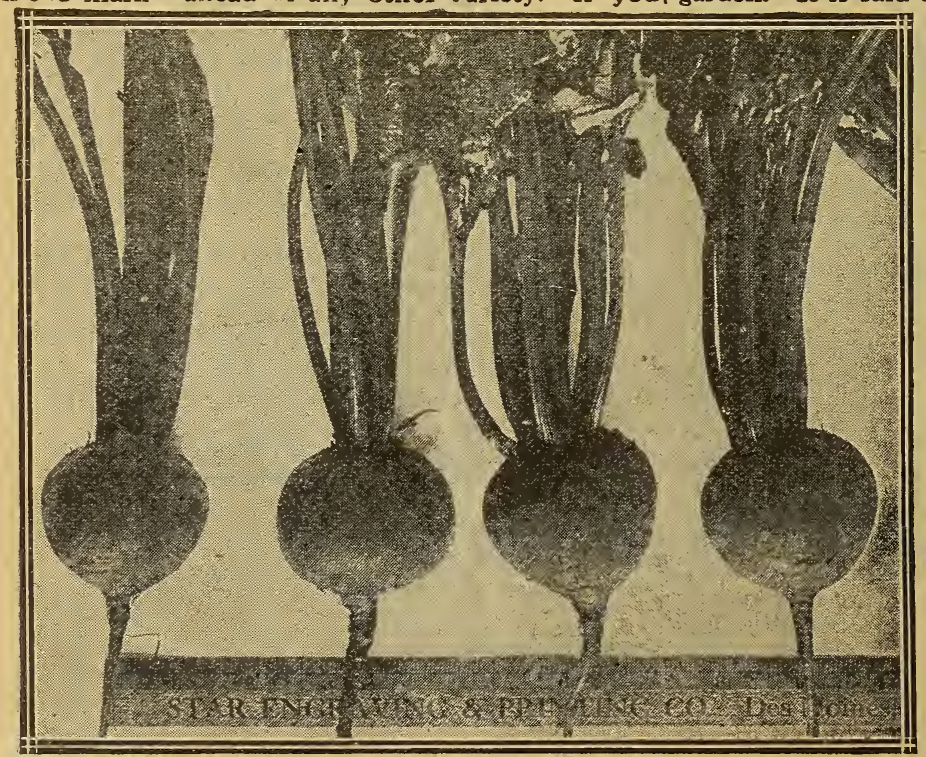

Crimson Globe Beets. The prettiest of all table beets. sort, too. Crimson Globe is a new variety from England, where they are great lovers of beets, and it is a dandy. Per. fect globe-shape, smooth, small. tap root, no side roots, early and very tender, Deep crimson color,

There are two varieties or strains known under the name of Esyptian. One is the o 1 d. fashioned extra-early or Flat Egyptian, while the other is the Crosby's or Improved Egyptian. It is larger and not so flat as the older type, but on the other hand, the older type has the ad. vantage of being a deeper red color. Generally speaking, the Egyptian is the earliest beet of all.

Table Beet Prices Pkt. Oz. 1/4lb. 1lb.

Blood Turnip..........5c 10c 25c $\$ .90$ Crimson Globe........5c 10c 25c .90 Crosby's Egyptian...5c 15c 40c $\quad 1.25$ Detroit Dark Red...5c 10c 25c .90 Eclipse, Special strain 5c $15 \mathrm{c} \quad 40 \mathrm{c} \quad 1.20$

Extra Eariy Flat EgypLong Blood..........5c 10 25 c 90 New Fireball $\ldots . . . . . . . .5$ c 15c 40 c 1.25 


\section{Stock Beets and Mangel Wurzels}

Some people call them cow beets, but whatever name you call them, they are certainly a very profitable crop to grow, especially for the dairy farmer. Still I don't know as they are any more necessary for the dairy farmer than they are to the general stock farmer, for all kinds of stock will eat them readily. Hogs will thrive on them pretty nearly as well as on $a^{\prime}$ falfa, and sheep will just about live on them all winter. They are very easily grown and will thrive in almost any soil, although, of course, a rich, fairly moist soil is the best.

They yield enormously. I don't suppose you would believe me if I told you what they actually yield, but it is a fact that I took twelve tons of them off of a quarter of an acre once. That, of course, is an extra heavy yield, but it is no trick at all to raise thirty tons per acre of them.

They are not hard to grow at all. Plant the seed in April or the first part of May in rows any convenient width. I have had them in rows 12 inches apart and from that on up to corn row width and I got about the same yield per acre whichever way they were planted, for the wider apart I plant ed them the larger they grew. They should be thinned out to about 10 inches apart in the row. Just about room to get a hoe between the plants, They will have to be weeded by hand about once. After that you can tend them with the cultivator.

As they grow almost entirely above ground they are very easily harvested. They should be left stand until there is frost enough to kill the leaves, but before hard freezing, strip off the leaves, pick them up and haul them in. They can be stored in any ordinary cave, cellar, or root house, just so they are safe from hard freezing, and fed all winter.

Use about twelve pounds of seed per acre. The seed can be put in by hand, but a drill is better. Better plant rather thick and thin to a stand.

\section{Varieties}

There really is no great choice of varieties of these stock beets. They will, any of them yield enough, if given good soil and good care, and there is no great amount of difference in feeding value.

The true sugar beet, Klein Wanzleben, is the richest of any, but is not suitable for growing for stock feed, as it is the poorest yielder of any, the smallest and grows deepest in the ground, so that it is hard to harvest. It is all right for sugar factory purposes, but that is all.

The Mammoth Long Red is the best known of any. It is very large and tall, yields well and is easily handled, The Giant Feeding Sugar looks like a cross between the sugar beet and the stock beet, but grows well out of the ground like the stock beets and yields well. It is white in color and quite rich, rather oval in shape. Stood third in yield for us, following Sludstrup and Long Red.

The Golden Tankard is deep yellow in color, rather a squared oval in shape, and sets entirely on top of the ground. The Eckendorfers, which come in both yellow and red, are about the same way.

You will see lots of catalogs offering different kinds of these beets under fancy names, but if you will test them side by side you will find they are practically always some of these standard varieties

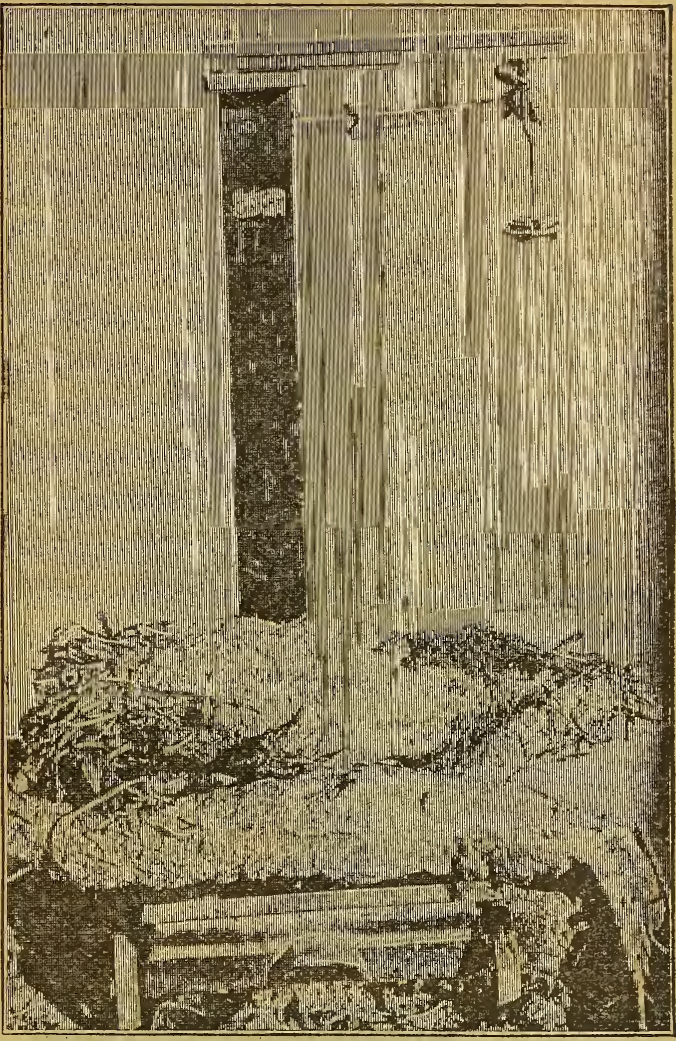

\section{Some Specimens of Our Long Red Mangel}

These are some of the biggest of the Long Red Mangel from our trial grounds. I thought I would weigh them just for curiosity. The 4 weighed 64 lbs., as you can see on the scale beam. They were not all big, however. The average size was 6.77 lbs. each. Figure that up at one beet to each 2 square feet.

renamed. We have tested everything we could find in this line, and the ones I have named cover the entire list of varieties that are worth while.

Prices of Stock Beets. Postpaid. Oz. 1/4-1b lb, Giant Feeding Sugar-ts. Postpaid. Rich in protein and sugar: good size.

Golden Tankard Mangel _......................... $05 \quad 15 \quad 55$ Medium size; easily harvested. Klein Wanzleben
Sugar beet, white flesh.

Mammoth Long Red Mangel ....................05 is 55

Yield enormously, large and ong.

Red Eckendorfer-..... largé and .ong. Short. thick beet; all above ground.

Yellow Eckendorfer..............
Same as above, excpt in color.

Special Offer: One pound each of any three varie. (ties of stock beets, three pounds in all, for $\$ 1.50$, postpaid. This would plant a quarter of an acre and give you a chance to try them. See Blue list for net prices on large lots.

\section{No Sludstrup This Year}

There is a fine Danish variety of mangels called Sludstrup, which we have been pushing, but we cannot offer it this year, as the seed is all Danish grown, and the Danish government has forbidden the export of it for this year. Use Giant Feeding Sugar instead, as it is very similar. 


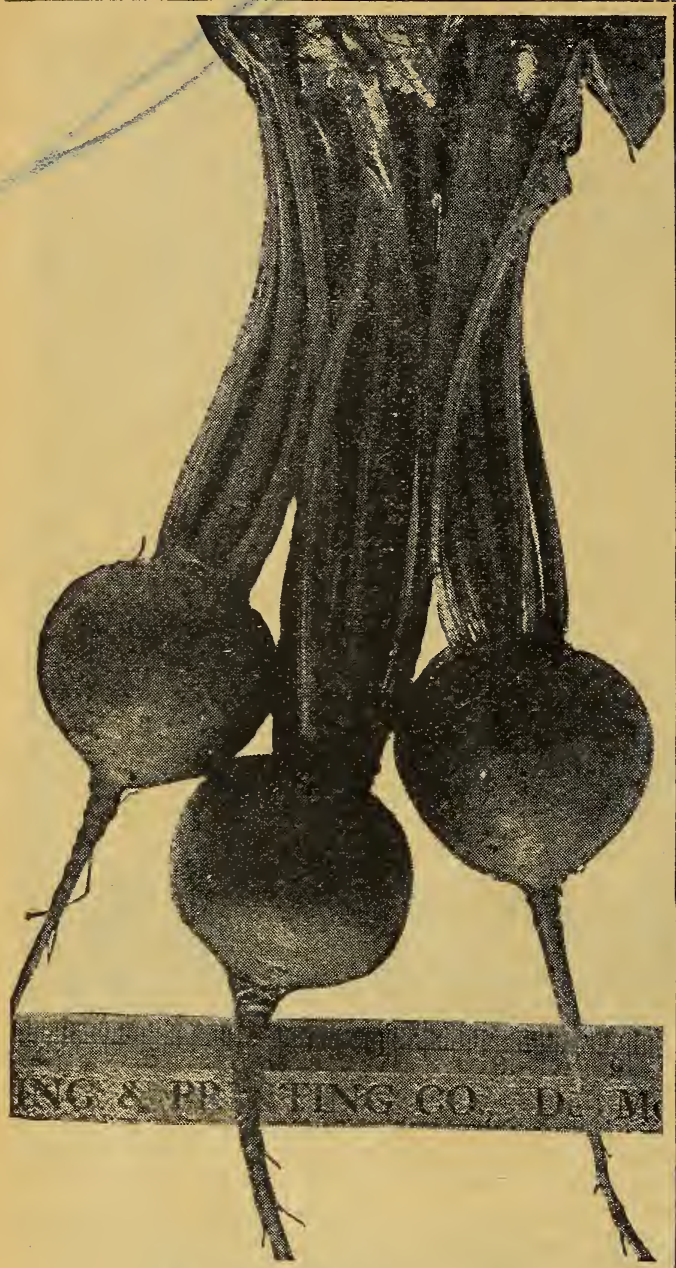

Beet. New Blood Red

\section{Beet ---New Blood Red}

I suppose most of you have given up getting an; thing new and distinct, and really worth while in an early tab'e bcet. But we happened onto one that I be.ieve will surprise you.

$\Lambda$ market gardener in Ohio, who is an enthusi ast on "single pla't se'ection", sent us a few seeds of this beet several years ago, and as we always do in su h cases, we planted it in our trial grounds. The bee's we grew were so fine that we saved them for seed and have been growing and increas. ing it since, till now we lave abnut $1 \mathrm{co} \mathrm{Jbs}$. of seed which we grew on our own grounds. It is in every way the best talle beet we have ever found, and as soon as we can work up seed erough we expect to push it hard, for as soon a it is known it is going to take first place everywhere

The most noticable thing about it is the exact uniformity. "Like as peas in a fod" d'nn't hardly express it. Starting original'y f om a single plant, and riç'c'y selected since, acc'unts for this. Every b et just 1 le every other beet, same shape, same size, same blood $\mathbf{r}^{\prime} \mathrm{d}$ colnr.

Tle co'or is the really valuable feature. Deep blood red wi hout s're ks, zones, rin s, or marbling. Just so'id blood red all through. You know how valua! le this will be.

And the leaves are the same way. Deep rich red, s'ightly rumpled or crinkly, and all the same co!or. Small tops like Egyptıan, but richer looking and more even color.

The bre's are shaned about like Eclipse, but more globe-shaped, ard more even in shape, and smoother. The prettiest bunching beet you ever saw. Eating quality fine.

In season it is a first early, as early as any we have ever found, and $r$ aturing the crop more evenly $t$ an any of the others, so that the crop can a'l be ma.keted in the first week while prices are high. $T$ is beet is fine for home garden, but will be especia:ly valuable for market gardeners.

PRI E: 15c per pkt, 2 pkts. for 25c. Cannot spare larger lots this year.

and a half or two inches through, and tie them in bunches of 3 to 6 each, to retail at $5 \mathrm{c}$. Wash nice and bright, keep them fresh, and they will sell like hot cakes.

Beets transplant easi!y when small, and I have often had fine success, especial'y for first early, by transplanting entirely instead of driiling seed. The little plants should be started in a hothouse or greenhouse, or shipped from the south, and moved when the leaves are about four inches long. Cut hack the tops and the roots slightly and set just like onion plants, about four inches apart in the row and any convenient width of rows. Set them just a trifle deeper than they grew before. They live very easilv.

If planted out very early, they will often come in two weeks ahead of the driiled beets ar.d cap ture the early market.

Like practically all crops, beets succeed best with rich soil and constant and thorough cu'ture. Garden wheelhoes like the Iron Age are the ideal tools for tending them. Use the best seed and the best varieties you an get. It's worth while. 


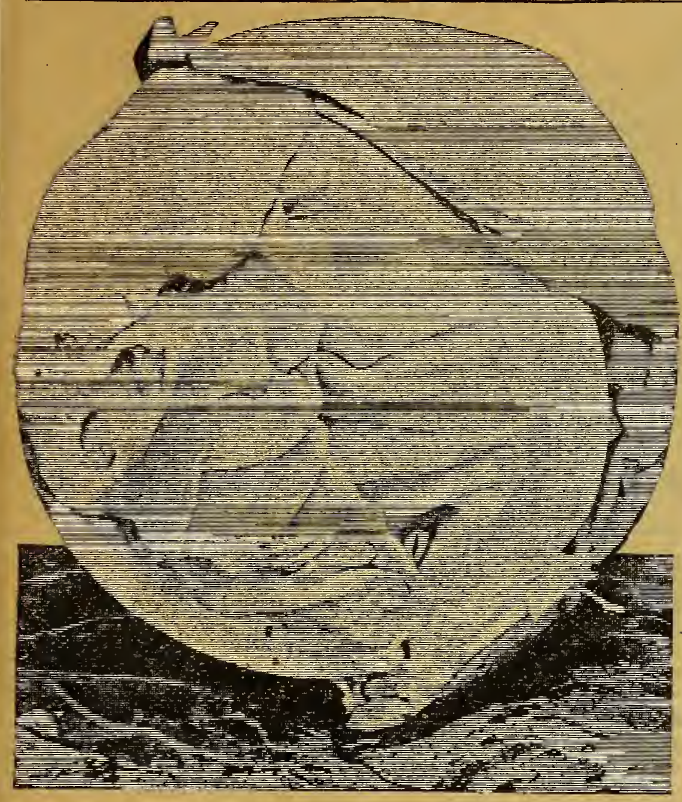

The Norseman. Greatest of All Early Cabbage

\section{New Early Cabbage The Norseman}

An entirely new type of early cabbage. As early as Early Jersey Wakefield, as large as All Head, hardier, solider, ana better quality than either.

I have always insisted that there was nothing better than Early Jersey Wakefield and All Head Early for early cabbage. But the Danish gardener who grows my Danish Ballhead winter cabbage for me sent me a sample of early cabbage seed and a long letter about it. He wrote that he had all the other cabbage growers in Denmark beat on the early cabbage and that he was sure it would beat anything we had in America.

I tried the sample and found it to be all he claimed. It is not much, if any, earlier than Early Je1sey Wakefield, but it certainly is as early, almost twice as large, rounded instead of pointed shape, very solid and slow to burst (you know the top flies off a Wakefield about the next twenty-four hours after it gets solid.) It differs from All Head in that it is deeper up and down, at least a week earlier and has round, close-fitting leaves like Wakefield, which fold in rather than turn ont. It is much hardier than All Head and will stand more cold weather and more hardship at all times. We gave it the name of Norseman.

It is an entirely new type of early cabbage, entirely different from any of the standard varieties and far ahead of them. The only other variety which it resembles in any way is the New Copen. hagen, which evidently belongs to the same group. The market-gardeners whe get in early on the Norseman cabbage will have a big lead over all their competitors and will repeat the experience of those who went in heavily on Early Jersey Wakefield and on All Head Early when they were first introduced.

\section{Its Record on Our Trial Grounds}

We checked up carefully all the standard varie. ties of cabbage in our trial grounds. The first cut ting of cabbage is always the one that pays best. In the first cutting Norseman showed 45 per cent of the heads ready for market, Early Jersey Wake. field of the best strain showed 38 per cent ready. Early Spring showed 20 per cent ready and All Head Early none ready yet. The Norseman besides were almost twice as large as ei' her the Wakefield or the Early Spring and brought a considerably higher price in market. They run absolutely uniform in weight, size and shape.

The seed is very scarce as yet and we canno: offer it in quantities larger than one pound. Price, pkt. 10 c, oz. 60 c, $1 / 4-1 \mathrm{lb}$. $\$ 2.00$.

\section{A Good Mate For Norseman}

In our trials of other Danish cabbages we found one that will be fine to follow the Norseman. It is the Danish Summer Ballhead. It looks like Norseman, same shape, same solid white head, same size, or maybe a trifle bigger, and about two weeks later. It and Norseman will make a fine team to plant together. Our seed is imported direct from the originator. Price, pkt. $5 \mathrm{c}, 0 \mathrm{z}, 30 \mathrm{c}, 1 / 4-\mathrm{lb}$. $85 c$.

\section{Norseman Averaged 6 Lbs.}

"Dear Sir: You say you like to have your custom ers write, so here it ghes. I want to tell you about the potat es I got from you. On a patch of ground $30 \times 80$ feet I got 22 bushel. How is that for spuds? I had the finest cabbage, rnised from the Norseman seed. Sold 300 heads that averaged 6 pounds. We had a very dry season. I will send for my seeds in the spring. Yours truly,

-D. W. Rielee, Parkerville, Kans."

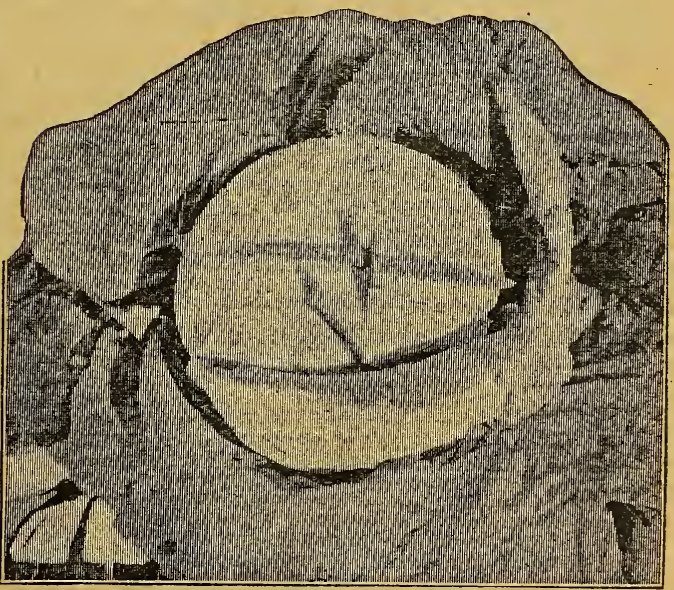

The Norseman Growing on Our Trial Grounds

Notice the deep round head, smooth and tight on top, the thick, vigorous outside leaves. and the healthy appearance of the plant. It is the nearest "wormproof" of any cabbage we have, as it grows so fast and is so solid and tight the worms can't get inside. 


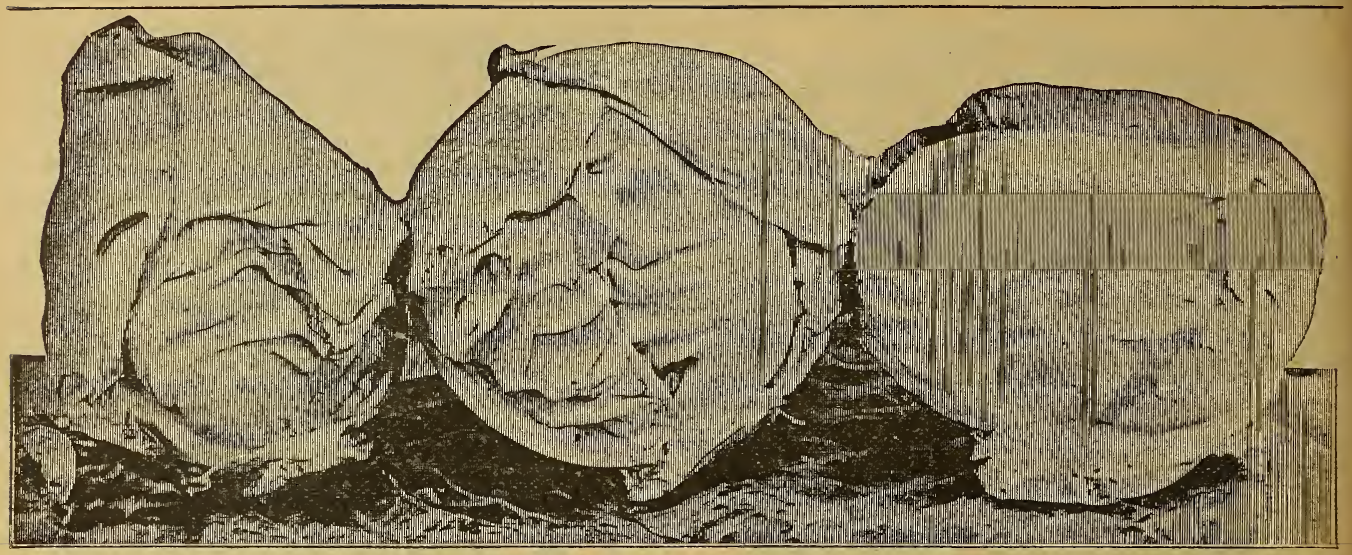

Early Jersey Wakefield

The Norseman

All Head Early

The Three Best Kinds of Cabbage

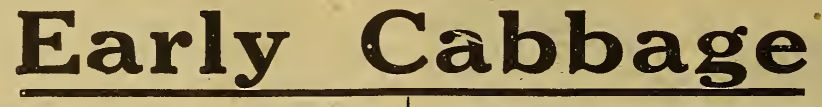

I consider the Norseman the best of all varieties of early cabbage. I haven't room to describe it in full here, however, so I have taken a page for it further over in the front of the book and you will find it fully described there. This, of course, is a new variety recently introduced.

Of the standard varieties I would place first of all the Early Jersey Wakefield. In my experience I have found it the best of all the standard early kinds and it has held its place at the head of all the list for a quarter of a century. It is a fair size, sometimes weighing as high as six or eight pounds on extra rich soil; pointed or conical in shape; very early; and almost sure to head. The leaves are slightly thicker than most other varieties and seem to stand frost exceedingly well. As the leaves are small it can be planted as close as a foot apart in the row.

There are a few varieties which are possibly a little earlier than this, such as: Etampes, Express, Lightning, and other extra early varieties, but they are all in my experience either too small or too soft to be of much use. The Norseman has the same thick, smooth leaves as the Wakefield, but the head is round or globe-shaped instead of pointed, and is larger and heavier than Wakefield.

The Charleston Wakefield or large Wakefield is simply a large selection from the true Early Jersey Wakefield and is similar in every way, except being a little larger and a little later. Early Winningstadt is pointed like the Wakefield, but not near so early. It is an old favorite, but has been largely superseded by the Wakefield.

The Copenhagen is a new variety recently in troduced from Denmark, which is quite early and at the same time is of good size. The head would be described more as round than flat. It is just about perfect globe-shaped; but in season it follows right after the Wakefield. It is of the same general class or type as the Norseman. It is very highly spoken of and bids fair to be one of the leading varieties,

Another good early or second early cabbage is the Glory of Enkhuizen, a new variety from Holland. It looks like the Norseman and has the same deep, solid globe-shaped head, but is not so early. I am sure it will please you.

The largest of all the flat-headed type of early cabbage is the All Head Early. It is perhaps a week later than Early Jersey Wakefield, but grows to be larger and stands longer withour bursting. It has a flat or slightly rounded head like the big late cabbage, and practically equals them in size. I have raised them to weigh $17 \mathrm{lbs}$. each; remarkably sure to head and a great money-maker under all conditions, This variety is also often used as a late caboage by planting it late in the season.

Henderson's Early Summer is similar to the All Head Early, but not quite so large and possibly a trifle later. Eurly Flat Dutch is also a very similar variety. In fact, there is very little to choose between these three, but I consider the All Head Early the best of the group.

Succession is slightly later than All Head Early, but still comes in ahead of the late varieties. It is very large; quite flat on top; fine quality; a heavy yielder and a good seller; but will not keep well for winter sales. Fine for August and September market and generally brings good prices then. This variety or one very similar is also sold as Vandergaw and All Seasons.

Danish Summer Ballhead has the good quali. ties of the Danish cabbages. The head is round, which is the best and most popular shape. It is very hard. which is characteristic of these Danish varieties. It is sweet and tender, which is something you don't always get in a summer cabbage.

Prices of Varieties on this Page. Prices of Varieties on this Page. Pkt. Oz. 1/4-1b. (1)

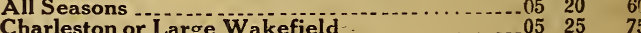

Copenhagen Market

Copenhagen Market

Danish Summer Ballhead ........... 30

Early Flat Dutch

Early Jersey Wakefield ................... 0530

Early Spring ......................

Glory of Enkhuizen

Early Winnlngstat

Fotler's Brunswick

Henderson's Early Summer...$\ldots \ldots$

Norseman -... $10 \quad 60 \quad 2.00$

These prices are all postpaid. See blue list for large lots. Special Offer: Any six varieties of cabbage, one 


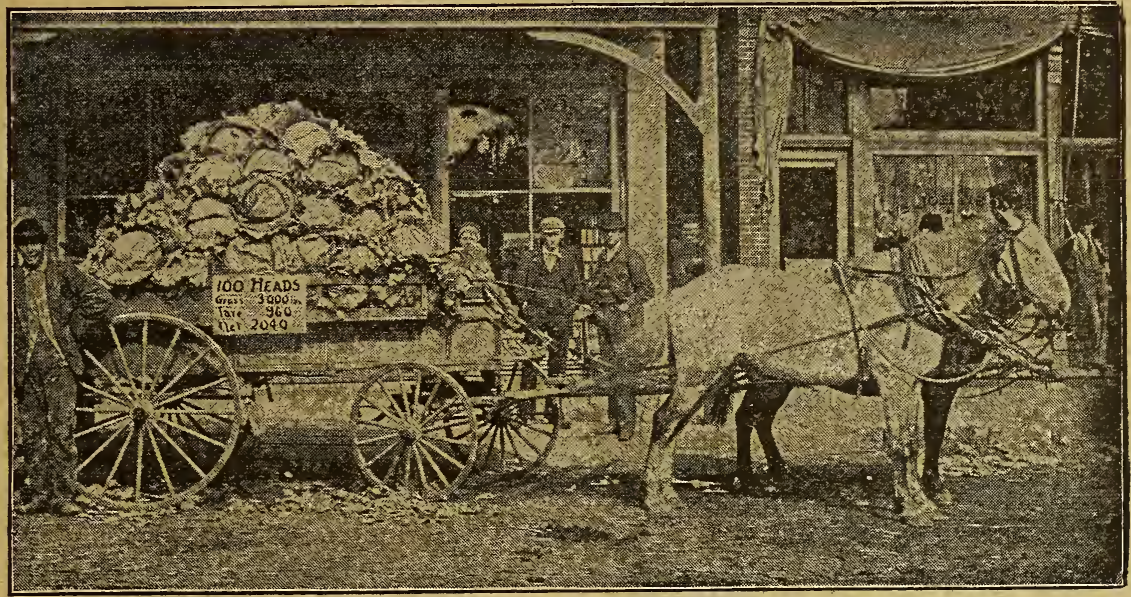

This is not an orflinary fake or ordinary overdrawn "catalog picture;" but is an actual photograph of a load of real cabbage grown by me Erom my special strain of Surehead, the same seed I will sell you. If you have any trouble getttng cabbagc to head, try this strain.

\section{Late Cabbage}

\section{See Page 15 For Early Cabbage}

My cabbage seed is all American grown, except the Hollander. You may find seed that will cost you more a pound, but you cannot get any better seed, no matter what price you pay. I do not, as some seedsmen do, tack my name to every variety and charge you two or three prices on the strength of it. I don't believe in that way of doing business. The list given below consists of mostly standard, well-known sorts and ones I have grown myself for market. I know them to be all right, and I have the best strains of them to be had. Cabbage has always been a brag crop with me, and the big load shown above has probably never been equaled; so you see I know what I am talking about. It was grown from the same strain of seed that I offer you.

Thare is a world of varieties of cabbage, but really there are more varieties listed in the catalogs than there are different kinds of cabbage, and the average gardener does not need over a half dozen of these. I have tried to cut my list down to varieties that are distinct, or where they aro similar I tell you so. I hope these candid and sensible descriptions will appeal to you.

I have the best luck with the late cabbage by drilling the seed right in the field where the plants are to stand, and then thinning it out afterwards instead of transplanting. I drill it about the first of June with anordinary garden drill, using a pound of seed to the acre, but it can be dropped by hand in hills, abnnt six or eight seeds in a place, if you prefer. When about three weeks old thin it down to a stand. It never stops growing, and you are sure of a stand whatever the weather may be. Try it.

The best known and most widely grown of all the late cabbage is the Premium Late Flat Dutch. It is the best strain of the popular Flat Dutch type, makes large, flat heads, vigorous growers and good keepers. The Large American Drumhead is very similar, but is sometimes coarje and always very large, but not so uniform nor so fine quality.

The Surehead is one of the best all-round cab. bages grown. It is large, solid, deeper and heavier than the Flat Dutch, and is fine-grained and keeps well for winter use. Certain to head. The main difference between this and the Premium Lato Flat Dutch is that the Surehead is about a week earlier, is rounder on top and generally of finer quality,

The Fottler's Brunswick is very similar to the Large American Drumk, ead, but earlier. A variety that is very popular in the South is the St. Louis Late Market, but with me, I can see no difference between it and the Premium Late Flat Dutch. In the northern states the Hollander, or Danish Ballhead, is very popular. It is grown especially in the great cabbage regions of Michigan and New York. Not over large, but very solid, and is said to keep until cabbage comes again. It does not seem to be a success south of Iowa, but anywhere north is all right. I import my seed of this variety direct from Denmark and have the true type. I use the "middle stem" or medium height strain,

A large, late, coarse variety is the Autumn King, but I find it good only for exhibition purposes and for growing for kraut factories. All Seasons is a large, flat cabbage of the drumhead type and is good for fall planting, but not late enough to keep well for winter use, as it rots easily around the stem.

Probably the best winter variety, all things considered, is the Corn Belt Cabbage, especially for the great central states. I have always made cabbage a leading market crop, and have been con. vinced of the necessity of some variety more suited to the climatic conditions of the central west than any of the known sorts. Our location here is about the center of what is known as the "corn belt," and in the majority of years the season is against a successful crop of late cabbage, as most of my farmer friends can tell you who have tried it. It is the dry July, August and September that makes the trouble.

(Continued on next page.) 


\section{Late Cabbage (Continued)}

We generally have plenty of rain in June to get the plants started, but then have to fight for it the rest of the summer. If they can hold out until rain comes in September or October, we are sure of a crop.

What is wanted is a late cabbage that is hardy enough to stand adverse conditions during the late summer and then make a big solid head in the fall. and that is what I think I can now offer you. The photo given below will give you an idea of its appearance and size. It is some like Surehead, but larger and a little later. It does not rot as easily and will stand more hand ing. When grown it has a bluish cast to the outside leaves and looks noticeably rugged and hearty. It is a typical rough-andready western product and has the true get there spirit. If you have become discouraged trying to grow late cabbage of the eastern sorts, try this one.

\section{Cabbage on Our Trial Grounds}

Our cabbage trials serve a double purpose. By it we can see whether our grower is doing as he oromised to, thit is giving us a stock that heads good, and the heads of even size and shape. Also we are able to compare the varieties we list with the new varieties that are coming out each year. We have added two or three varie ies the last year or so that we found in just this way.

The Norseman we found in this way; A gardener from Denmark sent us the sample of seed and it was the dry year we had six years ago I believe. We just couldn't get cabbage to head worth a cent. I noticed, however, that this stock seemed to be making a better go of it than the others, and when we came to check up it had made a better showing by far than anything else in the trials. I made up my mind right then that we ought to list it. See page 15 for de. scription.

All of our cabbage seed is tested for germination, and shows good strong test.
There is a Russian variety of cabbage which has been introduced within the last few years that has been found very profitable in many localities. it is called the Volga. It makes the same deep, round, very hard head as the Hollander, but grows much closer to the ground, and will succeed in the southern states where the Hollander is a failure. It is reported to be especially valuable in Texas, Lou. isiana and other southern states where the $\mathrm{Hol}$. lander is a failure, and I have made a great success with it here in Iowa. I have also had some very enthusiastic rcports on it from Kansas, Missouri and Oklahom?.

The Volga matures quicker than most late cabbage, so should be planted later, unless wanted for early fall market. We very often set out plants of this variety here in Iowa as late as the middle of July and make a gond crop for winter cabbage. I advise market gardeners everywhere to plant especially heavy of this variety. It makes a deep very heavy head, remarkably solid and white. I have notized that in selling cabbage from the field the buyers always were anxious to get over on the side of the field where the Volga was growing.

If you want a red cabbage, the best one I have ever, found is the Mammoth Red Rock. It is a late or fall cabbage, and while not really very mam. moth in size, it is the biggest you can get in red cabbage. It is dark red in color, very solid and sure to head,

\section{What About Cabbage Worms?}

I have tried everything from moral suasion to Paris green and from ice water to red pepper. Sometimes it seemed to do some good, and sometimes it didn't. Tobacco dust is good. It is not dangerous like Paris Green and really seems to drive the worms away. Dry road dust is good: so is strong brine. One clistomer writes that he makes a weak lye water, two teaspoonfuls to a bucket of water, and sprays that on and it does the business. Poul. try, especially young ducks, will often eat the worms.

Keep the cabbage grow. ing $f$ ster than the worms can eat it.

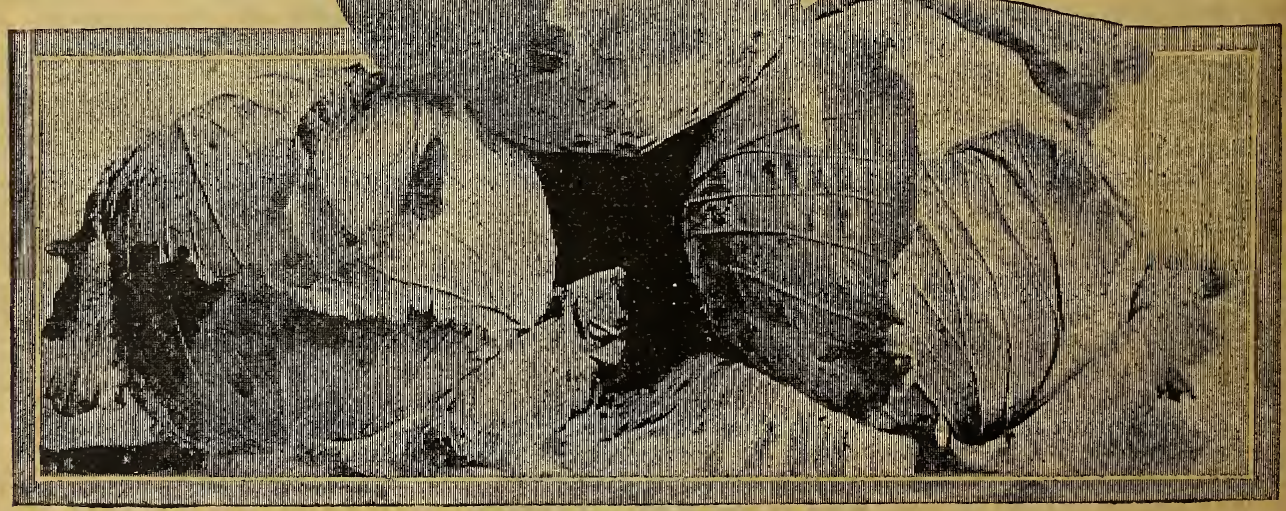

Cornbelt Cabbage. The Best Variety For The Great Central States 


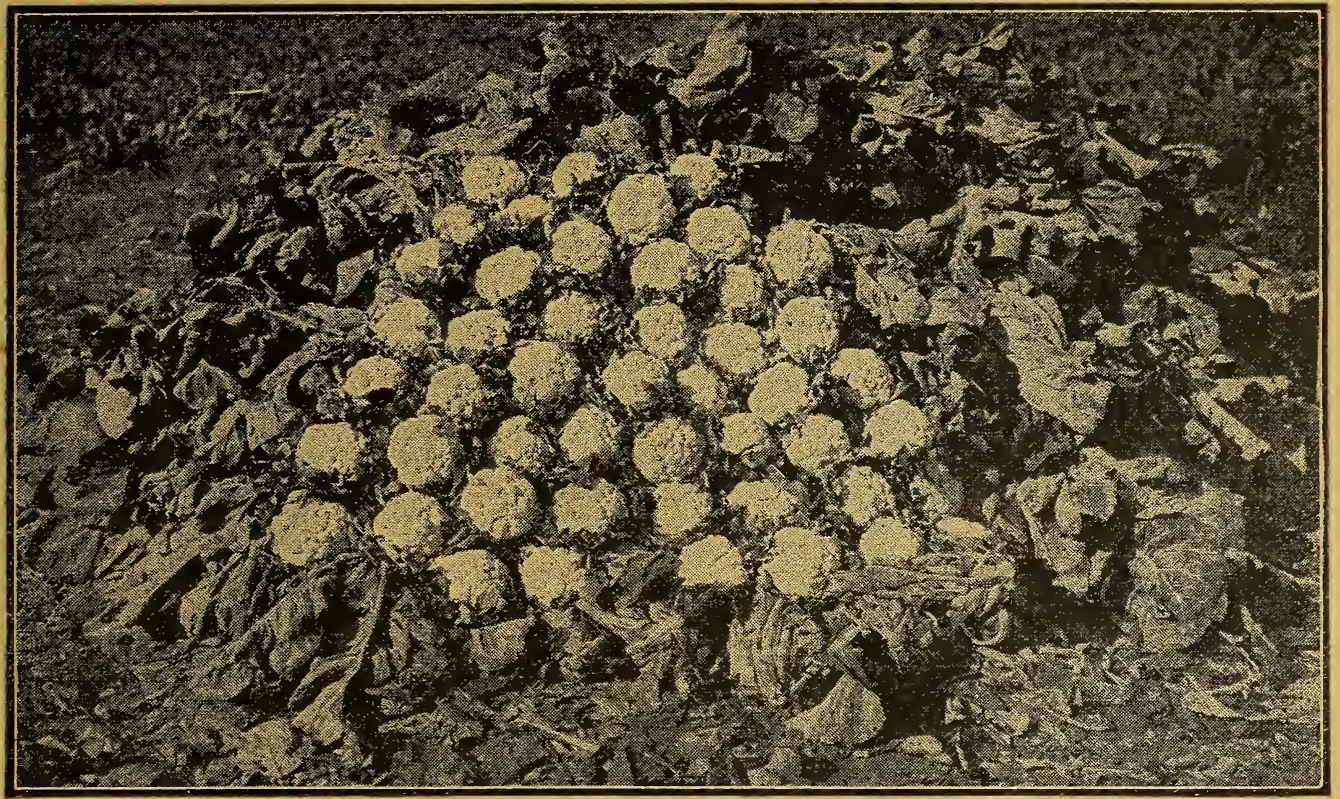

A Beautiful Pile of Copenhagen Cauliflower. This picture was sent us by our Danish grower. All our caulfflower seed is genuine imported Danish grown.

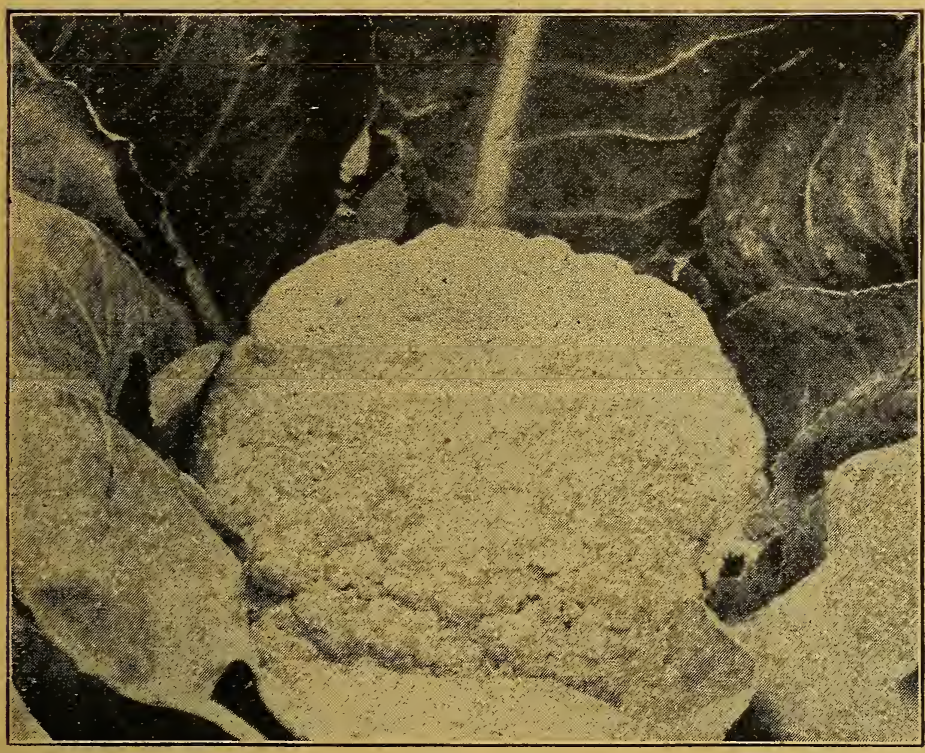

Cauliflower - Early Snowball Cauliflower

Someone has said that "Cauliflower is cabbage with a college education." Anyway, it is very similar to cabbage in manner of growth, and requires the same culture. It cannot stand hot, dry weather, so should be started as early as possible and handled like early cabbage. The best seed is all imported. coming from Denmark I do not handle any but the very finest grade of seed, and I know I can suit you.
The earliest of all the standard varieties everywhere is the Early Snowball. It is small, very early, pure white, and always sure to head, Can be set very close together. This is the kind that is always used for growing under glass. Danish Perfection is a new st ain much like Snowball, but better in some wavs.

Among professional gar deners or truckers, prohably th e most popular is the Early Dwarf Erfurt. It is not quite so ea ly as Snowball, but larger and heavier. It is very short. stemmed and $n^{\prime \prime} t$ inclined to become leggy, as some varie. ties do.

If you have had trouble growing cauliflower, it might be well for you to try the Dry Weather, or Copenhagen, for it seems to be ab e to stand all kinds of grief and will come nearer carrying through the hnt weather than any other I I $h$ ve ever seen. It is not quite so early as the o her two, but is still fairly early, giod size, and very sure to head.

\section{Prices of Cauliflower}

Dry Weather Plt. Pkt. 1/4-Oz. Oz. (Copenhagen) 15c 25c 75c $\$ 2.50$ Earliest Dwarf $\begin{array}{ccccc}\text { Earliest Dwarf } & 10 & 20 & 60 & 2.00 \\ \text { Erfurt } \ldots \ldots \ldots & \ldots 10 & 20 & 65 & 225\end{array}$ DanishPerfection.15 $25 \quad 75 \quad 2.50$ 


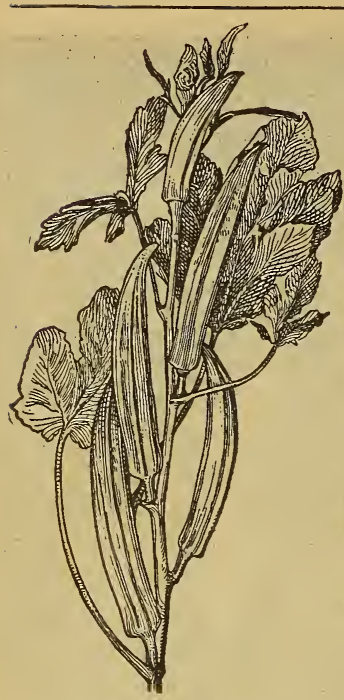

Okra or Gumbo

\section{Okra}

\section{or Gumbo}

This vegetable is but little known in $t h e$ north, but more north ern people ought to have it in their gardens, The pods are full of 1 i t t 1 e seeds like small peas. Pick these pods $w$ h e $n$ young and tender and cook pods, seeds and all, like string beans, Fine! Try it. There are sev. eral sorts, slightly different, and I have picked out the four best ones and mixed them. 1/2 oz. 5c, oz. 10c.

\section{Kohi Rabi}

This vegetable looks like a cross between a cabbage and a turnip and is better eating than either one. The leaves look like cabbage, only smaller. It makes a sort of tur. nip, but above ground, Grow it just like cabbage. It is fine eating, more delicious and tender than any turnip and is very easily grown. The variety we ase is the White Vienna. Pkt. 5c, oz. 20c.

\section{Eggplant}

This is a vegetable that should be more largely grown. People who have eaten it are always calling for it, as it has a rich flavor all its own that is fine. Plant and tend the same as peppers, and it is.just as easy to get a crop, except that flea beetles and other insects are hard on it, but you can generally get ahead of them with tobacco dust.

The most popular and best known variety is the New York Parple, which is very large, smooth, and thornless, and dark purple. The Black Beauty is very similar to it, but darker and not so large.

For an early variety and one easily grown, the Early Long Purple is popular. It is the earliest variety grown and bears abundantly, but is not very large.

Prices of Egglant.

Black Beauty

Early J.ong Purple.

New York Purple.

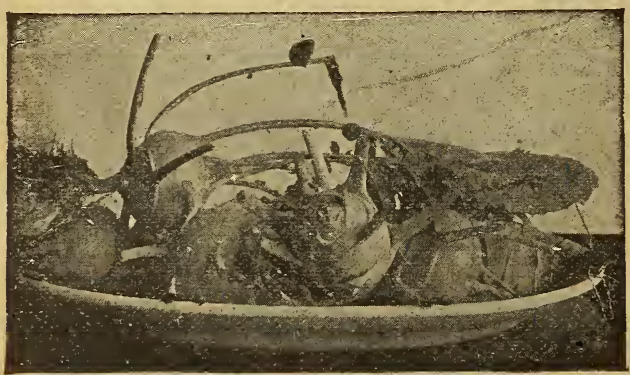

Kohl Rabi

Some one has called it a cross between a cab. bage and a turnip, but it is better than either.

\section{Celery}

If you once had a taste of home-growncel. ery, just from the garden, crisp, rich and fresh, you would never be without it. It is comparatively easy to $\mathrm{g} \mathrm{row}$, and really more people ought to grow it. I put directions on every packet of seeds, and be. sides I have writ. ten a little leaf. let on the sub. ject that gives a more detailed account of the work. It is free for the asking. You can grow celery as easy as Earliest and tenderest of all celery. cabbage.

The biggest. heaviest celery is Giant Pascal, which is much used by professional celery growers. It is slow and hard to bleach, but is fine when rightly handled, and is the best keeper of any.

One of the best varieties in quality, and one of the easiest to bleach is Golden Self-Bleaching. It is medium to large size, creamy white, healthy and vigorous. Will bleach itself if shaded on the sides, but, of course, does better if completely shaded or banked up with dirt.

Another variety much like this one, but earlier and slightly smaller is the White Plume. It is pure white in color, is very tender, and has a very delicate flavor. It is the earliest of all the varieties of celery and the tenderest, but it is not very large, and does not keep well.

We have a free leaflet on the growing of celery which we will be very glad to send free to those who care to have it.

The best celery seed in the past came from France, but the war has entirely upset it the last two seasons. We are offering this year strictly American grown seed from selected plants which we believe you will find to be exceptionally fine.

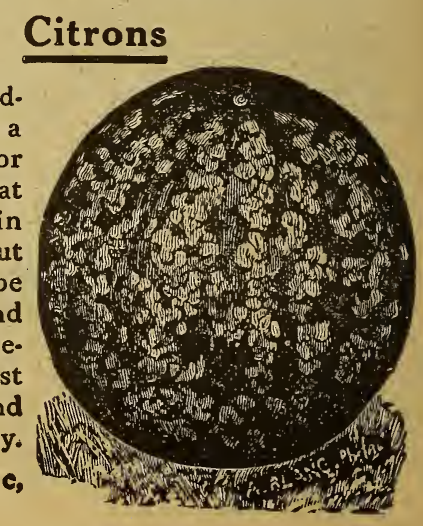




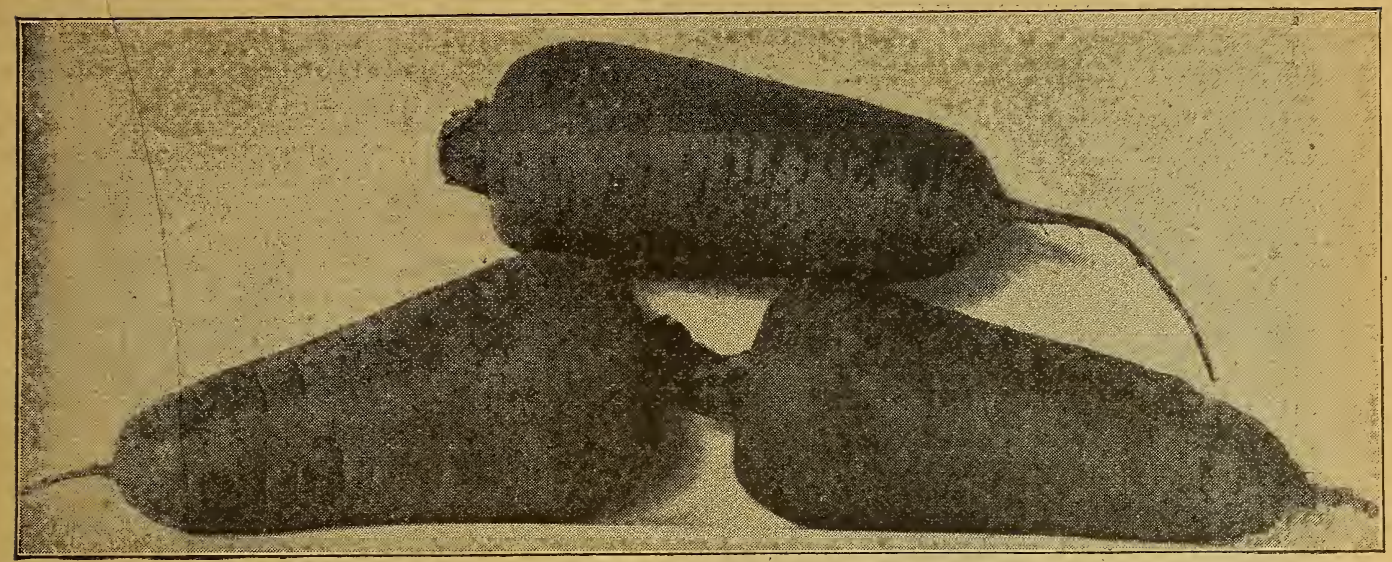

\section{Table Carrots}

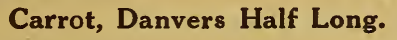

The most popular variety for garden use is the Oxheart, which is an early short, thick carrot of fine quality. Very popular for bunching when small. Deep orange color, thick side meat and very little core.

A smaller, similar variety is the Chantenay, but it is a little earlier and more slender in shape. Very tender and sweet.

If you want a larger variety, either the Half Long Orange, or the Long Orange would be the one for you. The Half Long Orange is also called Danvers Halt Long. It is medium size and good quality. This is the celebrated carrot of eastern markets and is grown in great quantities in Con necticut for the New York trade.

The Long Orange is the latest and largest of all the table carrots. A deep reddish orange in color, and with a very small core. It is also grown extensively for stock food, and it is richer and a better color than any of the stock carrots.

\section{Carrots For Stock Feeding}

Carrots take a front rank among the field products. Horses, particularly colts, eat them with the greatest relish and grow fat. Cattle winter in fine shape and cows increase in milk when fed carrots. Sow seed early in spring in drills far enough apart to use a one-horse cultivator. Five pounds of seed will sow an acre.

The varieties of carrots used for stock feeding are larger, later and coarser than the table varieties

\section{Most Popular Market Variety}

and make a much larger yield. Probably the most popular are the White Belgian and the Yellow Belgian. They are very much alike except in the color, one being white and the other lemon-yellow, They grow from a foot to 16 inches long. Very large and heavy. The white one is also sold under the name of "White Victoria." The Vosges, or Improved Short White, is shorter and heavier than the White Belgian, but otherwise very similar.

The crop of carrot seed was almost a failure this year, and prices are a little higher than usual.

Prices of Table Carrots, any variety, pkt. 5c, oz. $15 \mathrm{c}, 1 / 4$-lb. $40 \mathrm{c}$.

Prices of Stock Carrots, any variety, pkt. 5c, oz. $10 c, 1 / 4-1 b .30 c$.

\section{It Pays to Raise Carrots}

"We usually have figured our trial ground as an expense as far as cash receipts from the stuff we grow there is concerned. Of course it pays big in helping us to keep tab on our stocks. However, we sold from a plot of carrots, this season, at the rate of about $\$ 700$ per acre. These were not bunched, but sold by the bushel. From a space less than a square rod we dug four bushels which we sold at 2c per pound or $\$ 1.00$ per bushel. Not so bad.

\section{Our Carrot Seed American Grown}

Carrot seed has mostly been grown in France, until war upset things. There had always been a few grown in California. and when the French sup. ply was shut off, they started growing seed in ear. nest and are doing fine, The American seed costs more than the French, but I believe it is better.

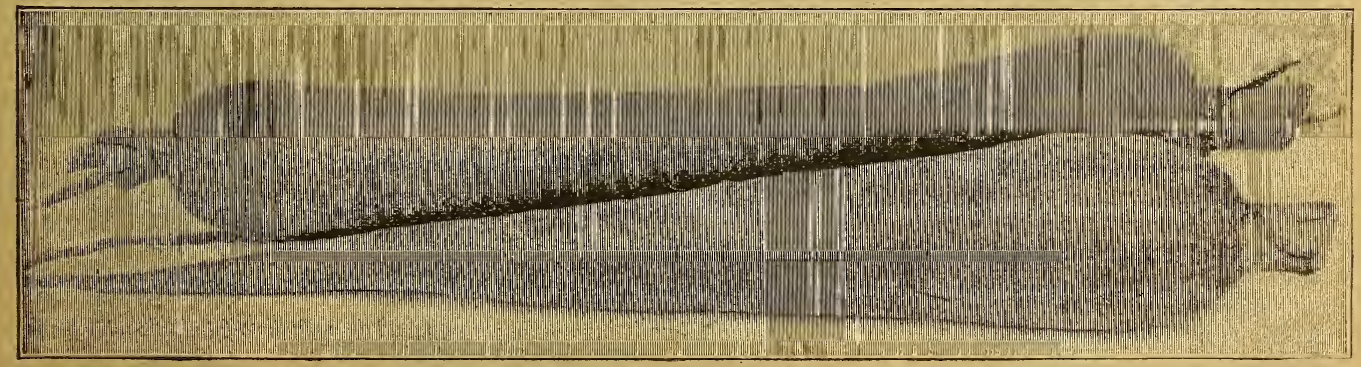




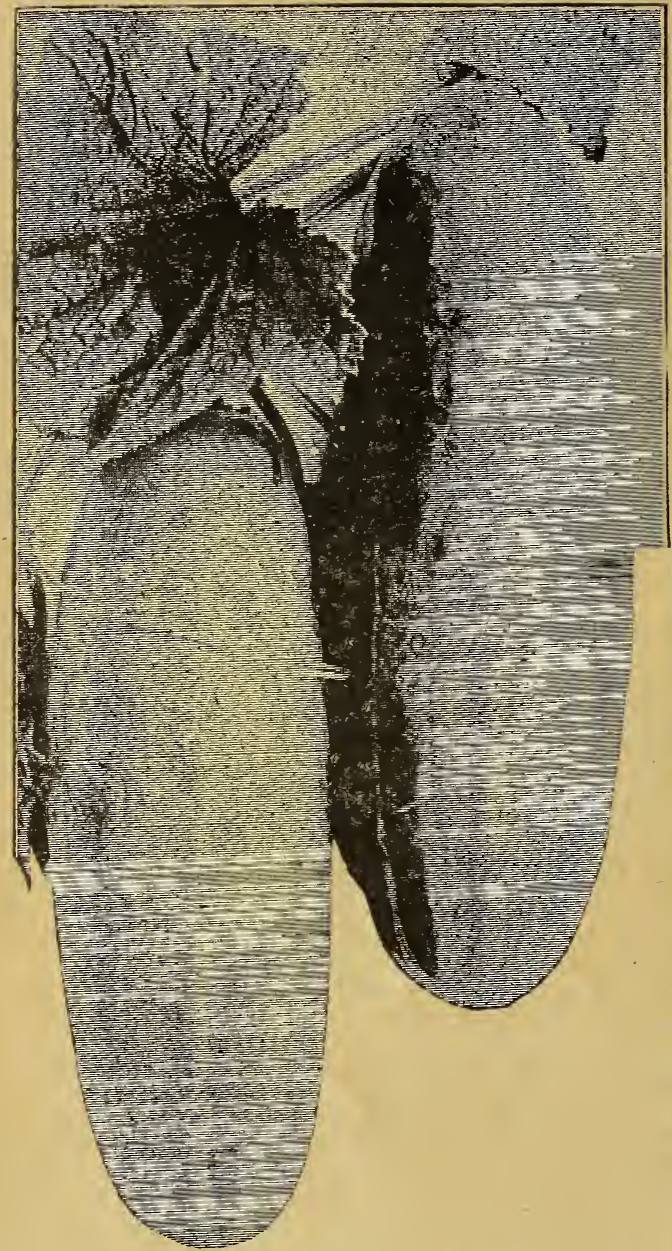

Evergreen Cucumber

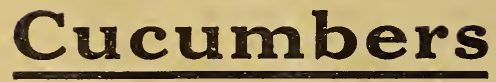

Cucumbers should have very rich soil, the richer the better, but will do fairly we.l almost anywhere. Plant about as early as you would corn, and put in plenty of seed. After the bugs get through with them, thin out so as to leave each vine plenty of room. Don't crowd them: That is what makes them grow knobby and crnoked sometimes. When they begin to bear, keep the m picked, as the vines will stop bearing if the cucumbers are left on. Use tobacco dust for the bugs.

The variety of cucumbers to choose depends on whit you want it for. The same cucumber that would be fine for pickles might be comparatively wnrthless for slicers, and many of the varieties making fine slicers are too shy bearers to be valu. able for pickling, so in order to get exactly what you want, you should grow two or three, or pos. sibly four varieties.

For slicers, the best variety I have ever grown is the Emerald, a new sort introdueed by the Liv. ingstons. It is the handsomest cucumber I ever saw-long, straight, and dark green, and as smooth as an egg. It has absolutely nn prickles or spines on it, and from start to finish it is perfectly smooth and dark rich green in color. It dues not turn yel. low in ripening, but remains the same color. It does not set thick enough to be valuable fnr pickles, but for slicers it is just the thing, as it will nutsell in the market all o'hers two to ones, besides it will keep a week after picking and look just as fresh as ever.

Another good slicer is the White Spine, which is well known everywhere. It is a large, very smooth cucumber, dark bl ish green color. Holds i's color rem'rkably well and docs not turn yel ow. There is a fine, special strain of White Spine, known as Henderson's Perfected White Spine. It is early, perfect shape, perfect dark g't en color, and a splendid market sort in every way. I have also the Arlington and Livingston strains if you prefer them. There is also a strain of White Spine sold as Cool and Crisp, which is ex'ra lung and slender, and one called Klondike, which is popular in the west.

If you want a long, slender, pickling cucumber, the best one is the old.fashioned Long Green. This is the old-fashioned, long, almost seedless, and dark green cucumber, $\mathrm{w}$ hich, under favorable conditions, will grow a font long or more, and makes a dellghtfully brittle, slender pickle. There is also a beauticul big cucumber known as the Fordhook Famous. Very large, almo t seedless, and requires favorable conditions to make a success. The Davis Perfect is a beautiful, verv large cucumber, and under favorable conditions is very profitable.

The biggest cucumber of all is the Goliath, or Giant Prolific, which is of the English type, very large, and long, and seedless, very often 18 inches long. If you want sornething extra early to make the very earliest small-sized slicers and good pickles later on, you should use Early Cluster.

Early Russian is very similar, although pos. sibly a trifle shorter in shape. These extra earlies all turn yellow quickly, and should be used w! ile comparatively small. For main crop pickles I like the Evergreen best of all. It is smouth, dark green, straight, and medium size. It comes the nearest to a general purpose variety of any of them, and I prefer to use it entirely for pickling. Chicago Fickle, and Everbearing are very similar, being special strains developed by the pickle factcries for commercial pickles. If you want a curinsity in cucumbers, you should plant the White Wonder, or, as it is sometimes called, the White Pearl, which never turns green at all, but is ivory white in color right from the start. It is as good as any ordinary variety, and a great curiosity. For forcing purposes, the best one is the Grand Forcing.

Prices of Cucumbers.

Pkt. Oz. $1 / 4 \mathrm{lb}$.

Chicago Pickle ........................... 05c 15c $40 \mathrm{c}$

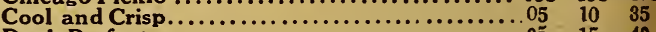

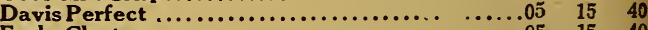
Early Cluster...................................05 $15 \quad 40$ Early Cyclone .................................05 ic 35

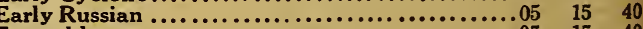
Emerald............................................ 15,40 Evergreen..................................... $15 \quad 40$ Everbearing.................................. 05 Fordhook Famous.......................... 05

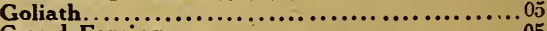
Grand Forcing...................... $05 \quad 15$ - 40 Henderson's Perfected White Spine............05 $\quad \begin{array}{llll}15 & 40 \\ & 05 & 15 & 40\end{array}$ Long Green $\ldots \ldots \ldots \ldots \ldots \ldots \ldots \ldots \ldots \ldots \ldots \ldots \ldots . .05$ 15 15 White Pearl... White Pearl... .......................... 05 $15 \quad 40$ These prices are all postpaid. For wholesale prices on large lots see blue list.

SPECIAL OFFER. 6 packets for 25c. For 25c you may select one packet each of six varieties of cucumbers. 


\section{Lettuce}

Lettuce is something that is found in every garden, and that every one is fond $c f$, at least in the early spring. It can be grown in any old cor. ner, but does best in rich, warm soil. Plant very early, the earlier the better, and don't get it too thick. If you want good-sized heads, it ought to be thinned to several inches apart each way.

Probably the most popular variety of all for early use is the Simpson, or, as it is generally called, Blackseeded Simrson. It does nnt make a true head, but a loose fluffy bunch of tender, light green or creamy leaves. Delicate flavor and grows very thickly.

If you prefer a smooth-leaved, $\mathrm{cr}$ as some people call them, cabbage-leaved variety of lettuce that is extra early, you use May King. It is the earliest and tenderest of the cabbage-head varieties, and if well tended on rich ground will make a true head almosĩ as solid as a cabi age head. The outer leaves are light green, slightly tinged with brown, and the inner leaves are creamy yellow. Fine rich, buttery flavor.

Another good head lettuce is the Hanson, although it does not make a true head like the cabbage variety. It is the largest of all the curled varie ties; dark green leaves outside and creamy white inside. The leaves are curly and tender, and form a loose head as large as an early cabbage. Slow to run to seed.

Some people prefer a red or brown lettuce. The best one of that color is the Prize Head, which is about the same as Simpson, except for color, which is a mixture of red and green. The leaves are very thin and tender. This is the one that is sometimes called "Beefsteak," or "All Cream."

In the true cabbage head or smooth-leaved lettuce there is the May King, which I have already mentioned, California Cream Butter, and the Big

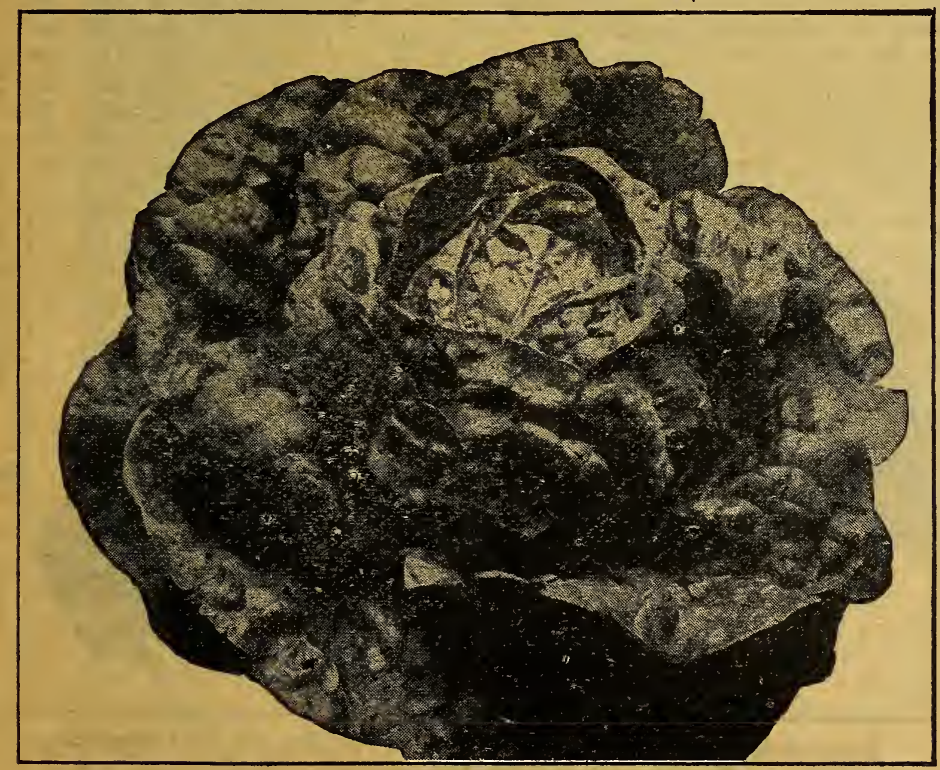

California Cream Butter-Best of the Cabbage Head Varieties

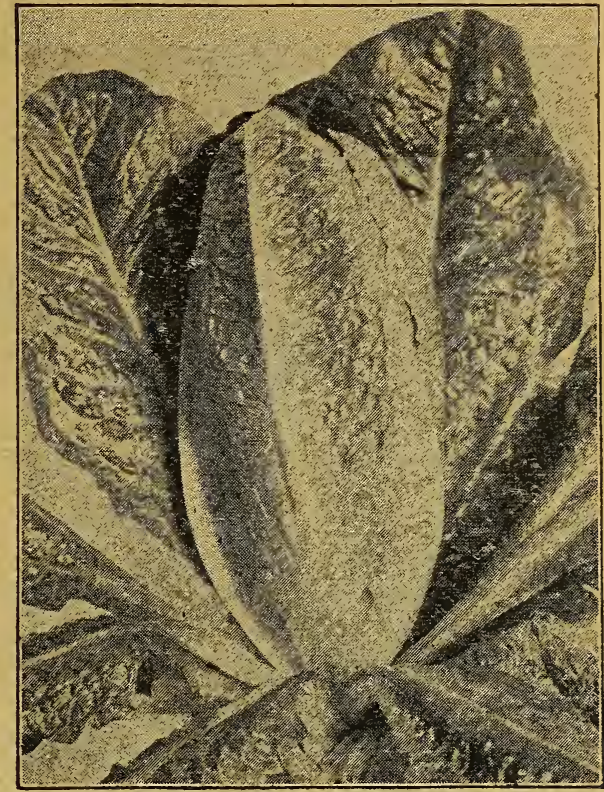

White-Heart Cos

Boston. The California Cream Butter is probably the best of all the cabbage-head varieties. It makes a flat, smooth head about the shape of Flat Dutch cabbage. The leaves are very thick and rich in flavor. It stands the heat well and is good all sum mer.

The southern growers who plant lettuce in the fall or winter for very early shipment north use the Big Boston. It seems to be the only variety that will stand winter-growing. At least, it is practic. ally the only variety that the southern growers will use.

For greenhouse use, the variety always used is the Grand Rapids. This looks somewhat like Simpson, but is slightly different in appear. ance, and for some reason suc. ceeds better under glass. The strain I have is especially selected for forcing and is fine. One peculiarity of this variety is that it is always weak in germination and $\mathrm{must}$ be planted thick and very care. ful y to get a stand.

There is an entirely dis. tinct type of lettuce known as Cos Lettuce, which is extens. ively grown in Europe, but not much known here. We have an excellent strain known as White-Heart Cos. The ap. pearance and manner of growth are well shown in the above illustration. When Cos lettuce is grown right is has a rich buttery flavor that is hardly equaled by any other variety.

(Continued on next page.) 


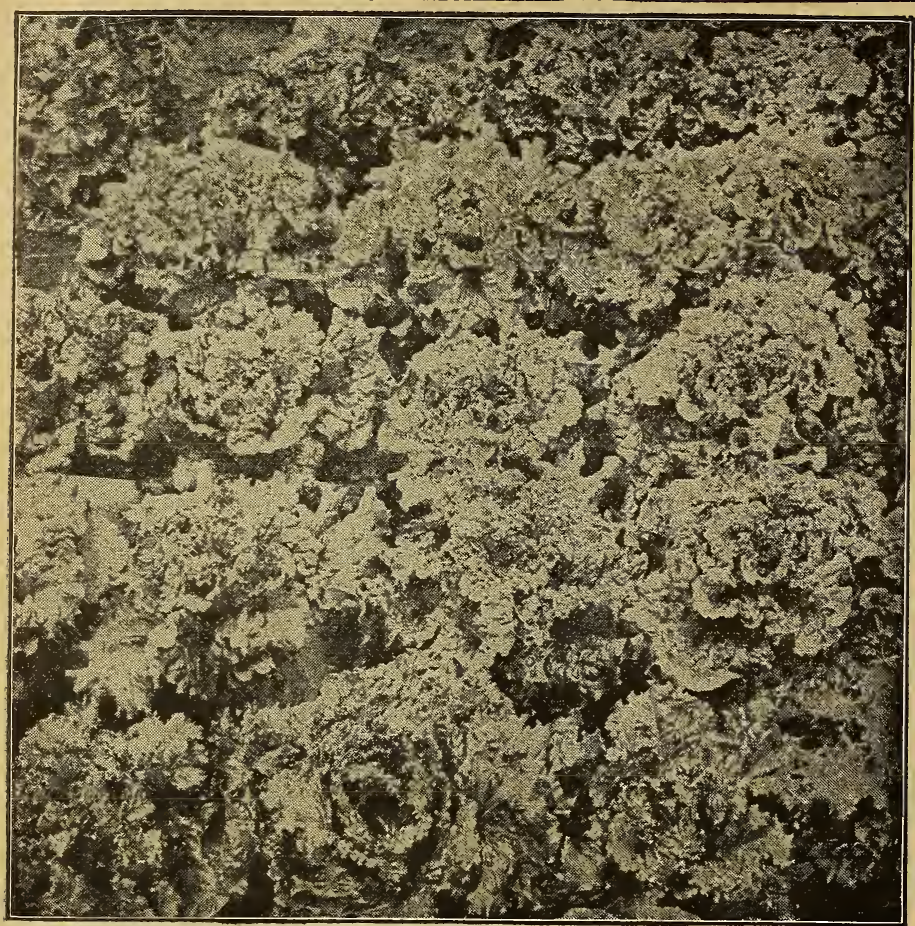

A glimpse of the lettuce in our trial grounds. Top row is Prizehead; next Hanson, then two rows of Simpson, and last a row of Grand Rapids. Plants are left a foot apart each way to head up. Don't they look nice?

\section{Lettuce (Continued)}

Wher the plant gets good size and begins to head, tie the tops of the leaves together so it will bleach out. This will make it tender and crisp.

You have no idea how much difference it will make in the quality and tenderness of lettuce to shade it some way to keep the hot sun off. Cheesecloth is cheap and makes a good covering. Plant the seed or transplant the plants in a bed six feet wide and as long as you want it. Make a frame as wide as the bed and tack the cheesecloth on and set the frame on stakes a foot or so from the ground. It is better to cover the sides, but not absolutely necessary.

It must be remembered that what you want in lettuce is a very rapid, tender growth, and that means that you should have the soil very rich and that the lettuce should never lack for either fertility or moisture. A lack of either will mean a stunted plant with tough and bitter leaves. Many ask why lettuce runs to seed so quickly. I1 is because the plants are crowded, or stunted, or both. With plenty of plant food and moisture. the plant will make a big growth of leaves before it will run to seed.
Growing Lettuce

\section{For Market}

Lettuce is a crop that pays well to grow for mar. ket if you can get it when other people have none, or if you can supply a better quality than any one else. It is easily grown u $\mathbf{n ~ d ~ e ~ r ~}$ glass either in a hotbed or regular greenhouse. It does not require much heat. It must have rich soil and be kept growing right along. Give it plenty of room. Most people plant it $t o 0$ thick. If lettuce is expected to make good-sized heads it must have at least six inches of room each direction, and a foot each way is better yet.

I have always had good success growing lettuce from plants. For an early crop out of doors it is a good plan to start plants in a hot bed and transplant like cab. bage, Or they can be ship. ped from the south,

The variety usually used for forcing under glass is the Grand Rapids, although the Simpson is also used, and for a smooth-leaved or cab. bage-lettuce, New York. For winter, outdoors, in south, use New York.

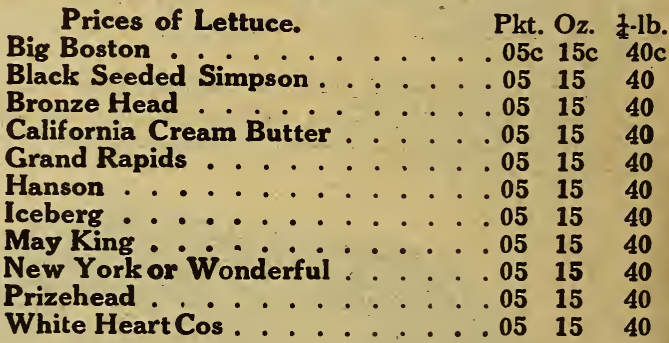

Big Prices of Lettuce.

$40 c$

0

0

40

40

40

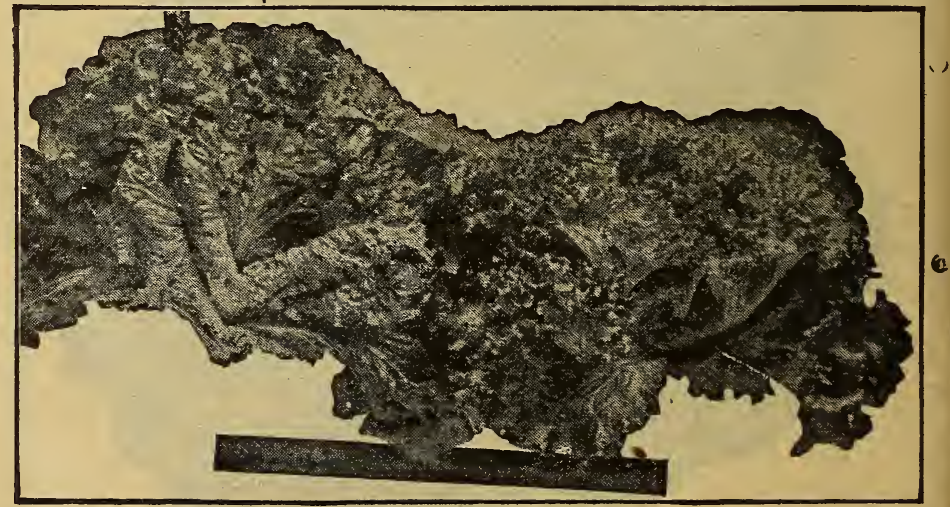

Typical Heads of Simpson and Grand Rapids, the two great forcing varieties. We have especially fine strains of these. 


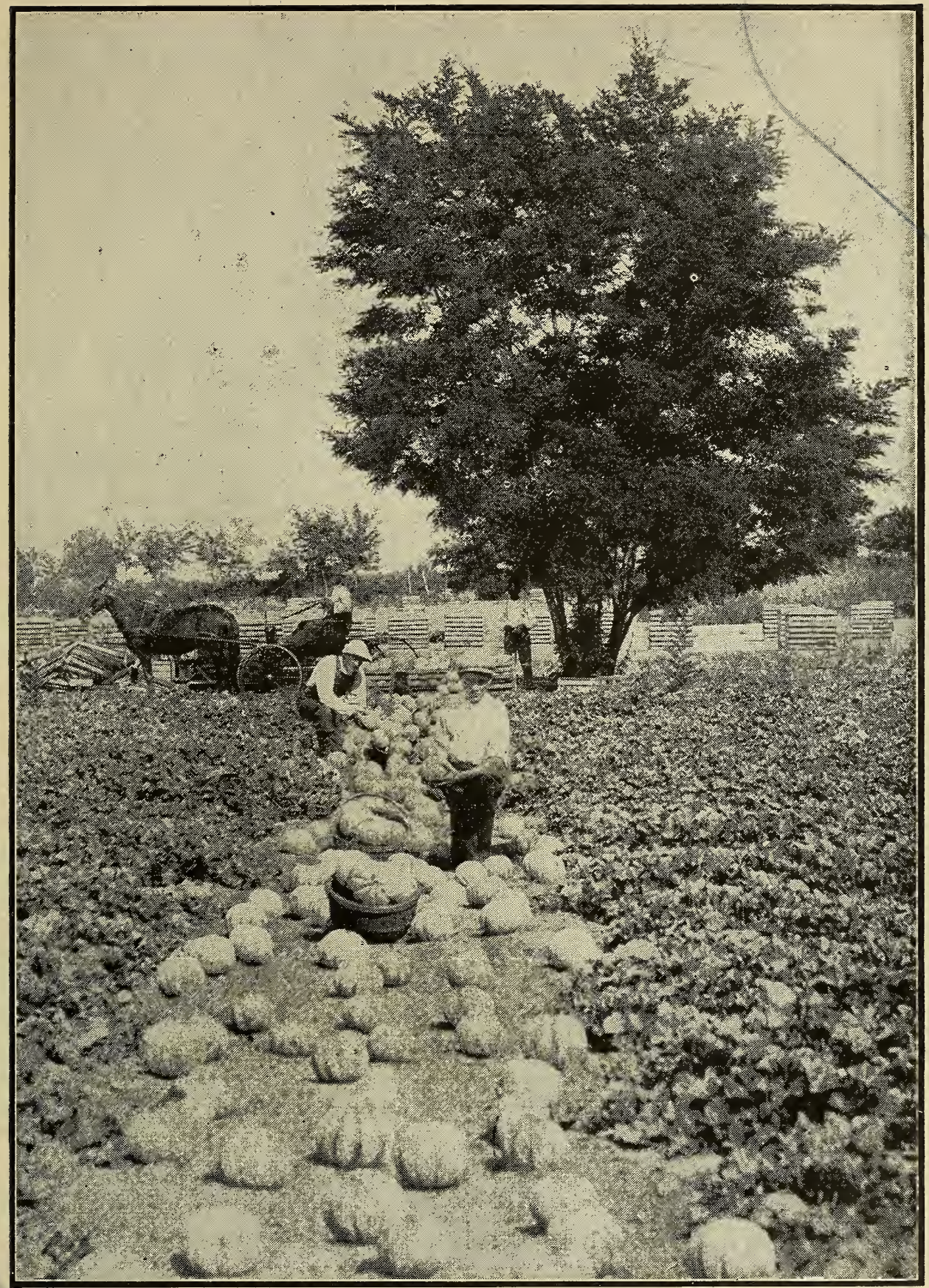

\section{New Greeley Wonder Muskmelon on the Grounds of the Originator}

THIS new melon has taken the Denver and Greeley markets by storm. It originated with 1 a German gardener at Greeley and he has been several years getting fancy prices for them in the home market and shipping them to Denver. It is large, early high quality, and a good shipper. Looks like Hackensack but cuts like Osage. Weighs 4 to 5 pounds. Has made four hundred crates per acre. This picture will give you a good idea of the size, shape, and yield. PRICES; Pkt. 10c, Oz. 25c. 

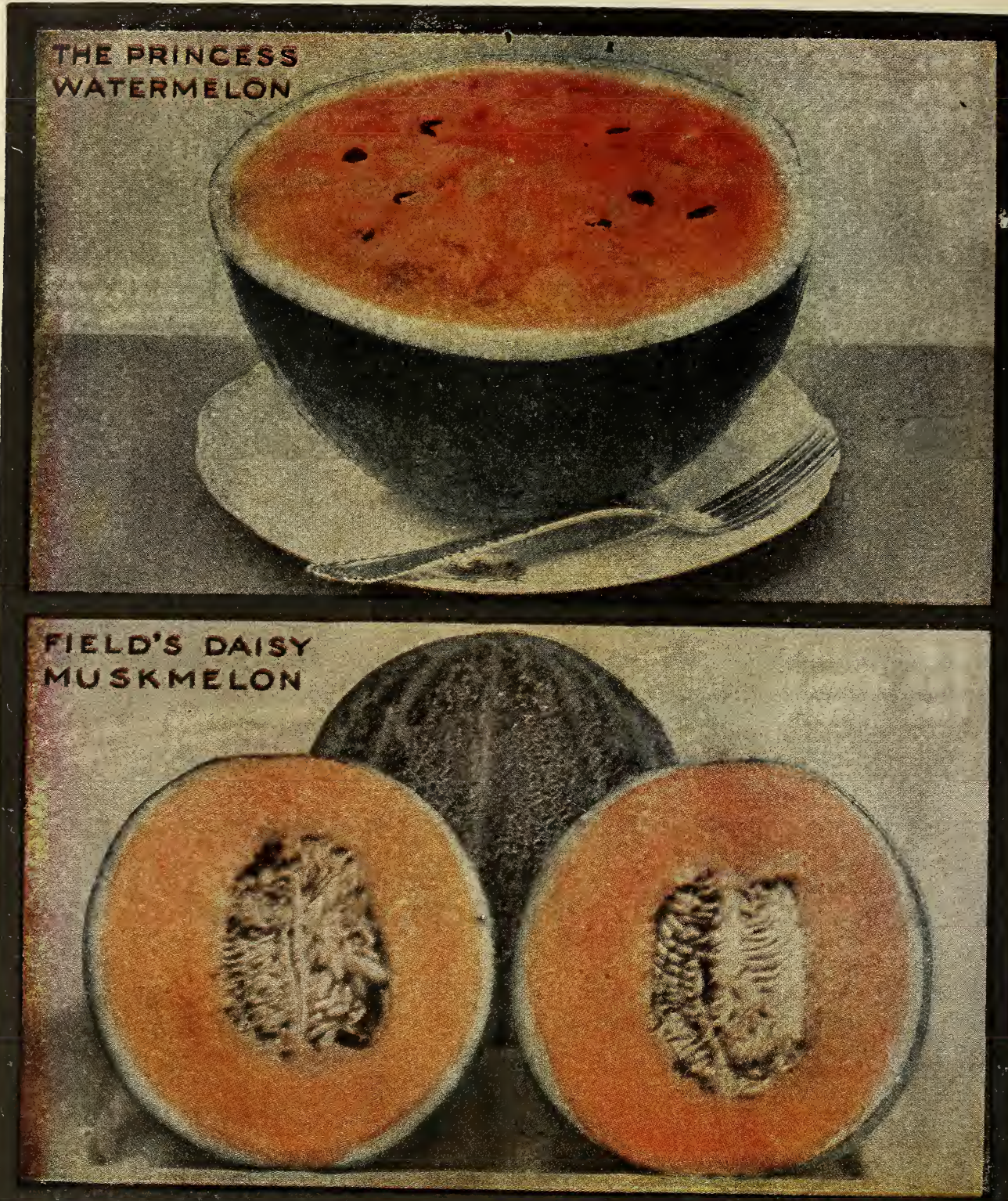

\section{TWO SPLENDID MELONS: PRINCESS WATERMELON AND DAISY MUSKMELON}

1 Pkt. of Each 20c, $1 \mathrm{Oz}$. of Each $40 \mathrm{c}$

HERE are two melons which you should plant by all means, whatever else you plant, for they are different from any others, and in many ways better than anything in the list. You will find both of them described further over, but briefly here is what they are:

The Princess is an individual-sized melon, introduced from Roumania, dainty little melons about six inches in diameter, absolutely round, skin very thin, flesh bright red and very sweet. Early and very prolific. A few hills will supply an ordinary family. Seeds hardly larger than apple seeds.

The Daisy Muskmelon looks some like an Osage, but is rounder, much earlier, and less likelv to crack open. It is the best muskmelon I have ever tasted. It has proven very resistant to both blight and drouth. It is ideal for home market, and also so solid that it ships fine. See full descripion on next page. 


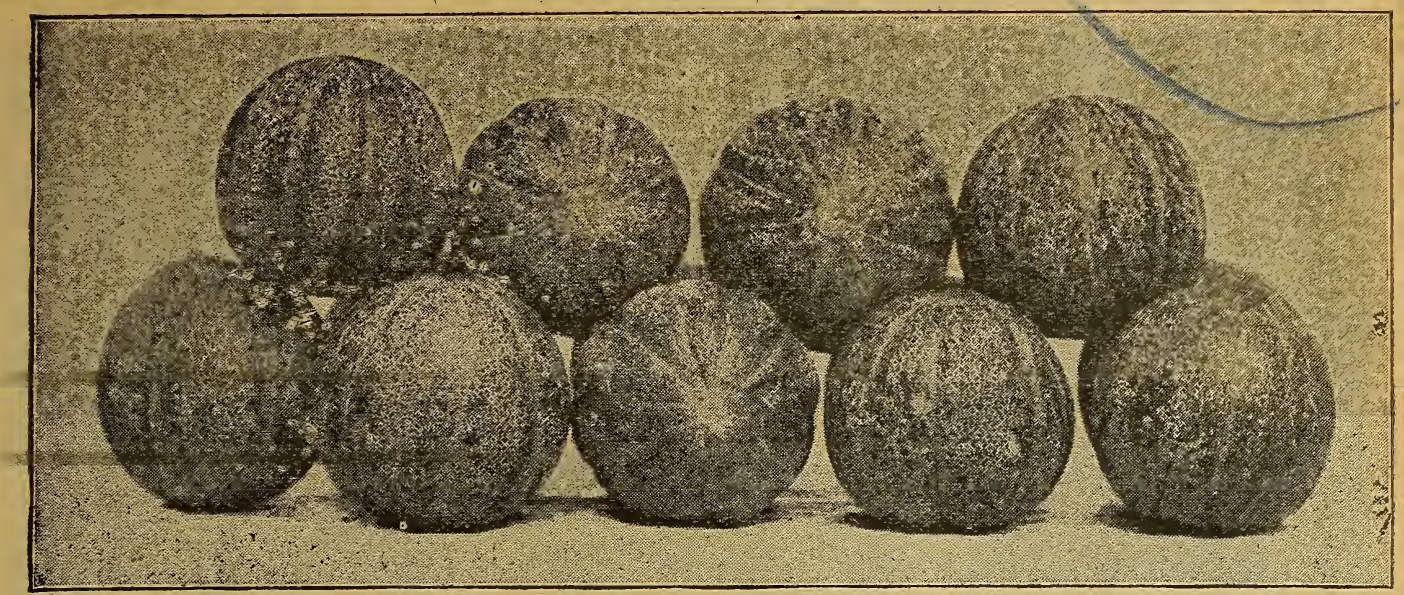

\section{Field's Daisy Muskmelon--The Best Melon of All}

Price, pkt. $10 c, 9 z, 25 c, 1 / 1-1 b .60 c, 1 b . \$ 2.10$.

This new variety originated with Mr. Affred handsome outside appearance and uniform shape. Apel, a market-gardener in the northern part of In size they will average about 6 or $\mathbf{7}$ inches in lowa, and it combines more good points than any diameter and weigh about three pourds each. And other melon I have ever grown, and I have had an they run absolutely uniform in size and appearextended experience with melons, both as market. ance, too. A pile of fifty of them won't vary an gardener and seedsman.

It looks somewhat like Emerald Gem, but is larger, more uniform in size and shape, not so deeply creased, thicker mi ated, especially at the blossom end, and a much more saleable melon in every way.

But above all other good points is its quality. I never tasted as good a melon in my life. It has the same rich orange-colored flesh as Osage, Emerald Gem, Perfection and Burrell's Gem, but it is far superior to either of them. It fairly melts in your mouth and is good clear to the rind.

You can see by the picture below how thickinch in size.

It is extremely early, which is exceptional for so large a melon. It is apparently blight proof, and stayed green and vigorous and bearing after all others were done. In market it outsold everything else, and, in fact, after people got a taste of it vou co:Idn't sell any other melon at any price. Price, pkt. 10c, oz. 25c, $1 / 4$-lb. 60c, lb. $\$ 2.10$.

That is what $I$ sa:d about the Daisy last vear, and the only correction I would make now wou'd be to make it stronger in every particular. In fact, it would be hard to make it too strong. I dsn't believe I ever introduced a new thing that was sc meated it is, and the above picture shows the absolutely satisfactory in every way, nor that came
so near pleasing everyone. In my garden.

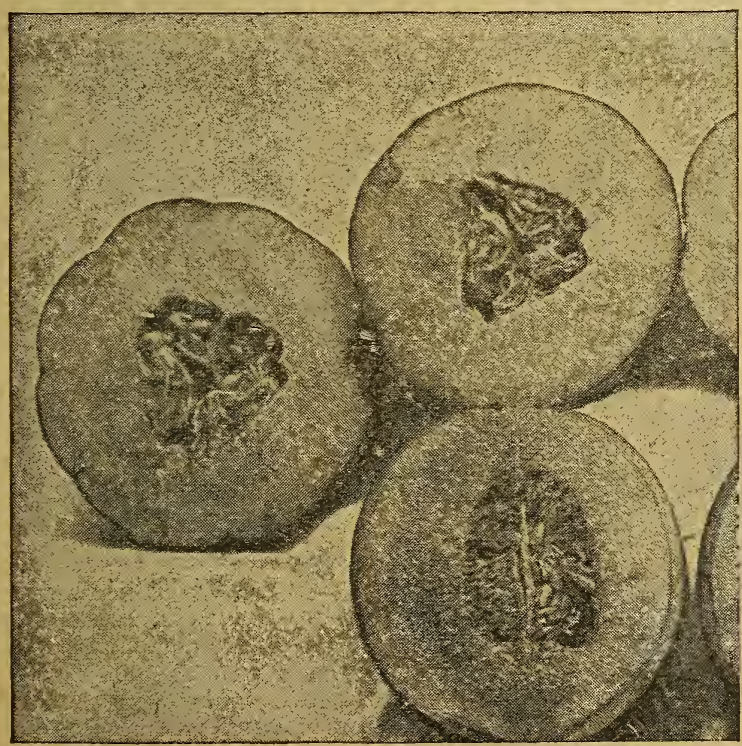

Field's Daisy. Cross section showing thick flesh so near pleasing everyone. In my gard Drought Resistant. We had it terribly dry here, almost everything in the garden was killed or bad ly crippled, bus the Daisy was fresh and vigorous right through dry weather and all Blight Proof. The Daisy showed no trace of blight all sum mer. We began to pick them the first week of August, and the vines were still green and vigorous the first week of October eight weeks later, and still loaded with melons.

High Quality. Absolutely I never ate so. good a inelon. Tnere is no chance for argument on that. In our trial grounds we had practically every known variety of melons, and the Daisy was the only one we would eat. The others found a poor market unless we failed to find any of the Daisy ripe. I had to get up early to. beat the boys to the patch.

Heavy Yield. They set very full, and No runts every melon made goud for a fancy price, but we saved them all for our own use and for seed. 


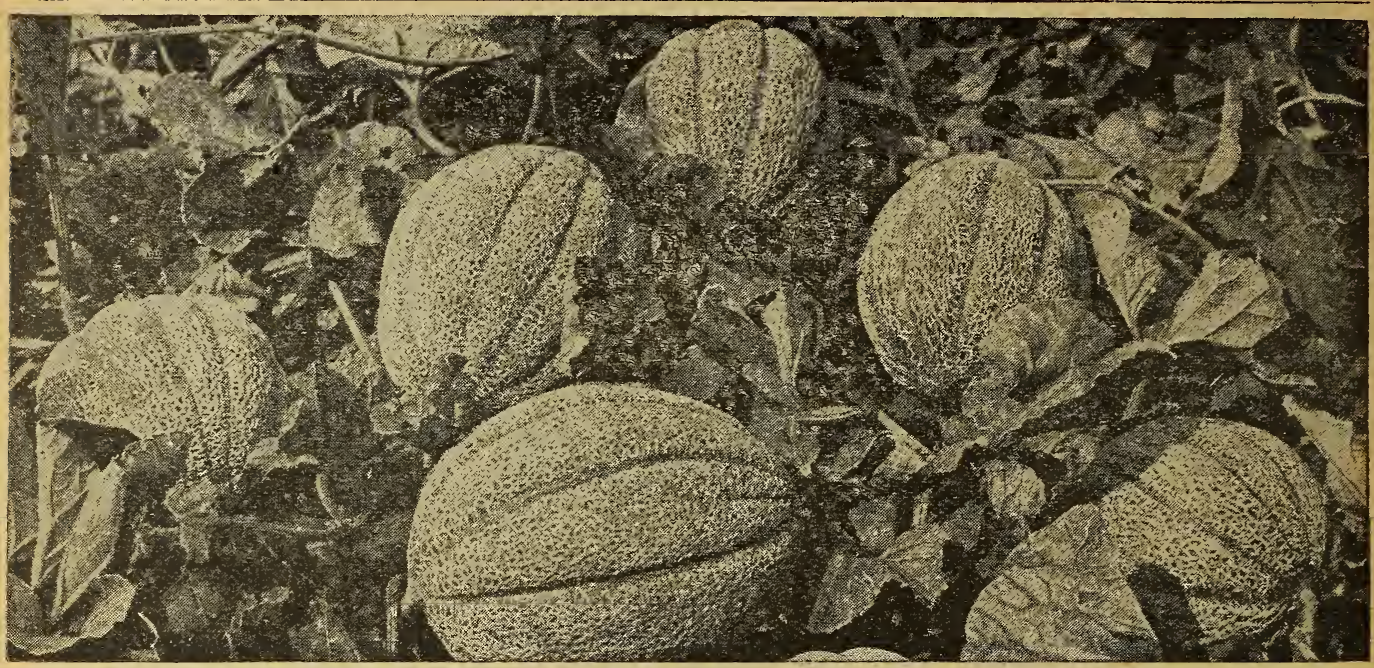

Netted Osage, the Finest Osage Melon Grown. Pkt. 10c, oz. 20c, 1/4-lb. 50c.

\section{Muskmelons and Cantaloupes}

I take a special pride in my muskmelon seed. I do not believe there is a man in the Unifed States who can furnish better seed or who does furnish any better seed than I do. Some of it I grow my: self, and some of it is grown by specialists in other parts of the country. Some of it, like Hackensack, I have grown in the east, as that is the native home of that melon. With others, like Osage and Emerald Gem, better seed can be grown right here in lowa. The various types of the Rocky Ford Cantaloupe are grown to perfection at Rocky Ford, Colorado. I have my seed of them grown there by specialists. Wherever it comes from, it is the very best that can be had. It is saved from selected melons, such as bring fancy prices on the market. No culls, frostbitten stock, or slick melons are allowed to be used. No seed is ever saved from blighted

\section{Yellow-Meated Sorts}

Personally, I prefer the yellow-meated varieties. Of these, the best one, all things considered, is Field's Daisy, which you will find fully described on page 25. Next to that my choice would be Perfection. It is the biggest of all the very large, often selling on our markets for $15 \mathrm{c}$, or even $20 \mathrm{c}$

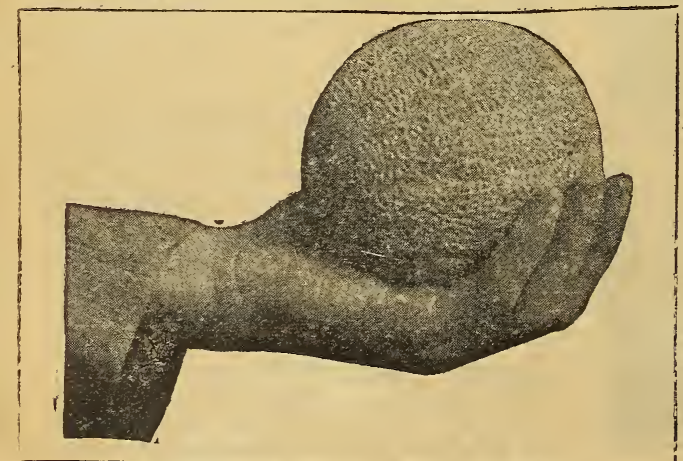

A Typical Standard Rocky Ford Muskmelon fields. Whether you want a $5 \mathrm{c}$ packet or $500 \mathrm{lbs}$. for a shipping association, I can fix you out to perfection. Ask for special prices on large lots.

\section{The Best Variaties}

It is really hard to say which is the best variety of muskmelons. They are all good, and it depends largely on your individual taste which one you think is the best. Some people like a yellow. meated melon, while others will have nothing but a greenmeated melon. Some people want a great big muskmelon that they can cut in slices, while others want a little nutmeg which simply needs to be cut in halves. For that reason we have to list a big lot of varieties and let you take your choice.

each, and you know it takes a pretty good muskmelon to do this. It is round, or slightly oblong in shape. Flesh deep yellow or salmon-color, and of the richest, sweetest flavor imaginable. It is very thick-meated, and in fact is the best variety I know of, and will surely suit you.

Another popular yellow-meated sort is the Osage, which is the standard variety in the Chicago markets, being grown largely in Michigan. It is not so large as the Perfection, but looks very similar inside. Distinctly oblong in shape, dark green skin and salmon flesh. Fine quality.

We have two types of the Osage. The regular Michigan type is nearly smooth, dark green, and large. The lowa type is heavily netted, very solid, and slightly earlier. If you prefer this type, ask for "Netted Osage."

In the smaller or nutmeg-sized muskmelons with yellow flesh, I prefer the Emerald Gem and Burrell's Gem, or, as it is sometimes called, Pink Meated Rocky Ford. They are about the same size, but different in shape and appearance, the Emerald Gem being practically globe-shape, smooth skinned, brownish-green in color outside, and very early. It is practically a smaller, earlier type of Perfection. 


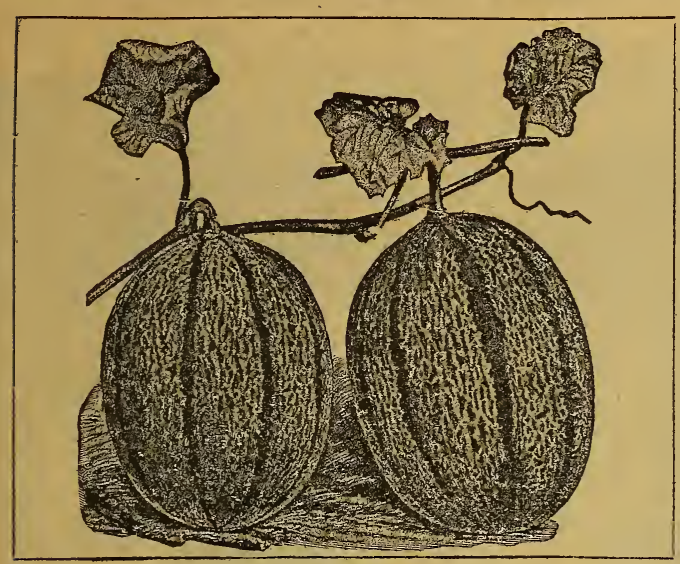

Muskmelons and Cantaloupes

The Burrell's Gem has the shape and much the appearance of the regular Rocky Ford, but has deep, salmon colored flesh like Emerald Gem or Perfection. It is not quite so early as the Emerald Gem or Rocky Ford, but it is great to yield, and in most markets outselis all other small melons. You might say that it has the Osage or Emerald Gem quality, with the Rocky Ford size, shape and shipping qualities. There is also another medium-size, yellow-meated muskmelon lately introduced, called the Fordhook, which is about as large as the Emerald Gem, but looks more like a Hackensack. I do not think very much of it and do not consider it as good as the ones I have already named. If you want the old-fashioned, big, ye!low, fragrant muskmelon, the kind we used to have when we were boys, you should plant the California Cream Cantaloupe. It is big: and yellow, and showy, but only fair in quality. The Banana is distinct and peculiar in appearance, having the shape and somewhat the taste of a banana.

\section{Green-Fleshed Sorts}

The best known and the most popular of all the green-fleshed muskmelons and cantaloupes is the Rocky Ford Cantaloupe, named after a district in Colorado, where it was first extensively grown There are a number of distinct strains of this popular type of small melon. but all are more or less similar. Small, egg-shaped, very solid, very sweet, a good shipper, great to yield, and always uniform in size. For the shipping market there is probably more of this variety grown than of all the varieties put together. I have all my seed of these grown at Rocky Ford, Colorado, by men who have made a specialty of cantaloupes for years. I pay them practically double the usual price, and I know absolutely that it is extra good. You couldn't get better seed anywhere at any price, so what's the use in going "bargain hunting."

I visited Rocky Ford in cantaloupe time" and studied into this cantaloupe business and the selection of the seed very thoroughly and I believe my grower has the best strain of Standard Rocky Ford there is grown there.

The shipping associations and the big growers there all grow what is known as Standard Rocky Ford. This means that it is a strain that has been selected and bred up until it is absolutely true to type and meets the high standard called for by all of the shipping associations. To meet their specifications it must run absolutely uniform in sizc and shape; must be very heavy netted even clear across the ends; must be very thick meated, high flavor. early in ripening and free from blight. When a cantaloupe meets all of these requirements, it is known there as standard. That is why everyone wants to get seed of the Standard Rocky Ford. It is just like buying thoroughbred live stock. You know what you are getting.

This is the type that is advised by the Colorado Experiment Station. My grower has made an extra choice selection of this seed and has won first prize in the cantaloupe shows year after year. The cantaloupes I show here will give you a good idea of the shape and general appearance. These are some cantaloupes from which we were cutting seed at Rocky Ford.

Next to the strain my grower is using, prob. ably the best would be Pollock's strain. This or practically the same is also sold as Eden Gem and Blinn's Rust Proof and Netted Rock. In fact, there are probably a dozen different named strains of Rocky Ford cantaloupes there, but to tell you the truth, I can see practically no difference amongst them and there is no need of listing more than one or two of them.

The southern growers, especially in Texas and Oklahoma, have a slightly different idea on the cantaloupes, and while they grow the same variety as the Colorado shippers, they have selected it slightly different and more according to their ideas. This is also the same strain that is most popular in Delaware and the Carolinas. It is called by them The Improved Rocky Ford - Southern Type. It is slightly larger than the regular Rocky Ford type, rounder in shape and showing more distinct ribs. My seed is grown by a noted melon shipper in Oklahoma and is highly selected. If you want a strain of seed less expensive than these two highly selected types, I can give you ordinary Rocky Ford, or Netted Gem. This is the regular commercial strain of seed and is the original type from which all other strains have bcen developed.

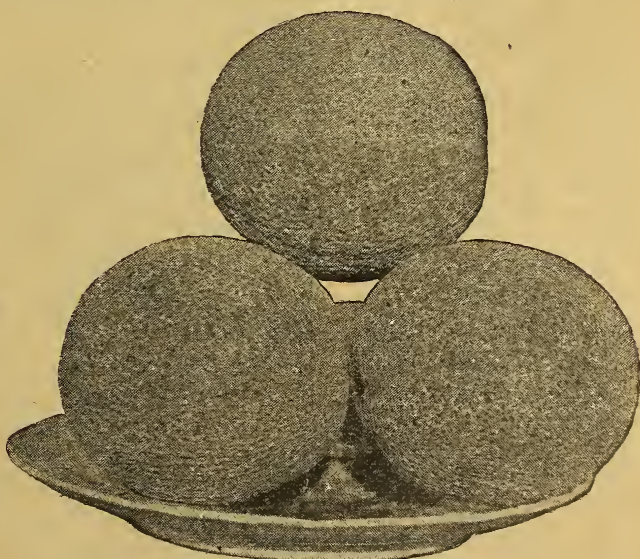

Pollock strain of Standard Rocky Ford. A highly developed Type. Eden Gem and Netted Rock are very similar. Notice rounded shape and heavy netting. These show the true Rocky Ford type. 


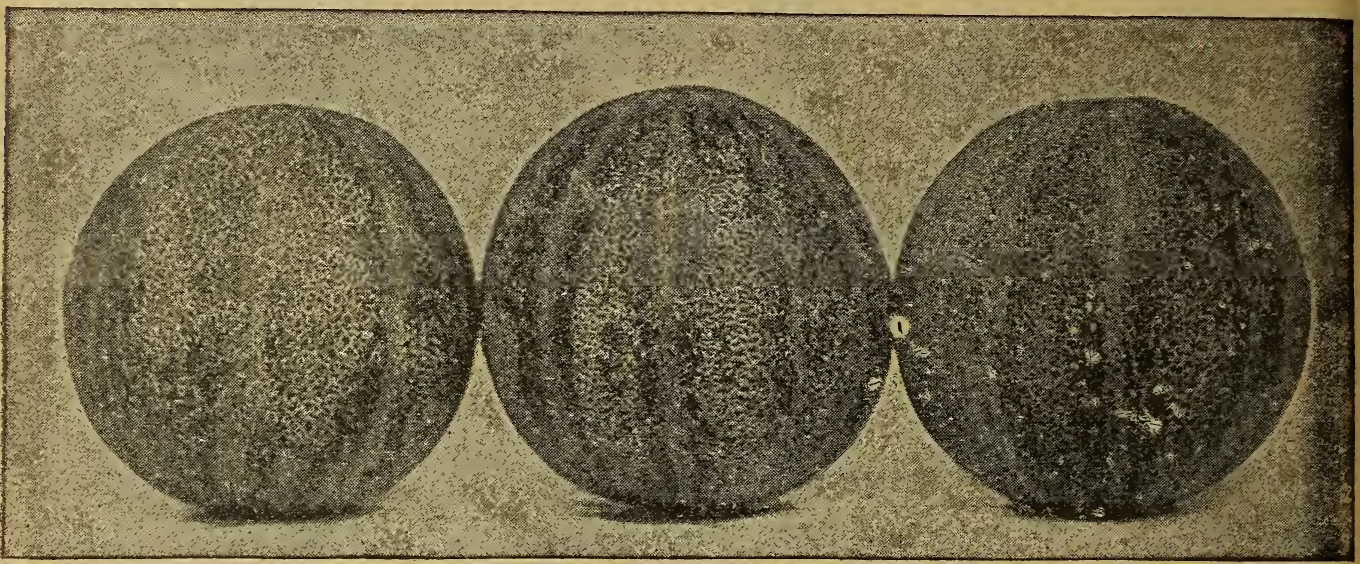

\section{Another Picture of Field's Daisy. Can You Beat It?}

\section{Muskmelons and Cantaloupes (Continued)}

There is a growing call for a yellow-meated cantaloupe of the same shape, size and general character of the regular Rocky Ford, and that can Le packed in the standa.d cr tes. This has been met at last by the Salmon-Floshed Rocky Ford, which is a regular Stand Ird Rocky Ford with sal. mon-colored flesh and the peculiar rich flavor of all that color. It has the typical Rocky Ford appearance in every way, but I think the flavor better and I find it is selling better in the markets than the regular sort. It has the same hig't flavor as Burrell's Gem, and the same beautiful co'or in. side, but it is better because it has the earl ness. rounded shape, solid $n t$, and standard size, of the best type of Rocky Fords.

We have a very fine strain of them grown for us by the best grower at Rocky Ford, Colo, and I am sure they will p ease you. There is a great de. $m$ ind from professinnal growers for the seed of this new strain, and I would advise you to place your order early.

The Green-Meated Nutmeg is the old.fash ioned, little, sweet nutmeg melon that has been the standa $d$ for a generation or more. Small, early sweet and prolific. Of the large green-meated melons, the best type known is the Hackensack. We have three strains of this. T'iv reguldr Hackensack is about like the Perfection in size, but is green-fleshed. It is large in size, fine quality, and fairly early. The Extra Early Hackensack is a week to ten days earlier ripening. Very nearly as early as Rocky Ford, but of course larger.

The Long Island Beauty is a special strain of the Hackensack, and is the largest of the three, but still fairly early, All are very fine-looking melons deeply ribbed, heavily netted, and of very fine flavor. The flesh is fine quality and clear green in color.

The Bayview is one of the old timers that is still popular. Very large, long-shaped, and generally good quality.

This practically covers the cream of the list in muskmelons and cantaloupes, but there are numer ous other good varieties, of which I keep seed on hand and can supply on special orders.
Prices on Muskmelons (Postpaid)

Pkt. Oz. 1/4-lb. Lb. Bananz........1) 20c 5 lc $\$ 1.75$

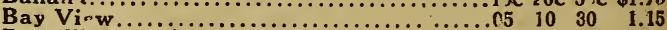

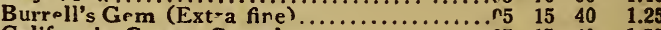
Califor ia Cream Cantaloup

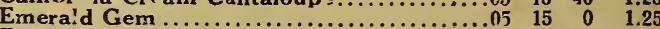
Extra Early Hack $t$ nsack.................... $05 \quad 15 \quad 40 \quad 1.25$ Field's Daisy................................. 1) $85 \quad 60 \quad 2.10$ Fordhook

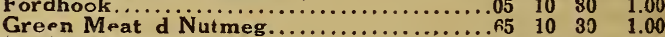
Hackensack .................................05 $15 \quad 40 \quad 1.25$ Improv d l ocky Ford.....................05 $15 \quad 40 \quad 1.25$

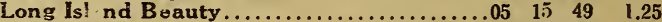
Netted Osage. Osage....................................... $15 \quad 40 \quad 1.25$ Perf ction.................................. 10 2) 50 i Rocky Ford or Netted Gem ................ $05 \quad 10 \quad 30 \quad 1.00$ Rocky Ford_Po lock Strain..................05 $15 \quad 40 \quad 1.25$ Salmon-Fis shed Roc $r y$ F ord................. $10 \quad 20 \quad 50 \quad 1.75$ $N$ t prices (not postpaid) $10 \mathrm{c}$ per pound less.

\section{The Greeley Wonder Muskmelon}

In teling about the different kinds of muskmelons and cantaloupes, If rgot to mention the Greeley Wonder, because it is a new one with us. It is a dandy, though and you should not overlook t. It originated at Gre ley, Colorsdo, with a German market gardener who grows it extensively for the Greeley and Denver m?rkets. It is in great demand an' brings higher prices than any other variety, because of its earliness, large size and fine quality. It looks like Hackensack for shape and general appearance, but it. has deep yellow flesh. is very solid and earlier than any other large melon. The quality is extra good. You should grow it by all means, Price, genuine Colorado grown seed: Pkt. 10c, Oz. 25c, $\frac{1}{4} \mathrm{lb}$. 60c, lb. $\$ 2.10$.

\section{Cantaloupe Seed For Big Growers}

I want to emphasize the fact that $I$ have the finest strains of cantaloupe seed, and the very best quality you can get anywhere. When I was at Rocky Ford I made a thorough study of this cantaloupe question and $I$ have no hesitation in saying that my seed was cut from the finest cantaloupes ever grown at Rockv Ford.

\section{Casaba Muskmelons}

There is considerable excitement now-a-days about the Casaba muskmelons. and in some climates and snme markets they are a great success. We can suriply seed of the best variety at pkt. 15c, 2 pkts. $25 c$, ounce $50 c$. 


\section{Watermelons}

\section{The Best Varie.ies}

It is mighty hard to make a choice of watermelons. They are all good, and I could be happy with any of them. I suppose there are something like three hundred varieties of water. melons listed in all the catalogs put together, but I have man. aged to boil it down to about twenty, and of these I would hate to throw away any of them, for they all have many good points.

Of course, a manaIways has

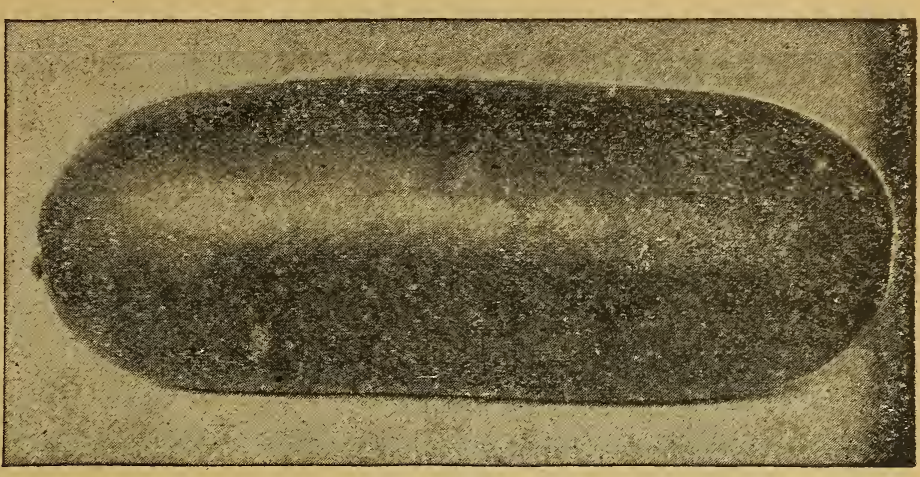
his personal preference, and for myself I belief that the Kleckley Sweet class are the best of the lot. This includes Kleckley Sw-et, Improved Kleck'ey Sweet, Halbert Honey, Tom Watson, and Monte Cristo. These varieties are all more or less similar, and each variety has is friends who claim it. the best one of the lot. Taken as a class they are the sweetest, biggest, best melons in the whole list. They are all long, dark green, and extra fine quality.

The Kleckley Sweet is the original strain and is probably the best known. It is too brittle to ship and haul very far for market, but if you have a near-by market and customers that will appreciate gand melons, you can do well with it. Bright red flesh and white seeds.

The Halbert Honey is slightly longer. more slender in shape, and slightly darker green in color. The Improved Kleckley Sweet is the Rocky Fo:d strain, and it is, in my opinion, the best strain of hleckley I have ever seen. It is absolutely uniform

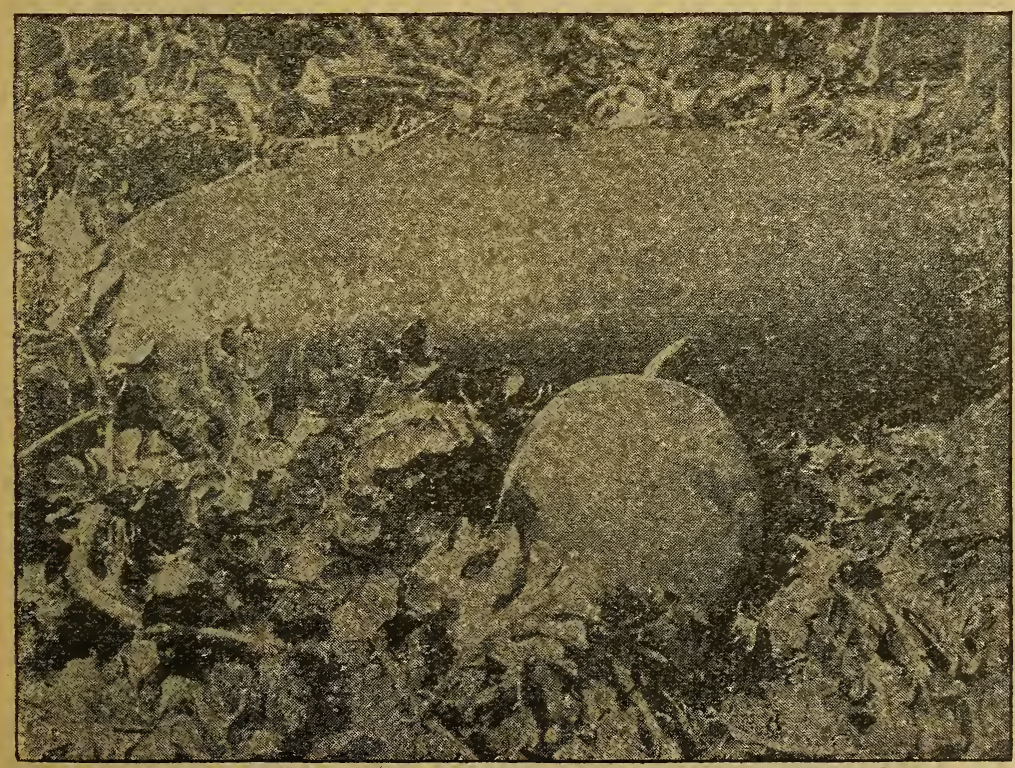

Improved Kleckley Sweet and the Princess. The best pair of watermelons in the 1 st for quality. Not a very good match in size, but they go along mighty fine together just the same. in size and shape. A little bigger-waisted than the standard Klechley and a little Jarger. Quality abso. lutely perfect. It does not break quite so easily in handling as the original strain, and for this reason is some imes ca'led the "Hard Shell Kleckley." It is an improvement in every way ov'r the Kleckley and you can't lose on it. But it is still too tender to ship well long dis'ances. The Monte Christo I find to be practically the same as the original strain. I can see no difference in the two.

Mclvor's Wonderful Sugar is another main crop melon. It lo ks like the old Rattlesnake, but is of much better quality. Large and long, medium early, and fine quality. Better quality than Sweet. heart and nearly as g od as Kleckley, handles well and is good either for market or h'me use.

The Iceberg is an improved Kolb's Gem. Better quality, and larger and better color. It is sometimes known as the "Blue Gem" owing to its rich bluish green color. Has very red flesh and very black seed. Outside dark striped. Almost round.

The Tom Watson is the latest develop. ment of the Kleckley type, and is evidently a cross between the $\mathrm{Kleckley}$ and some other variety. It is very large. I think the largest melon I have ever grown. Looks like a Kleckley on the outside, but ${ }^{3}$ lightly lighter in coilor, al. though the same shape and general appear. ance, and has the same red flesh and white seeds, but the seeds are darker than others of the Kleckley class. It $l$ as the same wonderful quality as the Kleckley, but has a ha $d$, tough rind that will ship with perfect safety. This makes it an ideal shipping melon. especialy for the south. 


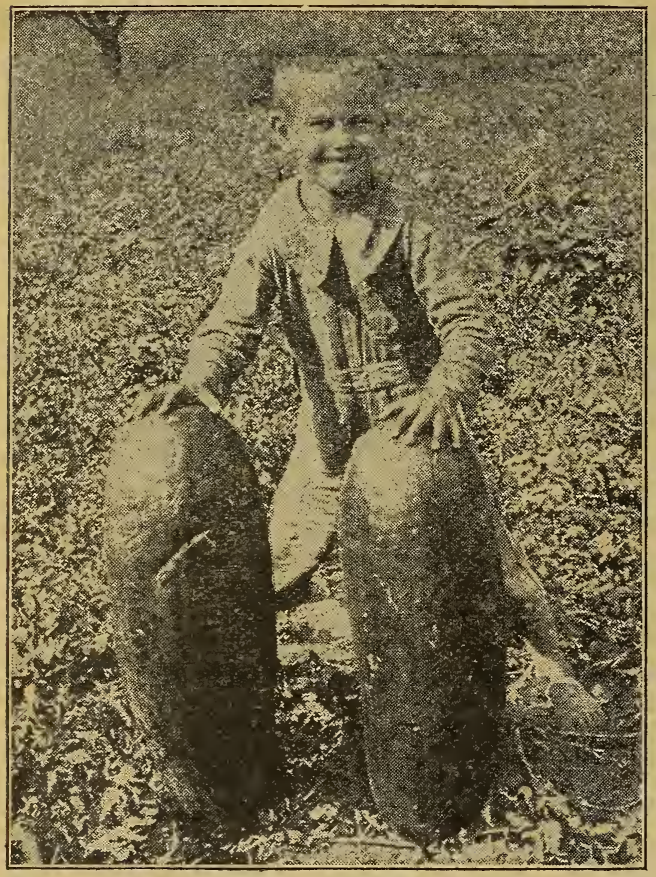

There's nothing fits a boy quite so well as a watermelon. These two "Tom Watson" and my boy are "three of a kind." They are all about 40 pounders.

\section{Watermelons (Continued)}

Other good shipping melons are the Alabama Sweet, Sweet Heart and Kolb's Gem. The Kolt's Gem was years ago universally favored in the South for a shipping melon, Round in shape, large and fine in appearance, bright striped, red meat and black seeds. It is tough enough to stand any amount of handling. It still has many friends, but Sweet Heart has rather taken its place on account of slightly better quality. Sweet Heart is a large, light-colored melon, heavy, black-seeded, round in shape, and always very large.

A shipping melon not very much known as yet is the Angel Kiss. It is very long, grey-colored, very sweet melon, highly spoken of in the South. It originated in Texas.

\section{Early Melons}

The early varieties of melons are usually smaller than the standard varieties I have de. scribed, but are very valuable, especially in the extreme north. ern states, and for first market everywhere. Probably the best known early melon is the Ice Cream, or Feerless. This is an old favorite and is still a standby in many places for an early market melon. It is very early and very prolific.
Cole's Early or Harris' Early are both nice little early melons, and similar in appearance. In fact, I believe they are the same variety. They are bright striped in two shades of green like the Kolb's Gem and Dixie, but rounder and earlier. Bright red flesh, black seeds, good quality, and very early. Always sell well and are good money makers. Florida Favorite is another good early melon, Long and slender; light striped outside; red flesh and white seeds. Very sweet and fair size, but rather thick rind. Phinney's Early has the same fault, too thick a rind for its size, but valuable on account of extra earliness.

The Princess is the daintiest little melon you ever saw, I had a full page about it two years ag?, but haven't room for so much space here. It is very early, small, very prolific, uncommonly sweet and sugary, skin not much thicker than an orange.

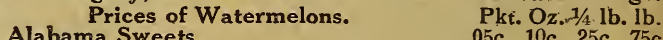
Alabama Sweets........................ $05 \mathrm{c}$ 10c 25c $75 \mathrm{c}$

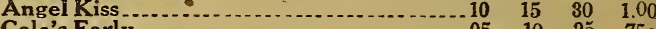
Carly Florida Favorite.............................. Fordhook Early Golden Honey Halbert Honey Hard Shell Kleckley.......................... Harris' Early............................ Iceberg Ice Cream or Peerless . Improved Kleckley .......................

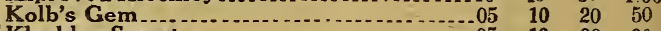
Kleckley Sweets........................ Mclvor's Wonderful Sugar................ Monte Cristo.................................... Phinney's Early Princess $\begin{array}{cccc}-10 & 20 & 50 & 1.75\end{array}$

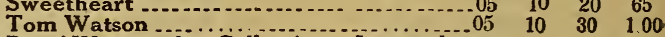
Boys' Watermelon Collection. Large pkts. 10c. Above prices include prepaid postage. See blue list for low prices on large lots.

\section{Tobacco Dust For the Striped Bugs}

The best remedy I have ever found for striped bugs on cucumber, watermelon and muskmelon vines is tobacco dust. This is simply a very strong grade of refuse tobacco, ground up into a very fine powder. Price, prepaid, 20c per lb.; by freight or express, 10c per lb., $\$ 1$ for 12 lbs. Special price on large lots.

\section{An Early Kleckley Sweet}

When our garden seed man, Walt. Pitzer, was inspecting some of our watermelon seed crops at Rocky Ford, Colo., last summer he stambled onto a private field of Kleckleys fully 10 days to 2 weeks earlier than any other field around. We got some seed from the man and can offer a limited amount at Pkt. $15 \mathrm{c}$, ounce 35c, 1/4-lb. $\$ 1.00$.

Your money back if you don't find them a week ahead of the regular Kleckley. 


\section{Some of Our Watermelon Contest Boys}

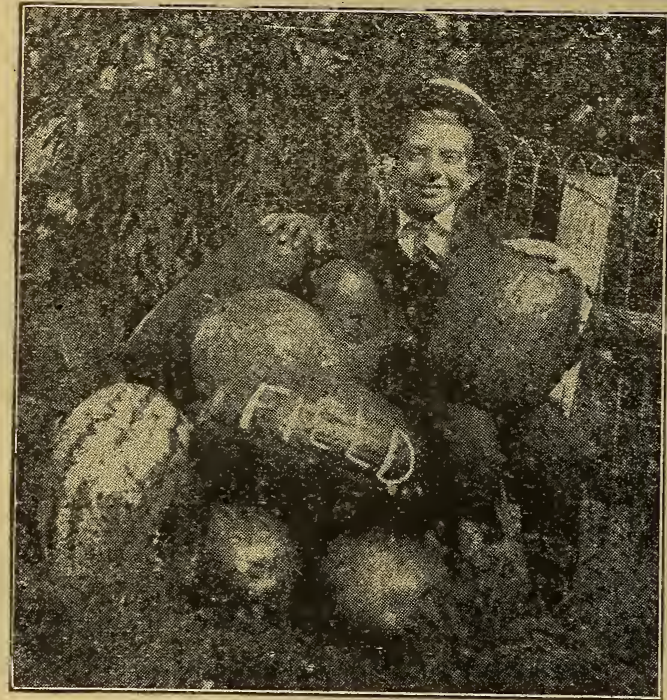

\section{Clifford Frederick, Blockton, Iowa}

"I am eleven years old and this is my picture taken with my watermelons raised from that package of your prize seed my grandma Frederick bought for me. I planted the seed early in May, kept the weeds hoed out. Had just fine luck. The melons were large and sweet. Some of them measured forty-eight inches around. I think Field's seeds are the best. Mamma also uses vour garden seed and says they can't be beat."

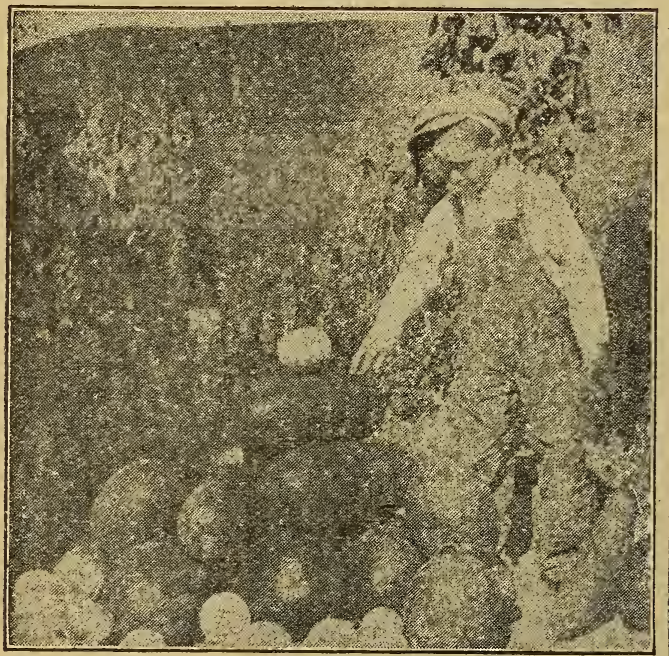

Homer Pike, Lusk, Wyo.

"I will send you a picture of my grandson Homer Pike. I have had him since he was about 6 months old, and he is quite a little gardener for 7 years old. You can see in the picturs some of the stuff he raised from your seed, He is very fond of Seed Sense. Will want sseds later on." -MrS. ANNIE F. Pease.

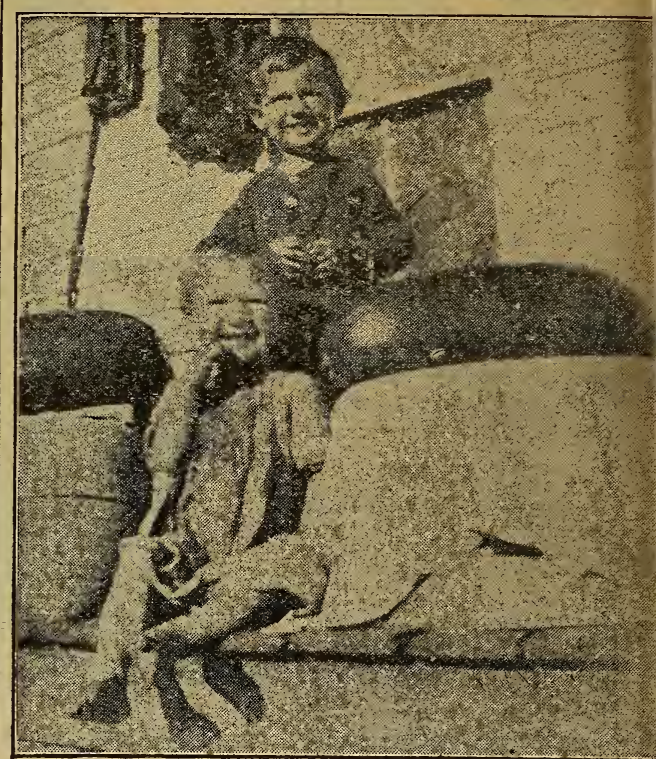

Alvin and Willard Herrick, Bethany, Nebr.

"We had the best garden around here and sight-see ers made many compliments on it. I am sending you : picture of the boys and Tom Watson melons and they ari sure fine. The Tom Watson melons weighed $23 \frac{1}{2} \mathrm{lbs}$ anc 22 lbs."

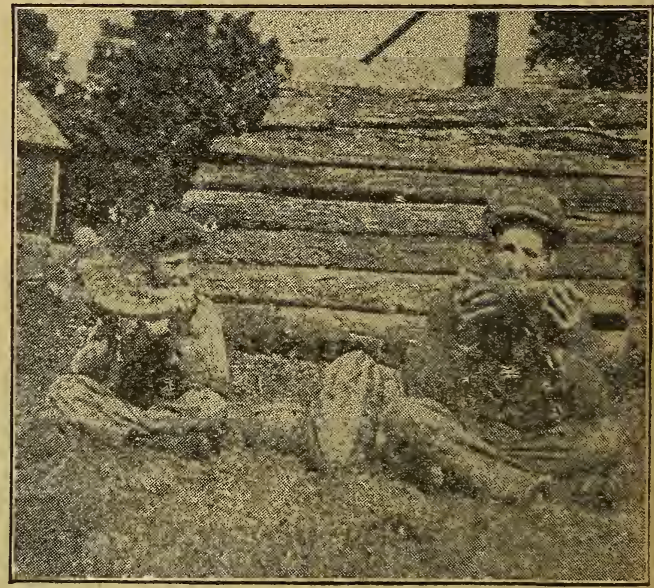

Philip Jenkins, Sioux Falls, So. Dak.

Mr. Field: "Enclosed find a picture of my brother, me, and some watermelons we raised. The weeds were pretty bad and we had to keep busy after the weeds. We hoed the melons about 5 times with a wheel hoe and we hoed and weeded them nine or ten times. The large melon was the biggest we raised. We had lots of good melons. My mother's chickens spoiled many of the melons. I took the picture with the camera I got for selling your seeds last spring." 


\section{Onions}

Continued

The best known of all the red onions, and probably the most widely grown of any, is the Red Wethers. field. It originated in Connec. ticut, but has been adopted by the west as its own particular variety. It is the standard big, red, flat onion, of good quality, good keeper, and favorably known in all markets.

The best known and most popular variety among the yellow onions is the Prizetaker. It is also called Span. ish King, and is the same bis onion seen in the round-cor. nered crates in the fruit stores in the winter time. It is very large, mild lian Brown. It is very early and at the same time and tender, and will outsell any otheronion where a wonderful keeper, and is especially popular in once known. Take it one year with another, it is probably the best yielder of any of the varieties. Its only fault is that it does not keep well for spring sale. It should be disposed of in the fall or early winter, being too mild and tender to keep well through until spring. A good combination would be to plant Prizetaker, Red Wethersfield and Large Red Globe. You would be sure of a good crop then, and could suit any kind of a buyer.

If you want a yellow onion that will keep solid all winter and sell at any time, I would advice the Ohio Yellow Globe and the Yellow Globe Danvers. These are very similar varieties. Both globe-shaped, hard, uniform size, good quality, and good keepers. The Ohio Yellow Globe is a special strain used by the onion growers in Ohio and Indiana, while the Yellow Globe Danvers is the strain more used in the west. There is also a flatter type, called the Yellow Danvers Flat, which is exactly the same as the globe-shaped variety, except that it is flatter and wider. This is the variety most used for yellow onion sets. There is also a small yellow onion known as Australian Yellow Globe, which is a pure yellow selection from the well-known Austra.

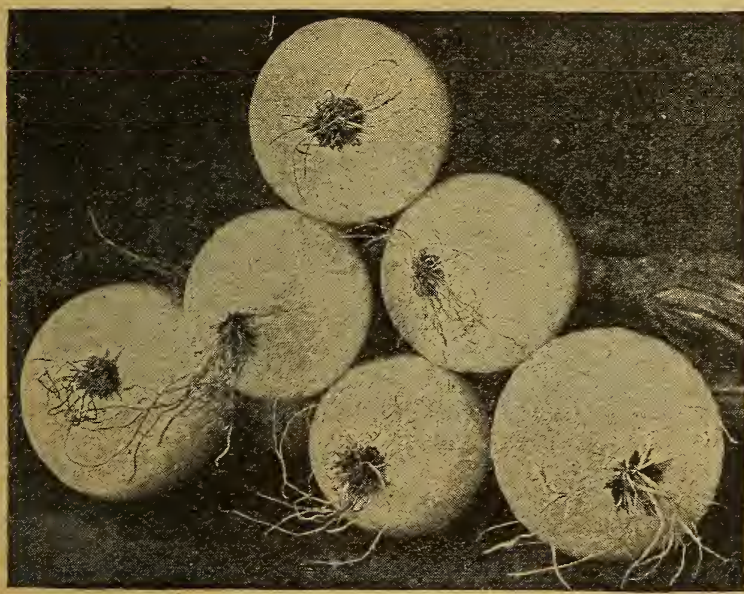

White Portugal or Silverskin the short seasons of the extreme northwest. Its fault is that it is too small for most markets.

The Australian Brown is the best keeper of the whole list. I have seen them keep until onions came again. It is about the size of a Yellow Danvers, but of reddish brown colnr. It will not, how. ever, run absolutely true to color, there will be some white, some pink, and some yellow ones in all of them, and all of this class are rather small. It is impossible to get them to come true.

In white onions the most popular variety is Soththport White Globe. This is the largest successful pure white onion. Perfeci globe-shape, very solid, keeps well, and in many city markets brings a much larger price than other colors. It is a poor seeder, and the seed is always high-priced. It is rather late and takes a long growing season to mature properly. If you want an earlier white onion, you should use the White Portugal, or Silverskin. This is about the same size as Yellow Danvers, but is pure white in color, early, and a good keeper.

A still earlier white onion is the Silver King. A large, flat onion of Italian origin; sweet and nice, but can't stand dry weather and doesn't keep well. The variety known as New Queen is more popular. It is smaller, but is still earlier and more sure to make a crop.

It is a flat, white, small onion, very early, tender and sweet. It is used for early bunching and for pickles. The White Barletta is very similar to New Queen, but probably slightly smaller.

For the mountain states and other regions with a short season, especially where irrigation is used, you should be careful to use a rather early variety, one that will be certain to ripen down well. For such places I advise Yellow Globe Danvers, White Silver King, Red Wethersfield, New Queen and Australian Brown.

An acre of onions will take from four to six pounds of seed and should make any. where from 300 to 900 bushels of onions. See our blue list for special prices on onion seed in quantities. Write for free leaflet on onion culture. 


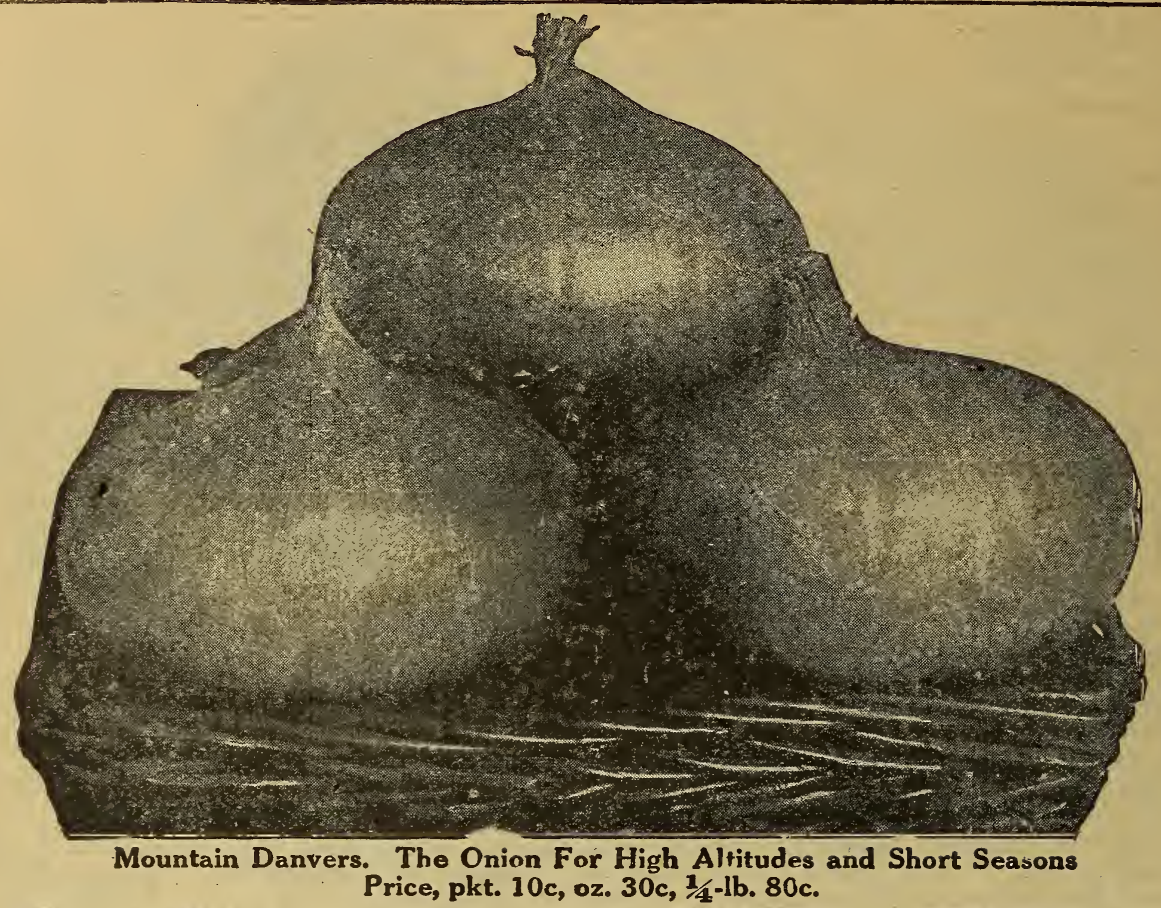

\section{A New Type of Onion}

\section{Mountain Danvers}

The great trouble in growing onions in the high altiludes of the mountain regions of the northwest is to get an onion that will mature properly. One that will ripen up hard and solid without any thick-necks or sprouty stuff.

1 hat irrigation country in Colorado, Idaho, Utah, Mont na, and the rest of that country, can grow the finest crops of ouinns on earth if they can get the right varieties. What they want is an onion of guod size, good bright color, a good keeper, and above all, very eariy.

I have a custumer in Colorado, up in a high valley at $7,6,0 \mathrm{ft}$. al itude, who has been growing onions for market for 19 years now, and by careful selection has worked up a type of onion that is a wonderful success for the $m$ unt in cuntry.

The start of it was a good strain of Danvers, but it has been selected and changed until it wouls not be correct to call it a $\mathrm{rtguiar}$ Danvers. It is about half way between a globe and a flat in shape, a very deep yellow color, laiger than ordinary Danvers, very early and absolutely sure to ripen, a perfect keeper, and a great yielder.

He has been getting 300 to 400 bags per acre (100 lbs. to a bag) right along, and sometimes as high as 600 bags, and gets top price for his onions on account of high quality and fine arpearance.

Last summer I had him plant an acre of selected bulbs for seed, a id I will have a limited amount of the seed for sale. For the mountain country it is the only sort I would grow, and for onion growers anywhere who want a handsome extra ear'y ye low onion it will be of great value. I would advise that you send in your order early, as I have only a small amount of this seed. and when it is gone I cannot get any more. I firmly bclieve that any onion grower in the mountain country colid afford to nay almost any price for the seed, for it is sure to be a great money maker.

Prices of Onions. Pkt. Oz. 1/4-1b. Australian, White...........................

Australian, Brown.................................

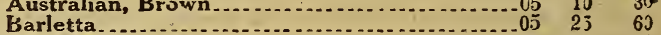

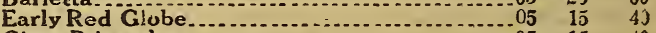

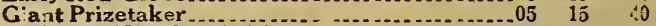

Globe Red Wethersfield.......................... 05 13 49

Large Red Globe...................................

Mountain Danvers................................. 10 20

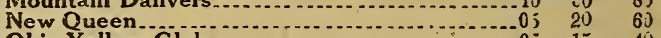

Ohio Yellow G̈lobe.......

Red Wethersfield.

Silver King -...

Silver Skin or White Portugal................... 15 50

Southport White Globe.............................. $25 \quad 75$

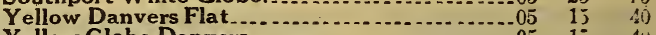

Yellow Globe Danvers............................

Yeliow Strasburg ............................. 15 is

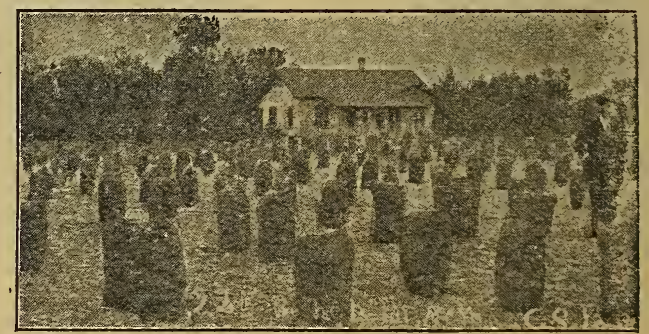

\section{A Big Crop of Mountain Danvers Unions}

This picture was taken in the onion field of the man who grows our N!ountain Danvers onion seed up in the mountains in western Colorado. This ficld made 1,226 bu. per acre. That's sure go i.jg some. 


\section{Onion Sets}

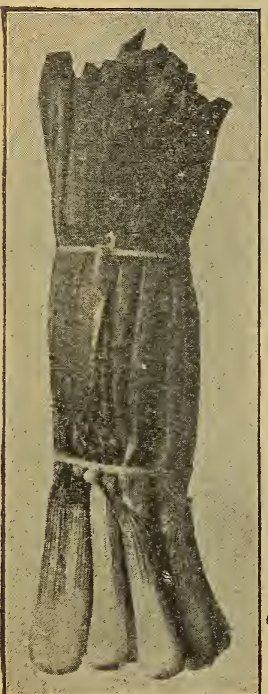

Bunch Onions Grown From Bottom Sets use.
There is probably more money in early bunch on. ions than in any crop the gardener grows. All you have to do is to set the sets very early in good $\mathrm{ri} \mathrm{c} \mathrm{h}$ ground and they are sure to make a crop. Always sell too. They take very little room, and I have often ta. ken off a dollar's worth to every rod of row. Buy some sets and try it. Fig. ure on about a gallon of sets to a square rod of ground. Bottom sets are the kind to

We have decided to screen out of ours all above an inch in diameter, and it makes the nicest grade of sets you ever saw. They cost us more this way, for there is a heavy loss on the oversize ones thrown out, but we still sell at the usual price and give you the benefit of the extra screening.

\begin{tabular}{|c|}
\hline \multicolumn{2}{|c|}{ Prices on Onion Sets. } \\
Either red, yellow or white \\
By mail, postpaid..........15c 25c $\quad$ 25 $\quad 65 \mathrm{c}$ \\
Multiplier sets, the same price. \\
See blue list for net prices on large lots. \\
\hline
\end{tabular}

Onion sets are 32 pounds per bushel, so one pound is the same as one quart.

Winter Onion Sets. These are hardy and will live and increase from year to year in any climate. They do not make a bulb, but only straight, green onions for spring use. Can be planted in the fall or early in the spring. The sets grow in bunches on the top of the stalk. Price same as other sets.

I do not use of sell the top sets, as I consider bottom sets betrer. These are simply little wee onions grown from the black seed, planted late and thick. They are about as big as the end of your finger, and when set out in the spring they come quick and make nice green onions for bunching, or if Ieft stand will bottom down and make big onions like ones from seed, but lots earlier. I can furnish them in red, yellow or white. Yellow are gener. ally best, as they are not so liable to run to seed. Multiplier sets are also pret. ty good.

About Sizes on Onion Sets. It is v e $r$ y important that you get onion sets of the right size. If just a little too large they will run to seed right away instead of making a good onion, The us u a 1 rule is to use every one below one and one-half inches in diameter, but we use none above one inch.

\section{Salsify \\ or Vegetable Oyster}

(One ounce will sow 50 feet of drill, 8 lbs. to the acre).

Why don't you grow salsi. fy? It is one of the most delicious and nutritious of vegetables and should be more generally cultivated for use in winter, when the supply of really good vegetables is so lim. ited. It has the true oyster flavor, and makes a delicious and inexpensive substitute for them to be used in soup, etc. Cultivate like parsnips.

Mammoth Sandwich Island. Average fully doub'e size of old Long White. Roots are white, smooth and notwithstanding their enormous

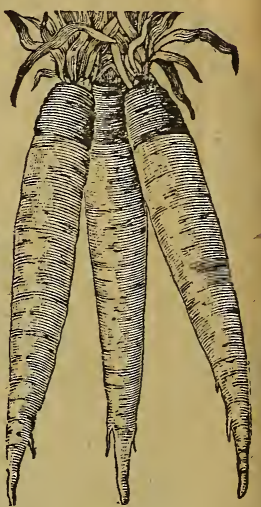

Salsify size, of superior quality. Pkt. 5c, oz. 15c, 1/4-1b 50c.

\section{Chicory}

Used as a substitute for coffee. Cultivate the same as carrots. Take up roots in the fall; cut in small pieces and let dry. When wanted for use it is roasted and ground like coffee. Pkt. 5c., oz. 15 .

\section{Mountain Grown Onion Sets}

We have been experimenting some for several years with mountain grown onion sets on the theory that they would be solider, hardier, and better keepers, and the results were even better than we had expected. It is my personal opinion that they are really worth twice as much as ordinary sets. They are as hard as a bullet, even size, bright color, and absolutely sound. In a field test in the market garden of my son Frank Field, they made about twice the yield per peck of sets over ordinary sets alongside.

We had a carload of these sets grown last sum. mer, and that is what we are offering now, as long as they last. When they are gone we will use the regular Iowa, Illinois and Nebraska sets, the best we can get, but they will not be as good as the Mountain grown.

Market gardeners especially should use these sets, and if you once see them you will understand why. Send 10c for postage and packing and I will send you a sample of all three colors.

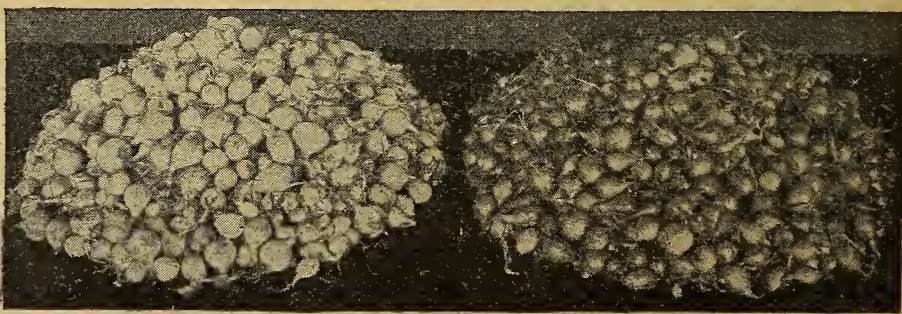

Bottom Onion Sets. Fine for green onions or big onions either 


\section{Peas}

Peas, as a rule, should be planted early in the spring while the ground is cool and moist, as they never do well in the hot part of the summer and very often will not come up at all when the ground is hot and dry. Smooth peas especially should be planted just as soon as the frost is out of the ground, the earlier the better. Wrinkled peas, while larger and more tender and of higher quality, never come as well, as they are more or less liable to rot in the ground. They should be planted before the hot summer weather. Peas do best ih ground that is fairly rich. If the ground is too rich the peas will run to vines. This is also true if the garden is at all shaded. Pea seed does not do well kept from year to year, and it is best to buy the seed every year.

\section{Peas for Market Gardeners}

We are well fixed on peas this year, both as to quantity and quality. We have held up the quality of our stocks in spite of the two or three poor crop years, and we can offer market gardeners some strains of peas that can't be beat. And our prices are right in line.

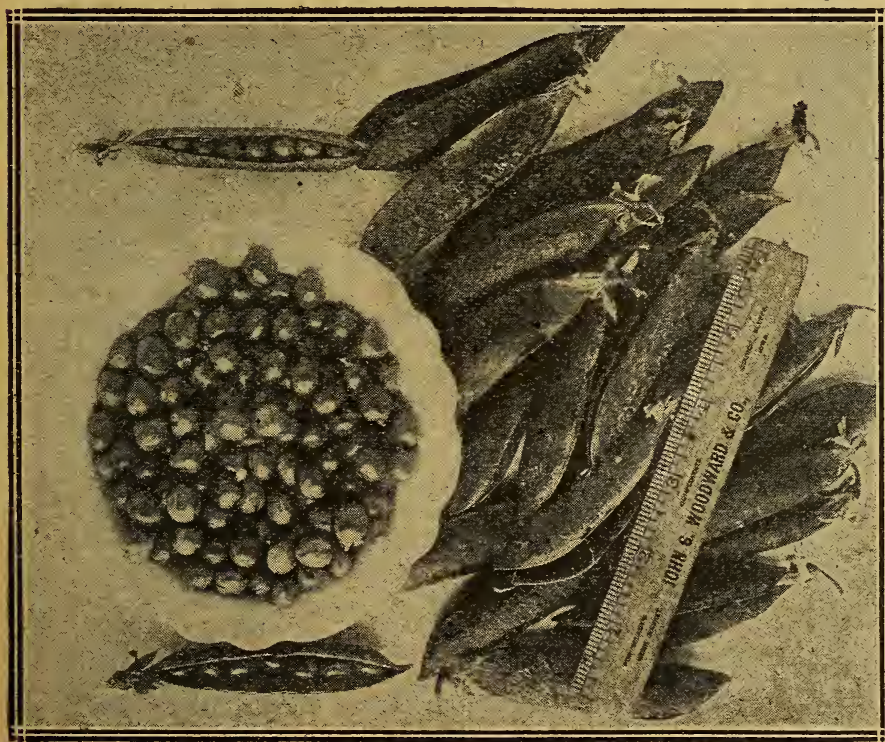

Little Marvel, the new extra early wrinkled pea. Dwarf and sweet like Nott's Excelsior, but earlier, hardier and heavier yielding.

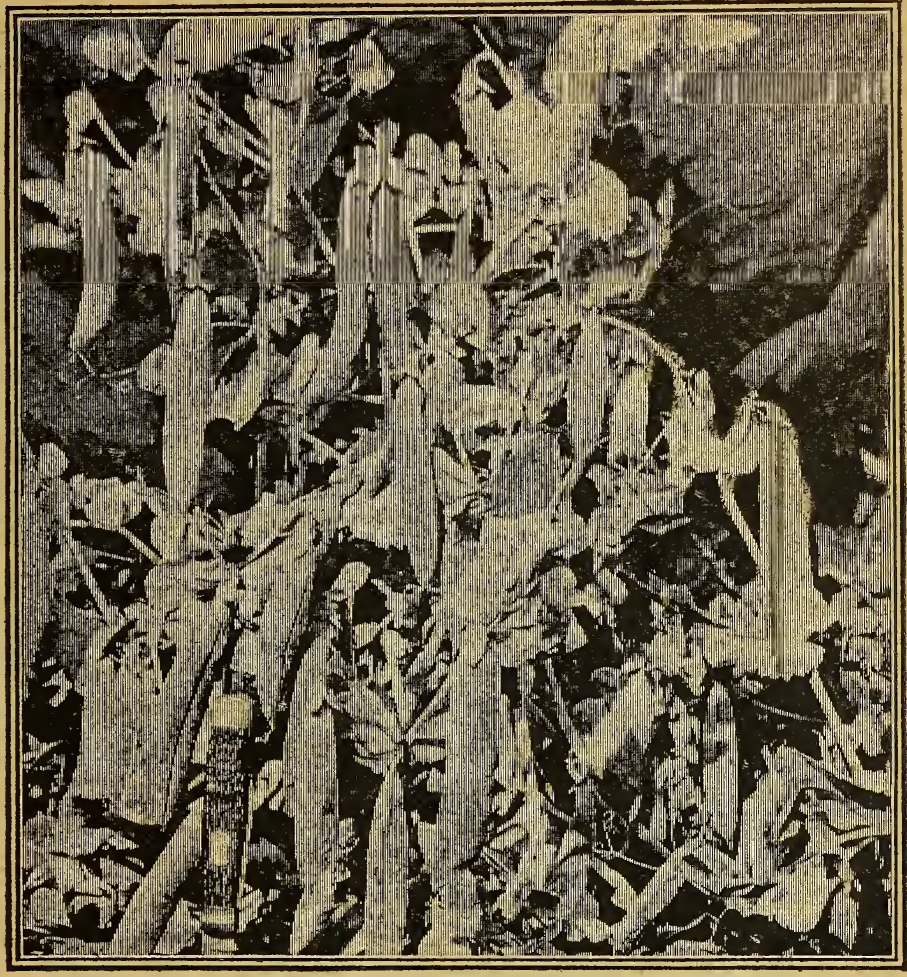

Filtbasket Peas. Best second early. Sure to grow and bear and a great yielder. Plant this to follow Alaska and Extra Early.

\section{Varieties of Peas}

The earliest variety of peas grown and the surest to make a crop is the Alaska. They grow about knee-high and set very full of rather small, dark-green pods, which are almost all ready to pick at one picking. Seeds smooth and blue when ripe. Compared with the Improved Extra Early, it is slightly earlier and not so large-podded, quality about the same. It is al ways sure to grow well and will come up and bear in spite of any kind of weather. Market-gardeners espec ially are advised to plant heavily of this variety, as it is a great money. maker. The Improved Extra Early is very similar, but is three or fous days later and generally a little taller. This is the brag extra early to which many seedsmen give first place usua. lly under some high-sounding name of his own. Pods are slightly larger than the pods of Alaska and the vines remain in bearing a little longer. Otherwise the two varieties are very similar, and both having smooth seed, they can be planted at the same time, very early, and the one will follow the other.

(Continued on rext page.) 


\section{Peas (Continued)}

For a larger, slightly later, mooth pea to be planied at the ame time as these two and to ollow them in the market, I vould advise Fillbasket. It comes n immediately after the Extra :arly, or say a week later than Ilaska, but is considerab'y larger han either one, both pod and ine; and with me it yields far nore than any other early pea, $r$, in fact any pea, early or late. hat I have ever seen. Like all mooth peas, it is sure to come $p$ and will not rot in the ground ke the wrinkled ones. With laska and Extra Ear'y for first ickling, and Fillbasket for second rop, and Dwarf Champion for lain crop, you are sure of pl-nty $f$ peas ail summer. All are halfwarf, growing from 14 to 30 iches high.

There are several other early eas, though none in my opinion ui e so profitible as the three. I ave named. Nott's Exc-lsior is le sweetest early pea there is. It is dwarf, very arly and a wrinkled pra wi:h b.g fat pods. It is lore easily harmed by bid wrather than smooth eas like Alaska and Fillbasket. The American Vonder is practically the same thing as Nott's_Ex. alsior:

Probably the most popular of the early wrinkled orts is Premium Gem, or, as it is more often

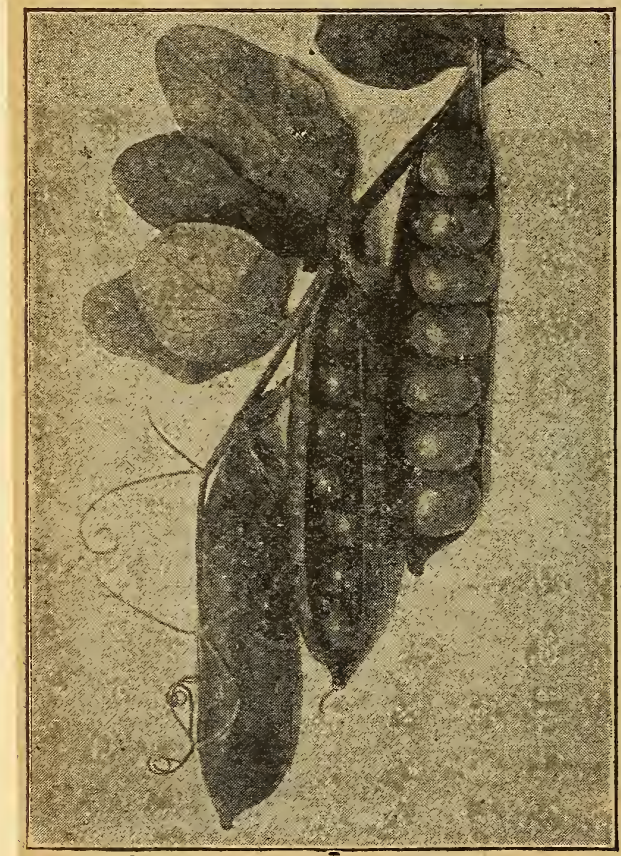

English Early

called, Little Gem. It is a second-early, coming in about with Fillbasket, grows about 15 to 18 inches high and bears heavily of large, plump peas. The pea is wrinkled and very sweet. Like all wrinkled peas, it is hardcr to get a stand than with the smooth ones, and does not stand unfavorable weather so well. A very similar variety, but slightly taller, larger and later, is t'e Advancer.

Gradus, Thomas Laxton, and Surprise, are other varieties of wrinkled, sweet early peas. They are all of very high quality, and the Gradus and Thomas Laxton especially have very large pods. the largest of all extra-early peas, but are very sensitive to dry weather and heat, and it is a hard mat. ter yet a good yield from them. If you want high quitity, big peds very early, and you are not particular about yield, it would pay you to try these three. All malse rather tall, slender vines.

Little Marvel is a new dwarf early wrinkled pea that is going to entirely take the place of American Wonder and Nott's Excelsior. It is of the same type, but earlier, hardier and heavier yielding. Laxtonian is like Gradus, but a much dwarfer vine and heavier yielder. It should take the place of Gradus, as it has all its good points and none of its weaknesses.

The more I see of Little Marvel the better I like it. It is good for either home garden or market. It has the best filled, heaviest pods I ever saw, and the quality is wonderful. When you acd to this that it is very early for a wrinkled pea, dwarf and compact in growth, and an enormous yielder. you will see what a prize it is. You wi l'make no mistake to plant heavily of it. Of course it is not quite so early and hardy as the smooth peas like Alaska and Fillbasket, and you will still need them for first early, but when Little Marvel comes on $t^{\prime} \cdot e$ market it drives all others out on account of its superior quality and heavy, solidly packed pods.

To follow sext on the market I would advise Laxtoniun with its big. showy pod of the Telephone type.: (See next page for prices.) 


\section{Peas \\ Late or Main Crop}

In the main crop peas the best one, to my notion, is the Dwarf Champion. This is a dwarf or bush form of the old-fashioned Champion of England. It grows about 18 inches high, stiff-stalked, and close-jointed, literally loaded down with big. fat pods, which always come in pairs. Peas large, thin-skinned and of the most delicious flavor. The canning factories use for their grade Horsford's Market Garden, which is a very similar variety; large, sweet, and heavy yielder, Everbearing is also quite similar, and is sup. posed to stay in bearing all summer. Alder. man is a new pea that is best described as an improvement on Telephone. Very similar, but better every way,

Stratagem, Telephone, Marrowfat and Champion of England, are all qig, tall, lategrowing peas, and and are great yielders. All have big, heavy pods, but need staking, as they grow all the way from 3 to 5 feet high. All are high quality except Marrowfat, which is smooth and only fair quality. The so-called sugar pea is the Dwarf Gray Sugar. This has pods about the same size as other peas, but they have no tough lining and can be broken up and cooked, pods, peas and all, like string beans. They are hardy and bear enormously.

The English are great people for peas, and have originated some very fine varieties. For several years I have been importing some of their varieties, and I have found some mighty fine varieties. Three of them I am offering to my custnmers. I call them simply English Early, English Second Early, and English Late. They are all big, fat, heavy podded peas, very fine in quality, and under favorable conditions are great yielders. They have the short-jointed, heavy stalk, and the broad-leaves typical of most English varieties.

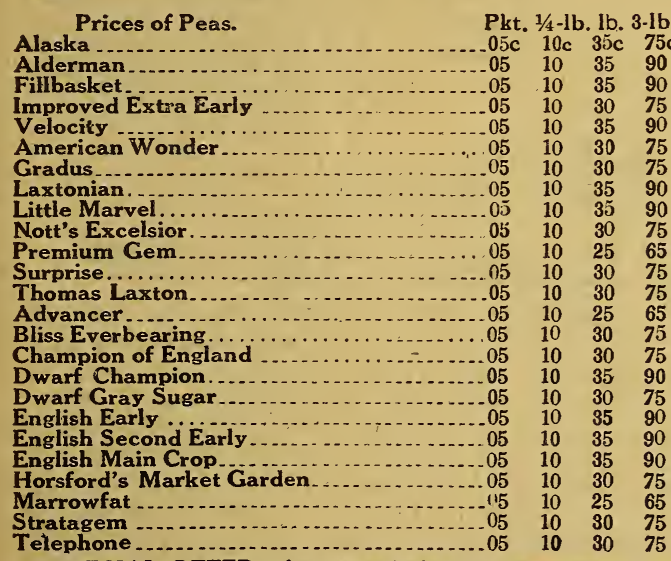

SPECIAL. OFFER: Any 3 varieties in the above list, $1 / 4$ lb. each, 25c. 1 lb. each, $75 \mathrm{c}$.

For larger amounts of Peas see Blue List opposite page 73. We quote larger quantities at lower prices and will be glad to have your order.

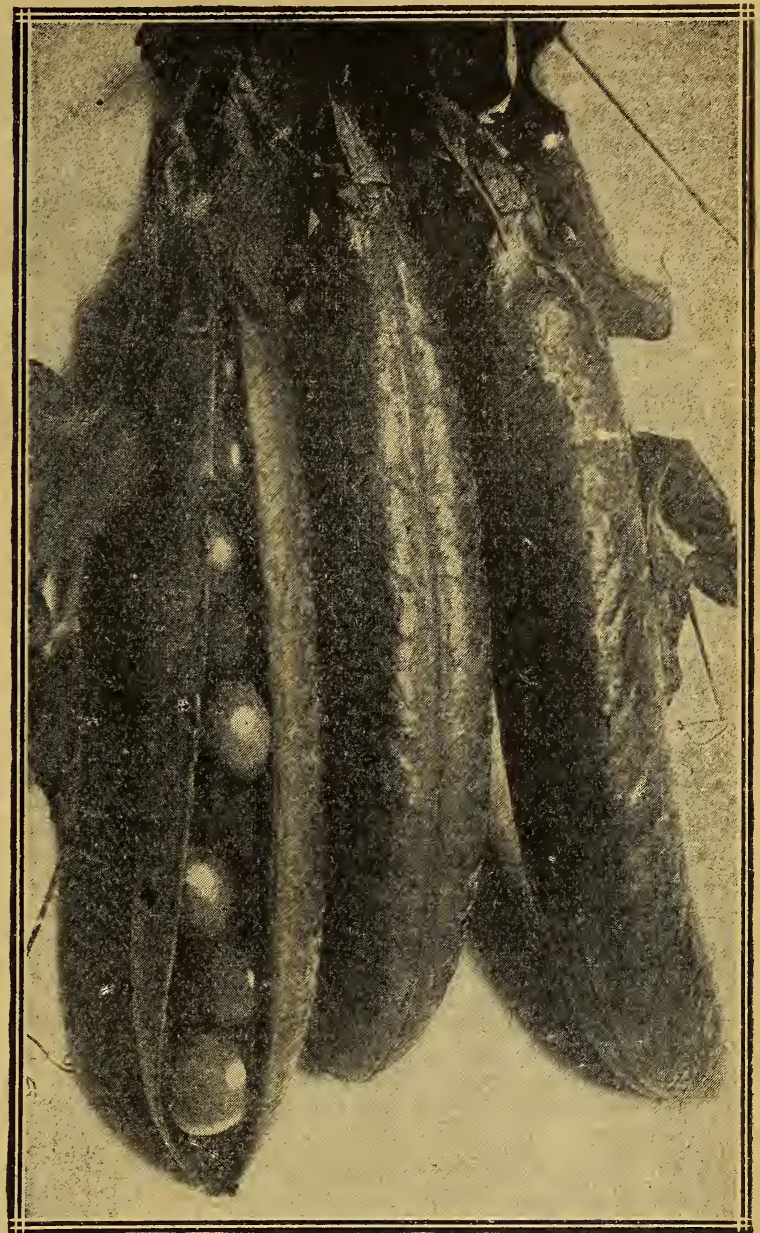

Dwarf Champion. Best main crop variety

\section{Northern Grown Peas}

We have all our seed peas grown in the north. partly because peas do better in the cool climate of the north, and partly to escape the pea weevils which bother seed peas grown in this climate.

We used to have them grown in Michigan and Wisconsin, but unfavorable weather and insect pests and poor farming were causing such poor yields and lowering the quality so, that we are now growing all our peas in the norhwest, and the quality we are getting from there is fine. Best seed peas I ever saw.

We have our own growers there, furnish the stock seed ourselves, have it grown on alfalfa land. and planted in rows and cultivated instead of being sown broadcast, as is the custom in Michigan.

We have the best seed peas we ever had. They are sound, plump vigorous, and high germination. They are as pure as peas could possibly be. We know every lot of them from start to finish. Know the seed it was grown from and saw them grow. ing. Our tests in the trial grounds show this north. western grown seed to be far better yielding, earlier. and stronger than eastern seed. 


\section{Pumpkins}

You might just as well raise some pumpkins as not. Plant a few hills where the corn is missed, and its done. Squashes do not do so well that way, but pumpkins seem to like it as well as having the whole field to themselves,

The biggest. showiest field pumpkin is the Big Tom, which is a selection from the old Golden Marrow or Michigan Marrow, and grows uniformly to very large size. Not so large, of course, as the coarse "Mam.

moth Pumpkins," but the biggest of all true pumo. kins. Both skin and flesh are of a deep orange yellow; cooks up nice and tender, and is good for either cooking or stock feed, although not quite so high in quality as Small Sugar and Large Cheese, and pumpkins of that class.

I have a specially selected strain of the Large Cheese pumpkin, which is called the Buff Pie pumpkin. We have always grown large amounts of Large Cheese pumpkins for table use, but we have had trouble to get and keep a uniform strain of them. They are inclined to vary considerab!y in size and shape, and some were thin-meated. For some time now we have been selecting them to get a strain of the true flattened type, clear buff color, uniform size, and with thick, close-grained 5esh. The photo below shows exactly the type, and I am happy to say we have got it very nearly to what we want. Notice how thick and finegrained the flesh is and how small the seed cavity. If you like a large cheese pumpkin for table use, $I$ am sure you will be highly pleased with this Buff Pie pumpkin.

The Small Sugar and Red Sugar pumpkin is the best of all pie pumpkins. It looks like a regular Yankee or Cow pumpkin, but is smaller and entirely different in quality. Very early and prolific, cooks very quickly and is the best quality of any pumpkin in the list. Next to it in quality I would put the Large Cheese. This is the flat, cream-colored, well-known "Sweet Pumpkin." Large and good for either table use or stock, If you want to plant pumpkin seed by putting it in the planter with the seed corn, this is the kind to use, as the seeds are small enough so that they will run through the planter boxes right with the corn. I have a big stock of these and sell hundreds

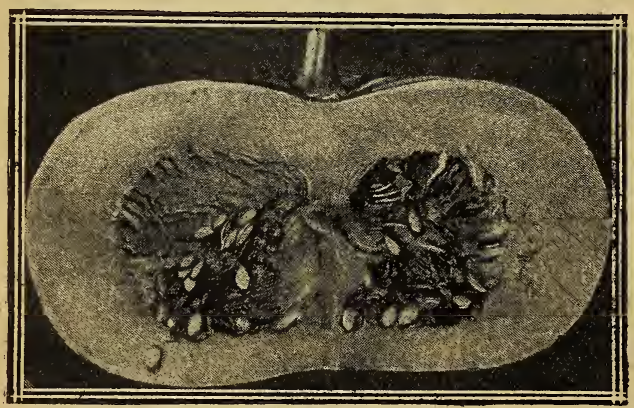

Buff Pie Pumpkin

of pounds evsry year for planting with corn.

The Yankee Field, or Cow pumpkin, is also very popular for planting in corn, but the seeds are so large that they must be planted with a hoe instead of being run through a planter. It is the big Yankee field pumpkin.

If you want to grow some enormous squashes or pumpkins, something big for exhibition purposes, you should get some seed of what we call our Exhibition Collection of Squashes and Pumpkins. In the trial grounds I always grow lots of varieties of these mammoth vegetables, having pretty nearly all the known varieties, both American and foreign. They are all imaginable shapes and colors, and of enormous size. many of them weighing overe 00 pounds. As there is not enough of each kind 3 pay to save the seed separately, I save the seed out of all the largest ones; mix it well, and put it up in ounce packages. As the seeds are very large, it would not be worth while to start with less than an ounce of seed. but this amount will give you a pretty good assortment of the different kinds than you ever saw before. The finest squash of all is the Banana Squash, shown on page 44 .

Lots of people have written in asking about the large pumpkin seed found in the Exhibition Collection, This is the Mammoth Tours. The seed is four or five times the size of ordinary pumpkin seed. Per pkt. 10c.

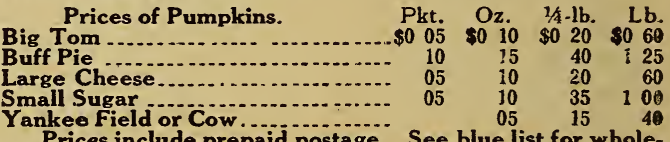

Prices include prepaid postage. See blue list for wholesale prices.

\section{For Squash and Melon Bugs}

Use tobacco dust. It is sure death to the little striped bugs, and it is some help on the big bugs. There is no real cure for the big squash bugs ex. cept to catch them and kill them by hand. When they first come, they are few, and it is not a very hard matter to dispose of them. When the eggs begin to hatch and the new crop of bugs come on. they are too thick to fight with any success. Strong tobacco dust will help some. The squash borers. which work later in the stems of the plants, can generally be driven away by tobacco dust.

Price, postpaid, $20 \mathrm{c}$ per lb.; by freight or express, $10 \mathrm{c}$ per lb:; 12 lbs. for $\$ 2.00 ; 100 \mathrm{lbs}$. or over, at $5 c$ per $1 b$. 


\section{Squashes}

Squashes should have very rich, loose soil, and plenty of room. Make the hills far apart, and don't crowd them. Put in plenty of seed, and, after the bugs get done with them, thin them out to about three plants in each hill.

Without a doubt, the king of all the varieties is the Genuine Hubbard. This is the big warty, hard-shelled, dark green winter squash. It is big, prolific, and fine quality. Will keep all winter and gets better all the time. For nearly a half century it has been the standard of qual. ity with which all others have been compared. The new extra warty strain is claimed to be a slight improvement over the old type, but I doubt if there is any real difierenee except a little in looks. Good, pure seed of this variety is always scarce and is especially short this year, but I have provided for a big lot of seed and am well fixed. If you want to plant a big field of them, write for special prices.

A somewhat similar squash is the Marblehead, which is sometimes called the Blue Hubbard. It is somewhat like the Hubbard, but lighter colored, otherwise I can see very little difference, except that it is not quite so good a keeper. There is also a smaller, yellow-colored squash, called Golden Hubbard, which somewhat resembles the Hubbard in shape and quality, Hard-shelled the same way, but is much smaller and orange-yellow in color.

If you prefer a soft-shelled squash, you should plant the Orange Marrow, or, as it is called, the Boston Marrow. It is the same shape and size as the Hubbard, but is soft-shelled and not so good a keeper. It is not so good a quality as Hubbard, but is much earlier, and more prolific. It is valuable for early fall sales, besides, many people prefer it because it can be cut with a knife. There is a small winter squash called the Delicious, which I believe is fully as good quality as the Hubbard. Some claim it is even better. It is about the same

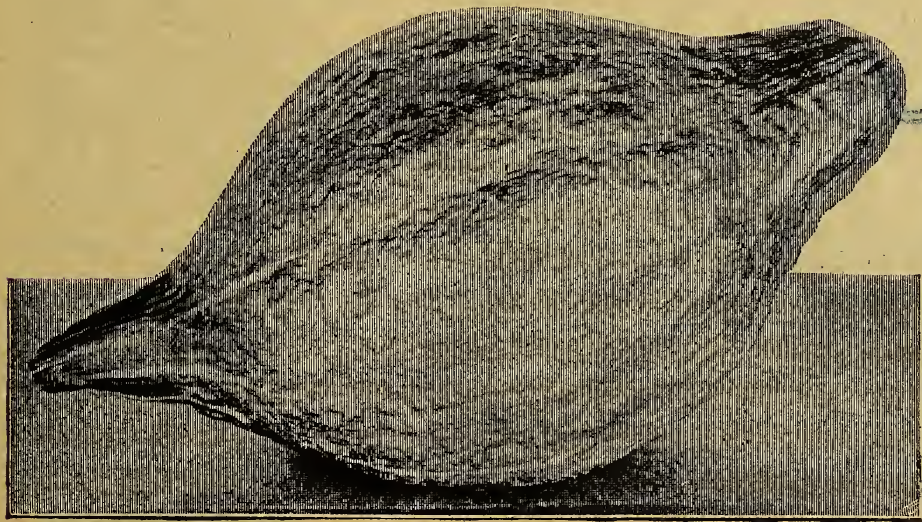

color as Hubbard, but different shape, being broad. at one end and pointed at the other. It is good for early fall or winter, and while not very large, it makes up for this in high quality. The Sibley, or Pike's Peak, is a good deal the same type of a squash as the Delicious. It is a small, light gray squash of most excellent quality, and while not hard-shelled, it keeps well for winter use.

The old-fashioned Turk's Turban, or Essex Hybrid squash, is also of good quality, but with us it is not a very heavy yielder, There is also a little odd-looking winter squash, called the Fordhook, which many people esteem very highly. It is about the size and shape of a big cucumber, bears enorm. ously, comes on the market early in the fall and will keep all winter. It is just a nice size to cut in halves and bake that way.

If you want the biggest squash you can get, regardless of quality, you should use the Mammoth, or Hundredweight Squash. These are very large. and coarse, and sometimes grow to weigh as much as $200 \mathrm{lbs}$. There are a number of strains of this Mammoth Squash.

The old-fashioned Cushaw, or Crookneck. I really don't know whether to call it a squash or. a pumpkin, but I will class it with the squashes.

Prices of Squashes. Pkt. Oz. 1/1/1b. Genuine Hubbard.

(Warted) ....

bard, (Smooth) $\ldots \ldots \ldots \ldots . . . .05 \quad 15 \quad 40$

Banana Squash. (See

Page 44)

Marblehead................ $05 \quad 10 \quad 25$

Orange Marrow

Sibley or Pike's Peak......05 $15 \quad 40$

Maminoth or Hundred

\begin{tabular}{llll} 
Weight_... & \\
Pattypan or Cymelon..... 05 & 10 & 25 \\
\hline
\end{tabular}

$\begin{array}{llll}\text { Pattypan or Cymelon. } & \\ \text { Fordhook }\end{array}$

Summer Bush Scallop. $\begin{array}{llll}\text { (Yellow) } \ldots \ldots \ldots \ldots & \\ \text { (White) }\end{array}$

Summer Bush Crook-

neck ................... 0510

Delicious ................... $5 \quad 15$

Exhibition Collection of

Mammoth Squashes -.. $15 \quad 40$

Special Offer: Any four varieties, 1 pkt, each, 15c; any four varieties. $1 \mathrm{oz}$. each, 25c; any four varieties,

Hubbard Squash $1 / 4-1 b$. each, $75 c$ 


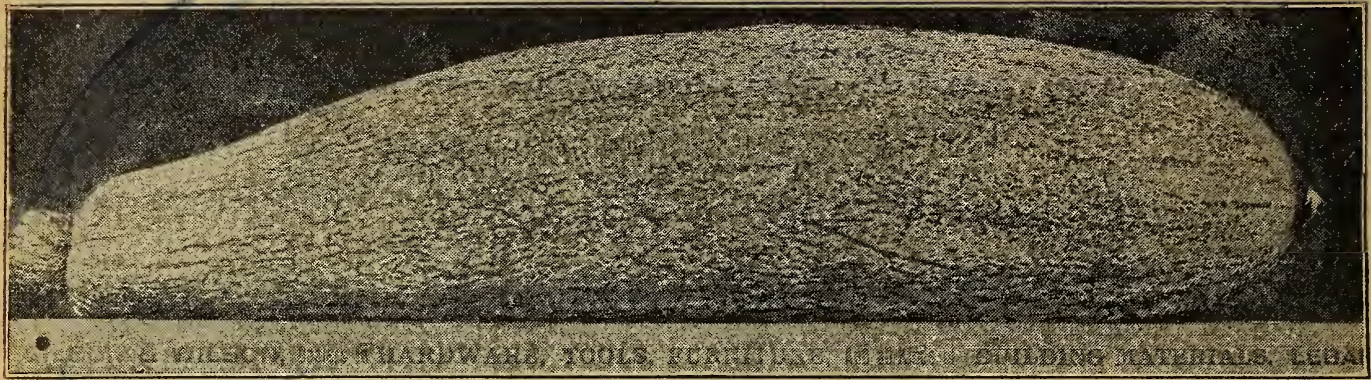

\section{The Banana Squash---An Old Variety Come Back}

This is not a new variety; but is very scarce. although it used to be quite generally grown a generation ago. It is probably the finest in quality of all squashes, large in size, a great yielder, a good keeper, and in fact is just about right in every way, but unforiunately it makes but very little seed and for that reason the seedsmen seem to have dropped it and is practically unknown to the present generation. I finally got a little start of the seed and by planting a large acreage I got enough to offer it for sale last year and I think I will have enough to supply all of you this year. The seed is bound to be high-priced, however, as it don't make_one-tenth the seed that other kinds do.

It grows to large size, generally over 2 feet long and sometimes over 3 feet. It keeps equal to a Hubbard, is better quality, more prolific and earlier. It has a tough shell, but not hard like the Hubbard. The pictures show its appearance better than I can deccribe it. Price, pkt. $10 \mathrm{c}, 0 z .20 \mathrm{c}, 1 / 4-\mathrm{db} .60 \mathrm{c}$.

Out around Greeley, Colorado, in that great trucking section, this is by far the most popular squash grown. I found them growing there in abundance and I thought it would be a good chance to get some seed, Lut I had to pay $\$ 1.50$ per $100 \mathrm{lbs}$. for the squashes and I only got a little handfull from each squash, so it did not pan out very well That was wher I was first getting a start. I have them grown or a big scale now here, and in Mich. igan, and in Colorado, and in Nebraska, so I manage to get enough seed to go round, but it makes so few seeds that it will always cost more for seed than other varieties, But its worth it. The only trouble is the squash bugs, same as with other squashes. And these you generally drive away with tobacco dust.

Here is what a man in Idaho says, who was growing some seed for me:

"The Banana squash did very well. They yie!d a large crop of squash, but a very small amount of seed. I believe I will have from 2 to $3 \mathrm{lbs}$. of seed out if several hundred squashes. A number of the very best baking squashes never had a seed in them, and $I$ rever got more than 24 to 36 seed out of them. The Barsina squash is one of the best varieties I have ever secn. Thev are thick-meated and of good flavor. They are, I believe, one of the very best for home use or canning." -J. F. Carnefix, Payetle. Idaho. them:

And here is what another man says about

"It is the most delicious of all the pumpkin and squash family for pies. My wife will put a few pieces in a kettle with a little water to start to cooking, and in 15 minutes it is ready to mix for the pies, and she will have pie baked within 35 minutes afier puting it in to cook. It is a splendid keeper and we have kept them till April. It simply is the best squash I have evsr seen in my 50 years' experience in gardenirg."

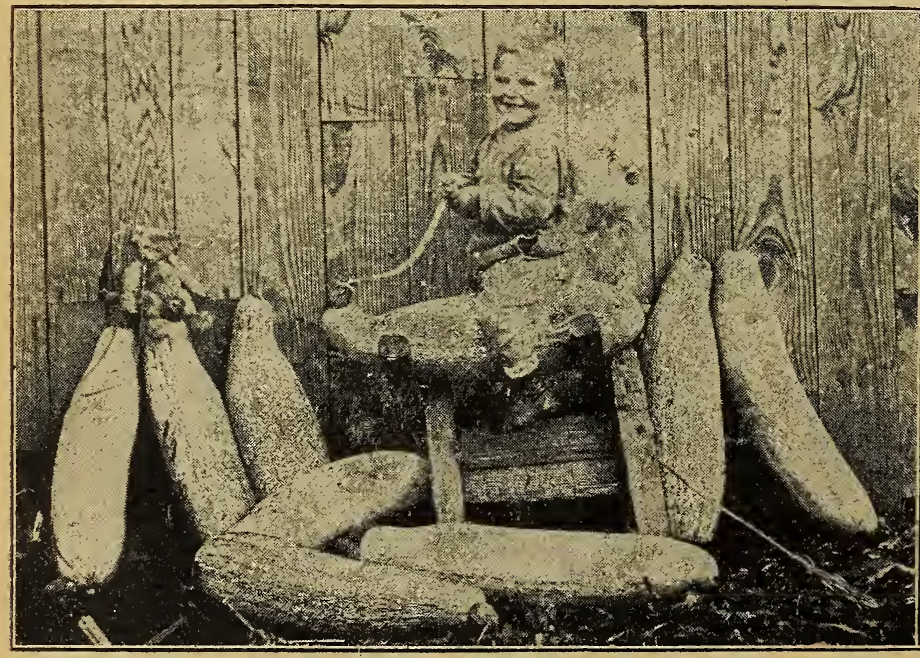

This splendid picture was sent me by "Sherman, the green coods man," Lebanon, Oregon. It is a good likeness of the Banana squash.

\section{Squashes Over $2 \mathrm{ft}$. Long}

Here is what a customer from Pennsylvania has to say: "Mr. Henry Ficld: Last spring I bought some seeds from you, among them was a packet or Banana squash. I planted them, and on June 10th a hard frost killed ail of the plants except two very small ones. These grew very fast though until September 10th, when another hard frost killed the vines.

There were then six large squashes on these two vines, (the lurgest squash more than two feet long) besides very small ones. The six squashes are nearly one size. I like your seeds very much and think I will order from you again next spring."

-Mrs. W. N. Johnson,

Dents Run, Pa. 


\section{Advice to the Young Market Gardener}

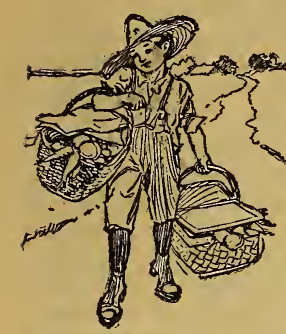

Maybe it is because I was a gardener myself so long, but I always did think the market gardening was a pretty good business to follow. I don't suppose a person would ever get rich at it. but there is a good living in it anyway and that is about all of us get at anything. I am supposed to be making more now at the seed business than I used to dt gardening, but I am getting only my board and clothes out of it and I always did have that, and I work ust as hard as I ever did.

I doubt if it pays to go into it on a big scale, and hire a lot of help to run two or three wagons, and have to hire men to do the selling, or ship to commission houses a long ways off. The best money one time with another is in the home market. Any town from 1,000 up is a gnod market. It may not seem like a very big opening, but it is a good sure average. You may nut get the high prices you sometimes do in a big city, but you have not the risk of losing all of it, as you do sometimes on a city market.

Don't try to cover too much ground. A few acres well tended are better than a lot of land half tended. Start with a few acres, keep it well enriched, and well tended. Provide for irrigation or at least a part of it if you possibly can. Grow food stuff, and get it up in nice shape. Do your own selling. Sell direct to the consumer and cut out the middleman. Deal liberally and honestly with your customers and charge a fair price and give good measure. I remember an old Irish friend of mine who used to say: "Henry, 'tis no sin to charge high if you give good weight and good measure." I always remembered it.

You don't have to have a whole lot of land to start with. Some of the most successful gardens I have ever known were little more than back yards.

Go up to the grocery store and make a list of the prices they are asking for stale, second-quality vegetables and then go home and put in an even. ing figuring out what can be grown on an acre or even a quarter of an acre of each.

Fair yields per acre, such as anyone may expect with good land and good care and ordinary weather, would be about as follows: Potatoes, 260 bu.; s weet potatoes, 300 bu.; onions, 200 to 500 bu.; beets, carrots, parnips, and turnips, 300 to $600 \mathrm{bu}$.; cabbage, 12,000 lbs.; tomatoes, 30,000 lbs.; sweetcorn, 1,000 dozen ears; peas and string beans in the pod, 100 to 150 bu., muskmelons, 15,000 , and so on. I have beaten those figures lots of times. Early radishes and bunch onions you can easy sell $\$ 5.00$ to $\$ 8.60$ worth from each square rod. I averaged $\$ 9.60$ per square rod on radishes one spring.

Of course, its not all fun. There are lots of long hours, and backaches, and hard work, and hot work, and getting wet in the rain, and all that, but it won't kill you, in fact, you even get fat on it. And you are independent. You always have some. thing growing, and you have some money coming in the year around, and you always have some change in your pocket.

It is not limited to any one locality. You can start. Probably your own town is as good as any. Try it and see. Garden stuff will always sell. If its hard times people eat more garden stuff arid less meat. Grow a little of everything at first till you find what pays and what don't, and then grow a more limited line, but don't confine yourself en tirely to one crop, for if something happens to that, you're done for then.

I am a great believer in gardening. I mean market gardening. Of course, everyone ought to have a good garden. That is taken for granted, so I will not have much to say about that. You know it already.

But I doubt if you realize the advantages of gardening as a business. I don't know of anything I would rather do if 1 had to start over again. It is the best thing in the world for a boy who wants to get to doing something for himself, and every boy wants that.

There is nothing he could go into that will cost so little at the start, and nothing that is so likely to be successful with a fair amount of sense and hard work. And you can start anywhere: You don't have to go off somewhere else. The chances are good in at least 19 places out of 20 .

Supposing now that you have made up your mind to try gardening next summer. What next?

The first thing to do is to get the land. Don't try to spread out and work too much land. Better 3. little good well-worked. than a lot of land half iended. You can do wonders on just one acre, 5 acres is a big patch and 10 would be the outside limit at least for the first year.

Get as close to town as you can. It saves waste time on the road. Of course if you already live a good ways out and naturally want to work at home or near there, you will have to do the best you can, but if you are not tied to one particular neighborhood, $g t$ near town.

Get the very best of land, even if it costs a little more rent. Poor land can be brcight up in time so it will yield well, but it takes time and work and money to do it, By all means get land that is ready to do business right from the first jump. The richer the better. It can't be too rich. And of course level and smooth if possible. Stumps and stones don't hurt the soil, but they are mean to work around. Still I would rather have rich new stump land than old, poor, smooth land. The cost of the rent is a very small matter compared with the yield of good land. There is lots more difference in the yield of good and poor land than there is in the rent.

Pay cash rent. I don't believe in share or partnership deals. Pay for what you get and have it all for your own. Of course if you happen to have a failure, the rent money will come hard, but the chances are you will not make a failure; Not a complete onc, anyway.

It may be that you can sell your stuff to the stores or market men and save some time and work, but as a rule I have always found it best to sell direct to the consumer. It takes a little more time but you get better prices. and you can work up a personal trade of your own. I have been through the mill myself. I rode a market wagon for twenty summers and if I should go broke today. I would probably start in market gardening.

HENRY FIELD. 


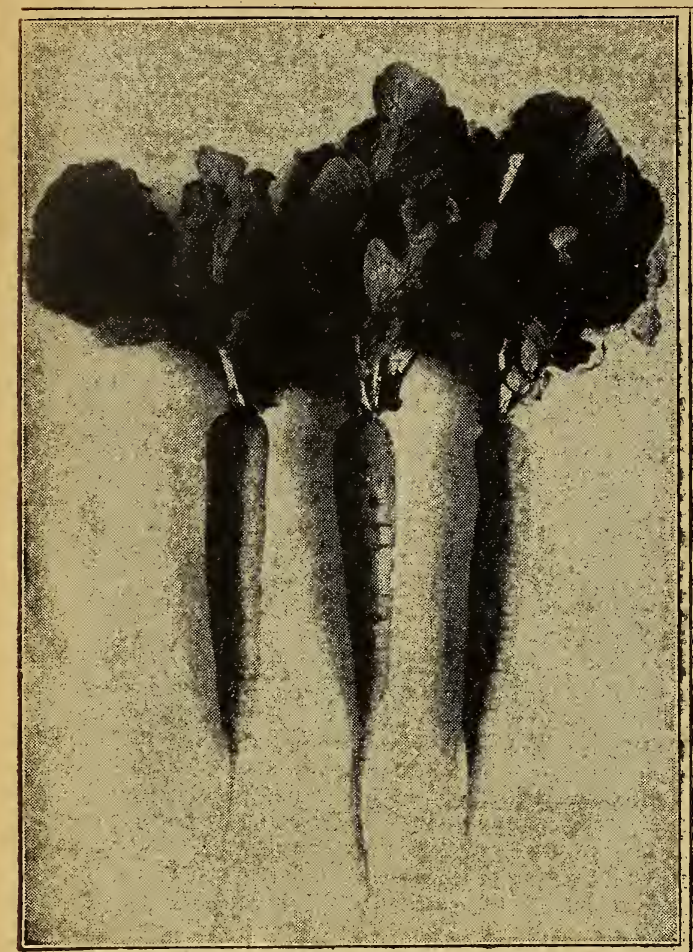

Radish, Long Brightest Scarlet

This we consider the best long red radish on our list. We have been trying out our present strain of it for two years now, and find it about perfect. Several years ago there was a radish out under this name that was not a success, as it got pithy too quick, but this one is all right either for home garden or market. It is practically the same. in every way as Icicle, except the color, which is the brightest red you ever saw. The tip, however, shades off to pure white. It is very attractive, but better yet, is remarkably tender, and sweet, and quick growing like Icicle.

If your taste or market calls for a long, red radish. this is the one to grow for first early. Price, p'kt 5c, oz. 10c, 1/4:lb. 30c.

\section{Radishes}

It is really hard to say which is the best var. iety of radishes. Different markets have different ideas about this, and if you expect to plant heavily of radishes for market, you should first find out what sort of a radish sells best in your particular market. In some places they want a long, slender, scarlet radish; other markets want a long, white radish; while still others will accept nothing but the short, round radish. In either case, if you grew the wrong kind you have trouble selling them. So find out first of all what your market wants, and then try to grow that particular type of radish. Of course, for a home garden it does not make so much difference, and any radish of good quality would grow. all right. For the big market find out what kind is wanted and grow that kind exclusive ly. For home market or garden you should grow a half dozen varieties.

\section{Varieties}

Probably the earliest class of radishes are the little round, red ones. This infludes the Early Bird, Non Plus Ultra, Early Round Dark Red, Scarlet Turnip White Tipped and Early Scarlet Globe. These are all very early, very tender and sweet, almost round and bright red with generally more or less of a white tip. Early Bird and Early Scarlet Globe are practically the same radish, solid, bright scarlet in color and more of a perfect globe in shape. In most markets it is the best seller. Non Plus Ultra is an extra early or forcing strain of this same radish. Scarlet Turnip and Scarlet Turnip White Tipped are more flattened or turnipshaped, one being scarlet and the other red with white tip. The Sparkler is a very fine special strain of the same variety, having a remarkably clear, bright color, and perfect shape and appearance. Crimson Marble is a perfect ball in shape and a deep red color. It is very early and always sells well. In early radishes of slightly longer oval or half-long shape, we have the French Breakfast and French Forcing, or Puris Beauty. The French Breakfast is the well-known, white-tipped, halflong, early radish, very tender, but gets pithy quick. Iy. The French Forcing is the one I sent out free for 0 or three years. It is the best forcing radish I ever saw, bright red, oblong, very early and very sweet. Does not last long, but is such good eating you won't give it a chance to last. Crimson Giant is an early red radish, looking much like the old Early Scarlet Globe, but more perfect in shape and color, and much larger. It comes in nearly as early as the first early, but keeps on growing and remains tender, solid and sweet until it gets as large as a teacup or larger. I have sold from them sometimes nearly a month on one sowing. There is also a radish which seems to be an improved strain of this, called Giant Butter. I have grown it only four years, but I am very much pleased with it. It has all the good qualities of Crimson Giant. and in addition is a little brighter red in color and a little earlier.

We have two new varieties to add to our list this season: The Rapid Red, pretty bright red, very early, small tops, and a good forcer. The Long Brightest Scarlet, not as large as Long Scarlet, and a much brighter red, shading to white toward tip. It makes a good appearance when bunched ready for market.

For winter radishes, the ones you can sow in the fall at turnip-sowing time and have for fall and winter use, the best kinds are the Chinese Rose Winter. The Mikado or Chinese White Winter is another good one. white instead of Pink. They grow to a large size without getting pithy, can be kept through the winter.

For the home garden many people prefer a mixture of radishes, so I have for y ears made what we call the All Season's Mixture, which is a mix. ture of all the different kinds of radishes, mostly early ones. I have sold this mixture ever since I first started in the seed business, and it has always given great satisfaction.

In the long red radishes probably the most popular is the Long Scarlet. This is the long, slender, brittle, dark red early radish which is so popular everywhere. The Cincinnati Market is a strain of this same radish, which has been highly developed for the southern shippers. It is very similar; but is lighter and brighter in color, slightly 


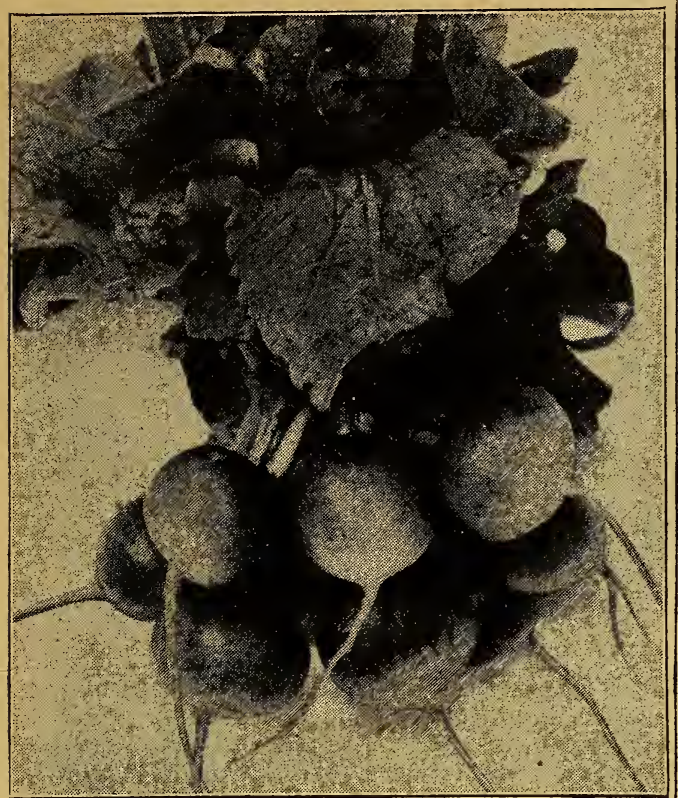

Scarlet Turnip White Tip Radish. These little round radishes can be had in either solid red, solid white, or red with a white tip.

\section{Radishes (Continued)}

earlier and smaller tops. It is very much like Icicle, except in color. The Icicle is probably the tenderest and sweetest of all the long radishes and the earliest. The only thing against it is the white color. Most people seem to prefer, for somc reason, the red radishes. But if you do not object to the color, the Icicle is the one you should grow. It is very early. Another long white radish is the Lady Finger. Comnared with the Icicle it is larger, later and will stand longer without getting pithy is the Strasburg. This is a very large, white radish, very late and egg.shaped, and never gets pithy. Often grows to weigh seven or eight pounds and can be cooked like a turnip. It is the kind to grow if you want something that will stand all summer. The Chartier is much like Lady Finger, except that it is pink and white in color, stands w Il through the summer.

Prices of Radishes.

Crimson Giant.

Crimson Marble.

Early Round Dark Red

Early Scarlet Globe ...

Early Bird.

French Breakfast .......

Giant Butter

Rapid Red.

Round White

Sparkler

Chartier

I cicle

Lady Finger.

Long Brightest Scarlet . . ..........

Long Scarlet

Strasburg

Chinese Rose Winter.

Chinese White Winter or Milkado .

Japanese Radish (Sakurajima)

SPECIAL OFFER: Any four varieties, $1 / 2-0 z$, each, 15c; any four varieties, oz. each, $25 \mathrm{c}$; any two varieties, oz. each, 15c. All postpaid.

\section{Plant Plenty of Radishes}

There is no garden crop that makes as müch money for the time and money spent as radisties. The seed is cheap, it is sure to grow, it will make a crop in 30 or 40 days, will get out of the way in time for other crops on the same ground, and if you happen to hit the market right you will make big money. If you dinn't make a hit you are not out much anyway. The important thing is to get them on the market early, earlier than anyone else. The first week on radishes is worth more than all the rest of the season put together. I have often sold as high as $\$ 200$ worth of radishes off of an acre of ground in one week and then had a lot left to plow under

Pick warm, loose soil, fall plowed if possible, and as rich as you can make it. Put on $10 \mathrm{lbs}$ : of seed per acre, either broadcast or d illed in rows 12 inches apart. If in rows, cultivate once or twice. and thin when small to 2 inches apart in the row. Then they will alf mature early and make goood specimens.

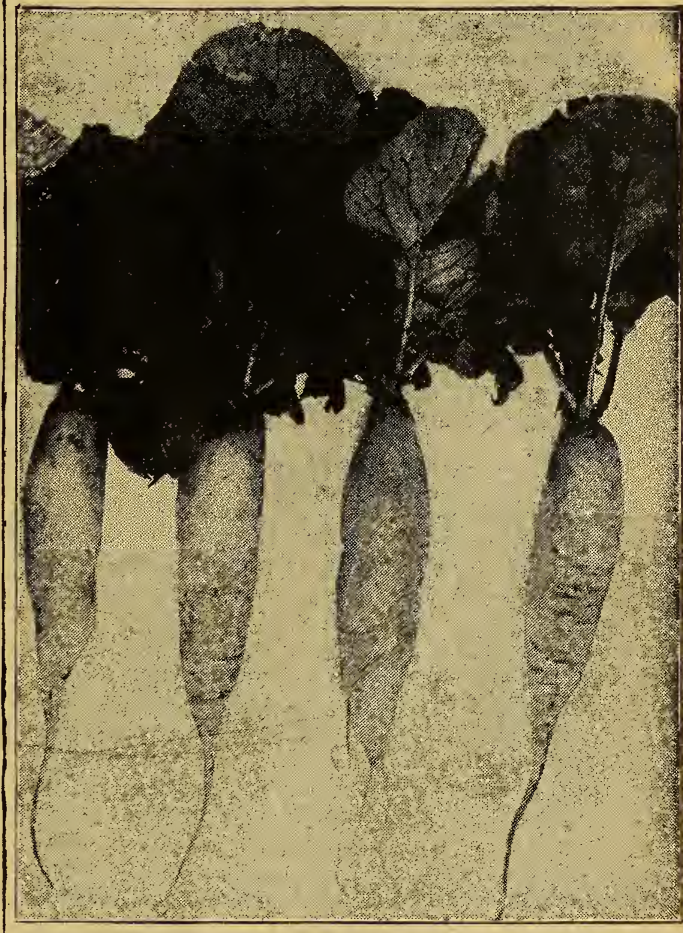

\section{Icicle Radish}

These are the tenderest and possibly the earliest of all radishes. They are pure white, tender. mild, and very quick growing. They get pithy quick, but that is true of all tender. sweet, early early radishes. We have a splendid strain of this variety, the true stuff. There has been a great deat of trouble over Icicle, many firms sending out instead Lady Finger and Strasburg, which are all right in their place, but no good whatever to a man who wants Icicle. We can give you the genuine, orig inal Icicle. 


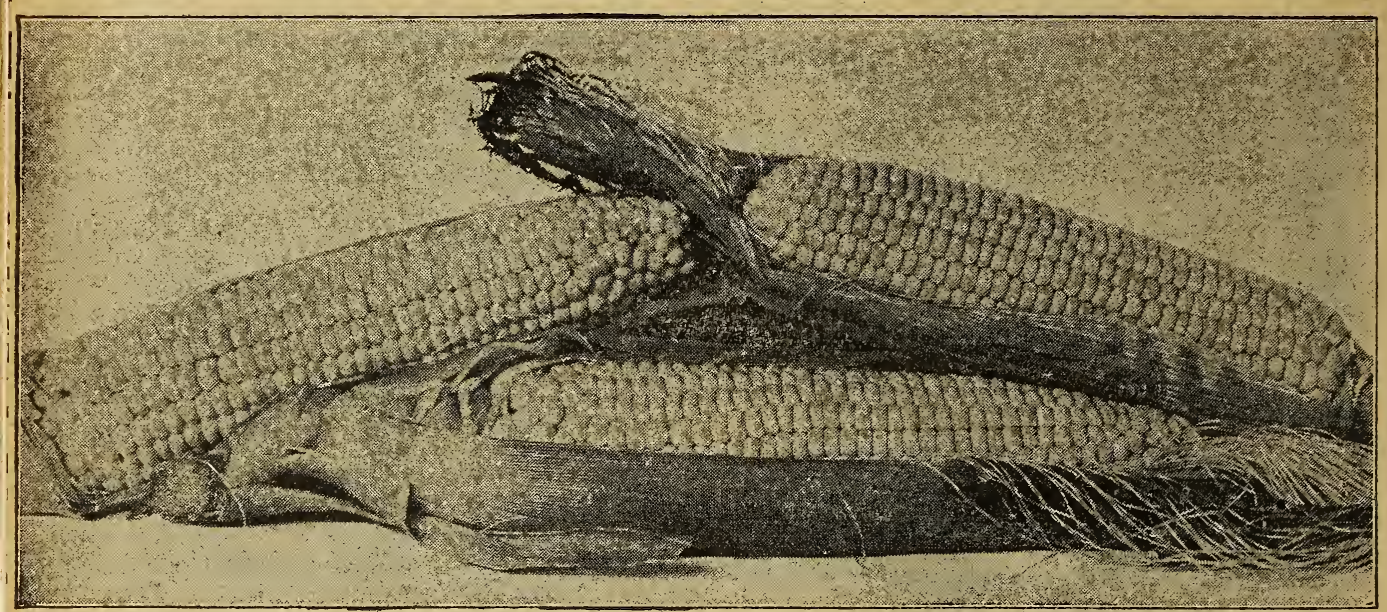

White Evergreen. The finest of all the Evergreen class. Deep grained, sweet, tender, and a great yielder

\section{Sweet Corn}

I grow large amounts of sweet corn for seed. and $I$ am in a position to make you very favorable pricos on large lots. Our crop was good this year and the finest quality I have ever seen. If you want very much seed, it will pay you to write for secial rrices.

Thereare so many good varieties of sweet corn, and I do not try to list them all. There is no use growing them all. The ones I offer here cover the whole season and each is the best of its season. I take particular pains in selecting my seed, and for sweetness, depth of grain, and freedom from mix. ture, I will back it up against anybody's corn.

\section{Varieties}

For a first-early sweet corn my choice would be White Mextcan. I have sold this for several years now as the best early sweet corn, and I am a stronger believer in it than ever. From the results of my own garden and the reports I get from customers, I don't see how it can be beaten for first-early. Not only early, but of extra-gorod quality. Compared with Cory the standard early variety, it is larger, langer ear, pure white, and does not show the Jbjectionable deep furnow between the rows. It was, whern first introduced, earlier than Cory, but I have been working to still farther increase the size and quality, and have sacrificed a little on earliness, so that now it is the same season as Cory, and is far ahead of anything of that season for size and quality. I still continue the original strain, which is about four or five days earlier than Cory, and have it grown for me in the northern part of Iowa by the originator, so as to retain the extreme earliness. The larger strain is all of my own growing here. Please specify whether you want White Mexican Extra Early or White Mexican Home-Grown.

Next to the White Mexican I prefer the Cory class of sweet corn as varieties for early market. This includes First of All, White Cory, and Peep ONDay. Probably the earliest of the three is the last named, Peep $O^{\prime} D a y$, but it is so very, very small that it is not generally satisfactory, The most popular one of this clase is First of All, which is practically the same an Red Cob Cory, a small early corn, probably the earliest fair-sized corn grown. It grows about waist high, and is ready for use often by July 4 th. White Cory is a standard early sort, beautiful white cob, and of fair quality and very early.

Golden Bantam is another good early corn. As indicated by its name, the grain. when ready for use. is a rich, creamy yellow color, deepening to an orange color when it ripens. I do not advise it as a market-sort, for its colar gives it the appear. ance of being old, but when once used it will be popular on account of its rich flavor. We also have a pink early corn of high quality called the Early Rose, coming in slightly later than Cory and White Mexican, and having the high quality of the later varieties. We have had a great deal of trouble. however, to get this variety to come true to type. It is evidently a hybrid, and broke so badly, reverting to half-dozen original types. that we have had to leave it out of the list for the last four years.

In the second early varieties, the best known is the Early Minnesota, which comes in just after Cory and White Mexican. A slightly larger and better second-early is Early Champion, which is probably the best of all the second-earlies. Long. sweet ears like the later sorts, and is in and gone before Evergreen is ready. Next following would be Early Evergreen, which is an early selection from the Stowell's Evergreen. Slightly smaller and about a week earlier. Ears are of good shape and fine quality. Black Mexican also comes in about the same season. It is a very sweet variety, medium early and fair size, but its color is against it, the grains being blue-black.

I especially want you to try White Mexican. I consider it by far the best early sweet corn grown. I know you will agree with me.

For the main crop of big, juicy, roasting ears, either for home use or for the canning factory, there is nothing equal to Stowell's Evergreen and it's improved strain, the White Evergreen. Both are very similar, juicy, sweet, solid ears; heayy yielders, staying green and tender for a lang time. The Stowell's Evergreen is the standard variety for the canning factories everywhere, while White Evergreen is more prized for home use and mar. ket-garden trade. 


\section{Sweet Corn Continued}

The finest corn of all for high quality is the Country Gentleman class. This includes Country Gentleman, Shoepeg and Zig Zag Evergreen. All are quito late, coming in after Stoweli's Evergreen. The Shoepeg is too small to be of much use. Country Centleman is medium size, very long, slender, grains zig-zag on the cob; very high quality, and the istandard everywhere with people every where who want the very finest quality in sweet corn, regardless of size. The Zig Zag Evergreen is supposed to be a straight cross between Country Gentleman and Str-Nell s Evergreen in an endeavor to get th: size of the Stowell's with the quality and appearance of the Country Gentleman. I doubt if this result was attained, but it is a good wariety anyway, and comes fairly near

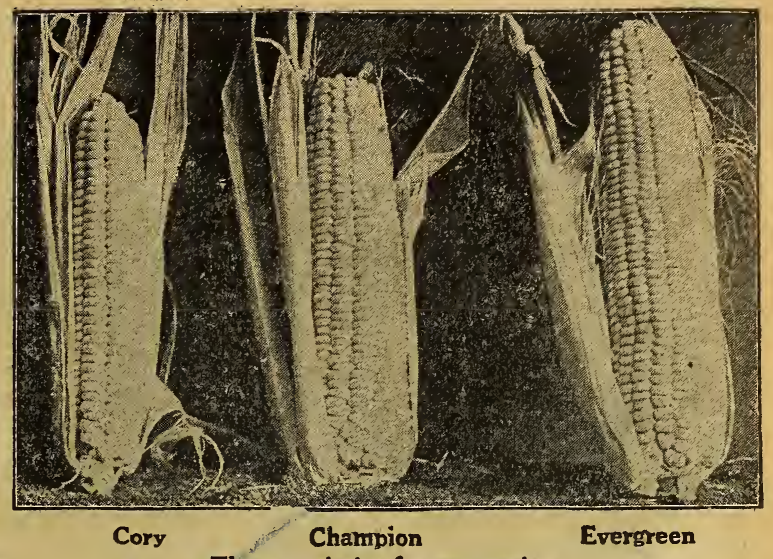

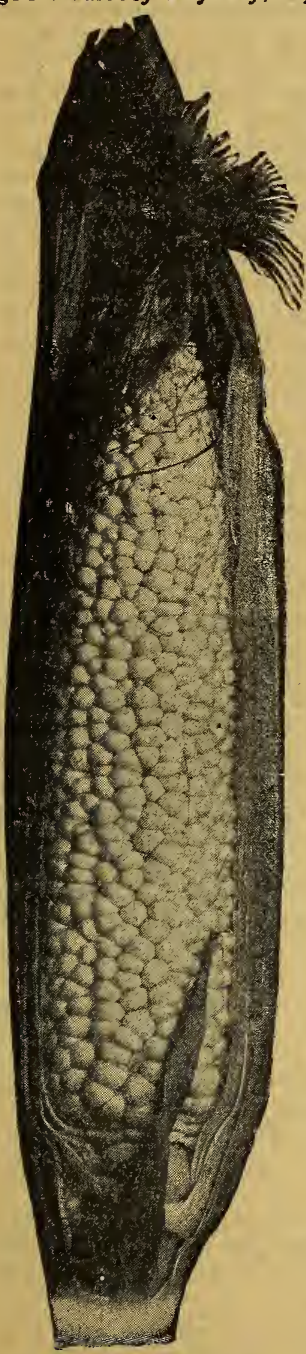

Country Gentleman

Noted for specially fine quality half way between the two parents.

We have been grow. ing for the past three years a new early sweet corn called Mayflower, and we like it very much. It is pure white, very early, and a heavier, thicker ear than either Cory or White Mexican. We are very much pleased with it. and I am sure you will like it, and should try it.

In the south, where it is hard to grow the true sweet corn on account of worms in $\mathrm{the}$ e a r s th $\mathrm{e}$ standard variety is Adams' Extra Early. This is not a true sweet corn, but it is good for carly roasting ears. Very early, and hardy, and free from worms. There is also a smooth corn used for roasting ears in the extreme west and north west and by the Indians on the plains. called the Squaw Corn. It is spotted in color, very early and very hardy. It is curious and interesting, and is useful for growing where other corn is a failure, but is small and of poor qual ity. There is also a var. iety grown in the mnun. tain states called White Australian, It is very hardy and will grow and mature in high altitudes and on dry land where other corn would fail. Like the other two men tioned, it is not a true sweet corn, and is not of high quality, but it will make roasting ears where roasting ears are scarce.
Early Mayflower. We have been experiment. ing with this variety for the last three years and we are well pleased with it. It proves to be just a little earlier than any other sort we have. For the past two years, in the trials, we have gathered our first mess of roasting ears from the Early May. flower. The quality has been good, in fact, better than most early kinds. It seems to contain a larger percent of sugar than is usually found in an early corn. The appearance of the dry grain shows that. A gardener here at Shenandoah grew the Early Mayflower this season and had the earliest corn in this locality and sold it as fast as he could hand it out at 25c per dozen ears. I pronounce it one of the best things in early sweet curn that has come out yet. You are safe in planting all you want of it. Prices of Sweet Corn.

Peep O'Day .

White Mexican (Extra Early)

Adams' Extra Early.

First of All

White Cory

White Mexican

Early Minnesota

Golden Bantam.

Early Champion

Early Evergreen.

Black Mexican

Zig Zag Evergreen

White Evergreen.

Stowell's Evergreen

Country Gentleman

Pkt. 1/4-lb. Lb. 3.lb,

05c 10c 25c 65 c

$\begin{array}{llll}05 & 10 & 30 & 80 \\ .05 & 10 & 25 & 65\end{array}$

$\begin{array}{llll}05 & 10 & 25 & 65 \\ 05 & 10 & 25 & 65\end{array}$

$\begin{array}{rrrr}05 & 10 & 25 & 65 \\ 05 & 10 & 25 & 65\end{array}$

$\begin{array}{llll}05 & 10 & 30 & 80\end{array}$

$\begin{array}{llll}05 & 10 & 30 & 80\end{array}$

SPECIAL OFFER: You may select any three varieties, $1 / 4-1 \mathrm{~b}$. each, for $25 \mathrm{c}$, or any 3 varieties, $1 \mathrm{lb}$. each, for $65 \mathrm{c}$. all postpaid.

\section{Evergreen Sweet Fodder Corn}

This is fine to grow for early hog feed. It makes finer, sweeter fodder than field corn and makes lots of good ears. We can supply a very fine grade of seed specially selected for large ears and deep grains, or we can supply a cheaper fodder grade. For prices on fodder sweet corn see price list on page opposite page 73.

\section{Sweet Corn in Large Lots}

If you have any notion of planting quite a field of sweet corn, be sure to write me about it, for I can do you some good. We are right in the heart of the best sweet corn country here and can grow sweet corn better and cheaper than any place in the United States. Anything from a peck to fifty bushels I can give you the right kind of seed and at a right price. Write for special prices. 


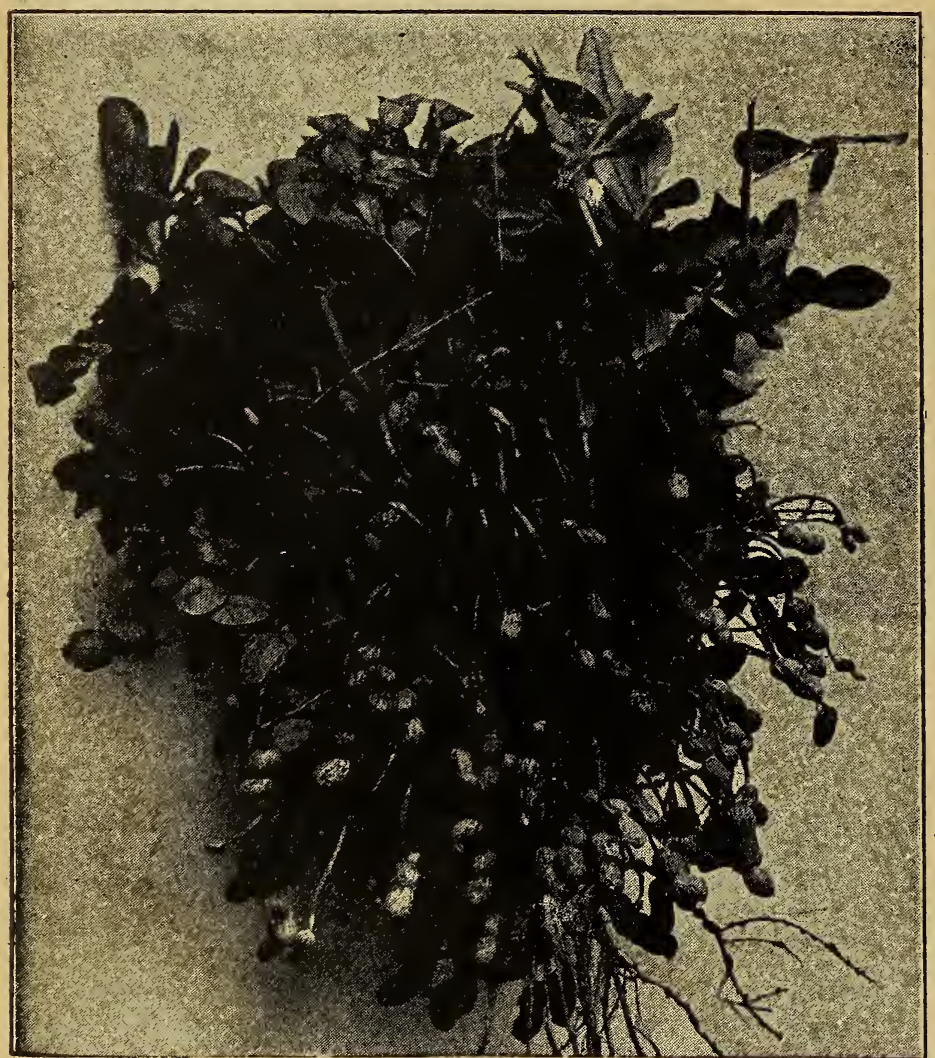

Peanuts as a Field Crop. Peanuts are very valuable as a field crop. They stand dry weather well, will grow on thin or sandy land, yield well, and make very rich and fattening feed for hogs. By using the Early Spanish variety they can be grown almost as far north as field corn, and have made a great success in the high altludes of the west, They should be planted in rows like corn or potatoes, a little later than corn and about as thick. Use $\frac{1}{2}$ bu. seed per acre. Ask for special price per bu., or see price list opposite page 73 ,

\section{Peanuts}

Few people know that peanuts can be grown in this climate. They may not make as big a yield as they do in the south, I don't know about that, but they certainly do turn out well. This you see by the photo given here of some that I grew last sum. mer in my test garden. Of course, I use northern seed. The southern seed would be everlastingly too late. Plant just like beans, after it gets thoroughly warm in the spring. Thin to a foot apart in the row and keep well hoed.

The earliest and best anes for the north are the Early Northern Feanuts. The, make small pods, but they are well filled, and are so prolific that they yield prac. tically as well as the big southern variety. The bush stands nearly upright like an early potato bush, with the peanuts clustered around the roots. This strain can be depended upon for a crop in any ordinary season, in any country where corn wlll ripen.

If you want somethirg really big, and live far enough south for a long season, you should raise the Jumbo or Southern Peanuts. These are the big southern variety, finer looking than the early kind. but more likely to get frost. bitten.

Price, either variety, 1/2-pint, 10c; pint, 20c; quart, 35c.

Write For Free Leaflet Giving Full Directions For Growing Peanuts.

\section{Popcorn}

The best way I know of for boys to make money is to plant popcorn, It is easily grown, yields well, and always is ready sale. It is a sure crop, too.

I remember once when I was about ten years old I made $\$ 17$ off a little patch about as big as a town lot, and popcorn did not sell as high then as it does now.

A couple of boys I know had a vacant lot planted to Baby Golden popcorn and they ralsed $500 \mathrm{lbs}$., which they sold at $5 \mathrm{c}$ a pound, clearing them just $\$ 25.00$. Now, wouldn't you like to do that? Popcorn should be planted just like field corn, only may be planted a little thicker.

VARIETIES There are several varieties, but the ones that have done the best for me are the Little Giant, Monarch White Rice, and Queen's Golden.

The Little Giant is a small ear, but a great yielder, and of finest quality. You can get an extra price for it anywhere after people get a taste of it.
The biggest of all is Queen's Golden. Large, yellow grains, smooth, and pops out very large. The standard market variety, grown everywhere for ahipping, is Monarch White Rice, which has large, white, sharp topped grains asd a mediumsized ear. In the south they call this variety "Squirrel Tooth Corn."

Prices of Popcorn.

Little Giant

Pkt. 1/4-lb. Lb. 3-lbs Monarch White Rice

Queen's Golden

Baby Golden $\$ 0 \quad 05 \$ 0 \quad 10 \$ 0 \quad 30 \$ 075$

If you want the daintiest, most delicious popcorn you ever saw, try the Baby Golden. For seed we sell sedected ears only, and sell the second grade ears for popping.

Price, Selected ears, $10 \mathrm{c}$ each, postpaid, or 3 for 25c. (An ear has about 400 grains and would plant about 100 hills. Shelled seed, Pkt. 10c, t-lb. $15 c$, lb. 40 c, 3-lbs. $\$ 1.00$.

SPECIAL OFFER: Enough popcorn seed for a good, big town lot fox $40 \mathrm{c}$. For $40 \mathrm{c}$ I will send postpaid 1 pkt. of Baby Golden, and 1 -lb. each of the other three kinds (total regular price 50. ) 


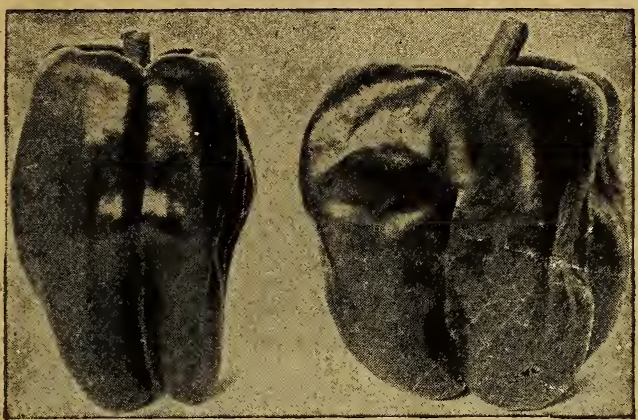

Ruby King $\underset{\text { Two Fine Mango Peppers }}{\text { Chinese Giant }}$

\section{Peppers}

Peppers should be started in the house or hot. bed and handled about like tomatoes. They seem to do well in almost any soil except that which is too low and wet. Give the plants plenty of room: in the row for best results. The seed seldom comes well planted out-of-doors. They need lots of heat and should be started in a hotbed or greenhouse.

The largest, sweetest, and best of all the mango or sweet peppers is the Chinese Giant. I have had them as large as a quart cup, but of course, they don't all grow that big. The Rural New Yorker, which is a mighty good authority, says editorially: "Chinese Giant pepper has given us great satisfac. tion the past summer. It is mild and well flavored, and appears to be one of the few sweet peppers that do not shock the unwary customer by suddenly developing a taste like a torch-light procession." It makes so few seeds that the true stock will always be scarce and high. A great big pepper, as jig as your two fists, will often have only a dozen or so of seeds.

The Yellow Chinese Giant is the same thing, but yellow in color and even better than the ori. ginal variety. It is not much known yet, but will eventually take the place of the other.

The most widely known and widely grown of all the mango peppers is the Ruby King. It is well-known everywhere and always sells well. It is not so large as the Chinese Giant, and is slightly more pointed in shape, but is somewhat earlier and sets more peppers to the bush. There is also a cross between this and Crimson Giant, which is known as $R u b y$ Giant, and has, to a large extent, the good qualities of both parents. It is generally sold in the market as Ruby King, but is larger and thicker meated.

If you want a mango pepper that turns yellow when it is ripe, you should use the Golden Queen. This is about the same shape as Ruby King, but is smaller, holds the green color for a long time, and then turns yellow instead of red. A small mango pepper about the same size as Golden Queen is the Bull Nose. It is sometimes used for mangos, but is pretty hot for that and not quite large enough. Another good small sweet pepper is the Neapolitan.

If you want a genuine hot pepper, the kind to use is the long, red Cayenne. This is the real redhot kind, grows 3 to 4 inches long and is very pro. lific, often one hundred or more to a single bush. Still smaller and still hotter varieties are Red Chili and Red Cluster, which grow about an inch long. very thick on the bush and very hot, These are the ones that are used for chili sauce. There is a still smaller and still hotter variety, known as the Bouquet Pepper. It is about a half inch long. hotter than double-distilled fire, and grows in thick clusters on a little dwarf bushes, often hundreds of them to a single bush until it looks like a big red bouquet of peppers, Price, any of the varieties named, pkt. 5c, oz. 20c; except Chinese Giant, Yellow Chinese Giant and Ruby Giant, which are pkt. $10 \mathrm{c}, 0 \mathrm{z} .40 \mathrm{c}$.

\section{Parsley}

Used for seasoning and garnishing. It is easily grcwn. Sow the seed early in the spring in rows like parnips or carrots.

Moss Curled. Best variety. Pkt. 5c, oz. 15 c.

\section{Parsnips}

Many people have trouble to get parsnip seed to grow well. The trouble is either old seed or it is planted too late. It should be planted very early. while the ground is cool and moist.

Hollow Crown or Long Smooth. The standard sort. Long, smooth, tender, and sweet.

Improved Half Long. Much like the above, but shorter and heavier. Fine quality. 25c.

PRICE: Either variety, pkt. 5c, oz. 10c, $1 / 4 \cdot 1 b$.

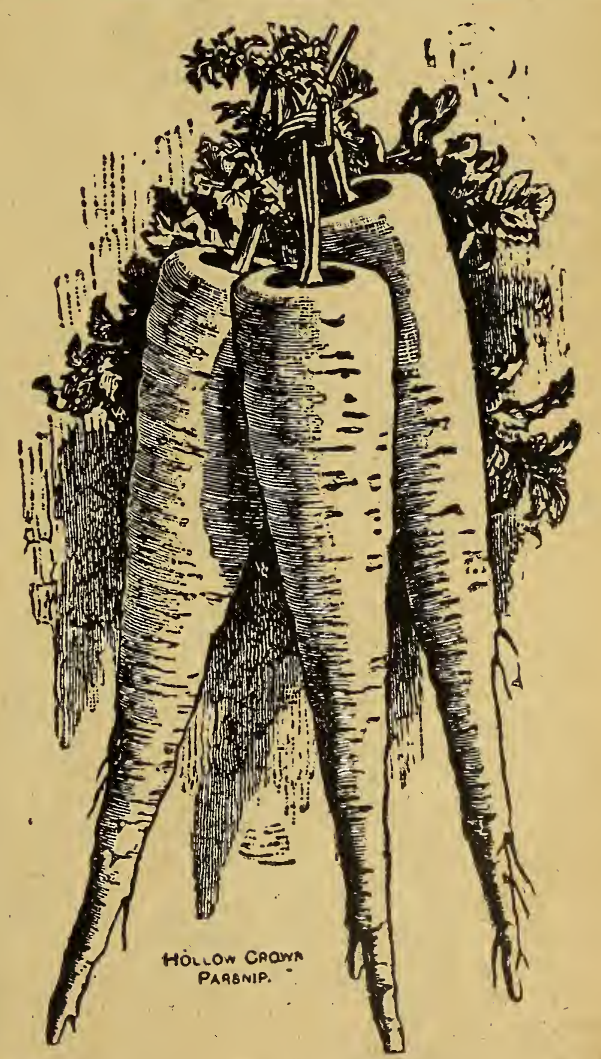




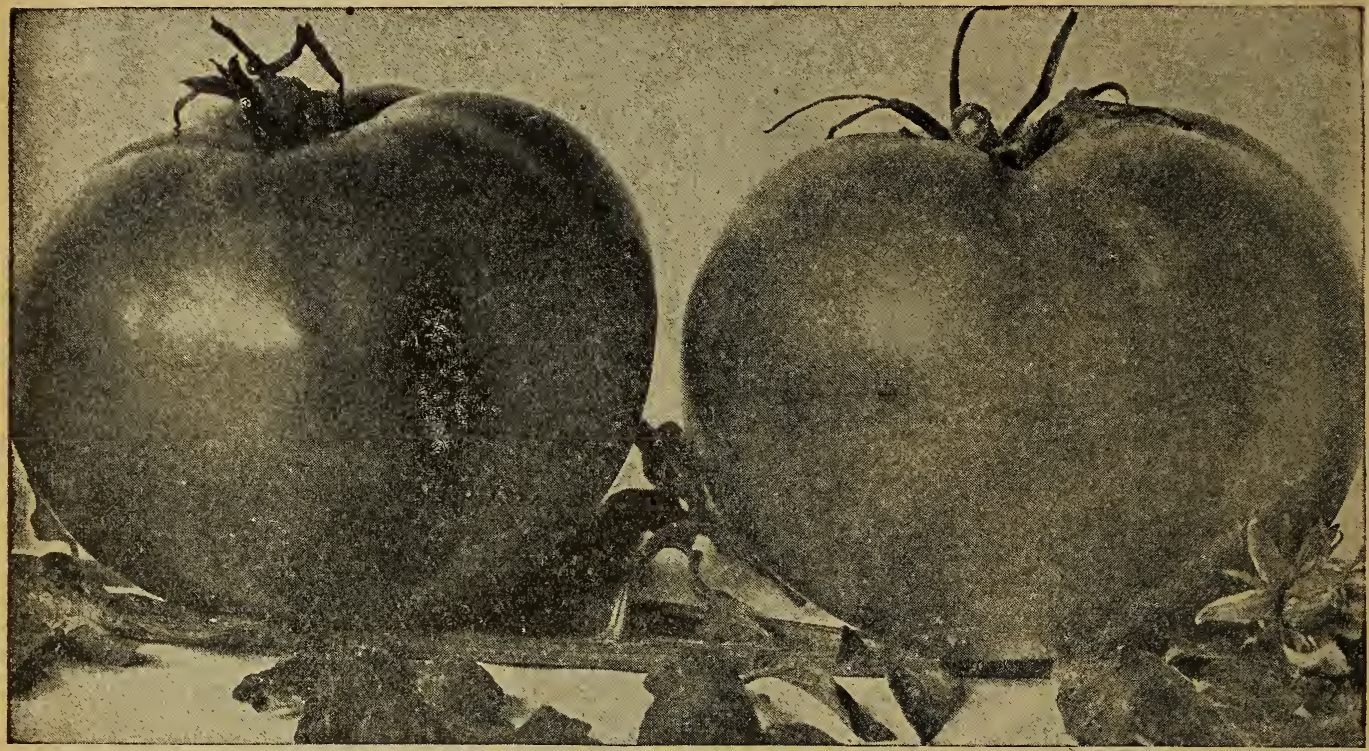

A pair of of typical Mississippi Girl tomatoes. The best tomato of all for canning and for main crop through the summer

\section{The Mississippi Girl Tomato}

There is a great demand for a perfect canning tomato, and we have been working along that line for several years, starting, of course, with the Stone type of tomato, for the Stone tomato has always been acknowledged as the finest of all canning tomatoes. What we have is not exactly improved Stone, although it is along the same line. It has the same deep red color as the Stone, but is slightly larger, more uniform in size and of remarkable ability to withstand hot, dry summer weather.

Perhaps you have all had some experience with tomatoes blooming all right, but failing to have fruit. This is especially common in Oklahoma, Arkansas, Mississippi, and other southern states. The Mississippi Girl is remarkably free from this failing. Here is the summing up of what we claim for the new tomato.

A wonderful deep red color, Uniform even size,

An enormous yielder.

Solid, deep red lesh

Freedom from cracking,

A long season of bearing, Thrifty, vigorous vines, Ability to stand hot weather, Apparently blight proof, Smooth as an egg.

Now, if these qualifications are what you are looking for in a tomato, you need go no further, for I am sure the Mississippi Girl will suit you.

The name was given it in honor of the girls of Mississippi who have done such wonderful things with their "Tomato Clubs". You know all over the south, and especially in Mississippi, the girls have been organizing clubs, not to do fancy work, or to study high brow literature, or to promote social aspirations, but for the humble and useful purpose of canning tomatoes, and they have done a wonderful lot of good, and incidentally, made a lot of money for themselves. We had some of the clubs experiment with this new to. mato before we placed it on the market. Amnng others we sent a lof of trial packages to the Mississippi Girl Tomato Club of Oktibbeha County. and they were so enthusiastic about its quality that we named it in their honor. While it does exceptionally $w$ in the south, it will do well anywhere in the country where tomatoes grow at all.

While not a first early, this tamato ripens quite early, and they stay good and hold their size clear through the summer.

This tomato would be a beauty to sell on the market for slicing purposes, but everyone who had it was so enthusiastic about it as a canning tomato that I have emphasized that particular advantag. more in the description. Price, pkt. 10c, 3 for 25c, $1 / 2-0 z .40$ c, oz. 75 c.

\section{The Pink Early June}

The only possible drawback to Field's Early June is that some markets object to a bright red tomato and demand a pink or flesh-colored tomato instead. The Early June is a fire red without a trace of pink or purple.

Two or three years ago, however, we found a single plant, evidently a sport or hybrid, bearing typical Early June tomatoes except that they were of a pink or purple color like Acme or Beauty.

It proved to be fixed in character and comes absolutely true to type. It is very early, smooth. and solid, like the parent, and with the Acme color. It is remarkably heavy yielding and is a great money maker. Some of the boys insisted that on our grounds it outyielded the regular Early June, but that may have been Imagination. Our steck of Pink Early June is limited, but while it lasts we will supply it at pkt. 10 c, 3 pkts. for $25 c$, oz. 75c.

\section{Tomato Plants}

The best way to get tomato plants is to grow them yourself or have them grown for you right close home. They a e mean things to ship. as they are so soft and tender that they bruise in the mail. If you cannot grow them, we can fix you out. Watch the March and April issures of Seed Sense for prices, or write and ask. 


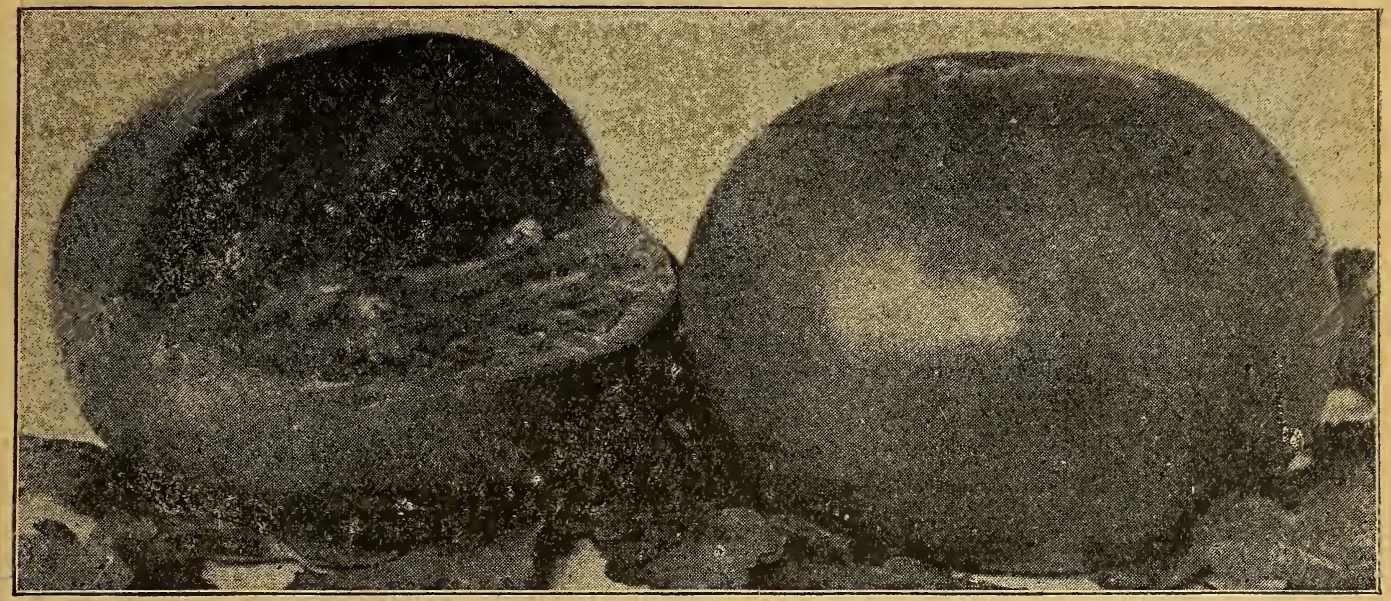

Field's Early June Tomato. Can You Beat It? Field's Early June Tomato

Pkt. 10 c, 3 for 25 c, $\frac{1}{2}$-0z. 75c, $\frac{1}{4}-$ lb. $\$ 2.25$, lb. $\$ 8.00$

History. This tomato originated with Rev. W. H. Rust, who lives about $\mathbf{3 0}$ miles from here, just across the line in Missouri. He is a country parson of the old circuit rider type. He has two country rharges. A little five-acre farm and a passion for gardening. His special hobby is tomatoes. For several years he has been trying to get a tomato that would be earlier and better than anything in the list. The Early June Tomato is the result of his twenty years of patient experimenting. When he first brought me some of the tomatoes I thought it was a Stone he had till I cut them open, when it was easy to see $I$ was wrong. When $I$ found he had been selling them since June 14, and was getting practically double price on account of high quality. I began to get interested.

After five years' trial with my customers all over the United States, I find that he was absolutely correct in all he said, and to tell you the truth, neither he nor I dare to tell it as strong as it really is, you wouldn't believe it. I would rather let the tomatoes talk for themselves. You'll have to believe it then.

It is earlier than Earliana, as smooth and harrdsome as Stone, and more prolific than either one.

I know that statement sounds pretty strong, but it's gospel truth and I've got the papers to back it up. I made the statement last year and I wish to make it more posiuve than ever this year. I got literally hundreds of letiers from customers about it, but I haven't room to print them. It would take a big book.

I am not going to give any long description of the tomato, as that one line tells the whole story. It looks like Earliana, and has much the same kind of vine, but is a little earlier, is smoother, redder, and much solider. Very mild, sweet flavor instead of the somewhat sour taste so common in early tomatoes. It bears much heavier than any other early tomato.

It looks just like Stone for shape, and color possibly rot quite so large. The flesh is as meaty, solid and seedless as a Ponderosa, and you know that's the limit.

Seed Grown by the Originator. I had Rey. Rust grow and select seed for me, and the seed I offer, unless otherwise specified, is grown, selected and saved by him. It is all from sound, smooth tomatoes, of even size and color, and ripened early.

Seed My Own Growing. I have a limited amoun. of my own growing, which I will sell at the same price. Also, I have some grown by Stephen Green, the celebrated tomato-grower of Ohio, and some in northern Iowa. These and my own were grown from specially selected stock seed, saved by Rov. Rust from tomatoes ripening in June. Price same as above

Your Money Back. If you do not find this new tomato to be all I claim for it, and more too, I will refund every cent of it.

A Money Maker. Just think what it would mean to have tomatoes ahead of any one else, and much finer ones, too. Rev. Rust sold over $\$ 100$ worth from 102 vines in the parsonage garden. These were sold not only on a city market. but in a little country town. You ought to be able to do as well,

Complete Directions. I will include with every package of Early June tomato seed. Iull and com. plete directions written by Rev, Rust. He is very anxious that this tomato should be a great success and wants to help all he can with directions for growing.

Rev. Rust's Own Description. Here is what Rev. Rust himself has to say of the Early June tomato. I asked him to make a brief statement re garding it for the catalog.

"I believe it to be the earliest of all. And not only is it early but large. In color it is crirnson red and very attractive. It is almost seedless, the flesh thick and firm, and the flavor delicious. have marketed it here for five years past and have never had a complaint on quality; and have $\mathrm{rL}$ ceived an average price of $5 \frac{1}{2}$ cents per pound fos the whole season." -W. H. RUST. 


\section{Main Crop Varieties of Tomatoes}

For main crop tomatoes there is nothing to equal the New Stone. This is the best representa. tive of the Livingstone type of big, solid, "beefy" smooth red tomatoes. It is the earliest of any of the large tomatoes, always smooth and remarkably free from rot. It is solid-meated. of good flavor and very prolific. In most localities this is the only one the canning factories will allow grown for them, It holds up its size clear to the end of the season, and after it once gets started bearing will bear heavily and continuously until frost.

Perfection and Matchless are very similar varieties, large, solid, blood-red tomatoes suitable for main crop or canning,

If you want an extra-large, showy tomato of very high quality, however, there is nothing equal to the Ponderosa class of tomatoes, This includes Ponderosa, Crimson Cushion, Beefsteak, Majestic, Tenderloin and several others. Most of these, however, are simply Ponderosa under another name and for that reason we don't use anything but the reg. ular straight Ponderosa. It is a very large tomato, almost seedless, sometimes a little rough, but is certainly the largest of all and the finest of all. We have been working for several years on a special strain of Ponderosa which we call the Shenandoah, but have never succeeded in working up enough true stock of it to offer for sale. We will send a small trial packet to anyone ordering seeds to the amount of $\$ 1$ or over.

What we are trying for is a smoother, rounder Ponderosa, more uniform in shape and color than any other type. There is also a dwarf or bush form of Ponderosa, which is sold under several different names, but is best named simply Dwarf Ponderosa. It is supposed to be the Ponderosa on a Dwarf champion bush, but with us has been late and a very shy yielder, and I would not recommend it.

Buckeye State is a fine, big tomato, almost as large as Ponderosa and smoother. Bonny Best is

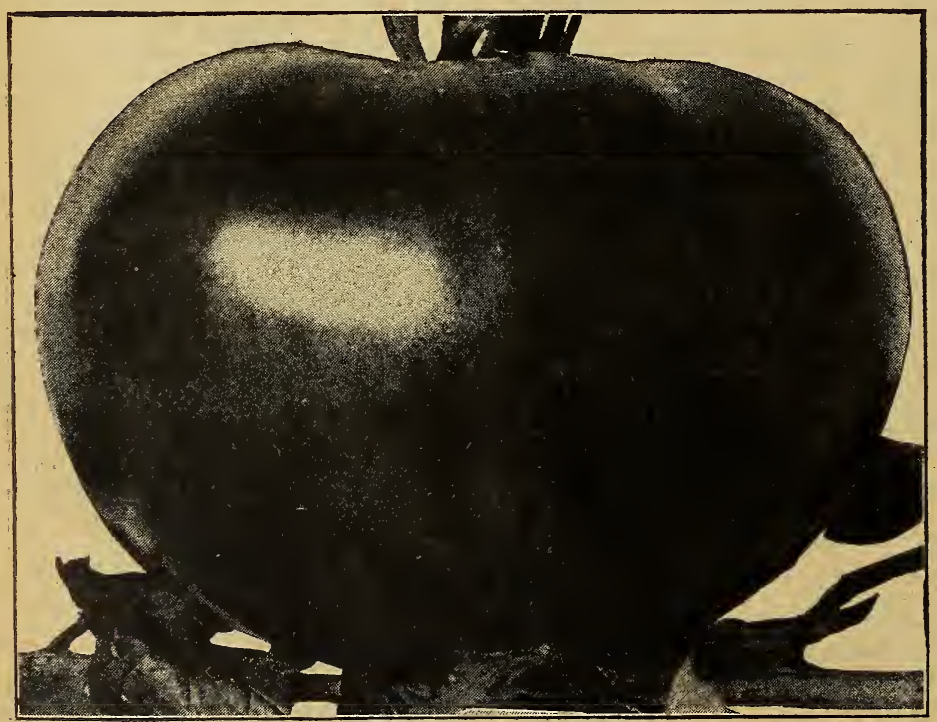

New Stone. Best of all the big, smooth, red, main crop tomatoes. also a very good variety. Large smooth, a good color and fairly early:

A great tomato for the south is the Mississippi Girl tomato shown on the preceding page.

Another tomato that is grown largely in the south, especially for shipping is the Livingstone Globe. It is a very fine purple tomato, globeshaped, and good every way. We have the true scrain.

\section{Early Varieties of Tomatoes}

Of course, I don't believe there is any tomato made so good as my Field's Early June, which I have described fully on another page. But there are lots of other good varieties of tomatoes, each one of which has some particular point of excellence.

Generally speaking, the best first-early tomato outside of Early June is the Farliana. It is of good size, fairly smooth, good quality and ripens an enormous amount of fruit very early. Later in the season the big main crop tomatoes go ahead of it, but for the first three weeks of the season, when tomatoes are high.priced and taste good, they will turn out lots of tomatoes. My seed of this variety is specially selected for me by a trucker who grows Earliana cxtensively to ship.

The Earliana is a scarlet or fire red color. In some markets this is an advantage, while others prefer a purple or pink tomato, or as it is sometimes called, flesh-colored, You should watch out about this.

While the Earliana is a fine tomato and a great money-maker in most markets, it would lose you money in a market that demanded a purple tomato. In such case you should plant June Pink, Acme and Beauty. June Pink is best described as a pink Earliana, as it has the same light, slender vine, is early and bears fairly well. It is not so large and smooth, however, as Acme, which for that reason is generally chosen by southern truckers as the va. riety to grow to ship north. Acme is a purple variety, very smooth, nice medium size, and very early, Beauty is very similar but even larger. It is a smooth, solid, fine-flavored tomato, alalmost as large as New Stone. but purple in eolor. Where the market calls for a purple or flesh-colored tomato, this is a fine one to grow. Is good size and of fine appearance, medium early.

Another purple early tomato is the Dwarf Champion. This is especislly desirable in some places on account of its very dwarf, stocky bush and holds the tomatoes up off of the ground well and does not run to vine in extra rich. soil, as is the case with so many tomatoes. It is early, smooth. purple-colored, is solid and of fair quality, but rather small,

Chalk's Early Jewel is a smoo h, bright red early toma to. A little deeper color than the Earliana, not quite so early but larger, smoother and of a little better appearance, 


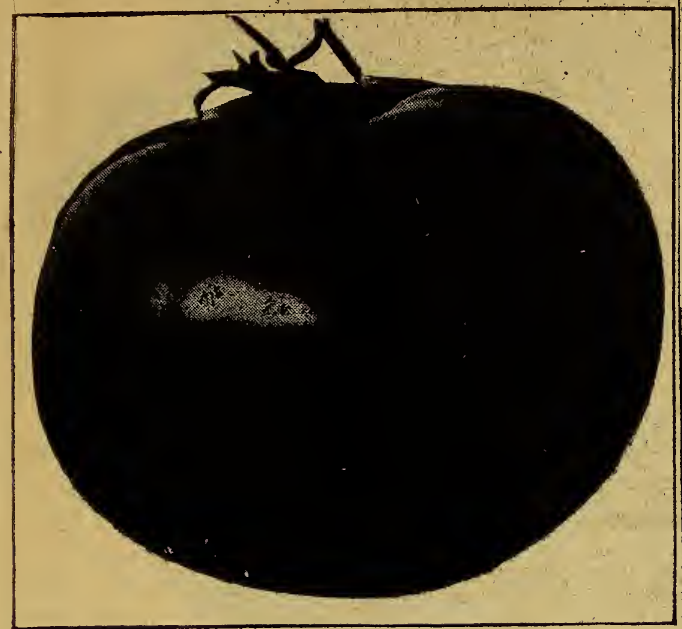

Bonny Best. A good early or second early tomato. It is fairly early, large and smooth, and a good yielder. A good tomato in every way,

\section{Miscellaneous Varieties of Tomatoes}

Of the small tomatoes for preserving or for sweet pickles, probably the best one is the Yellow Pear. A small, pear-shaped yellow tomato, which seems very hardy and yields enormously. The Yellow Plum is very similar. but slightly different in shape. There is also a larger yellow tomato known as Golden Beauty. This is a big, round, smooth, yellow tomato of very much the same size and shape as Beauty, but golden yellow in color.

A packet of tomato seed should make any. where from 100 to 500 plants, according to what luck you have. An ounce of tomato seed should make 2,000 to 4,000 plants.

For an acre of tomatoes you will need from 1,000 to 8,000 plants, according to the distance they are set, The usual distance between plants is $4 \mathrm{ft}$. by $3 \mathrm{ft}$. This would take 3,630 plants for an acre. Oth. er distances would take as follows:

$6 \times 6$. $1,2003 \times 3$

$5 \times 5$. $1,7423 \times 3$

$4 \times 2$. $5,4452 \times 2$

Prices of Tomatoes.

Acme

Beauty

Beauty ......

Bonny Best -

Chalk's Early Jewel. ......

Dwarf Champion

Earliana

Gold's Lariy June....

Colden Beauty .........

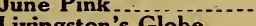

Matchless

Mississippi Gir.

New Stone

Pink Ear'y June.

Ponderosa

Shenandoah

Yellow Pear

4,840

7,2600

10,390 See Blue list for wholesale price on larger lots.

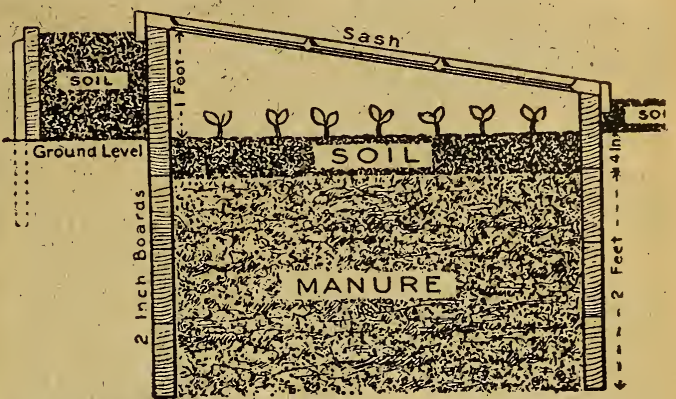

\section{Directions For Growing Tomatoes}

Tomatoes do best on soil that is moderately rich. as they run to vine too much on rich ground. Give the plants plenty of room each way and do not set them out till all danger of frost is past. The plants should be started in hot-beds about seven weeks before they are to be set outside, or if you have plenty of room in the hot-bed, eight weeks would be all right. In this latitude we generally set the plants about the first of March. . Of course, the plants can be started in a cold frame or a hot-bed covered with canvas, but the best way is to make an ordinary hot-bed covered with glass sash. This glass sash used to be quite expensive. but can now be bought for about $\$ 2.50$ each already glazed. This is for the $3 \mathrm{ft}$. by $6 \mathrm{ft}$. size generally used. Here is a cut showing how the hot-bed should be built. See page 67 for prices on hotbed sashes.

If your ground is very rich, so that ordinarily tomatoes make too much vine, you hould grow a variety that is naturally a little weak on vine growth. The Field's Early Jine, is especially good for such places, as it naturally makes a rather weak vine, and no matter how rich the soil may be, it never makes too much. Earliana is of the same nature. Dwarf champion makes a short, stiff stub. by bush and will stand rich snil all right.

Our new early tomato makes more vine than Early June, but still will work all right on rich soil. It has never failed to bear anywhere yet. 


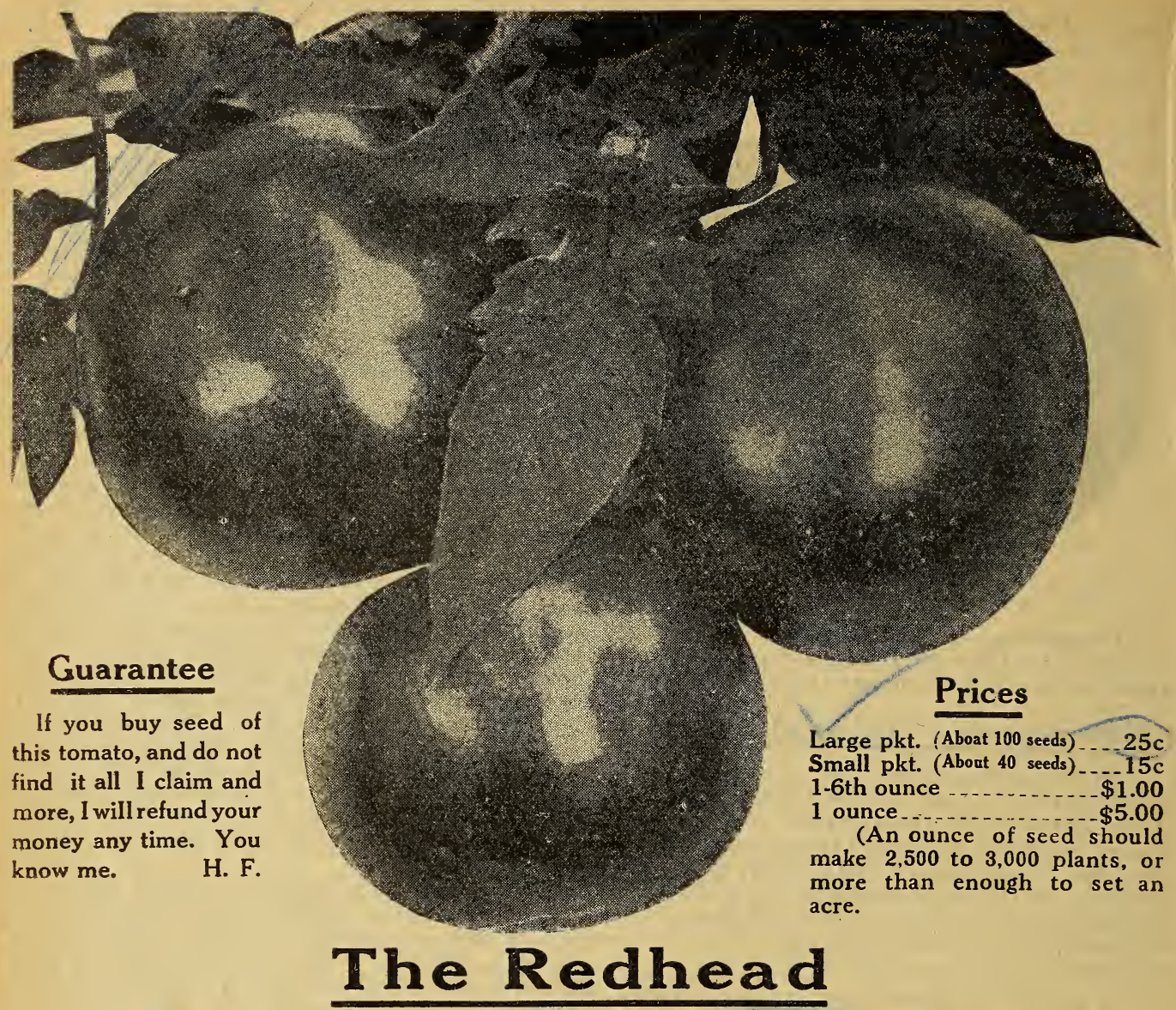

\section{A New Tomato that is Different and Better}

For eight years I have been hunting for an early tomato better than Field's Early June, which I first introduced in 1909, and I now have it in the new "Redhead."

The Early June has made good everywhere and has proven all that was ever claimed for it, hut there was never anything so good but what ihere was eventually something better, and that has proven to be the case with the Early June. It is good, but the "Redhead" is better,

During this eight years, I suppose I tried out 1,000 different strains of early tomatoes in our trial grourds. Customers sent in hundreds of them and $\mathbf{I}$ tried out all the crack sorts offered by other seedhouses, but none proved better than Early June, except this one. And unless it was better than Early June there was no use offering it, I first heard of this tomato two years ago in an odd way. I bought some canned tomatoes from a customer of mine who runs a home canner in connection with his market garden. They were so solid, meaty, bigh-colored and fine-flavored, that I immediately wrote to know what kind they were. Here is his reply:

"Friend Field: I certainly appreciate your kind letter, and note that you are stuck on our tomatoes. Now, Field, I am going to tell you a tomato story. The tomatoes you got are only the second grade. We had about an acre of these tomatoes, a private early variety of my own, and we sold over $\$ 600$ of early tomatoes

from it and then canned 2,000 cans of first grade, besides a few second grade, all from that one acre. Now. this sounds rather fishy, but I have the proof to back it up. The flavor of this tomato far excels anything $I$ have found in my 20 years of market gardening, and $I$ never saw anything in the tombto line that would compare with it in earliness, yield, smoothness and color."

Of course I was interested and he sent me some plants for the trial grounds, and sent Frank some for his market garden. They proved"to be away ahead of everything else we had, but we tried them out another year yet to make sure, and they did it right over again.

So we paid the originator $\$ 500$ to save us a sack of extra select seed from his first pickings, and we have it in the house now ready to divide with you.

Description. This tomato is a deep blood red, not yellowish nor purplish, but just red red. It is almost a globe, a little flattened; never rough or wrinkled. The photographs show this exactly. Does not crack easily; and seems practically re sistant to blight. Foliage and vine medium, neither light nor heavy. Cuts very solid, almost like Ponderosa. Very early, at least as early as anything on the market, and much bigger and better than any first early. Ripens clear to the stem, solid color. Makes a very heavy first set of fruits and keeps coming, holding size and yield well into the late crop. See prices above. 


\section{Turnips}

Early turnips should be sown, or bet. ter yet, drilled, very early, You can't get them in too early. They will come on quickly and be resdy to eat a couple of weeks befure the early potatoes are. They should be thinned out, however, to at least six inches apart in the row. Most people let turnips stand too thick. That makes them small and tough and bitter. Every early turnip should have a space of ground at least twelve by six inches, and late turnips a square foot of ground to each plant, Late turni $s$ can be sown in July and August and will keep grow. ing until the ground freezes. Use from one to three pounds of seed peracre.

For early u'e the best variety of tur. nips is the Early Milan. It is tender, sweet and very early. Looks like the old Purpl. Top Strap Leaf, but smaller and earlier. There is also a pure white strain of the same turnip called Early White Milan. No diffe ence except color. Snowball is fine for either early or late,

For main crop. and especially for fall sowing, the main standoy is the old-fashioned Purple Top Strap Leaf. Large, sweet and fine grain. The Purple Top Globe is practically the same turnip, but slightly deeper in shape and a little hedvier. On account of its shape it yields better than the old flat type. While Globe is much like Purp.e Top Globe, except that it is whise and somewhat later. There is also a yellow-fleshed turnip called Amber Globe, but I do not like it so weil as the ord.nary vari ties.

1 he Rutabaga, or German Sweet Turnip, is a different growirg turnip entirely. It has smooth leaves like a cabbage, grows slower than an orci nary turnip and much larger. The best variety has a purple top with a yellow flesh. This is the variety we use. They are not much of a success here in Iowa or south of here, but in the northern states they are quite valuable.

There is a long, slender turnip, called Cowhorn Turnip, which is much used for stock fecd. ing and for a fertilizer crop to plow under. It is

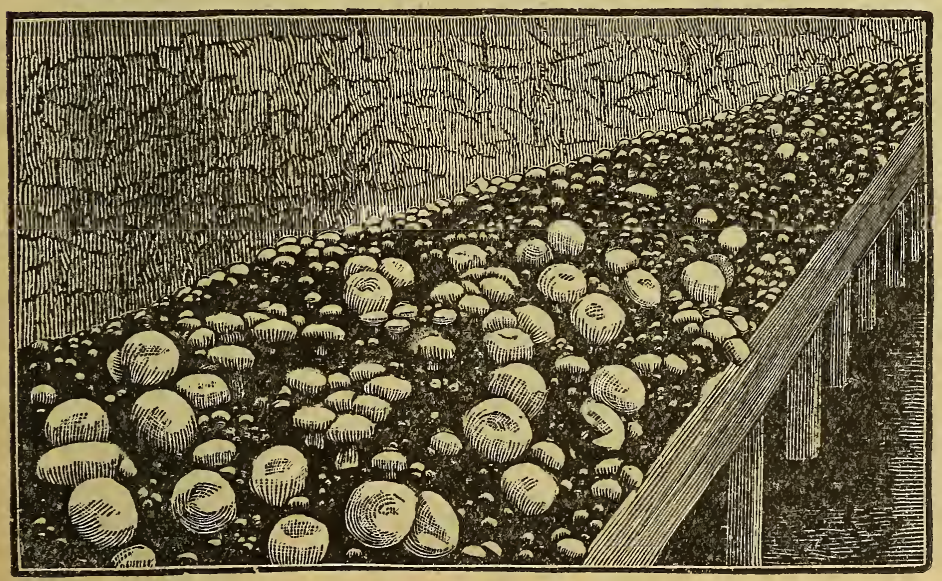

Mushrooms Grown in Cellar. They're Easily Grown. too big and coarse for table use, but is valuable in other ways.

\begin{tabular}{|c|c|}
\hline 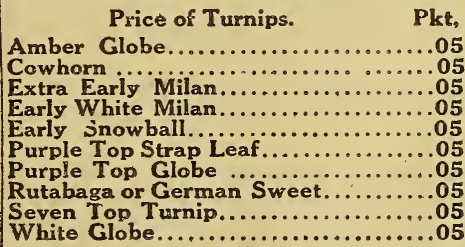 & $\begin{array}{r}\text { Oz. } \\
10 \\
10 \\
10 \\
10 \\
10 \\
10 \\
10 \\
10 \\
10 \\
10\end{array}$ \\
\hline
\end{tabular}

\section{Mushrooms}

Mushrooms can le grown with fair to good success by those who will take the pains to do the work right and have patience to overcome a pos. sible failure or two at fist. I do not advise the growing of mushrooms commercially with the ex. pectation of making a lot of money off of them un til you have had some experience,

Lambert's Pure Culture Spawn (produced under the new selective method which makes possible the segregation of varieties) is received absolutely fresh at frequent intervals from the m nufacturer. This spawn will produce mush. rooms of a specific variety, selected with special reference to size, color and pro.ificness. It abso. lutely eliminates all danger raising poisonous $\mathrm{mu} \mathrm{s} \mathrm{h}$. rooms. We keep on hand the cream-white variety. which is ) arcy and prolific; but can supply the brown or pure-whice varieties, if de sired. Each brick weighs from $1 \frac{1}{4}$ to $1 \frac{1}{2} \mathrm{lbs}$. and will spawn 10 square feet of beds. Sold by the brick Stand. ard brick, 35c, 5 bricks, $\$ 1.60$ postpaid; by express or freight, 10 bricks, $\$ 200$ 25 bricks, $\$ 4.50 ; 100$ bricks; $\$ 15.00$.

Illustrated book (Publi cation No. 3) on "Mushroom Culture and Pure Culture Spawn," 15c per copy, post paid, or free with each order of 25 bricks or more. 


\section{Odds and Ends}

Here are a lot of things having no special place in the catalog; so I have piled them all in together here. if you don't see what you want, ask for it. I probably will have it. If not, I can get it for ynu.

Gourds. I can supply any of the following varieties: Dipper, Nest Egg. Sugar Trough, and fancy mixed. Pkt. 5c, oz. 20c.

Collards. Grown in the south for greens. Like cabbage, only it does not head. I have the true Georgia seed. Pkt. 5 c.

Endive. Or German lettuce. Somewhat like lettuce, but more bitter. Can be bleached like celerv. Pkt. 5c.

Garden Lemon, or Vine Peach. Valuable for preserves. Pkt. 5c.

Ground Cherry. The old-fashioned yellow variety common in old gardens. Grows easily from seed. Pkt. 5c, oz. 30c.

Kale, or Green Kale. Grown from greens. Looks like loose, green, curly-cabbage leaves. Either tall or dwarf. Pkt. 5c, oz. 15c.

Kohlrabi, or Turnip-Rooted Cabbage. Pkt. 5c, oz. 20 c.

Mustard. Chinese curled, white. Black Giant Southern and the new Ostrich Plume. Any variety, Pkt. 5c, oz. 10c.

Parsley. Moss curled, for seasoning. Pkt. 5c.

Rhubarb, or Pieplant. The staiks are red. large and very tender. It is much like the Victoria, but larger and slightly redder. Pkt. $5 \mathrm{c}$, oz. $15 \mathrm{c}, 1 / 4 \mathrm{lb}$. $50 \mathrm{c}$, plants $\$ 1.00$ perdozen, all postpaid.

Sage, Mammoth: The best sort, Pkt. 5c

Spinach, Bloomsdale Savoy. Best variety, pkt. 5c

Sunflower, Mammoth Russian. Grown for chicken feed. 1/2-pt. 10c, pt. 20c. Ask for special prices on large lots.

California Casaba. A large, late, high-flavored muskmelon. grown almost universally in California. Pkt. 10c.

\section{Herbs}

Pkt. Oz.

Anise... . . . . . . . 05c 10c

Balm . . . . . . . 10 25

Basil . . . . . . . . 05 15

Borage . . . . . . . . 0515

Caraway . . . . . . 0510

Castor Oil Plant. . . . . . . . . .05 10

Coriander............ 0510

Dill ................ 0510

Hoarhound $\ldots \ldots 1020$

Lavender . . . . . . . . 0525

Majoram Sweet . . . . . 0515

Summer Savoy . . . . . . 05

Sage ........... 0525

Wormwood . . . . . 0520

Sweet Fennel . . . . . . . . . . 0510

Rosemary . . . . . . . . 0530

\section{Tobacco}

We don't grow tobacco commercially here in Iowa, and I really don't know about it myself, but lots of my customers have written in, asking that we get them some first-class, pure, improved varieties of tobacco seed. I wrote to friends and custom. ers in the tobacco growing districts, and among others I found a man in Tennessee growing remarkably fine White Burley Tobacco. He has made a specialty of this variety, selecting the best plants for seed every year, and I contracted with him to grow me enough of this select seed so that I could offer it to my customers. I have every reason to believe that he has a remarkably pure, fine strain of this tobacco, and I feel confident that if you want the best there is in tobacco, this seed would be the stuff for you to use. This is the variety sold as Sweet Burley tobacco. Pkt. 10c, oz. 40 c, 1/4-lb. $\$ 1.35$, lb. $\$ 5.00$.

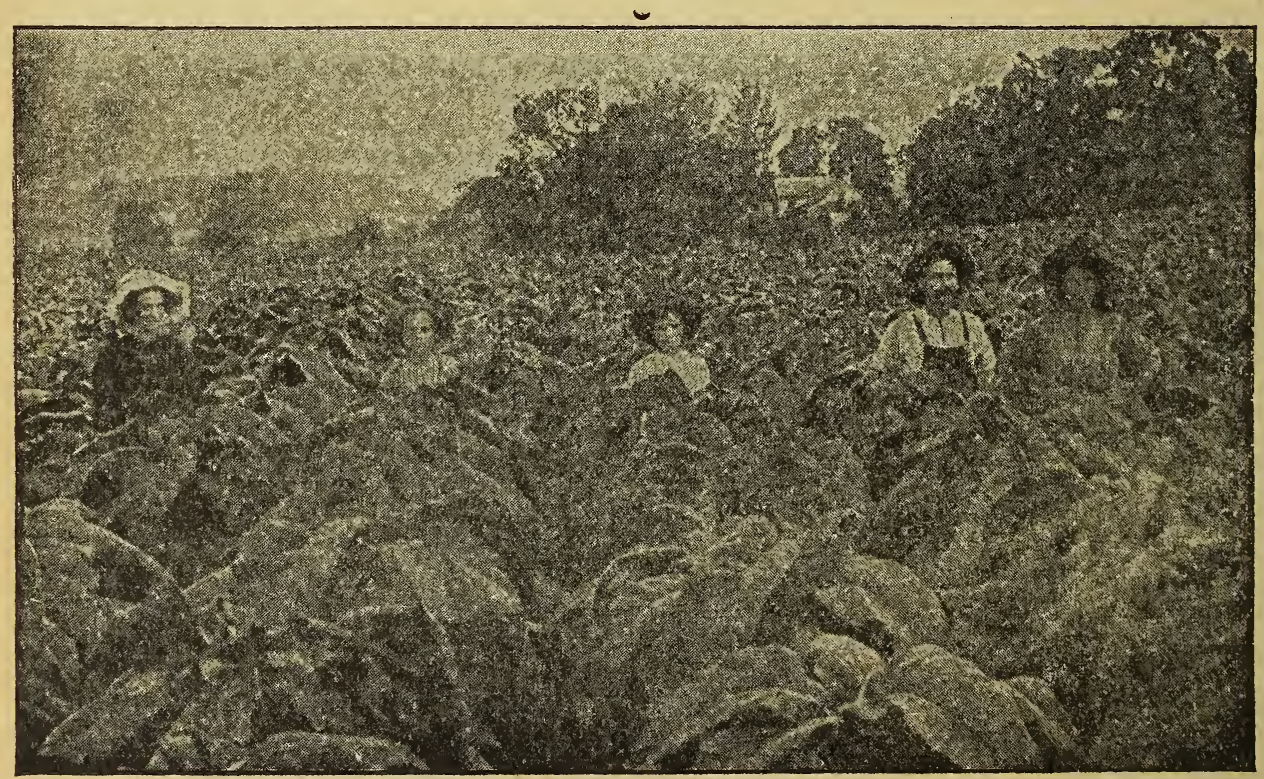

J. R Snapp, of Tennessee, who grows my Sweet Burley tobacco for me. This picture shows his home, his family and a beautiful crop of tobacco. The plants growing for seed are in a special small field back of the house. 


\section{Flower Seeds}

In making up my list of flowers I have had the farm flower garden in mind and have chosen ones that will grow and bloom with the le st care, the ones that will not complain if a few weeds are left in, and can stand a little dry weather in a pinch. I maintain the same high quality and liberal measure in flower secds that I do in other departments. They must be in keeping with the big fat packets of vegetable seeds and the seed corn in the ear. I handle only the very best strains, and I know they will please you. I get the secds in bulk from the best growers - American, German and Frenchand put them up in good, liberal, farmer-size packets, not the two-for-a cent size you sometimes get.

( ulture.-Most flower seeds should be planted shallow, say three times the diameter of the seed, and kept covered with an old cloth or carpet till sprouted to prevent drying out. Plant in rows for easy tending and keep the weeds pulled out, but be sure first that they are weeds, With slow-grow. ing seeds it is a good plan todrop in a few cabbage or radish seeds, as they will come up quickly and mark the rows for you.

Unless otherwise specified, the flowers are in mixed colors, as most people prefer them that way. On some I offer separate colors, but in such cases the colors are given.

Flowers For the Children. Nothing pleases a child so much as a flower garden of their very. own. Buy a few flower seeds for the children and give them a chance to have a little garden.

Unless specially mentioned these are flowers which blonm frum seed the first year and should be sown in the spring, All are easily grown and will succeed for any one.

\section{Flower Seeds, Condensed List}

I wish I had room to describe all the flowers in full, but I am running short on space, so will have to give simply a condensed list of them,

Old-Fashioned Flowers. I have included in the list all the old-fashioned flowers of our grand mothers' day. Look over the list and see the old friends you will find there.

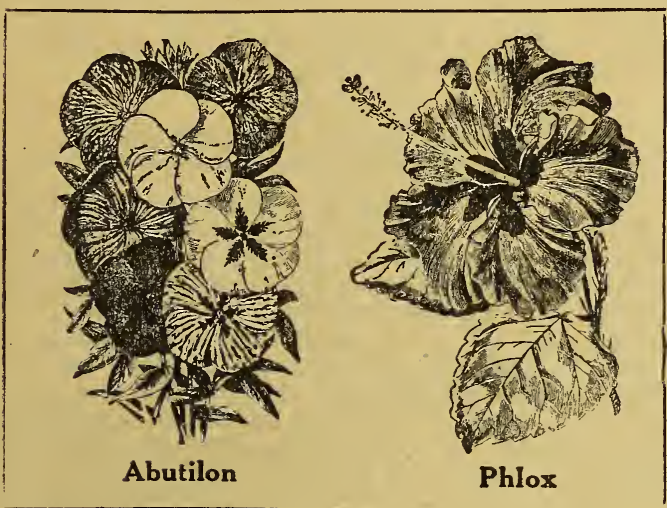

Abutilon. Finest hybrids, mixed

Ageratum Mexicanum. Blue

Albiflorum. White

Alyssum Benthami (Sweet Alyssum)

Alyssum (Sweet Yellow)

Asters. (See page 61)

Bachelor's Button (Centaurea Coanua)

Balsam Apple (Momordica Elaterium)

Baloon Vine (Cardiospermum)

Balsam or Touch-Me-Not See page 62.

Butterfly Flower (Schizanthus) . . . . . 05
Callinpsis Atkinsoni. Yellow and brown . . 05

Drummondi. Deep yellow . . . . . . . 05

California Poppy. . . . . . . . . . . 05

Canary Bird Vine. Fine climber . . . . 05

Candytuft. White............ 05

Mixed colors . . . . . . . . . . . 05

Canna. Mixed . . . . . . . . . 05

Canterbury Bells. Mixed.. . . . . . . 05

Carnation. See page 62.

Castor Bean. Mixed

Pkt.

Closia (C. pyramidalis plumosa). Mixed... 05

Chrysauthemum, Annual. Double white .1. 05
Coboea Scandens. Fine climber . . . . . 10

Coxcomb. (Celosia cristatu). Dwarf mixed . 05

Coleus. Foliage plant. Fine mixture . . . . 10

Columbine (Aquilegia). Double mixed . . . . 05

Coreopsis. Perennial; yellow . . . . . 10

Cornflawer. Blue . . . . . . . . 05

Cosmos. Mixed . 05

Cypress Vine. Red and white. mixed . . . . 05

Dahlia. Fine Single Mixed . . . . . . . 05

Finest Double Mixed

Daisy, Double. Mixed . . . . . . . . 05

Devi -in-the-Bush (Nigella) . . . . . . 05

Digitalıs (Foxgluve) Mixed . . . . . . . . 05

Everlastings (Helichrysum) Mixed ..... 05

Feverfew, Double white ....... 05

Forget-Me-Not. Blue . . . . . . . . 05

Four-O'Clocks or Marvel of Pery . . . . . . 05

Gaillardia grandiflora (Blanket Flower) . . . 10

Geranium. Finest double and single sorts mixed . . . . . . . . . . . . . . 10

Ghost Flower (Datura Meteloides). White, sweet scented ........... 10

Gladiolas. Mixed .. . . . . . . . . 10

Golden Feather (Pyrethrum) . . . . . . . 05

Gypsophila elagans (Angels' Breath) . . . . 05

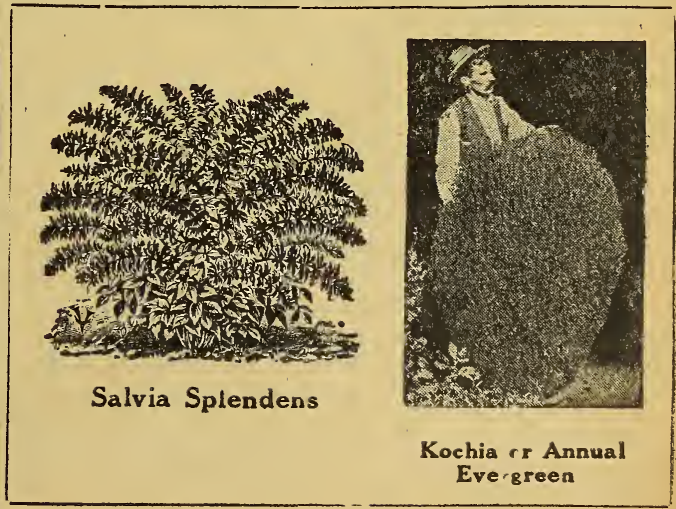




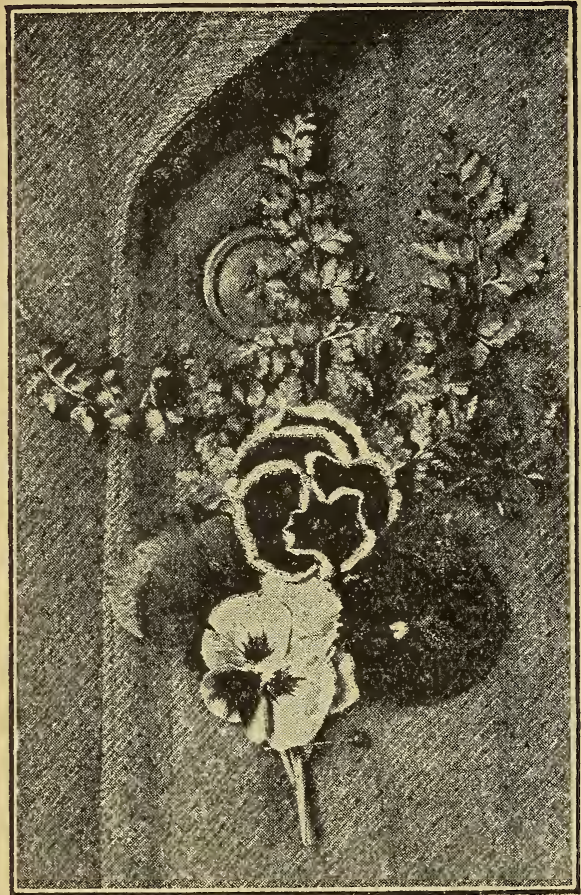

Panoies. (See page 64)

\section{Flowers, Condensed List}

Heartsease. Tufted, or bedding pansies Heliotrope.

Hollyhock. See page 62.

Hyacinth Bean (Dol chos Lablab) Mixed

Ilceland Poppy (Papaver nudicaule)

Ice Plant (Mesembryanthemum)

Japanese Mop. Beautiful climber

Joser h's Coat (Amerantus t, icolor)

Koc io tricophylla (Summer Cypress).

Lautana Hybrida.

Larkspur. See page 62.

Lobeha. Deep blue

Pure white

Love-L es-Bleeding (Amaranthus caudatus)

Love-hn-a-mist (Nigella Hispanica)

Marguerite Daisy

Marfgold. Dwarf Mixed

Tall Mixed

Mignonette. Sweet

Morning Glory. See page 62.

Moonflower. See page 62.

Mourning Bird (Scabios $\alpha$ ). Mixed

Nasturtinm. See page 63.

Nicotina affinis. New Hybrida

Pan:y. See page 64 .

Petunia. See page 63.

Pinks. See page 63.

Phlox Drummondi grandiflofa. Mixed

Pure white

Dazzling scarlet

Pale yellow

Portulacca (Rose Moss). Single Mixed Double Mixed
Primrase (Primula Japonica) . . . . . . 10

Salpiglosela Mixed ......... 05

S Ivia Splendens ........... 10

Sensitive Plant (Mimosa Pudica) . . . . . . 10

Smilax. Greenhouse climber. . . . . 10

Sunflower. Dwarf double ........ 05

Sweet Peas. See page 65.

Sweet Sultan (Centaurrea alba) . . . . . 10

Sweet William. Single Mixed . . 05

Double Mixed . . . . . . 10

Ten Weeks Stocks. Dwarf German. Mixed . 05

Tropaeolum. See Nasturtium.

Verbena. See pige 63.

Vinca. Mixed colors..........05

Violet. Sweet English .

Wallflower. Double Dwarf Branching. Mixed. 05 Wi d Cucumber. Native Climber . . . . 05

Zin ia. Finest mixture; large double ... 05

Miniature, Mixed ......... 05

\section{Native Plants}

If you are interested in native wild flowers write to Hope Field, Shenandoah. Iowa, as she ean supply seed, plants, or bulbs, of most of wild flow. eis that are native here. Snme of the ones to be had are Jack-in-the-pulpit, Dutchman's Breeches, Columbire, Solomon's Seal, Blue Phlox, Yellow Violets, Bloodroot, and many others. Prices of most varieties, $15 \mathrm{c}$ each; or $\$ 1.25$ per dozen. Special prices on quantities.

\section{Flower Seed Collections}

A great many people would rather buy theis flower seed in collections. It saves them money and also the trouble of making the selection: I have made up three that I believe will fill the bill Two of them are made up of annual varieties, both single and double, dwarf and climbing. They are suitable for bedding and for cut flowers; for bor ders or for backgrounds; for sunshiny places or shady places. In fact, I have made the collections large enough so that you would have something suitable for most any purpose.

One of the collections is made up of peren. nials and biennials. There is always a big demand for this class of flowers, as they are so easily taken care of. When they are once planted, they are al ways planted.

These collections are already made up and can not be broken, With them will be sent instruc tions for the planting and care of $t$ hem. I will also enclose with each collection a packet of a beauti. ful annual not listed in the catalog.

25c Collection of Annuals | Perennis ls and Biennials Candytuft................. 5c Canterberry Bells..... 5c Coxcomb. $5 \mathrm{c}$ Columbine Four O'Clock ............ 5c Coreopsis, Perenniaì.- 5c Marigold Morning Glory Morning Glory
Poppy, F nest $\mathrm{M}$ xed..... $10 \mathrm{c}$ Touch Me-Not............ 5c Pinks................... $5 c$

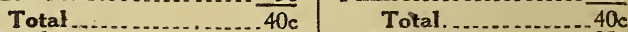
Special price .................. $50 \mathrm{c}$ Collection of Annuals

Asters..................... 5c| Petunia .............. $5 c$ Calliopsis ................... 5c Rose Moss Cypress Vine ............ $5 \mathrm{c}$ Salpiglossis............. $5 \mathrm{c}$ Everlastings..................... 5c Sceet Alyssum. Mignonette

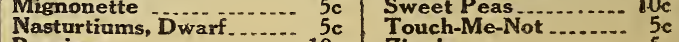
Pansies................... 10c 1 Zinnia.................. $5 c$ Tolal $80 \mathrm{c}$. Special price $50 \mathrm{c}$. 


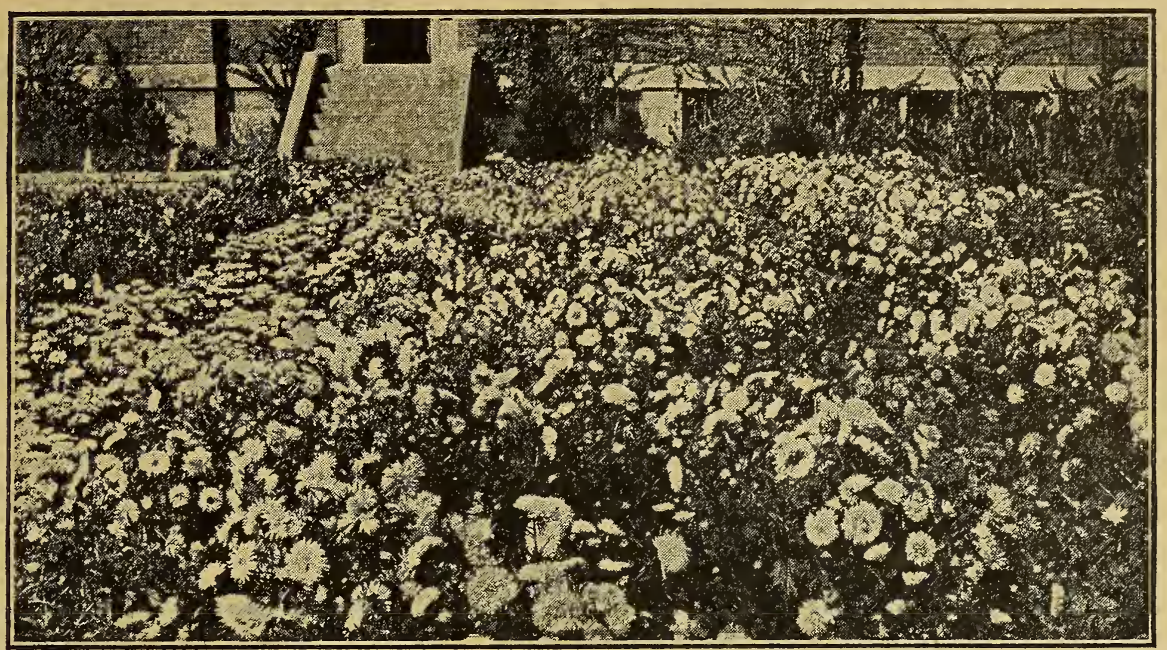

Asters In My Own Garden. These are in my flower garden between the house and the office You ran see the office steps in the back of the picture. They make a fine show during August. Sep tember, and Octobcr. Notice close what fine blooms tbey are. I sell you seed of the same kind.

\section{Asters}

Of flowers grown from seed, few are more satisfactory than asters. They are easily grown in any gond soil, in any location, and by any one. They will grow in open ground or in partial shade. They bloom at a time of the year when other flowers are scarce, and from July till frost they furnish a wealth of blonm The seed can be plan'ed either in the open groun" or in a hotbed or cold frame, or the plants may te started in a box in the house. There is a big list of sorts, but the ones I have selected are the ones I like best myself; and I am sure they will please you.

Florists' Mixture of Asters. This is made up from the cream of the list, all tall-growing, longstemmed soits, principally white, pink and red sorts with a sprinkling of other delicate shades. This is the mixture to grow for cut-flowers or extra fine ones for the 1 ome garden. Large pkt. $10 \mathrm{c}$, trade pkt. 25c, 1/4-oz. 50c, oz. \$1.75.

Florists' White Asters. Tall. Many flower. lovers prefer to have the white sorts by themselves, and for these I have made up a very fine mixture of tall, white asters, from all the best-known named sorts, such as Victoria, Hohenzoliern. Crego, Giant Comet, Giant Branching, Peony-flowered and Ostrich Feather. Large pkt. 10c, trade pkt. 25c, 1/4-oz. 50c, oz. \$1.75.

Flo-ists' Pink Asters. Tall. Similar in quality to the Florists' White Asters described above, but containing only pink, flesh and peach-blossom colors. Large pkt. 10c, trade pkt. 25c, oz. \$1.75.

Florists' Red Asters. Tall. This is the deep red section of the same extra-fine grade. Colors are various shades of deep red, ranging from cherry to depp crimson. Large pkt- 10c, trade pkt. 25 , t-oz- 50c, oz. \$1.75.

Florists' Blue Asters. Tall. Same extra-fine quality as the other Florists' Mixtures of Asters, but covering the blue shades, ranging from light blue or Javender to sky.blue and royal blue. Large pkt. 10c, trade pht. 25c, 1/4-oz. 50c, oz. $\$ 1.75$.

Floris' s' Mixture of Extra Early Asters. Dwarf. This mixture is made up from the best extra-early or June-flowering asters. They cover the whole range of color, but run strongest on whites, pinks, and reds. Large pkt. 10c, trade pkt. 25c, 1/4-0z. 50c, oz. $\$ 1.75$.

SPECIAL OFFER: One large packet each of the six mixtures, 50c. With these six separate mixtures of Florists' Asters you would be well fixed for commercial aster-growing. and for the home flower garden you would have the most wonderful lot of flowers that could be imagined.

Queen of the Market. A fine strain of early asters, specially valuable for commercial work Mixed all colors. Pkt. 10c, 3 pkt. 25c, $1 / 4-0 z$. 75c.

Peony-Flowered Perfection. Probatly the largest aster of any. Large, tall plants, and enormous peony-shaped flowers, 3 to 4 inches across. Mixed all colors. Pkt. 10c, 3 pkt. 25c, 1/4-oz. 75c.

Giant Comet or Poodle. Just lite a Japanese Chrysanthemum. Enormous flowers, 3 to 4 inches across, with long, twisted, curling petals. Very fine. Mixed all colors. Pkt. 10c, 3 pkts. 25c, $1 / 4$ c oz. $75 \mathrm{c}$.

Semple's Giant Branching. Late flowering very large and graceful. Born on a branching up right bush, Very free-flowering. Mixed all colors. Pkt. 10c, 3 for 2zc, $1 / 4$ oz. 75c.

Dwarf Bouquet. Charming little dwarf plants. covered with flowers, so that each plant looks like one big bouquet. All colors mixed. Plt. 5c.

Globe.Flowered Pyramidal. Bush grows in a pyramidal sha,, and is covered with flowers of per. fect globe share. All colors mixed. Pkt. 5c.

Choice Mixed. A gond mixture of asters con taining all colors, shapes and sizes. Pkt. $5 \mathrm{c}, \frac{1}{4}-0 \mathrm{z}, 25 \mathrm{c}$. Tall Mixed. A good mixture of all the tall sorts, Pkt. 5c. 1-0z. 25c.

Dwarf Mixed. All colors. Pkt. 5c, $\frac{1}{4}-0 z .25 c$.

White Mixed. All kinds, shapes and sizes of asters, all pure white. Pkt. 5c, $\frac{1}{4}-0 z .25 c$. 


\section{Balsam or Touch-Me-Not}

An old favorite, and always a success. The modern improved sorts are beauties, too.

Schmidt's Prize Double. The very finest to be had. All colors mixed. All the fullest double. Plt. 10c, 3 for 25c, 1/4-oz. 50c, oz. $\$ 1.50$.

Camelia-Flowered. Very double and large. Flowers all shades of color, and all covered with white dots. Pkt. 5c, 1/4-uz. 25c.

Dwarf, or Tom Thumb Balsam. Grow only about 8 or 10 inclies high. Very handsome; fuil louble. Pkt. 5c, $1 / 4 \cdot 0 z .25 c$.

Choice Mixed. All kinds and colors. Pkt. 5c, 4-oz. 15c, oz. 50c.

\section{Carnations}

The regular greenhouse carnations are rather hard for the amateur to grow, but are very fine if you can grow them. The Marguerite Carnations are not quite so large, but are much earlier and easier to grow. They will bloom the first year from secd, often in about four months from the time of sowing.

Dwarf Marguerite. A certain success. Sweet scented and fine in every way. Pure white, dark red, pure yellow, or all colors mixed. Pkt. 10c, 3 for $25 c$.

\section{Gourds}

These are in many ways the best vines on the list. They will grow remarkably fast, will grow in any location and are useful as well as ornamental. We can supply the folluwing varieties at $5 \mathrm{c}$ per packet each:

Fancy Mixed. All kinds from the little orange to the $5 \mathrm{ft}$. Hercules' Club. Over 40 kinds in all. time.

Nest Egg. Guaranteed to fool the old hen every

Dipper. The old-fashioned Missouri sort. pretty.

Orange. Small and highly colored. Very

\section{Hollyhocks}

A favorite with every one. Tall and stately and always handsome. Most beautiful when seen iil groups or long rows with a background of evergreens or shrubbery.

Finest Double Mixed. Pkt. 10c, 3 for 25c.

Finest Single Mixed. Pkt. 5c, $1 / 4-0 z .15 c$.

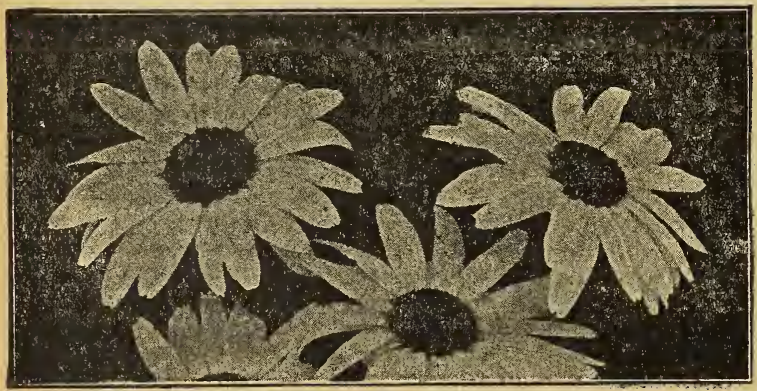

Shasta Daisy

\section{Morning Glory}

Imperis:- Japanese. The fines: of all Morning Glories. Far ahead of the old fashioned sort. This is imported seed and very fine. A wonderful range of colors. Pkt. 10c, 3 for 25c.

Choice Mixed. All colors. Pkt. 5c, oz. 25c.

\section{Larkspur}

Giant Emperor. Finest of all Larkspurs. Very free-flowering. Azure-blue, pure white, red, or all colors mixed. Pkt. 5c, all six for $\mathbf{2 5 c}$

Double Dwarf Rocket. Full double, a mass of flowers, and only a fout high. Mixed, all colors. Pkt. 5c.

Giant Double Hyacinth'Flowered. About 3 feet high and as double and solid as a double hya. cinth. Mixed. Plt. 10c.

\section{Cut Flowers}

We grow lots of flowers here, and often have large quantities of cut-flowers for sale. This is especially the case with peonies in May and June, iris in May. Phlox from July till frost. Dahlias fiom June till frost and Gladiolas in July and August. We $h+v e$ very fine varieties in all of these and can give you some fine stuff. Write and ask about what you want. We will make the price right.

\section{Other Plants}

Perennials are the best kind of flowers for planting in the cemetery, as they do not need much attention and are perfectly hardy. See page $5 !$ for full list. Also see page 126 for hardy shrubs and page 131 for hardy vines.

\section{Moonflower}

Giant White. This is the true, big white everblooming noonflower. A great climber. We have them climbing all over the seed house and they go 20 or $\mathbf{4 0}$ feet high in a remarkably short space of time. Pkt. $10 \mathrm{c}, 3$ pkts. 25c.

Mammoth Pink. Very much like the big white moonflower, but pink in color. A great climber. Pkt. 10c, 3 for 25 c.

Heavenly Blue. Flowers 4 to 5 inches across, in large clusters and produced in such abundance as to almost hide the foliage. Pkt. $10 \mathrm{c}, 3$ for $25 \mathrm{c}$.

\section{Special Offer}

One each of the three Moonflowers, white, pink, and blue, for $25 c$.

\section{Daisies}

These are among the most popular flowers and are easily grown from seed. The true daisies are white with yellow center. but the so-called English Daisy comes in colors.

Marguerite or Oxeye Daisy . . . 5c

Shasta Naisy . . . . . . . 10c

English Daisy, mixed colors . . . 5c 


\section{Nasturtiums}

These are about as satisfactory flowers as you can plant. They will grow and bloom anywhere, and in fact do better in thin, poor soil than in rich dirt. These come into bloom early and stay until frost kills them. Colors are all shades of red and yellow. The climbing sorts are fine to train up to a window.

\section{Dwarf or Tom Thumb}

A mixture made up of the choicest sorts in all colors. All make a rounded, compact bush, literally covered with bright flowers. Large pkt. 5c, oz. $15 \mathrm{c}$.

The following named sorts of Tom Thumb Nasturtiums are the best to be had. Prices same as on mixed.

Beauty. Yellow, flamed with scarlet.

King of Tom Thumbs. Scarlet flowers, dark foliage.

King Theodore. Bluish green foliage, flowers almost black.

Ruby King. Dark foliage, deep red flowers.

Spotted King. Dark foliage, spotted flowers

\section{Climbing Nasturtium}

\section{(Lobbianum)}

The very finest strain of all tall or climbing Nasturtiums. An improved strain, noted for its brilliant flowers and rapid growth. Will climb six feet or more, with flowers all the way. Fine mix. ture from named sorts. Pkt. 5c, oz. 20c. price:

The following named varieties at the same

Black Prince. Darkest of all.

Cardinal. Glowing scarlet.

Crown Prince of Prussia. Blood red.

Napoleon III. Golden yellow, spotted brown

Spitfire. Bright firery red.

\section{Tall Nasturtiums}

This is the ordinary tall or climbing Nastur. tium. It is a good stıain, but not nearly equal to the Lobbianum strain. Mixed, all colors. Pkt. 5 c, oz. 10c.

\section{Verbena}

Verbenas will stand more hot, dry weather during the summer and more cold weather in the fall than almost any annual we have. I always plant them in the tulip beds after the tulips are done blooming and they keep them gay all fall.

Mammoth Mixed. The finest, largest, brightest Verbenas it is possible to procure. All colors mixed. Pkt. 10c, 3 for 25c, 考.0z. 50c.

Red, White, Blue, and Striped. Separate col. ors, mammoth strain, the very finest, largest, brightest strains possible to get. Pkt. 10c.

Patriotic Verbena Collection. The red, white and blue, a striking cumbination of colors. Pkt. 20c.

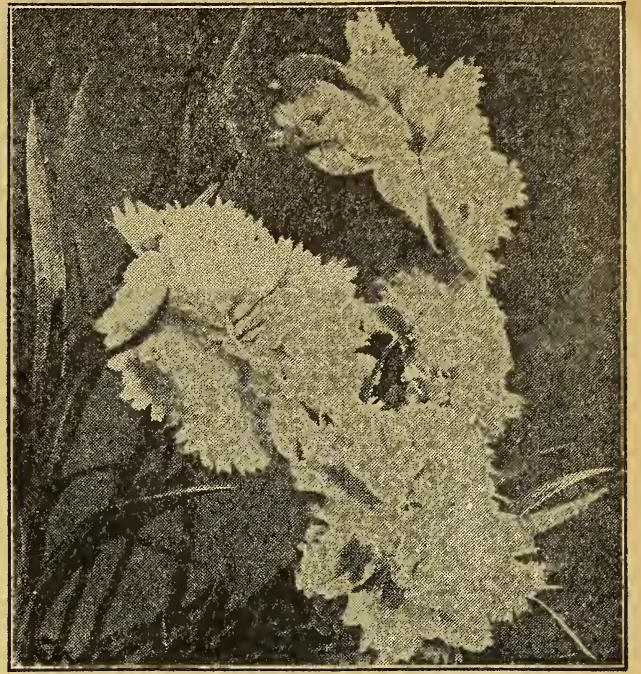

\section{Pinks}

One of the old favorites. Easily grown and should be in every garden.

Double China. Double fragrant flowers. I kt. 5c

Fireball. A very large, hardy garden pink very double and deep firery scarlet in color. Pkt. 10c.

Snowball. A fit mate for the Fireball. Just exactly like it, but pure white in color. Pkt $10 \mathrm{c}$

Grass (Clove Pinks). Very sweet scented. Hardy and will live for years. Always found in old. fashioned gardens. Mixed colors. Double and single. Pkt. 10c.

\section{Petunias}

One of the easiest grown annuals. Can be sown where they are to grow or can be started in a cold frame or window.box and can be trans. plarted later. Seed of the double varieties should be very carefully sown, as they are weak at the best, and the very weakest plants from them are the ones that are most likely to cnme double. The seed of the double sorts will produce only 20 to $30 \%$ double ones, but the rest will be very fine giant single sorts.

Hybıida. The ordinary old-fashioned petunia. Mixed colors. Pkt. 5c.

Snowball. Pure white, compact growing. medium-sized single flowers; very tree blooming and handsome, Pkt. 10c.

Giants of California. Flowers of enormous size, with beautifully ruffled and fringed edges and covering every known shade of color in petunias Pkt. 20c.

Double Mixed. The biggenuine double petunia A'l colors and shades. Of course they will 1ıot al come double, but at least 25 per cent or passibly more will be double ones. Pkt. 25c.

Giant Double Fringed. Saved only from the very finest fringed petunias of mammoth size. Wil bring generally $30 \%$ double flowers in every con ceivable shade. Pkt. 30c.

SPECIAL OFFER: One pkt. each of the different kinds offered for $65 \mathrm{c}$. These would cost $90 \mathrm{c}$ if bought separately. 


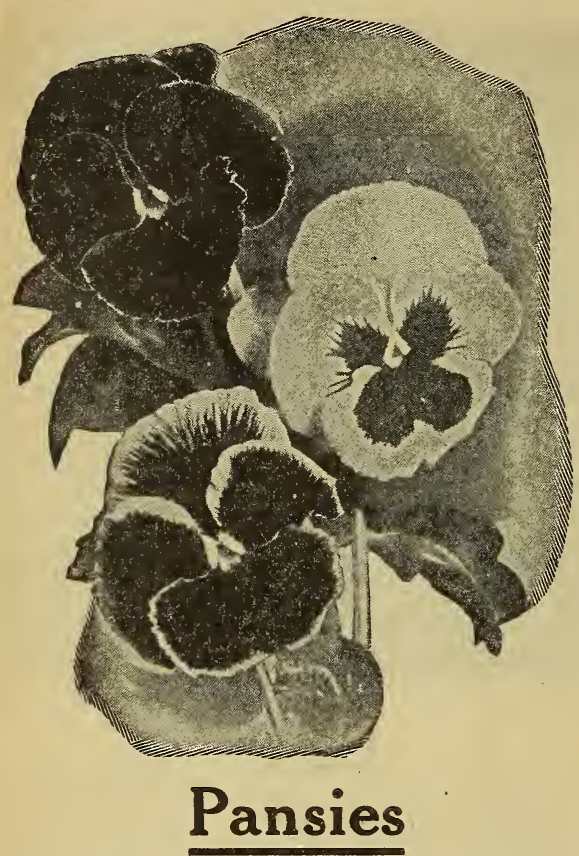

Every one is fond of pansies, and every one. tich or poor should have a bid of them. They are easily grown and a constant delight. Plint early in the spring, either outdoors or in the hotbed. Will do well almost anywhere. I have the very best German, French, and English seed, and for size and brilliant coloring $y_{c} u$ cannot beat it anywhere, Packets contain about 100 seeds each.

International Mixture of Show Pansies. This is a special mixture of the very finest and largest pansies from all the noted Euro. pean growers. If there are any better pansies to be had anywhere I wouldn't know where to look for them. All the big fellows are included, and under high culture blooms 3 inches or more in diameter may be ex. pected. It covers the entire range of color, from pure white to deep red and coal-black, with all the shadings ard combinations of colt rs in between. Pkt 20c, 2 for 35 c, $\frac{1}{8}-0 z$. $\$ 1.00$, nz. $\$ 6.00$.

Imperial German. This strain is from Schmidt, the great German florist, and is the cream of the German pansies. Very large and of beautiful color and form. All colors mixed. Packet $10 \mathrm{c}, 2$ for $25 \mathrm{c}, \frac{1}{8} \cdot 0 \mathrm{z}$. $75 \mathrm{c}$.

Choiee English Mixed. Not so large as the mixtures described above, but free-grow. ing and of very fine coloring. The kind generally used for bedding. Pkt. 5c, 6 for 25c, 吾-oz. 50c, oz. $\$ 2.50$.

Fairy Queen. A beautiful sky-blue pansy with white frilled margin. One of the dain. tiest and loveliest pansies I ever saw. Pkt. 10c.

Peacock Pansios. Dark red, and violet, and purple, blotched and marked like pea. cock feathers, and finished off with a mar. gin of pure white. The most beautiful pansy you ever saw. Pkt. $10 c, 3$ for $25 c$.
Named Giants. These named sorts are special colors which have been saved out and selected to come true to colur, size and shape. They are all of the Giant tvpe, the great big fellows with iong, s'iff stems; gorgeous colers and rufiled edges. Plkt. 10c, 3 for 20 c, all 8 for $50 c$.

Giant Azure Blue. Clear, brtiliant blue.

“ Emperor William. Deep ultramarine blue.

c Fire faces. Rich scarlet, with gold edge and yellow center.

ce Golden Yellow. Clear, deep yellow.

se King of the Blacks. Deepest velvety black.

ce L rd Beaconsfield. Velvety purple black,

Snow Queen. Pure white throughout.

Mauve Queen. Mauve, blotched with bluish car. mine.

SPECIAL PANSY COLLECTION. One pkt. each of the 13 pansies listed $\mathrm{r}$. $95 \mathrm{c}$.

25c PANSY COLLECTION. One packet each of the Imperial German Mixed, Choice English Mixed, Fairy Queen, Peacock, and King of the Blacks. All for 25c.

\section{Poppies}

These are my favorite flowers. They grow and bloom in any soil and in any kind of weatler.

Finest Mixed. These are the ones 1 had in my garden last summer. I saved seed fiom all the best ones of all kinds and made one grand mixture of it. I have all kinds and all colors, double and single. Many are the tall, stately kind. Pkt. 5c, oz. $40 \mathrm{c}$.

Double Peony-Flowered. Tall growing and look like a large peony. All colors and shades. Pkt. 5c.

Double Carnation-Flowered. Like a carnation but much larger. Pkt. 5c.

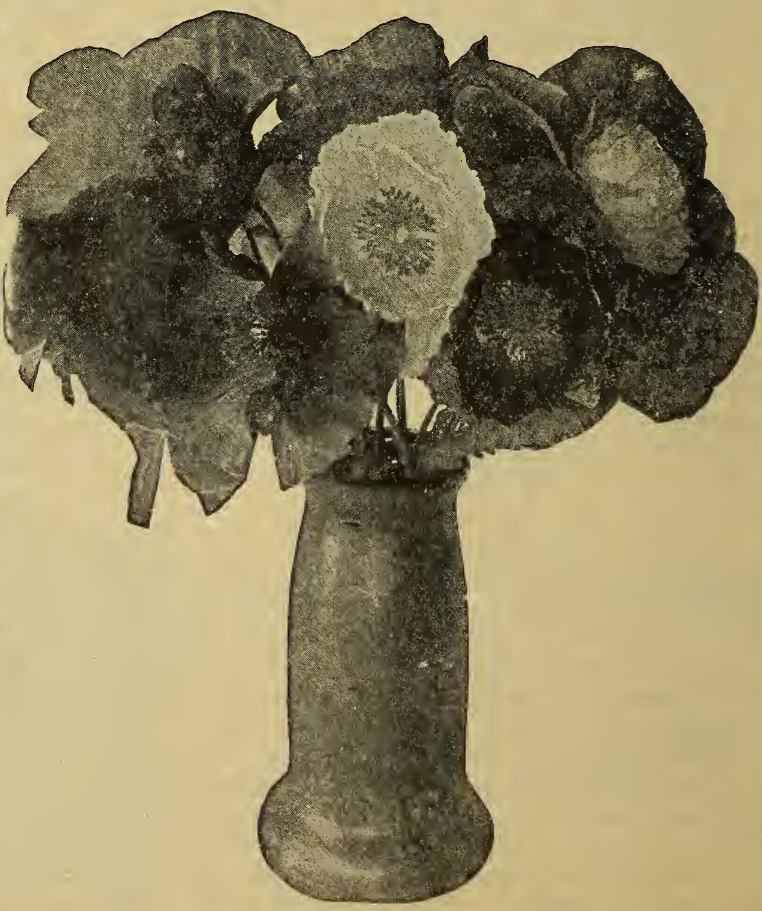

A vase of mixed p-ppies from my garden 


\section{Sweet Peas}

Sweet peas are probably the most popular flowers in America. They are loved bv every one, both for their beautiful coloril $g$ and for their delightful fragrance. I am a great lover of sweet peas myself and have paid a great deal of attention to them. I have the very finest strains of seed I can find, and you cannot get any better anywhere, no matter what price you pay. Plant very early in the spring, as early as you can work the soil. They wi 1 grow in any good garden ground where you could raise ordinary garden peas.

\section{Mixtures}

Finest Eckfords Mixed. This includes all the best Echfords of the Grandiflora type, and also a sprinkling of what are known as the California Giants. It has every imaginable color and shade. I have taken great pains with this mixture, and I am sure it will please you. Pkt. 5c, oz. 15c, 1/4-lb. $50 \mathrm{c}$.

Countess Spencer Hybrids Mixed. This is the wonderful new orchid-flowering 1 ace of sweet peas which has created such a sensation the last two or three years and originated a new class of sweet peas. The flowers are of a $v:$ ry large size, frilled and rufflid at the edges, and generally three or four blooms to a stem. They are different from any other t'pe of sweet peas, and I think are much finer. There is a wide range of rolor, mostly in soft, delicate shades. Pkt. 10c, oz. 25c, 迹-lb $75 \mathrm{c}$.

Perennial Sweet Peas. Triese grow sumewhat like an ordinary sweet pea, but live over from year to year Quite a curiosily. Pkt. 10c.

Cupid Dwarf Sweet Peas. Grow only about 8 inches bigh and need no stakes or trellis. Not so attractive, to my mind, as the big. tall-growing kinds, but quite a curiosity.

\section{Named Spencer Sweet Peas}

In this we have a new class of sweet peas which has attracted a great deal of attention for the last two or three years. Flowers of enormous size with both standard and wings waved, fluted and frilled, while the flowers are so loosely and gracefully set on the stems that they at once show their superiority to the older kinds. The vines are healthy and vigorous, growing taller than the ordi. nary varieties. The perfectly tormed blooms often measure two inches across. The original variety, called Countess Spencer, which originated in Eng. land, varied somewhat in color, but by selection and improvement of these variations a considerable list of beautiful varieties has been produced.

Asta Ohn. Lavender suffused or tinted with mouve. The best lavender in the list. Comes uniformly four blossoms to the stem and the stems are es pecially long.

Apple Blossom (Spencer). Standard primrose, showing veins of deep rose. Wings bright carmine overspiead on primiose. It is very large with especially large drooping wings.

Countess Spencer. Bright, clear pink, showing a little deeper at the edges. Very large, frequently measure two inches acro's. The stems are long and it is just ahout a perfect sweet pea.

Dainty Spencer. White edges with light pink, hooded form; very long stems.

Mixed Spencers. A mixture of these and other named varieties of Spencers. Pkt. 10c, oz. 40c.

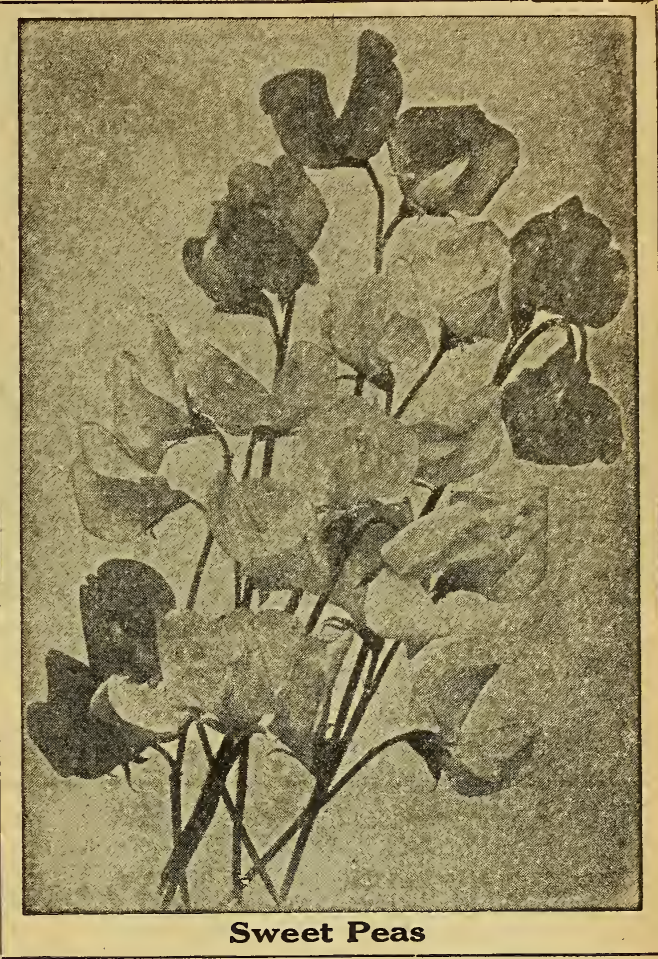

Helen Lewis. Rich crimson-orange with wings of orange-rose. Very large and with true Spencer form.

King Edwara (Spencer). Deep rich carminescarlet, of glossy effect.

Mrs. C. W. Breadmore. A lovely new "picotee" of true Spencer type. Distinctly pink edged upon a cream gi ound.

Mrs. Sankey. A pure white Spencer of finest type and good size.

Paradise Red Flake. Deep primrose, flaked or lightly striped rose red.

Prince of Austria. Chocolate and purple. B:ended and striped.

Prices; Any of the named Spencer varieties, pkt. 10c, oz. 40c.

SPECIAL OFFER: One small packet each of the above 10 specially selected named Spencers and 1 large packet Mixed Spencers, 11 in all, 40c.

\section{Named Sweet Peas, Frandiflora Type}

Dorothy Eckford. Best large; pure white; very fine.

Hon. Mrs. E. Kenyon. Best and largest yellow Jane Scott. Best large, deep pink.

Mrs. Dugdale. Bright rose-color.

King Edward VII. Best brilliant scarlet.

Miss Willmott. Deep orange color.

Othello. Best and largest maroon.

Navy Blue. The only gond bright blue,

Any of the above varieties, pkt. $5 c$, oz. 20 c.

SPECIAL OFFER: One packet each of the above named sorts. a pkt. of Cupids, and an oz. of the best mixed, 10 packages altogether, sent postpaid for $35 \mathrm{c}$. This collection will plant a double row 25 feet long. 


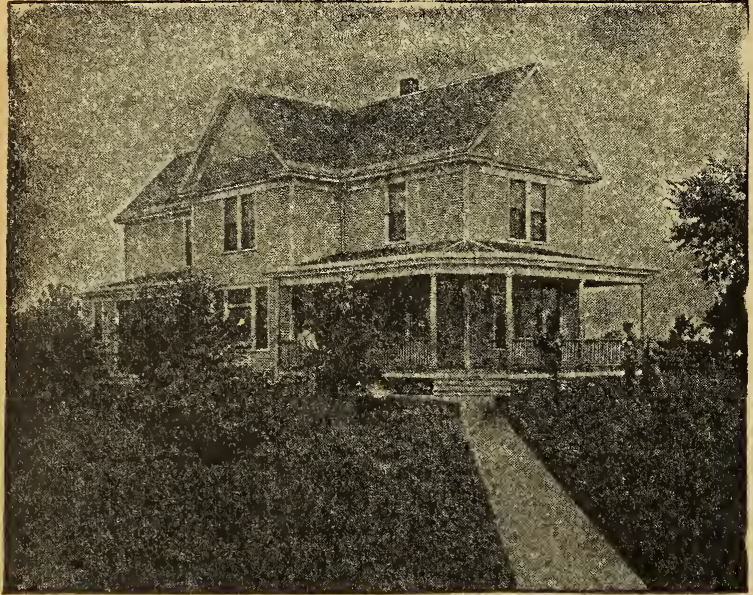

A beautiful front yard seeded with our Evergreen mixed lawn grass seed. Notice how even and smooth it is. You can just as well have your place look that way, too.

\section{Kentucky Blue Grass}

For those who want straight Kentucky Blue Grass we have a fine lot of good, pure seed, See blue list for price.

\section{White Clover}

Very often it is advisablete especially on poor clay soils. to make an extra heavy seeding of white clover. For this we can furnish a stock free from trash and weed seed. See blue list for price.

\section{Be-muda Grass}

For the south, esfecially for poor, rocky, sandy soiis this grass has been a splendid success. It is a low growing grass that spreads by rooting at the juints. It will stand any amount of Irimping, in tact you can hardly kill it out. It is the salvation for those trying to grow a gond lawn under hot, dry, unfavorable conditions. It winter kills in the north. See blue list for prices.

\section{Field's Evergreen Mixed Lawn Grass Seed}

Some people seem to think that it is a hard matter or impossible to get a nice ldwn started, but we have always fou'd it vely easy, if you use good seed and pay attention $10 \mathrm{~g}$ tting the ground prepared in good shape to stait with.

Preparation. In the first place you must, of course, have soil that is fairly rich. If it is real poor and thin, sandy, or scur, or heavy clay, you will have to add some good soil to it before you start. It must be worked up fine and melow, and free from sticks, trash, clods, and stones. You can't cultivale lawn grass after it is planted;so you nist do all your cultivation beforehand. When you get the ground nicely fixcd, sow the seed broadcast at the rate of one nound to three hundred square feet, and then rake it in so it will be covered nicely Of course, it must be kept moist until it gets well started. Grass is mighty tender stuff when it is young, and if it gets dried out down to the roots, it will kill out, but if you can keep it moist and growing untul it is two cr three weeks , ld, the chances are you will have no further trouble getting a nice lawn. Of course, the richer the soil, the better chance you will have and the quick $r$ you will get a good growih of grass. Rich soil, plenty of ministure, and plenty of good seed will give you a fine lawn in a short time.

The Seed. I have studied and experimented on the ldwu grass question a great deal and I have worked out a mixiure or combination of grasses that I consider just about right. It don't do to de. pend on any oue kind of grass alone. Kentucky Blue Grass is all right, $I$ ut it is slow to start and turns brown in $\mathrm{d}: \mathrm{y}$ weather. I use some of it in the mixture. In fact, it is the basis of all good lawn grass mixtures, but you can improve it mightily by using other grasses an 1 white clover along wi h it. If you want straight Blue Grass, I can furtish it, but I am positive you will have much better re sults from the mixture than you would with the straight Blue Grass. If you don't belieye it, try it out yourself.
Our Evergreen Mixture. I believe that our Evergreen mixture is the best mixed lawn grass you can buy anywhere. It is good, solid, clean seed, free frum weed seers and trash. It is guaranteed to show high germination and start quickly and evenly. It will thrive in any part of the country, and on any snil that is fairly rich and moist. It will stay green all summer and will make a smooth, velvety, close woven sod, which is what we all want.

Ready For Mowing in Four Weeks. If you will prepare the soil in good shape, and keep it moist until the giass gets started, you can have a lawn ready to mow in four wceks from the time you sow the seed and it wi'l keep coming and getting better all the time. Be sure and use plenty of seed, not less than one pound for each 300 square feet.

If you want to patch up an old lawn, which already has some grass on it, you could use less seed. but it is much better to use too much rather than not enough. Grass seed is ordinarily figured at $14 \mathrm{lbs}$. to the bushel, but I have used clean, solid seed and our mixture weighs 20 lbs. to the bushel and we sell it on that basis.

Price, by mail postpaid, 35c per lb. Price, by freight or express $\$ 1.35$ per peck. $\$ 5.00$ per bu. of 20 lbs.

\section{A Free Book For Market Gardeners}

If you have not already got it, you should write for my "B ok of a Thousand Gardens." It is free for the asking to those interested in gardening. Also you shouid read my series of articles "To the Young Market Gardener," beginning in the Decem. ber 1914 Seed Sense.

Seed Sense will be sent free this year to all those ordering seeds to the amount of $\$ 2.00$ or over. See that you get it. I am sure you will en. joy it. 


\section{Special Price on Hot Bed Sash}

Hntbed sash have ordinarily been rather high-priced. The local lumber tealers used to ask generally $\$ 3.00$ each for them, and often do yet. This was discouraging.

I wanted to make it as easy and cheap as possible for our customers to get hotbeds started, so I have made a deal with a big manufacturer of sash to make up for me several thousand sash, and at a price that will allow me to sell them right. Notice prices below.

\section{Send Your Order Soon}

You have to start hotbeds early, as they should be planted trom February 1st to April 1st, accord. ing to your location. Better get your sash ordered and on hand so you can be getting the frame built and ready for business. We can ship promptly at any time. Be sure and tell exactly which sash you want. The difference in price on different quantities is on account of the cost of crating, which is as much for one sash as for five. The prices below are absolutely net, and do not allow of any discount or freight prepayment. They are figured down close.

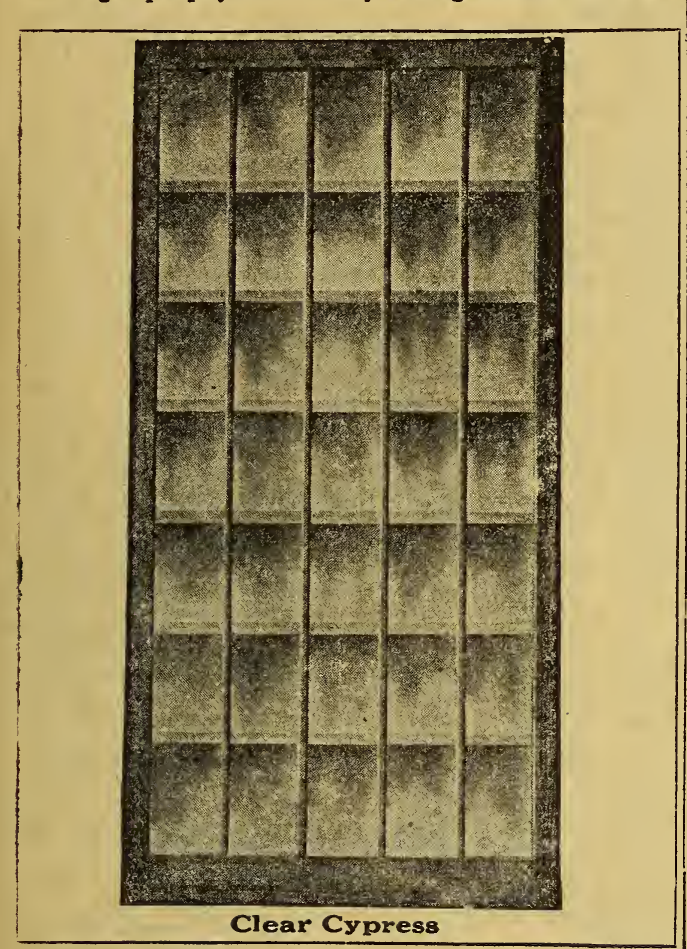

Hot Bed Sash, glazed complete, 5 rows 6 -inch glass. Sash made of best cypress.

Size $3 \mathrm{ft}$. by $6 \mathrm{ft}$. $1 \frac{3}{8}$ inches thick. Glazed comp!ete.

In lots of 25 to an order, price each..$\$ 2.05$

In lots of 5 to an order, price each $\ldots 2.10$

In lots of 3 or 4 to an order, price each .2 .15

In lots of 2 to an order, price each . . 2.25

In lots of 1 to an order, price each . . 2.50

Prices are for single strength glass. If double strength is wanted, add $20 \mathrm{c}$ per sash.

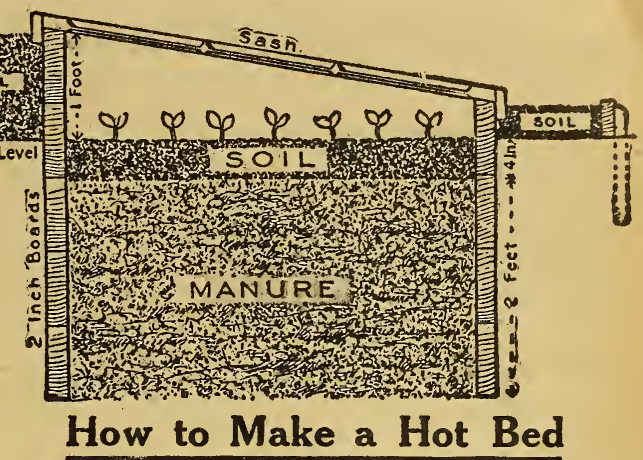

The hot bed is generally made $6 \times 6$ feet in di. mensions, with a pit 2 feet below the surface of the ground. The best size of hot bed sash to use is $3 \times 6$, glazed with 6 -inch or 10 -inch glass.

Select as a location land with good subsoil drainage, facing south, or southwest, and protected from the north and west winds by hillside, hedges buildings or trees.

Close the sash at night in order to retain the heat. This matter of ventilation is very important and must be attended to daily.

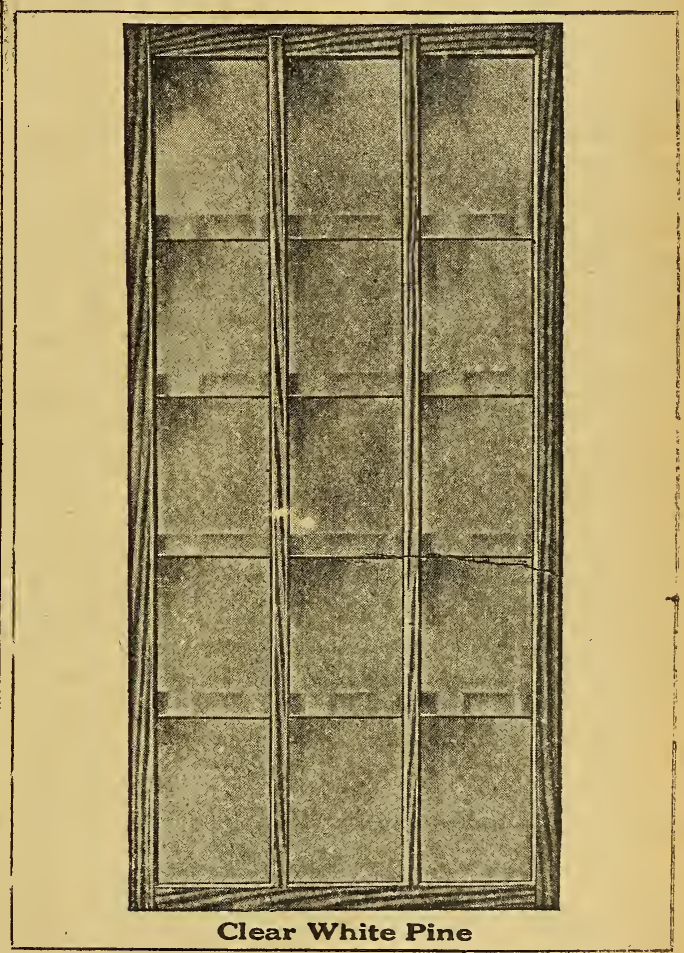

Hot Bed Sash, glazed complete, 3 rows 10 -inch glass. Sash made of clear White Pine.

Size $3 \mathrm{ft}$. by $6 \mathrm{ft}$. 18 inches thick, glazed complete.

In lots of 25 to an order, price each . $\$ 1.90$

In lots of 5 to an order, price each . 1.95

In lots of 3 or 4 to an order, each . . 2.00

In lots of 2 to an order, price each . . 2.15

In lots of 1 to an order, price each . . 2.25

Prices are for single strength glass. If double strength is wanted add $20 \mathrm{c}$ per sash. 


\section{Condensed Postpaid Price List of Garden Seeds For 1917}

This is a condensed list of all the garden secds that are described and priced in the 1917 catalog. I have written short descriptions here of each tem and put down the correct postpaid price.

Every thing is listed here, and the prices are the same as in the body the catalog. you can make up your order from this even better than rom the complete $c$-talog. as it is handier to get at.

Wholesale Prices For prices on large amounts of garden seeds to me bv freight or express ot your expense see blue hist.

1 Guarantee Safe Arrival of all money sent to me by check. iraft, or money order, or registered letter, and I guarantee safe arrival of

\section{Asparagus}

Bonvalett's Ciant. Very early, large, Pkt. Oz. 1/4-lb. lumbian Mammoth White. Has large white or

very light green stalks...................... $10 \quad 25$

Conover's Colossal. Standard sorts; large, green stalks.05 $10 \quad 2.5$ Palmetto. Very desirable; has bright green stalks. ....05 1025

\section{Beans}

Dwarf or Bush, Green Podded Snap.

Black Valentine. Very early: resembles Round Pod

$\begin{array}{lllll} & 05 & 10 & 35\end{array}$

Burpee's Stringless Green Pod. Very prolific and tender: round pods.............................. $10 \quad 35$

Early Six Weeks. Ân early, flat pod bean..........

Field's First Early. A very early, large, flat pod,

beavy yielder.

(See Page 9)

Giant Stringless Green Pö. Round pod; resembles

Burpee's, but later and larger ......................

Refugee, or 100 to 1 . Late, heavy yielding, round

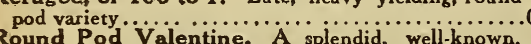

early variety

White-Seeded Stringless Green Pod. Same as Bur-

pee's Strungless Green Pod with whito seed. .........05

\section{Beans}

Dwarf or Bush, Wax or Yellow Podded.

Challenge Black Wax. Small round pod, prolific.

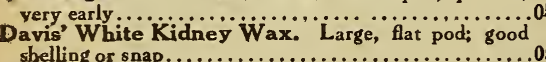

Golden Wax. Medium size, flat pod of good quality ..05

New Stringless Yellow Pod. Medium size, round,

tender pods $\ldots . . . \ldots \ldots \ldots \ldots \ldots \ldots \ldots \ldots \ldots \ldots \ldots$
Perfection Wax. Large, long, straight pod, prolific,

Perfection Wax, Large, long, straight pod, prolific,

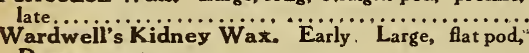

Does not rust. . .......

Pencil Pod Black Wax. Round pod tor home use..05

\section{Beans}

Bush Varieties for Shell Beans.

Burpee's Bush Lima. Good bean; but requires long

Dreer's Bush Lima. Quality and yield good. ‘ Bush

low and spreading ......................................

Dwarf Horticultural. Splendid shell bean...........
Fordhook Bush Lima. Best large-podded bush lima..05

Henderson's Bush Lima. Very prolific, small bean. 05

Prolific Tree. A good yielding field bean...........05

Red Kidney. Used extensively as shell bean ..........05

White Kidney. Similar to above, but has white seeds.05

White Wonder. An improvement on the old navy

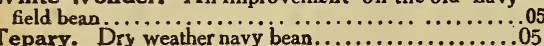

\section{Pole Beans}

Green Podded.

(See Page 11)

Cutshort or Cornhill. Short, straight pot, thrifty

vine, late ..............................

lific......................................... $10 \quad 35$

Horticuitural or Cranberry. Medium long pods, late.05 $10 \quad 35$

Improved Missouri Wonder. Early; heavy yielder,

splendid quality $\ldots \ldots \ldots \ldots \ldots \ldots \ldots \ldots \ldots \ldots \ldots .0 .515 \quad 40$

Kentucky Wonder. Long, Aleshy pod, early.......... 10 3.)

Lazy Wife. Too late to be of much value, except in

the sauth

White Creaseback. Small pod, prolific, late........... 10 . 39

White-Seeded Kentucky. Wonder. Medium large

\section{Pole Beans}

Wax Podded.

Golden Cluster Wax. Medium eariy, flat pods.

Galden Wonder. Broad, flat pods, good yielder,

medium early..............................10 25

Kentucky Wonder Wax. Pods long and broad.

Quality fine, early goods to you. If for any reason goods fail to arrive I will refill

These prices are Postpaid. Unless otherwise specified, these prices include prepayment of all postage, delivered anowhere in the U.S How to Sen Money. You can send the money any way you please, only it is not safe to send loose silver, and loose stamps are nuisance. Silver is almost sure to break out of the envelope unless extra. well Fvisapped.

Send Money Order, Draft or Check, if you can. Next hest is pape money in a registered litter. Failing there, send silver in a card wrappen and use as a last resort, stamps. Canadian stamps we can't use
(See Page 21)

Pole Limas

Extra Early Lima. Small; yields enormously; earli-

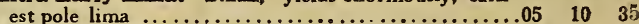

King Lima. Large, of high quality. rather late.........05 10 . 35

Seibert's Early Lima. Some earlier than King Lima;

$10 \quad 35$

\section{Beets}

(See Page 12)

For Table Use. $\quad$ Pkt. Oz. 1/4-lb.

Crimson Globe. Smooth, globe-sliaped, medium early.05 $10 \quad 25$

Crosby's Egyptian. Early, smooth, flattened, globe-

shaped, bright red ......................... $15 \quad 40$

Detroit Dark Red. Early, dark red, round, smooth..05 $10 \quad 25$

Eclipse (Srecial strain). Early, bright red, globe-

shaped, good size ............................ $15 \quad 40$

Extra Early Flat Egyptian. Very early, small tops..05 $10 \quad 25$

Long Blood. Late; flesh dark red..................05 $10 \quad 25$

New Fireball. Extra good, blood red, early variety..05 $15 \quad 40$

\section{Beets}

For Stock Use.

(See Page 12)

Pkt. $1 / 4-$ lb. lb.

Giant Feeding Sugar. Rich in protein and sugar; $05015 \quad 55$

Coolden Tankard Mangel. Medium size, easily har-

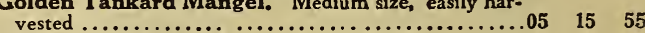

Klein Wanzleben. Sugar beet, white flesh........... $15 \quad 55$

Mammoth Long Red Mangel. Yield's enormously, $05 \quad 15 \quad 55$

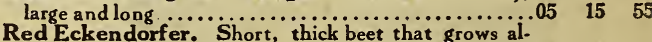

Red Eckendorfer. Short, thick beet that grows al-
most entirely above ground; very easily harvested...05 $15 \quad 55$

Yellow Eckendorfer. Same as above, except in color.05 $15 \quad 55$

Giant Sludstrup. Very high feeding value; yields well. Crop failure.

\section{Carrots}

(See Page 21)

Chantenay. Early and tender, medium size,

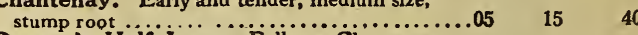

Danver's Half Long. Follows Chantenay,

yields well, good quality . . . . . . . . . . . . . .05

Long Orange. Late, flesh very tender, small core.05

Oxheart. Short, stump root, good quality, earlv.05

White Belgian. Long, pointed root; for stock. .05

White Vosges. Large, late stock carrot. Half

Yellow Belgian. Like White Belgian, except in

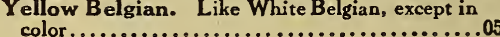

1540

1540

$10 \quad 30$

$10 \quad 30$

\section{Celery}

$10 \quad 30$

\section{American Grown}

(See Page 20) Pkt. Oz.

Giant Pascal. Large, late variety, good keeper ........ 5c 25c Golden Self-Bleaching. Creamy white, easy to bleach ..10 60 White Plume. Very tender and of delicate flavor........05 20

\section{Cabbage}

Early and Second Early.
All Head Early. Large, flat heads, full in center,

(See Page 16)

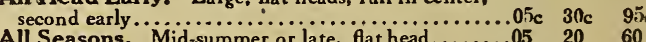

. 60

Charleston or Large Wakn

Copenhagen Market. Early, medium large, round

heads.............................10 $40 \quad 1.25$

Danish Summer Bailhead. Very hard, round head.05 $30 \quad 85$

Early Flat Dutch. Midseason, very flat ..., ....05 $25 \quad 75$

Early Jersey Wakefield. Extreme early, pointed

heads................................ $30 \quad 85$

Early Spring. Very early, round, flat heads........05 $20 \quad 60$

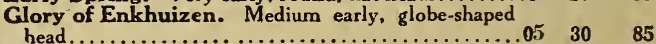

Early Winningstat. Medium early, pointed heads..05 $20 \quad 60$

Fotler's Brunswick. Low growing, second early, flat $\begin{array}{lll} & & \end{array}$

heads..................................

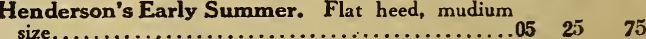

Norseman. Early round heads, very uniform. The

best early cabbage grown...................... is $60 \quad 2.00$ 


\section{Condensed Postpaid Price List of Garden Seeds (Continued)}

\section{Cabbage (Continued)}

Late or Main Crop. Autumn King. Very large, late, flat heads.........05c $20 \mathrm{c}$
Cornbelt. Large, solid, flat heads, good keeper.......
40 Giant Drumhead. Very late, of immense size; heads rather loose .............................. Hollander or Danish Balihead. Hard heading var. iety: does well north..$\ldots \ldots \ldots \ldots \ldots \ldots \ldots \ldots \ldots$ nf Large American Drumhead. Large, late flat head. 05 Mammoth Red Rock. Splendid for pickles and cold

slaw................................. 05

Premium Flat Dutch. A läre, solid, flat head, good

keeper.................................05

Savoy. Leaves very much crumpled and twisted. .05

Succession. Midseason or late; rounding tlat head..05

Surehead. Large, flat head, good ytelder and good

Volga. Large, round head, sweet, and tender...........

$25 \quad 75$

\section{Cauliflower}

\section{Danish Grown.}

(See Page 19)

Dry Weather (Copenhagen). Heads good

Dry Weather (Copenhagen). Heads good
size and compact...........................15c 25c 75 c 2.50
Earliest Dwarf Erfurt. Long growing, medium

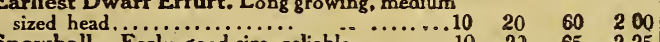

Snowball. Early, good size, reliable...........10 2J $\quad 65 \quad 2.25$

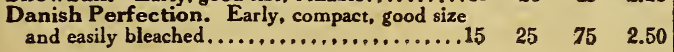

\section{Cucumbers}

Chicago Pickle. Medium short, pickling variety,...05c $15 \mathrm{c} 44^{\prime \prime} \mathrm{c}$

Cool and Crisp. Early strain of White Spine.....05 10 .0. 35

Early Cluster. Medium short. good early slicer......05 I5 40

Early Cyclone. Earliest of all, rather small.......05 $10 \quad 35$

Early Russian. Very early and short, good pickle...05 $15 \quad 40$

Emerald. Large, late slicing, always green.........05 $\quad 15 \quad 40$

$\begin{array}{llll}\text { Evergreen. Miedium size, good all purpose variety..05 } & 15 & 49 \\ \text { Everbearing. Rather short. Early Russian superior.05 } & 10 & 35\end{array}$

Fordhook Famous. Very large, late, slicing variety. 05

Goliath. A very large, late variety ......

Grand Forcing. Recommended to be a good forcer. 05

Henderson's Perfected White Spine. Medium

Long Green. Large, long slicing. Mighty fine ....05

New Twentieth. Century. Lonı dark green slicer. 05

White Pearl. Medium size, good for slicing .......05

White Spine. Medium long slicer. Good cropper.05

\section{Lettuce}

Big Boston. Large, butter head, good shipper .... (S 05

Black Soeded Simpson. Large, early, loose head.05

Bronze Head. High quality ....................05

head, fine quality $\ldots \ldots \ldots \ldots \ldots \ldots \ldots \ldots \ldots \ldots . \ldots \ldots$

Very pretty ....

Hanson. Cabbage head type; good summer variety. 05

Hanson. Cabbage head type; good summer variety 05
lceberg. Crisp head variety, very large ............05

May King. Very early, butterhead type............. 05

New York or W ndertul. Dark green, soüd head, 05

Prizehead. Redish brown leaves. Quality fine,

bunching ................................ 05

White Heart Cos. Elongated head, medium size...05

\section{Egg Plant}

(See Page 20)

$\mathrm{Pkt}, \mathrm{Oz}$.

Black Beauty. Earliest large variety; rich glossy skin ....05c $25 \mathrm{c}$ Early Long Purple. Small, but early . ..............05 25 New York Purple. Good size, pear shape; very popular..05

\section{Peppers}

Hot.

(See Page 44)

Pkt. Oz.

Bouquet. Very small, grows in clusters; red hot.........05c 25c

Cayepne. Long, hot pepper $\ldots \ldots \ldots \ldots . . . \ldots . . .05 \quad 25$

Red Clus. Used extensively in south for chili sauce......05 30

\section{Peppers}

\section{Sweet or Mango.}

Golden Queen. Largest of all mangos; late............10 $40 \mathrm{c}$

Large Bullnose. Medium-sized early, red mango ..........05

Spanish Pimiento. The genuine variety ...............

Ruby King. Larger and thicker meated than the above.....10

Sweet Neapolitan. Very early, medium-sixed; prolific... 05

Yellow Chinese Giant. Similar to Chinese Giant, except

color......................................10

\section{Onions}

Australian, White. Same qualities as Australian

(Seo Paige 35)

Plst. Oz $1 / 4.16$

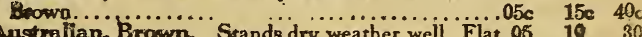

Basletta. Standard white pickler................ $05 \quad 25 \quad 60$

Early Red Globe. Medium size. For early market.05 15 40

Giant Prizetaker. A very large, mild onion, yellow.02 $15 \quad 40$

clobe Red Wethersfield. Globe strain of Red

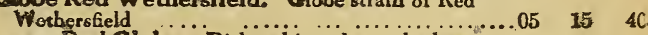

Large Red Clobe. Rich red in color and a heavy $05 \quad 20 \quad 60$

Mountain Danvers. Extremely early, slighty flat- 10 so 80

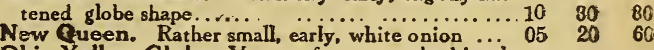

Ohio Yellow Globe. Verg uniform; standard in the

Red Wethersfield. " Standard flat variety, heavy

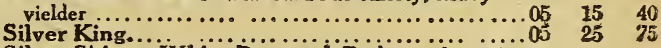

Silver Skin or White Portugal. Early, medium size.

Southport White Globe. Large and late, good keeper.05 $\quad 25 \quad 75$

Yellow Danvers Flat. Very good yielder and keeper. 05 15 40 \%

Yellow Globe Danvers. Runs very unform in size ${ }_{05} \quad 15 \quad 40$

$\begin{array}{llllll}\text { and shape } \ldots & \ldots \ldots \ldots & \ldots \ldots & 15 & 40 \\ \text { ellow Strasburg. Good variety to grow sets from.05 } & 15 & 40 \mathrm{c}\end{array}$ Onion Sets

(See Page 35)

Red, yellow and white bottom and English multiplier

Red, yellow and white bottom and English multipliers.
Any variety, by mail postpaid.......................15c 25c $65 \mathrm{c}$ Parsnips (See Page 44)

Hollow Crown. Large, long, heavy yielder........ $05 \mathrm{ck} \quad 10 \mathrm{c} \quad 2, \mathrm{z}_{\mathrm{c}}$ Improved Half Long. Much like above, but some

shorter ...................................05 $10 \quad 25$

Peanuts

(See Page 5.)

$1 / 2 \cdot P_{t}, P_{t}, Q t$

Early Northern. Small, early variety, prolific......10 $20 \mathrm{c} \quad 35 \mathrm{c}$ Jumbo. Larger and some later than above...........10 $20 \quad 35$ Peas

Smooth Early.

(See Page 38)

Alaska. Best extremo early ..... Pkt. 1/4-lb. 1b, 3-1b

Fillbasket. Long, fat pod. heavy yielder. Fol.

lows Alaska and Improved Extra Early ....il $05 \quad \begin{array}{llll}10 & 35 & 90\end{array}$

Improved Extra Early. Good yielder, well filled $\begin{array}{lllll} & & & \\ \text { Inods } & & \end{array}$

Velocity. Absolutely the earliest................. 05 10 $\quad 30 \quad 90$

\section{Peas}

(See Page 38)

Wrinkled Early.

American Wonder. Very dwarf, high quatity

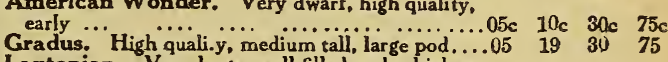

Laxtonian. Very large, well flled pods; highest

quality. Vine very dwarf ................ $05 \quad 10 \quad 35 \quad 90$

Little Marvel. Very high quality, good cropper.

$\begin{array}{llllll}\text { Dwarf } & & & \end{array}$

$\begin{array}{lllll}\text { Nott's Excelsior. Similar to American Wonder.05 } & 10 & 30 & 75\end{array}$

Premium Gem (Little Gem). Dwart, medium

sized pod; prolific .................... $05 \quad 10 \quad 25 \quad 65$

Surprise. Very early, quality fine, but not very

$\begin{array}{lllll}\text { hardy ..................................... } & 10 & 30 & 75 \\ \text { Thomas Laxton. Very much like Gradus..... } 05 & 10 & 30 & 75\end{array}$ Peas

Main Crop.

(See Page 38)

Advancer. Dwarf, medium.sized pod, main crop. $05 \mathrm{c}$ 10c $10 \mathrm{c}$. $25 \mathrm{c} \quad 65 \mathrm{c}$

Bliss Everbearing. Dwarf, strong growes, main $10-30$

Champion of England. Very late, should be

staked....................... should be

Dwarf Champion. Good quality prolific, dwarf .05

$\begin{array}{lllll}\text { Dwarf Grey Sugar. To be used like snap beans.05 } & 10 & 30 & \mathbf{7 5}\end{array}$

English Early. Dwarf, vigorous grower, large pods

$\begin{array}{llllll} & \text { of high quality } \ldots \ldots \ldots \ldots\end{array}$

fine

English Main Crop. High quality; lots of large

Horsford's Market Garden. D Darf, medium

sized pod, hardy vines .................... $05 \quad 10 \quad 30 \quad 75$

Marrowfat. Very late, taili, smooth seed............05 10 25

$\begin{array}{lllll}\text { Stratagem. Large pods, high quality, late......05 } & 10 & 30 & 75 \\ \text { Telephone. Very large pods, should be staked..05 } & 10 & 30 & 75\end{array}$

Alderman. Like Telephone, but better.......05 $10 \quad 35 \quad 90$

\section{Popcorn}

(See Page 50)

Baby Golden. Very small, yellow ..........10c $15 \mathrm{c} 40 \mathrm{c} 1.00$

$\begin{array}{llll}10 c & 15 c & 40 c & 1.00 \\ .05 & 10 & 30 & 75\end{array}$ 


\section{Condensed Postpaid Price List of Garden Seeds (Continued)}

\section{Popcorn-Continued.}

Queen's Golden. Large yellow variety........05
Monarch White Rice. Sharp-pointed grain, Pumpkins

Pkt, 1-oz. 1/4-1b, 1-1b.

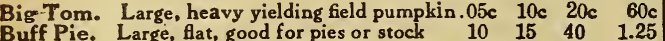
Large Cheese. Standard canning.good for nck. $05 \quad 10 \quad 20 \quad 60$ Small Sugar. High quality pie pumpkin........05 $10 \quad 35 \quad 100$ Yankee Field. Large red cow pumpkin........ 050.04 Radishes

Early Round Varieties.

(See Page 46)

Crimson Giant. Grows large and remains tender and

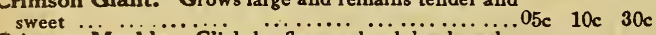

Crimson Marble. Slightly flattened, globe-shaped,

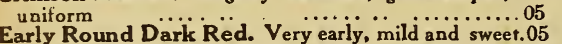

Early Scarlet Globe. Bright red. comes quick......05

Early Bird. Similar to above....................05

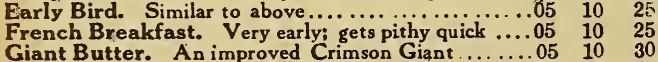

Rapid Red. Bright round red. Extremely early. Good

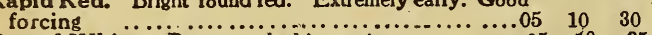

Round White. Best round white variety...........05 $10 \quad 25$

Scarlet Turnip White Tip. A very pretty, early

round radish ..........................05 $10 \quad 25$

Sparkler. Special strain of the above .........

\section{Radishes}

Half Long and Long Varieties.

Chartier. Long, light red; good quality............05c 10c 25c

French Forcing or Paris Beauty. Half long,

bright scarlet, very early.................... 10 25

Lady Finger. A long white. Main crop . . .., 05. $10 \quad 25$

Long Brightest Scarlet. Intense bright scarlet ......05 $10 \quad 30$

Long Scarlet. Large, medium late, good variety ....05 $0510 \quad 25$

Strasburg. Large, half long white, good summer radish.05 10

\section{Radishes}

For Winter Use.

(See Page 47)

Chinese Rose Winter. Standard for winter use....05c $10 \mathrm{c} 25 \mathrm{c}$

Chinese White Winter or Mikado. Very large;

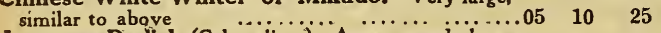

Japanese Radish (Sakurajima). An extremely large

white winter radish......................... $10 \quad 30$

\section{Salsify or Vegetable Oyster}

(See Page 44,)

Mammoth Sandwich Island......

\section{Squash}

Banana. Long, thick flesh, finest quality, good

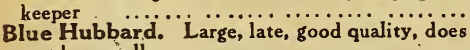

not keep well ..... ...
Boston Marrow.

Cushaw or Croockneck. Old-fashioned variety.

very popular $\ldots \ldots \ldots \ldots \ldots \ldots \ldots \ldots \ldots \ldots \ldots$
Delicious. Medium sizc, high qualitv, winter

squash

Early Golden Bush Scallop. To be used while

Exhibition Collection. A A mixture of squashes

and pumpkins

Gordden Hubbard. Fine quality; not a long keeper.0

Old-fashioned Hubbard (smooth). Very hard

shell, light grey, fine keeper

Genuine Hubbard (warted). Larger than above,

good keeper, high quality $1 \ldots . .$. Very early...

to be used while green

Mammoth or Hundred Weight. Very large,

Pattypan or Cymelon. White, $\ldots$ lat, scalloped

Sibley or Pike's Peak. Medium-sized, good

quality, keeps well $\ldots \ldots \ldots \ldots \ldots \ldots$....... 05

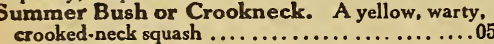

\section{Sweet Corn}

(See Page 48)

Pkt 1/4-1b. Lb 3-lb. White Mexican (Sioux City). Best real early

sweet corn .........................
Adam's Extra Early. Not a sweet corn; early

and hardy . . Early, dry corn, pink, good quality $05 \quad 10 \quad 25 \quad 65$

$\begin{array}{lllll}\text { First of All. Early, dry corn, pink, good quality } 05 & 10 & 25 & 65 \\ \text { Early Minnesota. A large early, eight-rowed ..05 } & 10 & 25 & 65\end{array}$

Golden Bantam, High quality; yellow at roast-

ing ear stage........................05 $10 \quad 30 \quad 80$

Early Champion. Midseason, large ear, good $\begin{array}{lllll} & & & \\ \text { yielder } & & \end{array}$

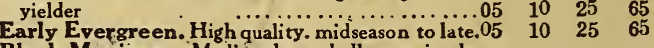

Black Mexican. Medium late, shallow-grained,

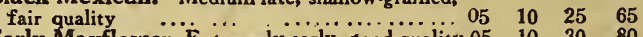

arly Mayflower. Extremely early, good quality.05 $10 \quad 30 \quad 80$

$\begin{array}{lllllll}\text { White Cory } & \text { Standard early variety } \ldots & \ldots . . & 05 & 10 & 25 & 65\end{array}$

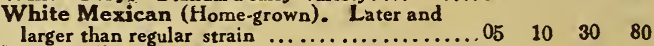

Zig Zag Evergreen. Good quality, medium-sized

ear ........................... $05 \quad 10 \quad 25 \quad 65$

White Evergreen. Large, deep-grained; very

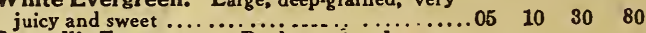

Stowell's Evergreen. Rank growing. large

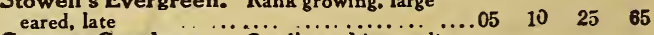

Country Gentleman. Small ear, hign quality, grain........ Tomatoes

(See Page 52)

Varieties are arranged as near as possible in order Pkt. Oz,
,

Field's Early June. Good size, smooth, solid, red, pro- $10 \mathrm{c} 75 \mathrm{c}$

Pink Early June. Smooth, medium-sized, compact bush,

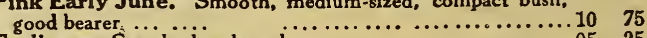

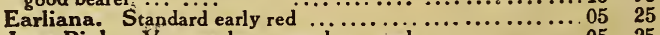

June Pink. Very early; somewhat rough.............. $05 \quad 25$

Bonny Best. Good size fairly early, red fruit.......... $10 \quad 35$

Dwarf Champion. Early pink tree tomato .............. $05 \quad 30$

Chalk's Early Jewel. Strong grower, smooth red tomato.10 35

Acme. Second early, pink tomato; good shipper...........05 25

Golden Beauty. Main crop, yellow variety $\ldots \ldots \ldots \ldots \ldots \ldots .0530$

Beauty. Main crop, pink, targe, good canner ............05 25

Mississippi Girl. Large, smooth, bright red.............. 10

New Stone. Good size, solid, bright red; good canner.....05 25

Matchless. Large, smooth, dark red..................05 25

Livingston's Globe. Medium size, pink, high quality......10 35

Ponderosa. Solid and meaty, very large, pink ..........10 40

Shenandoah. An improved strain of Ponderosa ........ 10

ellow Pear. Standard preserving tomato........ (See Page 57)
Pag Turnips Pkt. Oz. 1/4-1b.

Amber Globe. Yellow-fleshed; main crop..........05c 10c 20c

Cowhorn. Long, white stock turnip $\quad \ldots \ldots \ldots \ldots \ldots, 05 \quad 10 \quad 20$

Extra Early Milan. Extra early, purple top turnip..05 i0 30

Early White Milan. Very early, wh!te, flat turnip...05 1030

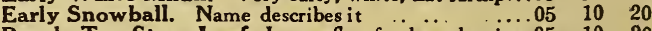

Purple Top Strap Leaf. Large, flat; for late planting.05 $10 \quad 20$

Purple Top Globe. Similar to above, but globe-shaped.05 $10 \quad 20$

Rutabaga or German Sweet. Yellow flesh, small tops05 1020

Seven Top Turnip. For greens.................05 $10 \quad 20$

White Globe. Large late, sweet turnip.................. $10 \quad 20$ Muskmelons

(See Page 26)

Pkt. Oz $1 / 4-\mathrm{lb}$. Ib.

Banana. Long, yellow melon; fair quality $\ldots .10 c \quad 20 c \quad 50 c \quad 175$

Bay View. Large, oblong, green-fleshed melon.05 $10 \quad 30 \quad 1.15$

Burrell's Gem (Extra fine) Pink-meated Rocky

Ford................................. $15 \quad 40 \quad 1.25$

California Cream Cantaloupe. Large, old-

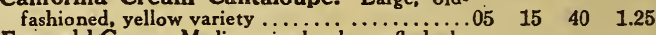

Emerald Gem. Medium-sized, salmon-fleshed,

fine quality .......................... $05 \quad 15 \quad 40 \quad 1.25$

Extra Early Hackensack. Said to be ten days earlier than Hackensack.................. $05 \quad 10 \quad 40 \quad 1.25$

Field's Daisy. Yellow-Aleshed; highest quality...10 $25 \quad 60 \quad 2,10$

Fordhook. Small, red fesh, fair quality.......05 $10 \quad 30 \quad 1.00$

Green Meated Nutmeg. Medium-sized melon.

Good quality.............................. $05 \quad 10 \quad 30 \quad 1.00$

Greeley Wonder................................

Hackensack. Large, round melon. green-fieshed.05 $15 \quad 40 \quad 1,25$

Improved Rocky Ford, Southern type. Larger

than standard ........................5 $15 \quad 40 \quad 1,25$

Long Island Beauty. An improved Hackensack.05 $15 \quad 40 \quad 1.25$

$\begin{array}{lllll}\text { Netted Osage. Salmon-fleshed, very uniform.10 } & 2 \text { ) } & 50 & 1.75\end{array}$

Osage. Thick, yellow flesh, fine quality ........05 $25 \quad 40 \quad 1.25$

$\begin{array}{lllll}\text { Perfection. Large, fine, yellow-fleshed melon.10 } & 20 & 50 & 1,75\end{array}$

Rocky Ford or Netted Gem. Small, well-

netted, green-fleshed, good shipper ..........05 $10 \quad 30 \quad 1.00$

Rocky Ford-Pollock Strain. Special selection $\begin{array}{lllll} & 40 & 1.25\end{array}$

Salmon-Fleshed Rocky Ford. High quality

good shipper..........................10 $20 \quad 50 \quad 1.75$ Watermelons

(See Page 29)

Alabama Sweets. Long, striped melon, good 05 c 10 c 25 c $75 c$ 


\section{Condensed Postpaid Price List of Garden Seeds (Continued)}

Watermelons-Continued

Angel Kiss. Long. grey-colored melon........10 15 30 30 1.00

Cole's Early. Smali, early, round, striped melon.05 $10 \quad 25 \quad 75$

Florida Favorite. Medium-sized, long, striped

melon .............................. $05 \quad 10 \quad 20 \quad 65$

Fordhook Early. Rather short and blocky; solid

red flesh ............................... $10 \quad 20 \quad 65$

$\begin{array}{lllll}\text { red tesh Honey. Best jellow-Aleshed melon.......... } & 20 & 50 & 1,75\end{array}$

Halbert Honey. Long, dark green melon of finest

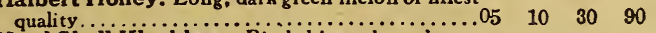

Hard Shell Kleckley. Rind thin and tough;

thick red flesh................................

Harris' Early. Like Cole's Early, but earlier...05

Ice Cream or Peerless. Medium early, medium

lce Cream or Peerless. Medium early, medium

improved Kleckley. Selected strain; originated

Kolb's Gem (Blue Gem). Nearly round, thick

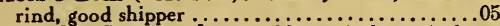

Kleckley Sweets. Large, oblong, dark green skin,

thin rind, bright red flesh; ideal for home use....05

Mclvor's Wonderful Sugar. Long, strieed meion.

fine quality, good shipper $\ldots \ldots \ldots \ldots \ldots \ldots \ldots .05$

Phinney's Early. Very early. small, fruit oblong

Princess. Smali, individual-sized melon ............

Halbert's Rubber Rind. High quality melon

that will satnd handling....................10

Sweetheart. Lar e, round, light green, shippe..05

Tom,' Watermelon Collection. Large pkts ..10

\section{Vegetables Used For Greens} See Page 45.

Collards. Popular in the south...............05c I5

Pkt. Oz. 1/4-1b.

Collards. Popular in the south.................05c I5c

Kale. Dwarf. Low growing; belongs to cabbage family 0.5
Kale. Tall. Stands 2 to 3 feet hig:i; leaves curly ....05 15

Mustard. B!ack. Very early. Goes to seed soon...05 10

Mustard. Chinese Broadleaved" Large, flat leaf,

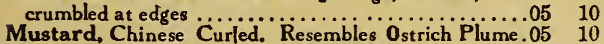

Mustard, Ostrich Plume. Well named. Very pietty.05 10

Mustard, White. Grown for seed..............05 10

Mustard, Fordhook Fancy. Veiy finely curled.......05 10

Spinach, Bloomsdale Savoy. Very early, good sized..05 10

Spinach Giant Thick Leaf. Later than above and

stands longer without going to seed .............05 10
Swiss Chard Lucullus. Belongs to best family.

Large, fleshylear, good for summer-use...........05 $10 \quad 35$

\section{Odds and Ends}

See Page 58

Pkt. $\mathrm{Oz}$

Chicory, laage rooted. A good substitute for coffee........05c 15 Citron, Red Seeded. Small, striped preserving melcn........05 15 Citron, Green Seeded. Round, light green; ..............05 15 Endive or German Lettuce. Dark green leaves; curly...05 15 Garden Lemon or Vine.Peach. Valuable for preserves.05 20 Garlic. Tastes like onion, only more so....Per bulb $10 \mathrm{c}$, per lh. 40c Ground Cherry, Yellow Old-fashioned yellow variety ....05 30 Kohl Rabi, White Vienna. Turnip-rooted va'baga........05 20 Leek, Large Flag. Used for soups..................... 20 Mushrooms. Lambert's Pure Culture Spawn. Per brick... ...35 Okra, Mixed. Cook pods whiie young for soups 5 bricks............ 10 i Parsl $y$, Moss Curled. Used for garnishing and sea-

soning -............................................... 15

Rhubarb or Pieplant

Sunflower, Mammoth Russian. Grown for chicken

feed ................................ 12-pt. 10c, pt. 20c, qt. 35c

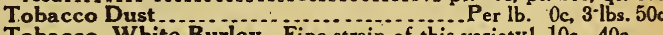
Tobacco, White Burley. Fine strain of this variety1.10c $40 \mathrm{c}$ Brussels, Sprouts ................................ 20

\section{Herbs}

(See Page 58)

Anise. Seeds have an agreeable, aromatic taste.

Annual...05c 10c

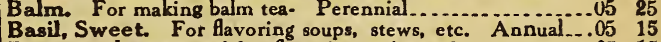
Borage. Leaves used for flavoring. Annual. ............. 05 Caraway. Seeds used for flavoring bread. Biennial ........05 10 Castor Oil Plant. Seeds are pressed to obtain oil. Annual.05 10 Coriander. Seeds used in conte tionery. Annual. ....... 0510 Dill. Sown for dill pickles. Annual.................... 0510 Hoarhound. For seasoning and cough remedy. Perennial. 0520 Lavender. Used largely as aperfume, Perennial. ......... 0125 Majoram, Sweet. Perennial .......................... 0515

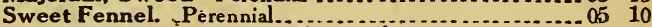

Rosemary. For seasoning. Perennial................... 05

Summer Savory. Used for seasoning. Annual ........... 0525

Sage, Mammoth Broadleaf. For seasoning and medi-

cinal purposes. Perennial ........................... 0525

Thyme. Leaves and young shoots used for seaso ning.

Perennial. ..................................... $05 \quad 30$

Wormyood. For seasoning and medicinal purposes, Per-

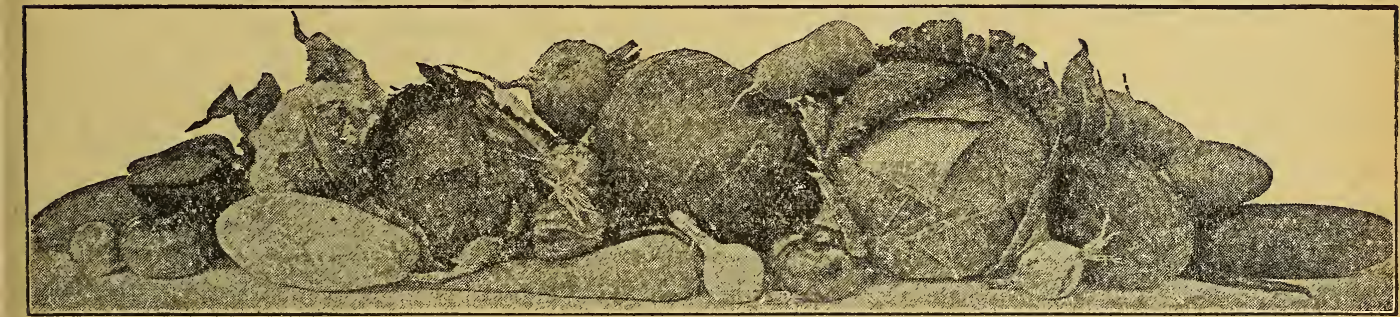

\section{Some Bargain Collections}

\section{No. 1 \\ Collection of New Varieties}

Seven New Varieties for 50c Postpaid

These are my lexders, the best $I$ have in the catalog. Naturally the new varieties are a little higher priced than the old standard sorts. and some people are inclined to pass them up on that account. I want all of you to try them, so I am go. ing to make a special price on them, so that there will be no excuse for any of you not trying them. I will, at the first of the season have them col. lected and packed all ready for mailing. Ther. when your nrder comes in all we will have to do will be to paste an address label on and send them out. Can't rhange the list on this account.
I will throw in some flower seeds for you, for I believe you will appreciate them.

1 Pkt. Cabbage, Norseman. Large, round, solid and very early.

1 Pkt. Muskmelon, Field's Daisy. Medium size. Very high quality.

1 Pkt. Onion, Mountain Danvers. Early, good keeper and heavy yielder.

1 Pkt. Mango Pepper, Yellow Chinese Giant. Yel. low sweet pepper.

1 Pkt. Squash, Banana. Good keeper; high quality.

1 Pkt. Beet, Blood Red. Better color than others, Crisn and tender.

1. Plkt. Tomato, The New Early. Very smooth, ex treme early: large, productive.

$1 \mathrm{Pkt}$. F lower Seed. Some popular variety. 
There's enough seed here to make a wagon No. 2 load of garden stuff and a whole garden of flowers. I really believe a bright boy can grow five dollars worth of garden stuff from it. Count and see how Tested Garden Seeds at 6c Per Ounce Special Bargain Collection

We have always had considerable call for a mixture of standard varieties of garden seeds, such as our All Seasuns Mixture of Radishes, as that way 1 good assortment of kinds can be had at a very low price. The radish mixture was the most pop. ular thing we ever put out, and we followed it with a mixture of lettuce. This year we have ds. cided to offer a mixture of all kinds of vegetables, and at prices that will induce every one to take hold.

These mixtures are made up from the standard varieties, and are mixed in the right proportions to give you a steady succession from early to late. It is all fresh, vigorous, tested seed, and for that reason we advise you not to plant it too thick. We are putting it up, not in little packages, but in straight ounces, big fat packages that will plant a big* long row. You will get a complete garden, con. taining nearly everything in the catalog, for $60 \mathrm{c}$ postpaid.

A full ounce each of the following for $60 c$ postpaid:

Radishes-All Seasons Mixture. A special mixure of early and late radishes we list. It will furnish radishes for a month. late.

Lettuce - Six of the best varieties. early and

Table Beets-Mixture of all varieties.

Onions-Big onions, little onions, red. white, yellow and brown. Enough seed to raise 10 bushels of onions.

Watermelons-Over 20 varieties. If you ran't find melons to please you in this lot you are hard to suit.

Muskmelons-12 different sorts-all good ones.

Pumpkins - All hinds. mostly pie pumpkins. This will plant a good-sized patch and make more pies than you can eat.

Squashes-Winter squashes of all known varie. ties, Contains Hubbard, Marrow, Cushaw and all the favorites.

Carrots-A mixture of five varieties. Long and short, early and late. yellow.

Turnips - Early and late, white, purple and

\section{A Conglomeration}

\section{For the Children's Garden. Free With Each} Order of $\$ 1.00$ or Over

Of course grown-up people can plant it too, if they want to, and if there are no children around that want it; but it is meant specially for the children. Every child just naturally wants to dig in the dirt and have a garden. And they want a little of everything in the garden. It would take a hundred rackets of seed to supply everything a boy or girl would like to plant.

So we have rolled the hundred packets into one. That is we have taken over a hundred different kinds of seeds and made one big mix of it all that will just suit the kids. They can plant it mixed that way or sort out each kind by itself.

many seeds there are. And when they grow, keep count of how many kinds you have.

\section{No. 3}

\section{Complete Garden Collection For $\$ 1.25$}

Many people, especially new beginners in gas dening, want me to chonse for them a complet assortment of staple varieties of seeds for an ordj nary garden, I have made up such a collection which I am sure will please almost every one Here it is:

3/1-1b. Sweet Corn

1 put. Turnips

1 pkr. Early Cabbage

1 pkt. Late Cabbage

1 pit. Muskm+lon

1 pkt. Watermelon

1 plst. Cucumber

1 oz. Early Radiehes

1 oz. Late Radishes

1 pkt. Onion

1 pkt. Carrots

1 pkt. Parsnip

1/4-1b. Popcorn

\author{
1 pkt. Tomatoes \\ 2 oxs. Early reas \\ $20 z$. Late Peas \\ 2 czs. Wax Beans \\ 2 ozs. Green Pod Beans \\ 2 ozs. Pole Beans \\ 1 oz Lettuce \\ 1 pkt. Salsify \\ 1 pkt. Early Beets \\ 1 pkt. Late Beets \\ 1 pkt. Early Squash \\ 1 pkt. Lnte Squash \\ 1 pkt. Pumpkin
}

This collection, amounting to $\$ 1.85$ at regular prices, 1 will send postpaid for $\$ 1.25$. I cannot make any change in varieties, as it is already made up ready to send.

No. 4

\section{School Garden Collections}

\section{Soeds at 2c Per Packet}

I believe that the school garden movement is one of the best and most usetul of the new ideas of education. It is absolutely all right. There is nothing better for a child than a garuen, and espec. ially a garden of its own. It gives a feeling of ownership and pastnership with nature that nothing e'se will give.

We have had lots of inquiries for collections of packe's of seeds especialiy a'tapted for childrens school gardens and have put up lots of special lots of that kind in the past, and we have also had experience with school gardens here at home and we have figured out about what will do best and will suit the children best.

This year we are putting up hundreds of special collections that are just wh t you want. Each collection consists of 10 packets of seeds, 6 of them being vegetables and 4 of them flowers. All easy to grow and sure to succeed, These will be packed in a special envelope appropriately printed. Each packet will have planting directions print $d$ on it. The packets will contain plenty of seed, and it will be good seed too. These collections of 10 packets will be sold at 20c, which is at the rate of $2 \mathrm{c}$ per packet. We cannot break the collections, as we will have them already put up.

This is a wholesale price and is meant to ap ply on orders for a considerable number of eollec. tions, say 10 or more at a time, but if you want to see one for a sample we will gladlv mail you a single set at the same price, 20c. We pay all the postage on these. 
Shipment. - By exnress or freight at buvers expense except as per special offer on next page. These prices do not nclude postage.

Postage Extra.-If small amounts are wanted by mail add 10 per pound or 15 c per quait to cover postag

Terms.-Cash with urder. We open no accounts.

Bags and Boxes Free. - We make no charge fur packing. OF WHOLESALE PRICES FOR

\section{Market Gardeners}

Prices Are Net. - No discounts from ' hese prices. For prices on smaller quantities than listed here, see general

Odd Sorts. - We can supply mo*t standard varieties, whether listed here or not, at usual vrices.

Special Quotations. - If you use extra large amounts of some one class of seeds, you are invited to write fur suecial q. otationa.

Iron Age Garden Tools.-We carry heavy stocks of these tools here in Shenandoah, and can make promot shio ent. By having th. $m$ come with seeds, you an savec i freight, Henry Field Seed Company SHEMARDCAH, IOWA

Notice These prices are expected to hold good all spring, but unseen emergencies may occur, or we may go sold out on some, so if you need large amounts, especially late in the season, better inquire first. and on a big order I can prepay it all, a s per special offer 0.1 and on a bi

\section{YOUR MONEY'S WORTH OR YOUR MONEY BACK}

It is mutually agreed and understood that any seeds or other goods ordered of us may be returned at any time within ten days after receipt if not sasisfactory, and money paid for them will be refunded, but we do not and cannot in any way warrant the crop, as it is dependent on so many condi. tions beyond our control. HENRY FIELD SEED CO.

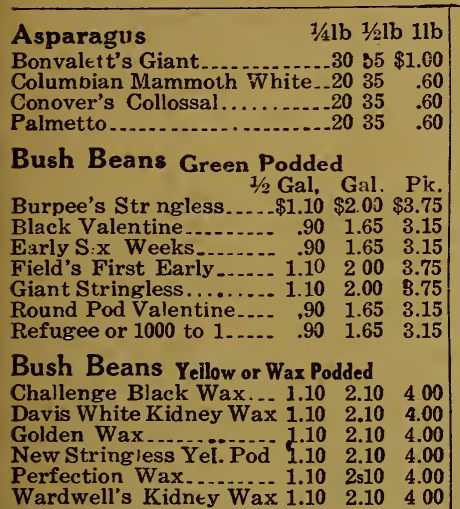

Bush Beans Varieties for shelled beans

Burpee's Bush Lima.... $\quad .85 \quad 1.60 \quad 3.00$ $\begin{array}{lllll}\text { Dreer's Bush Lima ..... } & .85 & 1.60 & 3.00\end{array}$ $\begin{array}{llll}\text { Dwarf Horticultural ...-. } & .75 & 1.35 & 2.50 \\ \text { Fordhook }\end{array}$ Henderson's Bush Lima. $\quad .85 \quad 1.60 \quad 3.00$ $\begin{array}{lllll}\text { Prolific Tree............. } & .85 & 1.60 & 3.00\end{array}$ $\begin{array}{llll}\text { Red Kidney } & \ldots \ldots \ldots \ldots \\ \text { White Kidney } & .8 . \ldots & 1.60 & 3.00 \\ \end{array}$ $\begin{array}{llll}\text { White Kidney.......... } & .85 & 1,60 & 3.00 \\ \text { Teparies } & 85 & 160 & 3.00\end{array}$ White Wonder .......... $.851 .60 \quad 3.00$

Pole Beans Green Podded

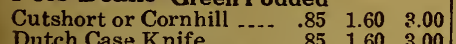
Dutch Case Knife.

$$
\text { berry - }
$$

Improved Missouri Wen-

Kentucky Wonder......

Lazy Wife

White Creaseback

White Seeded Kentucky

Wonder.............. $.85 \quad 1.60 \quad 3.00$

Pole Beans Yellow Podied

Gold=n Cluster Wax..... 1.102 .00

Kentucky Wondcr Wax .- 1.102 .00

Pole Beans Lima

Extra Early LIma....... . .75 $1.35 \quad 2.50$

$\begin{array}{llll}\text { Kine Lima } & . . .5 \\ \text { Seibert's Early Lima } & .75 & 1.35 & 2.50 \\ \end{array}$

Beets For Table Use 1/4-1b. 1/2-lb. Lb.

Bl od Turnip

Crosby's Egyptian ......

Crimson Giobe $\ldots \ldots \ldots \ldots, \quad .25$

Detroit Dark Red ........

Extra Eariy Flat Egyp-

tian ..........................

New Fireball

\section{Celery (American)}

Golden Self-Bleaching -. $1.85 \quad 3.50 \quad 6.50$

$\begin{array}{lr}.70 & 1.35\end{array}$

$\begin{array}{rr}.50 & .90 \\ .50 & .90\end{array}$

$\begin{array}{rr}.50 & .90 \\ .70 & 1.35\end{array}$

$.50 \quad .90$

.50
.90 $\quad$ Early Cluster........... .25 1/2-lb. Lb.

Beets (For Stock Use)

Giant Fe ding Sugar...--
Gold.n Tankard Mangel.

Kammoth Long Red

Mangel

Giant S udstrup

Red Ec endor er.......

Taarjoe .................

Cabbage Earb and Intermediate

All Head Early ........ $\quad .80$ 1/2-1b. Lb.

All Seasons $\quad .55 \quad 1.00190$

Charleston or Large

Copenhagen Market

$\begin{array}{lrrr}\text { Copen hagen Market _... } & 1.10 & 1.85 & 3.50 \\ \text { Early Jersey Wakefield. - } & .80 & 1.55 & 3.00\end{array}$

E rlv Winningstat.... $\quad .60 \quad 1,10200$

Extra Early Flat Dutch.

Fotler's Brunswick....

Henderson's Early Sum-

mer ...................

Cabbage Late Varieties

Avtumn King.........

ornbelt.

Hollander or Danish Baill

Head ......... Drun.

head.

Mammoth Red Rock.....

Savoy

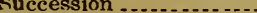

Volga _........

\section{Cauliflower Danish Grown}

Dry Weather or Copen-

hagen Dwarf Erfur

Snowball .....................

Carrots

Chantenay - C........

$\begin{array}{lll}\text { Danve 's Half Long..... } & .35 \\ \text { Song Orange. }\end{array}$

$\begin{array}{lll}\text { Long Orange. } & .35 \\ \text { Oxheart } & & .35\end{array}$

White Belgian ......

$\begin{array}{ll}\text { Yhite Voages........... } & .25 \\ \text { Yellow Belgian ........... } & .25\end{array}$

$\begin{array}{ll}.30 & .50 \\ .30 & .50 \\ .30 & .50\end{array}$

$.30 \quad .50$

.30 . .50

$\begin{array}{ll}.30 & .50 \\ .30 & .50\end{array}$

$\begin{array}{lll}70 & 1.35 & 2.60 \\ 60 & 1 & 10\end{array}$

$\begin{array}{lll}.80 & 1.55 & 3.00\end{array}$

$\begin{array}{lll}65 & 1.25 & 2.50\end{array}$

$\begin{array}{lll}55 & 1.00 & 1.90\end{array}$

$\begin{array}{lll}10 & 1.85 & 3.50\end{array}$

$\begin{array}{lll}55 & 1.00 & 1.90\end{array}$

$\begin{array}{lll}80 & 1.55 & 3.00\end{array}$

$\begin{array}{lll}55 & 1.00 & 1.90\end{array}$

$\begin{array}{lll}60 & 1.10 & 2.00\end{array}$

$80 \quad 155 \quad 3.00$

$\begin{array}{llll}.60 & 1 & 10 & 2.00 \\ 65 & 1.25 & 250\end{array}$

$\begin{array}{lll}80 & 1.55 & 3.00\end{array}$

$5 \quad 1.60 \quad 3.00$

oz. Oz. 1/4-lb.

$\begin{array}{lll}1.30 & 2.50 & 800\end{array}$

$\begin{array}{llll}.10 & 200 & 7 & 00\end{array}$

$\begin{array}{lll}25 & 2.25 & 7.50\end{array}$

b. $1 / 2-1 b$. Lb.

.601 .00

.651 .15

.601 .00

$\begin{array}{rr}.60 & 1.0 \text { ? } \\ 45 & 85\end{array}$

$\begin{array}{rr}.45 & .85 \\ 45 & 85\end{array}$

$\begin{array}{ll}.45 & .85 \\ .45 & .85\end{array}$

White Plume............ $1.00 \quad 1.85 \quad 3.50$

Cucumbers

Chicago Pickle

\section{5}

$.45 \quad .80$

$\begin{array}{rr}.60 & 1.15 \\ .45 & .80 \\ .45 & .80\end{array}$
1/4 Ib. 1/2-Ib Lb.

Evergreen................ $.30 \quad .55 \quad 1.00$

Emetald

$\begin{array}{llll}\text { Fordhook Famous....... } & .30 & \mathbf{5 5} & 1.00\end{array}$

Henderson's Perfected

$\begin{array}{lllll} & \text { White Spine_........ } & .25 & .40 & .80\end{array}$

$\begin{array}{lllr}\text { Klondike } & .25 & .40 & .80 \\ & .40 & .80\end{array}$

$\begin{array}{lllr}\text { White Spine............ } & .25 & .45 & .85\end{array}$

Eggplant

Black Beauty . . . . . $1.00 \quad 1.85 \quad 3.50$

Early Long Purple...... $.90 \quad 1.75 \quad 300$

New York Purple....... $1.00 \quad 1.85 \quad 3.50$

\section{Lettuce}

$\begin{array}{lllll}\text { Bl } \_ \text {ck-Seeded Simpson _. } & .35 & .60 & 1.10\end{array}$

$\begin{array}{lllll}\text { Big Boston } & .35 & .65 & 1.25 \\ \text { California Cream Butter } & .35 & .60 & 1.10\end{array}$

Grand Rapids ........... $.35 \quad .65 \quad 1.25$

Hanson................ $.35 \quad .65 \quad 1.25$

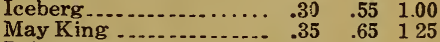

Prizehead ..............

$\begin{array}{llll}\text { White Heart Cos........ } & .35 & .65 & 120\end{array}$

Bronze Haad ............ $.35 \quad .65 \quad 125$

$\begin{array}{lllll}\text { New Yurk or Wonderful } & .35 & .65 & 1.25\end{array}$

Muskmelon

Bay V'ew . ............. $.25 \quad .50 \quad .95$

$\begin{array}{llll}\text { Banana (True) } & .9 \\ \text { Burrell'sGem (ExtraFine) } & .35 & .60 & 140\end{array}$

California Cream Canta-

louve

Emerald Gem $\ldots \ldots$.

$\begin{array}{llll}\text { Fxtra Early Hackersack } & .20 & .35 & .65 \\ \text { Field's Daisy } & .50 & 90 & 1.65\end{array}$

Fordhook

$\begin{array}{llll}\text { Green Meated Nutmcg.- } & .35 & .60 & 1.15\end{array}$

$\begin{array}{lllll}\text { Greeley Wonder......... } & .50 & 90 & 1.65\end{array}$

Hackensack............ $.20 \quad .40 \quad, 75$

$\begin{array}{llll}\text { Inprove I Rookv Ford .- } & .35 & .60 & 1.15\end{array}$

I.ong Island Beauty.....

Netted Osage ............ $\quad .40 \quad .75 \quad 1.40$

$\begin{array}{lllll}\text { Prage } & \\ \text { Perfection................... } & .40 & .75 & 1.40\end{array}$

Rocky or: or Netted Gem ,20 $\quad, 35 \quad .65$

Rocky Ford-Pollock Strain .35 $\quad .65 \quad 1.25$

Odds and Finds.

$\begin{array}{llll}\text { Mu tard, all varioti s ... } & .20 & .35 & .60\end{array}$

Spinach, Bloom.da!e

Spinach, Giant Thick

Rohl Rabi, White Vienna, 650 Failure.

$\begin{array}{llll}\text { Rhuba b or Pieplant.... } & .40 & .75 & 1.40\end{array}$

To acco Dust............

Bottom Onion Sets

(32 lbs. per bu.) Mountain Grown lb.

Onion S.ts, Red.

Onion Sets, White.

Onion Sets, Yellow

English Multiplier.

(Continued on next page.) 


\section{Wholesale Net Prices For January, 1917}

\section{Good to January 31, 1917 (Subject to stock unsold)}

\section{On Clover, Alfalfa, and Other Grass and Field Seeds Which Fluctuate in Price}

\section{Address All Orders to Henry Field Seed Co., Shenandoah, Iowa}

Prices are so unsettled on field seeds, especially clover and alfalfa. that I can not quote prices longer than one month ahead. Write for special quotations on seed wanted after date given above, or send along your order and $I$ will fill it at lowest possible prices.

Time Limit. Note that these prices are good only til! January 31,1917 , and if you co not buy in that tim , you should write for our new prices. We reserve the right to cancel these prices when stock on hand is sold.

These prices are $f$. $o$. 1 . Shenandoah, customer to pay the freight. If you want delivered prices we will make a special istimate for you on request.

No : xtra charge for sacks. All seeds are sold "sacks weighed in." Remember this when comparing prices.

Pices are st ictly net, spot cash and no discount.

Safe arrival guaranteed. Clover and alfalfa seed are generally double sacked, and everything is well packed. We guara tee that all seeds will reach you in good order.

Sold on approval. These seeds are priced and sold with the understanding that if not found perfectly satisfartory they may be returned at our expense and your money will be refunded. You can be the judge of quality,

Subject to inspection. Any seeds (especially clover, alfalfa and grass seed) purcha ed $f r(m$ us may be submitted to any State or National experiment station for test and inspection, and if they do not report the seed first-class it may Le returned at our expense and your money will be refunded.

\section{Clover (60 lbs. per bu)}

Medium Per bus

Mammoth Red

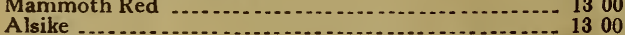

White 1 .

Crimson

Timothy (45 lbs. per bu.) Home grown.

Timothy and Clover Mixed (45 lbs. per bu.) Timo'hy-Alsike Mixture.

Timothy.Red Clover Mixture...................... 450

Alfalfa (60 lbs. per bu.) All non-irrigated. Per lb. Kansas-Nebraska .................................... Dakota grown
Montana grown Montana grown

Sweet Clover (60 $l^{2}$ s. per $(u)$ White Biennial (Hulled)

Yellow " (Hulled).

Yellow, Annual

Per $l b$ Unhulled)

Blue Grass (14 lbs. per bu.) Kentucky................ Perlb. English

Sudan Grass ............

Orchard Grass

Brome Grass

Red Top

Per $\mathbf{l b}$. Solid Recleaned Seed ............................... .16 Unhulled Seed

Grass Seed Mixtures Per lb. Permanent Meadow Mix .......................... $\quad .12$ Permanent Pasture Mix. Lowland Pasture Mix ..........

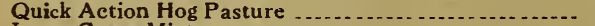
Lawn Grass Mixture... Timothy Alsike Mixture

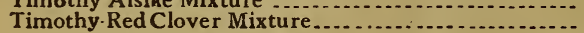

One grade only. We quote on one grade only, the highest possible grade. We do not believe in low grades, and do not wish to encourage the use of them. Good seed is the cheapest in the long run.

Reference. First National Bank, Shenandoah, Iowa.

Free samples. We will gladly send free samples of any kind of seed quoted here.

Subject to sale. All prices are subject to stock being unsold on receipt of order.

lowa grown. Wherever possible these steds a re Iowa grown. On special inquiry we will gladly tell you where the seed is procured if not lowa grown.

Tested Seed. All seed offered here is fir: $t$ tested by us for germination and purity insofa. as is practicable. We do not intentionally offer any seed that does not show high test for purity and growth. On most seeds we also get U. S. asd tate tests to verify ou owr.

Order early. When you are ready for the seed you will want it mighty quick. Better order early and have the sted ready. Freight blockades and delays sometimes inake lots of trouble for us and for those who order late. Besides, prices are sure to advance as the planting time draws near.

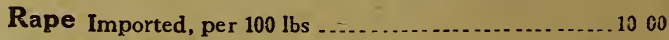

Fodder Cane (50 lbs. per bu.) Per bu.

Amber type (50 lbs. per bu.)

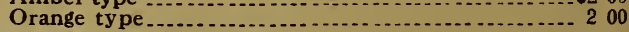

Kaffir Corn (56 lbs. perbu.) Perbu.

White, for fodder............................. Pe 80

Feterita (56 lbs. per bu.) .................... 400

Millet (50 lbs. per bu.) Pe-bu.

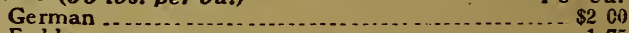

Fodder

Barley Beardless.............. 200

Speltz

Buckwheat

Japanese Silverhull $^{2 . . . . .}$.

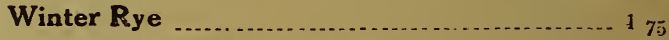

Stock Peas and Beans (60 lbs. per bu.) Per bie.

Cow Peas, Whippoorw II . . . . .

Cow Peas, New Era

Cow Peas, Mixed . . .

Soy Beans, yellow ................................ \& 25

Soy Beans, black

Soy Beans, black
Canadian Field Peas................................... 3860

High Grade Sorghums, Kaffirs, Etc Per lb

Short Orange Syrup Cane ...................... $\quad .10$

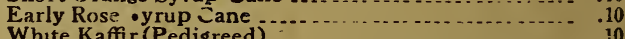

Bioom Corn, Evergreen

Biogm Corn, Evarf

Milc Maize, Dwarf
Shallu $\ldots \ldots \ldots$

(Any of the above $8 \mathrm{c}$ per lo. in tots of $5 j$ its. $c_{i}$ over.

Grass Seeder

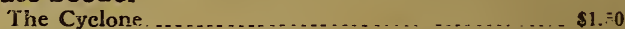

Littie Wonder

\section{These Are Wholesale Prices}

Good for amounts of 10 pounds or over of a kind. Add $2 c$ per $1 b$. for amounts of 5 to 10 pounds. Add $5 c$ per $1 \mathrm{~b}$. for amounts below 5 pounds. 


\section{Seed Corn}

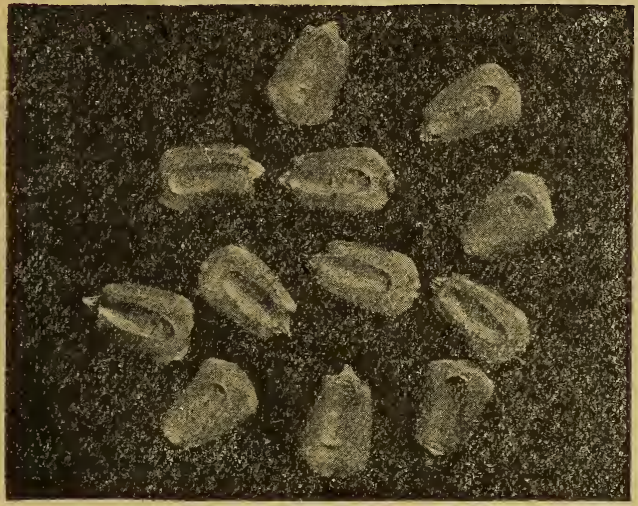

Graded Seed Corn

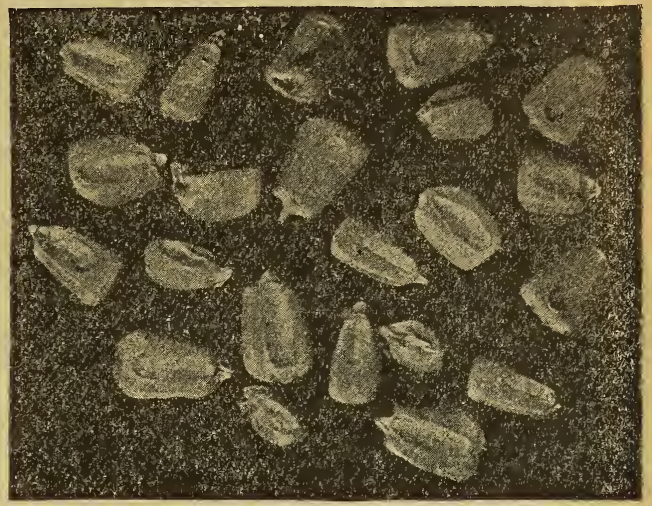

Ungraded Seed Corn

\section{Which Would You Rather Have?}

This picture, made from a photograph, gives the argument for graded seed corn better than I could give it in words. You have all seen the last kind, now I would like to have a chance to show you some of the first kind. I grade my shelled corn till it is as near as possible all one size, and I guarantee it to work perfectly in any corn planter.
All my seed corn is tested and subject to test. not as represented, we trade back. I ship either ear or shelled. If you say so, I will ship on ap proval.

I sell garden seeds that will really grow. and flower seeds that will bloom. Now, if you can't trade on that basis, there is no trade in you.

\section{The Seed Corn Business}

I wish I could make you understand how we big or little, who comes around and is at all inter handle the seed corn business and how much pains ested in seed corn, is shown everything we have we take to try and get the seed corn out in the in the seed corn line, very best possible way. The only real certain way to get you to understand it would be to have you come here and see for yourself. There would be no question about it then. I do not believe there was ever a man who came here looking for seed corn who went away without buying, if he really had any notion of buying. Lots of local farmers living near me come to me for their seed corn every year iustead of saving their own. Tha will give you some idea of what the people think who absolutely know all about my business.

I wish you - everyone of you - could come here and go through the seed house yourself. I would be mighty glad to take the time to show you everything in the building. You would understand then what we are trying to do better than I can possibly tell you.

I have been in the seed corn business for a great many years, and I expect to sell seed corn for-a great many years to come, and I know and you know that I couldn't s'ay in business unless I put out the right kind of seed. I am not foolish enough to think I could skin you on seed corn and get away with it. 1 know that as weli as you do. I know that the only way to stay in the seed corn business is to put out a little better seed than anyone else in the business, and that is what 1 am trying to do, and that is what I am doing, too, I really believe.

I always like to have visitors at the seed house. I am proud of what I have to show. Every man,

Pıof. Holden - I guess you all know him - for. merly of Ames, the most celebrated corn man in the world - was visiting here some time ago, and of course, I showed him all thr ugh the seed corn department. The big seed $\cos n$ tester with its thousands of samples of seed corn testing at once, the two big graders and the five little graders sort. ing and grading corn, the big room full of girls hand-picking the corn, and the big gang of mea. selecting, nubbing, shelling, or packing the corn in fact, the whole works.

He stood and looked it over and he said. "Field, why don't you tell people about this in your catalog? Why don't you try and make them understand what you are doing? I wish every far mer in Iowa could go through here and see this as: I have seen it. I had no idea any seed house in the country was handling seed corn like you are or taking so much pains with it."

Well, I have been trying to tell people about it, but somehow I can't make it seem real, like it would if you were here to see for yourself. You have heard men talk about seed corn before, lots of it was hot air, and I sometimes can't blame you much for thinking all seed corn is of the same brand.

I am running a real, legitimate seed corn business, free from all get-rich-quick schemes, hot air inflated prices, and exaggerated claims. If you ap prove of this kind of seed corn business, I would like to have your orders. 


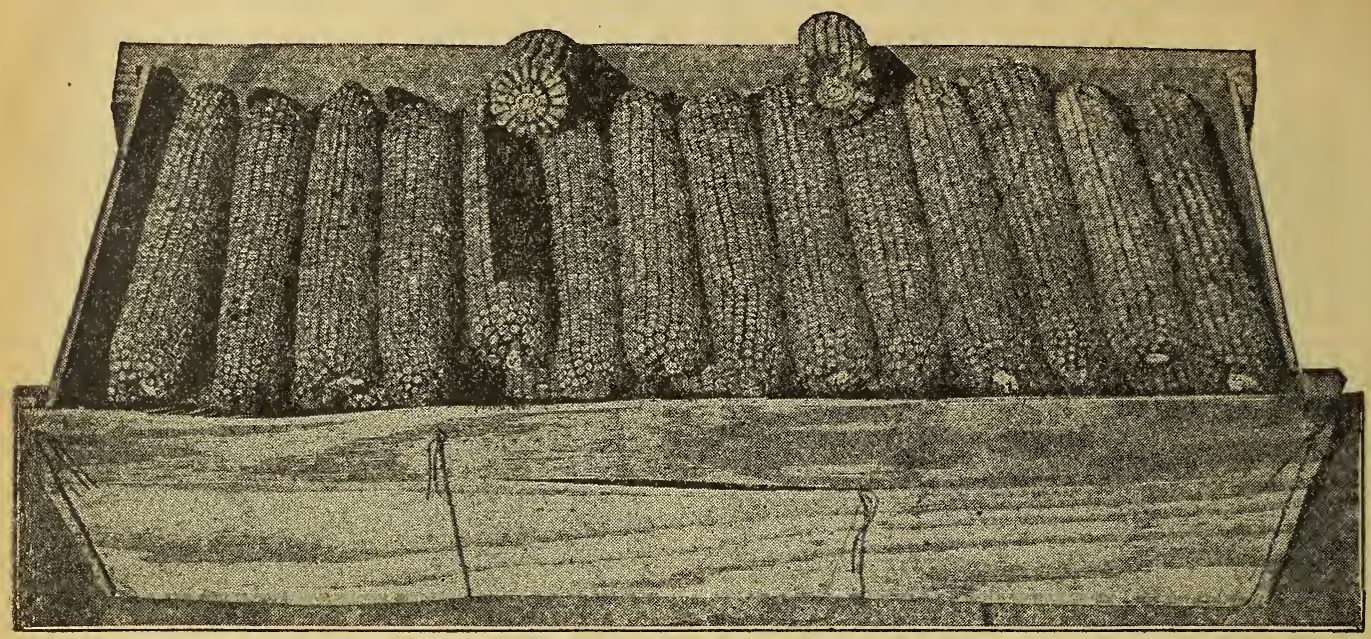

\section{A Crate of Our Iowa Type of Reid's Yellow Dent}

I don't claim that all our corn runs as good as this, but this shows the type Also I wanted to show you the kind of hipping crate we use. It is solid all the way arnund, sq. the mice and the freight handlers can't get into it. It is fastened with wires, so there's no danger of its coming apart. Generally, the corn is not as perfect on the butts and tips as that, however, for very often we will shell off part of the butt or tip, so we can see the cob and see what the grain looks like and juige as to its germination and soundness.

\section{Ear Seed or Shelled Seed}

You can take your choice, The corn is the same whichever way you get it, I was the first man in the seed business to push ear seed corn, and I probably have sold more of it than any other man in the business. I still offer it for sale, and it is here for you if you want it. I really believe, however, I can give you a better value in the graded shelled seed. The tendency in the last two or three years has been more and more toward turning out the very best possible grade of seed orepared all ready for the planter, We were the first film to offer graded seed. This year, in addition to the most rigid selection in the ear, the best possible mechanical grading, ne are hand-picking wur corn to remove any possible poor grains that may have escaped the grader.

This makes it easily possible for us to turn out a practically perfect grade of shelled seed. We test a sample of every lot of shelled corn and do not ship it unless it shows a satisfactory test, With the ear corn we make as careful a selection as possibue, but leave the testing to you. With ear corn you have some waste, prob. ably about twenty per cent to the bushel, whereas the graded seed is all clear seed, with no waste whatever. Now, I do not wish to influence you in your choice of shelled or ear seed, and I am perfectly willing to scll it to you either way you want it, but I tell you frankly that the gradid seed is the best and nine-tenths of what we sell is this graded seed. It used to be that two-thirds of all we sold was ear seed corn, but now not one bush. $\mathrm{el}$ in ten goes out in the ear. It is simply a case of better value the other way.

If you could get it in the ear and have it sraded, too, it would be all right. But you can't have both, so you will simply have to take your cho.ce. If you want ear seed corn, I am here to sell it to you, and it will be mighty fine corn, ton, but no matter how good it is, it will never shell up just alike, best you can do. If you order it shelled, you get it grader, and when you come to plant, you will agree that it is a mi hty nice way to have it. Any seed corn that is shipped you, if it doesn't look like you think it ought to, ship it back and I will refund eve.y cent you paid. I seil it subject to your own test and approval, I will sell yo 1 corn that you will be proud to show your neighbors, either the seed or the crop. I will sell you seed either in the ear or shelled, and if you want every ear tested, I wiil do that for you.

\section{The Four Vital Points of Corn.}

There are-four vital points on seed corn that 1 have always insisted on; and it will do no harm to sum them un here:

1. Germination.-It must grow and grow well. No matter how good a variety it is, it will do you no good unless it will grow. We test all our seed corn and sell it subject to your own test and rejection

2 Grading-It must be graded so it will run well in any plansive machinery, and we have fitted up so we can turn out mighty near perfect quality.
3. Thoroughbred Types - A man is always proud of corn that "shows breeding"-corn that looks al ke in the pile. This can come only from special breeding and selection from $y$ car to year, and this is what we have been doing for you.

4. Yield. - You want varieties that will give $\nabla$ ou big yields. This is the most important of all. What we all aim at is 100 bushels to the acre of shelled corn. Mighty few of us strike it, but we are working that way. In our seed business, we have always put yield ahead of fine points and have tried to send out varieties that wil give the far. mers big yields,

Now if these four main points on seed corn fit your ideas we shall be glad to have you try some of our seed corn. 


\section{Seed Corn For Your Locality}

Some people think that because we are in Iowa and they are in some other part of the United States we cannot furnish them suitable seed corn for their climate. At first glance this would seem to be true, and it would be true if we grew or ly a limited number of varieties especially suited to this soil and climate only.

But the fact of the matter is, we grow a wide range of varieties, snmething like thiriy in fact, and we grow special varieties for special localities. The corn that does best right $h$ re is a big rough corn, requiring about 100 to 110 day's season. but we also grow for the northern trade, small, eatly corn, as early as $\mathbf{8 0}$ days, and hardy enough to rinen anywhere in the corn belt, and we grow big, late varie. ties for the south, corn that will stand the hot summers and the droughty falls of Oklahoma, Texas and Mississippi. No matter where you live nor what kind of soil you have, we can fix you out with corn that will be a help to you. We have made a special study of the varieties of corn and their value for different localities and we intend to give you the benefit of it.

\section{lowa Seed Corn the Best}

The seed corn grown here is generally better than what you would get in your own locality, because it is grown under ideal conditions. Iowa, and especially this southwestern part of Iowa, is the ideal corn country. The soil, the climate, the rainfall and everything in that line, tends to grow the largest possible crops of corn and to mature it to its best possible condition. Our soil is warm and slightly sandy, which forces a ranid growth on the corn and alwavs dries it out perfectly.

The result is that the seed is vigorous, plump, hardy, and full of life. The same variety grown under adverse conditions, for instance in a cold, clammy soil, would look entirely different and would not make nearly so good seed.

Pride of the North, for instance, is an excellent variety for southern Minnesota, but seed of it grown here in southwestern lowa will make a much better crop in Minnesota than seed grown there. It is heavier, plumper seed, thoroughly matured, and grows off quick and vigorous, and all through the season will be about a week ahead of the weaker devitalized seed grown under hard conditions and subjected to early frosts.

I have tested this matter by sending samples of corn by the thousands to every part of the United States. One vear I sent out a set of ten varieties to over 10,00 f farmers scattered over every state in the union and I got reports back from thousands of them. The universal verdict was, that the seed grew vigorous, and healthy, and strong, and made a much better crop than homegrown seed, so you see this is not guess work with me. It is actual knowledge. If you don't believe it, try it on a small scale, say buy a bushel of corn from here and plant 7 to 8 acres with it, then com pare that with what you grow from your own seed and you'll see the difference.

\section{Your Check Is Good}

Don't wait to get a draft or money order. Your check will suit us just as well if you have the money in the bank to back it up.

\section{The Choice of Varieit?}

It is important, very important, that you choose the right variety. A great many failures in sending off for seed corn are due to customers picking the variety they want instead of getting corn that is suited to the soil and climate.

I propose to give you here a few pointers that will be of help to you in a general way. Of course, I do not claim that any state will run alike all over. so you will have to take these notes in a general way.

lowa. Practically any of these will be all right for the southem halt of the state, and all you will have to decide will be whether you want an early or a late corm. In the northern part of the state the standard varieties, such as Silvermine. Shenandoah Yellow, Reid's Yellow Dent, and Boone County white are not safe for a main crop, but should be grown on a small scale with an idea of selecting a type suitable to your climate. In a favorable year they will ripen all right and make an enormous crop, hut in a short season they will get caught by frost. For an absolutely certain crop use medium-early varieties, such as. Pride of the North, Shenandoah Special, and the early type of Silvermine. In the extreme northern part of the state use Extra
Day, Pride of the North, and Silver King.

South Dakota. In the southern part of the state, especially along the Missouri river, large varieties like Silvermine, Shenandoab Yellow, Reid's Yellow Dent, and White Elephant can be grown safely. For the north use the earlier sorts, such as Pride of the North, Extra Early White Dent, Shenandoah Special, Red 90 Day, Silver King.

Minnesota, Wisconsin and Michigan. It will be a good plan to plunt small amounts of several large varieties of corn for experimantä purposes and for fodder, but for a main crop take varieties like Shenandoah Special, Pride of the North, Silver King, and others still earlier.

North Dakota. Only the earliest varieties of com will succeed in North Dakota, Plant the flint varieties and small amounts of the earliest dent varieties.

Rocky Mountain and Pacific Coast States. Only the earliest varieties of corn can be grown. Experiment with Silver King, Extra Early White Dent, Red 90-Day, and the flint varieties.

Nebraska. In the southeastern part of the'state all the standard lowa varieties can be grown with good success, as conditions there are practically the same as in southwestern lowa. In the northern and western part of the state, however, the small varieties should be chosen and the farther north or west you go the smaller corn you should choose. White Elephant has done uncommonly well as far west as Furnas county and some years even further than that.

Kansas. In the extreme western part of Kansas. owing to the high altitude andidry seasons, only the smaller, earlier varieties of corn should be grown. Red 90-Day and the Extra Early White Dent have given good results in that part of the state. In the central and eastern part of the state the larger later varieties of corn should be grown. White Elephant, Boone County White, Cornplanter and Shenaridoah Yellow seem to do especially well.

Missouri. Except in the thin soils of the Ozark region, the large rank-growing corn can be grown all over the state. Cornplanter, White Elephant, Boone County White, Reid's Yellow Dent and Shenandoah Yellow have all done remarkally well all over the state except in the mountain regions. In the thin soil af the Ozarks white corm seems to do better than yellow, and White Elephant and Silvermine planted rather thin seem to give best results.

III ois, Indiana, and Ohio, Reid's Yellow Dent and Boone County White seem to be especially suited to the rich, black soil of these states. In fact this is the home of these two varieties. Cornplanter and White Elephant seem to do well except in the extreme northern part. The north tier of cour ties in Indiana and that part of Illinois lying north of Chicago need earlier varieties of corn for main crop and should use Shenandoah Special and an early type of Silvermine.

\section{Which Variety Shall I Plant?}

I suppose we are asked this question a thousand times a year. It all depends on your soil and season. Don't get too late a corn. You want one that will ripen in your locality. If your soll is thin or old and worn, don't get abig, rough, heavy corn, The Jand won't carry it. On old or thin land I would advise Silvermine, on land a little better, White Elephant, and on good strong land Corn planter and Shenandoah Yellow. On good land they will beat any corn you could grow, but on thin, poor land they would be likely to fail. 


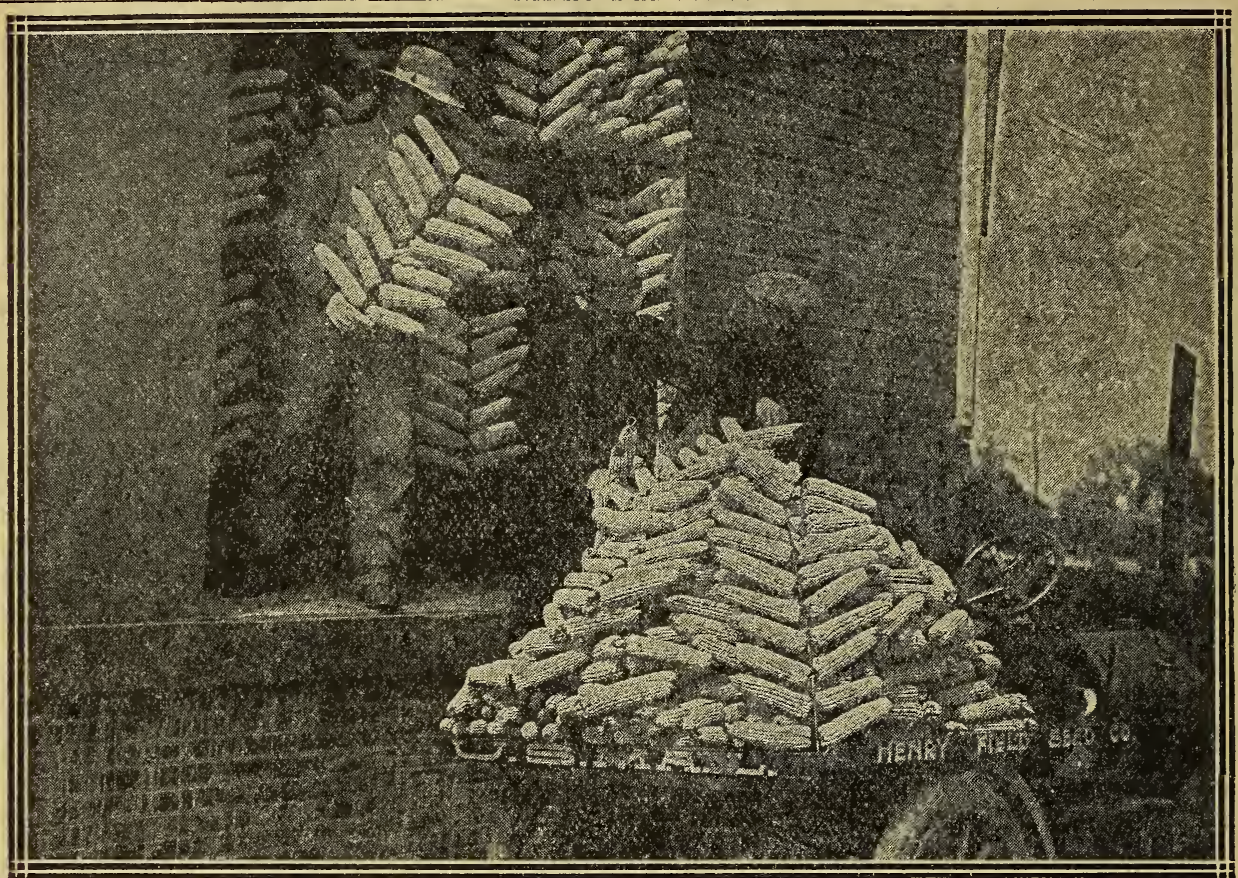

This Shows How We Make 100 Per Cent Seed Corn. Corn Handled This Way Can't Help Growing

This picture will give you a good idea of how we are making sure of good seed corn this fall. That's the only sure way. Hang it up and get it dried out before it freezes. We have had a gang of men at work at it since September and we have thousands of bushels of seed hung up All big, fine, sound ears, too. And they will all grow. You couldn't kill em with a club. It takes money and work and storage room and nerve to do it on the scale we have been doing it this fall, but when il's done, you've got something.

\section{Plenty of Good Seed Corn in lowa}

We always did and always will have the edge oveI the rest of the state and the rest of the worid on corn, and especially seed corn. It's partly in the soil, which is warm and rich and loose, and a little sandy, and ripens corn to perfection. And partly because we're pretiy good farmers here, and partly because we grow the right kind of corn.

And maybe we're just naturally favored and lucky. Or maybe its partly good luck and partly good management.

But anyway, we've got the goods. And we are willing to show you. We've got plenty of good, sound seed corn that will test 94 per cent. or better, and wc will ship it either ear or shelled, and ship it subject to your own test and approval.

And if you want 100 per cent. corn, we can give you "single ear tested." or as we call it. "cer. tified" seed corn, tested $\mathbf{6}$ grains from each year, and all six growing strong. That kind will cost you $\$ 5$ per bushel, but some people say its worth it. You are the judge.

The regular grade of good, first-class seed, ear or shelled, 94 per cent. or better, sold on approval, will cost you $\$ 3.00$ to $\$ 350$ per bushel.

And if you don't like the looks of the corn you can ship it back and we pay the freight both ways. Now, if we can't trade on that basis, there's no trade in you.

\section{This is the Seed Corn For You}

The seed corn grown here in Page County" lowa, is exactly the seed eorn for you to use It is grown near your latitude, in your kind of soil, and your kind of varieties. You know what to depend on. You are safe in planting it. Here is another thing, When you buy corn of me you know it was grown right here and not shipped in from away off some where in a different country and soil. Ourcorn is grown right here in these two counties, all except our extra early corn.

\section{Better Order Early}

My advice would be to get your order in early, so you can get the corn, and have plenty of time to test it. We have got plenty of seed, not much danger of running short, but I want you to get the seed in plenty of time to satisfy yourself that it is all $\mathrm{O}$. K. Also I am secretly hoping that after you have tested it you will tell your neighbor about it in time so he can order some too. Alsc when you order early we have more time to tend to you, and fuss around and get your order up in fine shape, just the way you and I want it.

So please order early. 


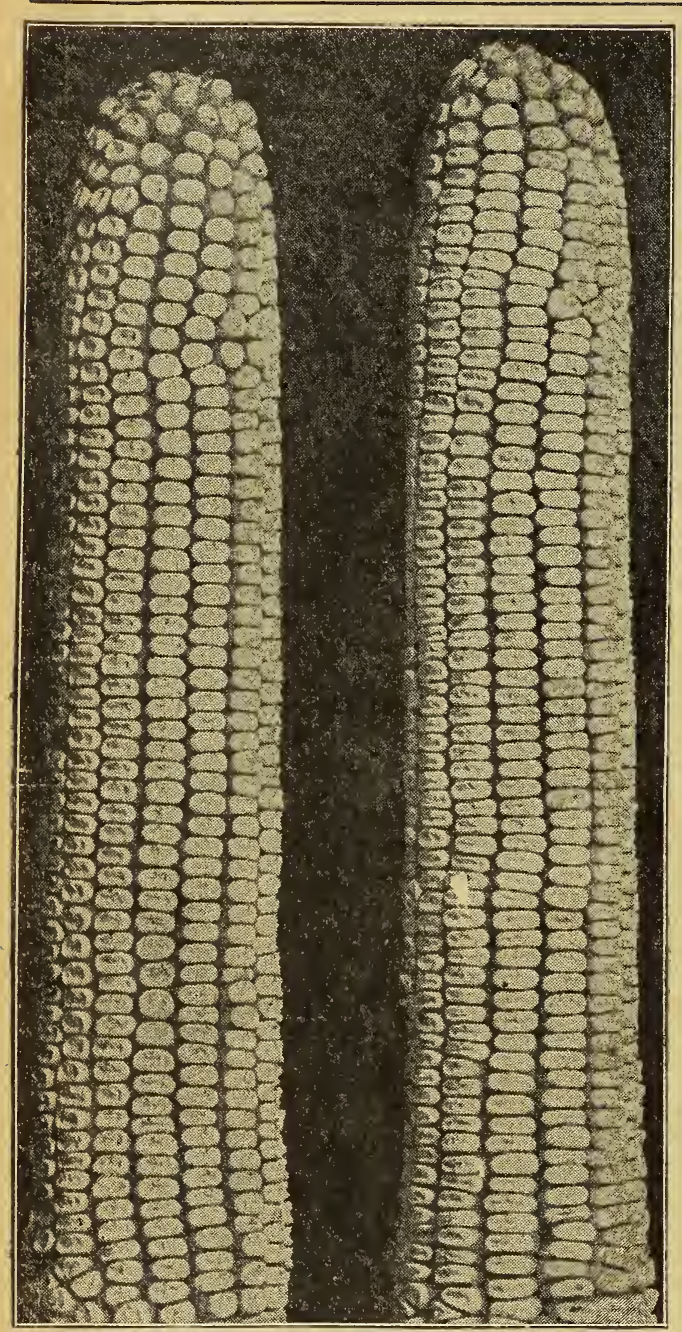

White Elephant

\section{The Largest Corn Grown}

This enormous white corn brought out by me a few years ago has proved to be the greatest win. ner in seed corn that has ever been sent out. I sold over 8,000 bushels of it last year and shipped it to practically every state in the union that grows corn, and I have had universally good reports from it. Even in New England it made a good crop. I have had hundreds of letters about it (maybe I can send you one from your locality if you wish), and not a kick in the lot. It has proved to be all that I claimed in size, appearance, arid yield, and a little earlier than I predicted. There is no corn anywhere near the size that is as early.

As early as Silvermine, it is nearly half longer, and in fact bigger than any white corn I have ever grown, except possibly the new "Cornplanter" corn; I won't swear that it will make 200 bushels to the acre, for I doubt if any corn ever did it, but it will come nearer to it than any other corn will. It and the Cornplanter are a revolt against the tendency of the last few years to breed corn down too fine. The farmers in this part of the Corn bult are getting tired of the little 8 or 9 inch cars with pretty tips and a little wee cob. What they want is a whacking big ear a foot long. with lots of corn on it, medium heavy cob, and a big stalk. It is the same thing that the Poland China hog men have just been through.

\section{Description}

A pure white corn of immense size and un usual length. Bulk of crop, if on good land, will run 11 to 13 inches. with occasional specimens 14 or even 15 inches long. The one in the illustration is about 14. Grain medium deep (five-eights inch), very wide and thick. Chalky white on top. and clearer below. Germ very large. Not so rough tcp as Silvermine, but of the true "dent" type. Rows 14 or 16, straight and close together. Cob pure white and medium size. Shape cylindrical with butt end slightly swelled. Notice in the picture. Season, about the same as Silvermine, say 100 days, Stálks abnut medium height and very heavy up to tlie enr, which is generally set at about five feet or a little less. Stands up uncommonly well. practically no down corn.

This corn originated $w i$ ih an old man a little farther down the valley, and has been selected and bred to a certain type for 15 or 20 years. None of us could get any seed of it till four or five years ago. I have never seen or heard of any corn like it anywhere else, and you will find it entirely distinct from other varieties.

Dozens of men who beught seed of this corn from me last winter have written me that they were having calls from their neighbors for all they had to spare tor seed, and that the only kick they had coming was that I did not induce them to buy more seed to start with. I honestly believe that this is the most profitable corn that can be found for the central Corn belt. It is vigorous, healthy, a rank grower and an enormous yielder. Early enough to ripen easily, ears a foot long, no down corn, and a corn that will always overrun in weight either ear or shelled. That kind of corn is good enough for me. How does it strike you Remember, the shelled seed is graded so it will work in the drop edge planters perfectly. This is a mighty big thing when you come to think of it.

I have said just about all I know of this wonderful corn; and say, if those fellows down in New England make no kick about growing it in that rocky, rough ground and fickle climate of theirs, how in the mischief can you farmers out here in the Corn belt knock, where you have the best corn in the world?

The White Elephant is not a show corn, and never will be. It is too large and to coarse to score well. It is not a pretty corn, except that "Hand some is as handsome does." But when it comes to bushels in the wagon box, its right there with the goods.

I have splendid reports on it from New York state; Michigan, South Dakota, Wyoming, Oregon, Arizona, and Texas, as well as all the regular central and southern corn-g owing states, and about the best photograph I ever had of it was sent me from Rhode Island. Think of it! You couldn't get much farther away from home with lowa corn. 


\section{"Cornplanter"}

Our Improved Boone County White Corn.

The demand in seed corn is for a big ear, moderately rough. and of fine quality. That is, it should show the deep grain, fine tips and butts, and other marks of good breeding. The trouble has been that when you got corn a foot long, it was coarse and in. clined to be a short grain. If you got the deep grain and fine tips, the ear would be little.

In the new Cornplanter corn, I have just what we've all been looking for, I didn't originate it myself, but I had to admit it was better than any. thing I had, and you know that means a good deal. A few years ago it skinned us all at our corn show--farmers, seedsmen and all.

It does a body good to get , well beaten sometimes. We got badly whipped and we thought we were well-fixed on the white, but a farmer from the north part of the councy came down with twenty-five ears of big, white corn that he entered in a free-for-all class, and we weren't in it for a minute. The prize was a new Avery corn planter and he got it, But I got that corn after the show and I have improved on what he had.

The corn was some he had grown from seed secured from a friend in II. linois, who had started with Boone County White. It resembles that corn more than any other, but is different in several ways,

After the show I bought the twen. ty-five years and planted about two acres and $a$ half with them, Owing to cut worms I got a poor stand, but I got about 200 bushels of the finest corn I ever saw. That is the start of what I offer now, I admit it is the best corn I have ever had on the place. It has the size, the form and the yield. The big, growthy type is there, and the quality, too, In the four years I have had it, I have improved it materially, and I don't be. lieve many corn-growers can show the equal of it, I know no seedsman can.

\section{Description}

A pure white corn on a white cob. Not a red cob in the lot. Ears over average length, The original twenty. five averaged twelve inches Inng. In a good crop, Season about the same as Boone County White, or a large amount of the ears will carry this length. say $1: 0$ days. Ripens in plenty of time in this lat. Not slender like so much of the long corn, but big itude and 100 miles north. Compared with other in proportion, Very deep grain, not overly wide. varities it is about two ir.ches longer than Bonne... Rows generally 20, sometimes 22 or 24, and occa. better shape, better grain and dries out better. sionally 18. As perfect shape as Rid's Yellow Not so long as $W$ hite Elephant, but rougher and Dent. That is the striking thing about it...big, larer around. No other white corn can compare long ears, beautiful shape, perfect butts and tips, with it, and I have tried pretty much all of them, and deep grain. Grains fit very tightly together, In yield it is ahead of allothers. There is no ques. showing square rather than rounded top. Stalk tion about this. All who have seen it growing ad. very strong and of medium height. Ears lap over, mit thit, and they report it a neighborhood ad. but shanks are not long enough to blow off easily. miration. 


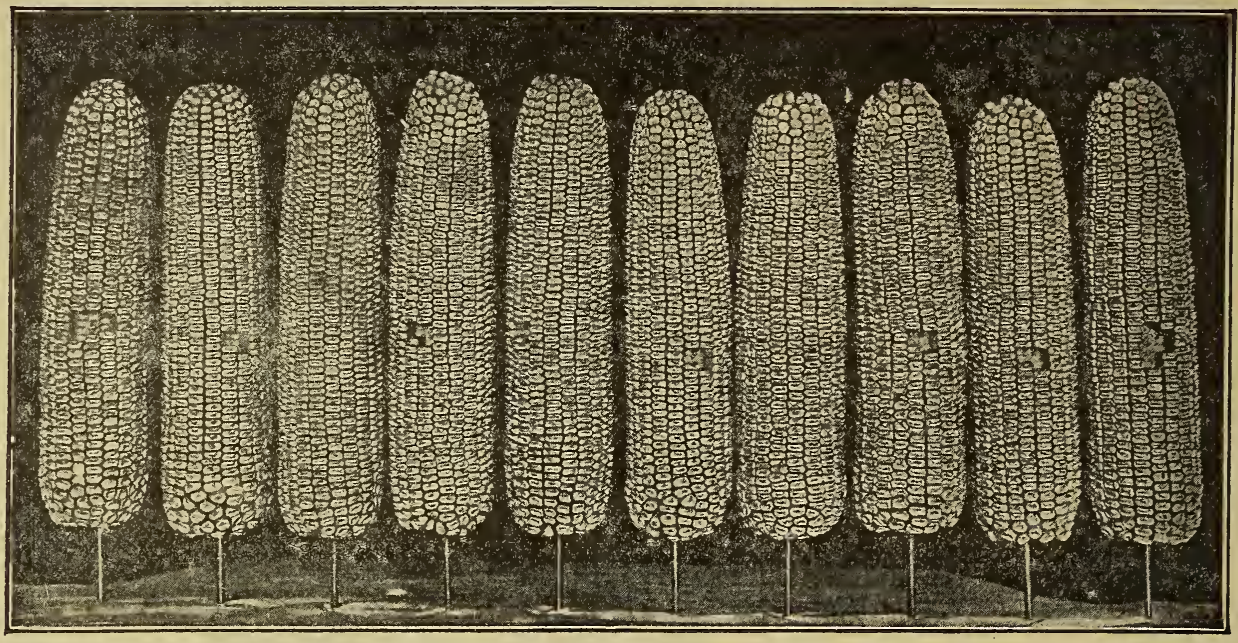

This picture shows what is supposed to be a perfect type of Boone County White, and is worth studying on that account. I don't want you to think though, that all my corn is as good as this - I wish it was; some day maybe it will be; I am working toward it.

\section{Boone County White Corn}

This famous Illinois corn is, in my opinion, a better variety than Reid's Yellow Dent, but is not so well known, It is being grown to a considerable extent here now and is becoming quite pnpular.

It is a very large white corn, somewhat like Silvermine, larger and later. It is larger around than White Elephant, but not so long.

Description. Ear 10 to 11 inches long, cylin drical, 18 tu 22 rows, generally 20 . Grain very deep and iather rough. Well filled at both ends. Cobs always white and medium size. Very large and a heavy yielder. Season 110 to 120 days. Not safe for planting north of Des Moines, but for anywhere south of there it is a very valuable corn.

\section{Imperial White---Red Cob}

This is a big. heavy, rank-growing white corn with a red cob. Most corn breeders object to a red cob in white corn, but the fact remains that many farmers prefer it, and it often seems to do better than the white-cob white. This may be just a fancy, but there is certainly a strong sentiment in many places in favor of red.cob corn.

It is certainly a good corn any way, and I know you will like it. The ear is large, deep-grained. and medium in thickness. Stalks very heavy and stand up well. No down corn.

\section{lowa Silvermine}

This is more generally grown throughout the corn belt and more widely and favorably known than any other white corn. It is a sure cropper, middling early, deep-grained, pure white and a good corn every way. On old, thin land it will make a better crop than any corn you sould plant, as it seems to be able to adapt itself to hard conditions. In fact, this is true of most white corn. but the Silvermine will come nearer to making a crop on thin land than any of them. On very rich land it has made some enormous yirlds, but I think that there the White Elephant would beat it. I have been selecting the Silvermine for several years with a view of getting the deepest possible grain and the highest possible shelling test. I have a strain now that I have not seen equaled anywhere. It is the true, rough-topped, deep-grained type that is so much sought for by most white corn men. Cob is very small and pure white. Rows generally 16 , very straight, and very close togecher. Shape cylindrical. Stalk a little below average height, about 8 feet on the ground. Season 100 days. If you want a new start of the best type of Silvermine you ever saw, I've got it, and can supply you with either ear or shelled corn. The shelled seed is all graded so it will work in any planter. As I have a big supply of it I shall be pleased to quote special prices on large lots.

\section{Johnson County White}

This corn originated in Johnson Co., Ind, and has won the grand sweepstakes prize at the national corn shows for the last three years. The corn is rougher and has a sharper taper than Boone Co. White. Rows are very straight and uniform. The stalk is rank with heavy joints and large broad leaves. Medium late maturing variety, requiring a growing season of 120 to 125 days. Mighty good corn and heavy yielder.

\section{Your Check Is Good}

Don't wait to get a traft or money order. Your check will suit us just as well if you have the money in the bank to back it up. 


\section{Shenandoah Special Corn}

Best Second Early ox Intermediate Yellow Com

There has always been a call from my customers in the northern part of the state and in Minpesota and the Dokotas for an earkier strain of the Shenandoah Corn. The regular type would generally ripen for them, but tiey would ocersionally get caught with an early frost and they wanted an earlier type os the same corn. We have bexn experimenting along that line for some time by selecting the earliest cars to ripen and planting them separately. These ears are generally smaller than the others, and smoother, as you have probably noticed. By keeping this up for a number of years, keeping the best ears all the time and throw. ing out any that were at all shallow, we have at last succeeded in fixing a strain that is the earliest dent corn that I have ever seen and at the same time almost as large as the regular Shenandoah type and fully as deep-grained. It is almost as early as Pride of the North, and much larger. There are few, even of the big varieties, that are ahead of it in yield, and none can approach it in combined yield and earliness,

It is simply the Shenandoah Yellow about an inch shorter, an inch less in circcmference and 10 days earlier. It is of the smooth or true "dent" type, instead of being rough like the parent, and the grain is harder. Color, a deep yellow with a light cap. It is remarkably thoroughbred and uniform in appearance and comes "as like as two peas." It is no cross bred stuff. Grain is very deep, and it weighs and shells out exceptionally well. The best specimen ears are about 9 inches long and $6 \frac{1}{2}$ inches in circumferenre. A little more tapering than the pacent and smoother and harder. lt should shell out about 88 . Cob small and red. Stalk comparatively short (ajout 8 feet), but sturdy and tough, and rather wide and spreading in appearance. Stands up well. I have had fine reports on it from everywhere. In the past summer it ripened nicely way up in Minnesota and the Dak. otas. It was also very successful in the East, and ripened there in many localities where it was thought that nothing but flint corn could be grown. The Farm and Home published this report of its behavior on the paper's trialgrounds at Spring. firld, Mass.: "A rank-growing yellow dent, esp.c. ially promising, Produced a large growth of fodder with big ears. which were well glazed and in the best condition to put in the silo at time of cutting.

\section{The Perfect Bushel of Corn}

Uncle Henry Wallace says: "The perfect bushel of corn is like the perfect family, or the perfect neighborhood - something very rare in this weak, erring world of ours. Go to your own crib and pick out a bushel of the best ears you can find, and see how rare is the perfect ear, one that comes up to the standard in every way."

I've got some pretty good corn, but I don't want you to think it is all perfect ears. Just the same, I am sure you cannot get better corn anywhere at any price. I know the corn I sell.

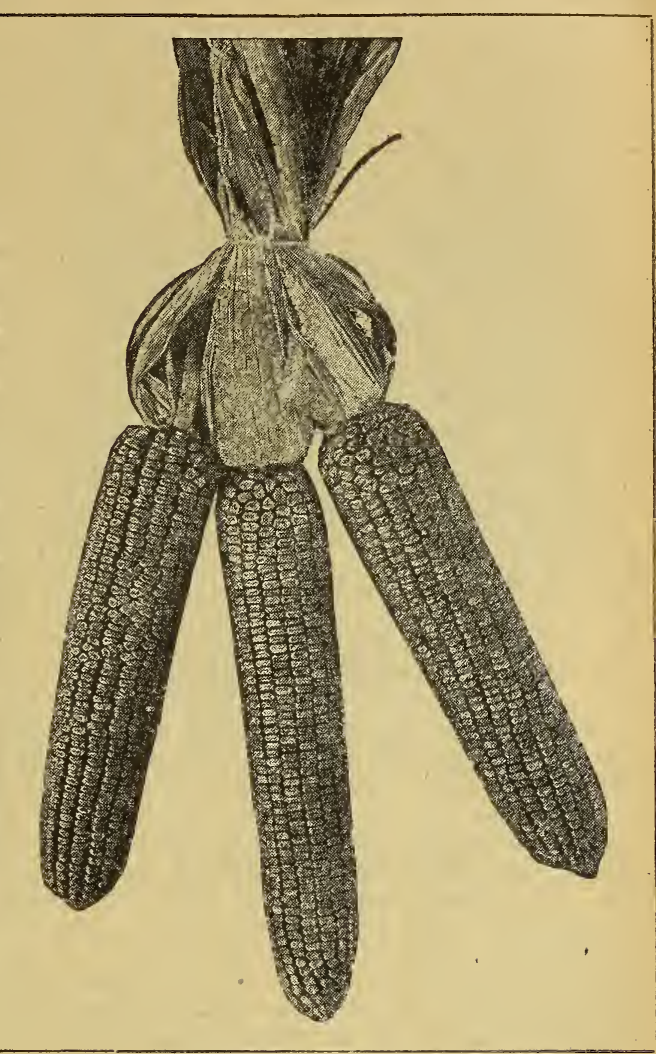

Shenandoah Special

\section{Reid's Yellow Dent}

This is the best advertised corn in America and has won more prizes at corn shows than all other corn put together. It is remarkably uniform and thoroughbred, and if you want something that that will make the prettiest corn you ever saw, the R. id is what you want. It was brought out first in Illinois, and the growers there got it down to perfection, but they got it down almost too fine. They went in for fine tips, straight rows, small cob, etc., and gradually ran it down in vigor and size till the first that came in here was poor corn, according to our ideas, and at first 1 refused to offer it.

We started in, however, to work it over to our idea of good corn, and now I am ready to offer a strain of Reid's that approaches the Iowa idea. It is rougher than the original Illinois type, bigger in every way, bigger stakss and more vigorous. The cob is larger, but not at the expense of depth of grain. It is still remarkably deep-grained, but we have increased the circumference of the ear.

It is mighty good corn. Color deep yellow with a rather light cap. Grains very closelv picked, butts and tips almost entirely covered over. Grains very deep and dented on top. Slightly rough. Season 110 days. If you have tried the Illinois type and found it a disappointment, I think this will suit you. 


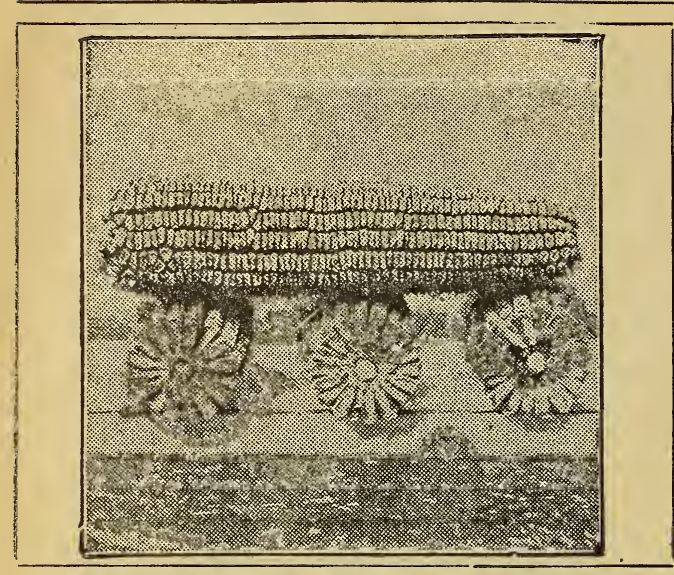

Pride of the North. Best 90-Day Yellow Corn

\section{Early Corn}

I have a big sale every year on early varieties of corn for replanting. If there comes a cold, wet spell about the last half of May, I am always covered up with orders for corn to replant with, but I always prepare for it, and have a stock of early varieties on hand all shelled up, graded and ready to ship. Send along your orders by mail, telegraph, or telephone, and I will fix you out.

For the northern part of the corn belt the varieties given here are the ones for the main planting. They are all early, hardy varieties that will ripen easily as far north as corn can be grown at all,

\section{Pride of the North}

\section{(Yellow Ninety-Day.)}

A very desirable first-early dent corn, suitable for main crop as far north as St. Paul. It is remarkably thoroughbred and true to type, and the strain I offer is the best I have ever seen. It has been carefully selected here for several seasons and is much better than most of the Pride of the North. Color deep yellow, grains quite deep, with very small, bright red cob. Rows generally 14 or 16 , grain rather narrow and inclined to be rough on top. It is generally about eight inches long, but as it a.most always makes two ears to the stalk, it makes a good yield, often equal to the big varieties. It is very hardy and will stand cold weather. Red 90-Day, or Early Bloody Butcher

This variety was brought here from Illinois the "grasshopper year" (1875), by farmers who had to replant their corn in June and July after the grasshoppers had eaten off the first planting.

In color it is a deep cherry-red with white cap; cob small and pure white. Ears 8 to 9 inches long and rather slender; generally 14 rows. Stalk medum height and moderately heavy ${ }^{\circ}$ Grains dented and sometimes rough. Remarkably thoroughbred and always comes true to type. It can be planted in this latitude as late as the middle of June and make a safe crop, Can be used as a main crop as far north as St. Paul.

\section{Flint Corn}

(Yankee Corn)

For the extreme northern part of the New England States, and for all extra thin, cold land anywhere. It is earlier and hardier, and will grow under most adverse conditions. Can s uppIy either yellow or white or a cheaper grade of the same corn for fod. der.

\section{Acclimated Seed Corn}

On most of these early sorts I can sup. ply Dakota, or Wis. consin-grown seed for

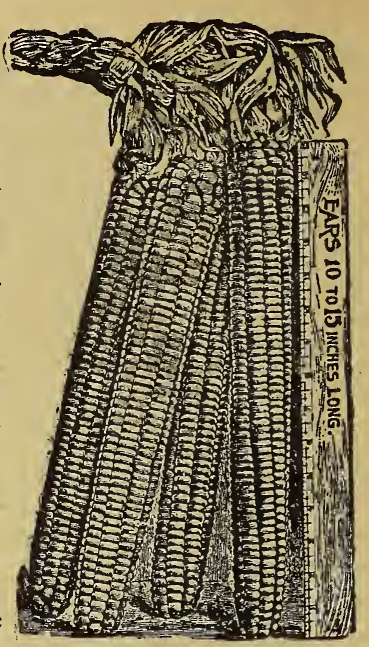

Flint Corn those who prefer it. The northern seed is apt to be a little earlier, but not so large, and is always a shallower grain.

\section{Improved Calico}

The old fashioned striped calico corn has al. ways been popular as a feeding corn. Not strictly an early corn, but is generally earlier than the big standard varieties. The color is a combination of red and yellow striped.

\section{Silver King}

The Best Extra Early White Corn

I believe that, all things considered, the best early white corn for main crop in Northern lowa, Southern Minnesota and Southern Wisconsin and for early corn farther south is the Silver King, or as it is sometimes called, Wisconsin No. 7.

It is a very early variety and at the same time is of good medium size, deep-grained and a heavy yielder.

\section{Extra Early White Dent}

(85-Day Corn). Very early white corn of the dent type; comparatively shallow grained, well dented, slightly rough, medium-sized ears, generally 12 rows of grain, the earliest of all white dent corn.

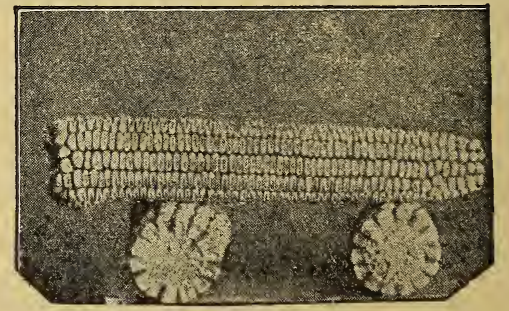

Extra Early White Dent

See page opposite page 73 for Corn Price List, Guarantee and General Instructions 


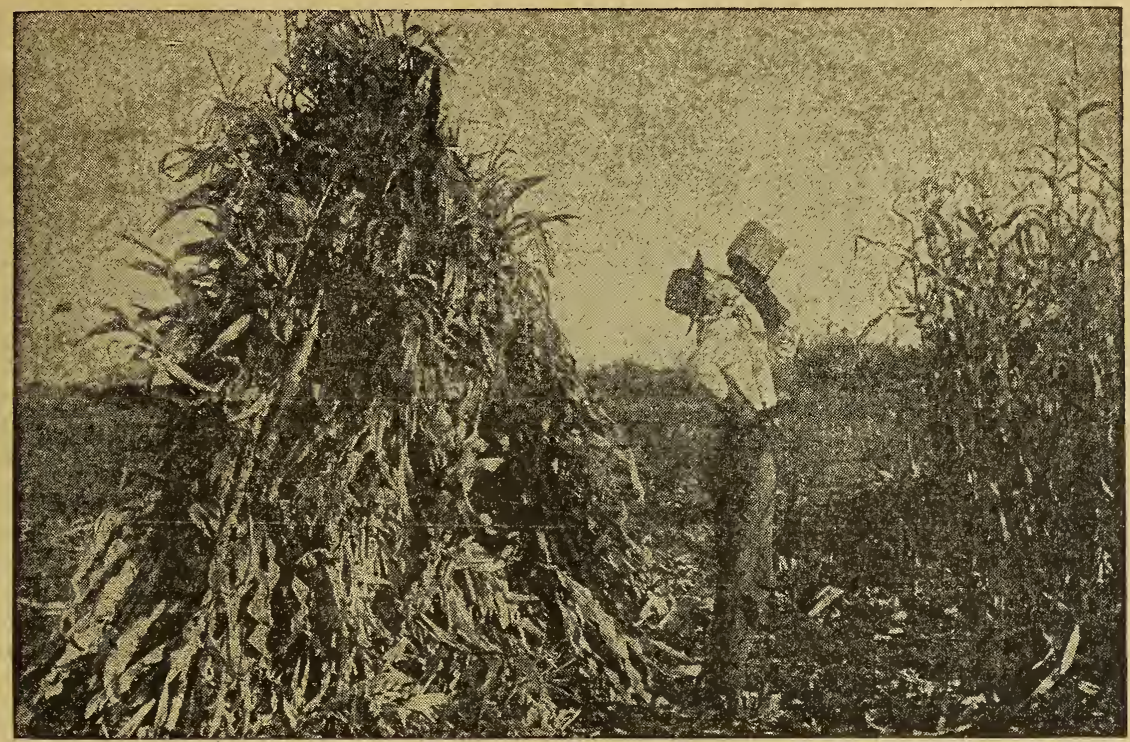

\section{Ensilage and Fodder Corn}

(For Prices See Blue List Opposite Page 73.)

There is a large and increasing demand not only in the east, but in the central west, for seed corn especially good for ensilage and fodder purposes It must be corn that will make a creditable show. ing of grain, It is important too, that it stand up well against the wind, so that it may be easily harveted. Western seed corn is for this reason much preferable to the eastern or southern seed, as it is used to the prairie winds and will stand up well in the face of winds that would blow down any eastern corn, This showed very plainly in my trial grounds. both this year and last, as corn from eastern seed went down badly, while the seed from lowa and other western states stond perfectly. I sold lots of corn last year to farmers in the eastern states, and this fall I wrote to a number of them asking how it stood up and how it succeeded in general. Almost without exception they replied that it stood far better than any other corn, making a better yield of fodder and grain.

Mammoth White Ensilage---A big, rank growing white corn, somewhat similar to White Elephant, but has been bred up with the idea of making an enormous crop of fodder. It makes big coarse ears that ripen easily in this latitude. Grows about 12 feet high on good land.

Leaming Ensilage-..-This is a special type of the leaming, very popular all over the east for fod. der corn. It grows about ten feet high, very leafy, stalks stand up well, and can be planted thicker than the big, white corn. Ears yellow, solid, fairly early, and of good size. Always can be depended upon for a good yield of both fodder and giain.

Fodder Flint Corn--.This is the principal corn grown in New England, and in fact, all through the extreme northcrn euge of the corn belt. It is hardier than the dent corn and will stand more cold an ripen much earlier than any dent corn.

Early Dent Fodder Corn---An early dent corn of medium height, ripening very early. Fine qual. ity.

Evergreen Sweet Fodder Corn---This is very much the same as the regular Stowell's Evergreen Sweet Corn, only not so carefully handled as the garden grade, It is of good germination, a vigorous, growthy type and good stuff in every way. It does not grow so large as field corn, but makes sweet fodder and can be planted very thick. It stools out much more than the field corn, and the stalks being finer the stuck will eat it up, stalks and all.

Early Sweet Fodder Corn-.-This is smaller than the Evergreen tupe of corn, but earlier, and is valuable for early feed, Specially valuable in the north, where extreme earliness is desired,

Fodder Cane---Many farmers use fodder cane and kaffir to mix with corr in silo. We can supply either one in good pure seed.

SPECIAL OFFER.--On any order of five or more bushels of ensilage or fodder corn, either all one or of different kinds. I will prepay the freight to any station north of the Ohio river, west of New York and Pennsylvania, and east of the Rocky Mountains. This includes all of the great central states. For 25 cents per bushel additional, I will prepay the fr. ight to New York, Pennsylvania, New Jersey and New England states.

Remember, this offer applies to ensilage and fodder corn only, and you must order five bushels or over at one time, and it must be specially mentioned when you order. It does not apply to other varieties of seed corn. 


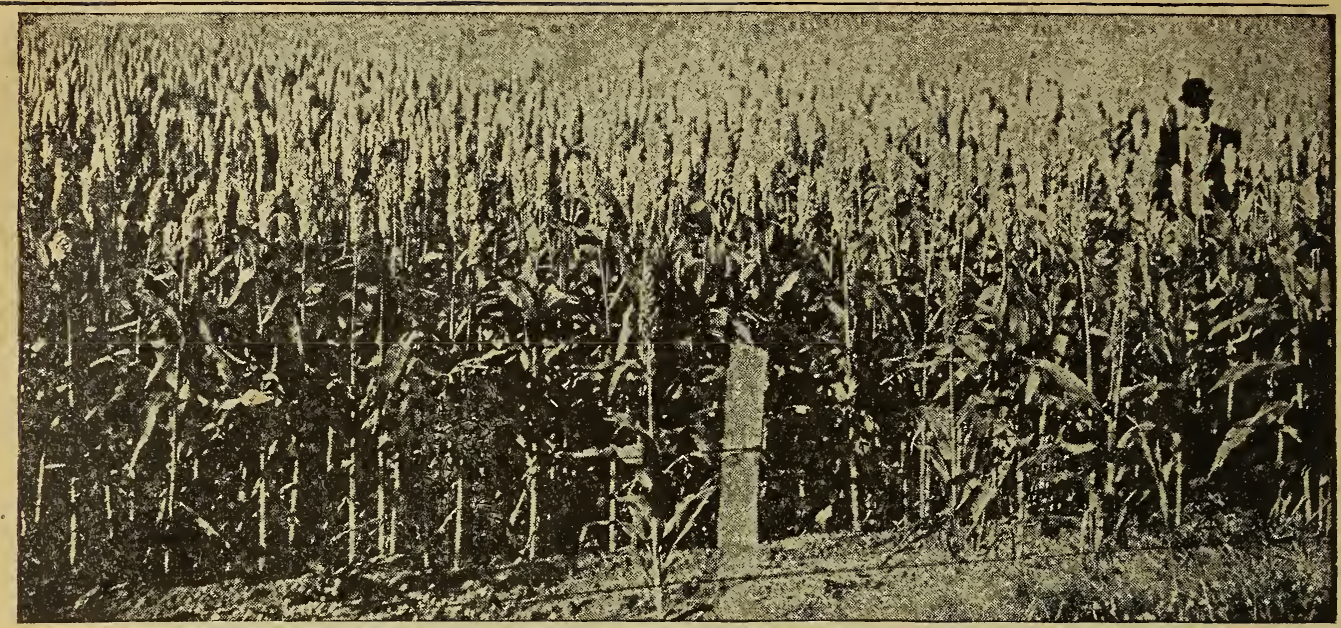

\section{Kaffir, Milo and Other Dry Weather Crops}

There is an increasing demand every year for the so called dry weather crops, such as kaffir corn. milo maize, feterita, shallu and other grain sorghums. In the greater part of Chlahoma, Kansas and Nebraska they are a more certain crop and a more profitable cop than field corn, and every year tsey are being more grown and more favorably known in other states all over the corn belt.

As a rule they will grow anywhere that fieid corn will grow and many places where, owing to a lack of noisture, field corn will not mature a crop at all. They will yield a crop of grain equal to a crop of field corn and besides will make an abundance of fodder, which can either be fed dry or put into the silo like ensilage corn.

There is a host of varieties of these grains, and unless you are wanting to experiment on a big scale it would not pay you to bother with all of them. I have tried practically all of them in my trial grounds and made quite a study of them, and the ones listed here are the ones I would advise you to grow. Any of these will be practically certain to succeed and we can furnish first-class seed of all of them.

\section{Feterita--The New'Grain Sorghum}

Feterita belongs to the same class as kaffir and milo, but is considerably earlier than either one, is said to stand drouth better and makes a larger, softer grain. In manner of growth it is about half way between laffir and milo, but the heads stand perfectly straight and erect and the grains are very lirge, pure white and comparatively soft. Can be fed without grinding.

We have received news from every section that fererita has withstood the drouth in practically every instance and has matured where kaffir and milo are complete fallures.

Feterita is the one crop that will beat the hot winds and drought by maturing thirty days earlier than kaffir corn and fifteen days earlier than milo. The feeding value of feterita as a grain and forage is equal in every way to kaffir, and we believe it to be much better on account of the grain being lar. ger and softer than kaffir.

Price, small amounts for trial, $10 \mathrm{c}$ per plkt., or $25 \mathrm{c}$ per $\mathrm{lb}$. Ask for special prices on larger amounts.

\section{Pedigree White Kaffir (Black Hull)}

The best authorities claim that it is just as im. portant to use selected heads of kaffir as select eas of field corn, We have arranged with a grow. er in Kansas to select abd save for us in the head, extra choice heads of kaffir from a strain he has been selecting for 18 years. See blue list for prices. Small amounts by mail, postpaid, $25 \mathrm{c}$ per pound.
Kaffir Korn for Fodder Purposes

We can furnish plenty of the ordinary grade of Kaffir corn, plenty good enough for sowing for fndder purposes, at a very reasonable price, As it requires 64 to $100 \mathrm{lbs}$, of seed per aere sown broad cast $f, r$ fodder, a cheaper grade is usually used for this, and we can furnish it to you ali right, but we would not advise this grade for growing grain. See blue list opposite page 73 for prices.

\section{Mlo Maize}

Next to kaffiir corn this is probably the bes! known of all the grain sorghuma. It does not grow so tall as kaffir corn, and as a rule does not yield as well under favorable conditions, but it ean be grown on less moisture and for that reason is quite largely grown in the western part of Kansas. Oklahoma and Nebraska, where Kaffir corn sometimes fails for lack of rain. The grains are con. siderably larger than those of kaffir corn and the heads, instead of standing straight up are inclined to droop more or less. Price, small amounts for trial, $20 \mathrm{c}$ per pound, postpaid, For large amounts see blue list oppusite page 73 .

\section{Shallu \\ (Egyptian Wheat.)}

I have been growing shallu in a small way now for two or three years and I like it very much. It makes a tall, rank growth of fodder, stands well and makes a big yield of grin. The heads sprangle out like broom corn. With us it grows taller and stands drouth well. 


\section{Sudan Grass}

The Great New Fodder Crop.

Last year when I told you about the merits of Sudan grass I suspect some of you thought that--.to put it mildly -I was stretching it a little, but another season of experience with it has proven rather that I did not tell it near strong enough.

It is undoubtedly the very greatest new crop since the introduction of alfalfa. That is the great thing about it-..it will grow anywhere, on any soil, and in any climate.

It is distinctly a fodder or hay plant. Ic produces lots of seed, but I do not think it will ever be grown much as a grain plınt. But it will make more hay or fodder, of a bet. ter quality, and with more ab. solute certainty of a crop, than nything else except alfal'a, and it has the advantage over alfalfa of being quick and easy to get.

It is certuinly "the poor man's friend." It will grow on even the thinnest of soil, and will make good in a dry season when everything else fails, and will feed a team and cow to every acre. The renter or small land owner who goes on a farm with no hay, can sow seed in May and begin cut. ting hay in July, and get another curting in August and another in September, Good hay, too.

Briefly, it is an annual plant, somewhat similar to cane or kaffir, but much more slender and fine. stenumed, easier to cure, hardier, quicker to mature, making a greater yield of better quality.

It stools like wheat and makes as high as 100 stems from a single seed. It keeps sprouting up and can be cut once a month. Ours planted in May was cut July 1st, when about five feet high, and by August 1st was five feet high again, and by September 1st was almost as high and ready for another cutting, The hay stays green, even after the seed ripens and if cut before frost makes the best of hay, besides a seed crop.

The best way to plant it is to drill it in rows corn row width and cultivate like corn. This takes from two to five pound of seed per acre. It can be cut by hand or with a mower or binder or corn binder. It handles easiest in bundles, as it is so long it tangles if handled loose, It cures easily and perfectly.

Many people in order to save the work of cultivating, sow it broad cast or drill it with a wheat diill, using about 20 pounds of seed per acre, and handle it with a grain binder. This gives about the same yield as the drilled crop and no cultivating, but takes more seed.

In an extremely dry country it should always be drilled in rows and cultivated so as to conserve the moisture. This is true of all crops in such countries.

The hay keeps easily, either loose, in bulk, or stacked or shocked in bundles. It can be fed

same as any hay, and has higher feeding value than any other hay except alfalfa. It yields about the same as good alfalfa, say 6 to 10 tons per acre of dry hay.

It is also fine to feed green as a soiling crop or to put in a silo like corn. It does not sour like cane, nor get woody like kaffir. Its greatest advan. tage over other crops is in its ability to withstand drouth. It will make a crop on less moisture than any other crop known. It was first introduced by the U. S. Depariment of Agriculure as a crop for the extremely dry regions of Oklahoma, Kansas and the Texas Panhandle, and they went crazy over it there. It made a crop every year in spite of dry weather, hot winds or anything else. It has prov. en equally valuable in other states, and has beer grown successfully in every state in the union. It is certain to supplant millet entirely and probably cane also, as it makes more and better feed thar: either and is easier grown and will stand more dry weacher.

It is important to get northern grown seed free from Johnson grass, and free from cane and kaffir hybrids. We are growing a big acreage of. seed here at Shenandoah, and can furnish genuine lowa grown seed, guaranteed free from Johnson: grass or hybrids, or weeds of an hind. Can also. furnish Colorado (mountain grown) seed and north west Nebraska seed to those who wish it, at the same price as Iowa seed.

Where ever you buy your seed, insist on a guar. antee on all the above points. They are import ant. Northern grown seed is far preferable to south. ern seed for planting either north or south. Price, see blue list opposite page 73 for price on quantities. Small amounts by mail, postpaid, 25c per lb. large pkt. $10 \mathrm{c}$. SPECIAL OFFER: I will mail, postpaid, 5 in the United States. 


\section{Miscellaneous Farm Seeds}

Note.-Prices on all farm seeds are subject to change. Small samples of any kind of farm seeds free. Large packages of any kind of field seeds for trial planting, 2 to $4 \mathrm{ozs}$., $10 \mathrm{c}$ postpaid. Price sub ject to 10 days acceptance. See blue list opposite page 73 .

Cowpeas

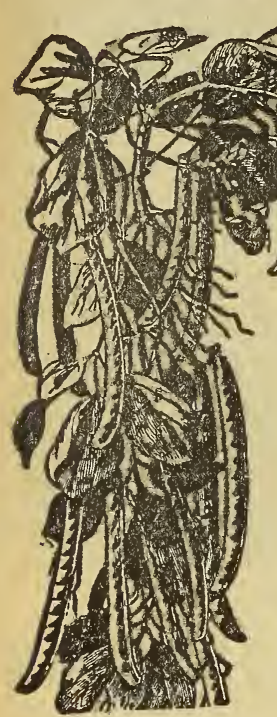

\section{Cowpeas}

These are not at all like the Canadian or Northern Field Peas, but are intended for summer or fall use, as they do best in hot weather. They are the kind grown so much in the south, where they take the place that cloverdoes in the north. They can be grown anywhere in the cornbelt fully as success. fully as they can in the south. You not only get a quick crop of green feed or hay, but the roots enrich the soil by gathering nitrogen as clover does. They will grow on any soil, no matter how thin, and will bring it up into shape quicker than any cron you can grow: They will make a fine growth where clover would be a failure.

Culture. - Cowpeas should not be sown until the ground is thoroughly warm, say about the time corn is coming up. They should be drilled, as they do much better that way than broadcast. I have sometimes drilled them with a wheat drill, using one bushel per acre. I have also drilled them with a corn planter. leaving them either full corn-row width, or straddling the rows and making the rows closer together. In this way you use from a peck to a half bushel per acre. They can be grown for hay or green feed, or can be plowed under for green manuring. I have tried every variety I could hear of and have decided that for the corn belt the Whippoorwill and New Era are the two best varie. ties.

Whippoorwill. Is a medium early sort, making a rather stocky and heavy growth of vine with a large amount of seed. It is probably the best gen. eral purpose variety grown. Seeds are speckled brown in color.

New Era. The earliest variety and the quick est to make heavy growth. They are bushy in form, rather than trailing, and will just about meet acruss a-foot row. For the northern part of the corn belt and for cruick results anywhere they are the best variety tis giow, making heavy yield of seed and a fine qua " $\mathrm{k}$ "

Mixed. Mary farmers, especially in the south, prefer to grow the cowpeas mixed, several varieties together, as they claim to get better results one season with another. A great deal of the seed we get is harvested from these mixed fields, and we have to sell it that way.

\section{Caution Regarding Cow Peas}

Be sure to say whether you want the Northern (Canadian) Field Peas, or the Southern Cowpeas. The Canadian Peas are a cool-weather crop and should be sown early. They are the ones to sow with oats. The cowpeas are a hot-weather crop, will net grow early or in cold weather, but make wo nderful growth in hot, dry weather. Say which you want.

\section{Canadian Field Peas}

This is the variety of peas grown so exten. sively in the north and northwest as a field crop. They are somewhat similar to the ordinary garden pea, but make longer vines and more pods. They should be sown very early in the spring, either alone or with oats or barley at the rate of from one to "wo bushels per acre. They may be cut and cured for hay or let ripen and threshed like small grain. They do not do well sown late in the season, as they grow only in cool weather.

\section{Small Amounts of}

\section{Cow Peas and Soy Beans by Mail}

I want every farmer to try at least a few cow. peas and soy beans, so I will send small amounts by mail, postpaid, as follows: Large package, $10 \mathrm{c}$, lb. $25 \mathrm{c}, 3$ lbs. for $60 \mathrm{c}$.

\section{Rve}

White Winter. The standard variety of winter rye. Fine seed.

\section{The Cyclone Seeder}

This is the best seeder made at any price. It is roomy, strong, works evenly and will sow any kind of seeds any desired thickness. It is fully guaranteed, and if not perfectly satisfactory may be returned at our expense. Price, $\$ 1.50$ net f. o. b here. If wanted by parcels post add postage for 5 lbs.

\section{Little Wonder Broadcast Seeder}

This is the first and only really good seeder sold at a dollar. It does fine work and is almost indispens. able to any farmer who has much seeding to do. It will sow any kind of seed, and sow it evenly. Price, $\$ 1.00$ net f. o. b. here. If wanted by parcels post add postage for 4 lbs.

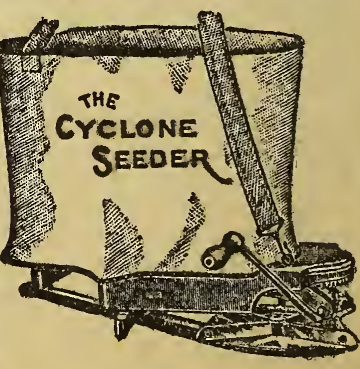

Price subject to change - See blue list opposite page 73. 


\section{Miscellaneous Farm Seeds---Continued}

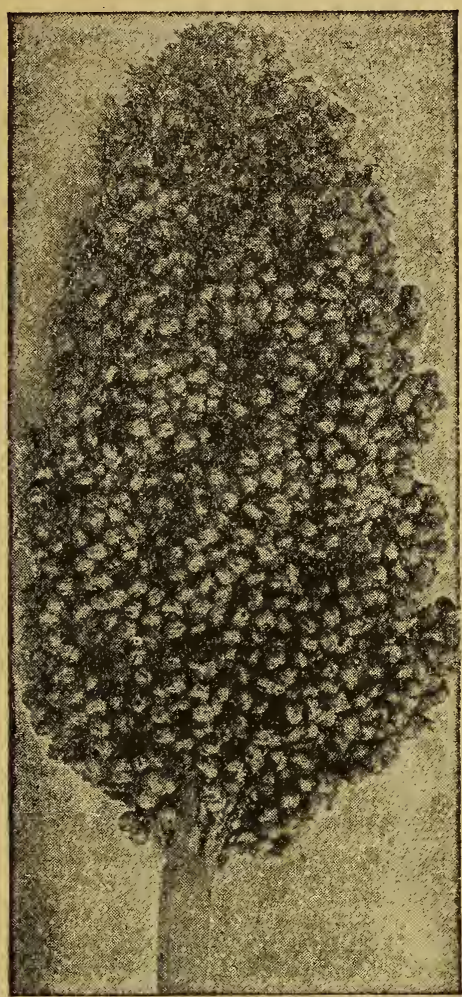

\section{Kaffir Corn}

The great fodder crop of western Kansas and Nebraska, valuable for both fodder and grain. In regions so dry that corn cannot be grown at all, kaffir corn will make a yield of 30 or 40 bushels per acre of seed, equal to corn in feeding qualities, hesides a large amount of first-clsss fodder - better than the best corn fodder and almost equal to cane. This grain is especially valuable for fowls, as it is a convenient size for feeding and seems to be just the right quality. It can be sown broad, cast at 75 lbs. per acre, or drilled in like corn, using about 5 or 10 lbs. per acre.

\section{M.llet}

True German. This is the millet that has enormous big heads and wide leaves. It is the rankest of all millets and makes lots of feed eitner as hay or grain. Can be sown as lnte as July in this latitude; and on that account is valuable where other crops have been washed out and lost.

Fodder. This is common or mixed millet, such as is grown everywhere for hay or fodder purposes. It is not so valuable as the pure German for seed purposes, but for hay or feed there is very little difference.

\section{Fodder Cane---Sorghum}

Most of the farmers of the west are getting well posted on the value and uses of cane, but the east has yet much to learn about it. Here, in con. densed form, are the points regarding cane: Pro. duces from three to eight tons (cured) per acre of valuable feed for horses and cattle; may be grown anywhere from Manitoba to Mexico; will withstand drouth and unfavorable conditions that would kill most fodder crops; principally grown for winter supply of forage, but may be used green for ensilage or for feeding as green feed. In this way it can be made the chief food for horses and cattle from August to May. Furnishes excellent pasture for hogs from June to frost; the seed is excellent for poultry and will increase egg production; dairy. men will find it of exceptional value as feed for mills cows, as it will grow thrifty and green in weather so dry that would ruin corn or ordinary crops, Cane can be cut two or three times in the summer if cut before it gets headed out; and in form makes splendid hay. The vaiiety used for fodder is slightly different from the special variety that is used for syrup purposes, as the stalks are more slender and more easily cured,

\section{Soy Beans}

\section{Soja Beans}

Somewhat similar to cowpeas, but make a stout, erect bush, instead of a vine. It is also earlier and hardier than cowpeas. Can be sown earlier and will succeed under more adverse con. ditions. They are grown as forage crop and as a soil renovator. They can be used as green feed, cured for hay, or cut for seed crop, and they are very valuable either way. Those who are interested should write to the Department of Agriculture, Washington, D. C., for Farmers Bulletin No: 58, which tells about them.

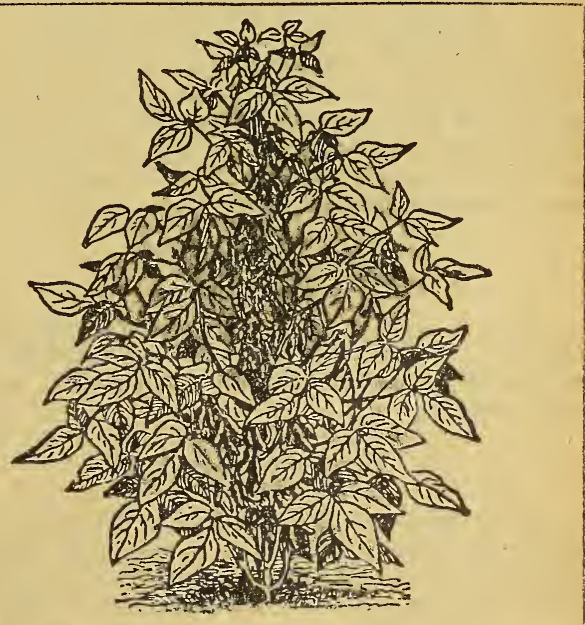

Soy Beans

Price subject to change - See blue list opposite page 73 . 


\section{Miscellaneous Farm Seeds---Continued}

\section{Broom Corn}

We are fetting some very fine broom corn from a grower in Obtatioma. This man makes a speclatiy of pure, higligrade stralns of broom corn, and $1 \mathrm{am}$ sure you will be pleased with this seed. We have two varieties, the Improved Evergreen, which is the standard varicty. grown largely in Kansas and Oklahoma, and the Dwarf, which is eariler and bctter adapted to thin land. Ask for special prices on large lots.

\section{Field Veteh \\ Winter or Hairy Vetch}

Valuable as a soil renovatur en very thin land and as a pasture crep. Somewhat similar to pea vines, but much finer and more wiry in growth. and so hardy that it will live out over winter. Does best sown in the fall like winter rye, when it makes a good cover crop fur winter and goud pasture tor spring, enrich:s the soil like clover when plowed under. Sow at the rate of 30 lbs. per acre broadcast or drilled, either alone or with equal amount of rye.

\section{Dwarf Essex Rape}

An annual plant of the cabbage family, grows very quickly in any weather and makes a big luose bunch of leaves, somewhat like cabbage leaves but long and narrow; grows all summer without going to seed. When eaten off it sprouts up from near the ground. Hard freezing kiils it. All kinds of sto. $k$ eat it readily and thrive on it, but I consider it most valuable for hogs, especially young siock. Broadcast, $5 \mathrm{lbs}$. per acre on well-preparcd land, early in the spring. and after it gets started it wit keep a dozen shoats to the acre all summer without other feed.

\section{Early Rose Syrup Cane}

This is another highly bred variety of cane for syrup-making. It is different from the Short Orange in being of the Amber type rather than the Orange. The grower who has this variery made 87 gallons of syrup last year from $\frac{1}{4}$ acre. The seed is strictly oure, hand-threshed from selected heads.

\section{Buckwheat}

This is very valuable for use on ground that eannot be seeded until late in the summer, as it san be sown as late as July 1 , and still make a sood crop.

\section{Sudan Grass}

I consider this the greatest new farm crop in. sroduced in the last 25 yesrs. I have been growing it now for three years and I am firmly convinced of its value. I have taken a full page for it further over. See the full page description, and see blue list for prices.

\section{Short Orange Cane}

\section{A Special Sorghum Cane For Syrup Purposes}

The cane that is grown for fodder will not do for syrup purposes, as it is genelally more or less mixed. It has not had any special selection, and has been grown more with an eye to todder than to good qualitic s for syrup making. There is a man up in Eastern lowa who malses the Lest sorghum syrup I ever tasted. I have been at him for a couple of years for seed, and have secured a supply tiom him for this coming year. Here is what he says about the variety, which he calls "Short Orange",

"I have planted this for sorghwm purposes for the last three years and find it far ahead of any other varie. ty. It is a vigorous grower, grod-sized stalks, not oves lo tall, and the beauty of it $i+I$ have never hud it blown down while others all around it went down, and the best of it is, it is from ten days to two weeks, anyway that much, ahead of any of the earliest around hese, and that much time means something. It is very swect and makes a lurge yield of syrup. I will do the best I can to get absalutely pure seed for you and in the best of condition. $I$ will $B^{\circ}$ through at heading time and select the seed for you, clipping out and throwing away the foreign heads, if any."

Now, this tells exactly what this variety is like. I believe it is by far the best syrup variety grown. The seed will be saved with special care and will practically all grow. Five to seven pounds will plant an acre, and the grower claims that it will make 200 gallons of sorghum to the acre.

\section{Miscellaneous}

Spring Vetch. This is different from the Hairy or Wint: $r$ Vetch, as it can be sown only in the spring very early and is not hardy for fall sowing, except on the Pacific Cuast or in the extreme south. In those regions it is used as a winter vetch. I do not advise it for use anywhere in the cornbelt. It is sometimes used as a spring sown crop in the extreme north.

Artichokes. We do not consider them of any value whatever. Better leave them alone.

Johnson Grass. A pest in most parts of the south, b.tt grow $n$ as a crop in some p'aces. It is a dwatf perennial sorghum, stands dry weather well and will grow on any soil, no matter how thin, spreads by underground root stalks. Better let it alone.

Bermuda Grass. A valuable pasture grass for the south, as it stands hot, dry weather beiter than any other giass. Bad to spread and practically im. possible to control. Don't plant it unless you are sure you have it where you want it to s.ay.

Sunflower. Valuable to grow for chicken feed Each plant makes a big head often a foot across. Plant and tend like corn and they will yield about the same. Price, $15 \mathrm{c}$ per $\mathbf{l b}$.

Stock Carrots. Very valuable for stock feed. Will yield 15 to 20 tons per acre with good culture. Feterita. See description on page 84 .

Stock Beets or Mangels. Much grown for cattle, sheep and hogs. Use 8 to $10 \mathrm{lbs}$. per acre. $45 \mathrm{c}$ per lb. 


\section{Alfalfa --."A Hogs Idea of Heaven"--- Coburn}

If I were raising hogs for a living I would have alfalfa for them on else I'd move to where I could have it. There is no feed on earth that will make as much pork, or as good pork, or make it quicker, or with so little work and risk and trouble, as al. falfa. Hogs and alfalfa just naturally dovetail in together better than any combination $I$ ever saw. Hogs rassed an alfalfa don't have cholera. Now hold on, brother, don't call me a liar till you've tried it and see. I've watched it pretty close and I have never found a case of cholera among hogs pastured on alfalfa, and kept away from too much corn.

Careful tests and experiments show that sows kept on alfalfa pasture, and alfalfa hay, average two or three more pigs to the litter (grown to maturity) give 30 per cent more milk, and the pigs at 3 months old are 25 per cent to 30 per cent bigger than pigs grown by any ocher method. The bone and muscle are so much better developed that alfalfa hogs never break down in fattening and shipping.

The finest and highest priced hams and bacon in the market are made from hogs grown on alfalfa and finished with just a little corn.

The Nebraska State Experiment Station, after careful tests, announced that hogs fattened on al. falfa hay and corn put on gain at a cost of $\$ 3.40$ per 100 lbs., while hogs on corn alone put on gain at $\$ 4.48$ per $100 \mathrm{lbs}$.

The lowa State Experiment Station reports that 1 acre of alfalfa is worth more than 3 acres of bluegraas pig pasture.

The Kansas State Experiment Station reports that a bunch of hogs fed on corn and alfalfa inad: $90.9 \mathrm{lbs}$. gain per hog in 10 weeks, while an exactl similar bunch fed on corn alone made $52.4 \mathrm{lbs}$. gain per hog in 10 weeks. In both cases the hors had all the corn they would eat, but the one bunch had the alfalfa in addition. They add: "These 5 " sults are not due to the feeding value of the alfalia. alone, but also to its influence in aiding the hots to better digest the corn."

I could go on this way forever, but what's the use? If you're determined to keep on growing ho ss on corn and cholera I suppose you'll have to be allowed to do it. But just the same when I retire from the seed business I'm going to have the niftiest little bunch of hogs you :ver saw, and they't] be raised on alfalfa and about one-fourth ration of corn.

Don't pasture your hogs on the alfalfa till it gets well established, say a year old or more, ant don't put over 5 big hogs or 20 shoats to the acre then, as it shouldn't be pastured too close. They won't hurt the alfalfa unless you starve them dor: 2 to digging for the roots.

\section{The Gospel of Alfalfa}

I want to warn you right now that if you get me started talking alfalfa I m not going to stop till I run out of paper. It's pretty near a religion with me, this alfalfa business, and for good many years I've been doing more missionary work for alialfa than I have for the heathen.

The neighbors say I'm crazy about alfalfa, and maybe I am, but it's a good bit like it was with one good brother here years ago, who went to a camp meeting and got full of the real old time religion, the kind they used to have when you and I were boys. In fact, he got more religion than he could hold, and it set him to jumping and shouting, he was so happy.

It was rumored to him that the neighbors said he was crazy. "Well," he said, "if I'm crazy, it's a mighty good kind of crazy anyway." And that's the way I feel about this alfalfa business. And I'm going to keep on shouting about it. If you don't get alfalfa it won't be my fault.

Now, I know lots of you have heard that it's hard to start, and that it isn't suited to your land. and that you've got to inoculate and do this and that, untilyou're going around in circles and scared to death about it.

Now, the most of that is just highbrow bosh.

The truth of the matter is, it's easier to get a start of alfalfa than it it red clover. Twice as easy. It will grow on any fairly good land that will grow clover, corn, wheat or potatoes, and some where they wouldn't grow.

It is not likely to do well on land that is sour, wee, uncommon poor, gumbo, nor hardpan close to the top, but cutside of these you can grow it about anywhere.
It will make about three times the yield of red clover. As to feeding value, counting good clover hay worth $\$ 10.00$ per ton, alfalfa is worth $\$ 14.00$ and timothy $\$ 6.00$.

I have a field here at Shenandoah that has averaged $6 /$ to 7 tons to the acre every year for about 15 years. It is on ordinary upland, just com mon soil, was never inoculated, was sown without any preparation, when I didn't know anything about alfalfa except that I wanted some.

All there is to it is to have the ground in good shape like you would for a big crop of corn or potatoes, work it till the weeds are killed and the ground louse on top and solid underneath. Sow the seed at the rate of 12 to 20 pounds to the acre any time between corn planting in the spring and corn cutting tine in the fall. Diill or broadcast. either is allright. Don't cover the seed over 1 inch deep. If you use a nurse crop it must be thin and must be cut for hay before it ripens, or it will smother the alfalfa.

Nuw, you remember at the old time revival meetings they didn't use to talk theology nor long arguments to us. They just said, "Brother, if you simply believe and have faith, the rest is easy. Cast away your doubts and make a start right now." Didn't they? And didn't they come through all right? It's the same way with alfalfa. You can grow it all right if you will only think so and have faith and make a real earnest effort. Quit worrying and get to work. Don't believe all this talls about it's being hard to grow.

And it s worth growing, It there is any crop on earth that will pay the bills and make a man rich and improve his soil, it is alfalfa. $\mathrm{H}$. F. 


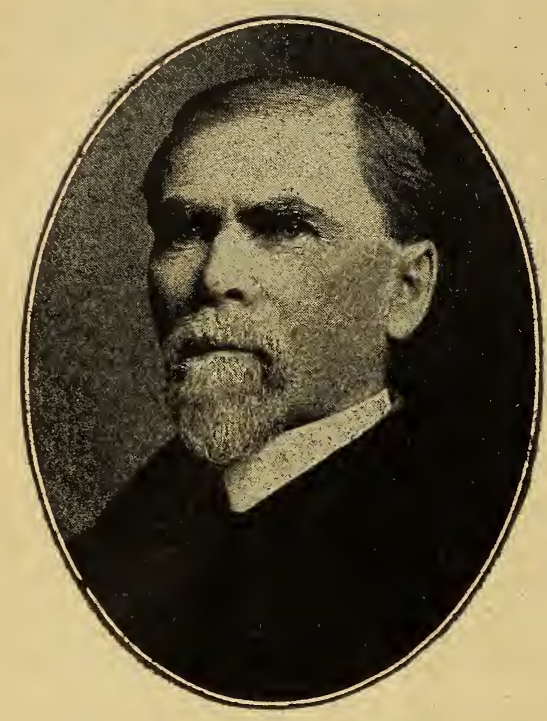

F. D. Coburn. The man who made Kansas rich by boosting alfalfa

\section{Alfalfa}

I am convinced that most of the farmers of the United States are missing a good thing by not growing alfalfa. In some sections it is grown heavily, but in nine-tenths of the country it is hardly known. I have been trying it here and watching it on the farms of my neighbors, and I have had a great deal of correspondence with customers in other states who have tried it. and I have come to the conclusion that there is hardly a locality in the the country where it cannot be grown. As I wanted to give my people the best possible information on this subject, I prevailed on Secretary Coburn, of Kansas, to write an article especially for me. This article is worth $\$ 50$ to any man who will follow it up. Ask for it. I have published it in pamphlet form and will be glad to send extra copies on request.

\section{Where It Is Grown?}

In buying alfalfa seed in is important to know where it was grown. For the corn belt we prefer and use Kansas and Nebraska seed. For the north we have Dakota and Montana seed. We don't use southern or far western seed.

\section{Northern Grown Alfalfa Seed}

My alfalfa seed is all northern-grown and non irrigated, and hardy. It is suitable for use anywhere that alfalfa can be srown at all.

Write to these Addresses for the Following Free Bulletin on Alfalfa:

Bulletin No. 137, issued by the Iowa State College, Ames, Iawa - Bulletin No. 76 and Circular No. 86 by the Illinois State College, Urbana, Ill. "Alfalfa on Every Farm" by the International Harvester Co., Chicago, Illinois. Department of Agricultural Extension.

\section{How to Get Good Alfalfa Seed}

\section{Probable Cost}

Coburn says: "Success cannot come except when good seed is used. Much of that on the market, especially imported seed, has been adulterated or is so mixed with weed seeds that it would be dear as a gift."

He didn't make it a bit too strong, either. I have seen samples of alfalfa seed that would be ten dollars an acre damage to a man if he got it for nothing. Full of dodder, buckhorn, dock, lambsquarter, and the Lord only knows what, Don't touch it.

You don't have to buy that kind of seed. Get yourselt one of these old-fashioned three-legged microscopes that sell for fifty cents, and examine closely exery sample of seed offered you. If you see anything suspicious in it, leave it alone. You can get the good seed if you insist on it.

I handle the best possible grade of seed, and sell it subject to approval. I get it direct from the growers in the best localities - no imported seed in mine. I ship it on the understanding that you can put it to any test you wish and if not satisfactory you can return it at my expense and have your money back. Now, if you want any better proposition than that, write it yourself.

Prices of alfalfa seed, subject to market change, 20c per lb., $\$ 20$ per 100 Ibs., $\$ 1200$ per bu. New bags weighed in free. This is for a guaranteed grade, subject to your own inspection and rejection. It is guaranteed to pass all state and national pure seed laws. Write for tree sample and latest prices.

\section{Good Alfalfa Seed}

Sixteen Samples From Ten Leading Seedhouses

\section{And Ours The Best}

'I have tested 16 samples of alfalfa seed sent out by 10 of the leading seed companies and the sample which seemed to me to be the most satisfactory was that furnished by the Henry Field Seed Co., of Shenandoah, Iowa. 9.5 per cent of the sample grew and I found no bad seeds in it. He quotes a price of $\$ 12.00$ per bushel and states that on a single order of 100 pounds or over he will pay the freight to nearby states."

This is a prettr. good old world after all. Some times 1 get discouraged because farmers will write in and teil me I am asking too much for my alfalfa seed and that they can buy it cheaper elsewhere, and so on. They can't realize that I ask more for my seed because it's worth more. They think it's all al ke and I'm holding them up.

But when 1 get a report like that one above, it means something to me. This came from one of the most noted County Advisors in the country. I didn't even know he had a sample of my alfalfa seed. But he had been making a quiet hunt for good seed for the farmers of his county and this is his report to them. It went out to every farmer who is a member of the association in that county. I don't dare give his name or the name of the county, for those men don't like to be quoted on a matter of this kind. It gets them in bad with other seed houses, but it's the Gospel truth just the same and you may be sure I appreciate it.

If that kind of seed is good enough for you. just help yourself. 
SPECIAL OFFER: I will send 20 pounds of the very best seed (suffi. cient for an acre) by prepaid express or parcel post anywhere in the United States for $\$ \mathbf{\$ 5 . 0 0}$. This will give you a chance to try an acre and see what it will do. (This offer does no; apply to Grimm).

\section{The U. S. Government}

\section{Condemns Imported Alfalfa Seed}

You will remember that $I$ have been fussing about imported alfalfa seed for the last three or four years. I never have believed that it was good stuff for cornbelt farmers to use. I did not have any great amount of real evidence to sustain my belief, but just the same I have been fussing, and kicking, and screaming about imported alfalfa just on general principles and insisting that everybody use American grown alfalfa seed, especially seed from Kansas, Nebraska or the Dakotas.

The U.S. Government is out now with a bulletin (Bulletin No, 138. Commercial Turkestan alfalfa seed, by the U.S. Department of Agriculture), stating that practically all of the alfalfa seed im. ported into the United States comes trom Russian Turkestan, which is a region in Asia, right in north of Persia, and that although it is imported into this country in large amounts, it is practically worthless for use in the United States. Also they state that practically all of it comes to this country from Hamburg, Germany, and for that reason has often been sold as German seed,although in reality there is no alfalfa seed grown in Germany for export whatever. This bulletin also tells how you can distinguish this seed and detect it easily.

If I had room I would print the bulletin in full and I think I will print part of it sometime anyway if I can possibly find room for it, but you should write to the U. S. Department of Agriculture, Washington, D. C., and ask for that bulletin No. 188 on Turkestan alfalfa and find just what worth. less stuff this Turkestan alfalfa is and how easily you can detect it when a merchant offers it to you.

\section{Grimm Alfalfa Seed}

Don't forget that we can furnish you with some fine Grimm alfalfa seed from western Dakota. This is from a field which has been standing for 15 years on high, dry ground and has never winter.killed the least, although it is a very exposed location. It has the typical spreading roots and creeping root stalks or underground stems.

You know the claim for Grimm alfalfa in addi. tion to extreme hardiness is that it has spreading roots instead of a single tap root and that it makes underground creeping stems like Quack grass or Canada thistle. These branching roots enable it to thrive on hardpan where the single tap root of other varieties would fail to penetrate and the creeping underground stems enable it to spread and thicken up and increase and also enable it to withstand close pasturing.

I am in shape to furnish you the genuine article at a reasonable price. We secured about 3,000 pounds of this and while it lastswe can sell it@ 40c per pound for any amount, much or little. Remember, however. that this price does not include postage.

\section{Alfalfa Seed by Mail}

If you want a few pounds of alfalfa seed to ex periment with, I can send it by mail at $35 \mathrm{c}$ per pound or 3 lbs. for $\$ 1.00$. (Except Grimm).

\section{Free Sample Alfalfa}

I will send free to anyone, a small sample of alfalfa seed for testing. Send it to your experiment station and ask them if it is good; if it has dodder or any other bad weed in it; if it is good, bright. sound seed that will grow.

An eastern experiment station bought seeds from a dozen or more seed houses and tested it. They reported that mine was the best and the only one they would care to plant for their own use. Small samples free. Large samples (several ounces) 10 cents.

The United States Department of Agriculture recently issued a bulletin about alfalfa, in which the statement is made that "The greatest care should be taken to get seed that is free from weeds. Dodder is one of the worst weeds so far as alfalfa is concerned."

I am willing to have my alfalfa seed put to any test you want - examire it yourself, let your neighbors look it over, send it to your State Experiment Station if you want to. If the seed isn't right I don't want you to keep it - sent it back at my expense. But I think I am safe when I make this offer, for I know the seed is the best that you or I, or anybody else, can buy.

\section{Our Alfalfa Four Times The Best}

"I bought 2 bushels of alfalfa seed. One from you and one from another fellow. It all looked good and I paid the same price for both, sowed both the same day with conditions exactly the same. I secured a good stand from both kinds of seed. The alfalfa from your seed has made a good growth and has done good considering the very dry season we had here asst summer. It yielded at least four times as much as the side of the field where the other seed was sown.

I have had some experience in raising alfalfa. I have had one field in alfalfa for 7 years and it is as good yet as it ever was. It has been cut from three to four times each year. The new seed was sown so that both kinds of seed would join the old in exactly the same way, making alt conditions the same. The side sown with your seed grew rank ana green and the other side was like the Arkansaw Traveler Corn; "it was the little yeller kind." The old field of alfalfa was from seed bought from you years ago and nas been entirely satisfactory. Yours truly, - Henry Riley, Lewistown, Ill."

Now, what do you know about that? I never would dare to make any such claim as that myself or you would think I was lying to you, but here is a man that knows what he is talking about and has had experience with alfalfa and he says that although he had a good stand from both bunehes of seed, mine turned out four times as good as the other.

It looks like there might be a little difference in alfalfa seed after all, don't it? Remember, if you want to start an alfalfa field I can sell you some more of the same good kind of seed that Mr, Riley got.

H. F. 


\section{The Pure Clover Seed Question}

There is no bigger question before the tarmers right now than that of pure clover seed The country is rapidly getting filled $u_{l}$ with bad weeds, and unless we can call a halt somehow, it will soon be an impossibility to get really pure clover seed The trouble is, so many farmers will buy an inferior grade of seed because of a little difference in the price. They think it is all about the same and one lot is higher because the holder wants more profit. Now, the facr is that the big profits are made on the low-grade seed. It is easier to take seed worth $\$ t$ wholesale and retail it at $\$ 8$ than it is to take seec worth $\$ 9$ wholesale and retail it at $\$ 10$ Any dealer will tell you so, if you can get him to admit the truth.

Now, here is what I am getting at: There is ro sense in buying poor clover seed and no aieed of of it. If you will spend 50 cents on a small micro. scope, or a few cents on postage stamps getting samples and sending them to your state experi ment station, you will learn a heap about clover seed. Don't buy any seed, even from a neighbor's farm, without strict examination. The bad weeds are getting to be everywhere nowadays and you are lable to get them where at least expected.

The worst offenders are the dealers in small towns who handle clover seed as a side line. They know very little about it and care less, just so they can make a good profit on the seed. There are wholesale dealers who are looking fur just this kind of customers, and they load them up with this devilish imported cull seed, and the merchant offers it to the farmers at a tempting price. The regular seedsmen, having a knowledge of the business, fine machinery for cleaning seed, and a repu. tation to maintain, are more likely to have pure seed. Now listen; Get a sample from each of your home dealers, and some from regular seedsmen. Send them all to your state experiment station, or get them under the glass yourselves, and then buy where you can get seed free from weeds. Buy only on a guarantee of purity. I will gladly furnish a sample of mine for this test.

You get more clover seed to the dollar in the high grades, anyway, to say nothing of the freedom from weeds. The low grades are all full of dead seed trash. You can easily see under the glass that lots of them are not more thas half good clover seed, and lots of the rest is downright calamity, about as dangerous as dynamite.

In one sample lately that was being offered by an implement dealer in a small town at $\$ 8.00$ per bushel, I found two kinds of dodder, two of dock, three of thistle (including the dreaded Canada thistle', both kinds of buckhorn, and a lot of weed seed that I don't know, and I hope I never will know. As a rule, the implement dealers in the small towns are worse offenders, as they are not posted on clover seed, but many seedsmen, who ought to know better, are sending out such stuff. It ought to be made a penitentiary offense. I told one seedsman friend of mine that he ought to get 60 days for selling such stuff. But he insisted that the farmers wanted something cheap and he had to give them what they wanted.

If that's the case, all right, but you'll have to go to him for it. I won't sell it. The seed I offer is subject to inspection and test. If it doesn,t look good when you get it, ship it back at my expense and you can have your money back. This applies to all kinds of seeds. I have mentioned clover especially as the most important.

\section{Clover Send on Approval}

All our clover seed is shipped subject to your own test and appreval, or test by any State Ex.

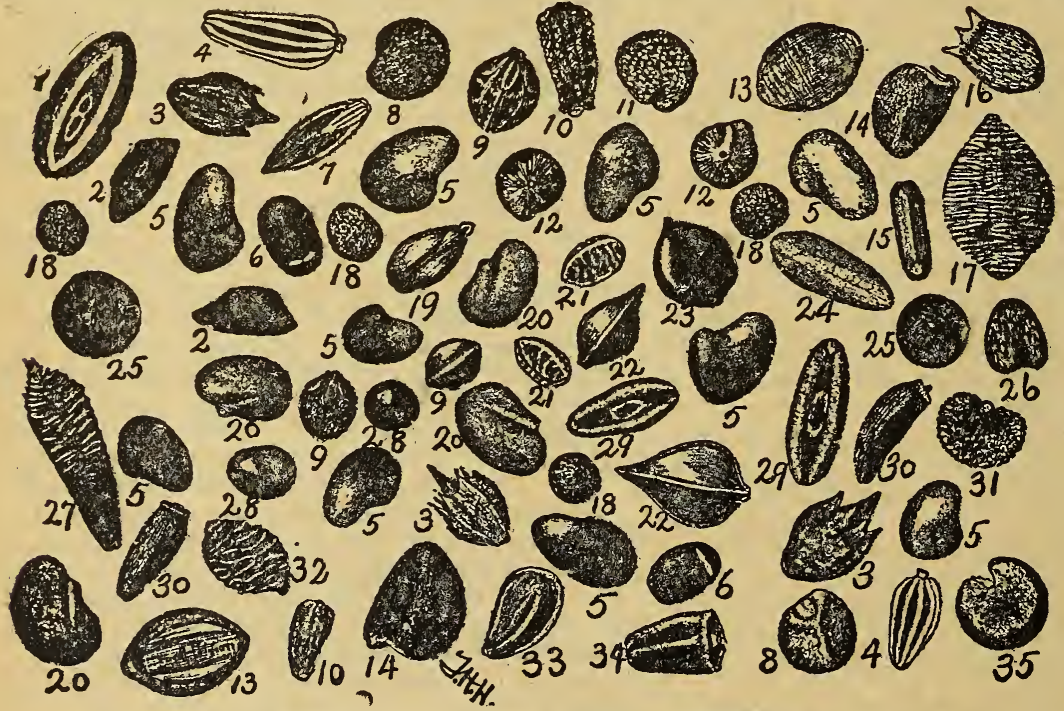

COMMON IMPURITIES OF CLOVER SEED. DESCRIPTION OF FIGURES periment Station, and if not found first-class it may be returned to us and the money will be re unded. We do not guarantee the crop, we can't do that, but we allow you to be absolutely your own judge as to the purity and quality of the seed.

\section{An Index to}

\section{Weed Seeds}

Alongside I am printing a drawing. showing all the more important weed seeds likely to be found in clover. Refer to it in looking over your samples. Get a microscope and hunt for these in your clove. seed

crabracted plantain; 2. black-seeded plantain: 3, ragweed; 4 ox-eye daisy; 5, red clover seed; 6 , catmi, crabgrass: 8, field dodder: 9, sorrel, 10, dog fennel; 11. chickweed; 12, lamb quarter: 13, green foxtail; prickly sida; 15, vervain; 16, madder; 17, yellow foxtail; 18, clover dodder; 19, healali; 20 yellow trefoil; 21, 26 alsike clover: 27 ox-tongue; 28 , pigweed; 29 , buckhorn; 30 Canada thistle; 31 , campion; 32 , wild geranium, 33 pepper grass; 34 , camomile; 55 mallow. 


\section{Clover Seed}

Ask for free Samples of Clover or Grass Seed. Small Sampler free. Large Packets for planting 10c.

NOTE-At the time this book went to press, prices on this class of seeds were in an unsettled condition. I want to make the lowest possible price to you, so don't depend on the prices given here, but write in for the latest. See the special price list following page 73 for prices on all kind of grass seed. Ask for free samples, too.

We handle none but a fancy grade of clover seed, and any quotation you may receive from us, whether specified or not, are based on the very highest quality.

Sold Subject to Test. All our clover seed, and in fact all our grass seed, is sold subject to state or national test. If not perfectly satisfactory in every way you may return the seed at our expense, and we will refund the money paid for it.

Safe Arrival Guaranteed. We pack Clover seed for shipment in the very best of sacks and generally double-sack it. We guarantee safe arrival in any part of the United States, and will stand good for any loss that may occur in shipping.

Insist on Tested Se. d. All our clover seed is re cleaned and sold subject to government test. I advise you most strongly to buy only that grade of seed. If you dont want to buy it of me. you can get it from some other seedsman, but don't take low grade seed and don't even buy from your neighbor unless the seed is thoroughly re-cleaned and has been examined for weed seed.

Medium Red. This is the most popular of all the clover family. It is what is commonly called red clover, or June clover, and is the variety grown all over the United States. It grows to perfection here in Iowa, and the seed grown here is the best in the world. It is bright and plump and almost universally free from bad weed seeds and I can offer inducements in the way of prices. Considering the high quality of seed we offer, we can give you better value than almost any one in the country. It is impossible to tell exactly at this time what the yrice will be, as at the time this page goes to press the market is very unsettled. Write for samples and wholesale prices.

Prices Subject to change. See Blue List

Crimson Clover. This is an annual clover that is widely used in the south and eastern states for all

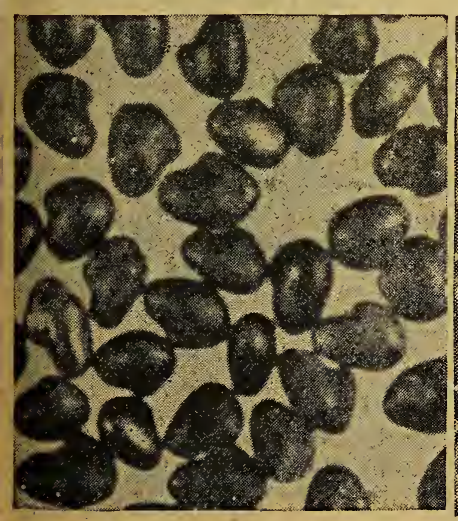

Pure Clover Seed. Large, plump, even size and no weed seed or trash

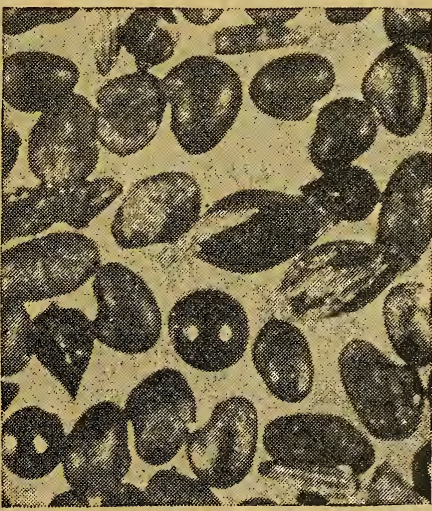

Trashy Clover Seed. Full of weed seed and miscellanous calamity. sowing. It cannot be sown in the spring with any tope of success, and is not hardy where peaches does not bear.

Alsike Clover. (Swedish Clover). This looks like a hybrid between red and white clover. It has a bloom somewhat like white clover. but more pink in color; it is especially suited to low, wet land where red clover will not thrive. It will grow on land that is almost a swamp, and will in time dry out the land and sweeten it up, so that other clover can be grown on it. It can also be grown on thin sandy land or stony hillsides, where red clover would not catch. The seed is very small and goes much farther than ordinary clover. Prices Subject to Change. Sce Blue List.

Mammoth Red Clover. This is a larger, later variety of clover, somewhat resembling the red or June clover. It is much ranker in growth, and for that reason is not suited to rich land. It is sometimes of value on thin land where other clover will not grow. It will also stand extremes of heat, wet or cold, better than o dinary ciover. It generally ranges in price about the same as ordinary clover or from $25 \mathrm{c}$ to $50 \mathrm{c}$ per bushel higher. Price Subject to Change. See Blue List.

White Clover (Dutch Clover). This is the low creeping clover that is used so much on lawns and in low land pastures. It is the hardiest of all clovers, will grow anywhere, and is of considerable value, especially in pastures.

Japan Clover: This is grown in the south, and is not advised anywhere else. We cannot supply it.

Burr Clover. This is another southern proposition. I do not consider it of any value except where other clovers and alfalfa fail.

\section{About Prices on Clover Seed}

At this writing it is impossible to predict the price of clover seed. The crop is still uncertain. Whatever the crop may be however, we will treat you right on price and will give yo' quality you can depend on. Iowa always has good clover seed, if there is any anywhere. The sooner youbuy the better. Write for special prices and samples at any time, and I will be glad to try and fix you out. If you don't want to wait for sarip. les; send the order anyway and I will treat you right on prices.

Be sure to state whether you want to fil according to amount of money sent, or ship you a certain amount of seed and re:und to you or call on you for the balance.

Amount of Clover Seed Per Acre Per Acre

Red Clover .... ............ 7 to $12 \mathrm{lbs}$

Red Clover with Timothy ..... 5 to $8 \mathrm{lbs}$. Mammoth Clover alone ...... 8 to $12 \mathrm{lbs}$. Mammoth Clover with T mothy 5 to $8 \mathrm{lbs}$. Alsike Clover...................... 6 lbs. White Clover.........................

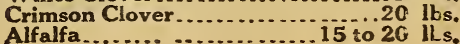




\section{Sw weet Clover}

Its Value. Sweet clover is used either as a feed crop or as a fertilizer to plow under to improve the soil. It is equal to red clover os aifaifa to plow under, makes a larger growth than either, grows faster and is easier to start.

What Soil to Sow It On. It will thrive on almost any kind of soil. It will grow on any soil that will grow clover o alfalfa and on many soils that will not grow either. It will grow and thrive on thin, sandv soil, hardpan, gumbc, rocky up.and, cley and alkali land

A Biennial。 Sweet clover Jives two years, It makes larse, rapid growth the first seasor and can be cut for hay o" pastured the last half of the - ummer, but does not bloom or bear seej. The second year it blooms, bears seed and dies. Will make two crops of hay or a crop of hay and one of seed the second year. Can be plowed under eithe fiist or second year. It makes a heavy yield of seed rich can we either thresnea or rulled,

Variety to Use. The oni) variety recommended is the big. white biennial variety,

Nelilotus Alba, We do not grow or advise the yelIt $w$, but if you want it I can get it for you very cheaply probably nine cents per pound.

When to Sow. It seems to do best sown very early in the spring. same as red clover. It does weil sown either alone or with a nirse crop of small grains. Use from ten to twenty pounds of seed per acre: Cover very shallow. It can also be sown on pasture or rough land right on top of the ground without breaking up, and is often sown on such land in the winter, especially the unhulled seed. The freezing and thawing seem to make it grow better,

Not Likely to Become a Pest. There is no danger of its becoming a pest. It dies at the end of the second year and unless allowed to re-seed, can not spread, It runs wild along the roads, but never er.croaches on cultivated land.

Good Feed. It can be pastured at any age, except. when quite small and stock soon learn to like it. It is claimed that it does not bloat stock at all. The hay is said to be equal to alfalfa, especially if cut before it gets old and woody.

A Profitable Seed Crop. It yields 10 to $15 \mathrm{bu}$. of seed per acre, and prices are sure to be high for several years to come, on account of the enormous demand,

Sweet clover has come to stay. There is no doubt about it. Ask any farm paper, any state col. lege, the United States department, or better yet any man who has grown $i$.

I firmly believe that inside of flve years it will be as common and as widely grown as red clover or alfalfa. It will not drive out either one, but will supplement them.

It has some advantages over either or both For one thing, it is pretty definitely settled that it will not bloat cattle under any conditions, It makes an enormous yield of feed or growth to plow under, It is easier to start than either clover or alfalfa. It is a sure seeder, It will thrive on many soils that will not grow clover or alfalfa at all

If you have thin, rocky, hard or sour soil which you wish to enrich, this is just the crop for y ou to grow, The tops will make feed and seed, and the roots will enrich the soil.

\section{Varieties}

There are three varieties grown in the United States and we can supply seed of all of them, but we do not advise any but the big white or Melilo. tus Alba, as we consider it by far the best,

White Sweet Clover (Melilotus Alba), A bi ennial, that is, it lives two years and then dies. Blooms and makes seed the second season. Grows from four to six feet high. Hardy everywhere, Will make a hay crop the first year, and two crops of hay or one of hay and one of seed, the second year, This is the variety that is always meant when you say simply "sweet clover." We car supply either hulled or unhulled seed. See blue list opposite page $\mathbf{7 3}$ for prices. 


\section{Sweet Clover (Continued)}

Yellow Sweet Clover (Melilotus Officinalis). A biennial, somewhat similar to the white variety, but smaller, more spreading or trailing in manner of growth, and not so good a yielder. The sseci of this variety is of en used to adulterate seed of the white variety, as it is very similar in appearance and generally cheaper, as it is not so much in demand. Occasionally some people want it however, so we carry it in stock, generally in both hulled and unhulled seed.

Yollow Annual Sweet Clover (Melilotus In. dica). A worthless, annual, short.lived variety. It is grown some in California and the seed comes from thcre. It is of no value whatever in this part of the country. We can get it for you if you wish.

\section{Look Out For Adulteration}

The high price of sweet clover seed and the reat demand for it have tempted lots of dealers to offer adulterated seed. The commonest practice is to $\mathrm{mix}$ in one of the yellow varieties. Also lots of dealers have used low grade alfalfa seed, as it looks much the same and is hard to detect. I have several times caught dealers, and even farmers, at these tricks. An expert can detect these mixtures, and you would easily detect them the secund season, but of course the harn would be done then.

Wherever you buy your seed. ask fur a guaran. tee that it is the true variety, unmixed with adulterants, and send a sample to your state college for test.

We handle only pure, unmixed seed and will sell it to you subject to test and ajproval by the state college or cxperiment station or the U. S. Government.

\section{Sweet Clover's Place in the Rotation}

Sweet clover works in admirably in any for $₫$ of regular farm rotaticn that calls for Red Clover and in many ways is better, Remember it does not take the place of Alfalfa, but of Red Clover. In sowing it, treat it just as you would Red Clover in every way, except that it does not like a loose, open seed bed. 1t will not succeed sown in the late summer or fall llke Alfalfa, but should be sown early in spring or on the frozen ground in winter.

A splendid four-year rotation would be: First year, small grain, with a crop of hay or pasture in the fall from Sweet Clover seeded with it in the spring. Second year, a crop of hay or pasture on the Sweet Clover, followed by a second crop of hay or seed: Third year and fourth year, corn, which should make about 100 bushels per acre.

If you have had bad luck with Red Clover jor want something better, try Sweet Clover.

Free Samples. We will be glad to send free samples for trial and testing at any time. Largé samples for planting (several ounces) 10c. .19vols

PRICES. As prices fluctuate on this seed I cannot give you exact figures now, but will refer you to the monthly price list opposite page 73, or will be glad to quote you specal prices by letter. at any time.

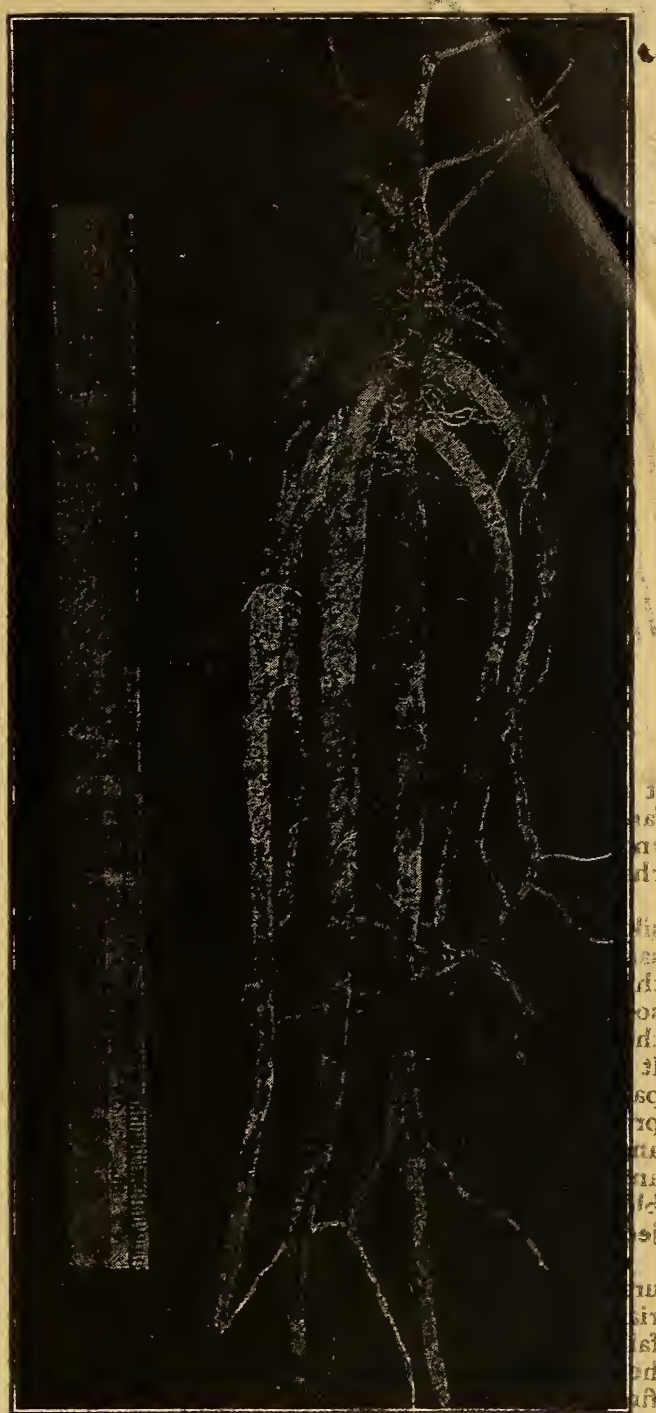

A Root of Sweet Clover the latest help in II oz worl Scil Building zar promirlosm gri

The greatest value of Sweet Clover is as crop to enrich the soil It works similar to Red Clover and Alfalfá, but in many ways better than either onc. The roots are very large and fleshy and con. tain an enormous amount of fertilizing material, especially nitrogen, which builds up a poor, thin soil very quickl Besides these roots penetrate the soil in every direction, break it up and then when they die and rot the soif tumbles back into these cavifies and is broken up in splendid shape for crop It is a natural process of sub. sbiling.

Sweet Clover is better than either Red Clover or Alfalfa beeaư se $t^{3}$ makes a big growth more quickly. It will do as much for the soil in two years as either of the others would do in fcu? $\mathrm{Be}$. sides it dies absolutely at the end of 'two years so there is ho temptation ta,keep it standing instud of picwing it under. 


\section{Other Grass Seed}

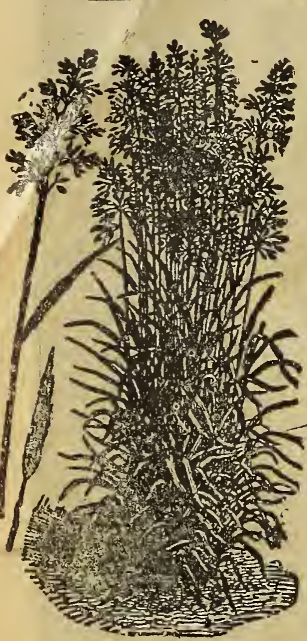

Blue Grass
NOTE-At the time this book goes to press, prices are in a very unsettled condition. I want to make the lowest possible price to you, so don't depend much on prices given here, but write in a id ask for the latest. On all varieties of grass seed I follow the same policy I do on clover and alfulfa, and handle nothing but a guaranteed or fancy grade. It is all sold sub. ject to state and national test, and is the very best it is possible to procure.

limothy. There is lots of timothy s e ed grows. here, and just east of us they $r$ a is e housands of acres, so we are in good shape to sup. ply you seed, We re-clean it and grade it ip carefully and give you a strictly fancy article. We guarantee it free from red top and free from iangerous weeds. Price subject to change, Sfe blue list.

Timo'ny-Alsike Mixture. A great deal of alsike is grown with timothy. The seed being the same size, it is impossible to separate the two, so the seed is sold mixed that way, It is just right to sow for a mixed meadow, and is much cheaper than buying the two separately and mixing them. It generally runs about two parts timothy to cne part alsike, but different lots will show different proportions of the two. It is the natural mixture. and if we had to buy the two varieties separately and mix them, it would cost much more. Probable price 10 to 12 cents per pound. Price subject to change. See blue list.

Kentucky Blue Grass. This is the best nat ural pasture grass known. It makes a thick, luxu riant growth that is good from early spring to late fall. This seems to be a natural blue grass country here and the seed grown in this region is the very finest. We also get considerable quantities of the seed direct from the growers in Kentucky. The seed used to be sold always in the chaff, but clean. ing machinery has been perfected now so that it is cleaned to solid seed, The standard weight is still 14 pounds to the bushel, but the seed is heav. ier than that, so it is generally sold by the pound, Price subject to change. See blue list,

Red Top. A splendid grass for low, wet land. Some of my neighbors who have river bottom land subject to overflow, make a mixture of red top, al. sike and blue grass and get splendid pasture with it. It is also good for sowing in new timber pas. ture or on thin hillsides. If you have good strong land that will grow timothy and clover. don't bother with ed top, but if you have land where it is hard to get a stand of timothy or clover, then by all means use red top. Price subject to change. See blue list,

Orchard Grass. A valuable grass for pasture on hay land ard especially good in new timber pasture. It furnishes the first green bite in spring and the last in fall, Well suited to shady places, such as orchards and groves. Sow 14 pounds to the acre, Prices subject to change. (14 pounds) See blue list,

Canadian Blue Grass. Somewhat similar to Kentucky blue grass, but smaller and growing closer to the ground. Valuable in thin, stony land and for mixing with other grasses for a permaneni pasture, Price subject to change. See blue list.

Miscellanenus Grasses. The miscellaneous varieties of grasses I have so little call for that I do not always have them in stock, but can quote you special prices on them if you want them and procure them for you any time.

Tall meadow oat grass, sweet vernal, creeping bent grass, meadow fox tail, red fescue, sheey fes. cue, water fescue, crested dog tail, English rye grass; Italian rye grass, wood meadow grass, meadow soft grass, hard fescue.

Grass Seed by Mail, Small quantities of the leading varieties of grass seed by mail or prepaid express at about the following prices; Timothy 20 cents per pound; red top, «5 cents per pound; blue grass, 25 cents per pound; orchard grass, 35 cents per pound; English blue grass 35 cents per pound.

\section{Pasture and Meadow Mixtures}

Most of our western farmers have not yet learned that pastures or meadows of mixed grass are far superior to clover or timothy alone. For either pasture or hay, best results are obtained from the use of grass seed in mixture. A number of species of grass will insure as much denser growth than the same amount of seed of one or two kinds alone and prove less ezhausting to the soll, as different grasses require different elements for their growth. With a number of varieties, you have a chance for a crop in any kind of season. I have studied the matter carefully and I believe I can fix you out with a mixture that will suit your conditions and do you some good.

Permanent Meadow Mixture. Will make the bes quality of hay, as the mixture contains such grasses as produce heavy growth and mature together. This mixture is one we send out for medium or average soils, If your soil is extra rich and strong, or especially wet, or thin or gravelly, or in some way different from ordinary soil, let us know the conations and we will vary the mixture to suit your requirements, Sow about twenty pounds per aire or in reworking an old meadow, use half this amount. Price, subject to change, 100 pounds, or over, 13 c.cnts per pound, less amounts at 14 cents per pound.

Special Low Land Pasture Mixtures. This mixture is intended especially for low, wet or overflow land, where it is hard to get a stand of clover and timothy. It is made up mostly of all the va. rieties of clover and grass that succeed best in low. moist land. Sow 15 pounds to an acre for new seeding, or less amount for re-seeding. Price, subject to hange, 100 pounds or over, 13 cents per pound, less amounts 14 cents per pound.

Timothy-Red Clovor Mixture. We generally have on hand natural mixtures of timothy and red clover, just the way they were threshed from the meadows here, and can sell them slightly below the cost of buying them separately, See blue list for prices.

Timothy-Alsike Mixture. See upper part of this page. Prices in blue list. 


\section{Pasture and Meadow Mixture}

\section{(Continued)}

Permanent Pasture Mixture. Selected with a view to giving a succession of grasses coming on constantly from early sprirg through the dry summcr weather and through the fall. It is permanent and keeps improving year after year, For new sceding use 20 pounds per acre, or for re-seed. ing an old pasture about 10 pounds per acre. Contains blue grass, meadow fescue, orchard grass, alsike, white and red clover, timothy and smal amounts of other srasses. Price subject to change, 100 pounds or over, 13 cents per pound, les. amounts at 14 cents per pound.

Quick Action Hog Pasture. Not permanent, but intended for quick results, where you wish to get lots of green feed as soon as possible for hogs or calves. or where you have odd lots of ground whieh you wish to put to use. Contains barley. w. ld peas, and such quick coming annuals as will make luxuriant growth in from six to eight weeks. Can be sown very early in the spring and will be ready for pasture by themiddle of May. For use later in the season, especially for sowing in July and August for fall pasture, Price, subject to change, 100 pounds or over, 436 cents per pound, less amounts 5 cents per pound.

Sweet Clover-Alfalfa Mixture. There is con siderable talk now about sowing sweet clover and alfalf together, and I don't know but what it is a pretty good plan. We sometimes have natural mixtures of these two on hand. Write for prices.

\section{Lawn Grass Seed}

There is great demand for a good, reliable, mix ed brand of lawn grass seed for almost every one wants a nice lawn. and sodding is generally too ex pensive. A good, velvety lawn can be secured easily and quickly from seed if the ground is in good condition and good seed is used. It should be sowed very early in the spring, very thickly. about a pound to each 200 square feet. Cover lightly by raking it in and if the weather turns dry, keep well sprinkled till the grass get sa good foothold. I make a mixture of the best grasses for the purpose in a proportion that will keep a good stand of grass all through the summer. The basis of the mixture is the best grade of blue grass, but I have added several other sorts that help it out immensely. Twen. ty pounds make a bushel and will seed a space about 60 by 100 feet. Price, by mail, postpaid, 35 cents per pound, 20 cents per $1 / 2$ pound. By freight or express, $\$ 1.35$ per peck, $\$ 5$ per bushel. Our seed is clean and solid and weighs 20 pounds to the bushel.

\section{Microscope for Examining Seed}

Examine your own seed. This is the same kind of microscope we use in the different depart. ments here at the seed house for examining small seed, It is the old-fashioned, three-legged kind. which is the most satisfactory kind for every.day use that we have ever found. It has a double lens and high power.

\section{Price $50 \mathrm{c}$ each, postpaid.}

See blue list opposite page $\mathbf{7 3}$ for latest prices on grass seed of all kinds.
Table of Legal at and Quantity Nt.

Variety Quantity per ac Alfalfa . . . . .

Barley . . . .

Beans, Garden ....... 1 bu

Beans, Soja . . . . . - $-\frac{1}{2}$ to $1 \frac{1}{2}$ bu

Beans, Navy . . . . . .

Bermuda Grass........... 5 lbs

Bluegrass,Ky. . . . . . 15 to $20 \mathrm{lbs}$

Bluegrass, English . - $-\frac{1}{2}$ to $1 \frac{1}{2}$ bu

Bromus Inermis . . . . 20 lbs

Broom Corn . . . . . . _ 3 to 6 lbs

Buckwheat.......... $\frac{1}{2}$ to $1 \mathrm{bu}$

Cane, for sorghum .....- 2 to5lbs

Cane, for fodder..-76 to $100 \mathrm{lbs}$

Clover, Alsike ..........6lbs

Clover, Sweet ...... 10 to $20 \mathrm{lbs}$

Clover, Mam, Red _._ 7 to $12 \mathrm{lbs}$

Clover, Med, Red ... 7 to $12 \mathrm{lbs}$

Clover, White . . . . . .

Corn, Field, (in ear $70 \mathrm{lbs}$

to bu.)............ 8 lbs

Corn, Pop (in ear 70 lbs.

to bushel)........6 to $8 \mathrm{lbs}$

Corn, Sweet........... 12 lbs

Corn, Fodder drilled . 10 to $\frac{1}{2} \mathrm{bu}$

Cow Peas...........

Feterita (Drilled) .....2 to $5 \mathrm{lbs} \ldots \ldots \ldots$

Feterita (Broadcast)_50 to 75 lbs

Flax . . . . . . .

Kaffir corn (in drills) -3 to $5 \mathrm{lbs} . \ldots . .56$

Kaffir corn (B'dcast) _. 1 to $2 \mathrm{bu} \ldots \ldots \ldots \ldots$

Lawn grass. . $1 \mathrm{lb}$ to 300 sq. ft. . . . _ _ _ _ . 20

Millet, German .......

Mill t, Hungarian ... $\frac{1}{2}$ to $1 \mathrm{bu} \ldots \ldots \ldots$

Millet, Siberian ........ to $\frac{1}{2}$ bu ...........

Mixture, Pasture ... 20 to 25 lbs .............

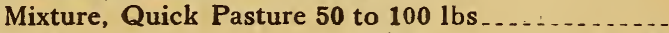

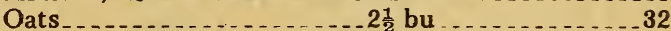

Onions (in drills) .........5 lbs .

Onions (in drills for sets) 60 to $75 \mathrm{lbs} . . . . .$.

Orchard Grass ......20 to $30 \mathrm{lbs} . \ldots \ldots \ldots . . .14$

Parsnips _._. 4 to $6 \mathrm{lbs}$

Peanuts.............. 1 bu .

Peas (smooth) ...... 2 to 3 bu _

Peas (wrinkled) ..... 2 to $3 \mathrm{bu} \ldots \ldots \ldots$

Potatoes, Irish _. . . . . . 10 bu . . . . . . . . . . 60

Pumpkin ...... 4 to $6 \mathrm{lbs}$

Radish ........... 8 to $10 \mathrm{lbs}$

Rape, Dwart Essex 5 to 8 lbs

Redrop (solid seed) _. 8 to 10 ibs . . . . . . . . . 14

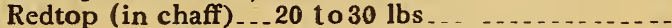

Rye

Speltz . . . . . . .

Sudan (Drilled) ....... 2 to 5 lbs.

Sudan (Broadcaat)...... $20 \mathrm{lbs}$

Tímothy _..........10 to 15 lbs

Timothy-Alsike .......... 20 lbs ... . . . . .

Tomato seed in hills . . . $1 \mathrm{lb} \ldots \ldots \ldots$

Turnip............. 1 to 2 lbs

Vetch ............ 30 to $40 \mathrm{lbs} . \ldots . . .60$

Watermelon

Wheat ........... $1 \frac{1}{2}$ to $2 \mathrm{bu} . \ldots$. 


\section{n's Rights in the Garden}

ed: There's no politics in e not going to get me into any sument, Not even on women's

though, that when it comes to oman has some righ.ts, even though enumerated in the constitution tes.

h, I believe that every woman rden. It's natural to want a gare dirt and watch th.ings grow and vegetables.

lly the woman on the farm. If I on a farm, I'd have a garden or have it wouldn't be a little, old weedy corext vorthe hedge, but a nice, big, clean piece und, the best land on the farm, fenced hog a chicken tight and plowed and harrowed by e men folks first thing in the spring.

And above all, a woman is entitled to good. first-class tools to work the garden with.

Honest, now, sister, what kind of tools have you got to tend your garden with? Show 'em up. I know just about the list anyway. It's an old common hoe probably rusty and dull, a rake with several teeth bruken or bent, and the haridle loose, and probably an old butcher knife and maybe a spade that the men wouldn't use to dig post holes with.

And you plant the seed by hand in a row made with the corner of the hoe or the end of the rake handle, stooping along and dropping the seed by hand and then coming along and covering them with your feet. It looked like sin, but it was the only way you could do.

Do your men folks plant and tenc' their corn that way?

No, Ma'am. They have the latest two row edge drop planters and riding cultivators. Several generations ago they used to plant and tend corn with a hoe, bu+ men don't put up with that kind of tools very long, at least not in their own work They get machines with wheels and seats on them, even if they have to go in debt for them.

But when it comes to paying out $\$ 12.00$ for an up-to-date tool that will plant easily and perfectly everything in the garden and tend it ten times as easy and fast as it can be done by hand in the old style-why then he'll holler like a stuck hog. Can't afford it-all foolishness-mother never had nothing of that kind-wouldn't work, nohow, a woman don't know nothing about machinery, anyway:

All right, brother. I hope when you get yours in the hereafter it'll be humping your lack over an old dull, rusty hoe, in a weedy, lumpy, crookedrowed garden with a sunbonnet and the thermom eter 97 in the shade.

But all joking aside (and I wasn't joking much anyway, that's mostly gospel truth), there ought to be an up-to-date garden driil and wheelhoe in every garden. Thy are as necessary as a cornplanter or a riding cultivator and don't cost one-fourth as much, A good garden is half the living, and it's a mighty hard matter making a good garden without good tools, It can be done, but it's up-hill busi. nesss.

With a drill you can plant the seed in nice straight rows, all just the right depth, evenly dis- trihuted, and so every seed will grow. Your seed will go nearly twice as far. It looks nicer, too. Looks like bustness. It gives you a garden you can be proud of.

With the wheel hoe you can tend the garden ten times as fast as you possibly could by hand and you do much better work besides. When the ground is just right to work, you can get over the who'e garden in one forenoon and kill the weeds before they come up. That is the secret of tending a gar den easily,

You can work both sides of the row at once and throw a little dirt into the row so as to cover up any little weeds that may be starting there. If you do it right you can do away with the hand. weeding entirely. Doesn't that sound good?

And it's easy. Any woman that can run a sewing machine can run one. You walk along standing straight with your shoulders back and your head in the air. The machine has big, light wheels that run easy and carry all the weight, Of course it takes some muscle, but no more than a carpet sweeper or a baby wagon,

The machine comes equipped with all the dif ferent attachrients and tools needed for any kind of work in planting or tending anything in the garden. It's guaranteed to work perfectly for anyone and in any kind of soil. It's so simple that any woman or boy or girl can get the hang of it in five minutes.

You can get the different styles ranging in price from $\$ 3.25$ to $\$ 12$ each, All are good, but of course the complete $\$ 12$ outfit is the best of any. I will ship them on approval.

You can raise a good deal more than enough extra stuff in the garden on account of it to pay for it the first year. Besides the satisfaction of making garden in an up-to-date United States way.

Yes, of course. you can get along without if. You can get along without washing machines, too, and sewing machines, and incubators and corn planters, and riding cultivators and self binders, combined listers and lawn mowers. But would you? The garden is the best paying piece of ground on the farm. Why not make it more profitable yet by using modern tools there, too?

Honest, sister, if you don't throw away that old rusty hoe and get a wheel hoe this spring I'll think you haven't the spunk of a mouse. If the old man wont let you have the money, don't feed him any garden stuff till he comes across. Starve him to it.

And by tbe way, some day I'm going to write an editorial on the subject ot a woman having to ask her man for every cent of money slie needs. It will be a hot one, too.

It's just the time of year to get the wheelhoe. You will find them described and listed in my catalog, or if you wish, I will send you a special catalog of them, We have them right here and can make prompt shipment. They're guaranteed satisfactory to you in your owr. garden or no trade. The ones I handle, the Iron Age, are the best kind made and are reasonable in price.

Now I have had my say and it's up to you, H. F.

P. S. I will not be responsible for any $\mathrm{di}$. vorce cases or assault and battery cases that may be caused by this editorial, 


\section{Garden Implements}

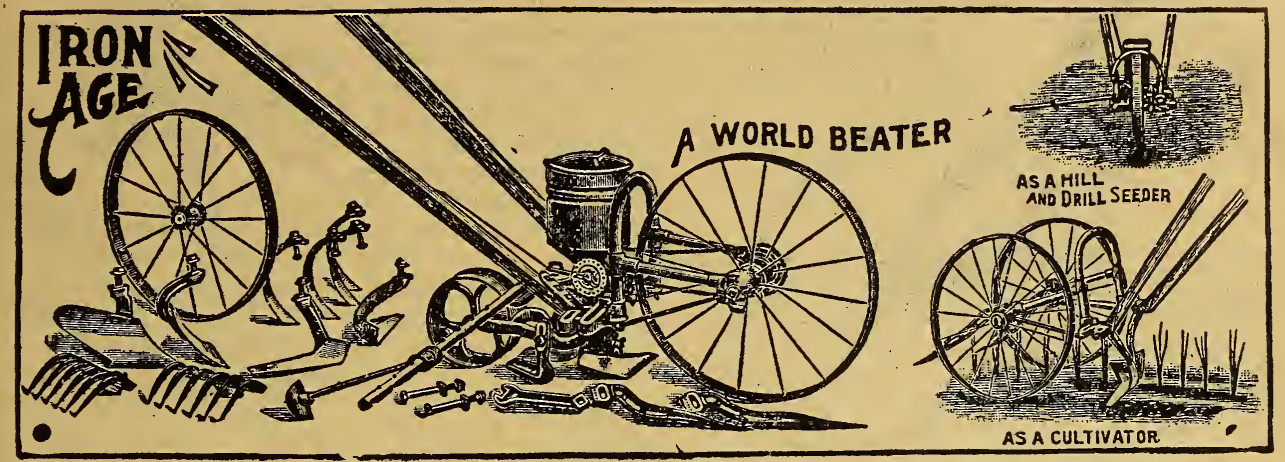

Iron Age No. 6 Combined, Price \$12.00, "-ne Best Garden Tool Made

It is a curious fact that the farmer who will have nothing but the very best of farm tools, such as riding plows, cultivators. seeders, etc., will use in his garden the same old implements that were used by his father and grandfather, or, what is worse yet, make his wife use them, There has been just as much improvement in garden tools as in other lines, but few farmers seem to be aware of it. With modern tools a garden can be tended in less time and in much better shape than by old methods. Besides, here is the finest part of it. the boys will do it and do it gladly, for it is a well known fact that a boy is generally crazy to run any machine that has wheels on it, It is the old drudgery of tbe hoe, rake and weeder that has disgusted him with gardening. Plant your garden in long, straight rows with a good drill and tend with a wheel hoe, and you will have by far the best garden you have ever had.

\section{Iron Age Garden Tools}

I have used the Iron Age Garden Tools for several years and have found them the best now before the public. I offer here the two best sellers, but I can furnish you any special tool you want. If these do not suit you, write for special catalog of all Iron Age goods,

Other Goods. I can supply a dozen other styles of the Iron Age make, but I have no room to show them here. If you don't see what you want, ask for it. Write for complete catalog of the Iron Age implements.

Shipped from Shenandoah. We keep these tools in stock here in Shenandoah, hundreds of them. and can make immediate shipment on everything listed in this catalog, We also carry some not listed here, and on all Iron Age goods we can have shipment made from the different Iron Age branch houses, whichever one is nearest to you.

\section{Iron Age Combined Drill, Double Wheel Hoe}

It is on the style of the Planet, Jr., implements that are so well known, but is in my opinion much better, It is a combination tool and can be used as a drill or as a wheel hoe and is a success either way, which is not always the case with combination tools- It is remarkably dura- ble and rd to break, being made of maleable iron in ad of castings.

Th whpels are high and do not choke easily. It will wrop either in a hill or drill and is easily adjusted. I strongly advise it as being superior to any other garden tool made. Complete with all attachments shown on this page, $\$ 12$, without the rakes and plows, $\$ 10.50$; if drill alone is desired, \$9. Ask for special delivered prices.

\section{Iron Age Double Wheel Hoe and Cultivator}

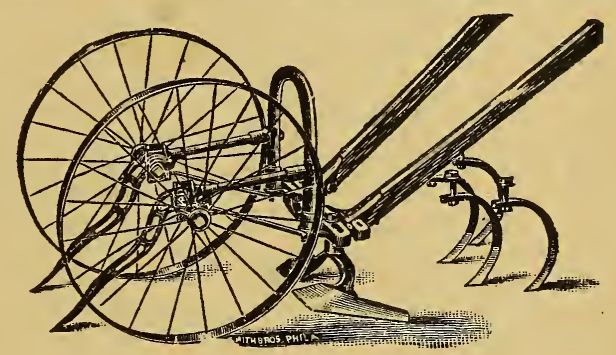

No, 13. Price $\$ 5.50$

For parties who wish a wheel hoe and cultivator independent of the drill. this No. 13 Iron Age is the best thing to be had. It is a twowheeler. working both sidcs of the row at once. It has two pairs of cultivator teeth and a pair of wide hoes, These are all the attachments that I have ever found necessary, but others can be had if wanted. For tending onions you have this and the Combined Drill and Double Wheel Hoe No. 6 shown above, then when the weeds get bad, you can work two cultivators at once, Price $\mathbf{\$ 5 . 5 0}$.

Iron Age No. 1 is like 13, except that it has all the tools and attachments shown on No, 6 . Price $\$ 7$.

You wouldn't think of tending corn with a hoe. Why not get in line on the garden and be up to date?

There is just about as much advantage in using a drill and wheel hoe as there is in using a corn planter and a cultivator instead of dropping the corn by the old-fashioned hand method used by our great grandfathers and then hoeing the crop. 


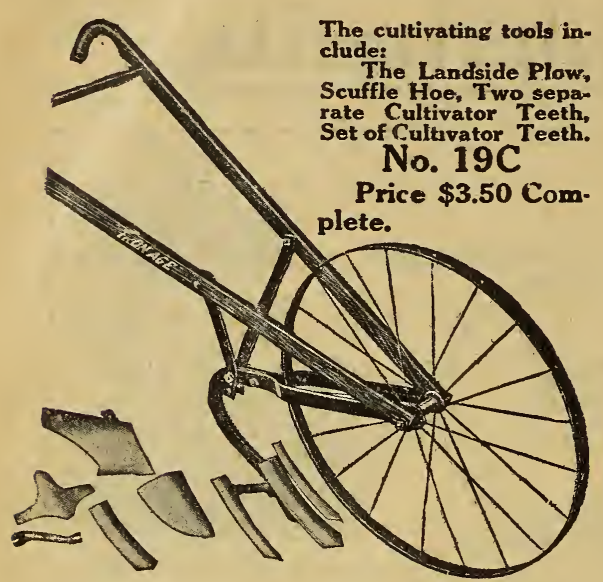

\section{Wheel Cultivator and Plow}

No. $19 \mathrm{C} \$ 3.50$

I you have never tried a wheel hoe for your garden, get one of these and see how easy it is to keep your ground under perfect cultivation. It is a. low-priced tool and will always be a convenient tool to have for many kinds of work, even if you do buy some of the other combinations later.

Many market gardeners use several of these tools and find their use very profitable - a simple solution of the cultivation problem.

It does th $=$ necessary plowing in many soils, opens furrows for seed for fertilizer and covers on the retuin trip. Has two sizes of single teeth that work between narrow rows, a scuffle hoe and set of three teeth on one bracket for hoeing and cultivating between the wider rows. The old way of hoeing is entirely out of date and unnecessary. With a tool of this kind the work is done in a tenth of the time and you go through ten times where you did once before - result, a better garden in every way, with less work-keeps the weeds down, the thorough cultivation is good for the soil and helps to hold moisture in the ground.

24-Inch Wheel. - The distinctive feature of this tool is its high wheel -24 inches - which some sections seem to prefer. The frame is an all steel arch in three parts-compact, light, durable. The working tools are attached in position easily and are adjustable, The plow turns a good furrow and is used for ridging or hilling the planis.

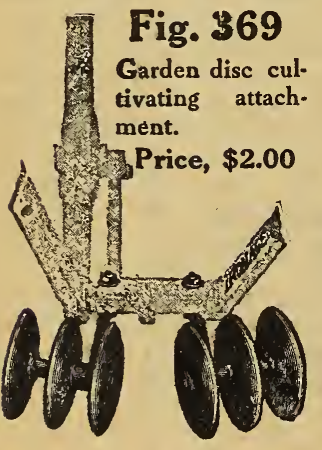

\section{Discs \\ For Wheelhoes}

This is made on the same principle as a big disc, but of the right size to attach to an Iron Age Wheelhoe. Work well in loose, mellow soil, but will not work in hard, cloddy, trashy, or wet ground.

Price, $\$ \mathbf{2 . 0 0 .}$

\section{Drill Attachment}

If you alre-dy have an Iron Age Wheel Hoe, such as No. 13 or No. 1, you can add this drill attachment and plant anything in the garden perfect. ly. It can be put on or off the wheelhoe part easily, as it is simply fastened by two bolts.

No. 6 Hill and Drill Attachment

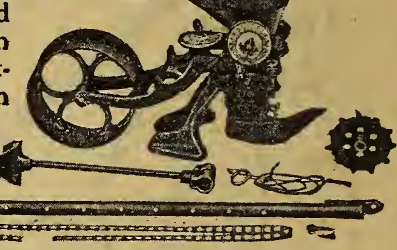

\section{Price, $\$ 5.00$ \\ Fig. 134}

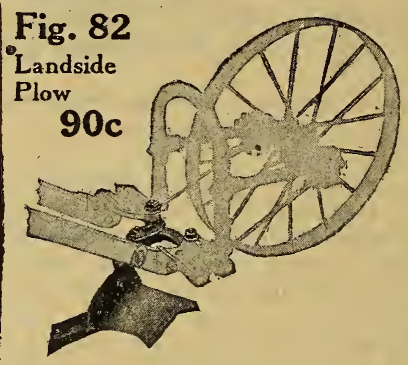

Price, Single 90c Double, $\$ 1.40$

\section{Landside Plow}

Can be attached to any Iron Age Whe elhoe, and $\mathrm{m} \mathrm{a} \mathrm{k}$ es the tool a perfect whe el plow with plow following the line of the wheel. Plows good, deep furrows and runs steadily. Can also be furnished made double like a lister

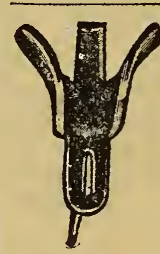

Fig. 145 Special onion set drill shoe.

\section{Onion Set Attach-}

Onion sets are grown in a wide, thick row. The seed is generally sown in a band about 3 inches wide. This requires a special drill shoe which can be used on any Iron Age drill. The gatherer is for cut. ting under the sets.

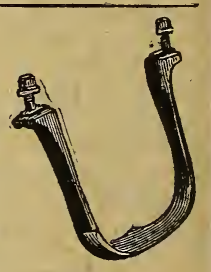

Fig. 33

Onion set gatherer Price, $80 \mathrm{c}$

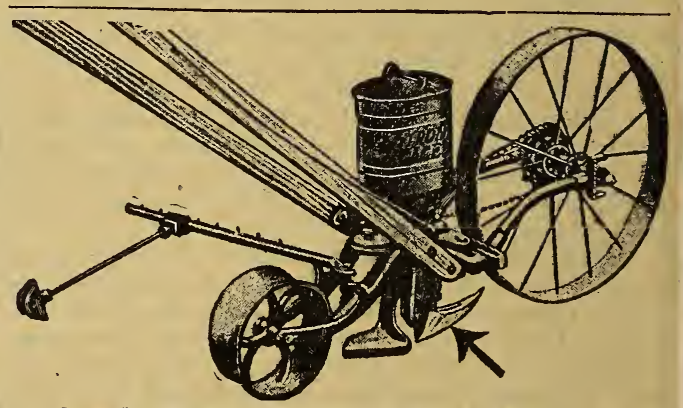

\section{Seed Drill No. 18B -.- Drill Only Price, $\$ 7.50$}

Especially For Onion Seed. - This is for the man who wants a drill only and especially an onion seed drill. It has no hilling attachment, but has a special drill shoe, which places the seed in a very close, narrow row, making cultivation easy.

Besides the No. 18B drill shown above, there is the No. 7, which is simply a No. 6 without any cultivator attachments. Price, $\$ 9.00$. 


\section{The No. 6 Iron Age}

\section{A Dozen Tools In One}

Diffenent things you can do with the Iron Age No. 6, Combined Drill and Double Wheel Hoe when the drill part has been set off and you want to use it as a Single or Double Wheel Hoe only.

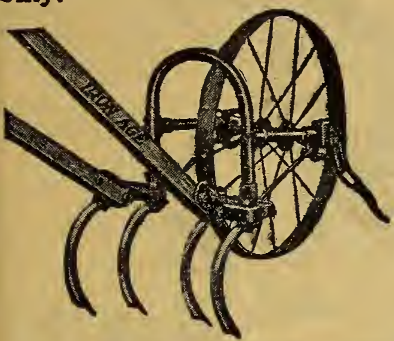

Cultivating teeth can be set to suit the width of rows

There isn't a thing in the garden you can't plant and cultivate with this implement.

Plant your garden in long, straight rows with a drill and you will make the seed go farther, get a better, more even stand, and you can tend the crop with half the work. Ask anyone who has ever used a garden drill or wheelhoe how it compares with hand work.

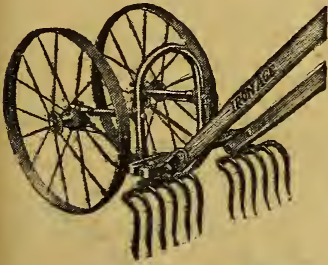

With rakes to go astride the rows

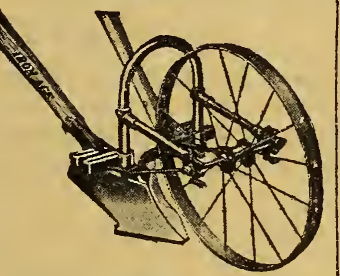

Plows set to open furrows of the combinations thit can be made from a No. 6, com bined drill and dou ble wheel hoe, as shown on page 99 , or from the No. 1 , which is the same thing with the drill part left out. There are lots of other combinations you can study out for yourself.

date in the garden line?

We can supply anything in the Iron Age garden tool line. If you don't see what you want, ask for it.

\section{The Boy and the Garden}

Here is a secret that ought to be worth $\$ 1,000$ to you. I can tell you how to get a boy to work in the garden gladly, enthusiastically and steadily.

Sounds impossible, don't it?

Well, here's how. You know how crazy a boy is over anything that has wheels on it? And how he is always trying to experiment and find an easier way to do the work? And how he likes to see quick results?

All right. Get him a wheelhoe. It's got wheels to it, and a wrench, and a lot of different adjustments he can make, and it does the work fast and he cain see that he is getting somewhere.
These hoes are about the $n$ icest things of any. You can set them this way to work between rows or use both wheels, turn the hoes the other way straddle the row and work both sides at once.

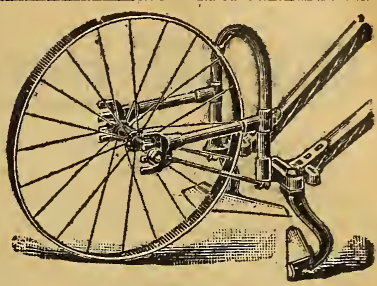

They come with No. 6, No. 1, No. 13, etc.

\section{Repairs on Iron Age Implements}

We carry on hand here at Shenandoah, all kinds of repairs for Iron Age tools. If we do not have them on hand we will have them sent direct to you from the factory or the nearest branch office, but we generally have them here. We can supply repairs for any Iron Age or Gem wheelhoe, or Iron Age or New Model drill, no matter how old. The cost will not be high either. Here are some of the ones called for and the prices. Prices do not include postage. You pay postage or express. Postage generally is about half the price of repairs.

\section{Repairs on Iron Age \\ No. 6 Combined Drill and Wheelhoe}

(Fit also No. 1, No. 4, No. 7, No. 13 , and other similar tools.)

2086 Wire link chain for drill (old style)............ \$0.20

2090 Pressed steel chain for drill (new style)

C40 Main frame for drill and double wheelhoe......

C19 Side hoe (specify right or left) C19 right,

C20 left ..........................

30 Cultivator teeth for wheelhoe, each

C59 Opening plow for No. 6 drill

2080 Wire wheel for drill or wheelhoe ................. $\quad .75$

2069 Marker stick complete (old style)...............

2070 Marker stick coinplete (new style) ..................4.

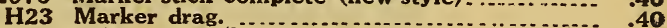

$\begin{array}{lll}\text { C38-39 Hopper lid (both halves) } \ldots \ldots \ldots \ldots \ldots \ldots \ldots \ldots \ldots & .40\end{array}$

\section{Repairs on Iron}

\section{Age Horse Hoes and Cultivators}

Plain wheel for horse hoe

Lever wheel complete (horsehoe)

Plain cultivator shovels, ( 2 in. to $4 \frac{1}{2}$ in. width, specify width wanted) each $\ldots \ldots$

Plain cultivator shovel, 6 inch................................

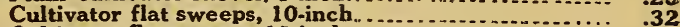

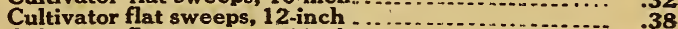

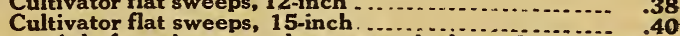

Ask for prices on others or send along about what you think the price would be.

I don't blame a boy for not liking to swing an old rusty hoe, or get down on his hands and knees and weed. You don't like to do st yourself. It's that kind of work that drives boys off the farm.

But I'll guarantee that with a new wheelhoe that boy will tend the garden till he pretty near wears it out, and he'll enjoy it. too. And he'll be proud of his work. And that means a whole lot to a boy. If you like to do it, it's fun. If you hate to do it, it's drudgery.

Shipped on Approval. Every "Iron Age" tool we sell is guaranteed to give perfect satisfaction is every way, and if not entirely satisfactory, can be returned at our expense, and your money will be refunded. You can try the tool out thoroughly for two weeks. 


\section{IRON AGE Horse Cultivators}

Gardeners and fruit growers always have use for onehorse cultivators and they are a fine thing. I ose two or three of them all the time. I list here three of the favorite ones, any of which I can recommend as all right. The prices are f. o. b. here, I can give you a delivered price if you will write and ask me about it. There are many other good styles and I can supply you any of the different makes at regular prices.

The IRON AGE people make probably the most com. plete line of cultivators in the United States. Besides the one-horse type of cultivators in all kinds and sizes, they make a full line of twohorse machines. If interested; write for special Iron Age catalog, showing all of them.

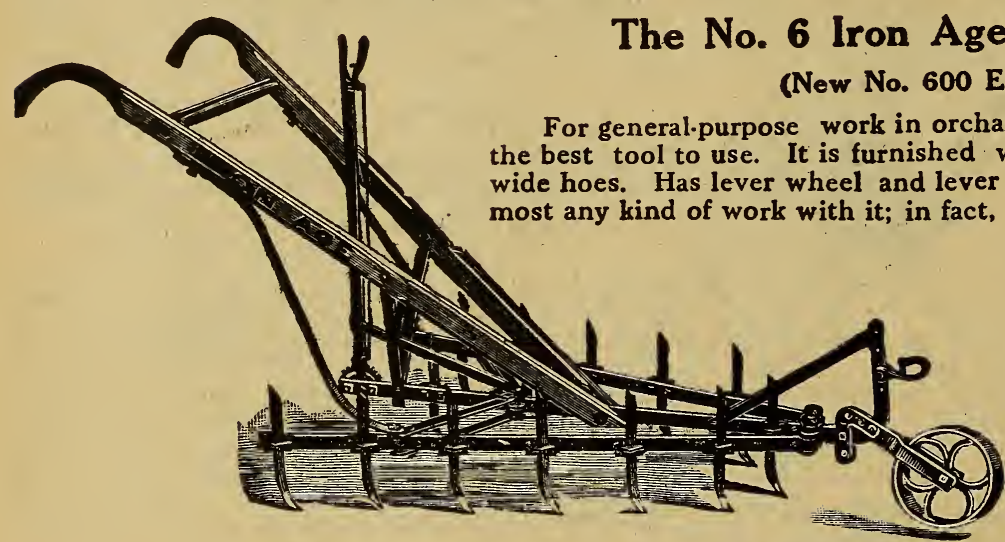

Iron Age No. 106 Harrow Cultivator. Price $\$ 5.00$

Iron Age No. 106 Harrow Cultivator

$$
\text { (New No. } 1014 \text { E. P.) }
$$

For fine work in small stuff and for creating the "dust mulch" so much desired there is nothing equal to the harrow-tooth cultivator shown here. It stirs and fines the dirt. kills the weeds and leaves the soil in the most perfect condition. It has gauge wheel and lever expander and can be controlled easily as to width and depth. It is the finest tool in the world for going through corn after it gets large. Price, complete as shown, $\$ 5.00$.

\section{Iron Age Potato Tools}

The Iron Age people make a full line of the best potato tools on the market. Their planters and diggers are especially fine. I have used them for years after trying nearly everything else. Write for special catalog and prices if interested. They can be shipped from branch houses near and save you freight.

POWER SPRAYERS. Write for prices and catalog on power sprapers and horse spray. ers. We handle them in the Iron Age make.

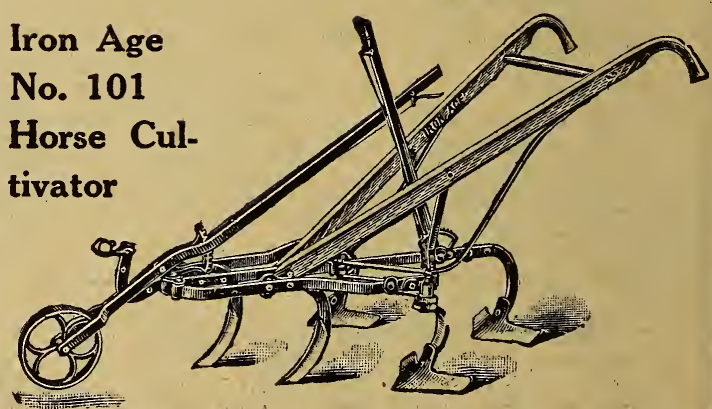

Price, $\$ 6.25$ (With two 10-inch and one 12-inch sweeps).

\section{A Cultivator With Sweeps}

The No 6 Cultivator with sweeps in the place of the three hind shovels. This makes a fine cultiva tion. Weeds can't dodge the sweeps. We use this tool a great deal, as it gives us level culture, stiring the surface of the ground and killing all the weeds without throwing up any ridge. It is used a great deal in the south. Price, as shown with lever. expande. and lever wheel, \$6.25. 


\section{IRON AGE Horse Cultivators Continued}

\section{Plain One-Horse Cultivator No. 10}

(New No. 1005.) Price, $\$ 3.15$. or $\$ 3.65$ with wheel

This is a plain, low-priced, one-horse cultivator for garden and farm use, has five shovels about 4 inches wide. Made of the best steel, is well built, light and strong. Can be narrowed or widened by means of clamp expander, and adjusted to any width from 14 to 30 inches.

\section{Write For Complete Iron Age Catalog}

The Iron Age people make every imaginable sort of tools for garden and truck work. They get out a catalog bigger than this one, telling you all about it. I will be glad to send you a copy free. Any. thing they list I can furnish you at the right prices.

We make shipment either from here, from the factory in the east or from one of their numerous branch houses all over the country.

Generally I can save you considerable on the freight. and often cut out the freight entirely.

\section{An Improved Harrow Cultivator}

\section{No. 3015EP.}

Combined Harrow and Cultivator with furrow closing attach. ment.

Price, as shown, $\$ 7.50$

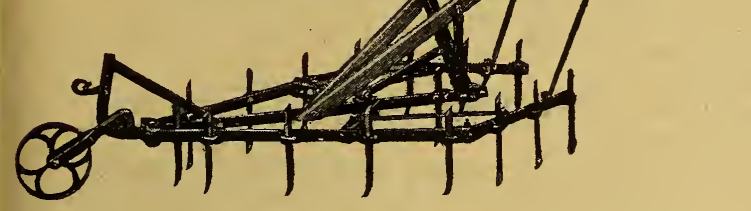

Don't be scared by the fear of high freight on garden plows. In many cases I can arrange to have them shipped to you from some other place than here, if it will save you on the freight. In most cases I can get them to you at not over $50 \mathrm{c}$ each for freight.

\section{Grass Seeders}

I show here the two best makes of grass seeders, "You pay your money and take your choice. They are both good, and I have used buch at different times. Of course the $\$ 1.50$ one is the best one, but the $\$ 1.00$ one is all right and does perfect work. Both are guaranteed.

\section{Little Wonder Broadcast Seeder}

This is the first and only really good seeder sold at a dollar. It does 1 fine work and is almost indepensable to any far. mer. It will sow any kind of seed evenly. Price, $\$ 1$ here. If wanted by parcels post add postage for $5 \mathrm{tb}$.
The strong point of this tool is the rear extension. It has 16 teeth in all, which can be adjusted for depth or angle, The rear teeth are closer together than those in front. stir all the ground, and drag the clods, stones. and trash to the middle of the row, where they belong. It can be expanded to 35 in. or narrowed down to 17 inches, The long frame and the rear attachment makes it run very steady. It is the finest cultivator we have ever gotten hold of, and we used one in our trial grounds all summer. This is the finest thing you ever saw for going through corn or potatoes the last time. The outer teeth next to the row can be set. shallower than the others if preferred; so as not to hurt the roots. Try it. Price, as shown, $\$ \mathbf{7} .50$.

\section{The Cyclone Seeder}

This is the best seeder made at any price. It is roomy, strong, and works evenly, and will sow any kind of seed any desired thickness. It is fully guaranteed, and if not perfectly satisfactory may be returned at my expense. Price, $\$ 1.50$ net $f_{0} 0$. here. If wanted by parcels post add postage for 5 lbs.

We do not ad. vise either the fiddle bow or the tin horn type of seeders, as the crank style seems to give much evener seed. ing.

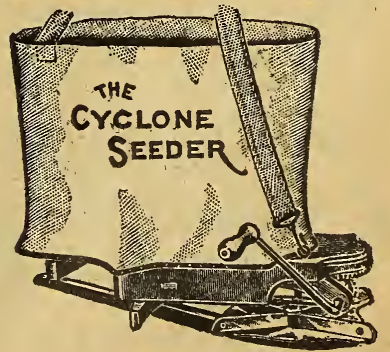




\section{Sprayers}

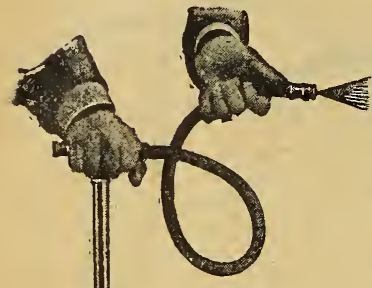

Junior No. 5

Price, $\$ 350$ three sizes which suit me exactiy. All are good, but of course the higher priced are the best.

\section{Junior No. 5}

(This Can Be Sent by Parcels Post. Weight 6 Ibs.)

The best small spray and force pump made. Does away entirely with the objectionable foot rests, clamps. leather suction and packing. Requires no fastening of any kind. Holds itself down and works anywhere. All the operator needs to do is to press the plunger down and it raises of itself. The upward stroke is made by a brass spring which presses the cylinder apart. The allbrass suction working within the brass cylinder with all-brass valves does away entirely with all leather, rubber and other packing. It is easily worked and will do more different kinds of work than any pump ever made. Will pump from a barrel, pail, tank, spring, or creek.

The farmer with a small amount of spraying ean put the barrel in a wagon and spray with as good success as his neighbor, who has an outfit that weighs and costs five times as much. Price, $\$ 3.50$ net f. o. b. here. If wanted by parcels post add postage for 6 lbs. Brass extension pipe, 3 feet for $50 \mathrm{c}$.

\section{Kant-Klog, Style G}

(This can be sent by parcels post, weight 9 lbs.)

The special feature of this sprayer is the new style Kant-Klog nozzle, which is the only nozzle that can be successfully cleaned without stopping the spray and removing the nozzle from the tree.

It is the only nozzle made which gives a round or flat spray, or a solid stream at will. A slight pressure of the thumb starts the spray; remove it and the spray stops instantly.

The sprayer body is made of heavy galvanized steel, top and bottom dome shaped and joined to the body under heavy pressure, making complete double seam. The air pump is made of heavy

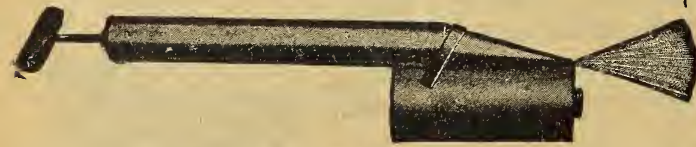

Handy Hand Sprayer, 50c
Junior No. 5

as a

Barrel

Sprayer

brass two inches in diameter, hose couplings of solid brass, ends heavily ribbed to prevent slipping off.

A few seconds working of the air pump gives you a powerful and elas. tic force, which will give you the $b$ : st possible continu. ous spray.

This s prayer holds four or five gallons, is easily carried or can be wheeled on a cart. and a few strokes occasionally with the pump will give you sufficient spray. Suited for spraying fruit trees, potatoes, vegetables, tobacco or cotton, for washing windows or

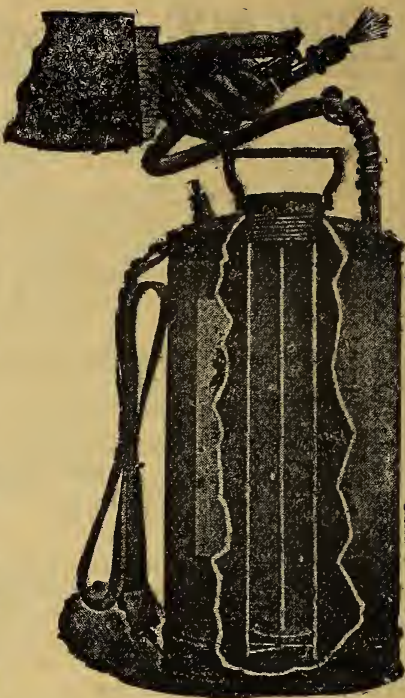

Kant Klog, Style G $1 \$ 5.25$ wagons, and for disinfecting or whitewashing hen houses or outbuildings.

It is the only sprayer I know of that will suc. cessfully handle whitewash, as all other nozzles are clogged by the sediment in the whitewash. I am so confident that this sprayer will suit you that I will ship it on approval to any responsible party. If it is not all that I claim for it, you can ship it back to me at my expense and I will refund your money. Not f. o. b. l. =rt,

Price, \$5.25 in galvanized steel; or in solid polished brass body, for \$7.55. If wanted by parcels post, add postage for 9 lbs.

Three feet of brass extension piping for reaching tall trees at $50 \mathrm{c}$.

\section{The Handy Hand Sprayer}

Not an exnensive machine, but does the work. Especially valuable in home gardening and spraying rose bushes. small fruits and henhouses, or for spraying fly-killer or insecticides on animals. Made of tin and good leather valves. Reservoir holds about a quart. Price, 50 c. If wanted by parcels post, add postage for $2 \mathrm{lbs}$.

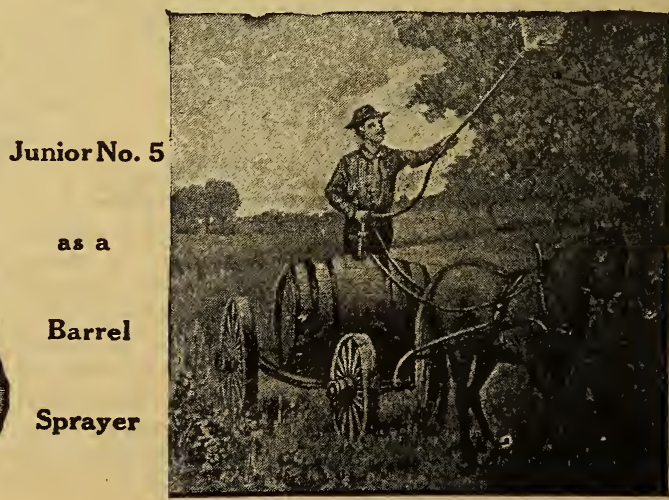




\section{Nursery Department rees, Plants, Bulbs, Shrubbery, Vines, Etc.}

This is not a new department with us ry any ins. I was really in the nursery business beI was in the seed business. The first catalng iued, a li:tle 4 raga circular, taked more about wberry and raspierry plants than it did about is.

I have always run strong to plants, and flowers, berries, ard such truck, and ttey have always cons derable space in the catalog, but more or scattered around in the book.

This year I am getting them all together here he back of the book where ynu can find them er and study them more intelligently. And I e put a special order sheet here, just in front cf $\mathrm{n}$, so that you can have a separate order sheet he plants and not have to mix them up with seeds.

Of course we are always g'ad to g^t th= orders, you can send them in any way you please and insult us at all. But it is nicer $f \mathbf{r}$ us, and you to have the plants listed senarate fr $m$ the is, for they are filled in a different place and we to cony them off before they are filed. Sn if list then. separately in the first place it will en matters a little.

Now, we have been growing and selling all of e things for a long time, but have not h: d room ill about all of them in the catalog till now. we are organized to take care ot it in $\mathrm{g}$ od re now, have grown an extra good lot of stuff, : a new packing shed a purpose for the trees, $i$ up a special p!ace in the basement for the $s$ and put in an experienced nurserym an in ge of it all, as I have so much to do I can't see all myself.

On the next 40 pages we have included the wing items:

Page

108-111

112-115

...118

116-117

I22

125

120

124

136

\section{Fruit Trees}

We can give you the finest lot of healthy, vig-

s, young fruit trees you ever saw. All grown here at Shenandoah, hardy and clean, and to name. And we won't charge you tree agent s either. We believe in young trees with lots ot system, more root than top. That is the of tree that will live well and bear quickly. A $r$ tree or even a 1-year tree, if thrifty, vigorous all the roots saved, will come into bearing rer than a 3.year tree. It will not look quite $\mathrm{s}$ when you get it, but it will bring results, and is what counts. We expect to handle 1-year ?year trees entirely. And we will dig it so as ve the roots.

\section{Strawberries and Other Small Fruit}

We have been growing and selling hundreds of thousands of berry l lants for years. We soid over a mil ion ot one kind i $f$ stra $u$ b.rities alone last year and nearly every' ne of them lived too. And we s Id almost as mary aspa:agus plants, and they all lived. And we have the finest patch of Everbearing strawberries you ever saw.

\section{Flower Bulbs and Plants}

You know already what we are on flower bulbs and plants. Some say we a e crazy atout them but anyway we have rut in a lot of time on them and have the best there is to be had in the country. Look through the list and see if I am not right.

\section{Ornamentals}

We can supply practically anything you want in the line of ornamentals. We grow oceans of that sort of stock; and what we do i ot gri w ourselves we can get from one or the other of the two big growers here. Lake and Welch. They are near ne ighbors of ours and good friends, and anything. they've got we can have.

\section{The Time to Plant}

Unless otherwise specified, all kinds of plants. trees and shrubbery shouid be plant $d$ in the spring. March, April and May, and the earlier the better. Here with us April is the month. Fu'ther soutb it might he March, and in the extreme north in May. As a rule we do not ship anything in this department befnre Morch 1st, nor l, ter than May 15 th, exc pt that special fall planting items are shipped in October.

\section{Free Delivery}

All prices quoted in this department, unless otherw.se specified, incl de free delivery by parcels post or prepaid express, and we expect to use parcels post on neally everything. That is the moderr way. Of course some thit gs are too large to go by parcels post and too heavy to go by express econo. mically, but I will mention them when I come to them.

\section{Order Early}

It is important that you get your order in early. Plants and trees of all kinds do mush bet er planted very early. The chances are always against success with late planting. Besides, the early orders are more likely to get the pick of the s'ock and do not run in o shortages and other troubles as late orders are likely to do. We always run short on some items before the spring seasnn is over, hut the early orders are always sure of getting exactly what is wanted. Send in your order and ne will book it and save the stock for you, and ship it whenever you say. 


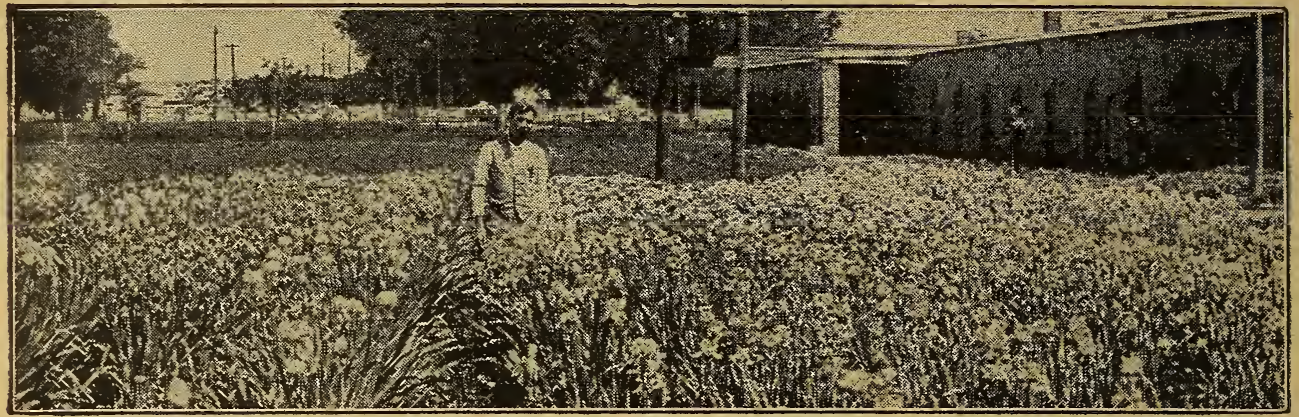

\section{A View of Part of Our Iris}

We have over fifty varieties in our garden by the seed house, and it is the most beautiful sight you ever saw. They were in bloom. from some time in April until the middie of June, and I believe we must have had hundreds of thousands of them.

T

E IRIS deserves to be better known and more extensively grown. I consider it one of the most beautiful of all hardy flowers. In the first place it is absolutely ha:dy; it will grow and thrive and bloom in any soil and in any climate; it will stand any kind of winter, no matter how severe, and will stand a dry summer that will almost kill anything else; it will increase and multiply, and always looks well, whether in bloom or not.

The few and common varieties of the oldfashioned garden have been increased by flower lovers and scientific plant breeders to a host of beautiful colors and rare beauties. I have in my own private garden over fifty varieties of this beautiful flower, probably one of the finest collections in the world. Here are the descriptions of some of the best of them:

Queen of Gypsies. The upper part of the flower is old gold. shaded with smoked pearl, while the outer petals or talls, as they are called, are dark maroon, yeined with light yellow. This makes a very striking combination of colors

Blue Siberian. This belongs to a different family of iris. All the others in this list belong to what is known as the German iris, but the Siberian is different in appearance. it grows quite tall and slender, with narrow, grassy foliage, and the flow. ers are of intense sky blue.

Princess Beatrice (Pallida Dalmattica). The standards or upper petals are fine delicate lavender in color, while the falls are a much deeper shade of lavender. Flowers are very large, extra fine, a superb variety for cut flowers; very scarce and sold at about $50 \mathrm{c}$ per plant.

Silver King. A beautiful pearly or silvery white. It is large and tall like Black Prince, but a direct contrast to it in color. The entire flower is all the same color, a beautiful silvery white through out.

Eldorado. Bright, golden yellow, with a slight veining of crimson on the outer petals. A very free bloomer and the most brilliant thing you ever saw: You can see it clear across the garden and it will be the envy of all your neighbors.

Ruby Queen. Nearest to a genuine red of any of the iris. Best described as claret red. A very striking color and a very rare color in iris. If you want something different from what your neigh. bors have, get this red iris.
Prince of Wales. Deep violet blue, with deeper purple color on the lower petals. Very large, intense coloring, free blooming, tall.

Jenny Lind. A beantiful combination of purp lish red and pearl in delicate shades.

Orientalis. This is somewhat like the Siberian iris, and in fact, belongs to that group, but in manner of growth it is more like the German iris. A very deep striking blue; the bluest thing you ever saw. A rare variety.

Queen of May. A delicate peach blossom pink. Increases slowly and we are sold out on it this year.

Black Prince. Large, tall, strong grower. Rich dark purple in color.

Blue Siberian. This belongs to a different family of iris. It grows quite tall and slender, with narrow, grassy foliage

White Siberian. Similar to the blue, except in color, which is white. Eldorado,

Sans Souci. Yellow. Practically the same as

Velveteen. Purple and old gold. A very striking combination,

Dwarf Pumila. Very early and very dwarf, only about six inches high. Solid purple color.

Dwarf White. Not quite pure white, but a light cream. Very early. Grows about 10 inches high. Berlin. Violet blue throughout.

Celeste. Pale azure blue.

Frederick. Lavender and purple.

White Swan. Creamy white throughout. Very beautiful.

Brittanicus. Blue and lavender.

Bismarck. Yellow and brown.

Candicans. Soft, light blue.

Price, any of these varieties, $15 \mathrm{c}$ each, 2 for $25 c, 4$ for 50 e, 8 for $\$ 1.00$. $\$ 1.50$ per dozen, either all alike or assorted. These will be good strong plants, guaranteed to live, bloom, and to prove true to name. Prices include delivery by parcels post, postpaid.

\section{The Iris For National Flower}

Some have suggested that the Iris should be our national flower as it is probably the only flowex that can be grown in every part of the United States. I don't suppose there is a state or a county where it can not be grown in all its beauty, and there is no other flower that will do it. 


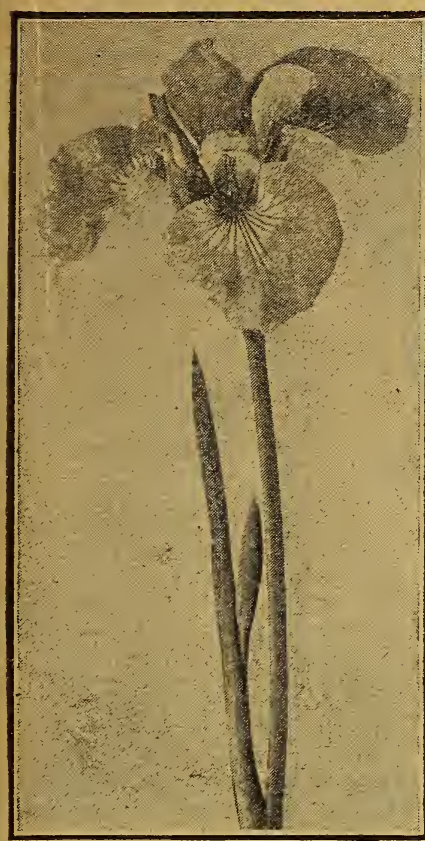

Blue Iris - Orientalis

Deep blue; bluest of all Iris

\section{Mixed Iris}

We have several rows of iris that are mixed varieties, where we have planted the odds and ends of named varieties that were left at the end of the season, or where we have planted small lots, of which we did not have enough to pay to keep it on the list of named varieties. Also, sometimes a stake will get knocked down and lost or the label on a box of plants will get lost. Then they have to go into the mixture. This mixture contains a good assortment of varieties and plants of some of our very finest ones will be found in it. They are in. creasing fast on us and we want to get them cleaned out, so I am going to make a special offer on them,

Special Offer
Mixed varieties of iris,
good, strong plants, 3 for
25c, or 90 c per dozen.

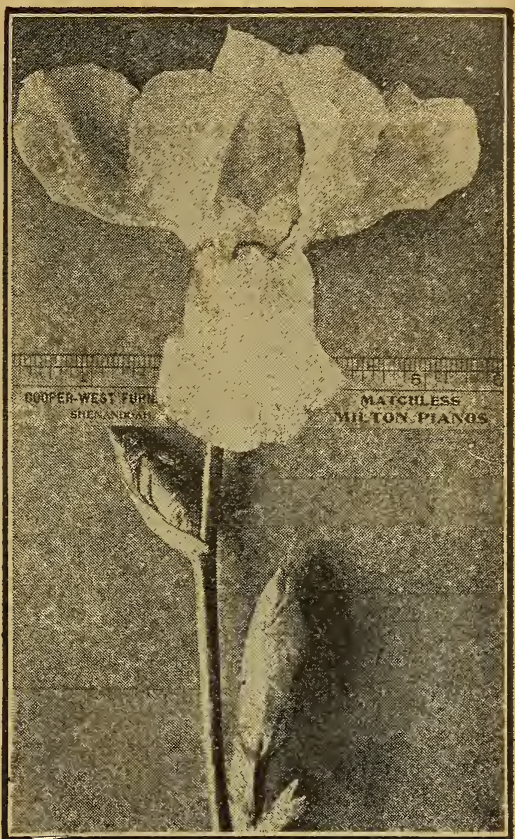

Princess Beatrice. The largest and possibly the most beautiful of the Iris.

\section{When to Plant Iris}

Iris is one flower that can be planted at almost any time of the year. I like best to plant it in the fall or early spring, but really it can be planted almost any time with a fair chance of success. It is one flower that $I$ have succeeded in moving while it was in bloom, and you know very few outdoor flowers can be moved when they are big and in bloom.

They will grow on practically any soil. We have some on good garden soil, some on a clay fill where we scraped dirt out of the cellar, some on

\section{Hardy Phlox}

These we consider one of the most desirable of hardy flowers. The flower-heads often measure from 7 to 9 inches across. Flowers as Iarge as a silver quarter, and in some cases as large as a half dollar. Comprises all shades from vermilion to white. They do best in a sunny location and rich soil, but are not particular and will do well any. where. Can be set either fall or spring, but not late in the spring. We have a long list of named varieties, but as very few people are acquainted with named sorts, we sell them mostly by color instead of name. Here are the colors we can furnish: Pure white (very fine). White, with red eye. Pink, with red eye. Solid red. Solid pink. Price, $15 \mathrm{c}$ each, 2 for $25 c, 5$ for $50 c, \$ 1.00$ per dozen, either ali alike or assorted colors.

Special Offer Mixedphlox, all fine plants all good strong plants, and good assortment of colors. 3 for $25 c, 6$ for $45 c, 75 c$ per dozen. rich ground and some on poor, and they all seem to thrive about alike. We have a row of them along the curb overhanging the pavement and they seem to enjoy it.

\section{Japanese Iris}

For some reason I have never been very successful growing Japanese Iris. They are mighty fine if you can get them to bloom, but they take lots of petting, and personally I very much prefer the other kinds of iris. Can supply Japanese Iris, mixed or assorted colors, at $20 \mathrm{c}$ each, or 2 for $35 \mathrm{c}$.

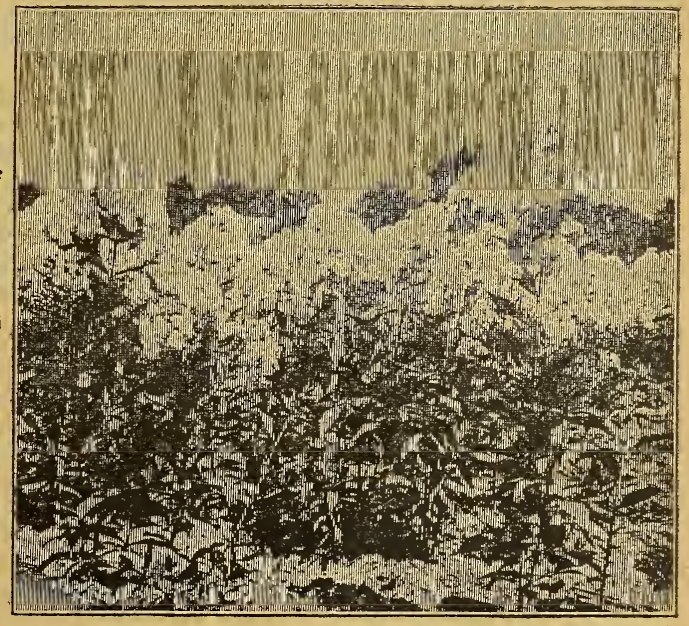

Pure White Hardy Phlox 


\section{The Peony}

The Flower for the Million and the Millionaire.

First of all in the list of harc'y fiowers I would put the peony. It is as hardy as a loak. lives for years, and gets better with age. It needs no protectinn, will grow in any soil. and $\mathrm{h}$ is absclutely no diseases or insect enemies. A millionaire could have r. ot hing finer, and no flower will do as well for the c o m mon gardener. The plants can be set either in spring or fall. but if set in the spring should be set very early. They will olten bloom the first year they are set, and always by the ncxt year. In addition to $\mathrm{my}$ al tady large and fine collection of peonies $I$ added the $H$. A. Terry collection, which was, in many ways, the finest in the world. Fa!her Terry had spent over fi'ty years developing the peony, and originated over 300 new varieties, many of them finer than anyth ng heretofore known. After his dealh I purchased his entire collection and mov'd it to my own grounds. His varieties are specially no*ed for bright clear colors, extreme hardiness and certainty to bloom. The following list is simply a selection of a few good varie. ties from my collection of over $3 v 0$ sorts. These are ones that I have chosen as extra good ones, certain to grow and bloom for any one.

There are plenty more in the complete list just as good, but I do not have room to describe them all, so I have chosen these to describe more fully.

I am certain that among them you can find any style of peony you want, and I know they are all good ones, for $I$ grow them on my own grounds and have seen them in bloom. All are double and most of them are very fragrant.

Prices given are for good strong plants of from 3 to 5 new eyes, either large divisions from old clumps, or complete plants of one ycars growth from small $\mathrm{d}$ visions or cuttings. See below for prices on large clumps.

\section{Pink Peonies}

(Ranging in color from a shell pink to almost crimson.)

Brightness (Terry).-Pure deep pink, tall, free bloomer

Elegans. - Outer leaves pink, center salmon color. Odd and beautiful

Gen. Canby (Terry). - Outer petals deep rose, center liggt rose, tipped white and fringed. Blooms early

Jupiter (Terry). - Crimson and bright rose, very large and early. Fine center

La Coquetfe. - Bright rose with creamy
L'Esperance. Snft, pale pink, slichtly s h a d ed with carmine. $V$ e ry early and fragrant. V e r y large and a fine b oome: Ne`rly always in Ll om for Memorial Day.

Mazie T erry (Terry). - Bright rose, tipped wich whi e. Large flower, globular, strong grower and free bloomer.$\$ 1.00$

Marie Honick$\operatorname{man}(\mathrm{T}$ erry) Ver y ta l, dark pink. Handsome.

Parmentierre... Light rose, free bloomer, fine..

Pauline.-Eright rose, fading to blush pink. Very fine..... Princess Ellen (Terry). - Bright rose, tipped white, very large, free bloomer tall, fine . . . . . . . $\$ 1.00$

Rel Victoria. - Bright rose, perfect , ower, strong grower .

Robert Burns. - Outer petals purplish rose, inside light rose, tipped white . . . . . Stella ((Terry) - Delicate rose, with crimson center. Fine... Terry's No. 4 (Terry). - Beautifui light rose, full globular flower, very large, center tipped white ... . . 1.00

\section{Red Peonies}

(Various shades of deep red from crimson to carmine.)

Crimson Queen (Terry).-_Solid crimso1.. blooming in clusters, fintly fringed, extra fine

Carnation (Terry). - Bright crims on throughout, center finely fringed ...... Ernest Hemming (Terry). - Bright crim. son throughout, Jroad petals, free bloomer, tall, strong grower, very large flower .... . Grace French (Terry). - Bıight crimson, globular flower. compact bush

Grandiflora Rosea-Tall, deep crimson, blooms late. Al old variety . . . . . . . Grover Clevelat:d (Terry).-In my opinion the best one of Terry's wonderful reds. Deep g owing r rimson. Very large flower, globular, and finely fringec. Just about perfect every way.

Humeii Carnea. - Large flower, bright .50 rose, strong grower, fragrant . . . . . Lillie McGill (Terry). - Deep crimson. .25 very large, strong grower and very free bloomer. Extra good . . * . . . * . . . . Mars (Terry).-Deep blood red, very free .25 bloomer, fine evi ry way .......... Pottsii - Very dark crimson, semi-double, .25 free bloomer, and very early . . . . . . . . Rhoda ( $T$, rry).-Be utiful light crimson, .50 perfect form, fref hloomer, fine in every way. 1.00 


\section{R॰d Peonies (Continued)}

Rachel (Terry). - An. other of Terry's wonderful dcep reds, glowing crim son, ful douvle and free blooming. Extra fine. . $\$ 1.00$

Rose Fragrans. - Very large, full double, perfect rose co'or. Has the co'or and $f_{i}$ agrance of an American Bealty rose. Strong grower, late . - The new,
May King.deep red, ex:ra red. See full description elsewhere. 1.00

\section{White Peonies}

(Including some which are blush white, light pink, or cream colored when fi st opening, but fading to wlite later).

Emily Hoste. - Pure white, edged with crimson, very fine

Iris Pleas.-Soft, light rose, full double.. .25

Esther (Terry). - Conside red by Mr. Terry as one of his finest, and named $a^{t}{ }^{t}$ er his wife. Ourer petals light rose, center finely fringed, cream tipped with light rose, free tloomer.

Festiva Maxima. - The largest and probably the best white pecuv grown. Very large and double, rich fragrance, pure white with a littie touch of scarlet on center peials. Hardy and sure to bloom anywhere.

Floral Treasure.-B ush pink, shading to almost whice, very fragrant and very large, often 7 inches across .

Globosa.-Very large, globe-shaped, pure white Miss Henninger (Terry). Outer petals soft, light rose, center light cream, tipped

white; tad ing to pure white. Extra good one.
Mrs. Dunglas.-.Pure white with a splash of crimson on center petals. Finely fringed.

Mrs. Rudd (Terry).-Pure white or slightly cream, center finely fringed, very fine.

Magnifica.-Very large bloom, white with creamy center

Queen Emma (Terry)-_Large, full double white, tinged with rose, making a very delicate silvery color, blooms very fi eely and large.

Terry's N . 6 (Terry). - Full double, white with tinge of light rose, very fine 1.
Whittleyii. - A favorite pure white com. mercial variety. A sure bloomer. . . . . .

\section{Postpaid}

These prices include delivery by parcels post, all charges prepaid. Remember this when com. paring prices.

\section{Discounts}

We will make the following discount on large rders of peonies at regular prices:

On orders for $\$ 1000$ or over, 5 per cent off. On o'ders for $\$ 25.00$ or over, 10 per cent off. On orders foa $\$ 50.00$ or over, 15 per cent off. double white varieties. 2uc each, 5 for $\$ 1.00$.

Doub) - Pink.-A collection of pink sorts rangin 3 from a shell pink to almost a crimson. 20 c each of for $\$ 1.00$.

.50 Druble Red.-Various shades of deep red. 20c each, 6 for $\$ 1.00$.

Mixed Double.-All colors. Hardly any two .50 alike. 20, each, i for $35 c, 6$ for $95 c, \$ 1.90$ per dozen.

\section{The Five Points of Excellence}

\section{The Peony Fills Them All}

Florists have often said that any flower, to be popular and valuable, should be perfect in these five points:

Beauty of form; Beauty of color; Fragrance; Hardiness; Adaptability as a cut flower.

Think st over and see what flower will fill that list outside the peony. The rose comes failly near, but it is weak, as a rule, on hardiness. The same 1.00 is true of tae lily. The gladiolas can fill the bill except for lack of fragrance. In fact, there is no 25 other that will fulfill all the conditions except the peony.

It is he hardiest of all flowers, has a delicious tragrance, will keep for a week as a cut fluwer, and there is no other flower that will equal it in gorgeous color, baautiful f:rm and immense size. It will grow ard bloom for anyone and in any soil. Ic is cheap enough so that the modest cottage can afford to have a few choice clumps.

I wish $I$ could put a half dozen c'umps of beau'iful peonies in every bare and forlorn look. ing farm yard in the $U$ ited States. Hundreds and thousands of them have not a sign of a flower or beauty of any kind. 


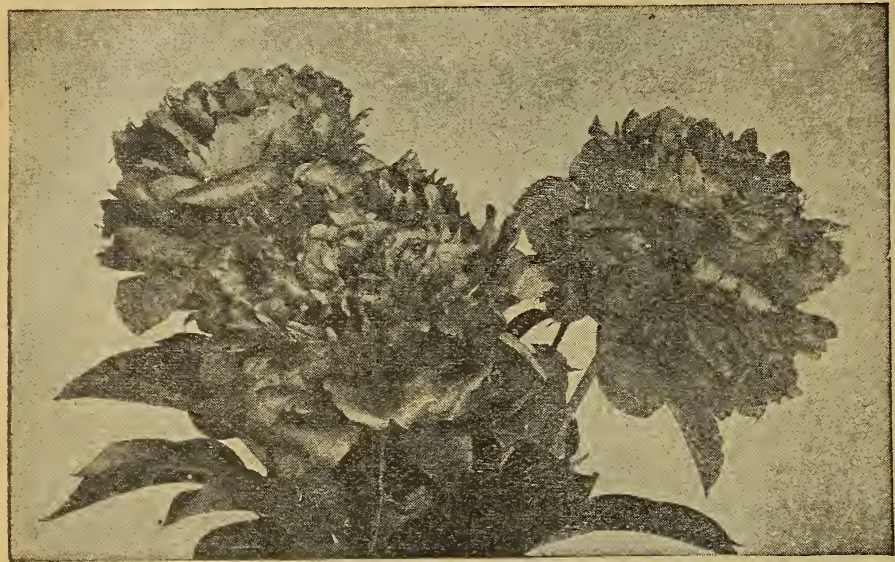

The New Peony May King

A new and distinct variety of peony, entirely different in growth and appearance from other varieties. Very early, blood red and very free flowering. I made previous mention of this new peony in my catalog last year and after another years' experience with it I wish to repeat most emphatically all I said of it last year and make it even stronger.

The striking points of this peony are its extreme earliness and its deep blood red color. It comes ten days to two weeks earlier than any other sort I have and was in full bloom for me last summer on May 12th. I believe May King, the Earliest and Reddest of All Peonies that in an early season it might

\section{Terry Seedling Peonies}

This is the same srecial offer I was talking about this time last year. I sold most of them, but still have part of them left, and while they last will leave the same offer open. I don't think they will last all season, but will let you know prompt. ly if you order after I am sold out.

They are mixed seedlings grown by Father Terry shortly before his death. They are all colors, shapes and sizes, mostly very fine stuff, some just common. They run about half double and semidouble and the balance single. They have never been culled or skinned out, but are just the way I got them:

I am digging them clean, dividing them, and making them up in collections of 8,25 and 60 each, and while they last will sell them at prices named below.

You will note they are not postpaid at this special price. The peonies I sell at regular prices I can afford to pay postage, but not on these bargain prices. They can be sent either by express or parcel post. If wanted by parcel post add postage when ordering. I estimate they will weigh, packed for shipment, about $\frac{1}{2} \mathrm{lb}$. per plant.

\section{Special Offer}

Now, here is the special offer I am going to make to you. I will sell you eight of these Terry seedlings for $\$ 1.00$, or 25 for $\$ 2.50$, or 60 for $\$ 5.00$, not postpaid.

Now, if you want a bargain of really choice peonies; this is the chance of a lifetime. It will give you a chance to get started on some good stuff at a small cost. Of course, I won't guarantee that they will everyone be absolutely fancy varieties. Most of them are extra fine, but some of them are nothing out of the ordinary. In any lot of seedlings there is a wide variation in color, form and quality, but these of Father Terry's represent the last and best work of fifty years of scientific breeding, and there probably never was and never will be again as choice a lot of seedling peonies.

There will not be enough of these to finish the season, but as long as they last I will fill your order. bloom as early as May 1st. It is medium in size, perfect half globe in shape, and the deepest, dazz. ling blood red. The bush is rather dwarf and the foliage entirely different in appearance from other peories.

Its history is peculiar. It was first found grow. ing near an abandoned house in Manti, the old de. serted Mormon settlement near here, which was settled by Mormon refugees during the exodus from Nauvoo to Salt Lake during the early fifties. On that account it is known locally here as the "Mormon Peony." I have known of it since I was a small boy, but never managed to secure a start of it till a few years ago, and then it took time to work up a stock of it, but now I have enough so that I can offer a limited number of plants for sale.

Now, it may be that others have this peony, but $I$ have never seen it listed in any of the catalogs, and it certainly was new to me, and everyone who has seen it here on the seed house grounds pronounced it entirely distinct and of remarkable value to the peony lover. It's extreme earliness. its hardiness, its free blooming habit and its deep blood red color, (which is especially rare in peonies) make it a combiration hard to beat. Price, $\$ 1.00$ each, $\$ 10.00$ per doz.

\section{Grow My Own Peonies}

I grow my own peonies right here on the seed house grounds, where I can see them every day. In the spring and summer I just pretty near live with them and I know every variety and almost every plant by heart. I know absolutely that they are true to name, true to color, healthy and vig. orous. You need fear no disappointment when you get peonies out of such a garden as mine. If you buy any peonies from me, or if you have bought any in the past, and they are untrue to name or fail to live, I will at any time replace them free.

Now, if you are at all interested in peonies, I surely ought to have your order.

\section{Peonies For Cut Flowers}

Growing lots of peonies, as we do, we always have lots of the blooms to sell as cut flowers in season. Ordinarily we can supply them for $\$ 1.00$ per dozen, postpaid, in postal zones 2 and 3. Do not advise shipping farther than that. 


\section{Complete List of Our Peonies}

The varieties which I have described in full do not make up our entire list by any means. We have over three hundred named varieties, lots of them very fine onts. I do not have room to give complete description of them, but here is a con. densed list giving name, color and price of most of our list. Would be glad to furnish you any of these you want. Some of them we have only in limited supply, but in most of them we have from 100 to 500 of a kind.
They are all growing on our grounds, and 1 checked them over when they were in bloom to make sure they were correct.

If you are a peony fancier you ought to be able to find what you want in this list

You will note in describing the color I have marked them W. P. and R., meaning white, pink and red. The white includes blush white and cream colored varieties. Prices include post age.

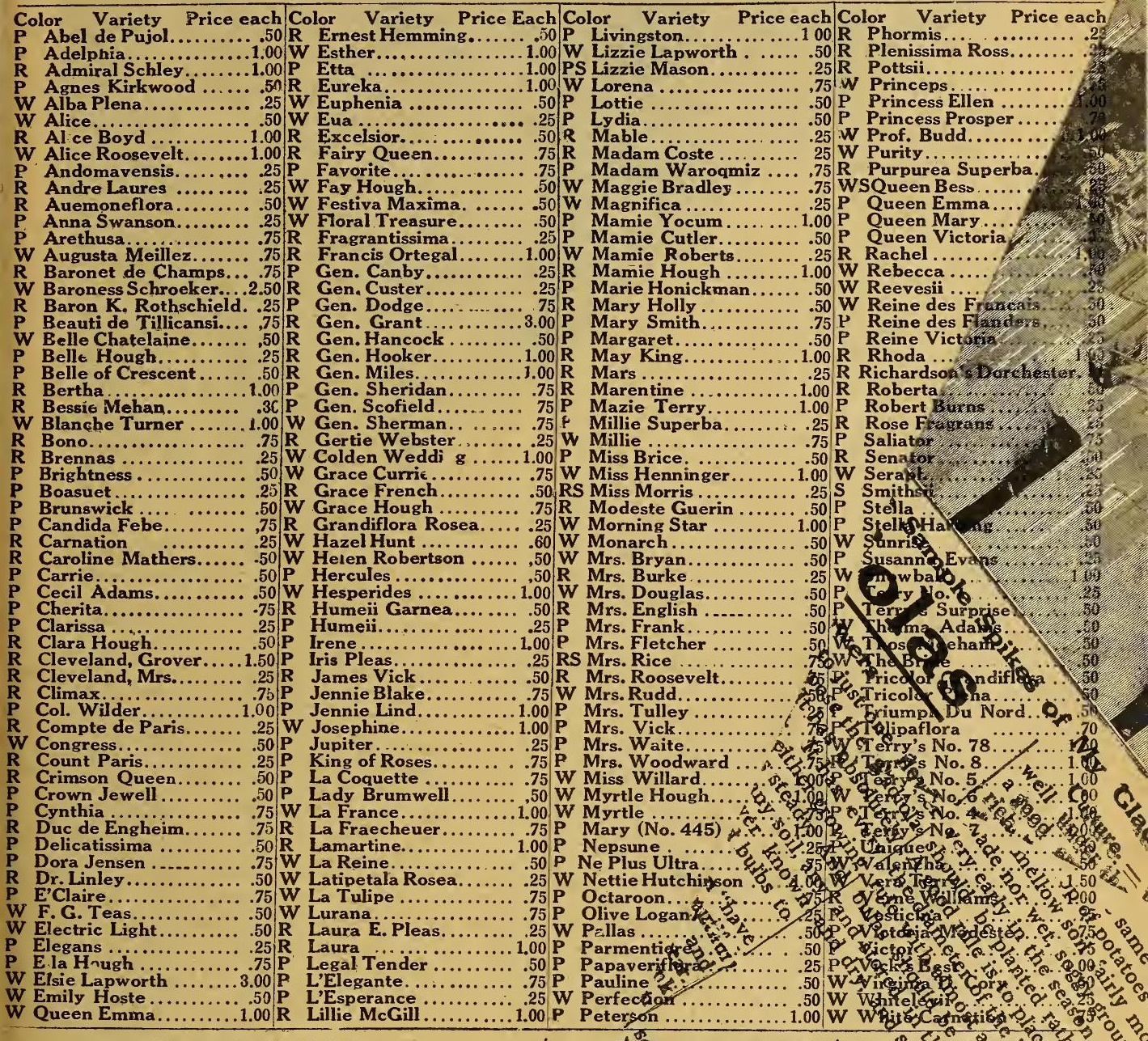

\section{Special Offer}

I realize that we have too many varieties and especially too many plants of rare and choice varieties, which are extra fine, but which are not well known to the trade. About one half of this list consists of Father Terry's chaice varieties, which are the finest known in peonies, but are unt known to the average grower, and so are compar. atively slow sale. We are crowded for room, pecially on some varieties, as they increase rapid so we make the following special offer:

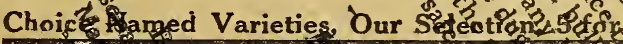

3) ve vih you chof

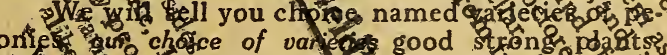

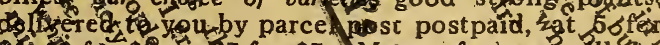

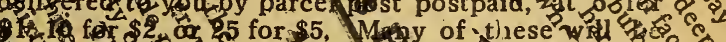

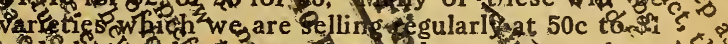
ench bat to

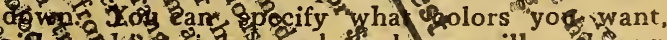

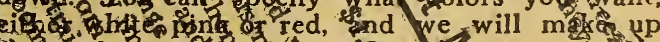

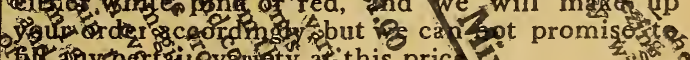

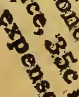




Gladiolas (Continued)

Light and Striped Mixture.-This mixture runs almost entirely to light colors, such as white, yellow, pink and white-striped, pink and yellow, and it contains practically no reds or dark colors. While the blooms are not quite so large as from the reds, nor the spilies so heavy and massive, these light cuiors are preferred by a great many people. Price, 4 uc per dozen, 35 for $\$ 1 . C 0$, postpaid.

Silver Trophy, or Gold Medal Collection.This is the celcbrated Cowee collection which has created so much excitement the last few years. It contains practically every known color and runs largely to large blooms and tall, heavy spikes. Price, 50 c per dozen, 25 for $\$ 1.00$, postpaid.

Giant Red Mixture. - This strain I secured from an Ohio grower who likes reds better than any other color. The stalks are of heavy, massive growth, often 4 to 5 feet high, with very large flowers of varying shades of red; especially fine for massing where red is wanted as the dominating color. Price, $40 \mathrm{c}$ per dozen, 35 for $\$ 1.00$.

\section{Choice Named Gladiolas}

\section{At 5c Each}

Any of the following, $5 \mathrm{c}$ each, 6 for $25 \mathrm{c}, 50 \mathrm{c}$ per doz., or 25 for $\$ 1.00$, either all alike or assorted to suit. Ask for special prices on lots of 100 or over.

America.-This is the wonderful variety an eastern seedsman paid $\$ 4,000$ for. In color it is soft pink, very light; spikes 2 to 3 feet long, with large spreading blooms. Will bring a higher price in cut-flower market than any other variety.

Mrs. Frances King. - In many ways the best in the list. A rank, thrifty grower, very large flowers, often 5 inches across, and a beautitully shaped long spike. Often almost two feet of flowers in bloom at once. Light scarlet, with deep markings.

Augusta.--Very popular with the florists. Prac. tically pure white with blue anthers.

Brenchleyer cis. - An old variety; one of the most brilliant reds. Whole spikes open at once.

Faust. - Deep velvety crimson with some white shading on two lower petals. Large size and strong spike.

Halley.-Delicate salmon pink, very large and bright, and very early. One of the best in the list. Fine for cut flowers.

(The 6 listed above are all exceptionally good, and every flower-grower should have all 6 of them in addition to whatever else is ordered.)

Lemoine No. 1.- Light violet and purple, with deep velvety purple throat. Long spike; free bloomer.

Madam Lamoine.-Probably the earliest variety grown. Large flowers; creamy white with scarlet throat.

Marie Lemoine. - Large spike of fine flowers. Upper divisions pale cream color, flushed salmon lilac. Lower division spotted violet and yellow.

Meadowvale. - Almost pure white, with a touch of crimson in the throat, and a trace of pink on the two ower petals. Very fine.

Independence. - A brilliant rose pink with richly marked throat and a long, strong spike.

Antoinette.-Of the Lemoine type. Quite early, bzautiful rosy pink color; medium size.

\section{Rare and Choice Gladiolas}

\section{At 7c Each, or $75 \mathrm{c}$ Per Dozen}

Any of the following, $7 c$ each, 4 for $25 c, 75 c$ per dozen, either all alike or assorted to suit. Al' 16 for $\$ 1.00$.

\section{Fine Whites.}

Glory of Holiand.-Pure white. The best and largest pure white in the list.

Snowbank. - Practically pure white, a strong grower and good size. Shows faint pink marking on lower petals.

Willy Wigman.-Very large, blush white, with large carmine blotch on lower petals.

White Excelsior.-Tall, long spike, pure white. 4 in the Yellow Class.

Klondike.-Beautiful cream color, with bright scarlet throat. Best nne of its color.

Golden West. - Brilliant orange, striped darker. Extra fine.

Victory. - Variegated, yellow and pink, tall straight spike.

Jean Dieulafoy. - Cream pink with conspicu. ous crimson blotch.

$$
4 \text { Beautiful Pinks. }
$$

Pink Beauty.-Earliest of all. Soft pink with heavy dark marnon blotch in throat.

Pink Perfection.-A beautiful solid pink, very large spikes.

Eugene Scribe.-Tender rose, blazed with carmine and red. Finely ruffled and frilled edges.

Wm. Falconer. - Clear rosy pink; very large and very fine,

\section{Velvet King 4 ' Odd Colors.} spike. Fine every way.

Empress of India.-Brownish black or black red. The darkest of all and wonderfully striking and at. tractive. Good size and a free bloomer.

Purple Prince. - A beautiful reddish purple color, mottled and blotched with cream. One of the girls here says it reminds her of plum juice and cream.

Bird of Paradise. - Beautiful striped pink and yellow. Large flower and la ge spike; with a large number of flowers open at once.

One bulb each of the 16 rare and choicesorts, all extra fine for $\$ 1.00$.

\section{Gladiola Bulblet Collection}

\section{Grow Your Own Bulbs}

These are the little, wee fellows, about as big as a pea, from which we grow the blooming:size bulbs to sell a year from now. Some few of them will bloom this year, but all will grow and make a bulb that will bloom next year. These are from our best mixture. Most growers refuse to sell these bulblets, but I have decided to offer a limited amount of them at 200 for $25 \mathrm{c}$ or $\$ 1.00$ per 1,000 , sent prstpaid. I will send out with each package full directions for growing them to blooming size.

\section{Special Trial Grounds Mixture}

We have for several years been grnwing a lot of little dabs of high priced novelties in Gladiolas, and specially fine seedlings under numbers, and so on, but it is too much trouble keeping the little tots separate so I am going to sell them as a mix ture, They are fine and you'lllike them. Price $60 \mathrm{c}$ per dozen straight. 


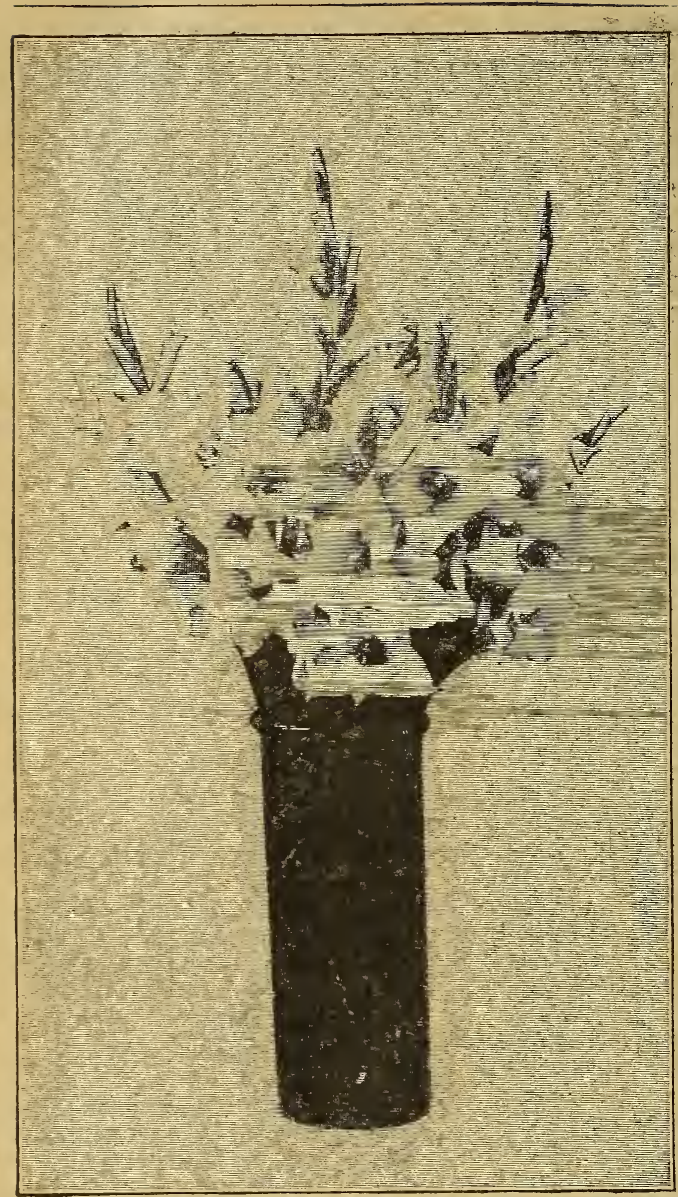

New and Striking Varieties

\section{At 10c Each, or 6 for 50c}

One each, blue, yellow, pink, white, red, and ruffled, each the very finest and best in its class. Price, $10 \mathrm{c}$ each, 6 for $50 \mathrm{c}, \$ 7.00$ per doz., either all alike or assorted.

Baron Hulot (Blue Jay). - The only strictly blue gladiola. Dark, rich velvety blue, which shades out in the house to a violet purple. Probably the rarest and most sought after color in the whole list.

Niagara. - The beautiful new cream-colored or yellow sort that has been winning prizes everywhere. Large wide open flowers on a long straight spike. Has always before sold at $25 \mathrm{c}$ to $30 \mathrm{c}$ each.

Panama. - A very fine flower somewhat like America, but of a deeper pink color, being more a cherry pink or rose color. Very large.

Peace. - A grand white variety. Flowers are large, wide open, with a heavy straight spike. Color glistening white, with faint lilac feathering on lower petals.

Princeps. - The reddest of all. Rich crimson with broad white blotches on the lower petals. Probably the largest flower in the list. Opens wide and flat.

Glory.-The best of the new ruffled and frilled type. Delicate pink and yellow.

\section{The Fairlawn Hybrids}

The most distinct and valuable new race of gladiolas brought out in the last ten years. If you are a lover of this beautiful flower I can assure you a rare treat in this coliection. Honestly and truly it is far ahead of anything I have ever seen in this line.

Its History. - The originator of this strain is Mr. C. L. Goodrich. He is a banker and amateur flower grower in northern Iowa. He is the greatest flower crank you ever saw, and although he has a bank and a farm to look after, he spends most of his spare time fussing around among his flowers He has probably done more in the line of hybridizing, scientific crossing and hand pollenizing than any flower grower in the United States, and he has confined his work almost entirely to gladiolas.

He started ten or twelve years ago with the best varieties he could buy in Europe and America and took these for his parent stock. He worked mostly crossing the very best known varieties. transfering the pollen by hand from one flower to another and thus knowing the exact parentage of each cross and its pedigree through several generations. His aim has been to get the best possible collection of deep reds, pure whites, clear yellows and delicately striped or penciled varieties and all in the very largest size, and he has succeeded won. derfully. All weak or poor seedlings have been rigidly discarded and nothing . but the very finest allowed to grow.

As fast as they bloomed and were passed as being sufficiently good for his collection he sorted them into four sections as follows: Red and deep pink, white, yellow, striped and variegated. The results from the blue were disappointing to him. He had the color all right, but could not get the size. All that showed clear blue colors so far have proved to be comparatively small, or if they have the size, they are weak in color, so he asks me not to offer any of his blues.

I am ready to offer this year in a limited supply the following sections at prices noted:

Each Doz. 100

Red and pink ......... . 15c $\$ 1.50 \$ 11$

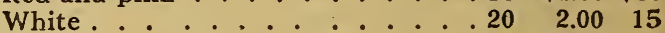

Yellow . . . 20 2000

Striped and variegated . . . . . 20200

Mixed, all colors . . . . . . . $10 \quad 1.008$

\section{Named Varieties Fairlawn Hybrids}

While Mr. Goodrich believes that gladiolas as a rule should be sold in mixed color sections he has selected a few of his seedlings which were of such outstanding merit and value that he thought they ought to be offered separately. Ones of which we have sufficient stock to offer bulbs are the following:

Agricola. - This is the first of tne Fairlawn Hybrids and has been used as the parent of many other varieties. It is very large, generally five to six inches in diameter, with peculiarly distinct stripes of white and light crimson band on lower petals.

Waterloo.-A seedling of Agricola from a cross with America. A very large flower. It is blended with light lilac and lavender marked with crimson on tips of petals. 
Shenandoah. - A beautiful flower of largest size. A seedling of No. 50. (A cross of Agricola and America) crossed with Daisy Leland. Fully as large as any of the parents and with none of the defects of any of them. Color, bright pink, but showing the Agricola parentage in penciling of crimson.

Decatur. - A seedling of Gov. McCormack (Childsi), from a seedling tracing back to Agricola and a large, pure white. Pure white ground, tips of petals marked crimson, throat marked and mottled with crimson.

Luther.-A large flower, combination of laven der and light lilac with a mottled throat. $\$ 1.00$.

Price, any of the above, 25c each, or 5 for

Special Offer One each of these five wonstrong bulbs, for $\$ 1.00$, postpaid.

Plant Gladiolas Early.-They like cool weather, and the earlier they are planted the better.

\section{Goodrich Seedlings}

These are the seedlings from which the wonderful Fairlawn Hybrids are being selected. They are from hand-pollinated crosses of the finest varieties known and contain some wonderful sorts. Price, $75 \mathrm{c}$ per doz., 100 for $\$ 5.00$,

\section{Wholesale Prices on Bulbs}

We grow generally millions of gladiola bulbs and can make low wholesale prices on large lots in any size or variety. We are especially strong on good, first-class mixtures and can suit you on both quality and price. If you can use 500 or 1,000 bulbs or over, write for special prices.

\section{Special Bargain Collection of Gladiolus Bu'bs}

\section{Blooming Size Bulbs for 90c Postpaid}

We had the finest crop of gladiolus bulbs this year we have ever gruwn, and we are going to celebrate by offering the greatest bargain in them that has ever been offered, I believe, -60 fine bulbs for $90 \mathrm{c}$.-Good bulbs too, not trash.

Most people prefer a mixture of colors, so 50 of the bulbs will be a mixture of all the best colors. Everything from white to dark red, with plenty of striped and spotted and variegated tints in between. A really first class mixture, with good colors, big flowers, and a long season of blooming.

Then I will put in 5 each of the two best named sorts, America, and Mrs. Frances King. You have doubtless seen and admired them, but they have always been high-priced till now, and you had to admire them at a distance,

5 America, the great "peach pink" colored one, big and fine, used to sell at $50 \mathrm{c}$ each.

5 Mrs. Frances King, the best big red. Bright "cherry red", grows 4 to $5 \mathrm{ft}$. high, extra large. 50 Mixed hybrid seedlings, all colors, all good.

60 bulbs in all, all blooming size, young bulbs, two to four inches in circumference, well packed in a box, with directions for growing, guaranteed to reach you safely and to bloom with ordinary care and soil. Sent postpaid for only $90 \mathrm{c}$ for the box of 60 bulbs.

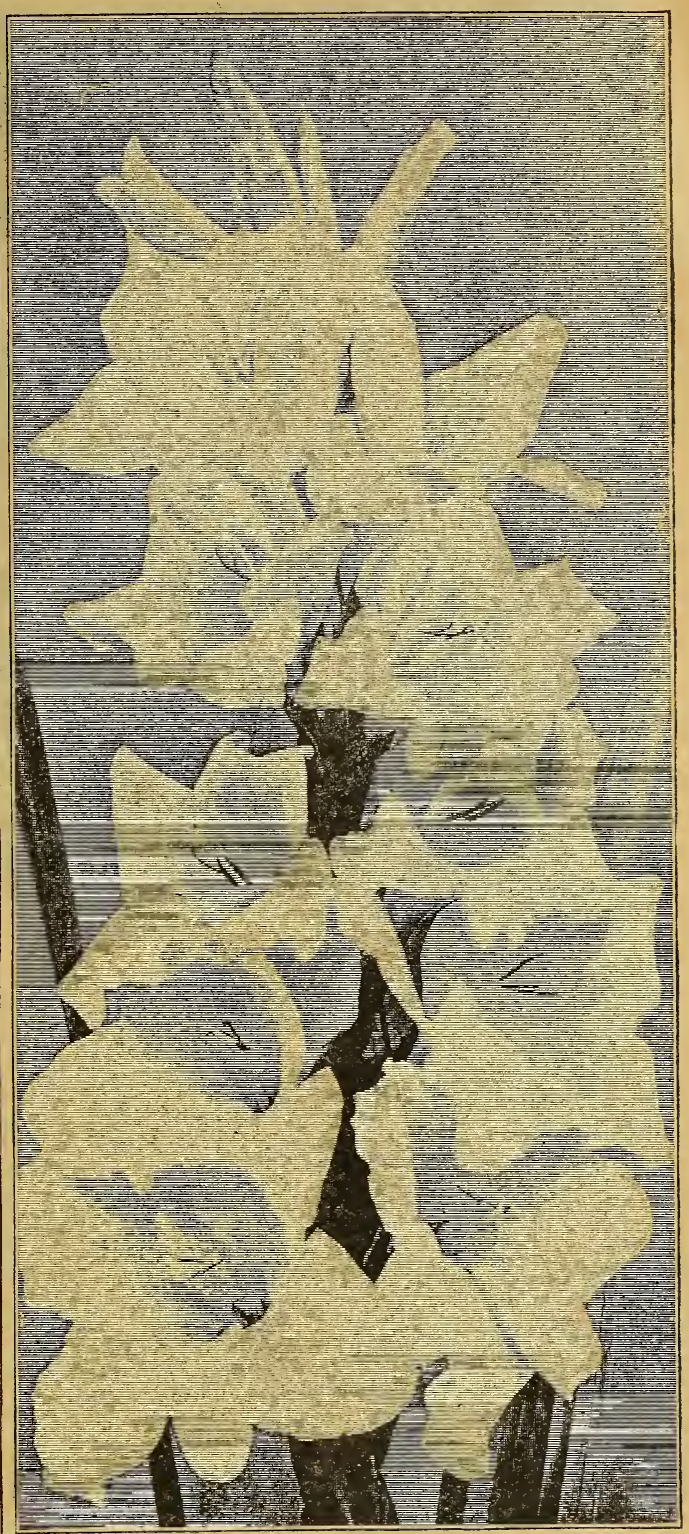

Niagara, the Great New Cream-Colored Sort

\section{Gladiolas For Cut Flowers}

Gladiolas make the finest cut flowers imagine. able. They are easily'grown, ship well, will keep for a week after they are cut and are popular every. where. They can be had in any color for any occasion.

For the woman or man who wants to grow a few cut flowers for profit. I don't know of anything better than gladiolas. You are almost certain to succeed with them and the cost of starting is comparatively small. You can grow hundreds of dollars worth of them on a small piece of ground. If you are interested in a quantity of bulbs for cut flower growing, write me for special prices. 


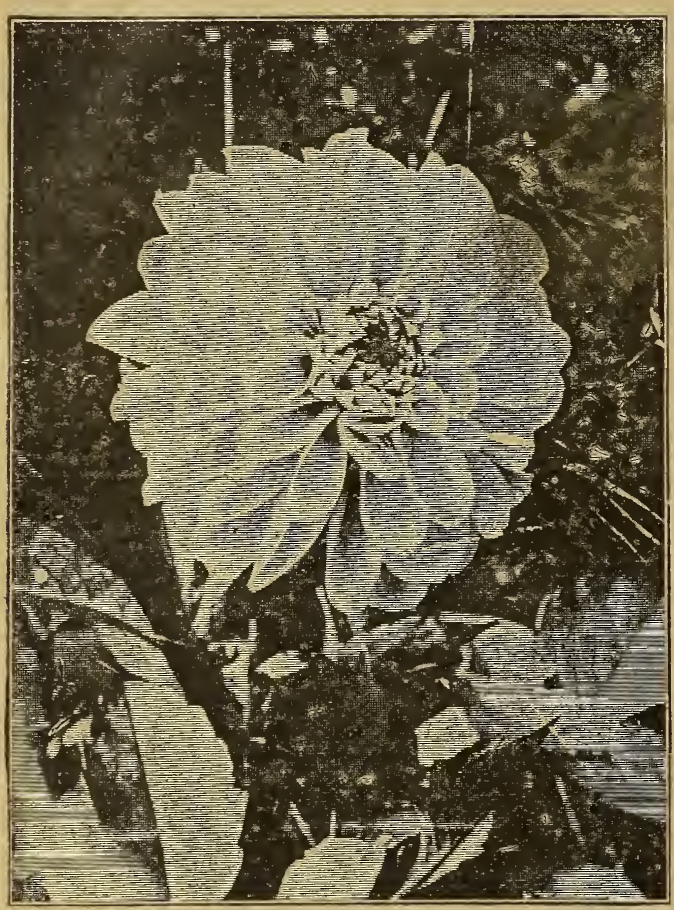

Dahlias, Show or Decorative - The Big Showy Kind

\section{Dahlias}

The dahlia is the queen of fall flowers, as the rose is of eatly sucumer. They much resemble a rose in appearance and. except for fragrance, they are the equal of roses in every way. They are as easily grown as potatoes, will grow in any kind of soil and give continuous bloom in the greatest pro. fusion from late June until after frost. They cover a time of year when flowers are scarce, and are fine for bouquets or decoraling of any kind. The colors range from pure white to the darkest red and show all the shades between. The roots can be taken up in the fall and stored like potatoes till spring, when a single hill can be divided into roots enough to make a big bed.

\section{Choicest Named Varieties}

There is an endiess list of named varieties of every color, shape and size; but about three-fourths of them are for the fancier or collector only, and are 110 account for common folks. What we want is a list of varieties that will bloom anywhere, for anyone, and good, distinct, bright colors. I have tried hundreds of rinds, and weeded them down to the list below. These all did well and bloomed fine here at Shenandoah last summer. I will guarantee them to do well for you. You could shut your eyes and pick good ones out of this list, for they are all good. I have divided them into three general classes. The first class show, decorative and fancy, includes all the big, well-known type of dahlias. They range from the flat, wide-open type, to almost globe snaped. The Cactus dahlias are the new class shown in the picture on next page. The Pom. pom dahlias are the little early, hardy fellows.

\section{Show, Fancy, and Decorative Dahlias}

15 c each, 2 for $25 c$, 5 for $60 c, \$ 1.25$ per dozen, either all alike or assorted.

Arabella.-To my mind this is the most beat tiful dahlia of the entire collection. The inner petals ate a clear, creamy yellow. shading toward the outside to a pink, making a beautitul combina tion of cream and pink that is hard to describe The flowey is of large size, perfect form, double clear to the center and the most free bloomer ever saw. Medium height, compact bush. What ever else yon get, you should have this one by all means. 20c.

A. D. Lavoni-A beautiful deep pink, perfea form, extra large, long st.ems, very free flowering. $20 \mathrm{c}$

B iron Schroeder. - Rich glowing purple, verw free flowering. Fine for cut flawers. The best one of all the purples.

Bird of Paradise. - White, overlaid with deep cerise pink. Very beautiful.

Burleigh.-Lar-gic carmine tipped white, Very free bloomer, Long, stifi stem. Wiil please everyone.

Gatherine Duer. - Irridiscent red. A glowi crimson under artificiai light.

Cuban Giant.-Dark crimson, very large, on tall, stiff stem.

Elsie Burger. - A good partner to Arabella. Similar in shape and appearance, but a different color. White, tipped with delicate lavender. It al. ways makes good.

Frank Smith.-Velvety maroon, white at tips. Very early, and free blooming.

Golden Beauty (Clifford W. Burton).-Best yel. low variety grown. Very free bloomer, beginning in July and blooming till frost. Very thrifty bush about four feet high and always full of bloom. consider it in many ways the most satisfactory variety grown. Flowers large, very double and clear golden yellow. $15 \mathrm{c}$.

Henry Patick. - A beautiful big, pure white. Very large. Splendid for cut flowers. Bush nften 5 feet high or more.

Jack Rose. - Brilliant crimson, the color of : Gen. Jackson.

Lyndhurst.-Best scarlet for cut flowers. Bril liant color and long, stiff stems.

Maid of Kent. - Bright cherry red, sometimes solid color and sometimes striped or tipped with pure white. Very fancy.

Manhattan Beauty. - Spotted and striped. crimson or amber ground. Beautiful.

Mrs. Hartong.-Bright golden bronze, overlaid with pink. Very large, fine for cutting.

Nymphea. - Silvery pink, shading to pearly white at center.

Penelope,-White, overlaid with pale lavender, Long stiff stems.

Queen Victoria. - Canary yellow, very free blooming. Perfect globular shape.

Sylvia.-Flesh pink, changing to white at cen. ter. A popular fforist sort.

Uncertainty. - Several shades of pink, white and red all on the same bush and often all in the same flower. A decided novelty in coloring. Free bloomer.

White Swan.-Pure white. The most popular white for cut flowers. A free bloomer and a strong grower, which is not always the case with other whites.

William Agnew.-Bright red. Very large. Prob. ably the largest bright red. 


\section{Growing Dahlias From Seed}

Few people realize that dahlias can be grown so easily, and cheaply, and quickly from seed.

Of course you can't tell what you will get, but that is part of the fun. It is like growing seedling apples. You may get nothing hut scrubs, or you may get something better tha lonathan or Delicious. You can't tell.

If you want to be sure of wsat you are getting, buy the bulbs by all means. But if you are willing to take a chance, and willing to go to some extra trouble. and will not stick up your nose if part of them come single and rather common looking, then plant some seed.

The seed should be startec early in the spring, like growing tomato or cabbage plants. Of course you can plant the seed right in the open if you want to, and they will, with good care, bloom before fall, but if you handle them like early tomatoes, they will come into blor m much sooner.

The plants transplant a easily as tomatoes, and should be set about the same distance apart in the garden, as they make large bushes.

You will get all colors ar 1 all shapes, some not much account, and some filse, but all interesting. You can save bulbs from the best ones for next year. Price, finest mixed sted, pkt. 10o, 3 pkts. $2.5 \mathrm{c}$.

\section{How to Save Dahlia Bulbs}

Dahlia bulbs, or roots or tubers, or whatever is the correct name for them, should be stored under the same conditions as Irish potatoes. That is, they should be kept fairly cool, and a little moisture will not hurt. We dig them when frost has killed the top, and pile them away in the cellar in boxes or barrels, leaving them in the clumps and with part of the dirt on them. If too warm they will sprout, and if too dry they will shrivel, so keep them away from the turnace.

In the spring, divide carefully and plant early, one bulb in a place. Remember the sprouts do not come from the bulb itself, but from the collar or neck, so in dividing be sure and save this neck or you will have no sprouts.

\section{Special Collection Offer}

\section{Named Dahlias for $\$ 1.00$}

We have a lot of choice varieties of dahlias of which we do not have enough to pav to list them, also we have a surplus of some of the ones listed, and we are willing to make you a bargain price on them. So here is the offer:

13 choice named varieties of dahlias, each one marked with name and color, one or more good strong live tubers of each, well packed in a box, and mailed postpaid for $\$ 1.00$. Our choice of varieties covering a wide range of color, and no two alike. Money back if not satisfied.

\section{All Live Roots}

The dahlias we ship are divisions of field-grown clumps, and are guaranteed to be sound and alive and to sprout with any ordinary care. Remember, the sprout on a dahlia root or tuber comes right at the neck or stem end. You often cannot see the bud or sprout at first, as it is dormant, but it will appear with warmth and moisture.

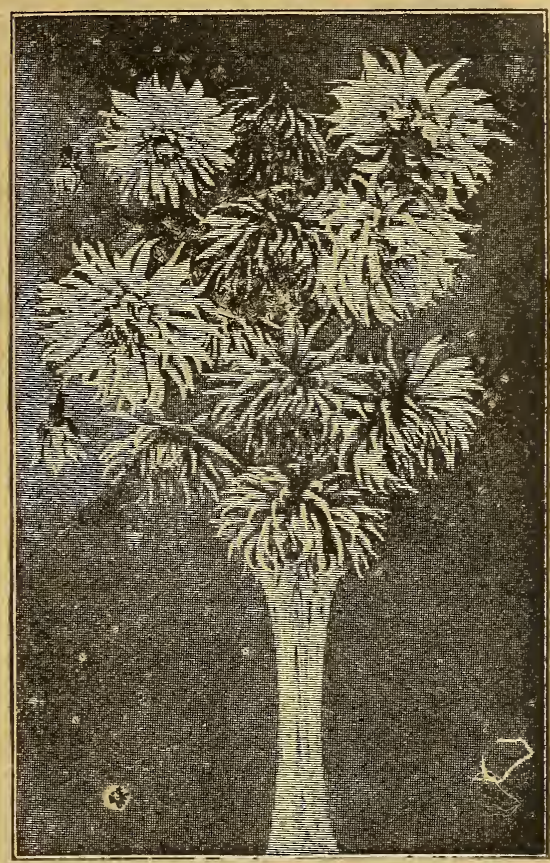

Cactus Dahlias

These are a new type, greatly admired for their grace ful shape and beautiful coloring. The petals are twisted and waved like a fancy chrysanthemum,

\section{Cactus Dahlias}

$15 c$ each, 2 for $25 c, 5$ for 60 c, $\$ 1.25$ per dozen either a 1 alike or assorted.

Blanche Keith. - The best yellow cactus. Brigh yellow, very free, very large flower.

Countess of Lonsdale. - A pleasing blend of salmon, pink and amber. The most free bloome? ot all cactus dahlias.

Kriemhilde. - The best pink cactus. Brilliant pink. shading to white at center,

Rhein Koenig. - The best white cactus. Pure snow white, 5 to 6 inches across.

Strahlen Krone. - The best red cactus. Rich cardinal red, very free bloomer.

\section{Pompom Dahlias}

15 c each, 2 for $25 c, 5$ for $60 c, \$ 125$ per dozen either all alike or assorted.

Catherine. - Pure yellow very free bloomer and vety early. Blooms steady all summer.

Rosalia. - Yeliow, edged with crimson. Very striking.

Snowclad. - Pure white. A free and sure bloomer. Literally covered with bloom.

Indian Chief - Bright intense crimson.

\section{Mixed Dahlias}

We have quite a lot of mixed dahlias, all colors and kinds, which we will sell cheap. They are mostly double, but some single. Cannot promise any special colors. They are good, sound sulbs. all good bloomers, and a bargain at the price. $10 \mathrm{E}$ each, 3 for $25 c, 7$ for $50 c, 15$ for $\$ 1$, all postpaid 


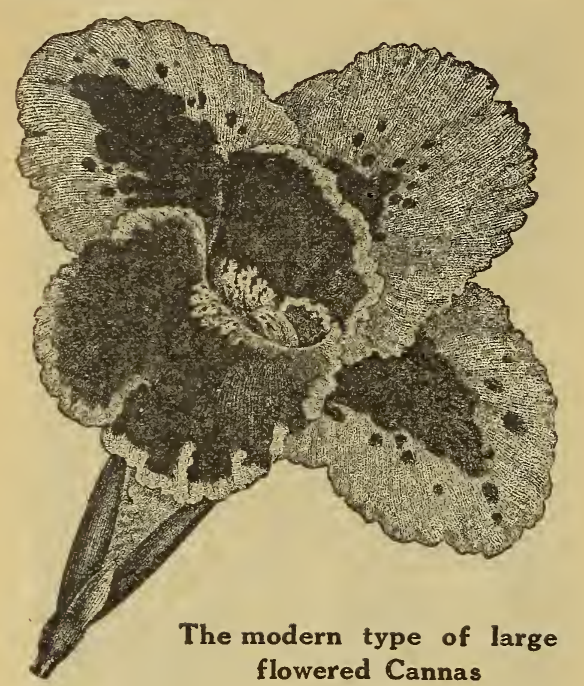

\section{Cannas}

These are fine for decorative effect on the lawn. They are tropical looking, and the rank green foliage and gay red and yellow flowers make a brilliant sight. Plant in rich moist soil when the weather is warm and settled. Better yet, start roots in a flower pot in the house and have them ready to set out when the warm weather comes.

\section{Either Dormant Bulbs or Growing Plants}

We generally send out dormant bulbs of the cannas during the early part of the season, taking care to send out only good live bulbs with nice sprouts showing.

As the season advances we generally send started plants six to 10 inches high. Provided they are alive and sound, I like the bulbs the best, but some people prefer plants, and late in the season plants are all we can send. Either should live all right with ordinary good care and plenty of warmth, but they can not stand cool weather.

\section{Special Canna Beds}

If you wish, I will make a selection of varieties for you for a compiete Canna bed, and will choose varieties that will match up well in foliage floom and height. Will guarantee to give you kinds that will please you.

Five Foot Bed. 13 plants as follows: 4 tall for center, 9 medium height for outside. Price $\$ 1$.

Seven Foot Bed. 19 plants as follows: 1 ex tra tall for center, 6 medium height for second circle, 12 short for outside. Price $\$ 1.50$.

Ten Foot Bed. 37 plants as follows: 1 extra tall for center, 6 medium height for second circle, 12 short for next circle, 18 still shorter for outer circle. Price $\$ 2.75$.

For planting around the outside of these canna beds the nicest thing to my notion is dasheens. They are like caladiums, but better and cheaper. Allow the same number as the outer row of cannas. Price $\$ 1.00$ per doz., postpaid.

\section{Choice Named Sorts}

Allemania. $5 \mathrm{ft}$. Very large flower, scarlet with yellow border.

Austria. $4 \mathrm{ft}$. Very large flowers. Pure canary yellow. Green foliage.

Black Beauty. $7 \mathrm{ft}$. Small red bloom, rich bronze foliage. Makes excellent background for the yellow varieties, fine for center of bed. Best red-leaf variety.

Burbank. $5 \mathrm{ft}$. Flowers canary-yellow with small crimson spots. Very large.

Charles Henderson. 3 to $4 \mathrm{ft}$. Bright crimson flowers. Green leaves,

J. D. Eisele. $4 \mathrm{ft}$. Green leaves and bright vermillion scarlet flowers.

Explorateur Campbell. $5 \mathrm{ft}$. Crimson bloom, green foliage.

Florence Vaughn. $4 \mathrm{ft}$. Green leaves and bright yellow flowers with red dot.

King of the Bronzes. $7 \mathrm{ft}$. Bronze foliage, small orange flowers.

La Patrie. $4 \mathrm{ft}$. Green foliage, pink bloom.

Majestic. $7 \mathrm{ft}$. Extra large green leaves, veir.ed and edged with purple, making a very beautifui foliage. Flowers small, bright glowing crimson.

Shenandoah. $3 \frac{1}{2} \mathrm{ft}$. Pink flowered, bronze foliage.

Any of the above named varieties, $10 \mathrm{c}$ each, 6 for $50 c$, or $90 c$ a dozen, postpaid, either all alike or assorted.

\section{Some Extra Fine Ones}

Any of these varieties, $15 c$ each, 2 for $25 c$, 5 for $50 c, \$ 1$ per dozen, either all alike or assorted.

King Humbert. $4 \mathrm{ft}$. The finest canna grown: very broad-leafed foliage, of a rich, reddish bronze color. Flowers orange scarlet, very large. Very free bloomer.

Indiana. $6 \mathrm{ft}$. Dark green foliage with glistering golden orange blooms. Six inches or more in diameter. Orchid flowering type.

Pennsylvania. $6 \mathrm{ft}$. Green foliage, deep orange scarlet flowers; very large, often 7 inches across.

Wyoming. $6 \mathrm{ft}$. Similar to Indiana in bloom, but with foliage a purplish cast; has the same large fine flowers.

Greenback. $7 \mathrm{ft}$. An enormous plant of foliage type. Broad rounded leaves resembling a banana plant. Does not bloom, but is a dandy for the tall plants for the center of a bed or for a back border.

\section{Choice Unnamed or Mixed Cannas}

I have a very fine collection of cannas in about 20 named varieties, but we have odds and ends, small lots of a kind, stray plants that get mixed in with other varieties, and so on, and these we put all together in a mixture. They are all first-class named varieties, but I can not promise you any particular color or variety, $6 c$ each, 6 for $30 c, 60$ c per dozen postpaid.

\section{To Save Canna Bulbs}

When frost kills the canna leaves. dig the bulbs and put them in a warm, dry place in the cellar, right in the clump. Early in spring, divide, and start in flower pots. 


\section{Miscellaneous Spring Bulbs}

These are all bulbs which are planted in the spring in April or May, and have to be taken up in the winter and stored in the cellar to be replanted again in the spring.

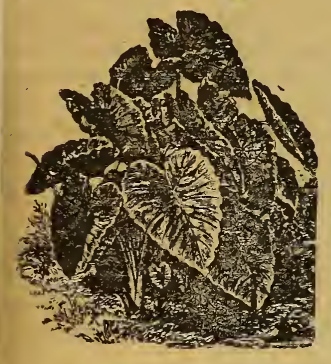

GAYADIOU

Dasheen. This is a new plant of the caladium family which has been boomed recently by the U. S. Department of Agriculture as a food plant for the south. I grew a lot of them here last summer and they did fine. I do not think they will ever be a success as a food crop except in the extreme south, but they sure are a fine ornamental plant. I consider them better than caladiums fo orna. ments, as they are hardier, taller, and more rapid growers, and the roots keep better through the winter. The root resembles a caladium, only smaller, but grows more easily. 10c each, 3 for 25c, $\$ 1.00$ per dozen.

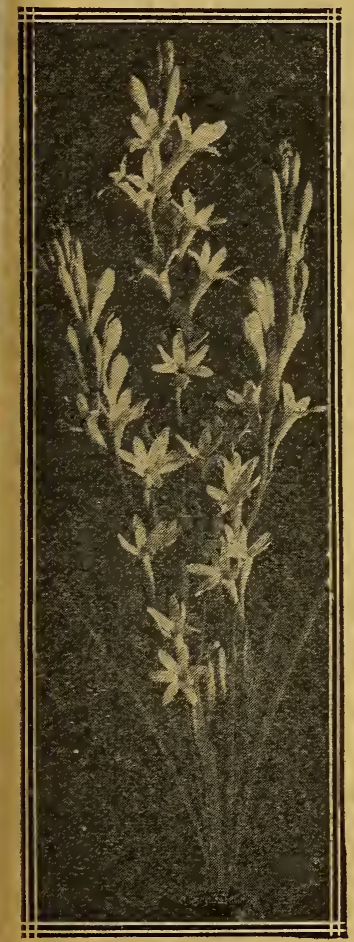

Mexican Tuberose

A big improvement over the old kind A summer blooming calla that does well in the open ground;grows about two feet high with immense dark green leaves, spotted and blotched with silvery white. Flowers are creamy white with purple blotches at base. Large bulbs. $15 \mathrm{c}$ each, 2 for 25 c.

Tuberoses. - Tall spikes of pure waxy white flowers of delicious fragrance Grow well anywhere, bloom all fall, especially fine for button-hole bouquets. Bulbs are extra large size and sure to bloom. 5c each, 6 for 25 c, 45c per dozen, postpaid.

Tigrida (Tiger Flower or Shell Flow. er). - Gorgeous sum. mer blooming bulbslooking somewhat like a tulip, but 1 a r g e $r$. Range in color through all shades of yellow and red. 3 for $15 c, 6$ for $25 c, 50 c$ per doz.
Spotted Calla. -

Madeira Vine. - A beautiful and. very rapid climber. Grows from 2 root like a potato. Leaves very thick and dark green, making a dense shade. Long sprays of small white flowers. $5 c$ each, 6 for $25 \mathrm{c}$.

Panama Lily. - This beautiful lily is entirely different from any other lily $I$ have ever seen. The bulbs should be panted in the spring after the cold weather is past. Last year we started ours in flower pots in the house and then transplanted them outdoors in May after they had started to grow. It blooms the first year and blooms very early, ahead of any other lily. Ours came in about Decoration Day, and was the most fragrant and beautiful thing $I$ ever saw. After the flower stalks die down the foliage is very showy all summer. Each 25c, $\$ 2.50$ per doz

\section{Lilies}

The lilies are among the most prized of all the garden flowers. They can be plantea as a rule either in the spring or fall, but the Japanese lilies arrive from abroad so late in the fall that we generally have to wait until spring, as the ground is nearly always frozen by the time we get them in. They do well planted in the spring and planted very early.

Lilium Auratum (Gold-Banded Japan Lily).The largest, and most beautiful of all the Japanese lilies. The flower is ivory white with a central band of bright yellow and numerous deep purple spots ................ 20c

Lilium Album. - A pure white lily with flowers opening out wide and flat. Perfectly hardy.20c

Lilium Rubram. - Very similar to the above, except that flowers are a dark pinkish.red . . 20c

Lilium Longiflorum. - This is the hardiest of the well-known Easter lily. Has long tubular flowers. Very fragrant and beautiful.20c

Liliu m Elegans.-Early flow. ered. Large up. right blooms, very showy and rang. ing in colors from orange to de e p red ....20 c

Lilium Tigrinum. - The well. known Tiger Lily. The flower is a deep orange - red with numerous black spots. It is very showy and hardy ... 20c

Lemon Lily (Hemerocallis). A very fragrant; hardy, old-fash ioned flower. It blooms in $\mathrm{May}$ very freely, in clusterson slender stems about $2 \mathrm{ft}$. high: Will grow; and thrive, and bloom anywhere. Price . . . 15c

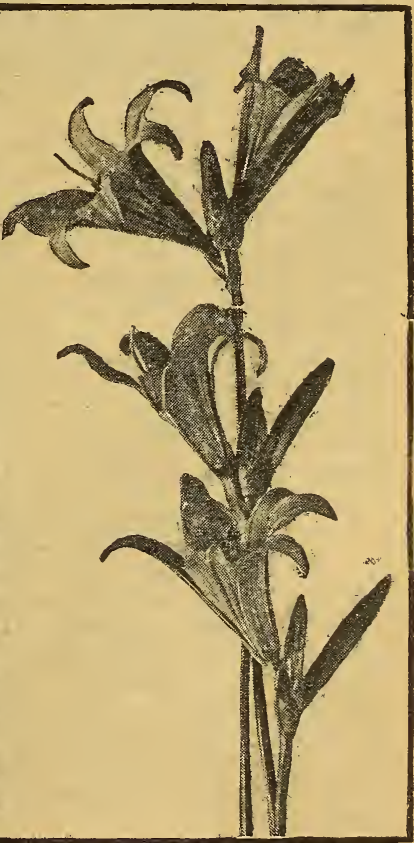

Lemon Lily 
All Hardy All of the plants listed on this is the li e permanently and ind finitcly from one planti.." They are a'l perfectly hardy in any nart of the cc 'ry, and all are easily grown. They should Le pla ted very early in the spring. Some of them can be planted in the fall also, but most of them are to be planted in the spring. They can. not as a rule, however, be planied late in the spring, but must be planted very early. In this tatitude that means sometime in April.

\section{Time of Shipment}

As most of these are growing out of dnors in the ground, we cannot fill orders $f$ in them during the winter, and we do not ship them until spring opens, so we can dig from the open ground. Also we cannot fill or cers late in the sp.ing, as the plants would be too f $r$ advanced to move with safety. Therefore, get your orders in early. You

\begin{tabular}{|c|c|c|c|c|}
\hline Names of Flowers and Plants & & & $\begin{array}{r}2-y \\
\text { Each }\end{array}$ & \\
\hline Achillea, the Pearl & $15 c$ & & & \\
\hline Anthemis & 15 & 1.50 & $30 c$ & 3.00 \\
\hline Bleeding Heart. & & & 30 & 3.00 \\
\hline Butterfly Bush & 20 & 2.00 & 35 & 3.50 \\
\hline Canterbury Bells .......... & 15 & 1.50 & 35 & 3.50 \\
\hline Chrysanthemum, Hardy, Pompom & 15 & 1.50 & 30 & 3.00 \\
\hline Columbine, Double Mixed.... & 20 & 2.00 & 35 & 3.50 \\
\hline Columbine, Single Mixed & 20 & 2.00 & 35 & 3.50 \\
\hline Coreopsis Lanceolata_. & 15 & 1.50 & 35 & 3.50 \\
\hline Daisy, Paris $\ldots . . . . . . . .$. & 15 & 1.50 & 30 & 3.00 \\
\hline Daisy, Oxeye or Margueri & 15 & 1.50 & 30 & 3.00 \\
\hline Daisy, Shasta & 15 & 1.50 & 30 & 3.60 \\
\hline Daisy, Alaska.. & 15 & 1.50 & 30 & 3.00 \\
\hline Delphinium ("'ardy Larkspur) & & & 35 & 3.50 \\
\hline Digitalis (Foxglove) & & & 35 & 3.50 \\
\hline Gaillardia $\ldots . . . .$. & 15 & 1.50 & 30 & 3.00 \\
\hline Gypsophila Panic & 15 & 1.50 & & \\
\hline Hardy Phlox, Mixed & 10 & 1.00 & 20 & 2.00 \\
\hline " "Pure white. & 15 & 1.50 & 30 & 3.00 \\
\hline Red & 15 & 1.50 & 30 & 3.00 \\
\hline Pink & 15 & 1.50 & 30 & 3.00 \\
\hline White, red eye & 15 & 150 & 30 & 3.00 \\
\hline " "Pink & 15 & 1.50 & 30 & 3.00 \\
\hline Hibisbus, Crimson & 15 & 1.50 & 30 & 3.00 \\
\hline Hollyhocks, Single_. & 10 & 1.00 & 20 & 2.00 \\
\hline Hollyhocks, Double & 15 & 1.50 & & \\
\hline Oriental Poppy & & & 30 & 3.00 \\
\hline Perennial Sweet Peas. & & & 35 & 3.50 \\
\hline Pinks, Diadem . . . . . & 15 & 1.50 & 30 & 3.00 \\
\hline Pinks, Grass . & 15 & 1.50 & 30 & 3.00 \\
\hline Pinks, Fireball & 15 & 1,50 & & \\
\hline Pinks, Snowball. & 15 & 1.50 & & \\
\hline Sweet William, Double & 15 & 1.50 & 30 & 3.00 \\
\hline Sweet William, Single. & & & & 3.00 \\
\hline
\end{tabular}

\section{Directions For Culture}

These hardy plants should be planted very early in the spring, the earlier the better. Many of them can also be planted in the fall, but Ilike early spring better. If you happen to move too early in the spring to transplant them then, they can be dug in the fall or even in the winter, and packed in boxes in the cellar till time to plant. Plant about the same depth they have grown before, generally with the bud or crown about two inches below the surface, can order any time during the winter and early spring and we will send them at the proper time Ordinarily we cannot fil 1 o ders for any of thesi I lants after May 10th. and ro.l'y it is risky planting them later than May Ist. Get your order in ir time to get ihem planted in April if possible.

About Prices All prices on this page includ prepayment of postage any where in the United States. Remember this wher ordering. Unless otherwise specified. plants listec (a) 15c wi 1 be sold $@ 2$ for $25 \mathrm{c}$ nr $\$ 150$ per dozen I hose listed @2ic each will be sold @ 3 f r 50، or \$2.no per dozen. Those list $\mathrm{d} @ 25 \mathrm{c}$ each wi] he sold @ 3 for 65c or $\$ 2.50$ per dozen.

Large Clumps On most of these plant: nished at double price, but this would not include postage. They would have to go by express at you expense.

\section{Descriptions}

Canterberry Bells (Campanula). - Handsomi blue or white, cup-shaped flowers, blooming in Jun and July. $\frac{1}{2} \mathrm{ft}$.

Columbine (Aguilegia.)-We have these hand some flowers in both double and single. The double $a^{-} e$ the regular cult vated European variety in al shades of Llue and pink. The single hybrids o three native sort?, the tall yellow of California, the blue and white Rocky Mountain sort, and the scar let and yellow of our Iowa timber. They are talles than the double and are very fine. $\frac{2}{3} \mathrm{ft}$.

Coreopsis Lanceolata. - Some what like a daisy but deep solid yellow in color. B:oom all summe and fall. Fine for either cutting or ornament. $\frac{1}{3} \mathrm{ft}$

Daivies.-We have quite a list of these, all fine and well worth planting. The Shasta and Alaska are very similar and really are but different strains of the same giant California Daisy. They grow about $3 \mathrm{fc}$. high with enormous white flowers 4 to 5 inches across, with small yellow center. They make large plants with literally hundreds of blnoms to a plant. Our field of them was a wonderful sight when in bloom. If any difference, the Alaska is the taller of the two, but there is very little difference.

The old-fashioned $O x$-eye or Marguerite Daisy is smaller, but very free blooming and satisfactory, and it is hardier than the Shasta type. The Paris Daisy is a European sort common in o'd gardens. De'phinium (Hard y Larkspur). - A beautiful tail plant, like the common annual larkspur, but hardy taller and deeper colors. $35 \mathrm{ft}$.

Digitalis (Foxglove), - An old-fashioned favorite. Tall spikes, bearing delicate white or pink bell-shaped flowers. $\frac{3}{4} \mathrm{ft}$.

Gaillardia (Blanket Flower).-A flower shaped like a daisy, but larger, and a brilliant blending of red, yellow, and brown in color. $2_{3} \mathrm{ft}$.

Gypsophila Paniculata (Baby's Breath.) - A branching trailing plant with a mass of dainty very small white flowers. Fine for trimming bouqu ts. and desirable for growing where a mass of delicate misty bloom is wanted to fill a bare spot in your garden.

(Continued on page 121.) 


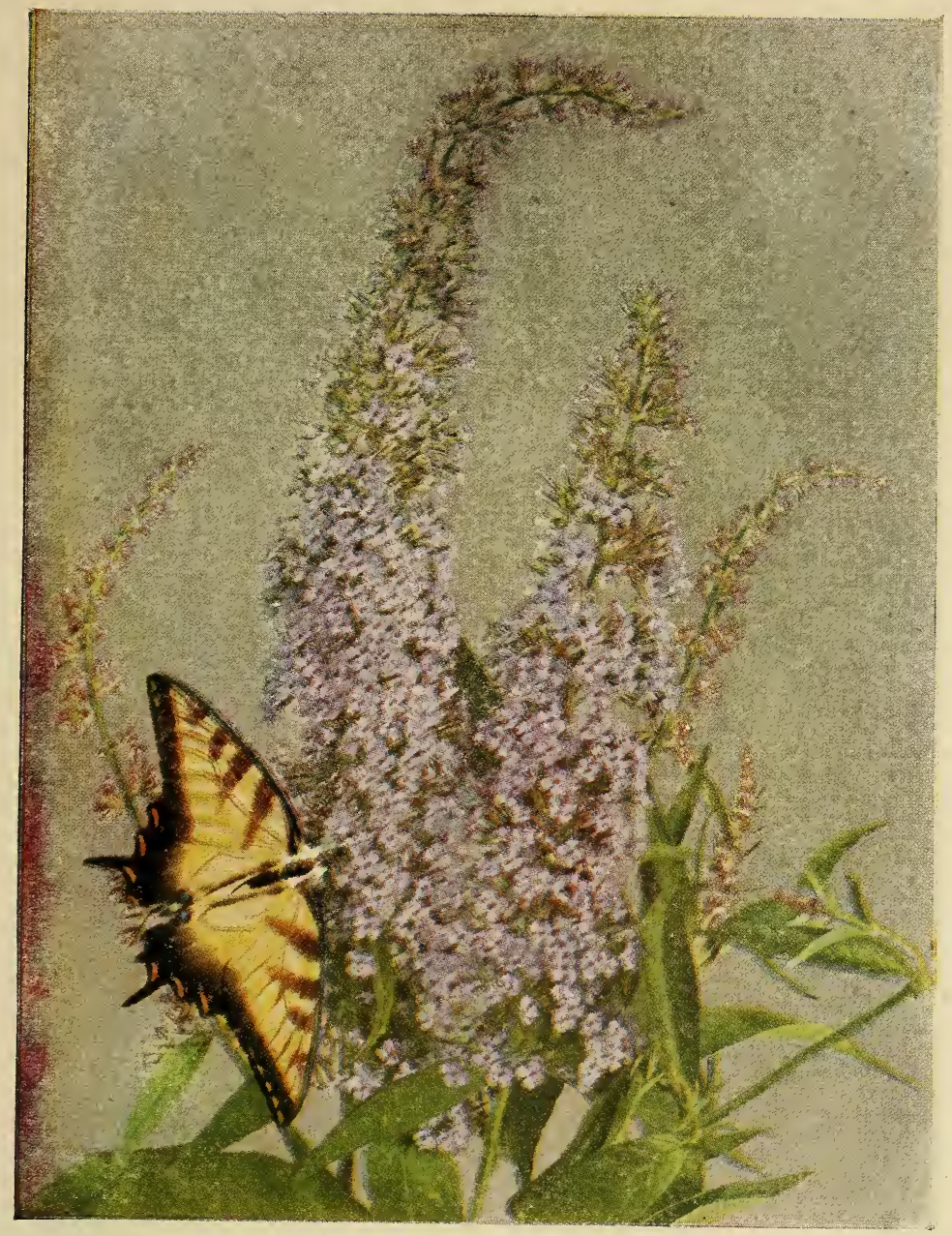

Printed in Our Own Private Printshop Of Course

\section{The Everblooming Butterfly Bush}

(Buddleia Variabilis Magnifica)

This is one of the most valuable and beautiful new plants introduced for years. It was recently discovered in Western China, and thrives in all parts of the United States. It is a hardy perennial, blooming prac. tically all summer, and blooms the first summer from small plants, continuing even after frost. Its hardiness, ease of growth, beautiful color, and piquant fragrance, make it popular everywhere. It is fine as a specimen plant, as a hedge, or as a background, but should not be planted in sod or extreme shade. It gets its name from the fact that it is very attractive to butterflies, and they come from everywhere to feast on its nectar. The picture shows well its color and general appearance.

Price: 200 each, 3 for 50 c, 7 for $\$ 1.00$ all postpaid.

\section{Henry Field Seed Co. : : Shenandoah, lowa}




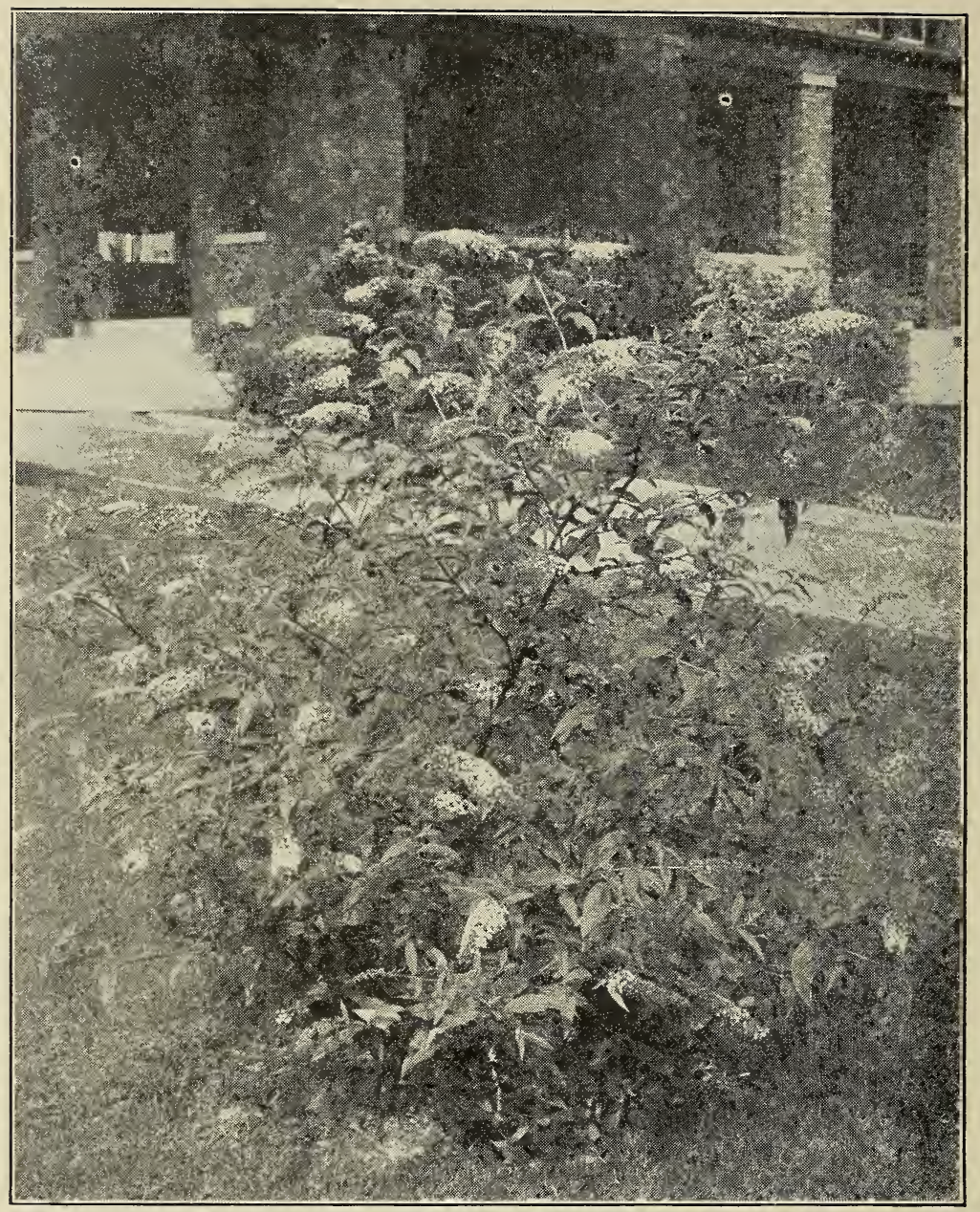

Printed in Our Own Private Printshop, Of Course

\section{One Year's Growth of the Butterfly Bush} [icture will give you a good idea of how the Butterfly Bush grows and how it will look on your lawn. With good luck it will grow this large the first summer from a small plant, and still larger the second summer. The tops sometimes kill back in the winter, but the roots always live and come up stronger than ever the next spring. The bloom is practically continuous all summer. Ours were beautiful all season from small plants set in the spring.

Price: $20 c$ each, 3 for $50 c, 7$ for $\$ 1.00$, all postpaid Henry Field Seed Company : : Shenandoah, lowa 


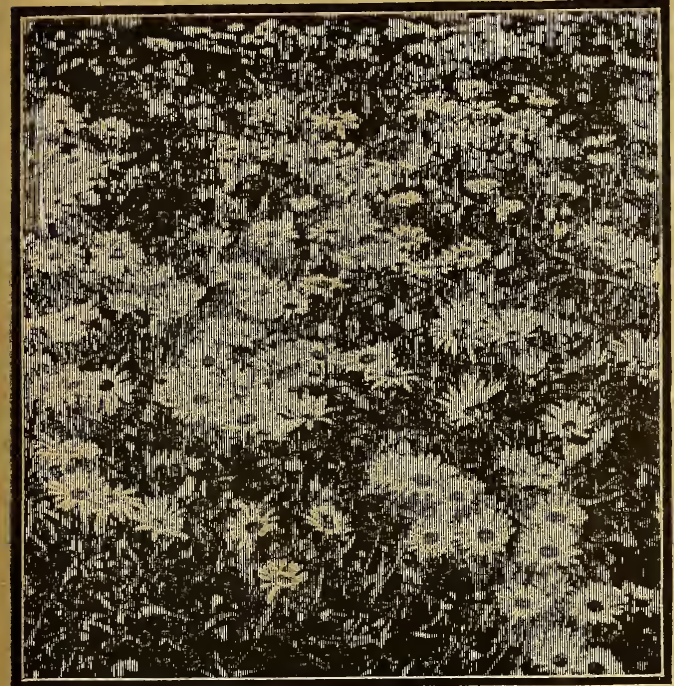

Shasta Daisies on Our Trial Grounds

Hardy $\mathrm{Phlox}$ - A very desirable hardy flower. It will grow anywhere, either shade or sun, will bloom on any soil, and make better clumps the older it gets. The pure white is especially fine. It can be had in a number of separate colors or in mixture. See list on page 120. 2 to $3 \mathrm{ft}$. high.

Hibiscus, Crimson Eye. - A tall showy plant of the mallow family. Looks some like a hollyhock, but lives for years. Has smooth shiny leaves. Bloom is very large, pure white, with crimson eye. 3 to $6 \mathrm{ft}$. high

Hollyhocks. - These are known and loved everywhere, and no old-fashioned garden is com plete without them. We can supply a splendid lot of them in either single or double, mostly mixed colors. The single varieties have the largest blooms and are the healthiest and best growers. The best way to plant them is as a background, say along the fence or next to the high wall of a house. Be careful to not get them in front of your other flowers, as they grow so tall they would hide them. 5 to $7 \mathrm{ft}$. high.

Oriental Poppy (Perennial Poppy.) - These are the big flaming scarlet poppies that grow as big as a plate, and make such a sensation when they bloom. The root is hardy, and the plants bloom better "and better the older they get. The plants can be transplanted either in the fall or late in the spring, and while they are a little hard to get to live, they are well worth the trouble. We have a fine lot of plants, now 2 years old. 2 to $3 \mathrm{ft}$. high.

Perennial Sweet Peas (Lathyrus Latifolius).Looks like the regular sweet pea, but lives for years, and gets better the older it gets. Will stand any amount of drouth and still stay green and blooming. Comes in white, pink, and red, or mixtures of these colors. A single plant, when once established, will make a great mass of vines. 5 to $8 \mathrm{ft}$. high.

Bleeding Heart. - Everyone knows this old favorite. It will grow well anywhere, and is one of the few flowers that will grow and bloom well on the north side of the house. 2 to $3 \mathrm{ft}$. high.

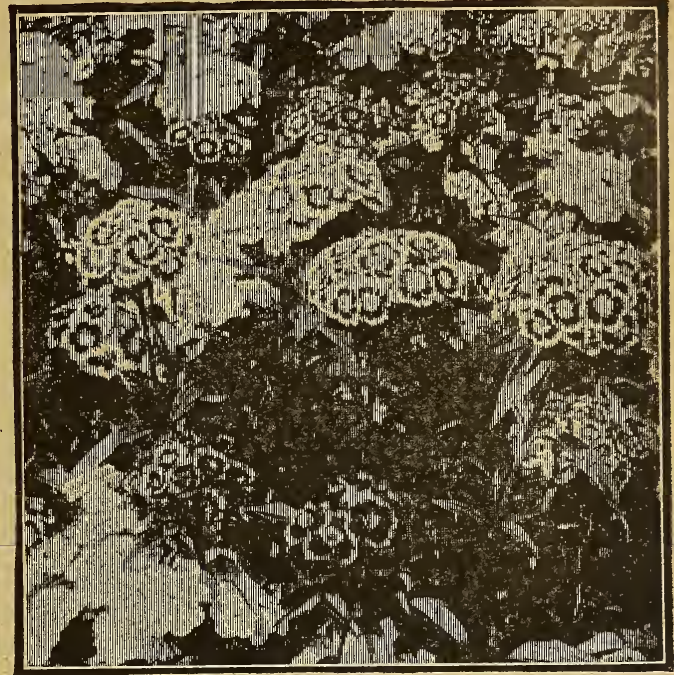

\section{Sweet Williams, An Old-fashioned Favorito}

Pinks. - We have a number of varieties of hardy pinks, but the best are the four we list, the Diadem. Fireball, Snowball, and the old-fashioned Grass Pink. The Diadem comes in all colors mixed and are remarkably bright in appearance. The Fireball is a big bright red, almost like a carnation. The Snowball is the same thing only it is white. The Grass Pink is a favorite in old gardens. It is small, but intensely fragrant. Comes in all colors, but mostly pink. 1 to $2 \mathrm{ft}$. high.

Swoet Williams. - Every one knows these beautiful old-fashioned flowers. They are hardy anywhere, and are sure to be satisfactory. Notice the picture above. They grow like pinks, but make great heads of blooms instead of separate flowers. 1 to $2 \mathrm{ft}$. high.

Butterfly Bush (Buddlea Variablis). - This beautiful plant is fully illustrated and described on the color plate opposite. It is a new plant, but has come to stay and will soon be in every garden. The sooner you get started with it the better. Will grow anywhere. 3 to $6 \mathrm{ft}$. high.

\section{A Mistake in Figures}

On page 120 the printers made the wrong guess at what I meant in my copy when printing the height of the different perennials. Where they have it $\frac{1}{2} \mathrm{ft}$. it should read 1 to $2 \mathrm{ft}$., etc.

Named Varieties of Hardy Phlox

We have quite a list of named varieties of hardy phlox, which we can supply to those who are interested. Prices same as quoted for separate colors on page 120.

Sulphide.-Deep orange scarlet, dark red center.

Maculata.-Rose purple, Blooms small, large heads. Miss Lingard.-Best pure white. Rather dwarf. Independence.-Pure white, large and quite tall. Eclaireur.-Dark crimson, very large.

Flambeau.-Salmon rose with deep crimson eye. Inspector Elpel.-Bright rose with crimson center. Le Soleil.-Light rose, with lighter center.

Amazon.-Pure white. Rather dwarf. 


\section{Fall Bulbs}

The bulbs and flowers listed on these pages are all what is known as fall bulbs. This means not that they bloom in the fall, but that they should be set in the fall. They are all early-bloom. ing flowers, blooming as a rule in March, April, and May, before other flowers come. They should be set out in October or November, either out-ofdoors in garden or in pots for house-blooming. Every year when the tulips and hyacinths are in bloom in the spring we get calls for bulbs from people who want to get them out right away, and they are generally surprised when they find that these bulbs can be bought and set only in the fall. Now, remember, if you want a nice bed of tulips and hyacinths, or narcissus, or crocus, or anything of that kind. you must set them in the fall in October or November. You can, however, send in your order at any time during the spring or sum. mer and we will book it for future shipment. When the proper time comes we will send the bulbs to you.

\section{Tulips}

No other flower excels the tulip in pure form. brilliancy of color and effective bedding. It is equally desirable for pot culture.

Prize Mixture Early Tulips. - In our Prize Mixture Single Early Tulips we pride ourselves in offering the best mixture in this country. Over 250 choice varieties, and the largest of bulbs. Price, 35e por doz., 100 for $\$ 2.25$.

Prize Mixture Double Early Tulips.-Our Prize Mixture Double Early Tulips are very choice and bloom a week or ten days later than the single. Not quite so tall or bright, but have excellent last. ing qualities. Price, 35c per dozen, 100 for $\$ 2.25$.

Early Tulips in Separate Colors.-Red, white, yellow, pink, striped. Price, 35c per doz., 100 for $\$ 2.25$.

Late Tulips. - Sometimes called May Tulips or English Tulips. Grow tall and large. Price, 35c per doz., 100 for $\$ 2.25$. Mixed all colors.

Parrot Tulips. - - Also called Dragon Tulips. Choicest of all. Often 6 inches across. Are striped, and spotted in all kinds of color combination. Price, 35 per dozen, 100 for $\$ \mathbf{2 . 2 5}$.

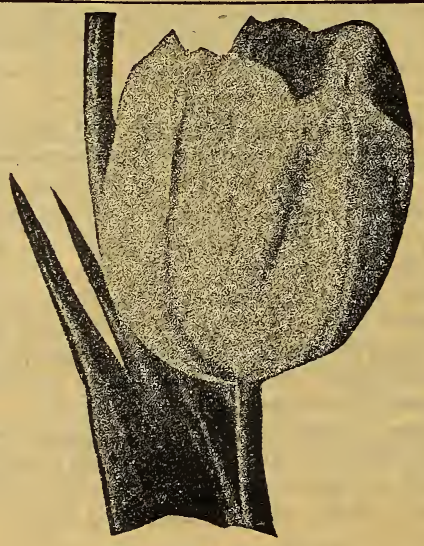

Tulips

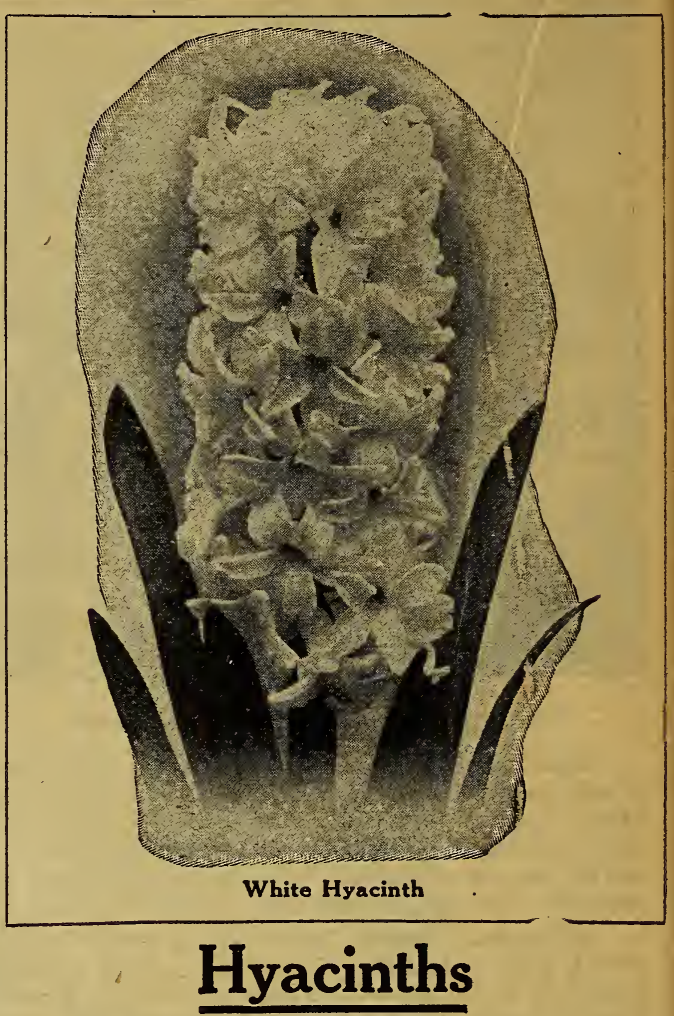

These are probably the best known and the best loved of all the Dutch bulbs. They can be grown either outdoors or in the house with equal success. All varieties except the French Roman are perfectly hardy anywhere, and once set out will bloom year after year without trouble. The single hyacinths are the best bloomers and the must sat isfactory.

Bedding Hyacinths.-Good sized bulbs, guaran teed to bloom. Fine for house culture and specially fine for bedding out, and at our low price can be planted in large lots. Can be had in red pink, white, blush white, deep b!ue, light blue, or mixed colors. Price, each $8 c, 6$ for $45 c, 85 c$ per dozen, 25 for $\$ 1.60$, or 100 for $\$ 6.00$, either separate colors, or mixed all colors.

Special Offer: One each of the 6 colors, $50 \mathrm{c}$; 6 each, 36 in a $1, \$ 2.60 ; 12$ each, 72 in all, $\$ 5.00$.

Dutch Roman Hyacinths. - A smaller and eariier variety of the regular Dutch hyacinths. Can be had in pure white or any color, or all colors mixed. Price, each $6 c, 6$ for 30 c, 60 c per dozen, 25 for $\$ 1.15, \$ 4.50$ per 100 .

Darwin Tulips. - A fine class of tall, stately tulips. All the rege now Price, $40 \mathrm{c}$ per dozen, 100 for $\$ 2.50$.

Named Varieties.-I have a good supply of all the named varieties of tulips and shall be glad to quote special prices on application. Ask for what you want.

All bulbs prepaid at prices quoted.

Bulbs on this page are shipped in October, November, and December only. They cannot be had in the spring at all. 


\section{Special}

\section{$\$ 1.50$ Collection of Hardy Bulbs}

These are all hardy hulbs to be planted in open ground September to December, and blooming in Narch, Afril and May. Nothing makes so fine a showing in a garden as a bed of early hardy bulbs ind few people realize how cheap they are, and how easily grown. In nrder t' get more people started growing them, I have made up this special coliecti' $\mathrm{n}$ at almost cost price:

2 White Hyacinths, 2 Red Hyacinths, 2 Blue Hvacinth ", 6 Hardy Narcissus ar Daffodils, 6 Tulips, 6 Early Double Tulips, 6 Parrot Tulips, 6 Darwin Tulips, 6 Crorus, 2 Narcissus (Von Sion), 2 Narcissus (Emperor), 2 Narcissus (Barri Con'picuous), 6 Spanish I. is. All of the above for $\$ 1.50$ postpaid, all first class bulbs.

\section{Special $\$ 1.40$}

\section{Collection of Bulbs for House Culture}

To be planted in flower pots from September to December and blooming f:om December to April.

2 White Hyacinths, early, very fragrant.

2 Red Hyac'n'hs, best variety for hruse culture.

2 Biue Hyacinths, best variety for house culture.

1 Chinese Sacred Lily, will bloom in wáter or d rt.

1 Doutle Sacred Lily, same as above, but double.

1 Calla Li'v, large, everblonming.

6 Tu'ips, bright colored, early variety, mixed.

6 Paper White Narcissus, very early and fragrant, and easi'y grown.

6 Froesias, Giant White.

6 Daffodils, mixed varieties.

1 Narcissus, Von Sion, $v^{\circ}$ ry large and double.

1 Narcis us, I mneror, largest variety grown.

6 Crncus, large size, mixed colors.

3 Jonquils, yellow, very fragrant.

This enti.e cnllection, worth at list price over $\$ 2.00$, sent postpaid for $\$ 1.40$.

\section{Special School Yard

Collection of Tulips, $\$ 1.60$

For plan'ing on school groun's there is nothing equal to tulips. They are sure to grnw and bloom, the children go wild over them, and they b'oom before school is out in the spring The troub'e with most flowers for school gardens is that they bloom in vacation, hut the tulips bloom in April or May when schonl is still in session. (Planted in the fall during the fall term).

I have mide up a snecial collect: on of tulips at a very low price, especially suited to schonl needs. Here it is: 50 Tulips, Fine : ingle Mixed, 25 Tulips, Parrot Mixed.

All for $\$ 1.60$, delivered postpaid. This is a special offer for schools only.

\section{Iris}

There is nothing finer than the German iris. They can be set either fall or in spring, but I really prefer fall. See full list in regular place in catalog, or in September Seed Sense.

\section{Narcissus or Daffodils}

Paper White Narcissus. - Finest of all for house culture. Can be bloomed in water like Chinese Sacred Lily or in dirt like other bulbs. Not hardy out-of-doors. Price, each $4 c, 4$ fúr $15 c, 40$ per dozen.

Emperor.-Largest of all. Price, each 5c, $45 c$ per dozen.

Empress.- White and yellow trumpet. Price, each $5 c, 45 c$ per dozen.

Barri Conspicuous. - Heavily stained orange scarlet. 3c each, 12 for 30 c, 25 for 60 c, 100 for $\$ 2.25$.

Poet's Narrissus. - Best known of all. White flowers with gold cups, bordered scarlet. Price, each 3c, 35c per dozen, \$2.50 per 100 .

Double Yellow Von sion. - Fine for either hnu'e or out-of-doors. Price, each $5 c, 45 c$ per dozen.

Mixed. - All varieties and colnrs. Price, $30 \mathrm{c}$ per doz., 25 for 60 c, $\$ 2.25$ per 100 .

\section{Miscellaneous Bulbs}

Chinese Sacred Lily.-The National Flower of China. Blooms best in dish of water without dirt. The bulbs ar: enormous in size, each one often making a half dozen stalks of bloom with a dnzen r more flowers on each. Very fragrant. Price, each $15 c, 2$ for $25 c$.

Crocus. - Either separate colnrs or mixed. Price, 20c per dozen, 25 for 40 c, $\$ 150$ per 100 . dozen.

Freesias. - Price, each 4c, 3 for $10 c, 30 c$ per

Spanish Iris. - A bulbous, hardy iris that should he planted in the fall like tulips. Colors very brig: t. Price, each $3 r, 25 c$ per dozen.

Calla Lily.-One of the mist popular and ornamental house lilies. Price, each 25c.

Jonqui's. Either single or dnuble. Similar to narcissus, but very fragrant. Price, each $3 c, 35 c$ per doz.

Snow rop.-Dainty little white flowers b?oom ing verv early. Price, each $2 c, 20 c$ per d..zen.

Easter Li'y. - The well-known house-blooming lily: flowers long, tubular in shape, and of a most delightful fragrance, large bulbs. Price each $20 c_{2}$ 3 for $50 c$.

\section{Nomed Tulips and Hyacinths}

Miny peop'e prefer the named varieties of tu. lips and hyacinths, and we have a fine list of them in the September Seed Sense. You can get any part cular color $y u$ want that way, and can make up your flower bed any way you like.

\section{For Full List of Bulbs}

This is just a condensed list of the bulbs we have for sale. For full list see the September issue of Seed Senss. We har several pages of bulbs there. We have all kinds of bulbs, anything you want, and sell then. at reasnnable prices. If you do not have the S. ptember Seed Sense, ' write and ask for one.

\section{Peonies}

Peonies can be set either in fall or early spring. but fal 18 best. See September Seed Sense or big catalog for full list. 

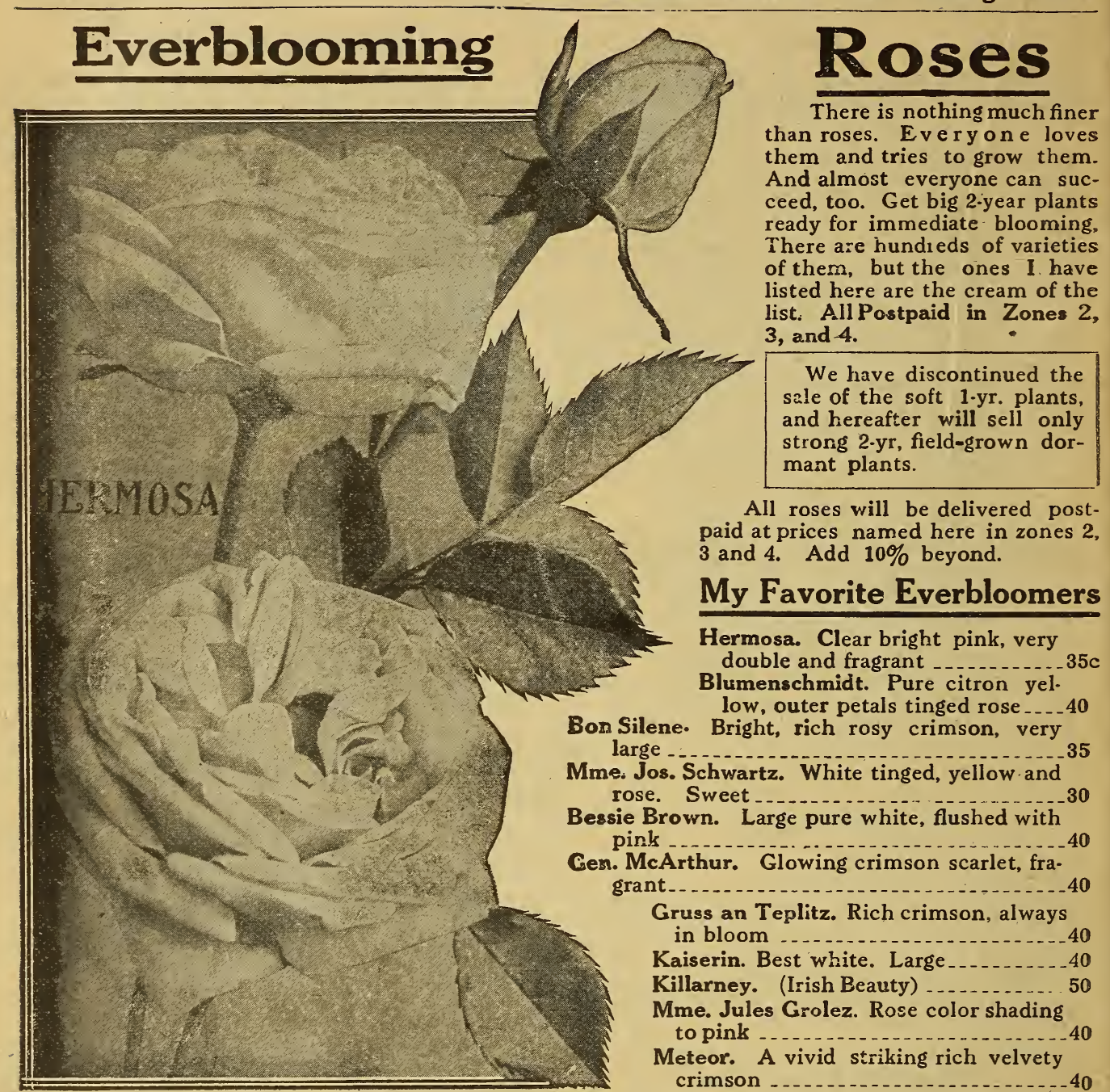

All roses will be delivered postpaid at prices named here in zones 2 , 3 and 4 . Add $10 \%$ beyond.

\section{My Favorite Everbloomers}

Hermosa. Clear bright pink, very

double and fragrant

Blumenschmidt. Pure citron yel-

low, outer petals tinged rose

Bon Silene. Bright, rich rosy crimson, very large

Mme. Jos. Schwartz. White tinged, yellow and rose. Sweet ...........

Bessie Brown. Large pure white, flushed with

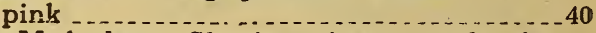

Cen. McArthur. Glowing crimson scarlet, fragrant_............ 40

Gruss an Teplitz. Rich crimson, always in bloom

Kaiserin. Best white. Large

Killarney. (Irish Beauty) . . . . 50

Mme. Jules Grolez. Rose color shading to pink .

Meteor. A vivid striking rich velvety

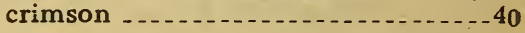

\section{Everblooming Baby Ramblers}

These dainty little Baby Ramblers or Polyantha roses have won the love of everyone. They are sure to grow and bloom, start blooming young, and keep at it so steadily that everyone is pleased.

These are not climbers, but little bush roses from 1 foot to 2 teet high. They will live out for years, or will do well in the house. They bloom in great clusters like the well known Crimson Rambler, but on a little bush, and they bloom steady all summer.

Red Baby Rambler. Immense clusters of 2-yr. rich crimson flowers. ................ $35 \mathrm{c}$

Pink Baby Rambler. Beautiful bright pink like Dorothy Perkins 7.................. 35c White Baby Rambler. Creamy white. Very free bloomer........................ $35 \mathrm{c}$

Special Offer F3: All three of these Ramblers in 2-year size for 80 c postpaid.

\section{Climbing American Beauty}

A true climbing form of the celebrated American Beauty rose. It has the same enormous blooms and the same wonderful deep rose color and exquisite fragrance. Every bloom perfect. Grows to a height of 15 feet, producing literally hundreds of blooms at one time. Can be grown practically any. where without protection. 2-years, 60c.

\section{Memorial or Trailing Roses}

These are a distinct type of roses, known bctanically as the Wichurianas. They are of ironclad hardiness, will grow anywhere on any scil. They are strong growers, but trail instead of clirmbing. Will creep and cover the ground like ivy. Beautiful glossy dark green foliage, remaining green nearly all winter. They bloom profusely in June and July. Especially valuable for cemetery planting or for covering banks or rookeries. Can be had in either white or pink. 2-years, 35c. 


\section{Hardy Roses}

\section{Hybrid Perpetual Roses}

This is a valuable class, as the varieties mentioned below are all perfectly hardy and produce large flowers like the General Jacqueminot. They produce quantities of roses in June, and some bloom again quite freely in the fall. No rose garden is complete without some Hybrid Perpetuds.

\section{My Favorite 12 Hybrid Perpetuals}

American Beauty. A great favorite. Color deep pink to crimson

Anna de Diesbach. Flowers extra large, full and sweet, color a beautiful carmine pink .

Baron de Bonstettin. Extra large flowers, solid, round and full. Dark rich crimson.

Captain Hayward. Beautiful bright crimson, perfect form, very sweet. . _.

Clio. Flesh color, shaded in the center with rosy pink_40

Frau Karl Druschki. The grandest white rose in exist. ence

General Jacqueminot. Brilliant shining crim. son

Hug' Dickson. Crimson shaded scarlet. A gold medal rose $\ldots . . . . . . . . . . . . . . . . . .40$

Magna Charta. Unusually fine flowers. Bright rosy pink _... . .

Marshall P. Wilder. Extra large, dark deep red, free bloomer

Paul Neyron. The largest pink rose in existence. Color is clear pink.

Ulrich Brunner. Color is brilliant cherry red. An exceptionally free bloomer.

Special Offer F5 The above 12 perfectSpecial Offer F5 ly hardy roses, in 2 . year size, the 12 for $\$ 4.00$.

\section{Old-Fashioned Hardy Garden Roses}

I advise 2-year plants only on these. These ar the old-time favorites of our grandmothers' days. Hardy, fragrant and sure to bloom every year. with. nut care or protection. Will thrive anywhere.

Mad. Plantier. Pure white, free bloomer and extremely recommended for cemetery plant. ing. Very double and fragrant ........ 35

Harrison's Yellow. Semi-double, bright clear golden yellow

Persian Yellow. Full double, deep golden yel. low _.........

Soleil D'Or. Blended coppery red and orange yellow, spicy fragrance . . . 50

English Sweetbriar (Eglantine). Fragrant foliage. Pink flowers . . _

Moss Roses. Can supply red, pink or white $\ldots 40$

\section{The Rambler Roses}

Crimson Rambler. Probably the best known of all climbing roses

Pink Rambler. (Dorothy Perkins). Better than the Crimson. Peach pink color __. _._._. 35

White Rambler. Like Dorothy Perkins, but white in color.

Yellow Rambler. Extra fine deep gold yellow_50

Special Offer F6 The full set of 4 Hardy Ramblers, red, white, pink and yellow, 2-years, $\$ 1.40$.

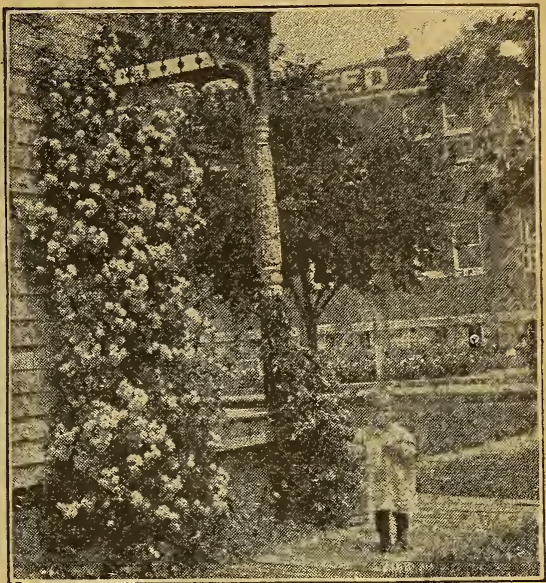

What is finer than a nice climbing rose? This shows a plant of Dorothy Perkins or "Pink Rambler." You can grow one like it in 2 years.

\section{Old-Fashioned Hardy Climbing Roses}

These are well known hardy climbers which can be depended on anywhere. $2 \cdot y r$. American Pillar. Absolutely the most free blooming single hardy climber. The flow. ers are borne in immense clusters, rosy pink, with golden yellow stamens..... 50=

Baltimore Belle. Double blush white in large

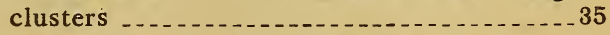

Gardenia. Buds bright yellow, opening cream color. Very fine ... _ _ _.

Prairie Queen. The old stand-by. Large flower, bright rosy red .................. 35

Russell's Cottage. Dark red, very double and full. Extra good..... 35

Seven Sisters. Large clusters of red roses, fade. ing to light pink

Universal Favorite. Large double flowers; beau. tiful rosy pink ................ 35

Special Offer F7 All of these climbers Special Offer F8 Any 4 of these $\$ 1.10$

\section{Special Varieties of Hardy Climbers}

Philadelphia Rambler. An improved Crimson Rambler, de eper red............. $40 \mathrm{c}$ Thousand Beauties (Tausendschoen), Bears multitudes of roses in white to pink _... 40

Flower of Fairfield. An everblooming Crim. son Rambler ......... 40

Blue Rambler. Not a true blue, but the near. est to it in roses............... 35

Excelsa. Best of all Ramblers. Like Crimson Rambler, but healthier and hardier. ...... 45

Special Offer F9 All of these special $\$ 1.70$ in 2-yea size. 


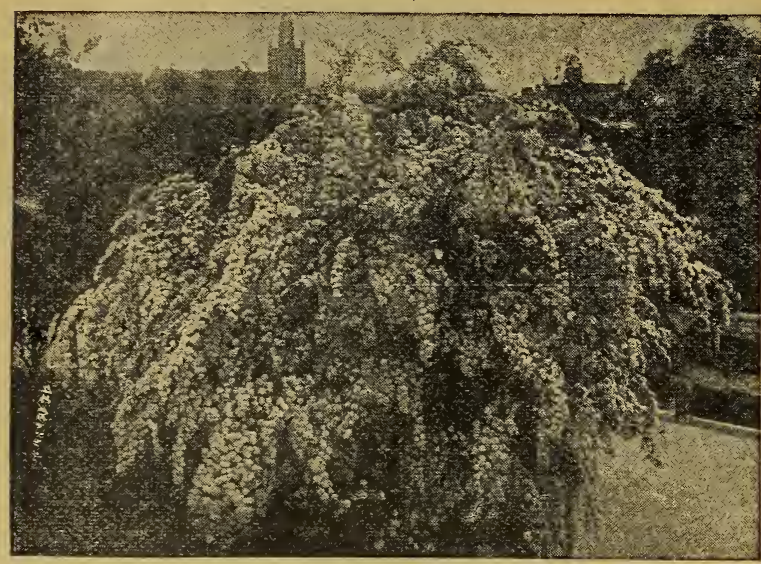

Purple Fringe. - A very much admired small tree or shrub with a curious fringe of hair like flowers that cover the whole sur. face of the plant in midsummer.

Bush Honeysuckle - A fine showy plant for either a single or for groups or hedges. Bush is always of nice even shape, and the blooms look much the same as the climbing hnneysuckle. We can supply it in either white, pink, or red.

Flowering Quince (Japonica).-A low Erowing, bushy, thorny quince, literally covered in early spring with glowing scarl.t blooms. Valuable for ornamental hedging or for specimen plants.

Spirea Anthony Waterer. - A new, crimson flowering spirea. Dwarfish and very compact growing. 15 to 18 inches in height and covered nearly the whole grow. ing seas $n$ with deep crimcon flowers. P. frectly hardy and fine for low clumps.

Spirea Van Houttii. The best of all Spireas Hardy Ornamental Shrubs

(See next page for prices.)

Flowering Almond. - An o:d time favorite flowering shrub. Blooms very early, and the branches are olten enticly covered with the showy double flowers. In our old garden we used to have just the $\mathrm{n}$ hite, but nnw you can have them in red and pink too. Mention which colnr you want.

Althea (Rose of Sharon). - Very handsome, hardy and free blooming in late summer and fill when most other shrubs are out of bloom. The flowers look more like a rose, and come in varinus shades of white, red, and variegated. Ask for the color you want.

Barberry, Purple Leaf. - Grows from 3 to 5 feet high, and spreads out in a half globe shape. Makes a beautiful single plant or is fine in groups or hedges. The foliage is of an attractive purple cast, and the yellow flowers and bright red berries are a'so very showy.

Barberrv, Common. - The same as the preceding except that the leaves are a bright green in color.

Barberry, Thunbergii. - A very pretty dwarf barb riy from Japan. Has glossy green fol age changing to a coppery red in the fall. Valuable as an ornamental hedge or for grouping. Grows more compact than any of the others.

Calycanthus. - The old-fashioned "Sweetscented shtub." Has velvety deep purple flowers early in the spring.

Dogwood, Red Barked. - Grows from 3 to 6 ft. high, and has large white blooms, but is especially valued for the b-ight red color of the twigs.

High Bush Cranberry. - Similar to Snowball, b"t the bloom is more open and spreading. Blooms profusely in May, follnwid later by clusters of bright scarlet fruit something like cranberries.

Deutzia. - A viry showy Jananese shrub of dense upright growth, bearing a profusion of showy white or rose colored flowers. Should be planted by everyone, as it is a sure bloomer and blooms freely.

Golden Elder. - Foliage is of a bright golden yellow color all season. Much used on account of its foliage effect.

Forsythia (Golden Bell). - Vigorous grower, the drooping branches with yellow flowers.
Lilac- Everyone knows and loves the lilac. It is the best of the old-fashioned flowers. Will grow anywhere, and in almost any soil. Blooms freely even when small. We can supply either the white or the purple in bo' $h$ the common lilac and the Persian lilac. The Persian is more slencier and willowy in growth, and has finer foliage, and is a great blonmer. Both are perfectly hardy.

Hardy Hydrangea (Hydrangea Paniculata Gran: diflora).-One of the best of all the ha-dy shrubs. Grows 10 a height of five or six feet and is perfectly hardy in all parts of the country. Flowers are white, changing to pink, and are borne in great pyramidal clusters often nearly a foot in length. Commences flowering in July and continues till November. Fine for cemetery planting.

Snowball. - A well hniwn old favorite. Grows 8 to 10 feet high Bears gr"at clusters of snowy white globes of flowers in May. Hardy anywhere.

Spirea Billardii. - A hardy, upright shrub. Grows from 4 tu $5 \mathrm{ft}$. in height, with brownish branches, leaves oblong and b ight green. Flowers produced in dense panicles of rich pink. Very showy for cut flowers. Blooms in July and August and frequently again in the fall, continuing until frost.

Spirea Van Houtii. - The grandest of all the spireas. It is a beautiful ornament for the lawn at any srason. When in flower is a complete foun. tain of white bloom. Just enough green of leaves showing to make it most attractive. A grand and graceful shrub attaining a height of 5 to 6 feet. Perfectly hardy everywhere. Fine for an ornamental hedge.

Syringa (Mock Orange).-A hardy, free flower. ing shrub with most showy, fragrant flowers. which appear in the late spring. Grows 8 to 9 feet in height with spreading and often arching branches. Leaves a bright green, flowers pure white, large, very showy, and fragrant. Should be in every garden.

Tamarix. - A hardy shrub of strong growch with foliage as light and feathery as asparagus. Very fine for single plants if kept trimmed, but lately has been much used for hedging and is indeed very nretty for that purpose. It will stand lots of prun ing and if kept well trimmed through the summe is even finer then the best of evergreen hedges, anc from a distance is frequently taken for such. The grow well on almost any soil. and will stand grea extremes of cold and dry weather. 


\section{Hardy Ornamental Shrubs Continued}

Weigela. - This beautiful shrub grows from 6 to 8 feet tall and blnoms in June and July. The flowers are produced in such profusion as to almost hide the foliage. They are fine for border or grouping and also as specimen plants for the lawn. The following three are the best varieties:

Weigela Rosea. - One of the most popular and the tallest growing. Foliage a very dark green, flowers bright rose.

Weigela Candida. - Of vigorous and upright habit. Flowers pure white and produced in great profusion in June and continues to bloom at intervals through the summer.

Weigela Eva Rathke.-A most charming new variety. A strong grower and of racef.l drooping habit. Flnwer a dark beautiful crimson, distinct and very fire. One of the best hybrids.

Flowering Currant.-A beautiful plant of easy culture. Much admired for their wealth of bright yel.ow flowers and their prevailing spicy odor. The leaves are glossy and turn brilliant colors in the fall. Perfeetly hardy and grows from 6 to $8 \mathrm{ft}$. tall.

\section{Condensed List of Hardy Shrubs}

Flowering Almond. white

Flowering Almond, red

Flowering Almond, pink

Althea, white

Althea, red

Althea, variegated

Barberry, purple

Barberry, common

Barberrv, Thun bergi

Calyanthus

Cranberry, high bush

Dogwood, red barked

Flowering Currant

Deutzia, white

Deutzia, pink

Elder, golden

Forsythia, Golden Bel

Purple Frin 6

\section{Prices of Hardy Shrubs}

\section{All Varieties Listed Above.}

$30 \mathrm{c}$ each, 2 for $55 \mathrm{c}, 3$ for $80 \mathrm{c}, 4$ for $\$ 1.00$, $\$ 3.00$ per dozen, either all alike or assorted to suit. These prices apply to all shrubs mentioned on this and preceding page.

\section{Prices Are Postpaid}

These prices include prepaid delivery, either by parcels po-t or express in zones $1,2,3$, or 4 . Add 10 per cent for prepay bey ond zone 4 .

\section{Extra Large Plants}

We can generally supply extra large or "specimen" plants of most of these shrubs, but they would have to go by express at your expense. They are harder to get to live than the regular size, but some want them. Price, $50 \mathrm{c}$ each, any amount.

\section{Other Plants}

Hardy shrubs are among the best kind of flowers for planting in the cemetery, as they do not need much attention and are perfectly hardy. See above for a full list. Also see spage $\mathbf{1 3 0}$ for hardy vines.

\section{Cemetery Plants}

There is a great deal of call for flowers and plants suitable for cemetery planting, and many people do not know what to plant, how to plant, or when to plant, so I am gathering together on one page here a number of different kinds of flow: ers and pl nts that come under this general class.

Peonies.-Probably the most satisfactory plant for cemetery purposes is the peony. It is absolutely hardy, and once set cut, will live for generations. It has no insect enemies or diseases, and it always blooms;obesides, it is generally in bloom by Decora tion Day, which is the time flowers are most wanted. They can be had in either white, pink, or red, and can be planted either fall or spring. Large plants, each 25c postpaid. See page 111 for fuil list.

Hardy Phlox. - These flowers are perfectly hardy and will live for years. They can be set either fall or spring, and will grow in any soil. They grow from 1 to 2 fiet high, and bloom from July till frost. They $\mathrm{c} n$ be had in either red, pink or white, $w$ ith various shades between, $\$ 1.50$ per doz., either all alike or assorted.

Roses. - These are always a favorite with every one for cemetery use. The only drawback is that they sometimes winter-kill in severe winter. Here are some varieties especially suitable.

White Memorial Rose. - This is the creeping rose that makes a mass of glossy green leaves and an abundance of pure white flowers late in June. Does not grow up into a bush, but stays close to the ground. Strong plants. Price, $35 \mathrm{c}$ each.

Madam Plantier (White). - Best of all hardy white roses. Very free bloomer. 35c each.

Baby Rambler. (Red). - Everblonming bush rose that gives an abundance of medium-sized red flowers in large clusters throughout the summer. Partially hardy, but should have a little protection Strong plants. $40 \mathrm{c}$ each.

Other Roses. - I can furnish any variety of roses you may want, Lut I do not have room th list them all here. See page 124.

\section{Grass Seed}

You can easily get a fine sod of grass started by sowing seed almost any time during the season, if there is moisture enough for the seed to grow. Work the ground up fine and mellow and sow a good mixture like our lawn grass seed at the rate of one pound for every 200 square feet. Thicker seeding would do no harm. We furnish a special mixture-just what you want. 35c per pound,

\section{Cut Flowers}

We grow lots of flowers here, and often have many cut flowers for sale. This is especially the case with peonies in May and June, Iris in May. Phlox from July till frost. Dahlias from June till frost and gladiolas in July and August. We have very fine varieties in all of these and can give you some fine stuff. Write and ask about what you want. We will make the price right.

\section{Hedge Plants}

For making a low hedge that will stay green and look nice all summer, there is nothing nicer than the California Privet. We ran furnish good thrifty field-grown plants at $\$ 6.00$ per 100 . 


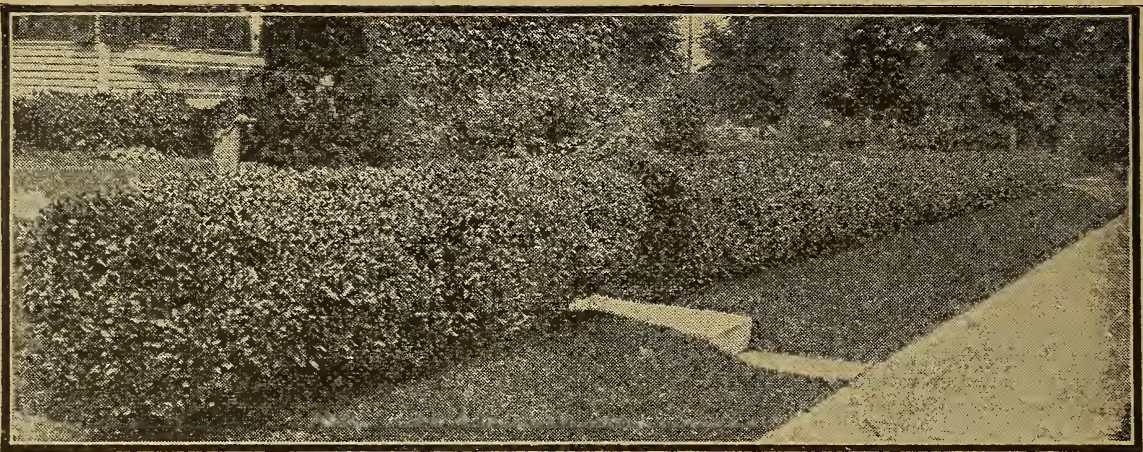

California Privet. Probably the best known of all the ornamental hedge plants

\section{Ornamental Hedge Plants}

The green growing hedge or ornamental plants take the place of the disfiguring fence and make a beanity of a necessity.

There are hedges for all sorts of locations and onditions, from the low hedge a foot or two high neant simply to mark the boundary of the lawn, co the tall dense hedge meant to shut out the view of an unsightly alley.

Of course it depends largely on the treatment and trimming given the redge, as most of them can be kept down low and trim by constant shedring, or can be allowed to grow tall and dense.

For all aroun hedge there is nothing more popular than the Privets. There are several varie. ties, but all are rapia growing, healthy shrubs, with glossy green leaves and a multitude of small branches.

The California Privet is the best known and in most ways the best one, except that it is not quite so hardy in severe northern winters. It sometimes kills back, but when trimmed will come again. For anywhere south of Kansas City it is safe any winter. North of there it may be damaged sometimes.

For the more northern localities I advise the Amoor River Privet and the Ibota, especially the frrmer. It is absolutely hardy anywhere and equal to any in appearance.

All the privets should be kept constanily sheared back. The more they are trimmed the better they get.

The Barberries are absolutely hardy anywhere, are handsome summer and winter, and require very little shearing. They do not grow quite so thickly as the privets, but are not intended for a tall hedge anyway. Will thrive north or south on any kind of soil. Covered with little red berries which hang on all winter.

There are three varieties of Barberries, all good. The common variety has bright green leaves, the Thunbergi is rather copper colored, and then there is a purple-leaved sort.

For tall, heavy hedges the Bush Honeysuckle, Siberian Pea, and Japan Quince, are all fine. They are perfectly hardy, grow quick and large, and can be kept sheared down if preferred.

For downright beauty there is nothing to equal a hedge of Spirea Van Houttii in full bloom along the side of a lawn or against the foundation of a house. The picture on the opposite page will give you a good idea of how they look.
For dry and windy location, or anywhere where a plant is needed to stand extremes of cold. or dry, or windy weather, there is nothing so good as the Siberian Tamarix or Tamarix Amur. I saw a good bit of it used for wind breaks around gardens in western Kansas. It has beautiful feathery leaves, and is very ornamental.

In planting a hedge, dig out a good sized trench, and fill in wi h good dirt. Set the plants a trifle deeper than they grew before, and about 1 foot apart in the row. It is always best to cut them back severely, almost to the ground in fact, so they will chrow up new branches all the same age.

There are a number of other varieties of shrubs sometimes used for hedge, but the ones named above are the ones most commonly used. If there are others you would like to use. I will be glad to make you special price on whatever you need.

\section{Prices of Hedge Plants Listed on this Page}

(These pr es are Not prepaid nor postpaid.)

Barberry, $P$ irple Leaved . Barberry, Common Barberry, Thunbergi. Buckthorm Caragana (Siberian Pea) $\begin{array}{lll}\text { Caragana (Siberian Pea) } & 9.00 \\ \text { Cydonia Japonica (Japan Quince) }\end{array}$ Bush Honeysuckie Osage Orange. ........ California Privet $\ldots \ldots$ California Privet (Extra Large) $\begin{array}{lll}\text { California Privet (Extra Large) } & \mathbf{6} \\ \text { California Privet (Small) } & 00\end{array}$ California Privet (Small)
Ibota Privet (Small) Amoor River Privet (Extra hardy) Tamarix Amur ........................... 12.00 Spirea Van Houttii ... 10.00

These prices are based on fairly large lots, but 25 or over will be supplied at the 100 price. Less amounts are slightly higher price.

We do not prepay the charges at these prices. They are based on the plants going by express at your expense. We pack in good shape without extra charge, and guarantee safe delivery by express.

It is best to figure on setting the plants one foot apart in the row to make a good hedge, so order as many as you have feet of hedge to plant.

All plants are field grown, thrifty and healthy, and at least two years old. They are selected for uniform height so they will make a nice even hedge.

\section{Annual Evergreen For Quick Hedges}

When you want a hedge in a hurry there is nothing to beat the Annual Evergreen or, as it is sometimes called, "Mock Cypress". It grows easily from seed, and makes a good hedge in 8 to 10 weeks. Price of sced, oz. 25c, pkt. 5 c. 


\section{Why Not Have An Asparagus Bed?}

Most of you have an idea that there is some great mystery about the growing of asparagus. and that you have no chance of success with it. Nothing to it. It really grows like a weed. Just give it good, rich soil, the richer the better, plenty of room and decent cultivation, and you can't help but succeed. It's mighty good eating in the spring of the year, too. Nothing better.

The best way to get a start is from the plants. We have literally millions of them. Best size is strong 1 year. Some people though prefer 2 year. Take your choice. We have both. 50 per cent extra for 2 year.

Set the plants early. It's all bosh, this talk about trenching and all that. Just get the roots in the ground right side up and covered about three or 4 inches deep. That's all. Keep them all well hoed all the first summer. Then in the fall mulch heavily and keep mulched heavy enough to keep the weeds down all the time from that on. Put plants 10 inches apart in the rows. Rows any convenient width apart. No crop the first year, but fair crop the next year and plenty from then on for 2 ) years to come. Cut every day or every other diy from early spring till peas come. Great money maker. Can't freeze out or dry out, or drown out, or hail out. Sure income. Regular pension. Sells readily at most places at $8 \mathrm{c}$ to $15 \mathrm{c}$ a pound.

Field culture 12,000 plants per acre. Home garden, with rows 2 feet apart, 100 plants for bed 10 feet by 20 feet.

\section{Postpaid Price List of Asparagus Plants}

These prices include delivery prepaid by either parcels post or express in zones $1,2,3$, and 4 . outside of zone 4 , add $10 \%$ for prepay. Prices are for strong 1 year. If 2 year plants are wanted, add $50 \%$ to prices.

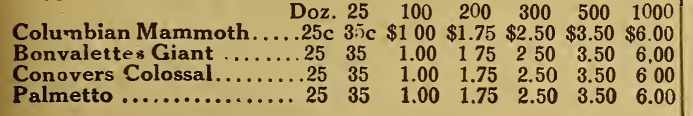

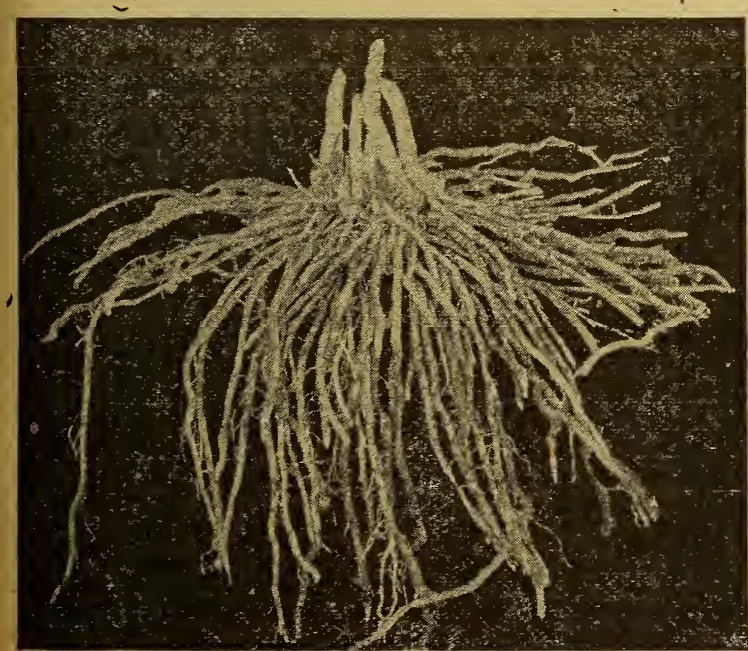

Asparagus Plant. (See prices above,)

\section{Varieties of Asparagus}

Really there is no great amount of difference in varieties of asparagus. It depends a great deal more on the soil and culture than it does on the variety. Any of them will be all right in good rich soil and plenty of moisture.

\section{Rhubarb or Pieplant}

We have the best variety of rhubarb that I have ever seen. It is the strain that is sometimes sold for wine plant. The stalks are very large, quite red in color, very tender and mild in flavor. It is early, hardy and just right in every way. We have no special name for it, but it is somewhat similar to the variety sometimes sold by nurserymen as Victoria, but in my opinion better. It was brought to this country by some of the early settlers and is well known in this neighborhood. The plants can be set either fall or spring and live very easily. They can be shipped safely by mail or express to any part of the country. See prices below.

Each Doz. 100

Rhubarb, 1 year (3 for 25c) _...... 10c $\$ 1.00 \$ 5.00$ Rhubarb, 2 year (2 for 25c:

Ask for special net prices on large lots to go at your expense.

\section{Horse Radish}

Maliner Kren, or Improved Bavarian.-This is an improved variety of horse radish from Bavaria, which is being rapidly adopted all over the United States as the standard variety. It can be grown from either cuttings or crowns. The crowns are the top portion of the large roots and will make a big hill the first year. See prices below.

Each Doz. 100 $20 \mathrm{c} \$ 1.00$ Horseradish crowns ( 3 for $25 c$ ) _ _ _ _ 10c $\$ 1.754 .00$

Write for special prices on large lots.

\section{Dasheens, Trinidad or Edible}

This is a plant newly introducsd by the U. S. Department of Agriculture as a field and garden crop in the south. They have a bulletin about them. Write for it. It is very interesting. The plant looks like the well known Caladium or Elephant's Ear, but is taller and hardier. The tubers are eaten like Irish po. tatoes, which they very much resemble.

These same Dasheens are rapidly tak. ing the place of the Caldium as ornamental plants. They are hardier, grow faster, and are better in every way, They are especially nice for an edging or border to a Canna bed.

\section{PRICES OF DASHEEN BULBS}

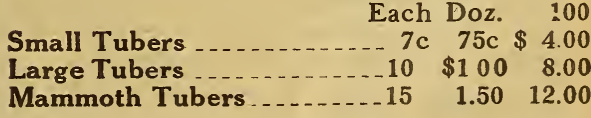

All prices on this page include delivery prepaid by parcels post or express in zones $1,2,3,4$. If outside of Zone 4 , add $10 \%$ for prepay.

See vegetable seed department for price on seed of Rhubarb and Asparagus. 


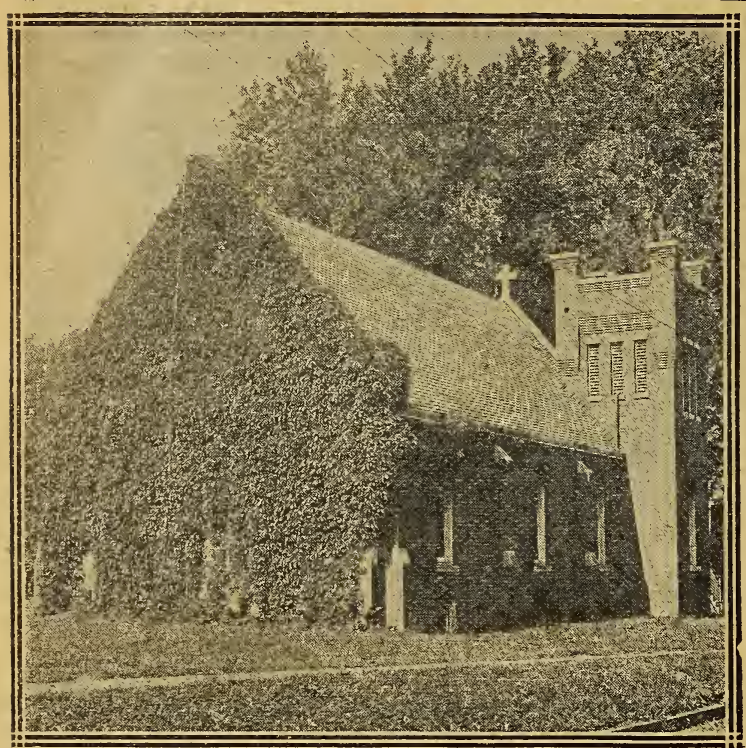

Hardy Boston Ivy (Ampelopsis Engelmani) on Episcopal Church, Shenandoah. Note how it clings to the wall.

\section{Ornamental Vines}

Everyone likes vines on a house. They are practical, beautiful and home-like. They give shade to a window, protection to a porch, and beauty to a pillar. Some of the varieties will climb and stick tight to a brick wall.

I have chosen a list of vines that can be de. pended on anywhere and will grow for anyone. All of the ones named on this page are perfectly hardy and easy to grow. They will grow in any kind of soil, but of course they will do best in good rich soil, fairly moist.

Most vines do best planted in the spring-the earlier the better. I do not advise fall planting for them. If planted in a row along a wall or fence they should usually be planted about 3 feet apart, On a building it is usual.y best to plant one or two at each window or pillar to be covered.

Boston IVy (Ampelopsis Veitchii). - This is the common in the eastern state and does best there. It clings very tightly to any kind of a wall - brick, wood, or stone, and does not need any support of any kind. The foliage is very dense and will completely cover the surface it climbs on. We have it an the seed house wall, as you may have noticed in some of the pictures. It is hardy, but here in the west suffers from dry weather, both in summer and in open winters, so that it kills back some; but in the eastern states it is practically the only ivy user. See prices on next page.

Cinnamon Vine Grow from a roo like a sweet potato, which is hardy and lives in the ground for years. A rapid grower when well established, but rather disappointing the first year. The Madeira vine is much better in my opinion.

These vines are all large 2-year field-grown stock. See next page for prices.
Trumpet Flower (Bignonia Radicans).A hardy native vine an extra strong grower, and always looks well. Has gl'ssy green leaves and large trumpet shaped flowers. Blooms prac. tically all summer and fall. Very useful for covering unsightly tences, stone piles, etc. Will climb anywhere if it can find anything to cling to. I have a vine of it that went over the roof of a shed by cling. ing to the edges of the shingles. Very easy to grow. See prices on next page.

Bitter Sweet (Celastrus Scandens.) - A well-known hardy native vine. Yellow flowers in June, followed by orange-colored po's, which split open showing red berries.

Matrimony Vine Anold-fashioned hardy shrub vine, grows any. where, and covered with a prousion of sca let berries. Good to cover walls or steep banks,

Perennial Sweet Peas These look like sweet peas, but are hardy the regular will live for years - getting better all the time. When well established will grow 10 or $12 \mathrm{ft}$. high. Colors from white to red.

Madeira Vine Grows from tubers like potatoes. which should be taken up and kept in the cellar over winter. Very easily grown, and will thrive in any location or soil. Will grow 12 to 15 feet high. Waxy dark green, heart-shaped leaves, and racemes of fine white blonm, very fra. grant. One of the best vin's for planting thickly along the front edge of a porch for quick effect. Should be bought by the duzen.

Hardy Boston Ivy (Ampelopsis Engelmanii).his is a variety most used hest. It has a leaf more like the American Ivy, but will cling to a wall almost as wtll as the true Boston Ivy. It has the advintage of being absolutely hardy to both drouth and cold, and never kills back in the least. In all the country west of the Mississippi I strongly advise it as the one to use. See prices on next page.

American Ivy (Virginia Creeper or Woodbine.)This is a native American vine and is hardy all over the country. It is a beautiful vine and the fastest grower of any. The only fault is that it will not cling to a wall, but needs some support. With a little support of some kind, how. ever, it climbs readily and is a beautiful vine. The foliage takes on very bright colors. See price on next page.

Wistaria Beautiful climbing vines, with great drooping clusters of purple or white flowers. Hardy anywhere. We have the American Purple and the Chinese White. See prices on next page.

Honeysuckle These are well known and loved by everyone. They are all hardy and easy to grow. They are great climbers and will grow anywhere. They range from white to yellow and red in color of bloom. The best one to my notion is the Halleana, or Hall's Japanese Honeysuckle. It is practically everblooming, very fragrant, and a great climber. All the Honeysuckles are fine to have. See prices on next page. 


\section{Ornamertal Vines, Continued}

Clematis Paniculata (Japanese Clematis.)-The best and hardicst of all the Clematis. Hardy, thrifty, and quic's growing. Has great masses of fragrant white flowers about the size of apple bloom, in July, August, and Sep. tember. Climbs readily where there is any sup. po:t or trellis. See prices in next column.

Clematis Jackmanii (Large Purple Clematis.)This is the beautiful, large to $g$ ow than the Clematis Paniculata, and does not make so tall a vine, but is well worth growing or account of the great beauty ofists flowers. Our plants are extra fine and sure to live with proper care. See prices in next column.

\section{Grapes}

This is one of the best and healthiest fruits we have. Everybody should have a few grape vines in the home garden. There is scarcely a yird so small either in the country or city that roo $n$ for fr. m one to a dozen or more grupe vines cannot be found. By selecting a few vines of early, medium and late ripening varieties, one may have grapes for the table for several months in the year. They can be plinted along side the house or trained over fences, trellises or doorways and made ornamental as well as useful. They do well on any soil, except low, wet ground. To sucreed best they should have a free exposure to sun and air. Have your ground mellow and plant about two inches deeper than they stood in the nursery. If planting along side fences, plant $6 \mathrm{ft}$.' apart. If in open ground, in rows $5 \mathrm{ft}$. apart, and six feet in the rows. Cut back well when planted out. Leave not more than three buds on vine the first year and then prune severely every year, cutting out the oldest wond and leaving strong new vines. We believe in the list we are offering is included all the best varieties grown in this country.

Probably the best known variety and the most extensively planted everywhere, is the Concord. It is a hardy vigorous grower, very productive, bunches large, berries juicy and sweet, not the earliest, but ripens over a longer period than most varieties.

Moore's Early and Worden ripen about two weeks, and one week, ahead of Concord. Moore's Early is not a heavy grower, but bunches and herric s are large and fine. Very sweet, fine for table, as it is very showy. Also it is the first good eating grape to ripen. Worden in growth is much like Concord. Fruit about the same in size and of excellent flavor.

Campbell's Early commences ripening soon after Moore's Early, and is a vigorous grower. Berties very large, but bunches not so well shouldered as Moore's Early. Keeps well and is a good shipper and good quality. Champion is a fairly good market grape, but poor quality. Very vigorous grower Bunches medium, compact. Fruit showy, and a heavy bearer, but too sour to eat well.

Among the white varieties Moore's Diamond and Niagara are about equal in growth of vine and hardiness and also in size of bunches and berries. Moore's Diamond is greenish white in color. Juicy
Postpaid Prices of Vines on Pages 130 and 131

These prices include delivery prepaid by parcels post or express anywhere in Zones 2, 3 and 4. Add $10 \%$ beyond. Strong 2-yr. Plants

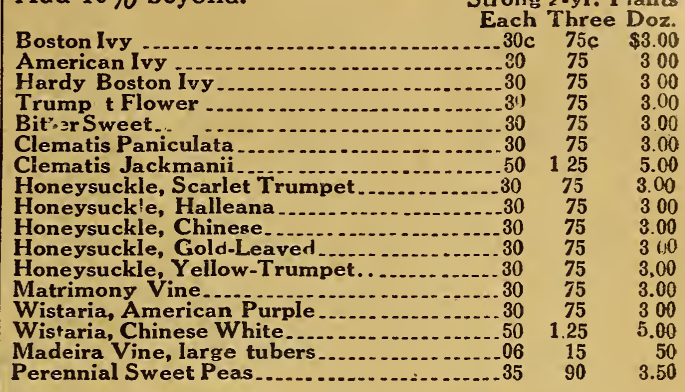

and tender. Niagara yellowish white. Skin thin but tough, a good shipper and market berry,

Elvira is a smallcr grape than either Niagara or Moore's Diamond, but bunches very compact and a great bearer, extensively grown as a wine $g$ ane. Pocklington is golden yellow when ripe. Fruit medium in size and very showy, sweet and juicy and with little pu!p, fine flavor.

Of the red varieties Agawam and Salem are the largesı berries and heaviest bunches. Agawam is an extra strong grower, fruit very dark red when fully ripe. Skin thick, pulp jui y and of a peculiar spicy flavor. A great bearer and splendid keeper, ripens ten days to two weeks later than Concord. Salem ripens late in September, coppery red in color, thin skin, sweet and tender, a good variety for both table and wine' as well as being a good shipper. Delaware is a fine table grape. Bunches small, but well shouldered. Berries rather small, light red, sweet, and without any hard pulp. Ex. tensively grown in the east $b$ th for table and shipping, earlier than either Agawam or Salem.

Catawba is a well-known old variety, bunches and berries large, red, turning to purple when fully ripe. Flesh somewhat pulpy, but sweet, juic one of the latest. Does not ripen well in the north, but is a very profitable variety for southern latitudes.

\section{Prepaid Price List of Grapes}

At these prices all grape vines will be delivered by parcel post or prepaid express, all charges paid, in zones $1,2,3$ and 4 . If you live outside of zone 4 , add $10 \%$ for delivery prepaid. ( 6 or more at dozen rate, 25 or more at 100 rate.)
Black Grapes.
Each Doz. 100

Concord .

Campbell's Early

Early Champion.

Moore's Early

Worden

White Grapes.

Diamond... $15 \quad 1.50 \quad 8.00$

Elvira_.........

Niagara

Pocklington ..............

Red Grapes.

Agawam .

Delaware

Salem $\ldots$

Catawba 


\section{Gooseberries}

Gooseberries sho 3 be plan.ed in gocu : $\varepsilon=$ tile so that is well drained. Plant in rows four feet part and two feet apart in the row -nd keep well mulchcd with old hay or straw. Do, ${ }^{+}$be sparing, put it on thick, four or five inches deep. This will retain moisture during the dryest weather and keep down weeds. What few weeds do come through can be easily pulled up. If not convenient to mulch, the next best thing is good cultivation. Go over them and stir the ground well. The American varieties are not subject to mildew, but to prevent it spray the bushes as soon as the leaves appear in the spring, and several times during the summer with Pottassium Sulphide. One ounce to four gallons of water.

Every family can have a bountiful supply of this valuable garden fruit at small expense and with little trouble. It is much sought after for culinary purposes and finds a reauly sale in all markets. In the varieties we list, probably the best known a e the Houghton and Downing. They are both old varieties that have been tested for years, and you can not make a mistake in planting either one of them. Houghton is the strongest grower, a good annual bearer and fruit of fair size. Downing is a more compact grower and the berries pale green and very large. Fine for dessert or canning. Champion is a strong grower, about equal to Houghton in growth, which it resembles somewhat. Berries large and of a brownish red color, a good market variety. Josselyn (or Red Jacket) is an American seedling, very compact, grows similar to Downing in looks, both as to bush and fruit. Hardy, but I do not think it is as prolific as Downing. Industry is about the only English gooseberry planted in this country. Berries are very large-largest of any variety grown here, dark red and good quality, spreads but little and requires little pruning.

\section{Currants}

Currants require about the same soil and cultivation as gooseberries to succeed well. Tops should be well cut back in planting out, leaving only two or three sprouts to grow the first season. They should be pruned some every year, cutting out the old and darkest looking wood; keep the center of bush open somewhat. Currant worms can be destroyed by White Helleboae, one ounce to three gallons of water and applied with sprinkler or sprayer. Plant about the same distance apart as gooseberries.

B'ack Naples is the only black currant ive handle and about the only variety planted to any extent in this country. We consider it the best of the blacks, but no black currant is fit to eat in my opinion.

In red currants we list three and you cannot go wrong on any of them. Cherry is large, very deep red, rather acid but fine for jelly. Fay's Prolific is not so red in color, but bunches very large and very productive. North Star is the strongest grower of all the red varieties and berries large and heavy clustered.

White Grape is the best of all white varieties. Bush strong and a vigorous grower. Clusters long and handsome, excellent quality and a fine table currant.

All delivered postpaid or by prepaid express at these prices, in zones 1, 2, 3 and 4 . (See map). If outside zone 4, add 10 per cent if wanted prepaid. Safe delivery guaranteed.

\section{Gooseberries}

( 6 or more at dozen rate, 25 or more at 100 rate.)

Each Doż. 100

Champion . . . . . . . 20c $\$ 2.00 \$ 12.00$

$\begin{array}{lllll}\text { Downing . . . . . . . . . . . } 17 & 1.70 & 10.00\end{array}$

Houghton . . . . . . . . 11

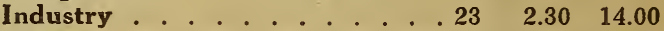

Josselyn . . . . . . . . . $20 \quad 2000$

\section{Currants}

Black Naples . . . . . . . . $12 \mathrm{c} \$ 1.00 \$ 7.00$

Red Cherry . . . . . . . $12 \quad 120$

Fay's Prolific . . . . . . . . . . $12 \quad 120$

North Star . . . . . . . . . . $12 \quad 120$

White Grape . . . . . . . . $12 \quad 1.207 .00$

Raspberries (Black)

Cumberland . . . . . . . . 10c $75 \mathrm{c} \$ 4.00$

Gregg . . . . . . . . . . $10 \quad 75400$

Kansas ... . . . . . . . $1075 \quad 70$

Raspberries (Red and Purple)

Cardinal (purple) . . . . . . 10c 90c $\$ 5.00$

Columbian (purple) . . . . $10 \quad 90 \quad 5.00$

Loudon (red) . . . . . . . 1090

Cuthbert (red) $\ldots . \cdots 1045$

St. Regis-Everbkaring (red) $\ldots \begin{array}{lll}15 & 1.00 & 6.00\end{array}$

\section{Blackberries}

Early Harvest . . . . . . . 10c $90 \$ 5.00$

Eldorado. . . . . . . 10905.00

Erie . . . . 1090500

Snyder . . . 10905.00

Grapes-See page 131.

Asparagus-See page 129.

Rhubarb-See page 129.

Dewberries

Lucretia . . . . . . . . $1090 \quad 500$

Miscallaneous Small Fruit

Strawberry-Raspberry or Tree

Strawberry. ..... 15c $\$ 1.25$

Juneberry, Dwarf . . . . . . . . 202020

Rocky Mountain Cherry . . . . . 2020

Himalaya Berry . . . . . . . . . 1515

Logan Berry . 252.50

Strawberries

(See full particulars on pages 135 and 136)

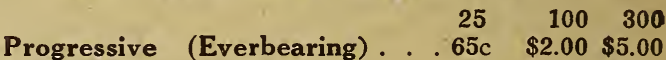

$\begin{array}{llllll}\text { Francis (Everbearing) } & \cdots & . & 65 & 2.00 & 5.00\end{array}$

Senator (spring bearing) . . . . . . $\begin{array}{llll}35 & 1.00 & 2.50\end{array}$

\section{Set Small Fruit Early}

Most small fruit should be set very early, the earlier the better, We will fill and ship all orders as soon as we think it will be safe to set the plants in your country. Send your order at any time now and we will book it to be sent at the proper time,

Orders that come in after April 1st are usually filled and sent at once unless ordered otherwise, Earlier orders are held and sent out generally from April 1st to April 15th, except for the south, where they are sent earlier. 


\section{Blackberries}

Blackberries are a fruit that everyone likes and can have with just a little effort and time. They require the same treatment as raspberries. Nip back new canes in growing season to three feet, causing them to throw out laterals. They do well on almost any soil and bear good crops of fruit. We list four of the very best varieties covering the season of ripening. Early Harvest is the earliest, a very compact, $d$ warfish grower, and can be planted closer than other varieties. Fruit rather small and very sweet. Not recommended for extreme north. Erie is another early blackberry, hardier than Early Harvest and much larger fruit. Very black and firm, is a splendid bearer and stands shipping well. Eldorado is also a good shipping berry. Very hardy everywhere; fruit large and borne in clusters, quality unsurpassed. Snyder, the best known and a favorite everywhere, extra heavy canes, often growing 7 to 8 feet if allowed to run up. Very productive, berries of medium size and very sweet, season of ripening longer than any other variety. Probably the hardiest of any.

\section{Dewberries}

Lucretia Dewberry is a variety of blackberry that trails on the ground. Perfectly hardy and very productive, ripens early, very large, is often one and $a$ half inches long, by one inch in diameter, rather soft, sweet and with no hard core. Does well on any soil.

\section{Strawberry Raspberry}

A fruit of Japans origin. Valuable for the ex treme north, as ths fruit is borne on the new growth and of course is hardy in any climate. Berries are bright scarlet, larger than strawberries, but of similar shape, rather partakes of the character of raspberries in that the seeds are covered by flesh as in the latter. Not much good for eating raw, but good for jelly and has a flavor peculiar to itself, Bush is low, growing 12 to 18 inches high. Quite a curiosity, at least.

\section{Dwarf Juneberry}

In habit of growth similar to current bushes, attaining about the same height, extremely hardy, fruit a mild sub-acid. Red, changing to purple when ripe, is a handsome growing shrub and very ornamental,

\section{Logan Berry}

This is getting to be a very popular fruit, but it cannot be grown here in Iowa, nor in similar climates. It does best on the Pacific Coast, especially in Oregon, but also can be grown on the gulf coast, and probably anywhere that the temperature does not go much below zero.

It is a cross between the wild blackberry and a red raspberry, but is much larger than either. It makes a bush like a black raspberry, but much larger and ranker. The canes will often grow $15 \mathrm{ft}$. long in a single season. The yield is enormous, where the climate is favorabie, and the berries are delicious. Very large, deep red, and very juicy. Shaped like a blackberry, but longer. Price, strong 2-yr. plants, 25c each.

\section{$\underline{\text { Raspberries }}$}

Raspberries are the most delicious and popular of our small fruits, except possibly strawberries. They are excellent for table use and in canning re. tain their flavor much better than some other of our small fruits. They are always in demand in season and bring good prices everywhere. They will do well in almost any soil.

Have the ground thoroughly prepared and plant in rows 5 feet apart and 3 feet apart in the row. Keep well cultivated and free from weeds and they will produce large crops and will well re. pay for all trouble. As soon as they are done bearing cut out the old wood so as to give strength and vigor to the new canes which is to produce your next year's crop of berries.

\section{Varieties of Raspberries}

Cumberland is the largest berry of all the black-caps, a strong grower, heavy bearer, and excellent quality. Keeps well and is a good shippes. Gregg is one of the oldest and likely the bees known of all the black-caps and still retains ites popularity wherever known. Good size, fine qualitys and one of the best shippers we have.

Kansas is earlier than either Cumberland or: Gregg, is a great table berry, moderately juicy and good flavor. Plants strong growers, stand drouthes well and is an all-round good berry to plant.

Cardinal and Columbian are both purple, bese of somewhat different nature in growth. Cardivers has a strong, vigorous upright cane, bright reddiskes bark, and extremely hardy. Fruit season somewhas late, but large and fine. Is very firm for a purple variety. Columbian is a seedling of Cuthbert and a cross between it and the Gregg. Very strom grower, but, unlike most red and purple varieties. does not sucker, but propagates from tips the same as black-cap varieties. Very hardy and has stood from 28 to 30 degrees below zero without injurg. Berries large, fine quality, and enormously pro ductive.

Loudon is among the largest of red varietie: and a fine, showy berry of good quality, not $\$ 0$ bright a red as the Cuthbert, but of a different flavor. Cuthbert is one of the old standbys, well known almost everywhere, sweet, and rich, very hardy, and one of the best late sorts,

St. Regis, or Everhearing Red, is an excel. lent novelty, a brilliant crımson in color, good size and one of the earliest to commence ripening and continues to produce more or less fruit until late in October, and said to be as hardy as any raspo berry.

\section{Himalaya Berry}

This berry has been heavily advertised, but 1 do not think much of it. It is too tender to live and bear in this climate, but in a favorable climate makes an enormous growth and lots of berries, somewhat like blackberries, but of only fair quality.

I have had it growing on our grounds for years, but never got but one cluster of berries, and they were too sour to eat. The roots lived all right and made enormous new vines each year, which killed to the ground in the winter in spite of mulching. Will probabl y stand about zero weather. 


\section{Transplanted Evergreens}

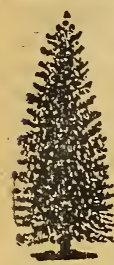

These trees are nursery grown, four or five years old, and have been transplanted 3 times to develop a good root system and enable them to bear tran plant. ing. We handle them in the most careful manner, and guar antee them to reach you in good condition, but we cannot guar-

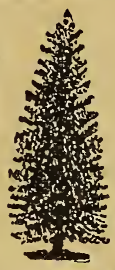
antee them to live, for evergreens are hard things to get to live at the best. Most of these trees wil run about a foot and a half high, and are stocky and heavy for their height. They are always sent by express or freight at your expense. We advise express.

Prices on Transplanted Evergreens.

(Not Postpaid.) Trees about $1 \frac{1}{2} \mathrm{ft}$. high. Each More

American Arbor Vitae .......................... $25 \mathrm{c}$

Balsam Fir $\ldots$

Irish Juniper

Swedish Juniper

Austrian Pine $\ldots \ldots$
Ponderosa Pine $\ldots \ldots$

Ponderosa Pine $\ldots \ldots$
Scotch Pine $\ldots \ldots \ldots$

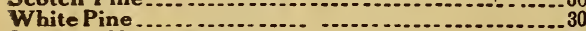

Spruce, Norway ........................................

Spruce, Black Hills ......................................

Spruce, Colorado Blue..................

Spruce, C olorado Green............................. 75

For $15 \mathrm{c}$ per tree extra we can ship evergreens with bur lapped ball of dirt on roots. We strongly advise this.

The Usual Distance of Planting

Apples . Apricot.....

Asparagis ... 1 to 2 feet between plants, in rows 3 to $3 \frac{1}{2}$ feet apart.

Blackberries . - 3 to 5 feet between plants, in rows 4 to 6 feet apart.

Catalpa, Black Locust, etc., for posts and timber, 6 to $8 \mathrm{ft}$. each way.

Cherry

Currant_-_ $4 \mathrm{ft}$. between plants, in rows $5 \mathrm{ft}$. apart, Gooseberries _- $4 \mathrm{ft}$. between plants, rows $5 \mathrm{ft}$. apart. Grape........... 6 to 8 feet each way Hedge Plants ........ 1 to 2 feet apart in the row Mulberries.

Ornamentals-The planting distance for ornamen tals varies with the kind of shrub or bush and the purpose for which it is used. Roses should be planted about two feet apart, hedge plants about one foot, other shrubs about $\frac{1}{3}$ to $\frac{1}{2}$ their height when full grown.

Pecan and Walnut .......-_35 to 40 feet each way

Peach _._._._. 20 feet each way

Pear............ 20 to 30 feet each way

Plum..........

Quince .. .

Raspberries, Black_.3 feet between plants, in rows 6 feet apart.

Raspberries, $\operatorname{Red}_{---3}$ feet between plants, in rows 6 feet apart.

Rhubarb_. $2 \mathrm{ft}$. between plants, in rows $4 \mathrm{ft}$. apart.

\section{Time of Shipment on Nursery Stock}

Except for fall bulbs and peonies, we do not ship nursery stock except in the spring. We do not advise fall planting of ordinary fruits and other nursery stock except in the south. We begin shipping as soon as it is safe to plant in the spring, taking the more southern states first.
Evergreen Trees by Mail, $\$ 1$ per 100 , Postpaid

Now, don't get unduly excited. These are not big trees, big enough to hang a hammock on. They are little seed ings, 2 years old, and from 4 to 6 inches high, or about 8 to 12 inches long, roots and all.

They are good stuff though, nice and thrifty, and heaithy, and guaranteed to reach you in perfect condition by mail.

They are grown by a nursery man who makes a specialty of evergreens and who is one of the few $n$ en who have made a success of growing them from seed. The little trees are not big enough to plant right out where you expect them to stand in the open, but should be grown in a sheltered bed in the garden for a year or two, then they will be ready to put where you want them. Of course this will be some bother, but it will be worth while, for you know what it will cost to buy $b \cdot g$ ones. You would pay anywhere from 20 c to $\$ 1.00$ apiece. You can buy these litıle trees for $\$ 1.00$ per 100 (some a little more), and grow them yourself and in two or three years have just as good trees as you could buy. These varieties are all ones that have been thoroughly tested and found to be absolutely hardy and reliable. Shipment will be made in April and May. Get your orders booked now while there is sure to be plenty of stock. Trees will be sent by mail pnstpaid at the proper time. If any variety is sold out you -will be notified, so that you can cancel or change the order.

Here is the List. Take Your Pick.

100 Norway Spruce, 2-yr. seedlings _..._._. $\$ 1.00$

100 Scotch Pine, 2-yr. seedlings ......... 1.00

100 White Pine, 2-yr. se edlings

100 Ponderosa Pine, 2-yr. seedlings ....... 1.00

75 Austrian Pine, 2.yr. seedlings.

25 Colorado Blue Spruce, 2-yr. seedlings... 1.00

25 Black Hills Spruce, 2-yr, seedlings _. . _. 1.00

All delivered postpaid. Safe arrival guaranteed. These are all put up in packages as listed above and packages cannot be broken, so don't ask for odd amounts.

Special Offer 3 packages for $\$ 2.70$, or 6 assorted to suit.

Complete planting instructions with each order. Write for special prices on larger lots of these trees, also on the large Evergreens, and also on a size between the two, which we sometimes have.

Number of Trees or Plants to the Acre Distance apart, $\mathrm{ft}$

1 by 1 ..

1 by 3

2 by 2 .

3 by 3 ......... 4,840

3 by 4

3 by 5 ......... 2,904

3 by 6 -

4 by 5

18 by 18

5 by 5

2,17819 by $19 \ldots \ldots \ldots$

6 by 6

1,74220 by 20

1,21025 by $25 \ldots$

7 by $7 \ldots \ldots \ldots \ldots$ by $30 \ldots \ldots$

8 by $8 \ldots \ldots \ldots \ldots$

9 by $9 \ldots \ldots$. 40 by $40 \ldots \ldots \ldots$

10 by $10 \ldots \ldots$ by $45 \ldots \ldots \ldots$

11 by $11 \ldots \ldots 0$ by $50 \ldots \ldots \ldots$

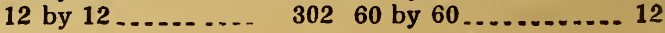




\section{The Everbearing Strawberries Have Made Good}

There can $r$ no possible doubt any longer about the Everbearing strawberries. $\mathbf{1}$ :y have made good, and then some. 'If you have been putting oft planting them waiting for them to show whether they are a good thing or a fake, you don't need to wait any longer. They have proved the last four seasons that they will bear all summer every summer, from earlier than the others till the ground freezes in the fall. Ripe berries, green berries, and blossoms all the time. As 1 the best berries you ever tasted, big, and ru, and sweet, and juicy. Real strawbercies.

\section{New Low Prices}

Here are' the new prices for spring 1917. 25 plants ...... ............. 65 c 50 plants

100 plants............. 2.00

300 plants..................... 5.00

500 plants

These prices a all postpaid, by par. cel post, safe desivery guaranteed. No lower prices on any amount. Plants are guaranteed to be genuine Everbearing, or I will replace them 2 for 1 .

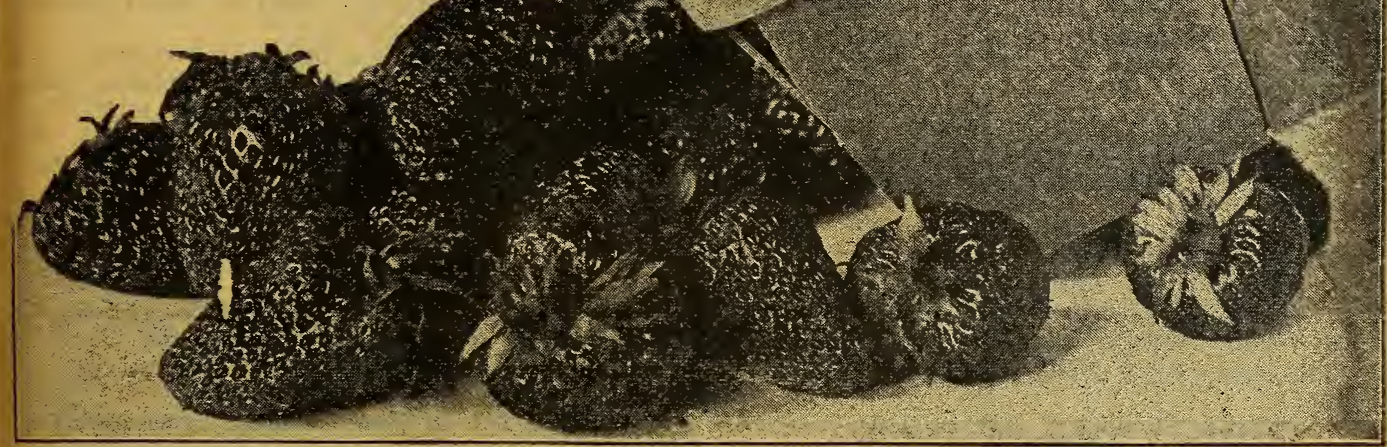

\section{Progressive Everbearing Strawberries}

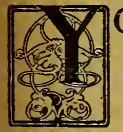

OU can have strawberries all summer now. The new Everbearing variety are just as easy to grow as the common strawberries, yield the same way in June, and then keep on bearing all summer. They are the only strawberries that will give you fruit the first season. They need no special care. Progressive is the best variety of 'hem. They are big, red, juicy, spicy berries that melt in your mouth We have the $t_{\alpha}$ ue Everbearing variety, healthy plants, grown on our own grounds, guaranteed true to name and to succeed with ordinary care.

Send your order now and we will send you the plants by parcel post at the proper time for planting.

Special Reduced Prices on Everbearing Strawberry Plants For next spring we are making lower prices on Everbearing strawberry plants than we have ever made, and they will be the best plants we ever had Our own growing, from new beds on new ground, guaranteed genuine Everbearing or I will replace them 2 for 1 . Orders should be booked now for spring delivery. 


\section{Everbearing Strawberries}

I suppose you think the Everbearing strawberries are a fake, and a fraud, and a few more un. pleasant things. I don't blame you. I used to think so myself.

I had them growing in my garden for four years before I was convinced. I didn't even tell anyone that I had them. And I didn't give them a fair show. I had them crowded in an out-of-the-way corner among some other stuff, and in poor ground, but they bore all summer in spite of it-bore fairly well. All you could expect from such treatment.

But I was like the man they tell about who aw a giraffe for the first time. I was certain that "there hain't no such animal." Finally, though, I decided there was really something to them, so I replanted them in good ground, 2 feet apart each way, tended them well, and gave them a decent show.

Wैell, I took it all back then. They yielded amazingly, and kept it up all summer. Big, dark red, juicy berries of the finest flavor I ever tasted. Commenced bearing as soon as they were set out, and never stopped. Bore on the new young plants as soon as they were rooted. Bore all fall till the ground froze. Spread and made plants, and blos. comed and bore fruit, in spite of the fact that everyone in the neighborhood tramped over them continually looking at them and picking berries.

Last spring we set several acres, and had berries all summer. Picked and sold a lot as late as October. And we have the finest lot of plants you ever saw.

I know they are straight, too. The genuine, true, Everbearing. I've watched them right from the start and pretty near know every plant by its first name. No chance for mistakes, or fakes, or guess work. And I'm going to see to it that they are dug and packed right, and reach you in fine shape.

\section{What They Are Like}

They look just like any other strawberry-that is, any extra good one. They are about the size of Warfield or Dunlap, maybe a little larger, very dark red, firm, and the sweetest; spiciest berry I ever tasted.

The plant is strong and vigorous, and yields enormously. I have seen as high as 100 berries and blooms on a single plant.

They bear at the regular season same as any strawberry, only heavier if anything. I never saw berries bear as full as mine did the second spring (13 months from the time they were set). This after they had already borne all the previous summer.

Then they keep on blooming and bearing all summer without a stop. Not so heavy as they did in June, but some berries all the time and an extra heavy setting in September and October.

They are the only strawberry that will give you any returns the first season you set them. With the ordinary varieties you wait a full year for fruit. With these you begin-getting fruit within six weeks after they are set, and more and more as the season advances. You get enough fruit the first year to repay you for the work and cost. Then the next spring you have a nice bed ready to make you big crop in May or June. And after that berries again all summer. Sounds good, don't it? They'll do it, too, if you give them good soil and good care.

\section{Care and Culture}

You must remember, though, that you can't get something for nothing out of these plants any more than with anything else. They must have good soil, good care and plenty of moisture. It's hard work bearing berries out of season and making plants, too, and getting ready for a crop next spring. If they have to fight hard soil, or thin soil, or weeds, or drouth, they will simply give up and quit; and you can't blame them.

Give them the best soil you have, the kind that would grow a big crop of potatoes, or corn, or cabbage, or onions. No harm to be a trifle heavy and moist. Set the plants early, the earlier the better. April is twice as good as May. Good distance for home garden is 2 feet each way. In the field $1 \frac{1}{2} \times 3 \frac{1}{2}$ feet.

Keep the ground stirred and loose all the time. Never let a crust form or a weed start. If it gets terribly dry, irrigate if you possibly can. I like the overhead sprinkling system, but the ditch system is all right. Any way, so you get the water on and down to the roots. Stir the soil as soon as it begins to dry after you water, so as to stop evaporation.

I don't believe in clipping the runners or blooms. Let them do as they please. Mulch with straw or strawy manure or cornfodder, when the ground freezes, and leave it on in the spring. It will help keep the ground moist. The Everbearing are perfectly hardy. No danger of winter killing.

\section{Varieties}

I prefer the variety known as "Progressive." There are lots of others, and I have tried most of them. Have kept the Progressive. The description above refers to them.

It originated in Iowa, and is a cross between one of the French everbearing sorts and Senator Dunlap, the best of all the regular American varieties. The Progressive has all the good points of the American parent and the one point of the French parent, continuous bearing. It has come to stay, and the sooner you'get started with it the better. Get started this spring by all means.

There has been lots of disappointment in the past and will be for some time in the future, from unscrupulous dealers palming of any old plants they happen to have as "Everbearing." I really believe that two-thirds of what have been sold the past 4 years were fraudulent. I am in a position, however, to give you the real thing. Plants that I absolutely know to be correct, and at a reasonable price.

\section{Everbearer for Commercial Growing and Shipping}

The only other Everbearer I would grow (in addition to Progressive) would be the Francis. For a shipping market it is the better berry, as it stands shipping better. The Progressive is too tender to ship well. Francis yields as well, about the same size, and will ship well or stand up over night in the boxes. Price same as Progressive.

Prices on Progressive and Francis. 25 plants, 65 c; 50 plants, $\$ 1.10$; 100 plants, $\$ 2.00$; 300 plants, $\$ 5.00 ; 500$ plants, $\$ 8.00$. 


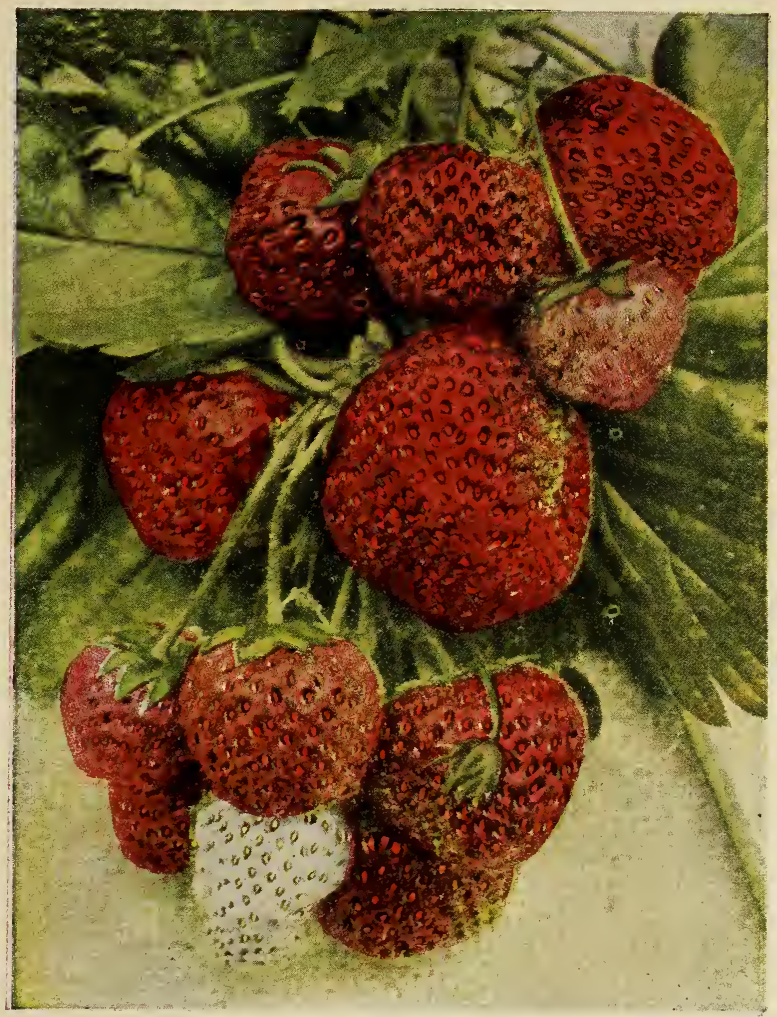

\section{Progressive Everbearing Strawberries}

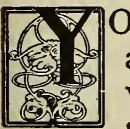

OU can have strawberries all summer now. The new Everbearing variety are just as easy to grow as the common strawberries, yield the same way in June, and then keep on bearing all summer. They are the only strawberries that will give you fruit the first season. They need no special care. Progressive is the best variety of them.

They are big, red, juicy, spicy berries that melt in your mouth. We have the true Everbearing variety, healthy plants, grown on our own grounds, guaranteed true to name and to succeed with ordinary care.

Send your order now and we will send you the plants by parcel post at the proper time for planting.

\section{Special Reduced Prices on Everbearing Strawberry Plants}

For next spring we are making lowe prices on Everbearing strawberry plants than we have ever made, and they will be the best plants we ever had. Our own growing, from new beds on new ground, and guaranteed genuine Everbearing or I will replace them 2 for 1 . Orders should be booked now for spring delivery.

New Prices for Spring $1917-300$ plants for $\$ 5.00 ; 100$ plants for $\$ 2.00$; 50 plants for $\$ 1.10$. All delivered postpaid.

\section{Henry Field Seed Co., Shenandoah, Iowa}




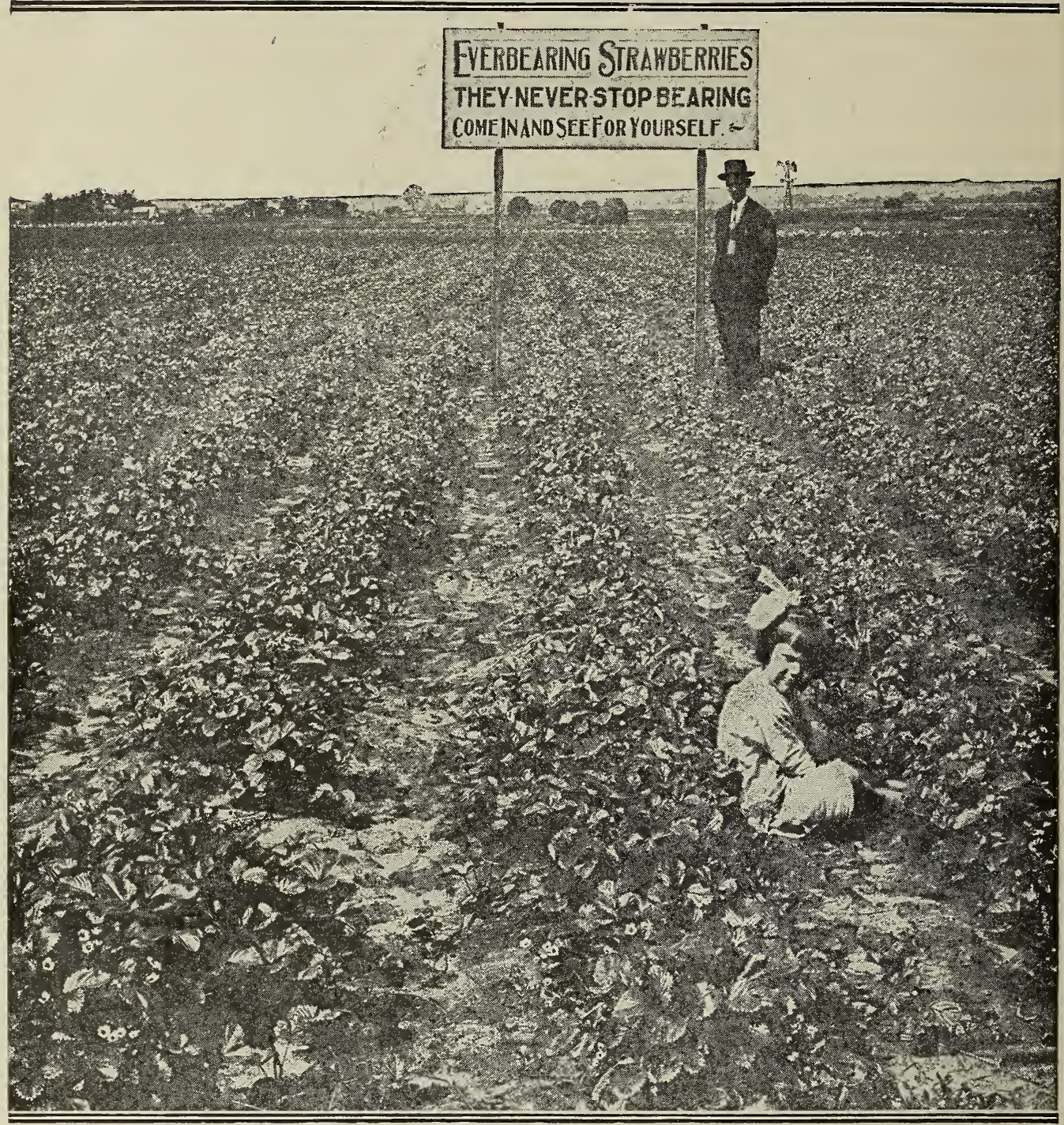

\section{Our Big Field of Everbearing Strawberries}

THIS will give you a good idea of how our field of Everbearing Strawberries looked in the summer. 1 You can't see all of it, but this is a fair sample. If you look close you will see they are full of blooms, and they are full of berries, too, but they don't show up in the picture.

The great whing about the Everbearers is that they start doing business right away instead of waiting till next year. Th are the only fruit you cin plant that will bear the first season. This patch, and in fact every patch o, unem we ever had, paid for itself in fruit the first summer it was set.

They make lots of runners (this field increased over 25 to 1 ) and most of these little new runner piants start bearing as soon as they get rooted.

We dig plants from new beds only. We set them in the spring, generally about $1 \mathrm{ft}$. by $3 \mathrm{ft}$., and with our good land and good cultivation they will cover the ground solid by fall with new plants. Then in the spring we dig it all up clean, throw away the old mother plants. and sell or use the young, vigorous ones.

The big sign is one we put up for the benefit of the doubters. The man is a visitor from Colorado, and the little girl, of course, is R'

If you ever come to Shenandoah, come around, and I will show you a strawberry patch like this loaded with berries any time in the summer or fall. 


\section{Pears, Apricots and Quinces}

\section{Russian Apricots}

This fruit is a close relative of the plum and peach, combining the qualities of both. Ripening as it does be. tween the cherries and peaches, the apricot is a most welcome fruit. The tree is hardier than peach and re. quires about the same soil conditions and treatment. Should be planted on a northern or western slope to pre. vent early blooming.

Alexander. Fruit medium to small, of light orange yellow, flecked with red. Flesh tender, juicy and very good quality. Season July.

Superb. This is a $n$ e w variety. introduced fromKansas and of strictly Russian type and excels all others.

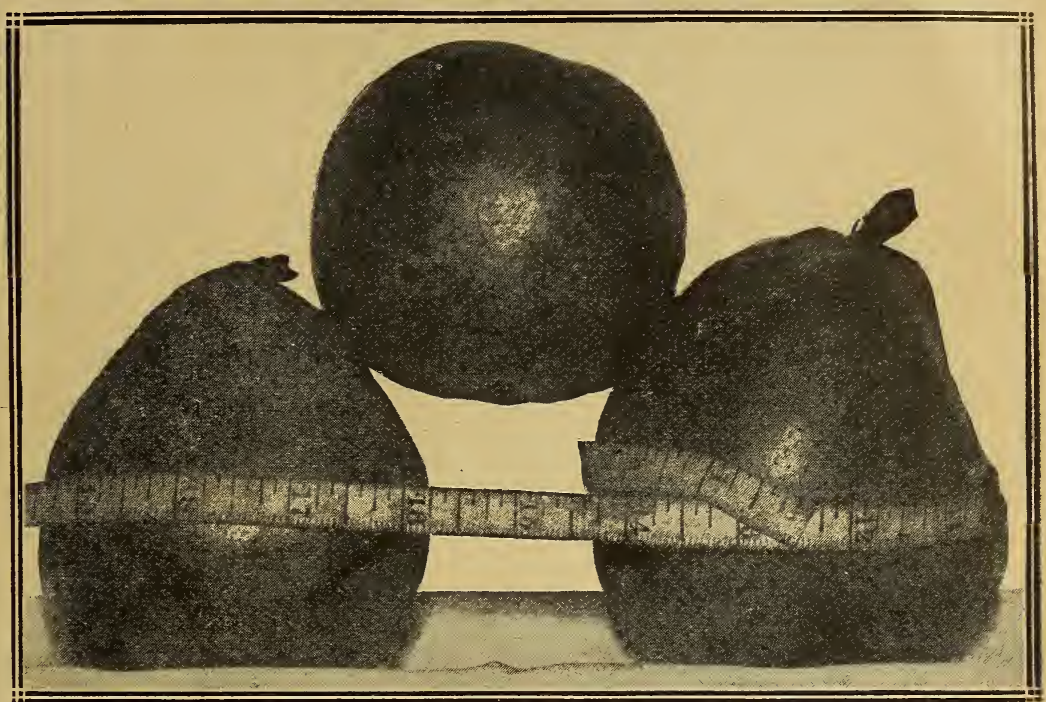

Some Fine Samples of Pears and Quince. The quince is the round one on top. Of course, pears don't always grow as big as that, but they do sometimes. Wouldn't you like to set your teeth into one of these in the picture? You can grow just such pears in your home garden.

\section{Pears}

The cultivation of this fruit is rapidly extending, as its value is appreciated, and the demand is increasing every year, making it a most profitable tree to plant. The melting, juicy texture, flavor, and delicate aroma of the pear give it rank above all other fruits with the possible exception of the grape. Gathering the fruit at the proper time is one important point to remember in connection with the successful growing of this fruit. Summer pears should be gathered at least a week before they are fully ripe. and autumn varieties ten days or two weeks. Most varieties are heavy bearers, and when trees are too heavily loaded, the fruit should be thinned when about one-third grown, else it will be poor and the tree injured.

Bartlett is one of the most popular of pears. Large, buttery, melting, with rich flavor. Juicy and richest of quality. Tree a vigorous, upright grower, hardy. and a great bearer. Season August and Sept.

Keiffer (Or Keiffer Hybrid). This is a seedling of the Chinese Sand Pear crossed with the Bartlett add probably the most popular pear grown. Color yellow with red cheek where exposed to sun. Flesh white, juicy and rich. Tree a very strong, upright grower, a late keeper and valuable market variety. Season late. October and Nov.

Seckle (Or Sugar Pear). Widely known and the standard of excellence in pears. Tree very erect, but rather slow grower. Very hardy and abundant bearer. Fruit small, rich, yellowish brown, very sweet, and highest flavored pear known. Sea. son September.

Dwarf Duchess. Dwarf pear are budded on Quince stock and do not grow very large and can be planted much closer together than standards, which makes them suitable for garden or town lots or any place where you have but little room. They should be planted deep enough to cover the union of the pear and quince three or four inches. and about one-half of the previous summers growth cut off each spring, They should not be trimmed up moreothan a foot above the ground. The variety most grown as a dwarf is the Duchess De Angouleme, or as it is called, Dwarf Duchess. It is the largest of our good pears and succeeds best grown as a dwarf. A good keeper.

\section{Quince}

Champion. Originated in Connecticut. Fruit very large and handsome. Cooks as tender as an apple without hard spots. Color greenish yellow,

Orange. An old standard variety. Fruit roundish, somewhat irregular in shape. Color bright yellow. Very fine flavor and a good bearer.

\section{Prices of Pear, Qnince and Apricot Trees}

For 1 to 5 trees, each . . . . . . . . 45c (Either all alike or assorted.)

For 6 trees or more, each . . . . . . . . 40c (Either all alike or assorted.)

For 30 or more trees, in tens, each . . . . 35c (All alike, or assorted in tens.)

These Prices Are Prepaid. These prices are for strong 1-year budded trees, on 2-year roots, and include prepaid delivery, either by parcel post or express, anywhere in zones $1,2,8$ or 4 . Add $10 \%$ for prepay beyond zone 4 .

Parcel Post. If sent by parcel post these trees will have to be cut back some, as they are too tall for the limit of length when packed.

Older Trees. We can furnish 2-year trees at the same prices. but they would have to go by express or freight at your expense, 


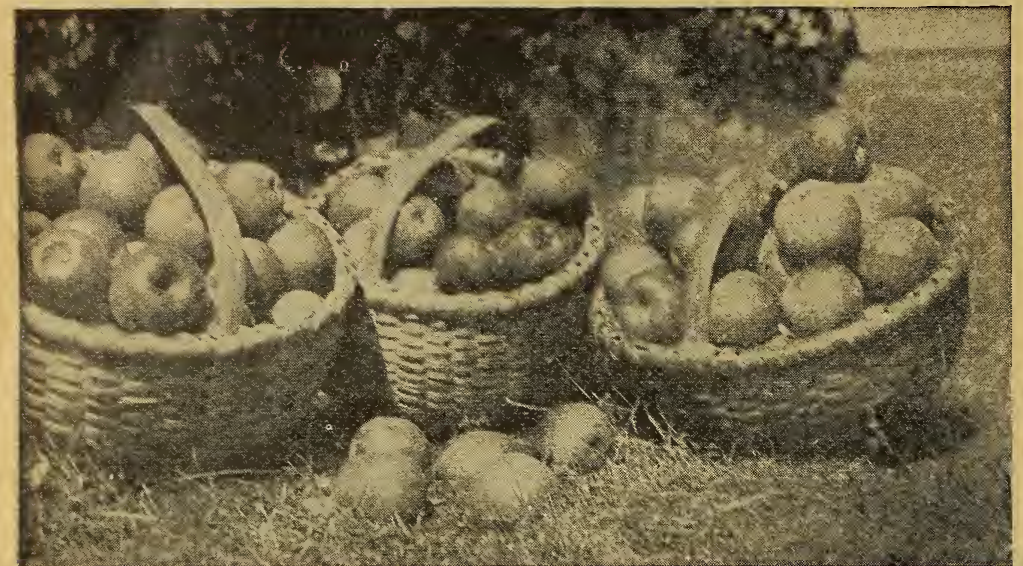

Don't they make you hungry for apples? You can grow just such apples yourself, and eat them fresh from the tree.

\section{Apples}

(See next page for prices).

The apple is easily the first in importance of all fruits, the growing of which is today one of the leating enterprises of the United States. It will thrive on any well drained soil, its period of ripen. ing extends over a longer period than any other fruit, and by careful selection of varieties, a constant succession can be obtained.

For family use no fruit is more indispensable or as healthy as the apple. No one who has a place to plant should hesitate to plant an orchard, or at least a few trees for family use.

Good apples are worth as much today as California oranges and you can grow them right in your ow n garden or door yard. Good apples are always in demand at fair prices, and if given the same care as other farm crops, will yield greater returns.

Plant a few summer and a few fall, but mostly winter varieties. In this way you may have apples the year round, for our hardiest winter sorts will keep until May or June, and the earlier varieties ripen early in July. All you need is proper soil conditions and a determination to give your trees proper attention at the right time and you are sure of success.

In the following list you will find what we consider the best for general planting, both for commercial or family use, including as it does the best leading surnmer and fall varieties and also almost all the leading commercial sorts in winter varieties.

\section{Early Apples}

Duchess (Duchess of Oldenburg). Origin Russia. One of the Ironclads, Tree an upright, vigorous grower and extremely hardy. An early and annual bearer, fruit large, greenish yellow with red stripes. Flavor pleasant, but rather tart for most people for eating. Just fine for cooking and a favorite where. ever known. Season, July and August.

Early Harvest. Medium size, roundish and smooth, bright straw color when ripe. Flavor different from Duchess, not as tart, very productive. Ripens in July.
Red Astrachan. Another of the Ironclads and $\mathrm{resembles}$ the Dutchess somewhat in growth and color of fruit, but not so large. Tree more spreading than Duchess. Fruit above the medium in quality. Flesh white, crisp and very juicy and good.

Red June. The tree is a very fine, erect grower, very hardy and bears when young. Fruit of medium size, oblong and very red when fully ripe. Has a sprightly agreeable flavor and very good for eating out of hand. In most sections ripens a little later than Early Harvest. A good early apple.

Yellow Transparent. Also of Russian origin. One of the most valuable early apples, fruit medium size, with clear transparent skin. Flesh white, juicy and fine grained. Very fragrant when fully ripe. Fine for eating or table. Ripens in August.

\section{Crab Apples}

Every orchard should contain a few crab apples. Almost all the different varieties are extremely hardy, annual bearers and begin bearing early, usually the second year.

Florence. This crab originated in Minnesota with Peter M. Gideon, who also produced the Wealthy apple. Tree hardy and spreading, rather inclined to overbear, medium size. color carmine when well colored. Excellent for cooking, and jelly, and valuable for early market.

General Grant. Tree vigorous and upright, fruit larger than Florence and dark red, almost black when well exposed to sun. Flesh white, moderate fine grained, mild sub-acid flavor. Late; ripens last of September.

Martha. Raised from seed of Duchess of Oldenburg. A rapid grower and good bearer and very free from blight. Fruit large and very handsome. Color glossy yellow shaded with light bright red. Tart and very juicy, superior to most varieties for jelly and fair to eat from hand, if you like a tart apple.

Red Siberian. A very hardy small crab, much in favor for jelly and preserving. They average about one inch in diameter and grow in clusters. Skin smooth and shiny. Bright red and very showy. Flesh clear, almost transparent. Vigorous grower. Ripens August to September.

Yellow Siberian. Identical with Red Siberian except golden yellow instead of red.

Whitney (Whitney's No. 20). Tree very rapid, hardy, upright grower and uniform head. Fruit large to very large. 2 to $2 \frac{1}{2}$ inches in diameter. Yellow, striped with red and mostly covered with red on sunny side. Flesh yellow, very juicy and fine grained, flavor rich, almost sweet. Tree a great bearer. A hybrid apple and really deserves a place among the apple list. Recommended for northern latitudes as one of the best, 


\section{Winter Apples}

Ben Davis, Black Ben Davis, and Gano, are all related, and in habit of tree and shape, and size of fruit, very similar. They are too well known to need much describing. Trees are all fine growers, and very heavy and annual bearers, Fruit is large and handsome. Ben Davis is brightly striped with red. Gano is more brilliant in color and a little firmer in flesh. Black Ben Davis is very dark red, almost black where exposed to sun. They are not best in flavor, but are good. They are all great keepers and have been money makers for the com mercial orchard men everywhere.

Delicious. This apple is the most talked of and commands today the highest price in the market of any apple in this country. It originated on the farm of the late Jesse Hiatt, near Peru, Madison County, Iowa, about 19 years ago and the original tree still flourishes and bears annually. Resembles Gano somewhat in shape, but is more pointed at the blossom end. Color a brilliant red changing to a golden yellow at the blossom end. Flesh fine grained, crisp, and juicy. Flavor sweet, slightly touched with acid. In keeping qualities equal to the best. The best eating apple in the list.

Grimes Golden. An old standard. Tree vig orous, upright, spreading, A good early and annual bearer. Surface rich golden yellow. Flesh yellow, crisp with spicy sub-acid flavor. An early winter apple and particularly desirable on account of its late blooming.

Ingram and Janet are very much alike. Ingram being a seedling of Janet. Tree more up. right and fruit larger. Smooth, yellow striped with red, flesh yellow. Very juicy and a good keeper. Janet is a fine shaped tree, rather slow growth, enormous bearer. Fruit medium and small. In color about like the Ingram, a late keeper, very pleasant flavor, crisp and juicy.

Jonathan. One of the best winter varieties in regard to quality and flavor. Tree slender and spreading, fruit of medium size unless thinned on tree. Bears young, skin thin, nearly covered with red stripes, deepening into brilliant dark red in the sun. Flesh pinkish white, very tender and juicy. Largely planted for commercial purposes, not hardy in extreme north.

Winesap. A valuable old and well known variety. Tree a moderately vigorous grower, open irregular tops, Fruit medium size, skin thick and very tough. Color dark red. Flesh yellow, fine grained, rich and crisp. Quality excellent, an early and heavy bearer and a splendid keeper.

York Imperial. This variety originated in Pennsylvania, is being planted extensively east. west, and south as a commercial variety. Not hardy in extreme north. Medium to large in size, color white, shaded with crimson. Flesh yellow, juicy, sub-acid. An excellent shipper and commands good prices.

Rome Beauty. Large, roundish, very slightly conical, and of uniform size, almost covered with bright red on pale yellow ground. Tender, juicy, not fine grained, but of splendid quality.

Northwestern Greening. A Wisconsin seed. ling, extremely hardy and very vigorous grower. Fruit large, greenish yellow, resembling Grimes Golden in shape and color, but larger, flesh yellow, firm, fine grained. Very smooth and attractive.

\section{Prices of Apple Trees -.. All Varieties}

I have decided to make a flat price on all the different varieties of apple trees. Some are harder to grow than others and the demand makes some worth more than others, but it averages up about so so. Here are the prices, Crab apples same price as other apples.

For 1 to 5 trees, either all alike or assorted, each . . 25c For 6 or more trees, either all alike or assorted, each . 22c For 30 or more trees, either all alike or assorted, in tens.20 C

These Prices Are Prepaid These prices are for strong 1-year trees with 2-year roots, and include prepaid delivery either by parcel post or express, anywhere in zones $1,2,3$, or 4 . For points outside of zone 4 , and $10 \%$ for prepay. Safe delivery guaranteed.

Older Trees If you want older trees, we can sup. ply 2-year stock at the same prices, but not prepaid. We make no charge for packing, but you pay the freight or express charges. In case you want the older trees, be sure to mention it clearly in ordering, and do not mix sizes in the order. That is, make the order all 1-year or 2-year, so there will be no confusion about the prepay.

Stayman's Winesap. This is one of the Winesaps and is being largely planted any where as a commercial variety, especially throughout Colorado and the Pacific coast states, where it is taking a leading place. Dark rich red, flesh firm and crisp. Ex. ceedingly juicy and tender. Tree a very vigorous grower and resists drouth well.

White Winter Pearmain. One of the best and most productive yellow winter apples. Is being planted heavily throughout the west as a commer. cial variety. Medium to large, conical shape, color light yellowish green with brownish red cheek. Flesh white, fine graineu, good quality and an excellent keeper and shipper.

\section{Fall Apples}

Fameuse (Or Snow Apples). An old well. known variety, medium size. Color a deep crim. son and flesh snowy white, of high flavor and best quality. Season September.

Maiden Blush. A large, rather flat apple, with a beautiful blush on side next to the sun. A pleasant, mild sub-acid flavor and a valuable apple for cooking, market or drying,

Peerless. Originated in Minnesota about 18 years ago and has grown in favor with the fruit growers everywhere. Fruit above the average in size and well colored. Excellent for cooking or eating. Tree a fine upright grower with dark green foliage. Extremely hardy and ripens September to October.

Price's Sweet. A very strong, upright grower in nursery and orchard. Fruit large oblong in shape, surface yellowish green, somewhat splashed and striped with dull red. Flesh yellow, moderately juicy and very sweet. Season October to November.

Wealthy. Originated in Minnesota about 1861 and is almost too well known to need description Fruit large, rather flattened in shape, skin smooth, whitish yellow, shaded with deep red in sun. Flesh white, tender, juicy and very good. This variety is par excellence and easily takes the lead of all fall apples. Should be in every orchard. 
Peaches

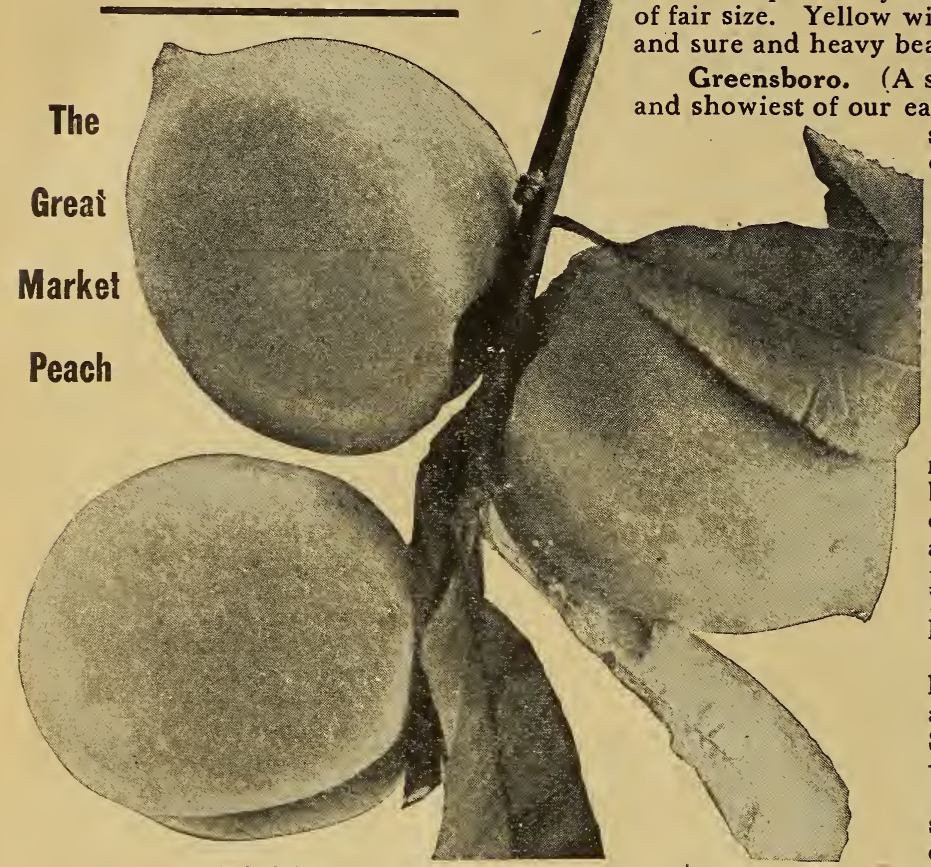
nd sure and heavy bearer.

Triumph. (A yellow Freestone.) Blooms very late, but ripens very early, about with Alexander. Fruit of fair size. Yellow with crimson cheek, good grower

Greensboro. (A semi-cling.) One of the largest Skin yellow with splashes of bright red. Highly colored in the sun. Flesh white. Splendid quality.

Carman. (Freestone.) Very large, handsome, resembling Elberta in shape. Creamy white with deep blush, skin tough, but flesh tender. Very juicy and of fine flavor. Very hardy, a profitable market variety and good shipper.

Mountain Rose. Above the medium size and very attractive, because of its white and red coloring. The flesh is white, juicy and of the best flavor. The best peach of its season and one of the best in flavor. An old stand-by. Ripens early in August.

Champion. (Freestone). Is large, almost round. Very juicy and sweet. Yellowish white. Some red on sunny side. Flesh white with red next to pit.

Crawford's Early. (Freestone.) Among the best of our early yellow varieties and much

E 1 b e r t a

$\mathrm{E}$

VERYBODY delights in the flavor of a fine, juicy peach. In the extreme northern section of our country they are not hardy enough to make them profitable, but in the central and southern states everyone may have peaches in plenty with but little trouble or expense. They succeed best on high, dry and well-drained soil, and are a sure crop if planted on northern or western exposure. In order to preserve the healthy growth of the tree and maintain a high quality of fruit, the tree should have good care and careful pruning at the proper time. Peaches are borne on wood of the previous season's growth and it is essential that they should be pruned some almost every season to let in light and air and remove dry branches. Keep your trees in good shape. The ground should not be seeded, but kept in good cultivation. Fertilize with some good soiling crop-oats, rye or cow peas, plowing it under while green. Wood ashes, if you can get them, not piled up around the trees, but scattered well. is a good fertilizer.

It takes but a short time for them to come in. to bearing, Keep the trees in good shape and you will be well repaid with good crops of fine fruit. The following described varieties have been selected from an extended list after fruiting a great many varieties, and furnish a succession of fruit covering almost four months, commencing about July 10 in most sections. The varieties are listed here in the order of ripening, enabling you to make a selection covering the entire season.

\section{Varieties of Peaches}

Alexander. An early cling peach of medium size. Greenish white, almost covered with deep red. Rather thin skin and very juicy. in favor for market purposes. Fruit oblong, very large. Color bright yellow, with red cheek. Flesh very yellow, juicy and fine flavor. Tree a fine grower and very productive. Ripens August and September.

Lemon Cling. Very large and beautiful. Lem. on shaped. Light yellow with red cheek. Flesh firm and rich, rather sub-acid flavor. Ripens in August.

Chinese Cling. A large, creamy, white peach. Fruit oblong, skin almost transparent with mottled red cheek. A well known and very popular variety in most peach sections. Season, late August.

Crosby. (Freestone.) Medium to large if fruit is thinned on tree, but liable to overbear. Do not depend too much on props. I have seen orchards of this variety entirely ruined by allowing trees to overload themselves with fruit. The tree is one of our hardiest. Fruit bright orange in color, somewhat splashed with red, Flesh yellow, somewhat red at pit. A fine canner and very popular as a market peach. You can not make any mistake in planting this variety. Ripens about the middle of September.

Elberta. Supposed to be seedling of Chinese cling, but is perfect Freestone. The great market peach of the southwest and favorably known over the whole country. Not as vigorous in growth as most varieties, but hardy even in the north. Very large, yellow with red cheek. Flesh firm and of high quality and exceedingly prolific.

Salway. (Freestone.) One of our latest ripening varieties. Inclined to be too late. Some sea. sons have seen them hang on trees in latitude of central Missouri and Kansas until freezing weather. Large, somewhat irregular in shape. Flesh yellow and firm. A late market variety.

(Continued on next page.) 


\section{Peaches}

(Continued)

Heath Cling. Very vigorous, upright grower. Fruit very large, creamy white with delicate red blush. Flesh white, slightly red at pit. Juicy and sweet. A valuable peach for canning.

Nectarines. The fruit may be described as a thin-skinned peach with a plum pit. We do not rec. ommend them to our customers, for we believe there are much bet. ter fruits of same season. They require about the same treatment as the peaeh, and we can furnish the Boston, one of the best varieties, at $40 \mathrm{c}$ each.

\section{Peach Tree Prices}

\section{(All Varieties)}

For 1 to 5 trees, each . . . 25c (Either all alike or assorted.)

For 6 or more trees, each. (Either all alike or assorted,)

For 30 or more trees in straight tens, each . . . . 20

These prices apply to all va. rieties listed.

These Prices are Prepaid. These are for strong one-year budded trees, on two-year roots, and in. clude prepaid delivery either by parcel post or express, anywhere in zones $1,2,3$, or 4 . Add $10 \%$ for prepay outside of zone 4 .

Parcel Post. If sent by parcel post these trees will have to be cut back some, as they are too tall for the limit of length when packed. Older Trees We can furnish older trees at the same prices, but they would have to go by express or freight at your expense.

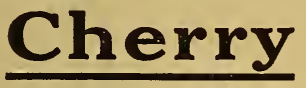

The cherry is one the finest and most delicate dessert fruits. They are being planted more and more each year and there is always a brisk demand on the market for the fruit. Although a very perishable fruit, the period of its use may be prolonged to five or six weeks by a proper selection of fruits. Aside from their fruit value, they are very ornamental for yard or lawn.

Cherries thrive on almost any well drained soil, but will not succeed on heavy ground with wet subsoil. The trees should be low headed and with the exception of the formation for the head, little or ro pruning is necessary. Our trees are all budded on important Mahaleb cherry stocks, which makes a strong, healthy tree, and does not sprout from the root, which is a nuisance when common Morello stocks are used. With but very little care the trees are very prolific. The varieties we list are among the best for general planting, either for family use or market.

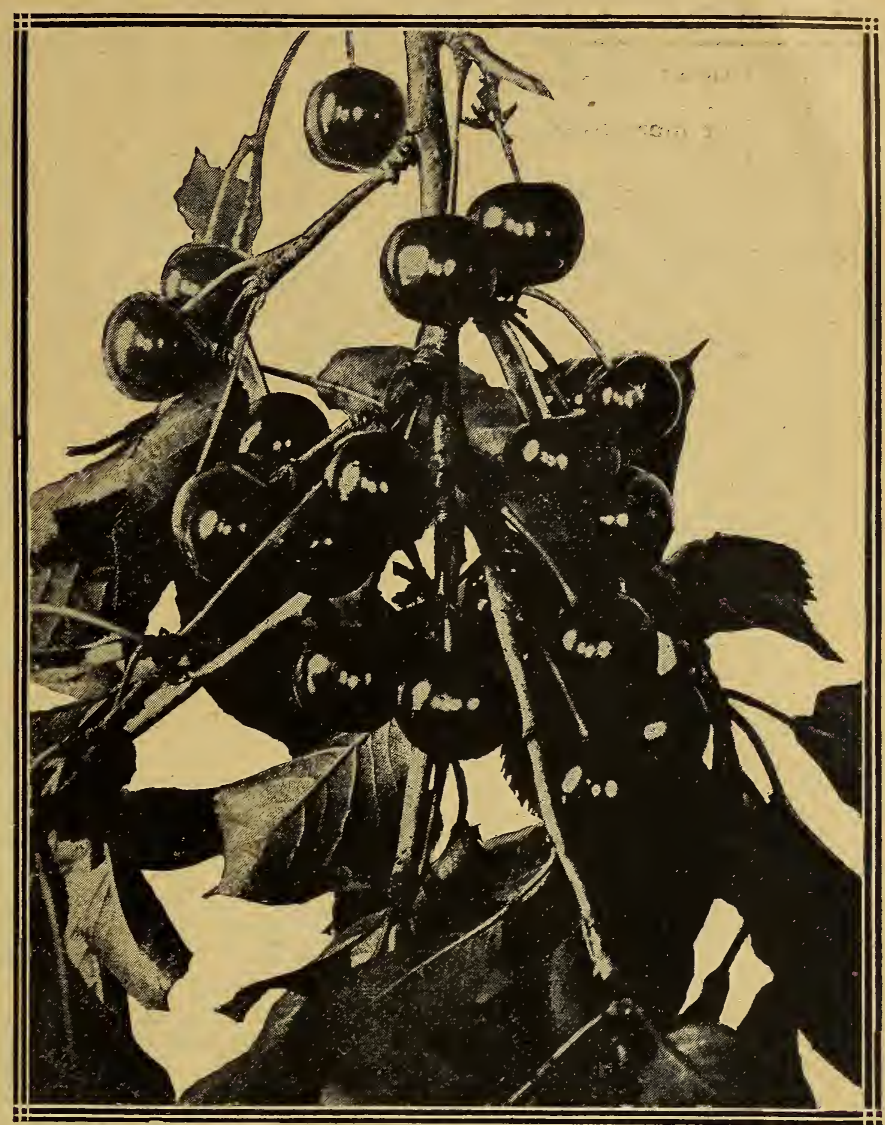

erry. (See next page for prices.)

\section{Varieties}

Early Richmond. This is an old reliable and very productive variety. One of the most popular sorts and unsurpassed for cooking. Medium size, bright red, and very juicy. Very hardy, will stand the most severe weather. Ripens in June.

Large Montmorency. Large and finer and ripens about ten days later than Early Richmond. One of the finest flavored cherries of its class. Thin skin and very meaty. Valuable for canning and preserves, and a splendid market sort. Fruit large and round, very slightly heart-shaped, dark red, be. coming nearly black when fully ripe.

English Morello. A large variety. Tree some. what dwarfish and slow grower, but very hardy and productive. Fruit large, very dark red, almost black, juicy, sourer than either Early Richmond or Montmorency. An enormous yielder. Valuable variety for market. Season July and August.

Dyehouse. Very similar to Early Richmond. In some localities ripens a little earlier and largely planted for early market. Not so good an all around cherry as Early Richmond.

Gov. Wood. A big sweet cherry. One of the Heart or Bigarreau family, sometimes called Oxhearts. A rich and delicious, large, light cherry. Flesh firm, sweet, and juicy. Tree a strong and a very upright grower and fairly productive.

(Continued on next page.) 


\section{Prices of Cherry and Plum Trees, All Varieties}

For 1 to 5 trees, either all alike or assorted, each

For 8 or more trees, either all alike or as. sorted, each . . . 40c For 30 or more trees, either all alike or assorted in tens, each

\section{These Prices Are All Postpaid}

These prices are for strong 1-year budded trees on 2-year roots and include prepaid delivery by parcel post or express, anywhere in zones $1,2,3$, or 4 . Add $10 \%$ for prepay beyond zone 4.

Parcel Post

If sent by parcel post these trees will have to be cut back some, as they are too tall for the limit of length when packed.

\section{Older Trees}

We can supply 2-year trees at the would have to prices, but not prepaid. They pense.

\section{Cherries (Continued)}

Wragg. Similar to English Morello, but said to be hardier in tree. Originated in Iowa. Usually a sure cropper.

Bing. Originated in Oregon and is considered on the coast as one of the most profitable sorts. Very large, dark brown, almost black. Flesh sweet and very solid. Season July. Not a success in this central west country.

Dwarf Rocky Mountain Cherry. A great novelty for all sections of the rountry, bears from time of setting out, seldom grows over $4 \mathrm{ft}$. high. Perfectly hardy everywhere, fruit a rich red, changing to black when very ripe. Fine flavor, meaty, somewhat like our sweet cherries and season of ripening after all others are gone.

\section{Plums}

The plum tree will accomodate itself to most situations not absolutely wet, but. like the pear and other finer fruits, succeeds best in well.drained heavy soil with some clay.

Plums should be planted about 10 feet apart and bear much better if 5 or 6 varieties are planted together, mixing them up well in the rows.

The native varieties are perfectly hardy every where and will stand the severest cold without injury. European varieties are all hardy and will succeed as far north as Minnesota and South Dak. Japanese sorts are more tender, but do well most years in Nebraska and southern Iowa.

The American kinds are excellent for dessert fruit, and for cooking and canning are excellent. Most varieties are inclined to overbear and to produce large and most perfect fruit should be thinned when about one-third grown. This, however, is seldom done.

\section{Native or Americana Plums}

DeSoto. Fruit medium size, oval. Orange overlaid with crimson, and with numerous small dots. Flesh firm and juicy. Season Sept.

Forest Garden. Fruit large, nearly round. Purplish red when fully ripe, and covered with yellow spots, of good quality and very good market variety. Season August to September.
Surprise. This is considered by many to be the finest in quality of any of the cultivated varieties of the native plum, and the hardiest of the type. Fruit large, color very dark red, nearly round, and with many small, yellow dots. Very small seed, flesh sugary sweet, melting and juicy, and of a fine flavor and excellent quality. Tree an upright, vigorous grower, and is everywhere reported very productive. Ripens in August.

Wyant. Large size, color red, almost purple when fully ripe. Flesh yellow, sweet and good flavor. Wyant is generally classed as a Freestone and is nearly so. Season September.

Stoddard. Large size. Purple and red, very mild flavor. Fine for canning. Tree bears very young. One of the best. Ripens in September.

\section{European Plums}

Lombard. Dark violet red, juicy, and pleasant. A great bearer and peculiarly adapted to light soils, Succeeds were many European varieties fail and probably the most profitable and popular one under general cultivation.

German Prune. A valuable plum of good quality for dessert, but most used for drying. Large, purplish blue, with a thick blue bloom. Flesh firm, sweet, and pleasant, and separating readily from the seed. Season September.

Shropshire Dawson. The very largest of the Dawson variety. Much used and one of the best for preserving. Tree vigorous, hardy and enormously productive.

\section{Japanese Plums}

Abundance. Of medium size, large if thinned. Amber color with markings of red, and distinct bloom. Very juicy and sweet if well ripened. Early.

Burbank. When properly thinned this plum is very large, nearly round. Orange yellow dotted and marbled with red. Flesh yellow, sweet, meaty, and quite firm. Tree vigorous and spreading. Needs close pruning. A good shipper and keeps well. Very early.

Compass Cherry Plum. Absolutely hardy everywhere. In shape, size and coloring of the fruit they resemble both cherry and plum. Color bright red; deepening to a dark vine color when fully ripe. Its early bearing is truly wonderful, often producing fruit on two-year trees. Especially recommended for elevated sections where but little rain falls.

\section{Large Family Apple Orchard, \$9.50 Delivered}

Don't forget our special offer on the back of the yellow order sheet of a large family orchard of 50 trees, a good selection of varieties, for $\$ 9.50 \mathrm{de}$ livered by parcels post or express. Turn back and look it up. It will sure please you.

Also notice the other collection offers there. I have gone to a great deal of pains to make these collections just right. and they ought to suit most any one. Here is the tamily orchard list:

1 Red June, 2 Duchess, 2 Yellow Transparent. 1 Snow Apple. 2 Maiden Blush, 2 Wealthy, 5 Gano, 5 Grimes Golden, 5 Stayman Winesap. 5 Rome Beauty, 5 Jonathan, 5 York Imperial, 5 Janet, 5 Winesap.

These 50 trees will be sent prepaid by parcel post or express for $\$ 9.50$ in zones $1,2,3$, or 4 , or for $\$ 11.00$ beyond zone 4. Safe delivery guaranteed. 


\section{Growing Trees From Seedlings}

The nicest, and easiest, and cheapest way to get started with trees is to buy the 1-year seedlings. These are one years' growth from seed and are nice, straight, healthy little trees generally from a foot to a foot and a half high, well rooted, easy to ship, and sure to live. They are much easier to get to live than the larger trees, and are much cheaper to buy. I strongly advise this size, but also list below the larger, older trees if you wish them These seedling trees go very nicely by mail and can be send to any part of the country with abso. lute safety.

\section{Postpaid Price List of Shade and Forest Trees}

\section{1-Year, From Seed or Cuttings}

At prices below these trees will be delivered prepaid by parcels post or express, anywhere in zones $1,2,3$ or 4 . Add $10 \%$ for prepay outside zone 4. 6 or more at the dozen rate. 50 or more at the 100 rate. Ask for prices per 1,000.

\begin{tabular}{|c|c|c|c|}
\hline & Each & Do & \\
\hline & . $5 c$ & & $\$ 1.00$ \\
\hline & 5 & 30 & 1.00 \\
\hline Speciosa, 1-year & $\mathbf{5}$ & 30 & \\
\hline American Sweet, 1-year & .10 & 60 & \\
\hline n White, 1-year . & . 5 & 30 & \\
\hline $1-5$ & 5 & 30 & \\
\hline yea & 5 & 30 & 1.0 \\
\hline & 5 & 30 & 1.0 \\
\hline 80 & $\mathbf{5}$ & 30 & 1.0 \\
\hline & .10 & 60 & 4.0 \\
\hline 1-year & .10 & 60 & 4.0 \\
\hline & .10 & 60 & 4.0 \\
\hline 1.year. . . & .10 & 60 & 4.0 \\
\hline ow, Russian Golden, 1-year & 10 & 50 & 3.0 \\
\hline
\end{tabular}

\section{Prices on Shade Trees in Larger Sizes, Mostly 2-Yr.}

\section{From Seed, Cutting, or Graft}

These prices are not postpaid, and the trees are mostly too large to go by mail anyway. They must go by express or freight at your expense. These trees will range from $4 \mathrm{ft}$. to $6 \mathrm{ft}$. high, ac. cording to variety. All are strong and thrifty and well rooted. Ask for special prices on larger lots or larger sizes.

Ash, White

Box Elder

6 or

Catalpa, Speciosa . . . . . . . 15

Elm, American White . . . . . . 15

Hackberry . . . . . . . . . . . . 35

Larch . 35

Locust, Black … . . . . . 25

Locust, Honey . . . . . . . . . . . . 35

Maple, Soft .

Maple, Sugar or Hard . . . . . . . 50

Maple, Weirs Cut Leaf . . . . . . . . 40

Horse Chestnut . . . . . . . . . . . 75

Mountain Ash . ... . . . . . . . 40

Russian Olive . . . . . . . . . . . 35

Poplar, Carolina . . . . . . . . . . . 15

Sycamore 35

Willow, Russian Golden . . . . . . . 15

Weeping, Cutleaved Birch . . . . . 75

Weeping Willow . . . . . . . . .40

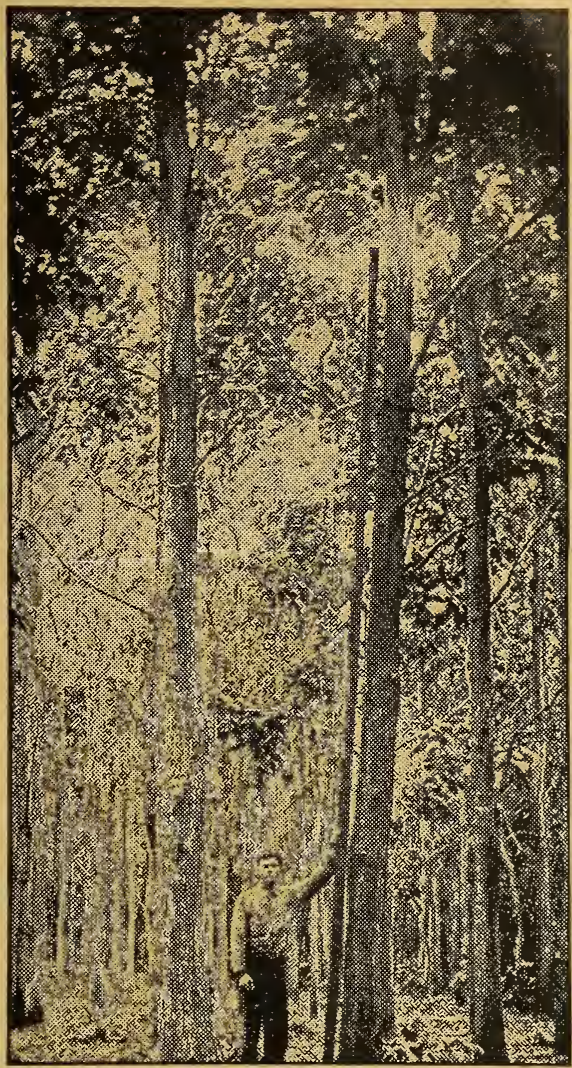

A commercisl grove of Catalpa Speciosa planted ten years on an Iowa farm. About half the trees originally planted have been cut out for firewood and posts, paying all expenses to date. The trees that are left, about 400 per-acre, would make over 2,000 good posts, worth $15 \mathrm{c}$ each; or 400 telephone poles, worth from $50 \mathrm{c}$ to $\$ 1.50$ each. What could you grow that would pay bet. ter. Price, seed $\$ 2.00$ per $\mathbf{l b}$. postpaid, or $25 \mathrm{c}$ per 02 . An ounce should makə 200 trees. Trees (1 year from seed), \$1.00 per 100, postpaid. Ask for prices on larger lots.

\section{Special Offer on Catalpas}

We have a specially fine block of 2-year Catalpa trees, grown right here at Shenandoah, that we are going to clean out at a bargain. They are 4 to $5 \mathrm{ft}$. trees, nice and straight, and thrifty, and first class in every way. Just the thing to plant for quick effect. In a few years they should make you trees like the picture above.

These trees are too large and heavy to send by parcel post, but they will go nicely by freight, and we will guarantee safe arrival and in good condition. We box or bale them without extra charge. You pay the freight, but it will not be high.

PRICE: $\$ 5.00$ per 100,50 for $\$ 3.00,30$ for $\$ 2.00,10$ for $\$ 1.00$. (We also have a few very nice Ash, Elm, Norway Poplar, and Maple, at the same price. These prices are for trees in even multiples of 10 , as we do not like to breals bunches.) 
Jowe's Leading 


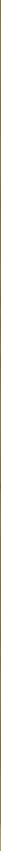




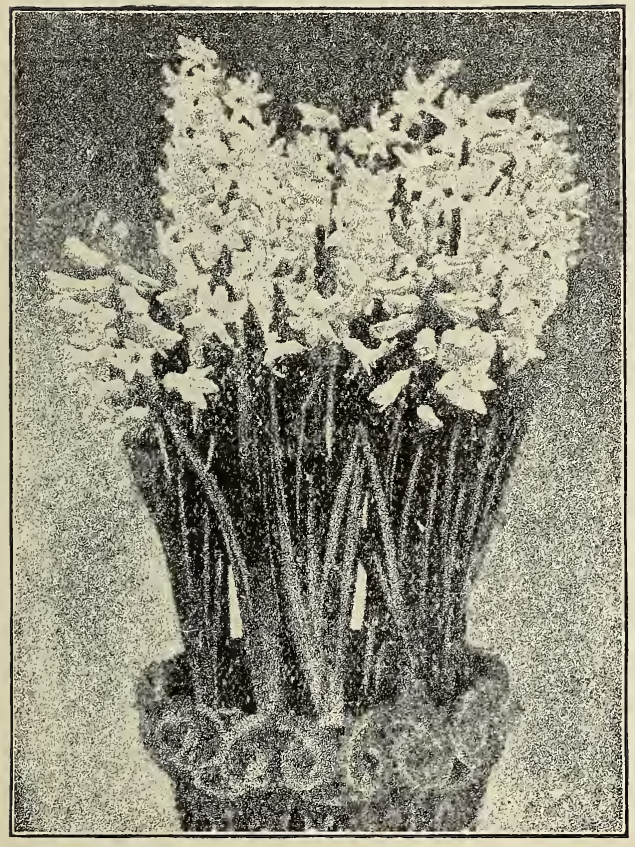

\section{Surprise Collection of Dutch Bulbs}

\section{Half Price to Clean Up}

At the end of the season for selling Dutch bulbs we always have a surplus on hand of some sorts. We can never come out quite even. Sometimes it will be too many Hyacinths, or it may be Tulips, or it may be Daffodils, or it may be some varieties of all of them.

I generally plant these out myself, but we have got our places all about full this year, and not much room to plant any more.

So I am going to give you some real bargains in them, I will make them up in $50 \mathrm{c}, \$ 1.00$ and $\$ 2.00$ collections that will be a pleasure and a surprise to you. I can't tell you just what will be in them. for it will depend on what we have in surplus, but they will be all good varieties, good bulbs, and first-class stuff in every way, and they will be put in at just about half the regular prices.

Send along $50 \mathrm{c}$, or $\$ 1.00$, or $\$ 2.00$, or whatever you feel like spending, and let me know whether you want them for indoor or outdoor planting, and I will send the bulbs at once postpaid, and I will guarantee they will please you and that you will have your money's worth and then some.

Just pin this slip to your order, or specify. that you want the Surprise Collection.

\section{Henry Field Seed Company}

\section{Shenandoah, -:- -:- -:- lowa}




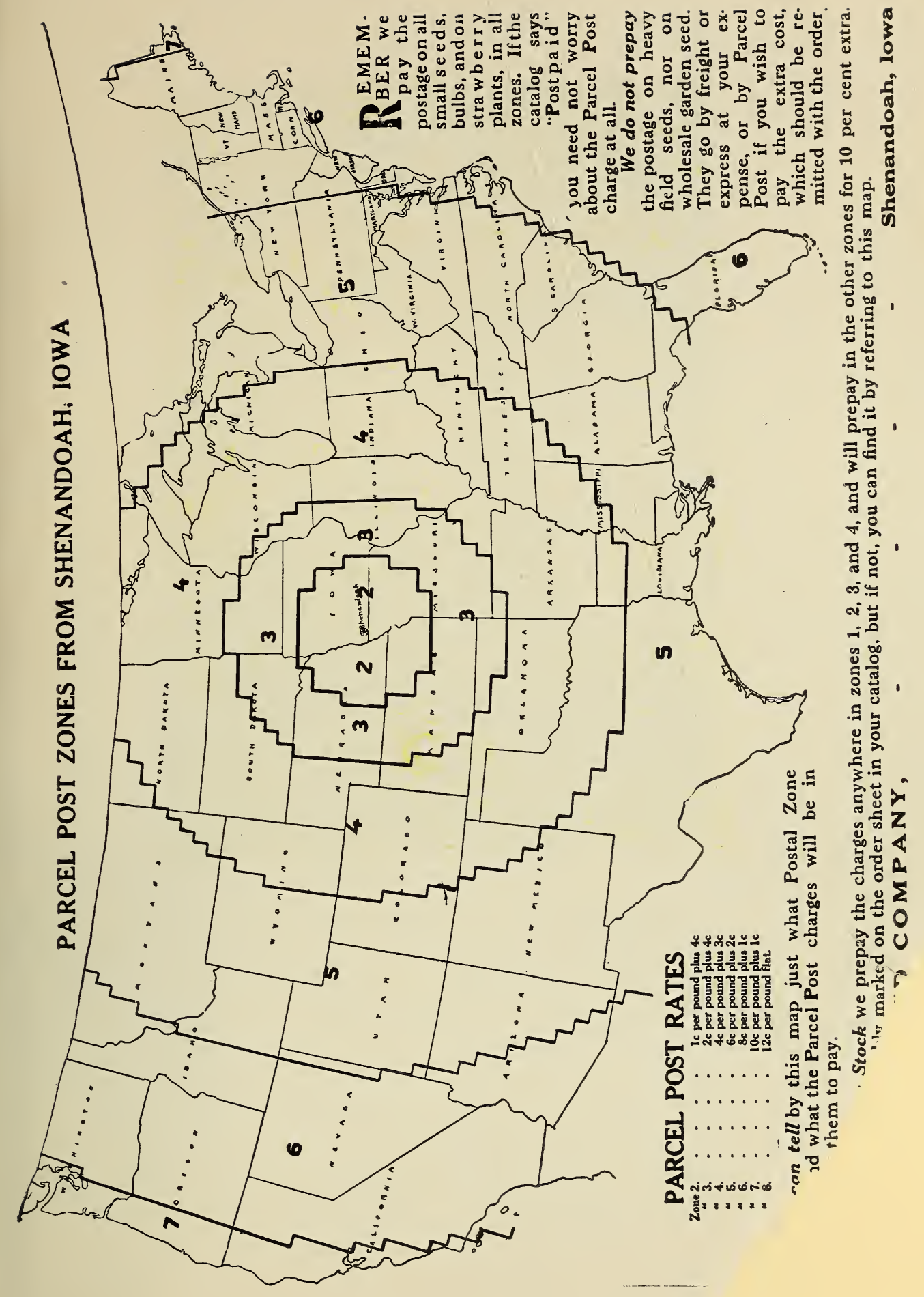




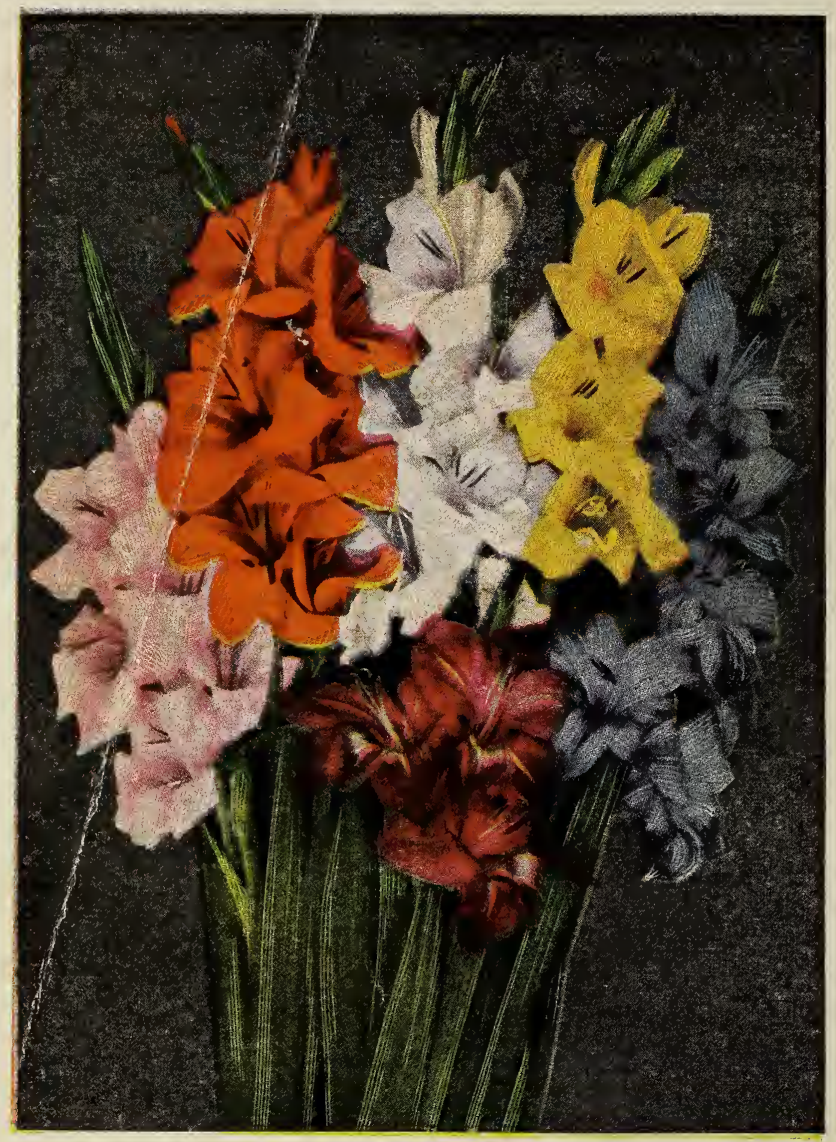

\section{The Gladiolus -- Queen of Flowers}

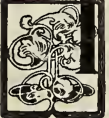

believe if I were limited to just one flower, I would choose the gladiolus over all the others. It will grow and bloom for anyone, in any soil, and any climate. It is beautiful either growing or picked. It has all the colors of the rainbow. It will bloom in 3 months. I want every one to grow th.m, so I have made up a special collection of 60 bulbs, containing all the colors shown above and many others. 5 America, 5 Frances King, and 50 finest mixed, all colors. All blooming size, sound bulbs.

This collection of 60 bulbs mailed postpaid for $90 \mathrm{c}$ HENRY FIELD SEED CO., Shenandoah, lowa 